Michael Daxner,

Hannah Neumann (Hg.)

Ipinatuskuns

Wie die Auslandseinsätze

der Bundeswehr

Deutschland verändern

[transcript] EditionPolitik 
Michael Daxner, Hannah Neumann (Hg.)

Heimatdiskurs

Edition Politik | Band to 

Michael Daxner, Hannah Neumann (Hg.)

\section{Heimatdiskurs}

Wie die Auslandseinsätze der Bundeswehr

Deutschland verändern

[transcript] 


\section{(9) $(1) \Theta$}

Dieses Werk ist lizenziert unter der Creative Commons Attribution-NonCommercial-NoDerivs 4.0 Lizenz (BY-NC-ND). Diese Lizenz erlaubt die private Nutzung, gestattet aber keine Bearbeitung und keine kommerzielle Nutzung. Weitere Informationen finden Sie unter https://creativecommons.org/licenses/by-nc-nd/4.o/deed.de/.

Um Genehmigungen für Adaptionen, Übersetzungen, Derivate oder Wiederverwendung zu kommerziellen Zwecken einzuholen, wenden Sie sich bitte an rights@transcript-verlag.de

\section{(C) 2012 transcript Verlag, Bielefeld}

Die Verwertung der Texte und Bilder ist ohne Zustimmung des Verlages urheberrechtswidrig und strafbar. Das gilt auch für Vervielfältigungen, Übersetzungen, Mikroverfilmungen und für die Verarbeitung mit elektronischen Systemen.

\section{Bibliografische Information der Deutschen Nationalbibliothek}

Die Deutsche Nationalbibliothek verzeichnet diese Publikation in der Deutschen Nationalbibliografie; detaillierte bibliografische Daten sind im Internet über http://dnb.d-nb.de abrufbar.

Umschlaggestaltung: Kordula Röckenhaus, Bielefeld Lektorat \& Satz: Michael Daxner, Hannah Neumann Druck: Majuskel Medienproduktion $\mathrm{GmbH}$, Wetzlar Print-ISBN 978-3-8376-2219-5 PDF-ISBN 978-3-8394-2219-9

Gedruckt auf alterungsbeständigem Papier mit chlorfrei gebleichtem Zellstoff.

Besuchen Sie uns im Internet: http://www.transcript-verlag.de

Bitte fordern Sie unser Gesamtverzeichnis und andere Broschüren an unter: info@transcript-verlag.de 


\section{Inhalt}

Wie der Einsatz in Afghanistan Deutschland verändert - Einleitung

Michael Daxner und Hannah Neumann 17

GRUNDZÜGE

Heimatdiskurs -

ein deutsches Problem?

Michael Daxner | 15

Heimatdiskurs -

mediales Konstrukt und empirische Realitäten

Hannah Neumann | 69

\section{Dimensionen}

Von „wilden Bergvölkern“ und ,islamistischen Bazillen“ Die Darstellung der Intervenierten in Afghanistan

Janna Aljets, Alexander Biegler und Anna-Lena Schulz | 93

Von friedlichen Aufbauhelfern und professionellen Kämpfern Die Darstellung der deutschen SoldatInnen im Heimatdiskurs

Laura Mae Herzog, Christian Kobsda, Hannah Neumann und Anna Oehlaf | 137

Wie der Westen auszog, Afghanistan zu zivilisieren Legitimationsmuster des Afghanistaneinsatzes zwischen 2001 und 2010

Farisa Al Ahmad, Zerrin Günes, Jeldrik Hanschke, Hannah Materne, Hannah

Neumann, Konstantin Rosenberger, Miriam Schelp und Carolin Stehr | 167

Die Bundeswehr in Afghanistan Analysen an den Grenzen des Heimatdiskurses

Christopher Robotham und Sascha Röder | 201 
Von Mücken und Elefanten Reflexionen über den Terrorismusdiskurs

Florian P. Kühn | 243

InterventionsTheater

Der Heimatdiskurs und die Feld- und Truppenbesuche deutscher Politiker - eine Forschungsskizze

Berit Bliesemann de Guevara | 273

„Durchbruch“" zur „Trendwende“?

Eine Analyse des Fortschrittsberichts Afghanistan 2010 der Bundesregierung im nationalen und internationalen Kontext Vanessa Janzen | 303

Ausblick und Perspektiven

Michael Daxner | 331

Autorinnen und Autoren | 335 


\title{
Wie der Einsatz in Afghanistan Deutschland verändert
}

\author{
Einleitung
}

Michael DaXner Und Hannah NeUmanN

Wir kommen spät, hoffentlich nicht zu spät, mit unserem Buch. Mehr als zehn Jahre dauert nun eine Intervention in Afghanistan, die mittlerweile zu einem lang andauernden asymmetrischen Krieg geworden ist. Seit den 1990er Jahren ist die Bundeswehr auf dem Balkan aktiv und hat mit ihren Einsätzen im Kosovo, in Afghanistan und am Golf das pazifistische Nachkriegsnarrativ zunehmend in Frage gestellt. Wir schreiben keine Interventionsgeschichte, wir machen auch keinen Rundumschlag gegen eine deutsche Außen- und Verteidigungspolitik, die durchaus Kritik vertragen kann. Uns interessiert, wie sehr die Auslandseinsätze der Bundeswehr und die aktive Rolle Deutschlands bei Interventionen unser Land, genauer, unsere Diskurse, unsere Themen, unsere Probleme, verändert haben.

Dieses Buch ist das Ergebnis einer Forschungsgeschichte, die Michael Daxner in seinem Eröffnungsbeitrag Heimatdiskurs - ein deutsches Problem? kurz wiedergeben wird. Weder ist die „Interventionswissenschaft" eine eingeführte Unterdisziplin der politischen Wissenschaften, noch ist die diskurskritische Aufarbeitung von Interventionen Gemeingut der kritischen (politischen) Diskursanalyse. Wir sind gerne Grenzgänger zwischen den Sozialwissenschaften und einer Reihe von anderen Disziplinen, die wir brauchen, um zu verstehen, wie Auslandseinsätze - wie ihre Folgen: Krieg, Invalide, Veteranen, Gefallene, verarbeitet und verdrängt werden. Es handelt sich im besten Sinn des Wortes um „Work in Progress“, sowohl, was die Theoriebildung betrifft, als auch im Hinblick auf eine ungewöhnliche Zusammenarbeit, die zu diesem Sammelband geführt hat. 
Seitdem der Begriff Heimatdiskurs eingeführt wurde (2009), lag er auch der Interventionstheorie zugrunde, soweit sie in Forschung und Lehre an der FU Berlin aufgebracht wurde. Vor allem in fortgeschrittenen Seminaren und im Rahmen eines Teilprojekts im Sonderforschungsbereich 700 spielte diese Theorie eine Rolle, an der ja u.a. drei Mitglieder des Teilprojekts C9 (Daxner, Koehler, Zürcher) mitgearbeitet haben. ${ }^{1}$

Hannah Neumann, ausgebildete Medienwissenschaftlerin, promoviert über Interventionen in Liberia und auf den Philippinen und bildet eine wichtige Brücke zwischen einem recht gut bestellten Feld der Medienkritik zu den Auslandseinsätzen und dem transdisziplinären Ansatz des Heimatdiskurses. In ihrem Beitrag Heimatdiskurs - mediales Konstrukt und empirische Realitäten versucht sie, diese Brücke ,politik-“lastig zu verdeutlichen und führt damit zur Diskurstheorie hin, wie sie stärker in anderen Beiträgen aufscheint. Gemeinsam mit Michael Daxner führte Hannah Neumann 2010/11 ein Forschungsseminar durch. Dabei konnten einige Studierende zur Mitarbeit an diesem Buch gewonnen werden. Die Gruppendynamik dieses Prozesses war in mehrfacher Hinsicht bemerkenswert und im Ende sehr positiv: Die Altersspanne zwischen der jüngsten Autorin und dem ältesten Verfasser beträgt mehr als 40 Jahre. Damit sind zum Beispiel die Bewertung der deutschen Kriegs- und Nachkriegsnarrative, und auch eigene Erfahrungen in den Friedens- und Konfliktstudien oder im politischen Umfeld, durchaus unterschiedlich und oft stark vermittlungsbedürftig notiert; die zu Tage tretenden Brüche und Unvereinbarkeiten wurden teilweise recht aufwändig bearbeitet und selbst Bestandteil der Analyse. Dass sich einzelne Autoren(gruppen) aneinander und am Ausgangskonzept des Heimatdiskurses gerieben haben, ist ein wichtiges Nebenergebnis, das wir nicht versucht haben zu glätten.

Es gab einen bemerkenswerten und erfreulichen Prozess der Emanzipation der studentischen Verfasser und Verfasserinnen, die sich in Gruppen organisiert hatten. Was als Lehrveranstaltung begann, wurde zunehmend zum gemeinsamen Forschungsprojekt. Vier Kapitel folgen dieser Gruppenarbeit und fassen Ergebnisse der umfassenden Forschungsarbeiten für den Leser zusammen. Dabei sind nicht unbedingt alle Gruppenmitglieder AutorInnen. Der Beitrag Von „wilden Bergvölkern“ und „,islamistischen Bazillen“ von Janna Aljets, Alexander Biegler und Anna-Lena Schulz arbeitet die Darstellung der Intervenierten afghani-

1 Erste Ergebnisse des Forschungsverbundes sind 2010 erschienen in Bonacker, Thorsten; Daxner, Michael; Free, Jan H. u. a., Hrsg. 2010. Interventionskultur: zur Soziologie von Interventionsgesellschaften. Wiesbaden: VS Verl. für Sozialwissenschaften. 
schen Zivilbevölkerung und Kombattanten im Spiegel zwischen 2001 und 2010 mit Hilfe einer Metaphernanalyse auf. Der Beitrag von Laura Mae Herzog, Christian Kobsda, Hannah Neumann und Anna Oehlaf Von friedlichen Aufbauhelfern und professionellen Kämpfern zeichnet den Wandel des Soldatenbildes zwischen 2001 und 2010 auf der Basis einer vergleichenden Stichprobe aus der Süddeutschen Zeitung und der $Y$ (Bundeswehrmagazin) mit Hilfe einer Framinganalyse nach. Der Beitrag Wie der Westen auszog, Afghanistan zu zivilisieren - Legitimationsmuster des Afghanistaneinsatzes zwischen 2001 und 2010 von Farisa Al Ahmad, Zerrin Günes, Jeldrik Hanschke, Hannah Materne, Hannah Neumann, Konstantin Rosenberger, Miriam Schelp und Carolin Stehr gibt einen Überblick über die (De-)legitimation des Afghanistaneinsatzes auf der Basis einer Analyse von Kommentaren und Leitartikeln in der Süddeutschen Zeitung zwischen 2001 und 2010. Der Beitrag von Christoper Robotham und Sascha Röder Die Bundeswehr in Afghanistan - Analysen an den Grenzen des Heimatdiskurses, setzt sich mit der Darstellung, und vor allem Einordnung, des Einsatzes in Afghanistan zwischen zivilem Friedenseinsatz und militärischem Kampfeinsatz in taz, FAZ und Die Zeit auseinander und nimmt eine konstruktiv kritische Distanz zum Konzept des Heimatdiskurses ein. Diese vier Themenschwerpunkte ergänzen eine erst neuerdings systematische Analyse von Interventionen aus der Perspektive von militär und Bundeswehr-orientierter Öffentlichkeit. ${ }^{2}$ Das in ihnen ausgebreitete Material ist nur ein Bruchteil der untersuchten Texte, weitere Ausarbeitungen sind über die Webseite unseres Projektes $\mathrm{Cul}$ tures of Intervention ${ }^{3}$ zugänglich.

Florian Kühn zeigt in seinem Beitrag Von Mücken und Elefanten - Reflexionen über den Terrorismusdiskurs wie der maßlose Einsatz von Terror/Terrorismus in der Semantik des Heimatdiskurses für Fehlsteuerungen von Politik verantwortlich ist. Berit Bliesemann de Guevara beleuchtet in ihrem Beitrag InterventionsTheater. Der Heimatdiskurs und die Feld- und Truppenbesuche deutscher Politiker - eine Forschungsskizze wie viel Wissen und Wahrheit Truppenbesuche von Politikern tatsächlich fördern und vor allem welche diskursiven Strategien von den Akteuren vor Ort verfolgt werden. In Janzens Beitrag „Durchbruch“ zur „Trendwende“? Eine Analyse des Fortschrittsberichts Af-

2 In diesem Jahr sind hierzu zwei weitere Sammelbände erschienen: Seiffert, A., Phil Langer, und Carsten Pietsch, Hrsg. 2012. Der Einsatz der Bundeswehr in Afghanistan. Schriftenreihe des sozialwissenschaftlichen Instituts der Bundeswehr. Wiesbaden: VS. und Chiari, B., Hrsg. 2012. Auftrag Auslandseinsatz. Freiburg: Rombach.

3 Die URL zu den angegebenen Texten ist www.culturesofintervention.org/projects/ research/homeland-discourse. 
ghanistan 2010 der Bundesregierung im nationalen und internationalen Kontext, schlussendlich, liegt eine ins Detail gehende Textanalyse des Fortschrittsberichtes der deutschen Bundesregierung vor.

Wie es sich für eine erste Zusammenfassung eines noch lange nicht erledigten Forschungsfeldes gehört, sind durchaus Differenzen und kontroverse Positionen in Theorie und Empirie vorhanden und werden in diesem Band sichtbar. Aber unsere gemeinsame Leitidee hat uns zusammengehalten und inspiriert: Die Empathie für die Intervenierten und das Verständnis für diejenigen Intervenierenden, die nicht einfach blind einem Interventionsauftrag folgen. Wir haben uns gegenseitig, über Fach- und Hierarchiegrenzen hinweg, durch Erkenntnisse bereichert, die in den stark fragmentierten akademischen Claims sehr oft untergehen.

Die beiden Herausgeber, Michael Daxner und Hannah Neumann, danken allen, die mit ihren Beiträgen dieses Buch möglich gemacht haben; wir danken auch den Studierenden, die an den Gruppen mitgearbeitet haben und keine Beiträge geschrieben haben, uns aber bis zur Drucklegung begleitet haben. Wir danken Herrn Ackermann und Herrn Bledjian vom Auswärtigen Amt, die der gesamten Forschungsgruppe eine Vorstellung des Konzepts im Oktober 2011 ermöglichten. Ständig beratend standen uns Tom Koenigs, Jan Free, Urs Schrade und Jan Koehler zur Seite. Das Manuskript wurde hilfreich und genau durchgesehen von Birgit Seemann. Schließlich danken wir Frau Astrid Poppen vom Transcript-Verlag für heute selten gewordene gute Lektorierung und geduldige Betreuung.

Matthias Claudius: „,..S'ist Krieg,...und ich begehre nicht Schuld daran zu sein" hat sich zu einer Attitüde entwickelt, die in der hohen Politik und am Stammtisch feste Plätze eingenommen hat. Das Problem der Haftung für die Teilnahme, nicht für den prognostizierten Erfolg oder tatsächlichen Misserfolg, wird häufig ausgeblendet. Kritische Haltung reicht nicht aus, wenn die Schuld an der Intervention und erst recht an ihren Misserfolgen bereits auf jemanden, der nicht WIR ist, übertragen wurde. Die Wissenschaft kann sich das nicht leisten. Mit Haltung schafft man keinen Frieden. Prinzipien - seien sie noch so hehr helfen nicht als Bekenntnis, sondern nur in der Praxis. Zu dieser Praxis gehört auch, zu erkennen, woher denn unsere Prinzipien und scheinbar unangreifbaren politischen Positionen kommen. Eine Untersuchung über Kosovo oder Afghanistan, ist immer auch eine über Deutschland, und uns selbst. Der Befund darf nicht schon dadurch eingeengt werden, dass man ohnedies weiß, wofür und wogegen man ist. Und gerade bei unserem Thema bedeutet alles (vieles) verstehen noch lange nicht alles verzeihen oder gutheißen. Aber auf diesem Kurzschluss beruht ein Teil der Halbbildung und der fatalen Folgen des Heimatdiskurses für die 
Wirklichkeit der Interventionen. Variierten wir Claudius zu „...es ist Krieg, und ich begehre zu wissen, wie wir ihn beenden können“, dann muss der Anspruch gar nicht moralisch eingeengt sein. Es gibt viele gute Gründe, Krieg nicht zu wollen und ihn zu beenden. Aber wenn diese Gründe nicht in den Heimatdiskurs eingehen, wenn sie den Sachzwängen oder der schlichten Unwissenheit geopfert werden, haben sie wenig Chance auf Umsetzung.

Unsere Leserinnen und Leser werden viel von der Komplizenschaft der Wissenschaft mit ihrem Thema erfahren. Wir können der Erkenntnis keine Unschuldsvermutung zur Seite geben. Wenn wir bloß die Stereotypen, Vorurteile und Erfindungen, die wir zu den Kosovaren oder Afghanen täglich reproduzieren, auf den Prüfstand stellen, dann erkennen wir, wie wenig weit wir uns von der vor-aufgeklärten Weltsicht kolonialen Klassifizierens entfernt haben (siehe hierzu vor allem Aljets et al. in diesem Band). In welche Zivilisation gehört die Freude über Osamas Tod? Warum waren die alpinen Taltrachten mit einer quasi Kopftuchpflicht vor grade mal 60 Jahren so viel weniger archaisch als der Tschador? Was macht die Rückständigkeit einer „Stammesgesellschaft“ aus, wenn wir bei uns den Proporz zwischen Bayern und Franken hochleben lassen, und zudem den Unterschied von Ethnien und Stämmen gar nicht benennen können? Wir in der Wissenschaft sind also nicht nur Komplizen mit dem von uns untersuchten Geschehen, sondern auch mit dem Stoff, den wir analysieren; mit dem Diskurs - und müssen uns doch kritisch gegen ihn wehren. Was abfällt ist vielleicht, hoffentlich, ein wenig Erkenntnis, wie das Unsagbare des Kriegs und der Gewalt doch so gesagt werden kann, dass anständigere Politik daraus werden möge.

Kleine Lesehinweise: die Beiträge sind in sich geschlossen, mit eigener Bibliographie. Es gibt kleine Varianten im Gebrauch geschlechtsspezifischer Endungen: wo angebracht, arbeiten wir mit dem großen I (SoldatInnen), meistens verwenden wir den geschlechtsneutralen Plural oder das natürliche Geschlecht. Die zahlreichen Querverweise zwischen den Beiträgen sollen Dopplungen vermeiden. Definitorische Redundanzen sind manchmal nicht zu umgehen. 

Grundzüge 



\section{Heimatdiskurs - ein deutsches Problem?}

MICHAEL DAXNER

Es geht um die deutsche Beteiligung an den Interventionen im Kosovo, am Horn von Afrika, vor allem in Afghanistan, und die Einsätze der Bundeswehr an diesen Unternehmen out of area. Wir wollen wissen, wie die Einstellungen zu diesen Interventionen zustande kommen, wie die Medien die vorbewusste Urteilsbildung zum Einsatz unserer Bundeswehr in Afghanistan aufgreifen; wie die Politik durch diesen „Diskurs“ gesteuert wird. Und warum nennen wir ihn den Heimatdiskurs? Diese Frage will ich zunächst beantworten. Dabei kommt es auch darauf an, klarzustellen, wer spricht, wer zum Thema etwas zu sagen hat und wer ich, wer wir sind, wer Man ist.

Ich werde eine sehr kurze Forschungsgeschichte mit einigen grundlegenden Verbindungen unseres Themas zur Interventionstheorie verbinden. Die Frage, wer in diesem Buch spricht und über wen wir sprechen, ist bedeutsam (1 Wir); danach erfolgt eine Annäherung an das Thema, sie setzt die Motivation der Einleitung fort (2 Fragen an das Thema); der Bezug zur Interventionsforschung wird hergestellt (3 Interventionsgesellschaft); Beispiele erläutern unsere Vorgehensweise und zeigen die Probleme, die wir thematisieren (4 Der Heimatdiskurs entfaltet sich); schließlich werden Hypothesen und ein Theoriesegment vorgestellt (5 Das Thema wird Wissenschaft). 


\section{WIR}

Es gibt drei Ebenen, die zu Beginn auseinandergehalten werden, damit man die verschiedenen Stimmen, die zur Sprache kommen, unterscheiden kann: das Ich des Autors markiert eine spezielle Theorie und Empirie von Interventionsgesellschaften, die ich seit meinem Dienst bei UNMIK im Kosovo ab 2000 entwickelt habe. Theorie und Empirie führen zu einem Wir eines Forschungsverbundes, der in Oldenburg seinen Ausgang nahm und nach einer Tagung 2008 an der FU Berlin platziert ist. Und drittens gibt es ein dichtes Netzwerk eines virtuellen Forschungsfeldes, also auch ein Wir, dessen Konturen im Prozess von Forschung und Kooperation sich gerade festigen und herausbilden. Hieran sind eine Reihe von Kolleginnen und Kollegen am SFB 700, an der Helmut-Schmidt-Universität Hamburg, am CCS Marburg und viele Studierende, Doktorandinnen und Doktoranden beteiligt. Einige sind Autorinnen und Autoren dieses Buches.

Das im Verlauf dieses Textes durchgängig verwendete Wir ist ein kollektive Bezeichnung, die Autorschaften und konkrete Kommunikationen oft unschärfer als die Argumente und Begriffe erscheinen lässt. Wir sind die Komplizen des Heimatdiskurses, wir lassen ihn erscheinen und indem wir ihn erklären, machen wir Politik und Wissenschaft zugleich. Da ich für die Genealogie und das Netzwerk unserer Zusammenarbeit mitverantwortlich bin, komme ich des Öfteren auch als individuelles Subjekt vor, ich bevorzuge aber das zweite, das komplizenhafte Wir, als beständige Konstante eines ,,Work in progress“.

Am Anfang dieser Arbeit stand allerdings mein Heraustreten aus einer anscheinend nicht in Frage stehenden wissenschaftlichen und politischen Arbeit im Bereich von Hochschulreform, also dem Verhältnis von Universität und Gesellschaft. Auch der Bruch, meine Arbeit im Kosovo, begann noch mit Hochschulpolitik - ich war dort Bildungs- und Hochschul"minister" für UNMIK - und ging doch bruchförmig in etwas anderes, die Konfliktforschung und Interventionswissenschaft, über. Viel von dem Material, - Quellen, Dokumente, Archiv und Gespräch - das wir verwenden, ist subjektiv durchtränkt: Heimkehrerliteratur, Erlebnisberichte, Reiseaufzeichnungen, und höchst persönliche Schilderungen von Befindlichkeiten von Menschen, die die Grenze des Öffentlichen und der Politik an einer „Front“ erleben, die nicht automatisch eine des Krieges und der Vernichtung, aber oft eine an der Grenze von Leben und Überleben ist. Vieles in unserem Material erscheint anekdotisch, anderes ist rezyklierte Information, die immer wieder aufgewärmt wird, und viele wissenschaftliche Analysen sind einseitig auf eine vorausgewählte Leserschaft zugespitzt. Das Material aber ist der Stoff, aus dem auch die Mandatsverlängerung für Afghanistan, aus dem der Umbau der Bundeswehr, aus dem das Gefühl der Bevölkerung für Veteranen 
und Soldatenbegräbnisse, aus dem Sonderjustiz und Bewusstlosigkeit gleichermaßen gemacht sind.

Es muss betont werden, dass unsere Absicht weder eine diskursanalytische ist, noch eigentlich kulturwissenschaftlich sich in die Verhältnisse von Kultur und Krieg bzw. Intervention der Gegenwart, im Rahmen der deutschen Politik, einbringen möchte. ${ }^{1}$ Wir haben den Heimatdiskurs als einen wesentlich die Entscheidungen und Praktiken der Gesellschaft im, und in Bezug auf, die Auslandseinsätze („Interventionen“) beeinflussenden geortet und müssen versuchen, ihn zu verstehen um ihn denen, die Entscheidungen treffen und denen, die sich dazu verhalten, zu erklären. Das gilt auch denen gegenüber, die ihn zu verstehen meinen und denen, die sich selbstbestimmt dazu zu verhalten glauben; jede Diskursanalyse unterliegt dem Problem der Komplizität. Die Offenlegung der Grundmuster und Subtexte eines Diskurses ist immer Kritik und Handlungsanweisung bzw. Sprechhinweis zugleich. Damit wird eine Arbeit am Heimatdiskurs notwendig politisch und fordert einen rational begrenzten Regress der Wissenschaft dahingehend heraus, dass sie die endlos nach hinten erweiterbare Reflexion ihrer eigenen Voraussetzungen an einer pragmatischen Stelle abbrechen muss: Dazu sind einige Rückgriffe nötig, die zugleich epistemologisch gebraucht werden können: woher wissen wir, was wir wissen und wie ist dieses Wissen zustande gekommen? Dies geschieht, wie gesagt, immer im Rahmen der sozialwissenschaftlichen Freiheit, Anfang und Ende und Intensität dieses Rekurses festzulegen, also nicht endlos in unauslotbare Tiefen hinabzusteigen; das unterscheidet uns von der Philosophie.

Zwischen den Wir unseres Zuordnungsmechanismus steht Bourdieus Anspruch, dass Wissenschaft leisten soll, dem Bürger die Meinungsbildung zu ermöglichen. Zwischen dem kollektiven Wir der Deutschen und dem Wir der wissenschaftlichen Gemeinschaft gibt es mehrfach gebrochene Beziehungen. Gibt es in Fragen von Krieg und Gewalt - man würde gerne sagen, in den „Neuen Kriegen“ - die Differenz von Experten und Laien so klar wie früher? ${ }^{2}$

Die Loyalität der Wissenschaft, quasi im Staatsauftrag die Anthropologie des nationalen Kollektivs zu dekonstruieren, ist ein prekärer Topos. Politische Anthropologie, Interventionsforschung, und die dazu gehörigen Sozial- und Kulturwissenschaften sind - soweit theorieorientiert und im „Grundlagenbereich“, in der Forschungsfinanzierung weitgehend staatlich reguliert (Nordstrom 2009:

1 Die u.W. einzige nachhaltige Beschäftigung in Deutschland mit diesen Phänomenen auf einer diskursanalytischen Basis findet sich in der Zeitschrift KultuRRevolution.

2 Lyotard leugnet diese Differenz schon bei Vietnam, und in der Tat ist dies eine postmoderne Setzung, die Differenz zu verringern oder gar aufzuheben. 
71ff); es gibt viel Unbehagen an der Forschung, die sofort mit Krieg oder Kriegsverbesserung assoziiert wird (vgl. SZ „Ungeliebte Militärforschung“, 27.2.2012, Chiari 2012: 38f.). Der Staat ist implizit auch ein Komplize der Forschung, und doch wird es im Bezug auf den Heimatdiskurs etwas komplizierter als zum Beispiel bei der physikalischen Grundlagenforschung. Die Dekonstruktion seines eigenen weltpolitischen Handelns und der damit verbundenen innergesellschaftlichen Konsequenzen stellt ein eigenartiges Verhältnis von unbehaglicher Mischung aus Erkenntnisbestreben und Aversion gegen Kritik her, das zu tiefgestaffelten Legitimationsübungen des Adressaten „Staat“ führt. Andererseits ist die so genannte autonome Forschungsfinanzierung nie frei von der Verdächtigung, wir betrieben ja doch „,nur“ verkappte wissenschaftliche Politikberatung. Man kann sinnvolle Aussagen zum Thema Intervention fast nur machen, wenn man sich in ein affirmatives Verhältnis zu genau den Systemen begibt, die man auch kritisiert. Oder man bewegt sich in einem moralischen Diskurs, der sich unsensibel gegenüber empirischen Befunden zeigen muss, wo seine Prinzipien angegriffen werden, häufig in parteipolitischen Beschlussdiskussionen oder gegenüber Militärs innerhalb von festgelegten Auftragsstrukturen, in denen sich Empirie nicht gegen Definition durchsetzen kann.

Ein Problem ist, dass wir uns zwar eindeutig auf der Expertenebene befinden, aber eine offene Flanke gegenüber einer von den Laienkollektiven abgesetzten politischen Deutungshegemonie bestimmter Gruppen haben - z.B. Abgeordnete, professionelle Regierungsberater und „Pundits“3. Zu Letzteren werden wir unweigerlich selbst gerechnet, wenn wir öffentlich argumentieren, ohne uns erkennbar die Grenzen und Formate wissenschaftlicher Äußerungen aufzuerlegen. Wenn wir Experten und Laien gleichermaßen den unterschiedlichen Kollektiven zuordnen, die im Diskurs agieren und reagieren, also die Wir analysieren, bemerken wir, dass wir diese verschiedenen, einander überschneidenden Gruppen auch als solche begreifen können, die mitreden, mitreden wollen und mehr oder weniger können, und doch ein Man repräsentieren. Sie beziehen ihr Wissen aus den Massenmedien, ohne ihre Quellen zu problematisieren (Bussemer 2010 sowie das ganze Schwerpunktheft der vorgänge Nr. 192/2010). Ein gutes Beispiel ist das furiose Buch von Engelhardt (2010). Die Medien beeinflussen den Heimatdiskurs, sind aber vor allem von ihm getrieben, oft über die

3 Pundit (engl.) meint neutral einen Experten, der sich den Massenmedien als Kommentator anbietet. Der Begriff wird oft sanft ironisch verwendet, wenn die Pundits auch nicht mehr wissen als die Experten von Think Tanks. Interessant wird es, wenn auftragsgebundene Think-Tanks ihren Experten unzensierte Öffentlichkeit erlauben (müssen) und dann ihre Auftraggeber in objektivem Licht zeigen (müssen). 
Medien, und da diese sich selten ihrer eigenen Getriebenheit bewusst sind bzw. dieser Ausdruck geben, ist das, was letztlich zu folgenreichen Entscheidungen und komplexen Legitimationsprozessen führt, nicht an der Oberfläche zu sehen (vgl. Neumann in diesem Band). Diese Beobachtung macht unsere eigene Arbeit mit Medien plausibel.

Hier ein bemerkenswertes Beispiel: Für die USA ist es nicht möglich, einen Krieg (War) zu verlieren. Es gibt immer einen Feind (Enemy), der entweder virtuell ist (Terror), oder neuerdings gruppenspezifisch benannt wird (Taleban, Al Qaeda etc.) und solange der Feind ist, muss er besiegt werden. Deutschland hat im 20. Jahrhundert mühsam gelernt auch auszusprechen, dass und in welchem Ausmaß man Kriege verloren hat und besiegt wurde. In Deutschland durfte man lange Zeit nicht von Krieg sprechen, dann durfte man, hatte aber keinen Feind.

\section{Abbildung 1: Merkel nennt es Krieg}

\section{FAz, 19.12.2010 \\ Merkel nennt es Krieg}

\section{Die Kanzlerin auf Blitzbesuch in Afghanistan. Treffen mit Karzai}

Quelle: Frankfurter Allgemeine Zeitung, 19.12.2010.

MAN kann über das „es“ mitreden. Jeder, der eine bestimmte Art von Zeitungen liest, weiß das „es“ sofort zuzuordnen. Es kann nur um Afghanistan gehen. Für jedes der differenzierten Wir bedeutet dieses ,es“ etwas anderes, aber immer wird es mit Krieg gleichgesetzt, die Klassifikation ist erfolgreich beendet, ab nun ist der Auslandseinsatz Krieg - und zwar unabhängig von Völkerrecht, Kriegsrecht und Konventionen.

Der Krieg bindet die Kollektive aneinander - und eint sie in der Komplizenschaft. Die Grundformel für diese Komplizität hat Dirk Baecker aus den Sozialwissenschaften heraus formuliert: Wir können die Komplizenschaft in beschränkten und modifizierten Fällen auf die Gemeinschaft aller Wir-Kollektive ausdehnen, die in Deutschland sich zum Afghanistan-Einsatz verhalten. Mit der Freigabe des Kriegs als Rahmen für ein konkretes Geschehen entstehen auch neue semantische Bestimmungen. Es gilt, ein ganzes Vokabular neu zu ordnen: Kriegsheimkehrer, Veteranen, Gefallene; für die Invaliden haben wir noch keinen richtigen Begriff, und an den Gefallenen orientieren sich neue Diskursvarianten: Helden, Krieger, professionelle Interventionssoldaten; gleichzeitig entsteht ein neues, zusätzliches Wir, das sich über die Gefallenen mit der Heimat, mit der deutschen Politik, gegen sie oder ohne sie, formatiert. Verteidi- 
gungsminister de Maizière reagierte im Februar 2012 mit Unverständnis, dass sein Publikum mit den Vorschlägen zur Ehrung von Veteranen nichts anfangen konnte (,Verteidigung - Bundeswehr: Widerstand gegen Veteranenehrung am Volkstrauertag. SZ, 16.2.2012). Veteranen sind in der Gesellschaft noch nicht angekommen, der Heimatdiskurs bereitet sie aber darauf vor. Ein anderes Beispiel ist die Umdeutung von Reservisten in der Interventionsarmee (Bonacker et al. 2010, Daxner 2011, Müller 2012).

Und noch eine Vorbemerkung, die wiederum auf die Wir des Anfangs eingeht und sie in gewissem Sinn erweitert, entgrenzt, und doch wiederum einschränkt: Im Alltagssprachgebrauch kann Wir ja auch bedeuten ,wir Deutschen“ oder „Alle“, für Soldaten kann es die NATO, die Bundeswehr, die Kompanie meinen, für die Leitartikler eine imaginäre, durch rationale Urteile verbundene Intelligenz. Die folgende Übersicht gibt nicht alle Varianten an, die eine je verschiedene „Vergemeinschaftung“ (über Werte, soziale Zuordnungen und funktionale Differenzierung) erfahren.

WIR - der Nationalstaat Bundesrepublik Deutschland in seiner souveränen Außen- und Sicherheitspolitik.

WIR - als Entsendestaat von Militär und Polizei, als Mitfinanzier und Ausrüster einer Intervention, als Heimatland von gefallenen, Veteranen, und Verwundeten.

$W I R$ - die Bundesrepublik Deutschland in einem Geflecht supranationaler Verpflichtungen und Allianzen (UN, NATO, Bündnisse (OEF), Konventionen (Menschenrechte). WIR - „Deutschen“, deutsche Bürgerinnen und Bürger in einer moralischen und pragmatischen Beziehung zu den Menschen in Afghanistan, die aus diesen Beziehungen (Empathie, Ablehnung, wirtschaftliche und kulturelle Interessen) Politik machen wollen und Entscheidungen zu beeinflussen suchen.

WIR - die wir heute hier wissenschaftlich und als ExpertInnen darüber diskutieren, was wer im Einsatzgebiet und daraus abgeleitet, bei „uns“, erwarten kann. (Daxner 2011a)

Dieser Formalismus wird uns sehr hilfreich sein. Wenn wir etwa feststellen, wieweit nationalistische Ressentiments ein Wir bestimmen, das zu wissen meint, was „unsere“ Soldaten im Kampf mit den Taleban tun dürfen und sollen, dann wird eine ganz komplizierte Rückbindung dieses Wir auf Gesellschaft und Staat in der Bundesrepublik deutlich. Nun ist bei den meisten Interventionen von den beteiligten Nationalstaaten selten die Rede; supra-nationale Bündnisse, bilaterale Abkommen und alle möglichen Sachzwänge lassen die nationalstaatliche Struktur der sog. Internationalen Gemeinschaft (als einer hegemonialen!) in den Hintergrund treten, auch, weil es sich bei den intervenierten Ländern meistens nicht um Nationalstaaten im modernen Sinn handelt - und weil die Nationalstaaten 
strukturell auf dem Rückzug sind. Wenn aber rhetorisch „,nationale Interessen“ vorgebracht werden - wie in der Euro-Krise - dann ist die nationale Konstitution eines Wir gegenüber globalen, lokalen und hybriden Varianten (,transnational“) keineswegs trivial, weil sie mit Hilfe von aggressiven Spielarten im Heimatdiskurs zu einer Radikalisierung von politischen Entscheidungen führen kann; oder aber zu keinen Entscheidungen führt, weil man lieber sich einer Führungsmacht anvertraut, als national bestimmt, dieser entgegentritt.

\section{Fragen an das Thema}

Das Land im Krieg - undenkbar; Deutschland wieder an allen Ecken der Welt militärisch präsent - ein Albtraum oder Unterwerfung unter die Realitäten, die so gerne alternativlos genannt werden? Eine moralische Verpflichtung, die unser Land von Einsatz zu Einsatz treibt, das Böse tun, um das Gute zu erreichen, Krieg zu führen, um Frieden zu schaffen?

So grob wird selten ein Argument gebraucht, aber auch feinere Schattierungen dieser Fragen sind noch beunruhigend genug. Waren wir nicht zu Recht stolz darauf, dass Deutschland sich aus der Nachkriegszeit heraus zu einer entwicklungsfähigen Demokratie und einem glaubwürdigen Konzept internationaler Solidarität entwickelt hatte; dass dieses Land bei aller Westbindung, Bündnisloyalität und Dankbarkeit gegenüber den früheren Alliierten eine eigenständige Position in der so genannten internationalen Staatengemeinschaft eingenommen hatte. Vorbei die Zweifel, ob nicht der Faschismus unter einer dünnen Oberfläche noch auf eine weitere Chance lauerte, wie das in den 60er Jahren durchaus noch diskutierbar war. Vorbei die Selbstbeschreibung „Wirtschaftsriese - politischer Zwerg", die unsere Nachkriegsstellung in der Welt charakterisierte.

Nach 1989 waren wir doch bereit, die Friedensdividende mit einzustreichen. Die Balkankriege der frühen 90er Jahre belehrten uns schnell eines Besseren. Und schon standen wir im Kosovo, führend an KFOR beteiligt. Heute sind wir einer der wichtigsten Partner des militärischen Teils der Intervention in Afghanistan 2001-2014. Das Abzugsdatum steht zwar schon fest, aber ob es halten wird, ist ungewiss. Werden wir also dabei sein, wenn es weiter geht? Gerade hat sich die Militärgeschichte des Themas bemächtigt, und das ist ein sicheres Zeichen dafür, dass der Wandel im Begriff ist, ins kollektive Gedächtnis unserer Gesellschaft zu treten und die Narrative des Nachkriegs-Deutschland erneut umzudeuten.

Die Wissenschaft muss auch deshalb Antworten suchen, weil das, was bei

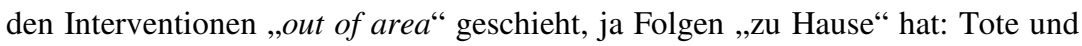


Verwundete, Traumatisierte und Veteranen kommen „,zurück“; der Militäreinsatz kostet unheimlich viel Geld. Private Sicherheitsfirmen kämpfen nicht nur vor Ort, sondern machen sich auch zu Hause an allen möglichen öffentlichen Orten breit und verunsichern uns mehr als sie uns schützen. Demagogen aller Schattierungen reden uns ein, dass wir Abstriche bei der Freiheit machen müssen, um Sicherheit zu erhalten.

Die Wissenschaft, die Universität, ist Forum für die Fragen der Zeit (Karl Jaspers). Dass die Probleme relevant sind, dass die Probleme identifiziert werden müssen, dass man der Politik Lösungsvorschläge anbieten muss, ist keine Wahl aus Gesinnung oder politischer Parteinahme. Man kann sehr wohl die Intervention in Afghanistan für richtig erachten und trotzdem fast alles, was in ihrem Rahmen geschieht, kritisieren; oder man kann sie von Anfang an ablehnen, und dennoch mit jeder Kritik einen Verbesserungsvorschlag für eben diese Intervention einbringen. Man kann sich darauf zurückziehen, dass wir eine Parlamentsarmee haben und Bündnisverpflichtungen dazu, oder man beruft sich auf die Mehrheitsmeinung oder gar Mehrheitsstimmung der Bevölkerung.

In diesem letzten Absatz gibt es kein Wir und kein Ich mehr, sondern nur noch MAN. Wer und was ist dieses Man, das einen Diskurs aufbaut und sich bewegen lässt, der entscheidend zur Meinungsbildung, Ideologisierung und Verdrängung eines Einsatzes deutscher Truppen fernab in Afghanistan beiträgt. Einen Diskurs, den es vor dem Kosovo-Einsatz nur sehr unterschwellig, wenn überhaupt, gegeben hatte, und der mit dem langjährigen Afghanistaneinsatz zu einer wichtigen Komponente in der macht- und herrschaftsbezogenen Dynamik der Intervention werden sollte.

Unsere Fragestellung war von Anfang an nicht darauf gerichtet, wie die Staaten sich zur schwindenden Norm der Souveränität und zum Nichteinmischungsgebot verhielten, sondern was diese Haltung bzw. die Interventionsakte mit den beteiligten Gesellschaften - den intervenierten und den intervenierenden - machen.

Einen Teil der Fragen haben wir ohne speziellen Deutschlandbezug in der Theorie von der Interventionsgesellschaft aufgehoben. Der Kern dieser Theorie ist, dass Intervenierende und Intervenierte eine neue Form der Gesellschaft herstellen, die irreversibel ist, wenn sie auch nicht von Dauer sein muss oder sein soll. Wenn man die Literatur nur an den Beispielen Kosovo und Afghanistan studiert, kann man bereits Hinweise auf speziell deutsche (oder amerikanische, britische, europäische etc.) Deutungsvarianten finden, erweitert man diese Liste um weitere Interventionen, dann ergeben sich weitere Dimensionen - Eingriffstiefe, Machtstrukturen, Gewaltstrukturen, Ergebnisse bezogen auf globale Sicherheitsarchitekturen etc. - einschließlich einer Verdatung, die der Normali- 
tätsthese eine besondere Variante gibt. ${ }^{4}$ Interventionen sind normal. Auf bestimmte Umstände reagiert die so genannte Internationale Staatengemeinschaft eher mit einer Intervention, als dass sie eine solche unterlässt. Das hat sich seit Libyen und Syrien nur scheinbar geändert.

Für mich bedeutete das die Frage nach einer Anthropologie von Interventionen. Zudem konnte jeder nachvollziehen, dass das Mandat von UNMIK, als Staat zu agieren, doch etwas anderes war als das Wie ein Staat zu agieren. Fragen von Regierungsform (Governance), Legitimität und Effektivität sowie fundamentale Beziehungen zwischen der intervenierten Gesellschaft und den Intervenierenden traten sehr schnell zutage: die Intervenierten waren mehrfach gespalten, in ethnische Mehrheiten und Minderheiten, in Rückkehrer aus der Diaspora, Daheimgebliebene, Kämpfer und gewöhnliche Residenten, Junge und Alte, Männer und Frauen. Und dann noch einmal entlang politischer und kultureller Feinstrukturen, Kapitalmischungen und Statusdifferenzen. Was von all dem ,zu Hause“ wahrgenommen wurde, stand zu untersuchen noch aus. Unsere Arbeit wurde, wenn sie denn anfangs wahrgenommen wurde, sehr bald aus einem ganz bestimmten Blickwinkel kritisiert: dem der Normalität von Intervention. ${ }^{5}$ In den ersten Absätzen dieser Einleitung wird aber schon deutlich, dass es sich um ein Interpretationsproblem der Nachkriegsgeschichte handelt, bei dem es auch darauf ankommt, die Position des Interpreten auszuleuchten. Dass es sich um ein deutsches Problem allein handle, ist unwahrscheinlich, dass es sich

4 Die Normalisierungstheorie von Jürgen Link spielt für uns eine wichtige Rolle, kommt allerdings unmittelbar weniger zum Ausdruck als in verschiedenen Anwendungen: Seine Theorie des Normalismus ist einer der bedeutsamsten Beiträge parallel zur Diskurskritik. Dabei steht Link meinen Forschungen kritisch gegenüber (Link 1999, 2000, 2009 und 2010; Parr 2010).

5 www.german-foreign-policy.com (aufgerufen am 20. Mai 2010). Der Text ist wortgleich bis paraphrasiert sehr oft nachgedruckt und als Abwehr von Veranstaltungen, Vorträgen usw. verwendet worden. Noch im Dezember 2011 (www.asta-marburg.de) wurde der Vorwurf zitatlos wiedergegeben; die Meldung wurde unkommentiert von der Piraten-Partei Marburg-Biedenkopf übernommen (www.piratenparteimarburg.de/aggregator/sources/14). Denn das Nichtwahrhabenwollen des Faktischen und des empirisch Belegten ist ein Teil des Heimatdiskurses selbst. Am 10.2.2011 verbreitete www.bundeswehr-wegtreten.org/akt_2011 eine Version über die ,,,unehrenhafte“ Verabschiedung von Kriegsforscher M.D., worin geschlossen wurde, ich würde für die Bundeswehr arbeiten, was weder in der Vergangenheit noch gegenwärtig stimmt. 
um ein globales Problem auf einer Dimension handle, ist empirisch leicht zu widerlegen. Worum also geht es?

Dass Deutschland sich mit etlichen anderen Staaten des westlichen Bündnisses und einigen NATO-Aspiranten und Mitgliedern der Partnership for Peace am Kosovo-Einsatz beteiligte, wird von vielen als Bruch mit dem bisherigen Nachkriegsnarrativ der Bundesrepublik betrachtet. Dass die NATO eine vom Verteidigungsfall entfernte Operation zu einer jahrelangen Intervention ausweitet (Afghanistan) oder diesen Fall gleich gar nicht beansprucht (Libyen), zeigt ganz andere Interventionsstrukturen und Legitimationen als frühere Operationen oder davon völlig unterschiedene Kriege wie den der USA und ihrer „freiwilligen“ Koalitionäre gegen den Irak (2003). Was uns vielfach besonders übel genommen wurde, war aber eine andere, eher schlichte Beobachtung: unabhängig davon, ob wir eine Intervention für völlig illegitim halten (Irak 2003) oder sie als Bestandteil der neuen Weltpolitik analysieren (Afghanistan) - also ambivalent bzw. „,neutral“ uns verhalten - finden wir bestimmte Merkmale von Interventionsgesellschaften in beiden Fällen, und bei anderen Interventionen ebenfalls. Wir haben also eine These aufgestellt, die die Trennung von Interventionsursachen und Interventionsfolgen behauptet. Das ist kein ganz nebensächlicher Befund. Er besagt nämlich zunächst nichts anderes als eine weitgehende Universalität von Interventionsfolgen gegenüber der Kontingenz, von Interventionsanlässen. Wie das in die Entsende- und Einsatzländer „transportiert“ wird, hat uns angesichts des kurzlebigen Gedächtnisses über Interventionsursachen zu interessieren. Gibt es eine Reisefähigkeit der Interventionsgovernance?

Am Ende des Einsatzes in Afghanistan steht die Umwandlung der Bundeswehr in eine Interventionsarmee als Reformvorhaben auf der Tagesordnung. Die Einsätze bringen damit notwendig und empirisch ein Verhältnis des Nationalstaates Deutschland zur intervenierten Gesellschaft im Kosovo bzw. in Afghanistan hervor. Mit anderen Worten: durch den Auslandseinsatz wird eine strukturelle Beziehung zwischen den Systemen der deutschen Gesellschaft und denen der intervenierten Länder hergestellt. Wir werden später feststellen, dass es auch Beziehungen zwischen den Lebenswelten der beiden Gesellschaften geben muss. Mit dieser Festlegung werden mehrere Fragen aufgeworfen: worin unterscheiden sich die deutschen Qualitäten dieser Beziehungen von denen anderer intervenierender Staaten? Welche Folgen haben die Interventionen für die deutsche Gesellschaft, für ihr Regierungshandeln, für ihre Innenpolitik, für ihre Kultur, und für ihre supra-nationale Einbindung? Gibt es bei den Intervenierten besondere Folgen der spezifisch deutschen Anteile an der Intervention?; oder werden diese durch übergeordnete militärische Institutionen (KFOR, ISAF) oder zivile Einrichtungen (UNMIK, OSZE, UNAMA etc.) überbaut, quasi homogenisiert? Wir 
müssen hier die Theorie der Interventionsgesellschaft ganz verkürzt wiedergeben, um den Rahmen anzugeben, in dem der Heimatdiskurs auch wirkt. Nicht nur in der Heimat, sondern durch Verhalten und Reflexion der im Einsatzland tätigen Intervenierenden, wird der Diskurs transportiert. Dadurch entstehen ja vielfach die Fragen, die der Heimatdiskurs selbst aufwirft: Sind wir im Krieg? Wohin mit den Veteranen? Wie ehrt man Kriegstote? Wofür stehen wir in Afghanis$\tan$ ?

Wenn es aber um die Antworten geht, dann haben wir die Erfahrung gemacht, dass der Weg über die Theorie der Interventionsgesellschaft oft sehr viel besser verstanden und angenommen wird als die notwendige und oft aufwändige Erläuterung dessen, was wir nicht wollen: nämlich eine weitere Variante der ideologiekritischen Medienanalyse zu Auslandseinsätzen zu leisten, wiewohl viel Ausgangsmaterial identisch ist (anderes aber von den Medien überhaupt nicht zur Kenntnis genommen wird, z.B. die Forschung vor Ort und ethnologische wie soziologische Analysen vor der Diskursanalyse des Heimatdiskurses). Deshalb stehen auch hier die zusammengefassten Thesen zur Theorie der Interventionsgesellschaft am Anfang.

\section{Die Interventionsgesellschaft}

$\mathrm{Ob}$ und unter welchen Umständen eine Gesellschaft Bewusstsein von einer Tatsache entwickelt, ist ein kompliziertes Problem. Schon die kollektive Kenntnisnahme von einem Ereignis oder einer Entwicklung - immer eine große Mehrheit, nie ,alle“ - lässt Schlüsse auf die Filterfunktionen von Macht und individuellen Denkvorgängen, Gefühlen, Befindlichkeiten zu, die keineswegs eindeutig und in der ausgesprochenen Feststellung bestimmt sind. Wenn uns etwas am A.... vorbeigeht, erklären wir es für irrelevant oder wir verdrängen, dass es für uns sehr wohl wichtig sein kann. Wenn wir versuchen, einer Sache Bedeutung über unsere Interessen hinaus zu verleihen kann es sein, dass dies aus dem Bestreben Macht über andere zu gewinnen geschieht, oder weil wir die Reaktionen auf eine von uns eingefädelte Sinngebung sehen wollen.

Wir wollen diese komplexe Diskussion hier eingrenzen. Es geht darum, in welchem Maß die Auslandseinsätze der Bundeswehr und die deutsche Interventionspolitik Gegenstand der öffentlichen Erörterung geworden sind; inwieweit sich Individuen subjektiv betroffen fühlen, ohne objektiv betroffen oder beteiligt zu sein - an diesem Punkt kann man schon sehen, wie schwierig es ist, festen Boden unter die Füße zu bekommen. Subjektive Betroffenheit (,Das geht uns alles an, weil...") und ihre normativen Bindungen, objektive Betroffenheit z.B. 
als entsandter Soldat, sind jeweils durch öffentliche und private Umstände bestimmt, die ganz und gar nicht feststehen und von allen anerkannt werden. Es ist eine Sache, ein Problem zu erkennen und Lösungen anzustreben, und ein anderes, dieses Problem zu thematisieren, seine Lösung erstrebenswert und ,politisch“ zu machen. Wie wird das Problem der Auslandseinsätze zum legitimen Gesprächsthema - zu dem, worüber MAN spricht? Wer darf welche Lösungen mit welcher Autorität erörtern? Wie wirkt das, was legitim erörtert wird und was sich sonst wie Bahn bricht, auf die Entscheidungen und das Regierungshandeln und die Befehlsstruktur und die Interventionspraxis von Bundeswehr und Zivilisten im Interventionsland? Welche Rückbindungsschleifen, Verdrängungen, Verschiebungen, welche Strategien gibt es, sich mit Problem und Thema zu befassen? Und nicht zuletzt: was ist das Erkenntnisinteresse von Wissenschaft an der Beantwortung dieser Fragen bzw. die welches Wissen wird produziert, damit es in diesen Diskurs eingeht?

Wir werden ihn Heimatdiskurs nennen und nicht einfach Interventionsdiskurs, sofern er sein Zentrum in einem Land hat, das sich aktiv an einer Intervention engagiert und Truppen für diese Intervention entsendet. Es ist dies ein zentraler Diskussionspunkt in unserer Forschungsgruppe. Kein Heimatdiskurs ohne Intervention, aber etliche Interventionen ohne Heimatdiskurs oder seine Äquivalente in anderen Gesellschaften, d.h. auch Sprachen und Begriffen. Und warum es bei uns die „Heimat“ ist, muss noch begründet werden. In letzter Zeit, nach dem angekündigten Umbau der Bundeswehr, zeitgleich mit der Übergangsphase zum Truppenabzug aus Afghanistan, wird das Thema auch in Deutschland deutlich auf diesen Zusammenhang orientiert: militärgeschichtlich und politisch, aber auch stark subjektiviert.

Die Hauptthesen zur Interventionsgesellschaft sind relativ apodiktisch und hart konturiert; Modifikationen, Einschränkungen und Erweiterungen haben sie seit $2008 \mathrm{zu}$ einer belastbaren Theorie werden lassen, die in einigen Aspekten nicht den gängigen Hauptströmungen der wissenschaftlichen Politikberatung und der politischen Wissenschaft folgt: 
Thesen zur Interventionsgesellschaft ${ }^{6}$

Jede Intervention erzeugt eine Interventionsgesellschaft.

Interventionsgesellschaften sind bestimmt durch die dynamische Beziehung von Intervenierenden und Intervenierten. Diese Beziehung führt zu teilweisen Verschmelzungen, kollusiven Verhältnissen und zur Entwicklung neuer Gesellschaftsstrukturen, die nicht einfach Kompromisse zwischen den Strukturen der beiden Gruppen sind. Diese neuen Strukturen sind weitgehend irreversibel.

Alle Interventionsgesellschaften sind strukturell einander ähnlich und vergleichbar, unabhängig von ihren höchst unterschiedlichen kulturellen Erscheinungsformen.

Die Systemebene dieser neuen Interventionsgesellschaft steht in einem besonderen Spannungsverhältnis zur Lebenswelt der Intervenierten. Damit werden unmittelbar die Institutionen (Spielregeln) dieser Gesellschaft und alle Aspekte von Governance auch auf der mikro-sozialen Ebene betroffen (Konfliktregelungen, Traditionen, Werte, Habitus).

Daraus ergibt sich zwingend die Entstehung einer Interventionskultur in der Interventionsgesellschaft.

Bei der Steuerung der Beziehung zwischen Intervenierenden und Intervenierten spielt vor allem der Heimatdiskurs der ersteren eine entscheidende Rolle.

Die beiden folgenden Thesen beziehen sich nur auf Afghanistan, dienen aber dem Kontext der im Heimatdiskurs erläuterten Verhältnisse:

Die Verschmelzung bzw. kollusive Verbindung von intervenierten Afghanen und intervenierenden internationalen Akteuren ist nicht vollständig und nicht gleichmäßig. ${ }^{7}$ Sie erhält durch den bevorstehenden Teilrückzug von ISAF eine besondere Dynamik, weil die Übergangsphase (Transition) bis 2014 dem Geschehen große Aufmerksamkeit sichert.

Es gibt einen Gewaltmarkt in Afghanistan, $d$. h. viele Gewaltunternehmer profitieren davon, dass Gewaltanwendung nicht de-eskaliert wird; ob andere Gewalt mit genau dem Ziel der De-Eskalation oder des militärischen Sieges anwenden, lässt sich weniger denn je mit Sicherheit sagen. Das beeinflusst die Abzugsdebatte in Deutschland.

6 Die Versionen der Theorie haben seit 2008 eine geringe Variabilität und Ausdifferenzierung gegenüber dem ursprünglichen Text erhalten. Die vorliegende Fassung ist die letzte und umfangreichste, wie z.B. in Daxner 2011 (Vorgänge) verwendet wird.

7 Kollusion ist die Komplizenschaft zwischen zwei identischen, unrechtmäßigen Handlungen, die aus unterschiedlichen Ergebnissen zu wechselseitiger Abhängigkeit führen. Wenn etwa eine deutsche Straßenbauinitiative Taleban bezahlt, um den Schutz des sonst gefährdeten Bauvorhabens zu erkaufen; die wollen die Straße nicht, werden aber von der lokalen Bevölkerung, die sie sehr wohl möchte, zur Akzeptanz gedrängt. 
Wie wir über Afghanistan sprechen, hat Einfluss auf die Wirkung unseres Bildes von Afghanistan und damit auch auf Deutschlands Einfluss in der Welt (vgl. Janzen in diesem Band) und auf die Legitimation durch eine sich informierende Öffentlichkeit. Die Theorie konzentriert sich nicht auf den Staat, sondern die Gesellschaft. Nicht Herrschaft und Regierung stehen im Mittelpunkt, sondern Macht und Institutionen. Die Interventionen mögen von Staaten als Akteuren ausgehen, sie erzeugen aber Strukturen und Kommunikation unter sozialen Gruppen und Individuen, die die Bedingungen und Merkmale von Interventionsgesellschaften repräsentieren. Es wäre nun auch hier möglich, die gesamte Theorie in ihren Elementen zu erklären. Wir verzichten an dieser Stelle darauf, weil es uns um den Heimatdiskurs geht, verweisen aber auf die ständige Weiterentwicklung der Thesen und die Ausdifferenzierung der Theorie seit 2008.

Im Folgenden setzen wir uns explizit mit zwei Aspekten auseinander: Was bedeutet es, dass Interventionsgesellschaften eigene Interventionskulturen ausbilden? Und: wie kann man den Heimatdiskurs, primär in Entsendeländern, fassen und dekonstruieren? Diese beiden Aspekte sind durchaus theoretisch anspruchsvoll und praktisch folgenreich. Sie betreffen ja nicht nur die Konkretisierung der Behauptung, durch jede Intervention entstünde eine neue, nicht bloß vertikal neu gelagerte Form von Gesellschaft mit ihren durch die Intervention geschaffenen Konflikten; sie behaupten auch, dass zunächst vor allem die Intervenierenden durch einen speziellen Diskurs (teil)gesteuert werden. Damit werden Problembewusstsein, Themenauswahl, Legitimation und Rückbindung im Kontext von Interventionen lange vor der Meinungsbildung und den formalisierten Prozessen der politischen Entscheidungen in Gang gesetzt. Wir werden sehen, wie der Heimatdiskurs die Medien treibt viel mehr als er von ihnen getrieben wird; wir werden sehen, welche alten und welche neuen diskursiven Praktiken den Heimatdiskurs strukturieren und von ihm strukturiert werden.

\section{Modernisierung und Befreiung - legitimierende Diskurselemente}

Zwei Subtexte jedes Interventionsdiskurses sind schwer bloßzulegen. Den meisten militärischen Interventionen seit Kolonialzeiten sind mehr oder weniger offene Modernisierungskonzepte eingeschrieben. Dies spielt heute mit der Rückständigkeitsvermutung gegenüber den Objekten von Demokratieexport und exekutiven Vollmachten von Intervenierenden, z.B. bei der Finanzwirtschaft und bei Projektleitungen, eine Rolle. Der zweite Subtext heißt Befreiung. Was in der Dekolonisierung evident erschien - Befreiung von Fremdherrschaft und Aus- 
beutung - ist heute ein unterschwelliges Legitimationsinstrument für die Intervenierenden, oft auf der Suche nach öffentlicher Zustimmung.

Modernisierung gehört zu den wichtigsten Elementen der Phänomenologie von Interventionen, sie ist ein Hauptgrund für die These von der irreversiblen neuen Gesellschaft, die von der Intervention hervorgebracht wird. Das Befreiungsmotiv ist ein Antagonist jener Friedenskonzepte, die die Intervention strikt ablehnen. Es gilt hier einen kurzen, aber ganz wichtigen historischen Exkurs einzufügen: die Geschichte der intervenierten Länder beginnt nicht erst mit der Aufmerksamkeit, die diese Länder durch die Intervention erhalten.

Die nicht-intendierte Ethnologie früherer Reisebeschreibungen und Reportagen geht in den Corpus nicht-massenmedial vermittelten Wissens ein, das der Archäologie bedarf, um als Werkzeuge von besserem Verständnis dienen zu können. Für die Region Afghanistan gilt dies beispielhaft für Kisch (1993), Schwarzenbach (2001) und Quest (2006). Sowohl in den kollektiven und kulturellen Gedächtnissen ist eine Fülle von Wissen eingeschrieben, das sozusagen „weiterarbeitet“, während es als Gewissheit oberflächlich erscheint.

Interventionskultur hat nichts mit einer „Kultivierung“ der Intervention durch die Intervenierenden zu tun, im Sinn des Alltagsbegriffs, etwa wie „Esskultur“. Der Begriff meint jene speziell durch die Intervention sich aus der Verbindung von Intervenierenden und Intervenierten entwickelnde Kultur, die dann wieder ins Entsendeland rückgespiegelt wird und in die Interventions- und Heimatdiskurse eingeht. Dies soll die letzte „Vorbemerkung“ zum Heimatdiskurs sein, den wir nun in den Mittelpunkt rücken.

\section{Der Heimatdiskurs - Erste Näherung}

Zunächst die allgemeinste Definition des Heimatdiskurses, um diesem Ausschnitt der Interventionstheorie einen ersten begrifflichen Rahmen zu geben:

Heimatdiskurs bezeichnet die Summe aller diskursiven Praktiken und Strategien, die sich mit der Legitimation, Anerkennung und Bewertung von Politik und Truppeneinsatz außerhalb des nationalen Territoriums befassen.

Im Falle Deutschlands ist das eine Beschäftigung vor allem mit der Außen- und Verteidigungspolitik im Kontext der Einsätze im Kosovo (1999ff.) und Afghanistan (2002ff.), aber auch zunehmend im Kontext globaler Innenpolitik, des Kriegs gegen den Terrorismus, der Abwehr von Piraten auf Handelsrouten etc. 
Der Heimatdiskurs strukturiert maßgeblich die öffentliche Meinung, die Wechselwirkung von Medien und Öffentlichkeit, die Hintergründe politischer Entscheidungen und die Legitimationspolitik für Auslandseinsätze und globale Bündnispolitik, nicht nur auf militärische Aktionen out of area beschränkt.

\subsection{Kurze Geschichte unseres Begriffs}

Wie kommen wir zu diesem Begriff? Die Entstehungsgeschichte des Terms ist zunächst mit meiner Arbeit im Kosovo und meiner Auseinandersetzung mit der deutschen Rezeption der Diskurstheorie verknüpft. Der Begriff tauchte aus meinem Vorbewusstsein auf, als ich eine Beschreibung dessen suchte, was in Deutschland - zu Hause, daheim - zum Auslandseinsatz auf dem Balkan gesagt wurde. Der Begriff der Heimat erschien als angemessen, weil er als einziger sowohl ironisch als auch pathetisch verwendet werden kann. Man kann gut erklären, warum die römische patria und die französische patrie als Vaterland für unseren Zweck ebenso wenig brauchbar sind wie Mutterland, warum Heimatliebe kein Patriotismus sui generis ist usw.

Ich wollte einen wissenschaftlichen Begriff erzeugen, der gleichwohl Ironie und Pathos einschloss. Heimat kam in meiner Jugendliteratur hauptsächlich auf den Blick nach Hause aus der Fremde vor, oder beim folkloristischen Heimatverein, oder in den reaktionären Formulierungen heimatvertrieben und heimattreu. All das ungebrochen pathetisch, und wenn schon in meiner Perspektive akzeptabel, dann in der Blochschen Verbindung von wahrer Heimat als wahrer Demokratie. Ironisch war unsere Einstellung zum assoziierten Volkslied, oder zur Kleingeisterei gegenüber dem Kosmopolitismus (der ja nicht nur global, sondern auch heimatlos war, wie die Juden, die ja auch keine Heimat hatten, jedenfalls bis 1947). Alle weiteren Prädikate bekam der Heimatdiskurs, nachdem ich den Begriff erstmals erprobte und verwendete. Die Arbeitsgruppe übernahm ihn, er wurde in die Theorie geschrieben, und jetzt ist er ihr Bestandteil. In gewissem Sinn ist er ein Neologismus. Wir befassen uns nicht mit Heimat, aber im Zusammenhang mit dem Diskurs gewinnt das Wort eine definitions- und ausdeutungsfähige Qualität. Wir wollten auch ein wenig provozieren, weil ja die Heimat nicht vorkommt im neuen Interventionsdiskurs deutscher Sprache.

Unsere These ist, dass der Heimatdiskurs im Kontext der deutschen Auslandseinsätze vor allem in Afghanistan die politischen wie auch die moralischen und kulturellen Systeme massiv beeinflusst und dass die Eingriffspraktiken in den Diskurs dem gegenüber relativ unkoordiniert und wenig strategisch erfolgen. Unsere Eingangsdefinition ist deshalb idealtypisch, unsere Arbeitsbasis empirisch unterlegt. 
Mit der systematischen Befassung mit dem Heimatdiskurs aus der Interventionstheorie heraus wurden erste Schichten ab- und aufgedeckt. Wichtige und griffige Beispiele früher Analysen waren Strucks Rechtfertigungssatz, sowie die Totenkopf-Affäre und in zunehmendem Maß die Frage, ob wir im Krieg uns befinden, und wenn ja, wie, warum und wozu? Die Totenkopf-Affäre ging um Soldaten, die sich bei einer Patrouillenfahrt in Afghanistan mit menschlichen Gebeinen, darunter einem Totenschädel, vergnügt hatten und dazu ein entblößtes Glied ins Spiel brachten (Google 356 Hits am 21.8.2012 unter „TotenkopfAffäre - entblößtes Glied“"). Der Gang der Aufdeckung, Kommentierung, Skandalisierung und Bewertung der Affäre ist so typisch für den Beginn der offenkundigen Phase des Heimatdiskurses wie wenige andere Ereignisse. Wenn ein Student auf einen Totenkopf uriniert und das wird durch Zufall bekannt, wird ganz anders reagiert. Aber hier sind das ja Soldaten, unsere Soldaten, im Auslandseinsatz: und jede Menge Vorwissen, Halbwissen und Spekulation geht in Mutmaßungen über die Reaktion, z.B. „der Taleban“, „der Muslime“ gegen uns. Wird man uns jetzt in Deutschland angreifen, werden unsere Soldaten in Afghanistan größeren Gefahren ausgesetzt sein? Man schämt sich fremd in der Heimat, man fühlt sich bedroht.

\subsection{Der Krieg erreicht uns}

Warum war es nicht opportun, bis 2009 vom Krieg zu sprechen, in dem wir uns befinden, oder den wir gerade nicht führen, obwohl wir in ihm sind? Wie kommt also der Krieg in den Heimatdiskurs? Minister zu Guttenberg bemüht die Alltagssprache, und dann bestimmt Kanzlerin Merkel, dass es Krieg „ist“. Nutzanwendung: Vielleicht meint Krieg etwas anderes für die, die ihn als schlimmstes aller Übel ansehen, und die, die ihn zur Legitimation eines normalen politischen Handelns ansehen, also einen bewaffneten, nicht-internationalen Konflikt. Damit werden z.B. die Trennungen von Moral- und Völkerrechtsdiskursen angesprochen, die aber in der täglichen Rede nicht vorkommen.

Ein Beispiel: woher wissen wir mit einem Mal, wie es in Afghanistan aussieht, was der Hindukusch bedeutet, was Paschtunen sind, und dass die Taleban stets „radikal-islamisch“ sind, wie der öffentlich rechtliche Rundfunk sie stereotyp benennt? Der Diskurs transportiert eine bestimmte Menge an Wissen und eine bestimmte Form, die private Ethnologie und Länderkunde, teilweise aber auch öffentliches Gemeingut repräsentiert. Eine Kollegin, die mit einem Afghanen verheiratet ist, wird regelmäßig gefragt, ob ihr Mann „Paschtune“ sei, wenn sie diese Tatsache mitteilt. Nutzanwendung: Es ist notwendig, das Wissen auf 
seine Herkunft und Legitimation zu untersuchen, um seine Geltung zu bestimmen.

Oder wir spielen die Frage durch, ob unsere Soldaten eher für unsere Freiheit und Sicherheit oder für die der Afghanen ins Feuer gehen und vielleicht sterben, und was das eine und das andere mit uns macht. Nutzanwendung: die Diachronizität der Begrifflichkeit innerhalb eines Diskurses und damit Ungleichzeitigkeit in der Politik werden in vielen Diskussionen oft taktisch übertrieben oder vernachlässigt. Im Einzelfall müssen sie aber genau rekonstruiert werden, um keine Artefakte zu produzierten.

Kurz: was die einzelnen Ereignisse des Einsatzes für die verschiedenen Wir bedeuten, ist ganz und gar nicht evident oder ausgemacht, sondern hängt vom Heimatdiskurs ab und von der Konstitution einer Meinungsgruppe in einer definierten und nicht-beliebigen Machtkonstellation, die in einem Bezug zur politischen Macht und damit zu Entscheidungen über diese Ereignisse steht. Wir schauen nicht in die Bundeswehr hinein, die wenigen Studien, die wissenschaftliche und thematische Nähe zu unseren Überlegungen zulassen, sind eher komplementär zu unseren Überlegungen (v.a. Seiffert 2012, Chiari 2012).

Die Beispiele häufen sich, je länger die Interventionen andauern. An jedem einzelnen Beispiel konnte man, wenn man sich im Interventionsgeschehen auskannte, erkennen, dass etwas nicht stimmte. Aber oft war das, was man an Bruch oder Unstimmigkeit zu erkennen meinte, nicht sagbar. Nicht so sehr, weil es verboten war es auszusprechen, sondern weil man Schwierigkeiten hatte, auszudrücken, was man als unstimmig erkannte, gegenüber jenem Man, das von all dem nur eine Meinung, aber kaum eine Ahnung und schon gar kein Wissen hatte. Die Dekodierung des Gesagten führt in Abgründe von verschlungenen Deutungen, deren Konsequenzen unübersehbar sind - und manchmal brisant bis an die Grenze der normalen öffentlichen Verständigung gehen.

Spätestens beim Satz, dass am Hindukusch unsere Sicherheit verteidigt werde, zeigt sich dieses Problem sehr scharf. Was der Verteidigungsminister Struck in diesem Satz ${ }^{8}$ und seiner Regierungserklärung meinte, war den Experten klar: wenn man die Terroristen weit ab von zu Hause (Heimat!) bekämpft oder gar besiegt, dann ist es weniger wahrscheinlich, dass sie zu uns kommen, Anschläge machen, unsere Sicherheit bedrohen. Der Sinn des Satzes war klar, aber schon der Kontext höchst unscharf, und ob an diesem Satz irgendetwas stimmte, d.h. empirisch zu belegen war, bleib unklar. Innerhalb kürzester Zeit grub sich der Satz ins kollektive Kurzzeitgedächtnis, erfuhr Varianten mit bedeutungsvollen 
Verschiebungen ${ }^{9}$ - Freiheit statt Sicherheit - eine Vielzahl von Datierungen und Auslegungen, die weit in die Laienwelt hineinragen und sich vom Ausgangspunkt, dem „Krieg gegen den Terrorismus“, weit entfernen. Damit bespielen wir einerseits ein weiteres Feld - Terrorismus, 9/11, wie hängt Deutschland da mit drin? - andererseits verweisen wir auf eine geopolitische Tatsache, dass wir uns out of area, am Hindukusch, verteidigen - übrigens war damals wie heute nie klar, gegen welchen Feind oder Angreifer.

Dieses Wir spielt nun in einige Dimensionen hinein, die bereits genannt wurden, und sie zeigen die ganze Breite, wenn nicht Tiefe eines Diskurses, der anfangs wenig Sinngebung für eine Kriegsbeteiligung oder eine Einsatzverweigerung zu liefern in der Lage war, aber die dünnen Decken eines realitätsunempfindlichen nationalen Selbstverständnisses schnell durchbrach. Für manche dieser Wir-Identitäten wurde der Hindukusch (wo liegt er, wo ist Afghanistan?) zur Außengrenze, wenn nicht unseres Landes, so unserer Interessen. Für andere blieb er im Wortsinn äußerlich und Afghanistan war weit weg. Hindukusch kennen heute viele Menschen, denen der Gebirgszug noch vor einigen Jahren völlig unbekannt war. Hindukusch steht für das, was sich da hinten, in Afghanistan, abspielt. (Die folgende Analogie ist wichtig und liegt näher als man denkt: vor einigen Jahren war es die jüdischen Klezmer-Musik, die den Erinnerungsdiskurs des Zweiten Nachkriegsnarrativs - Auschwitz - in das kulturelle und öffentliche Bewusstsein transportieren half und zur Legitimierung eines Segments jüdischer Kultur beitrug). Wir wissen so gut, was der Hindukusch ist, wie wir wissen, was die Taleban sind - radikal islamische Terroristen, was die Afghanen sind - Paschtunen, was die Scharia ist - ein Gesetz das Frauen steinigen lässt etc. Dieses Wissen ist ein öffentliches Meinungsgut. Es wird überwiegend, nicht ausschließlich, von Massenmedien transportiert, aber diese Medien sind keineswegs Urheber des Diskurses, sie sind so getrieben wie auch die Öffentlichkeit, die Politiker, die Kulturschaffenden. Manche Begriffe verfestigen sich: Taleban werden zum Modell und reisen um die Welt, z.B. nach Nigeria. ${ }^{10}$

Der Begriff Heimatdiskurs ist ohne (s)eine Verbindung zum Krieg in unserer Sprachtradition kaum zu verfolgen. Im Forschungs- und Arbeitsprozess wird diese Bedeutungsachse immer wichtiger. In Parenthese muss man daran erinnern, dass Heimat und Frieden auch eine Tradition hat, die als Kippfigur und Utopikum eine Rolle spielte und in der Friedensbewegung gegen 1981 noch einmal eine wichtige Funktion haben sollte (Aschmoneit/Daxner 1984). Abgesehen davon war der Heimatbegriff bei den Intellektuellen und der Linken verpönt,

$9 \quad 240.000$ Hits 8.2.2012 (Freiheit); 250.000 Hits (Sicherheit), am 8.12.2012.

$10 \quad 8,8$ mio Hits (!) am 8.12.2012. 
sei es aus ideologischen Gründen, sei es aus damit verbundenen Geschmackstabus (Kitsch, Anachronismus, oder eben ,rechts“ - Heimatvertriebene und Heimkehrer waren damals, um 1980, noch nicht so weit von 1945 weg, vom alles beherrschenden Nachkriegsparadigma).

Intensität und Aufmerksamkeitseffekte aus dem Heimatdiskurs korrelieren ganz stark mit wahrgenommener Unsicherheit im Einsatzgebiet, mit der Dauer des Einsatzes, mit den Toten und Veteranen. Deshalb hat Afghanistan hier größere Bedeutung, aber die Vorbereitung und unterschwellige Verbreitung hat bereits mit dem Kosovo-Einsatz begonnen, etwa mit Scharpings Kriegstagebuch. Medizinische Metaphern sind gefährlich; wir sprechen mit Selbstvorbehalt von einer Inkubationszeit, in der der Auslandseinsatz stark auf das „Hier“ fokussiert war, als Entwicklungshilfe in Uniform u.ä., und das „Dort“ eine völlig erfundene oder einseitig erinnerte Ergänzung darstellte. Die schärfere Trennung von Hier und Dort erfolgte, nur scheinbar paradox, als Krieg (dort) mit seiner Unsagbarkeit (hier) verbunden wurde, und zugleich die Unsicherheit und die ersten Toten die öffentliche Aufmerksamkeit erregten. Inkubation ist insoferne ein ziemlich angemessener Begriff, als sich langsam Symptome von Diskurseinwirkungen zeigten: nicht nur, dass wir im Krieg sind, den wir weder begonnen haben noch eigentlich führen; auch dass aus Toten (Verunfallten?) Gefallene werden, dass die mangelnde Ausrüstung der Bundeswehr zu unvollkommen erklärenden Variablen für die Erfolglosigkeit der militärischen Handlungen ins Bewusstsein trat, ${ }^{11}$ spielt hier eine Rolle.

Mit der Entsendung deutscher Soldaten in Einsätze, die weder in UNmandatierte Peacekeeping-Missionen gefasst sind, noch der Verteidigung der Sicherheit des Landes oder dem Schutz seiner Grenzen dienen, wurden ganz andere Normen aufgerufen als die Friedens- und Schuldhaftungsprinzipien der ersten fünf Nachkriegsjahrzehnte. (Daraus leiten einige polemisch eine Militarisierung oder gar Kriegsneigung der deutschen Politik ab, was angesichts der Haltung der Bevölkerung zum Afghanistaneinsatz mehr noch als beim Kosovo absurd erscheint). Wichtiger ist etwas ganz anderes: Deutschland beginnt seine out of area Einsätze gerade zu dem Zeitpunkt, als neue, normative und weltgesellschaftliche Konzepte wie Human Security, Responsibility to Protect und Menschrechtsbasierte Interventionsgründe die alte Souveränitätsdoktrin mit ihrem Nichteinmischungsgebot auszuhebeln begannen. Interventionen werden moralisch begründet und normativ legitimiert, sie sind keine realpolitische Wahl (allein) mehr. Nicht ein Frieden in konzentrischen Kreisen um hegemoniale Ak-

11 Vgl. www.afghanistan-blog.de/?p=3077 (aufgerufen am 23.Juil 2010); Wehrbericht 2012. 
teure steht jetzt im Vordergrund, sondern Mechanismen globaler - und damit lokaler - Konfliktregulierung in der Auseinandersetzung zwischen liberal state building und seinen Alternativen.

Die erste Annäherung an den Heimatdiskurs lässt sich so zusammenfassen: Deutschland ist ein Akteur in einem weltpolitischen Interventionszusammenhang geworden, der dem Staat und seinen Bewohnern noch fremd ist. Seit der Beteiligung an der Kosovointervention werden die Legitimation und Sinngebung der Auslandseinsätze auf vielen Ebenen hinterfragt, wobei der Heimatdiskurs als Beweger (Movens) selten klar ersichtlich ist. Viele Verzweigungen des Heimatdiskurses stehen in partiellem Widerspruch zu einander, etwa eine neue nationalistische Strömung und eine weltgesellschaftlich orientierte der humanitären Interventionsgebote (vgl. Collins 2008).

\subsection{Heimatdiskurs - Die Macht im Dunkel des Nichtgesagten}

Ein „deutsches Ereignis“ war die Ausstellung „Vernichtungskrieg - Verbrechen der Wehrmacht 1941-1944 (Heer 1995; 2004; Scheil 2003). Hier hat ein einzelnes Ereignis einen retroaktiven Umdeutungsprozess wenn nicht bewirkt, so doch beschleunigt und das Nachkriegsnarrativ vom Weltkrieg erheblich korrigiert. Auch hier haben verschiedene Elemente zusammengespielt: das Gewicht des Empirischen reduzierte die Macht des Imaginären - Indizien und Beweise drängten die voluntaristische Ehre der Wehrmacht in die Defensive und spalteten das tatsächliche Geschehen von der noch dominanten Vorstellung von den soldatischen Tugenden und der Tugendhaftigkeit der Vätergeneration an der Front ab. Wir verfolgen die Wehrmachtsausstellung nur in Hinblick auf den letztgenannten Aspekt: wieweit haben die imaginären und einem Kontinuitätsimperativ unterworfenen Vorstellungen vom soldatischen Handeln in die Legitimation der Auslandseinsätze Eingang gefunden? Wieweit werden sie durch die empirischen Befunde ermutigt oder widerlegt? Dass man die Wehrmacht nicht mit der Bundeswehr gleichsetzt, versteht sich. Dass man die Diskurse vergleichen sollte, ist aber in diesem Punkt auch unvermeidlich. Der Rahmen, in dem dieses geschieht, ist das heute gegenüber 1995 und natürlich noch mehr gegenüber der alten Bundesrepublik veränderte Konzept des Nationalstaats; und damit die Deutung des Nationalen.

Eine Hypothese lautet: Es handelt sich beim nationalistischen Element des Heimatdiskurses um einen Anteil von Hysteresis im wahrgenommen Konzept der eigenen Gesellschaft gegenüber intervenierten Gesellschaften. Deutschland ist heute viel weniger souveräner Nationalstaat als vor 40 oder noch vor 20 Jahren, das erleichtert die Interventionen als Eingriffe in die Souveränität anderer Staa- 
ten. Aber Nationalismus als gesellschaftliches Phänomen orientiert sich nicht so sehr an den Staatskonstruktionen als an den kollektiven Habitus gesellschaftlicher Einbettung. Und in denen spielt der Topos der Nation nach wie vor eine große Rolle. Bei unserer Hypothese wird unterstellt, dass die individuelle Erfahrung, die in der Hysteresis eingeschlossen ist, auf die imaginäre Nation als erstrebenswerter oder schlicht eingelernter Vergangenheit projiziert wird.

Hier wird verständlich, warum wir den Heimatdiskurs als deutsches Problem ansprechen. Andere Gesellschaften haben ihre analogen Diskurse, aber wir würden sie nicht automatisch als „Heimat“-Diskurse ansprechen, sondern, wie bei Homeland und home-front deutlich werden wird, anderen Narrativen zuordnen.

Wir müssen hier einen Exkurs machen, der in Teilen immer wieder in diesem Kapitel und im Buch wiederkehrt. Es geht um die Analogien und Differenzen zu den USA. Diese haben eindeutig ihre Variante von Heimatdiskurs, dort über Homeland ausgetragen. Da die USA in vieler Hinsicht gewolltes oder schlicht auferlegtes Rollenvorbild nach 1945 waren, sind bestimmte verdrängte, bzw. erst in den letzten Jahrzehnten gewachsene, Differenzen von großer Bedeutung für unsere deutsche Einordnung in das Interventionsgeschehen. Dabei dürfen wir auch nicht übersehen, dass die konservative Ablehnung der Amerikaner, der rechte Antikapitalismus und das kulturelle Überlegenheitsgefühl (Zivilisation gegen Kultur) keineswegs als Subtexte ausgedient haben,

Die objektivierende Übernahme von neuen oder fremden Vorstellungen gehört zu den Effekten dieser Macht der Diskurse: der amerikanische Warrior ersetzt im Bild des Soldaten den Staatsbürger in Uniform bzw. das Ergebnis der Inneren Führung. Wie sehr unterschiedlich die verinnerlichten Vorannahmen sind, kann man gut an der deutschen bzw. amerikanischen Reaktion auf vergleichbare ehrenrührige Handlungen von ISAF Soldaten in der Totenkopfaffäre (2006) und beim Urinieren auf tote Afghanen (2011) sehen. In Deutschland ging es in der öffentlichen Auseinandersetzung um Verhaltenskritik eines Einzelfalls, in den US hatte der damals noch aussichtsreiche Republikanische Präsidentschaftsbewerber Perry darauf hingewiesen, dass es ja nicht so schlimm sei, auf tote Menschen zu urinieren - Perry sagte, es sei ,überzogen hier von einer kriminellen Tat“ zu sprechen (Reuters, 15.1.2012). Andere relativieren den Akt im Vergleich zu Gräueln an Lebendigen; was ja auch stimmt, aber den Sachverhalt verschiebt. Im Kampf verübte Gräueltaten und vor allem außerhalb des Kampfes verübte Verbrechen werden in den USA der ontologischen Ehre der Armee vollständig untergeordnet - wie im Fall der privaten Massaker im Irak vor 8 Jahren. Die Armeejustiz beugt sich diesem normativen Atavismus, obwohl sogar Präsident Bush Ermittlung und Strafe gefordert hatte - das Ergebnis ist ein Freispruch fast erster Klasse für Massenmord (Julie Watson, AP, 24.1.2012). In einem an- 
deren Fall sind die Urteile für die Mörder erwartbar hoch, aber ihre Vorgesetzten kommen ebenfalls ungeschoren davon. Das alles erinnert an die Verteidiger der Wehrmacht bei den ersten Auseinandersetzungen um die Wehrmachtsausstellung, es ist heute in Deutschland aber kaum mehr vorstellbar.

Man könnte sehr vorsichtig begründen, warum und in wie fern der Ehrbegriff dem Konzept der Bundeswehr und dem Staatsbürger in Uniform nicht mehr mit Vorrang zugeordnet ist. Wir haben Soldaten, keine Krieger. Aber vom „demokratischen Krieger" sind wir auch noch weit entfernt. Deutschland und die USA haben ihre Heimatdiskurse, andere Länder haben sie nicht, noch nicht oder nicht mehr. Aber die Krieger-Tradition, die Vietnam überlebt hat und heute das Eingeständnis von militärischen Niederlagen oder Erfolglosigkeiten zudeckt, spiegelt den amerikanischen Auserwählungsmythos - Exceptionalism - institutionell im Kodex für das Militär wider. Dem Diskurs sind kritische Infragestellungen nicht inhärent. Das können wir am Beispiel von Jim Gant, Major im Irak und in Afghanistan, erfahren ablesen (Gant 2009).

Vor allem die Ehre ist es, die sich zwischen die Beziehungen der Soldaten und ihre gesellschaftlichen Zugehörigkeiten schiebt. Ehre macht nur Sinn im Zusammenhang mit Macht. Sie anzugreifen, zu verletzen, fordert die Macht heraus. Wo immer die Krieger kämpfen, sie tun es auch im Namen der Ehre, die wieder dem Patriotismus, der Nation oder der Institution Militär zugeordnet werden. Ehre kompensiert Einschränkungen der Freiheit, schlechte Bezahlung, Lebensgefahr und die Abkopplung von moralischen Grundlagen des Zusammenlebens (es gibt auch andere Ehrbeziehungen, aber keine ohne Macht. Das unterscheidet sie grundsätzlich von der Menschenwürde. Im Namen der Ehre wird diese oft vergewaltigt). ${ }^{12}$

Die USA können ihren Heimatdiskurs auf eine lange und in ihren Effekten plausible Genealogie begründen - vom Unabhängigkeitskrieg über die Monroedoktrin und den Imperialismus des ersten Roosevelt bis hin zu den siegreichen Interventionen im ersten und zweiten Weltkrieg. Da das Land bis 9/11 auf eigenem Territorium nicht angegriffen wurde bzw. angreifbar schien, machte out of area in ganz anderen Kontexten verständlich als in den kleinen europäischen Nationalstaaten mit oft weit entfernten kolonialen oder eben nach-kolonialen Einsatzorten. Da alle wichtigen Kriege nach 1945 nicht gewonnen wurden - Korea, Vietnam, Irak, Afghanistan etc. - muss der zeitlose Krieger die Ehre der Armee

12 Ehre und Würde werden oft schlampig oder aber mit Absicht vermischt. Übersetzungen aus anderen Sprachen sind oft problematisch, weil z.B. das französische honneur durchaus auch Elemente von Würde bei sich trägt und von dignitée unterschieden ist. 
hochhalten (vgl. zur neuesten Kriegslegitimation Engelhardt (2010), ${ }^{13}$ vgl. auch Bacevich 2012).

Krieg ist nicht sagbar, und doch sind wir mit ihm komplizenhaft verbunden. Wir müssen das in vielen Details analysieren, um auch zu verstehen, wie weit wir uns von der Interventionsgesellschaft in Afghanistan entfernt haben bzw. wie nahe wir ihr sind: d.h. wie nahe an der nach-vollziehbaren Empirie wir sind.

\subsection{Erzählungen und Bilder vom Krieg ${ }^{14}$}

Die komplizierte Verbindung von Bild und Text in der Diskursanalyse hat uns in der Forschungsarbeit zunehmend beschäftigt. Sie steht aber nicht im Zentrum der theoretischen Ausgestaltung des Heimatdiskurses, sondern eher in unserer methodologischen Auseinandersetzung (vgl. auch Martin van Crefeld 2006, der die Kriegsgeschichte neu kontextualisiert; vgl. auch Aljets et al. und Neumann in diesem Band).

Die Ästhetisierung von Krieg und Gewalt ist so alt wie diese Phänomene selbst. Mythische und rituelle, pathetische und ironische Darstellungen und Verdichtungen illustrieren die Erzählungen von Krieg Gewalt und Terror, den ja die meisten, die heute als mediale „Audience“ erscheinen, nicht in Echtzeit erleben; aber sie hatten immer die Folgen erlebt und sie interpretieren die Deutung der Bilder ebenso in ihre Lebenswelt hinein, wie die Deutung der Erzählungen. Die mündliche Überlieferung musste bildhaft sein, um ihre Zuhörer zu fesseln und dauerhafte Bilder zu verfestigen - Homer oder die Geschichten von Davids Kriegen. Noch bis ins 20. Jahrhundert hinein gehörten die Kriegserzählungen zum Curriculum der Allgemeinbildung, die die Eliten vom Rest der Bevölkerung abhob, nicht ohne als einigendes Band eine Variation der Erzählungen eben diesem Rest zuzusprechen. Vieles hat sich mit Photographie geändert, vieles mit den audiovisuellen Medien und der Echtzeit des Berichts.

13 Engelhardts Buch ist in Kreisen der Friedensbewegung und Kriegsgegner in den USA ein Bestseller und inhaltsreich als Presseanalyse, ohne konkrete Datierung der meisten Zitate. Neben dieser Kritik fällt aber ins Gewicht, dass im Grunde ein umgekehrter Interventions- und Kriegsdiskurs den Autor leitet, er hätte gerne eine USA, die der Rhetorik des Peacetalk und des Präsidenten Obama gerecht wird, anstatt im Newspeak das Gegenteil zu tun von dem, was gefordert wird.

14 Wir arbeiten hier mit Bildern, meist Fotos aus der Presse. Viele der sprachlichen Bilder repräsentieren den Wandel der bewaffneten Konflikte, wie sie das unverzichtbare Buch von Martin van Crefeld „Gesichter des Krieges“ (2006) darstellt. 
Wissenschaft wird in die Deutungsprozesse dort einbezogen, wo sich die Narrative ändern oder der Bestätigung bedürfen - man bedenke den Aufwand, den Darstellung und Deutung der französischen Revolution oder des amerikanischen Bürgerkriegs in der Fachliteratur erfahren; zeitnäher ändert sich hier einiges: Die Reportage wird immer stärker zur vieldimensionalen Grundlage sowohl von Wissenschaft wie Journalismus, sie ist Legitimation des Geschehens wie der Deutung und zugleich Kritik dieser Legitimation. ${ }^{15}$ Sie beruht auf Konstruktionen und Rahmen (Frames) und sie ist der direkte Zugang zur Empirie (und erzeugt damit Spannung zwischen Wirklichkeit und Realität, zwischen subjektiver und objektiver Deutung des Ereignisses und die Verortung des Interpretierenden in einem Wert- und Politik- Zusammenhang). Damit sind wir in die Gegenwart und das Problem des Heimatdiskurses gesprungen.

In Frankreich findet sich in den U-Bahnen noch immer ein Schild, das die Aufforderung enthält, Sitze freizumachen für

- Aveugles de guerre - Kriegsblinde

- Aveugles civiles - Zivilblinde

- Mutilés de guerre - Kriegsversehrte

- Femmes enceintes - Schwangere Frauen

Der Krieg wird hier vom Zivilen abgesetzt, besonders hoch bewertet (wer fürs Vaterland etwas geleistet hat und dabei Schaden erlitten hat, wird besonders geschützt). ${ }^{16}$ Ähnliches gibt es auch in italienischen Massenverkehrsmitteln zu finden. Der Kontext ist nicht ohne weiteres sichtbar, er wird aber offenbar von allen verstanden. Es handelt sich um das kollektive Vorbewusste. Das Vorbewusste kann dekodiert und auf die Ebene des Diskurses durch seine Analyse und Kritik gehoben werden. Der HEIMATDISKURS strukturiert das Vorbewusstsein und ist deshalb eine Macht. Das begann schon beim Einsatz in Kosovo. Ganz entscheidende „Bilder“ über den Balkan waren geprägt von Karl May, den die politische Elite 2000, also die Generation 1935-1950, noch gelesen hatte („Der Schut“, „Durch die Schluchten des Balkan“ u.a.); sie waren auch geprägt durch die Jugoslawien-Urlaube, die gerade nicht nach Kosovo oder Südserbien geführt haben, sondern an die Adria, sie waren geprägt durch das Gegenstück zum Orientalismus, den Balkanismus; und sie waren geprägt von vielfältigen aktuellen Ein-

15 Die Reportage ist eine der Grundlagen der amerikanischen Sozialforschung seit den 1930er Jahren.

16 Noch heute werden die Kriegskategorien, aber auch Kriegerwitwen in den Tarifbestimmungen der Pariser Metro explizit erwähnt: www.parisinfo.com (aufgerufen am 1. Februar 2012). 
flüssen der kroatischen und serbischen Diaspora in Deutschland, durch das Balkan-Bild und die Politik des Nachbarn Österreich, durch die Bilder vom „Albaner" (zwischen Kriminalität und Arbeitswütigkeit). Was man aber zum Beispiel viel zu wenig wusste, dass sowohl Bosnien als auch Kosovo muslimische Länder sind, mit „resurfacing“ Religiosität. Damals schon schrieb der Verteidigungsminister an seinem „Kriegstagebuch“ und weckte Assoziationen, die der Friedensgestählten Nachkriegsgeneration eher skurril vorkommen mussten (Scharping 1999, 1999a).

Der kritische Spott über dies u.E. wenig relevante Buch verkennt die Bedeutung der kontrafaktischen Inanspruchnahme der Kriegsmetapher, mehr war sie nicht, und zwar als Korrektiv zum Nachkriegsprinzip: nie wieder Krieg! Einen Subtext bildet die Verbindung von Außenminister Fischers Diktum Nicht wegschauen ${ }^{17}$ mit Krieg als Konsequenz.

Da war die trockene dickleibige Selbstreferenz des deutschen ComKFOR General Reinhardt schon programmatischer: „KFOR: Streitkräfte für den Frieden“ (Reinhardt 2001). Generäle für den Frieden, Wissenschaftler für den Frieden...Was wurde da evoziert? Warum hatte nach Bonn- Petersberg 2001, dem deutschen Engagement bei OEF, also im War on Terror, und dann beim mandatierten ISAF-Einsatz niemand offiziell gleich von Krieg gesprochen? Aus meiner eigenen Erfahrung ziehe ich das nicht verallgemeinerbare Fazit, dass man den Krieg ausblenden konnte, weil man es nicht besser wusste. Der Fehler lag schon 2001 darin, dass man es nicht besser wusste.

Exkurs: Ich kann es nur subjektiv aufdröseln, muss das Kollektiv für einen Augenblick verlassen. Kosovo im Juli 1999 - ich war da für den Europarat - bot alle Schauplätze, die wir von den letzten Bildern eines Krieges in seiner Endphase kennen, de facto waren die Kampfhandlungen schon vorbei. Brennende Häuser, verstopfte Straßen, anklagende Gespräche allenthalben und unkontrollierte Racheakte, bevor ein Ausnahmerecht oder gar allgemeine Rechtsregeln gerade dieser Rache Einhalt gebieten würden. Diese Bilder passten irgendwie in einen ,,anderen“ Krieg, den ich aus Erzählungen und Bildern kannte. Später, bei UNMIK, gab es die Berichte unserer Sicherheitsleute und eigene Erfahrungen der Zusammenarbeit mit KFOR, CivPOL, lokaler Polizei etc., u.a. um Schülertransporte und Schulen zu sichern. Ich habe mich nie gefragt, ob das zum Krieg gehört (,Alltag im Krieg") oder sein Widerspruch ist, wenn ich nicht darauf angesprochen wurde. Erst in der Reflexion wurde aus der Erfahrung eine Art moderierter und moderater KriegsBerichterstattung. Den ersten Eindruck von Kabul habe ich sofort im Tagebuch und auch

17 Joschka Fischer: Rede am 7.4.1999 (Sekundär-zitiert nach Nico Fried „Fischer: Ich habe gelernt: Nie wieder Auschwitz“ SZ 24.1.2005). 
in ersten Berichten als „Stalingrad“ festgehalten, weil ein großer Stadtbezirk wie das berühmte Bild mit der im Schutt freistehenden Esse sich aufdrängte. Ich habe die Kriegsvokabel übrigens früher als der Mainstream verwendet, musste aber stets dazu ausführen, dass es zwar Krieg geben kann, aber wir ihn nicht führen. Ich kann von mir sagen, ohne auf andere zu schließen, dass es nie mein Problem war zu reflektieren, wie man sich im Krieg verhält, sondern was zu tun ist - und ich habe in meinen Berichten darauf geachtet, zu erzählen was ich tue, und nicht wie mich fühle. Dass das nie sauber getrennt werden kann und also gelingt, ist ebenso klar wie ärgerlich.

Nicht untypisch war, dass als erstes vom Krieg im Zusammenhang mit Versicherungsleistungen gesprochen wurde. Sterben und Verletztwerden als Arbeitsunfall oder als force majeure (Höhere Gewalt)? Und dass das Friedenslager der politischen Öffentlichkeit den Krieg sozusagen über das Konfliktgebiet hinaus globalisiert begrifflich ausweitete. Es ist nicht vermessen zu unterstellen, dass das Vokabular der Auseinandersetzung um den Krieg von den Gegnern der Intervention geprägt wurde und teilweise wird. Für die Verwendung der Kriegsmetapher gilt jedenfalls „Die Zensur ist die offizielle Kritik“ (Marx 1976: 3).

Wenn es aber um Kriegs-Bilder geht, müssen wir auch noch andere Linien bedenken. Im ersten Nachkriegsnarrativ - dem Zweiten Weltkrieg - herrschte häufig das Bild, das ich Stalingrad nennen möchte, das nach 1945 durch unzählige apologetische Belletristik der Landserliteratur und der Ehre der Wehrmacht (nicht aber 08/15 mit seinen kritischen Elementen (Kirst 1994) geprägt wurde. In den weiteren Narrativen (also Shoa nach 1962, Vereinigung nach 1989, und womöglich 9/11 nach 2001) werden die Kriegsbilder teilweise erneuert - Vietnam mit den mächtigen Bildern (My Lai) - teilweise sind die alten Bilder aber unheimlich zäh; am Leben erhalten und in letzter Zeit - es ist Krieg! - geradezu wieder aufgelegt: Orden, Gedenkstätte für die Gefallenen, Posen. Die Fackelzüge haben ohnedies nie aufgehört, die alte Wehrgeschichte lebendig zu halten, und die Innere Führung, die ja aufgeklärt bildlos ist, zeigt sich beileibe nicht so gefestigt.)

Wir können viele Bilder zeigen, auf denen Soldaten im Friedenseinsatz als Krieger und als Helden gezeigt werden - in Haltungen, Posen, Kontexten, die die Unterströmungen und Subtexte des (west)deutschen Nachkriegspazifismus scheinbar unterlaufen. Scheinbar, weil es nicht ausgemacht ist, dass einfach ,der Schoß noch fruchtbar ist, aus dem das kroch“. Dass jetzt allmählich der Selbstbetrug unserer moralischen und pragmatischen Sonderstellung aufgeweicht wird, ist - angesichts der globalen Sicherheitspolitik - ,,an der Zeit“", andererseits ist es auch eine Chance für eine Neuorientierung ohne Rückfall in den alten Militarismus. 
Diese Sätze bedürfen der Erklärung. Der Soldat als Krieger und Held ist ein langstehendes Motiv von Nationalismus, Patriotismus und der Legitimation hegemonialer, gewaltsamer Politik. Es gibt hier sicher nationale und regionale Differenzierungen, die für die konkrete Geschichte von Militarismus, aber auch von festgestellten Bildern, Leitbildern, bedeutsam sind. Uns geht es darum, dass diese Bilder von Pazifisten wie Remarque oder Ossietzky rational angegriffen wurden, aber im „Ernstfall“ Bestand hatten. Eine der großen demokratischen Leistungen der Bundesrepublik nach 1945 war die schrittweise Dekonstruktion dieser Bilder. Eine der Rahmenbedingungen dafür - sozusagen eine von mehreren Schutzhüllen - war die uns auferlegte Pax Americana während des Kalten Kriegs. Die Bundeswehr spielte eine symbolische und eine logistische Rolle, aber out of area war out of the question. Die Rückfälle, auch in der Bundeswehr, gab es sehr wohl, aber sie waren nicht systemisch und gefährdeten nicht die Vorstellung, die sich mit dem Staatsbürger in Uniform verband. Für den aber gab es kein Bild. Paradoxerweise hatte der Soldat im Friedenseinsatz nicht schon bei Blauhelm-Missionen Gestalt angenommen. Seine Stunde kam im Kosovo. Da hatte sich aber in der Zwischenzeit Erhebliches verändert. Interventionen wurden der neorealistischen Praxis zunehmend entzogen und stark normativ gerechtfertigt. Dafür gab es erst einige, später mehr Bilder und Metaphern.

Nicht zufällig war der Entwicklungshelfer in Uniform einer der ersten diesbezüglichen Begriffe. Kinder werden gerettet - und können sich entwickeln.

\section{Abbildung 2: US Soldat mit Baby (li.) und US Soldat während eines} medizinischen Programms in der Nähe von Kandahar (re.).
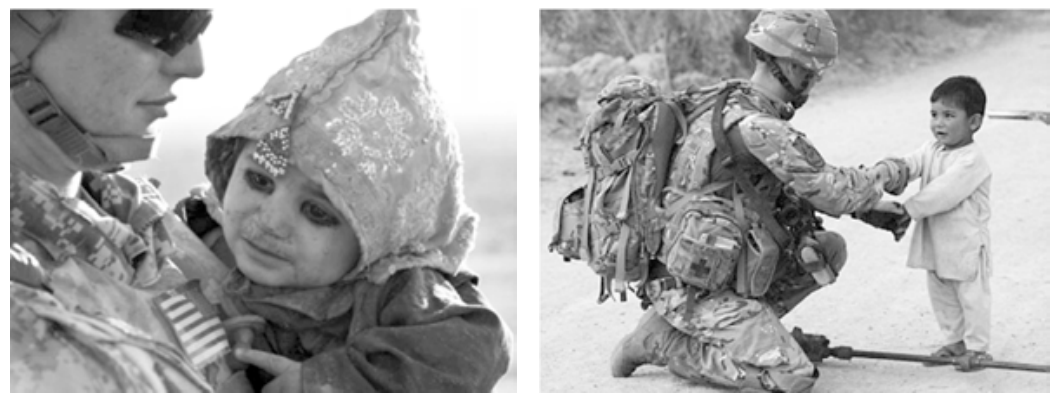

Quelle: http://www.upi.com/News_Photos/Features/A-bounty-of-babies/5328/4/?ref=t (aufgerufen am 23. Juli 2012) und http://www.metro.co.uk/news/883755-uk-soldierjailed-and-dismissed-from-army-over-stabbing-afghan-boy (aufgerufen am 28. Juli 2012).

Es gab und gibt wieder Erzählungen vom Krieg, und das sind nicht nur Erinnerungen von Heimkehrern oder politische, normative, Kommentierungen. Aber 
das Pathos des Heimatdiskurses schlägt voll zu, wenn die Gefallenen aufgebahrt und bestattet werden.

An dem folgenden Bild (Abbildung 3) kann man eine besondere Dimension der Diskussion festmachen. Aber wichtiger war, dass ich selbst die deutsche Flagge nicht angemessen fand. Es wird ja nicht „für Deutschland“ gekämpft, sondern unter dem supra-nationalen Anspruch von NATO oder UNO, vielleicht bald auch Europa. Sagte ein Leutnant: „Ich habe mich bei der Bundeswehr verpflichtet, weil ich Dienst am Vaterland leisten möchte. Unter einer NATO- oder gar UN-Fahne möchte ich nicht aufgebahrt werden“. Das hatte ich als Alternative vorgeschlagen, wenn schon neue Symbole eingeführt werden sollten. Sonst müssen die alten herhalten, was bei schwarz-rot-gold ja noch besser ist als schwarz-weiss-rot (historisch eine Frage der Bildung der Soldaten und der Öffentlichkeit), aber insgesamt ist die rituelle Bindung ans Vaterland noch wenig gebrochen. (Rilkes „Cornet“ hat wohl eine ganze Generation von 1914 fasziniert, damals ging es aber um ein imaginäres Vaterland, ein Prinzip).

\section{Abbildung 3: Sarg eines gefallenen Soldaten}

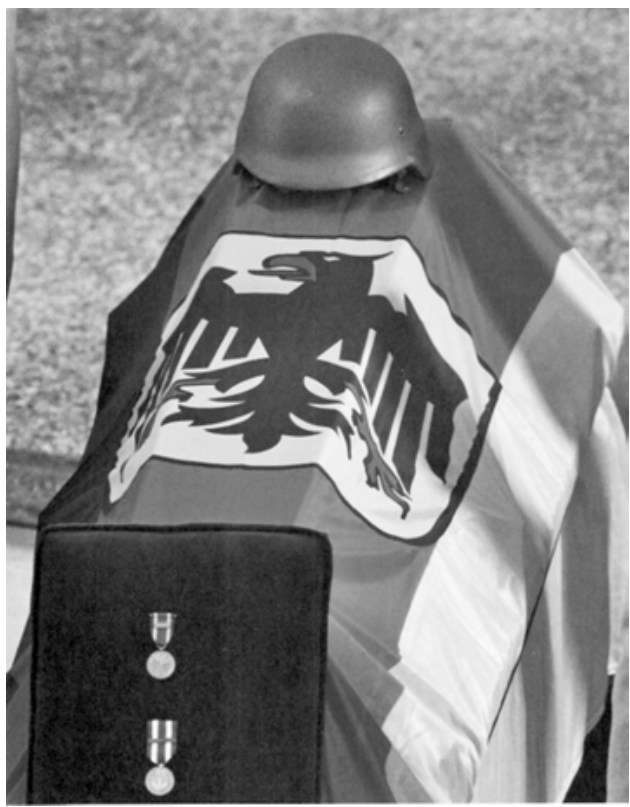

Quelle: Kornelius 2009

Nun wäre zu fragen, ob nicht die Alternative auch problematisch ist: statt des Heimatbezugs ein personales Heldentum zu ehren, also den Krieger als eine eh- 
renvolle Kategorie für sich zu feiern. Dazu müsste es vor-nationale Vorbilder geben oder es würde ein neuer „Stamm“ imaginiert. Beides hat es in vielen Gesellschaften gegeben. Im Totenritual erkennen sich die Lebenden. Nun sollte man das Problem für die Gegenwart der Bundeswehr aber nicht überhöhen, denn die Armee ist einfach keine, die dauernd und in verschiedenen Stadien von Kriegen und Kämpfen sich befindet. Aber es kann vorausgesehen werden, welchen Einfluss die Toten haben, die nach Haus kommen. Die Verrenkungen, die die Amerikaner um ihre Brown Bags machen (die Hüllen, in die tote Soldaten eingepackt sind), ob man sie filmen darf oder nicht, sind nur ein Vorzeichen für das, was kommen kann. Die Unterschiede zwischen dem deutschen und dem amerikanischen Umgang mit Gefallenen hat neuerdings auch die Presse thematisiert, meist sehr stark personalisiert, um dann Hinweise auf Verallgemeinerung zu geben (z.B.Mingels 2012).

Abwesenheit von Pathos kann aber auch problematisch sein: bei einer „Ehrungsveranstaltung“ des niedersächsischen Landtagspräsidenten am 2.3.2012 wurden Polizisten, THW, AufbauhelferInnen und NGO-Angehörige geehrt: mit einer Rede des Präsidenten, einer Rede der Staatssekretärin des Inneren, mit Musik und Buffet. Alles politisch korrekt, nüchtern - nur: keiner der Geehrten kam zu Wort; was sie denn dort in Afghanistan tun wurde auf Allgemeines, Unkonkretes beschränkt. Und das Militär wurde an diesem Tag nicht geehrt, es war separat geehrt worden - siehe Pariser U-Bahn.

Bei der Frage, ob Wir (Deutsche qua Deutschland) im Krieg seien, kann man gut verfolgen, dass in dem Augenblick, wo der Begriff freigegeben, also autorisiert, wurde, auch ein Blick auf die Phänomene freigegeben wurde, die diesen Begriff anwendbar machen. Die Friedensbewegung verknüpft den Out of area Einsatz als unabhängige Variable mit der Tatsache, dass wir uns im Krieg befinden. Sie braucht den Krieg, um den Einsatz zu diskreditieren. Die Befürworter der Intervention wiederum sehen den Krieg als mehr oder weniger notwendiges oder kollaterales Akzidens zu den höheren Zwecken des Einsatzes. Woher wissen denn die Menschen hier, in der friedlichen Nachkriegs-Sozialisation, wie das ist „im Krieg“ zu sein? Entweder alte Bilder werden bemüht oder neue müssen geschaffen werden.

Die Bilder aus den Kampfzonen, in denen Bundeswehrsoldaten auch kämpfen, aber im Wortsinn keinen „Krieg führen“, erinnern an Bilder von früheren Kriegen und knüpfen verdächtig einfach an die Kriegsnarrative an, die heute der Großelterngeneration zugehören - oder sie „erfinden“ sich scheinbar neu. Das geht aber nicht ohne die Rollendefinition der Soldaten, die da einbezogen sind übrigens auch der Soldatinnen, die hier eine eigene Funktion haben, auch im 
Heimatdiskurs. ${ }^{18}$ Die Identifikation der Funktion von Militär in out of area Einsätzen im Rahmen großer supra-nationaler Verbünde und/oder spontaner Koalitionen - das ergibt ganz andere Rollenbilder als die traditionellen Nationalarmeen an Bildern hergeben. Nicht zufällig ist die gerade begonnene und völlig unausgereifte Reform der Bundeswehr unter dieser neuen Rolle und als professionelle Streitmacht skizziert (Professionalität aber stellt den Staatsbürger in Uniform vor ein Deutungsdilemma). Nicht zufällig werben Bundeswehr, österreichische, ukrainische und schwedische Armee mit analogen, lebenslang befriedigenden Berufsstereotypen, die zwischen humanitär und kämpfend oszillieren, aber jeweils nur die soldatische Erscheinung in einem subjektiven Akteursumfeld zeigen und den politischen Kontext fast ausblenden. ${ }^{19}$

Der zentrale Begriff ist ja nicht Soldat, sondern „Soldat“ in Bezug auf seine/ihre Gesellschaft und seinen/ihren Staat. Wir haben klassisch die Aufspaltung in Helden und Gefallene. Diese sind nicht kongruent mit Siegen und Niederlagen. Dafür gibt es auch wieder Bilder. Die Heroisierung des Oberst Klein (Kommandeur, der das Bombardement der entführten Tankwagen bei Kunduz am 4.9.2009 befohlen hatte) bringt das ganze Repertoire der Heldenherstellung in Anwendung. ${ }^{20}$ Das funktioniert aber nur im eingeschränkten Kontext. Der Held muss sich von den andern, „Nichthelden“ unterscheiden. Wenn alle Helden werden - „unsere Bundeswehr am Hindukusch“, würde das auch eingetretenen oder erwarteten Erfolg, der Sieg heißt, bedeuten müssen - etwas zynisch angesichts der Tatsache, dass z.B. die britischen Niederlagen in Afghanistan sogar bis heute überlebende Lyrik hervorgebracht haben. Theodor Fontanes „Das Trauer-

18 Das ist übrigens besonders deutlich diskutiert worden am Beispiel der auf der Gorch Fock aus dem Mast gestürzten Offiziersanwärterin. Aber kämpfende Frauen passen in das deutsche Soldatennarrativ noch weniger als in anderen Ländern.

19 Siehe beispielhaft: http://www.youtube.com/watch?v=Kd2MrhDIXgQ (Bundeswehr,); http://www.youtube.com/watch?v=DaOdAZx0j8g (Schwedische Armee); http://www.youtube.com/watch?v=cH_E6YSQqTo (Ukrainische Armee) und http://www.youtube.com/watch?v=v0YMrwlbodE (Österreichisches Bundesheer), alle aufgerufen am 1.Februar.2012.

20 Das Buch ist u.E. so problematisch, weil es dauernd die Ebenen der persönlichen Empathie mit Oberst Klein und einzelnen Soldaten mit den Umständen und gesellschaftlichen und politischen Strukturen vermischt, das Klima schwankt zwischen ,unsere Bundeswehr kann das nicht“, „...soll das nicht“, und „müsste, sollte, dürfte“. Es ist scheinbar eine scharfe Kritik an der Intransparenz der Politik, die aber durch diese Vermischung abgeflacht wird (vgl. den Beitrag von Florian Kühn in diesem Band). 
spiel von Afghanistan“von 1857 (Fontane 1905) ist ein bekanntes Beispiel, auch im Englischen. Kriegslyrik gibt es natürlich bis heute in und zu Afghanistan.

Unsere gegenwärtigen Bilder von soldatischen Tugenden, sofern sie autorisiert und vorstellbar sind, beziehen sich auf Helden im Widerstand (gegen die Nazis), und diese lösen die gewalttätigen Nazis allmählich und kontrovers z.B. bei Kasernennamen ab. Bei den Attentätern auf Hitler spielt noch ein anderes Notat mit: sie waren erfolglos, wurden zu Opfern und haben sich geopfert. Die Nähe zum Bild des Märtyrers ist hier überdeutlich. Deshalb ist die dauernde, und von ihrer Quelle losgelöste Frage, ob unsere (deutsche) Sicherheit am Hindukusch verteidigt wird, damit verbunden, ob, wer dort fällt, „für uns fällt“, Blutzeuge unserer Freiheit ist.

Weniger dramatisch, aber nachhaltig ist die Frage bei den seelisch und kör-

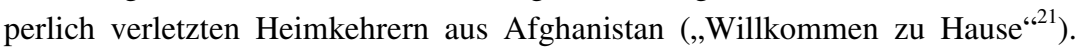
Uns erreichen Bilder, die sich scheinbar dann leicht festsetzen, wenn wir sie so oder ähnlich kennen - Soldaten in der Freizeit, oder beim verteilen von zivilen Gütern an Kinder oder beim „Retten“ - oder tot, im Sarg, umgeben von pompes funèbres und Ritualen. Im Feldlager von Mazar gibt es ein Kriegerdenkmal, das könnte auch bei uns zu Hause stehen, überall auf der Welt. Wir lesen unser Bild vom Soldaten, Helden, Krieger etc. in die Bilder der Reportagen hinein. Da wird der Friedenseinsatz mit Bildern garniert, die dem Frieden zu widersprechen scheinen. In diesen Bildern spielt sich die Komplizenschaft mit dem Krieg und seine Ablehnung ab.

„Das hieße jedoch, dass die soziologische Forschung sich als Teil der Gesellschaft begreift, die einen Krieg führt. Und dies hieße, dass der erste Satz der Forschung ein Ja zum Krieg enthalten müsste. Sei es, dass man pessimistischer Weise annimmt, dass diese Gesellschaft an ihrem eigenen Untergang arbeitet, sei es, dass man optimistischer Weise annimmt, dass jedes Phänomen dieser Gesellschaft letztlich dazu dient, herauszufinden, wie es weitergehen kann - der Krieg ist in beiden Fällen Teil der Gesellschaft, die man beobachtet...Diesem ersten Schritt, dem Ja zum Krieg, müsste jedoch sofort ein zweiter Schritt folgen, nämlich das Nein zum Krieg, wenn die soziologische Forschung ihrer eigenen Beobachtung Rechnung tragen will, dass es zum Phänomen des Krieges in der Gesell-

21 Willkommen zи Hause. SWR, ausgestrahlt 2.2.2009 (der Film sollte im September 2008 gesendet werden, wurde aber aus politischen Gründen und wegen eines UEFAEreignisses mehrmals verschoben). Am Tag nach der Aussendung erscheint der Artikel von Winfried Nachtwei www.nachtwei.de/index.php/articles 802; PTBS, die Posttraumatische Belastungsstörung, wird Gegenstand von Bundestags- und Bundeswehrdiskussionen, zunehmend auch von Belletristik. 
schaft dazugehört, dass er abgelehnt wird....Mit diesem Ja und Nein macht sich die soziologische Forschung zum Komplizen der Gesellschaft, die einen Krieg führt, und damit auch zum Komplizen des Krieges. Sie stimmt ihm zu und sie lehnt ihn ab.“ (Baecker 2002: 21f.)

Von solchen Deutungen weiter entfernt sind die Gesellschaften, in denen der Krieger anders notiert ist, allen voran die USA. Josef Joffe (2009) hat als einer der Ersten darauf hingewiesen, dass es für Deutsche bei internationalen Einsätzen ein Problem sei, weil wir keine Tradition des Warrior hätten. Ob man es bedauert oder nicht, die Beobachtung stimmt. Fighters und Warriors entstammen kulturellen Kontexten, die auch Patriotismus und Nation anders begreifen als wir unser Verhältnis von Staat und Gesellschaft. ${ }^{22}$ Darauf müssen wir jetzt nicht eingehen, soviel aber ist klar: mit der Ausrichtung der Bundeswehr auf ihr neues professionelles Bild nähern wir uns einem eigenen Bild vom Berufssoldaten, der ein „Krieger“ ist. Die Frage, wie wohl wichtig, ist nicht so sehr, ob das notwendig ist und ob es in einer Demokratie angemessen ist, sondern was wir jetzt mit einem solchen ungelösten Problem machen, das ja unmittelbar zur Lösung ansteht. Gegen die Tugendlehre argumentieren Völkerrecht, Kriegskonventionen usw. nicht mit der Indienstnahme des Einzelnen für ein nationales oder patriotisches Ziel, sondern orientieren sich an Tatbeständen, die rechtlich greifbar sind, wie Angriff oder Gefangennahme. Das kollidiert notwendig mit der normativen Legitimation von Interventionen und mit der tugendbasierten Professionalisierung der demokratisierenden „Mission“ im Mantel und im Gefolge von Interventionen.

(1) Soldatinnen und Soldaten sind Bürger einer liberalen Demokratie.

(2) Sie handeln im Auftrag der Bundesrepublik Deutschland unter dem Primat der Politik und verfügen über republikanische Tugenden.

(3) Als Instrument der Politik, deren Tätigkeit essentiell mit der Androhung und Anwendung von Gewalt verbunden ist, haben sie das Ethos von Kriegern, das ihnen ermöglicht, Gewalt als äußerstes Mittel zur Eindämmung und Begrenzung von anderer Gewalt anzuwenden. (Herberg Rothe et al.: 31)

Der zweite Punkt verweist explizit auf die republikanischen Tugenden: die müssen sich fast zwangsläufig gegen das positive Recht im konkreten Einsatz stel-

22 Die Studentin Olga Zeveleva hat in ihrer Hausarbeit „The Warrior Concept in American Society of Intervention“ eine aktuelle Zusammenstellung von Ansätzen zu diesem Kriegerkonzept in einer anderen Gesellschaft geleistet (FUB, HS 15353, 2011). 
len. Es ist aber schwierig daraus abzuleiten, wie sich Soldasten dann verhalten müssen. Der dritte Punkt ist gefüllt mit historischen Assoziationen, die weit in die Vergangenheit und vormoderne Bilder zurückreichen. Aber für die Gegenwart müssen solche Bilder erfunden und gefunden werden, soll nicht unversehens der Krieger wieder einer werden, der seinem „Vater ähnelt“23. Das ist das Ergebnis einer pessimistischen Weltsicht, die die völlige Abrüstung und Demilitarisierung aus den Konzepten genommen hat; aber vielleicht ist es auch eine Konsequenz aus der Responsibility to Protect, aus der Human Security? Wenn man den Fall Myanmar durchspielt, dann hätte der Einsatz von Militär zur Rettung der Flutopfer auch bedeutet, den Regime Change anzustreben, was ohne Gewalt wohl nicht möglich gewesen wäre. Die Vorstellung, welche Bilder uns aus den Flutgebieten und welche uns aus der Hauptstadt erreicht hätten, kommt nahe an den Anfang unserer Ausführungen, wie schwer der Soldat als Entwicklungshelfer und Katastrophenretter vorstellbar ist. Und noch etwas Zweites ist hier wichtig: Dass wir die Bilder vom Krieg bzw. der Gewalt und vom Terror, nicht mehr binär kodieren, als Bilder vom Sieg oder der Niederlage. (,Zwischentöne sind nur Krampf/im Klassenkampf“, Wolf Biermann), das war einmal. Die binäre Kodierung gehört den imaginären Welten an (Wir oder die Achse des Bösen). Nun kann man diese Argumentation auf verschiedenen Ebenen auf Deutschland und einen deutschen Diskurs hin fokussieren. ${ }^{24}$ Wenn wir probeweise drei Modi unterscheiden: Helden, Märtyrer, Professionelle (Krieger oder Kämpfer), kann man schon die Deutungsmuster und ihre Unvereinbarkeit erkennen. Die scheinbare Entheroisierung in der professionellen Freiwilligenarmee genügt umso weniger, je stärker das soziale Aufstiegsmotiv die patriotische Überzeugung bei der Wahl des Soldatenberufs übertrifft.

Eine besondere Variante des Soldaten spielt eine größere Rolle als vermutet: der Soldat als Ethnologe bzw. Anthropologe. Er wirkt mit an den imaginären Bildern vom Dort, er beschreibt nicht nur seinen Situation, sondern die der Intervenierten, oft mit gleichgültig-objektivierendem Blick, oft mit Empathie. Da die anthropologische und ethnologische Komponente der Kriegsführung sowohl kritisch kommentiert als auch affirmativ angewandt wird (zu divergierenden Ansätzen auch Eckert 2004; Barcott 2008; Waterston 2009; Daxner 2010; Koehler

23 „,ich bin der sieg/mein vater ist der krieg/der friede ist mein lieber sohn/der gleicht meinem vater schon" (Erich Fried 1946).

24 Für die differenzierte Betrachtung der neuen National(ismus)diskurse ist die Zeitschrift kultuRRevolution unverzichtbar; im Rahmen des anti-militaristischen Paradigmas sollte man sich der Zeitschrift Wissenschaft\&Frieden orientieren, neben einer Vielzahl von Internetplattformen. 
2012) ergänzen die Befunde sowohl das Expertenwissen um die Intervenierten bzw. die Interventionskultur, als auch, vor allem in Briefen und Berichten, die öffentliche Wahrnehmung des anderen Landes, einschließlich aller Stereotypen, Ressentiments und eigener Projektionen - von Machtphantasien bis zu sexuellen Wunschbildern. Für den Heimatdiskurs werden die Privatethnographien dann wichtig, wenn sie in der Öffentlichkeit haften bleiben. Wissenschaftliche und belletristische Literaturkritik findet hier ein reiches Feld, wir haben nur einzelne, für die Analyse relevante Beispiele untersucht.

\subsection{Andere Länder - andere Heimaten}

Wir haben schon darauf verwiesen, dass komparatistische Ansätze schwierig sind, weil es anderswo keine „Heimat“-Diskurs gibt, die Übersetzung stößt an die Grenzen der objektiven kulturellen Differenz. Home-Front ist eine interessante Wortschöpfung der britischen Wissenschaftlerin Gillis Youngs, weil „front“ ja eindeutig notiert erscheint und sich tatsächlich auf eine ethische Auseinandersetzung bezieht, wie sie in Heimatdiskursen stattfindet. Zu Homeland haben wir bereits einiges gesagt, wobei wir den Hinweis von Hidber dankbar aufgreifen, dass die Übersetzung von Heimat als „,category of belonging“ eine transkulturelle Brücke zu Vaterland und Nation herstellen kann. ${ }^{25}$ Was wir allerdings faktisch feststellen können, dass Äquivalente zum Heimatdiskurs sich nur dort entwickeln (können), wo die Öffentlichkeit hinreichend über die Tatsache des Einsatzes informiert ist und sie als nicht-normal empfindet. Das erklärt, warum in Ländern mit langer kolonialer Tradition und post-kolonialer Praxis wie Portugal oder Großbritannien die Tatsache, dass staatliche Armeen in weit entfernten Operationsgebieten tätig sind, als normaler empfunden wird. Bei den USA, als für uns hegemoniale Militärmacht, ist das etwas anders, obwohl dieser Staat ja dauernd out of area operiert und über 1000 Stützpunkte in aller Welt unterhält. Wir bezeichnen dies als die Globalisierung des Warriors, als Rollenmodell oder Leitbild oder aber als Gegenideal. An einem Beispiel der journalistischen Bearbeitung der Auslandseinsätze in Afghanistan kann das erläutert werden.

Sebastian Jungers War (2010) ist ohne Zweifel eine Ausnahme unter den Kriegsbüchern der letzten Zeit. Es ist die Reportage eines eingebetteten Journalisten von den Kämpfen im Korengal-Tal im östlichen Afghanistan, nahe der pakistanischen Grenze. Hochliterarisch und zugleich minutiös akkurat, das Ge-

25 Annette Hidber schreibt eine Doktorarbeit über den Vergleich von Identitäten zwischen israelischen und deutschen Soldaten unter meiner Betreuung. 
genteil eines Kriegstagebuchs. Das Buch knüpft an bestimmte VietnamTraditionen an und an die Losgelöstheit der aktuellen Kämpfe vom politischen Rahmen und von den Frames der Intervention. Tim Hetherington, der in Libyen getötete renommierte Photograph, hat dazu ein Buch gemacht, das überwiegend aus Portraitphotos besteht; dazu noch einige wenige Aufnahmen der erbärmlichen Gefechtsstände im gebirgigen Gelände, ein paar Einblicke ins Lagerleben, und Fotos von Tattoos und Emblemen (vgl. Hetherington 2010). Die meisten Gesichter zeigen eines deutlich: so sehen keine Krieger aus wie wir sie in den Engrammen unserer kulturellen Bildung haben. Sie sind eher an den Schützengräben von Verdun anschließbar, wie von Remarque beschrieben. Oder an die Stelle bei Junger, wo es um Sieg und Niederlage heißt: „It's been the kind of week that makes people back home think that maybe we're losing the war..." (Junger 2010: 125). Verletzliche, verletzte junge Menschen, deren Professionalität auch im Kontrast steht zur technischen Rahmung (auch ein „Frame“, wenn man so will), dass der elektronische Krieg mit Infrarot, lautlosen Kampfhubschraubern, Fernlenkwaffen und Satelliten immer wieder auf die Attacke im Kampf Mensch gegen Mensch, Scharfschützen und Hinterhalte im Wald stößt. Auf einigen Bildern sieht man, wie sich die Soldaten im Gefechtstand „balgen“. Dazu schreibt Junger, dass nach ein paar Tagen ohne Kampf die Spannung so unerträglich wird, dass sie sich gewaltsam, ohne jede Freundschaft oder das Aufeinander-Angewiesen-Sein zu zerstören, entlädt, bis hart an die Grenze des Ernstfalls (Junger 2010: 23f). Und implizit wird immer wiederholt, dass diese Warriors sehr oft in ihrem Platoon, in ihrer Kompanie, die einzigen Freunde ihres Lebens (gefunden) haben. Beides sind fast archaische, jedenfalls vormoderne Muster. Die Bilder sind schwer auf den „demokratischen Krieger“ zu überschreiben, und doch - wird dieser sich im „Ernstfall“ des Kampfes anders verhalten? Und mit welchen Erzählungen wird die Militärsoziologie arbeiten müssen, wie werden die Erzählungen der überlebenden Heimkehrer, ihrer Angehörigen, ihres sozialen Umfelds in die größeren Narrative ihrer Gesellschaft und Zeit aufgelöst werden? Ein gelungener deutscher Versuch, dieser Darstellungsform nahezukommen, findet sich bei Stefan Kornelius (Kornelius 2009).

Der bettelnde Beinamputierte ist heute auf den Straßen von Kabul gegenwärtig, aber er ,erinnert“ (noch) nicht an unser Alltagsstraßenbild. Die Verletzungen sind andere geworden, und sie werden anders repräsentiert, vor allem medizinisch, um im Bereich der Wohlfahrts-Governance aufgehoben zu sein - das kann man an der Diskussion von PTSS (Post-traumatisches Stresssymptom) studieren. Just ein paar Tage nach der Ausstrahlung von „Willkommen zu Hause“ befasste sich der Bundestag damit und kurzzeitig war es ein Medienthema. De facto sind Heimkehrer-Neurosen und -Psychosen aber nur bedingt in den breiten Symp- 
tombereich des PTSS einzuordnen. Die Beziehung zur Realität des Einsatzes und zum Krieg wird gekappt, wo sie beim Amputierten noch deutlich unabweisbar war. Ich möchte gerade an dieser Stelle niemanden provozieren: aber es scheint mir, dass wir mit Toten (Gefallenen) leichter umgehen als mit Invaliden und Veteranen.

\subsection{Stereotype Bilder aus dem Krieg}

Alle Schulneubauten weltweit sehen gleich aus, alle Krankenzimmer sind sich ähnlich. Wenn Soldaten Schulausrüstung an Lehrer und Schüler verteilen oder Spatenstiche für Neubauten machen, wird wenigstens das Ausgangsnarrativ Soldaten bei Friedenseinsätzen - aufgerufen, zugleich mit einer Portion ironischer Ungläubigkeit. (Dazu sind die doch nicht dort). Es wird aber auch angedeutet, dass es ohne Soldaten nicht geht. Das ist für den Heimatdiskurs eine wichtige Bruchstelle. Soldaten von humanitären Interventionsarmeen (also nicht Angriffskrieger wie im Irak-Krieg von 2003) sind meist nach den Kampfhandlungen der Kontrahenten vor Ort, was fälschlich als post-conflict bezeichnet wird, und besser post-war bezeichnet würde, selbst wenn der Krieg noch nicht gänzlich vorbei ist. Jedenfalls ist der Krieg als Quellkonflikt vorbei, und Konflikte der Interventionsgesellschaft sind analog denen der Nachkriegsgesellschaft. Wenn die Intervention mit Militär erfolgt, was oft, aber nicht immer der Fall ist, dann ist ein Problem, ob das Militär die politischen Vorgaben der Intervention erfüllen kann (und will); und ein anderes, wieweit es sich gegenüber der Politik verselbstständigt.

\subsection{Der Heimatdiskurs schreibt sich in die Kultur ein}

In der Literaturwissenschaft gibt es eine ganze Menge an Untersuchungen zu den Verbindungen zwischen verschiedenen Genres und den Diskursen des Militärischen, des Patriotischen, des Nationalen etc. Die Brücke zu den Sozialwissenschaften wird häufig und mit Gewinn gebaut. Im Alltag unserer Forschung ist das nicht so einfach, teilweise scheitert das Erreichen dieser Brücke an der Diachronie der Diskutierenden (zwischen dem Wissen und der breiten Bildung der Studierenden und der Lehrenden), teilweise an der Enge der Fachkulturen. Der „alte“ Krieg hat die Bilder und Begriffe geprägt, er ist voll von anachronistischen, heroisierenden und sinnlichen Bild-Elementen und Assoziationen. Es gibt geradezu eine Beruhigung, wenn man hört, wie Soldaten kämpfen, sich gegenseitig mit Gewehren erschießen, wenn es gar den Kampf „Mann gegen Mann“ gibt. Beruhigung deshalb, weil die rationale, äußerst weit entfernte Steu- 
erungszentrale der meisten Angriffe weder sinnlich vorstellbar ist noch den Prozess vermittelt, dass in vielen Fällen die technische Rahmung eines Angriffs doch beim einzelnen Soldaten, beim Kämpfer ankommt. Der Drohnenkrieg ist ein gutes Beispiel für diese Unvorstellbarkeit und auch Unsagbarkeit. Es gibt eine Einschreibung des Kriegs als Normalität in die Alltagskultur. Das ist im Übrigen etwas anderes als die oft beklagte „Militarisierung“, die ja bestimmte intentionale und ideologische Voraussetzungen hat. Dass der Krieg dazugehört, ist für uns so fatal, weil wir uns angewöhnt haben, ihn nur woanders als dazugehörig zu wissen. Es ist ein oft unbeachteter Aspekt der Theorie zur Interventionsgesellschaft, dass die Intervenierenden Anteil an ihr haben. Wenn man keine Worte und Bilder für etwas hat, worüber man mitreden möchte, wählt man oft alte oder erprobt neue, aber häufig sind es "falsche“ im Sinne der Nichtübersetzung dessen, was man sagen möchte. Diese Erprobung ist entweder eine Einübung in Normalität, oder sie ist Ausdruck einer noch nicht geronnenen Einstellung zu einem Wandel. Wir betonen noch einmal, dass Normalität nicht automatisch in „richtig“ oder eben „falsch“ zu übersetzen ist. Sondern, dass man sich mit einem Phänomen auseinandersetzen muss, das so nicht voraussehbar war.

\subsection{9/11 und der Heimatdiskurs kommt in Fahrt}

Es folgt ein Abschnitt, in dem ich mit Bildern unterlegte Beispiele dafür gebe, wie der Heimatdiskurs sich verbreitet. Es handelt sich um eine Auswahl, die mehr auf Breite denn auf Tiefe ausgerichtet ist und eher ,unscheinbare“ Momente in die Theorie hineinzieht.

Nach 9/11 hat Karlheinz Stockhausen viel Unmut auf sich gezogen, als er den Anschlag ein großes Kunstwerk nannte und das auch einigermaßen ausführlich begründete. ${ }^{26}$ Bilder vom Krieg und von Terror haben immer eine gewisse Faszination auf die Kunst und die Rezeption dieser Kunst ausgeübt, die Verbalisierung durch Stockhausen war vielleicht kurzfristig anstößiger als Bilder, Karikaturen und Anspielungen.

Wenn es nicht um terroristische Akte oder um unfassbare große Zahlen geht, hat das konsumierende Publikum nichts dagegen, große Verbrechen künstlerisch serviert zu bekommen, Meisterdiebe, Postraub, Überlistung der legitimen Gewalt usw. Aber die Ästhetisierung des Antithetischen, des Feindes, ist verboten. Es ist interessant, dass nach dem Tod von Osama bin Laden vor allem verbal, aber

26 Interview am 16.9.2001 www.stockhausen.org/hamburg.pdf (aufgerufen am 14. Mai 2011) sowie viele Blogs und Kommentare bis heute (ca. 47.000 Ergebnisse bei Google). 
auch in kommentierten Fotos und Videos eine gewisse, „kleine“ Ästhetisierung dort stattfindet, wo man die gezielte Tötung in westliche Kommentaren verurteilt, während seine „hässliche“ Fratze (er selbst bzw. die von ihm inspirierten Taten) dort besonders herausgebildet werden, wo die Tötung als solche gebilligt wird.

\section{Abbildung 4: Übungsmanöver}

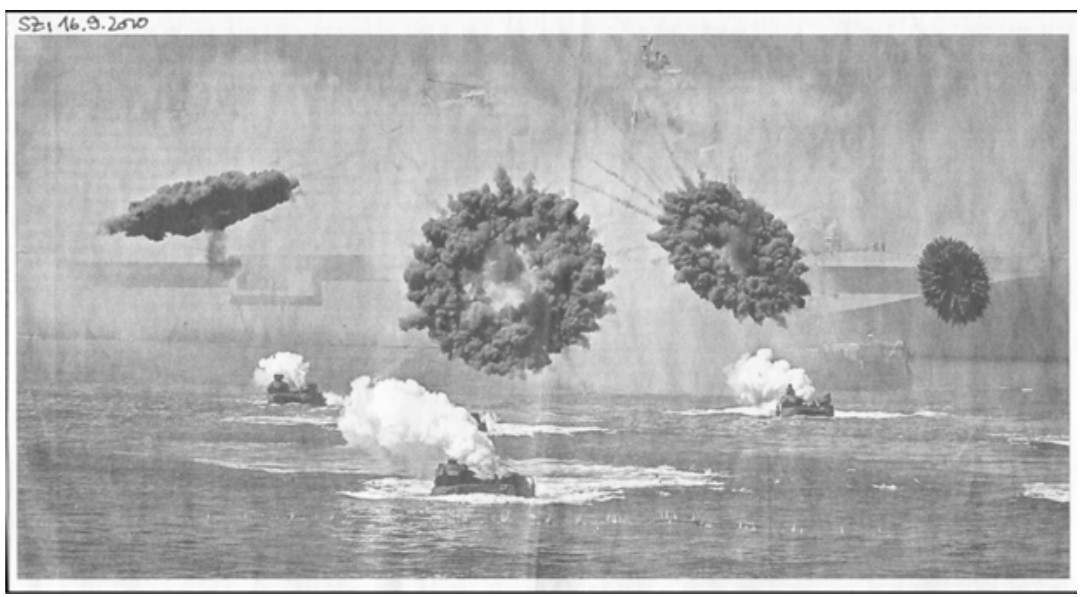

Quelle: Süddeutsche Zeitung, 16.9.2010.

Der moderne Krieg kennt nicht nur die „kontrafaktischen“ Soldatenbilder, sondern auch eine abstrakte Ästhetisierung, die man am besten in der Atompilzsymbolik von Hiroshima nachverfolgen kann; heute werden Manöverbilder gezeigt, die nicht ohne weiteres als Kriegsbilder zu identifizieren sind. Man müsste auf die Theorie des ornamentalen übergehen, wollte man hier den Befund genau erläutern, dass es sich nicht so sehr (aber auch) um eine Verharmlosung handelt als vielmehr um die Herausnahme des agierenden Kriegers oder Kämpfers aus dem Kampf- und Tötungsvorgang. Die Objektivierung des Objektiven, möchten wir das nennen. (Der nächtliche Angriff auf Bagdad im ersten Golfkrieg bot eine derartige Ornamentik (,Feuerwerk“), die massenmedial in Echtzeit um die Welt ging und ihren Kontext nicht ohne weiteres enthüllte.)

Als Ergebnis von 9/11 entsteht eine Homeland-Rhetorik in den USA, die sich zunehmend verfestigt, und deren Zweck offenkundig eher die Erhaltung des amerikanischen Exceptionalism (Franck 2001; Danner 2011) ist als tatsächlich wirkungsvolle Schutzmechanismen aufzubauen, die von den bisherigen Sicherheitsagenturen nicht gewährleistet werden könnten. Diese Rhetorik wird teilweise auf Bündnispartner übertragen, obwohl die Halbwertszeit von 9/11 entgegen 
allen Prognosen relativ kurz ist und sich heute mit den Anschlägen auf das WTC nicht mehr allzu viele restriktive Maßnahmen rechtfertigen lassen (hier gibt es nationale Unterschiede). Aber natürlich gibt es handfeste und materielle Spuren, und also auch im Diskurs. Florian Kühn hat dies in der maßlosen und auch in der Sache ungerechtfertigten Überschätzung der Terrorismus-Semantik plausibel dargestellt (vgl. auch seinen Beitrag in diesem Band).

Aber 9/11 hat die Auslandseinsätze der Bundeswehr zwischen zwei Polen aufgespannt, während man vor dem September 2001 auf die Entwicklung hin zu R2P gespannt sein konnte. Jetzt bildet diese Entwicklung, die weltgesellschaftlich und transnational ist, einen Brennpunkt, während der andere eine supra-nationale oder bilaterale Loyalitätshierarchie zum Fundament hat, mit den USA als zunehmend schwächerem, aber noch immer übermächtigem Pol. Dass die deutsche Beteiligung an Krieg und Intervention unter den Umständen, wie sie Afghanistan und davor Kosovo gegeben hatten, „,normal“ wäre, kann man nicht behaupten. Dass sie sich nicht wiederholen und zum Normalfall werden könnte, kann man ebenso wenig abtun. Es hat den Anschein, dass sich der Heimatdiskurs auf die zweite Option einrichtet. Dafür spricht die angefangene Reform der Bundeswehr; dafür sprechen auch die verstärkten Bemühungen, Interventionen in völkerrechtlich verbindliche(re) Rahmen zu setzen, wie die Diskussion um den Einsatz in Libyen zeigt. Und die Diskussion um die gezielte und in Kauf genommene Tötung von Osama bin Laden zeigt ein weiteres Mal, dass der Wert der staatlichen Souveränität erheblich in Zweifel gezogen wird, gerade wenn eine normativ begründete Intervention - in diesem Fall punktgenau und singulär - durchgeführt wird. Wenn der Ansatz des Heimatdiskurses akzeptiert oder wenigstens weitgehend für sinnvoll gehalten wird, dann sind seine Schnittstellen mit anderen Diskursen von Bedeutung und alle Vermittlungsebenen, in denen er sich manifestiert. Die Emergenz dieses Diskurses, sein Auftauchen als Ergebnis und Bedingung der Verstätigung von out of area Einsätzen, hat die Erzählungs- und Darstellungsebenen erheblich verändert. Ich überlasse die medienkritische Deutung dieser Veränderung den Experten für dieses Gebiet und konzentriere mich auf die Verbindung zu einer Politik, in der - und das ist entscheidend - das Dispositiv der künftigen globalen Innen-/Außenpolitik Deutschlands noch nicht festgelegt ist. Dieser Zustand des Fluiden, Unfertigen, hat Vorteile - er schafft Raum für demokratische Verhandlung, für Transparenz, für Rückholbarkeit.

Nicht erst mit Jungers War wird eine Kampfsituation gezeigt, in der das ,eigentliche“ zu Hause der Soldaten zunehmend der Gefechtsstand wird. Das äußert sich in der Reportage ausführlich, weil das vorgeschobene Camp und die behelfsmäßigen Außenposten die sozialen Orte sind, in denen Freundschaften und 
„existentielle Gedanken“ sich austauschen, das Wichtige ist hier das Virtuelle in einer fernen anderen Realität. Das ist ein anderes „Home“ als das in den Home Stories gezeigte. In deutschen Medien wurde bis vor kurzem gerne das „BattleHome“ von amerikanischen Soldaten gezeigt, erst spät kommen deutsche Lagerstories dazu.

Abbildung 5: Cover des Süddeutsche Zeitung Magazins „Abstieg“ (li.) und Ausschnitt aus der Zeit ,heranreitender Taleban“ (re.).
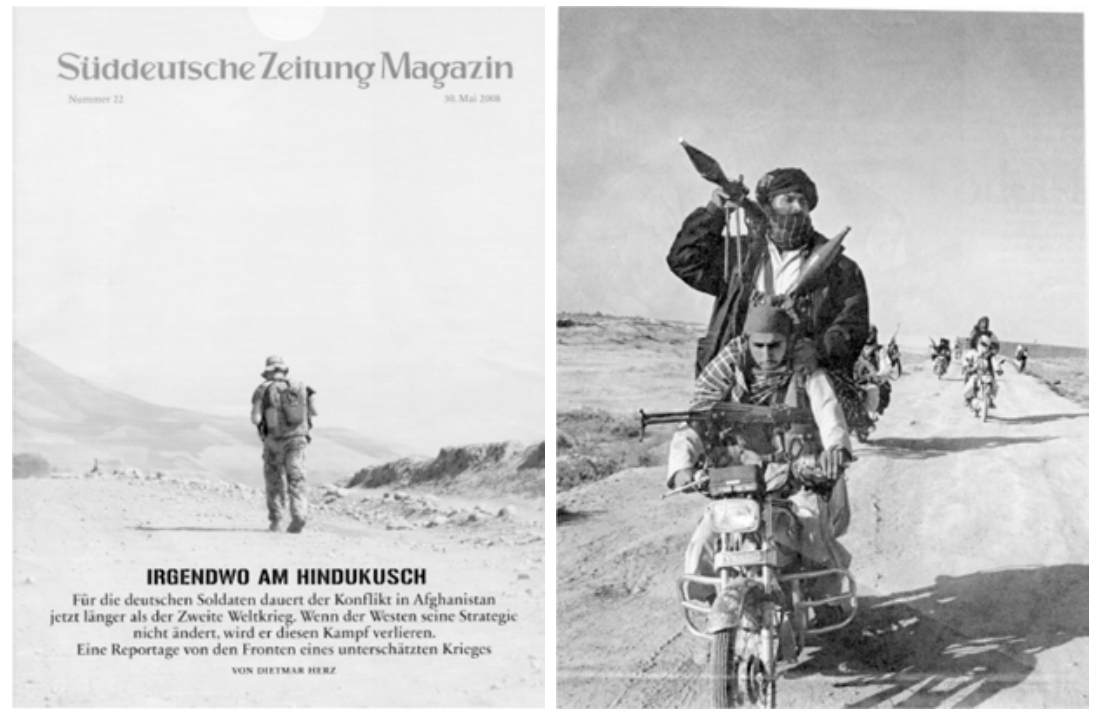

Quelle: Süddeutsche Zeitung Magazin, 30.05.2008 (li.); Die Zeit, 19.06.2008 (re.).

Solche Darstellungen finden sich bei Junger nicht, die Ikonologie ist bei ihm persönlicher und reduzierter. Das erste Bild hier ist deshalb interessant, weil es auf dem Titel, also programmatisch, einen „negativen“, resignierten Eindruck vermittelt - deshalb nenne ich es Abstieg, weil ja zum Horizont hin ein Abgrund ist. Auch das ,,irgendwo“ demonstriert Gleichgültigkeit, Erschöpfung. Ganz anders die etwa zeitgleiche Wahrnehmung der Taleban: die „reiten“, tendenziell immer selbst- ergänzend wie eine feindliche Gang im Western herein.

Mit diesen Bildern werden Bedürfnisse befriedigt, sich bestätigt zu fühlen, dass der Einsatz ohnedies vergeblich sei - was dann politisch umschrieben heißt, dass der Kampf/Krieg „militärisch nicht zu gewinnen sei“. Wobei sich ja keine Bilder denken lassen, in denen der Kampf gewonnen ist. Wie solche Bilder verfertigt werden, kann man anhand der Geschichte des gestürzten SaddamDenkmals in Bagdad nachlesen (vgl. Maass 2011). Aber die klassische Siegespa- 
rade ist so unwahrscheinlich wie die jubelnden Massen nichtssagend wären, jetzt, wo jeder Bildausschnitt vielfach bearbeitbar und in unterschiedliche Interpretationen eingebettet ist. Außerdem: wer hätte denn wen besiegt? Ein immer wiederkehrendes Motiv der Hoffnung ist in den letzten Jahren die Situation, wenn würdige Taleban-Anführer sich aufstellen, ihre Waffe abgeben oder eine weiße Fahne tragen und sich der Regierung anschließen. Diese Bilder sind insoweit ent-kontextualisiert, als sie nicht mehr erklären, wie und warum es zum Sinneswandel gekommen ist - und es macht einen Unterschied ob durch Drohung, durch Gewalt (,militärischer Teilerfolg“), durch Einsicht, Taktik oder rationale Güterabwägung. Die Unterwerfungsgeste wird zum Emblem des Erfolgs.

\subsection{Hat Deutschland sich verändert?}

Wir verlangen eine Menge vom Heimatdiskurs. Gehen wir zu den Ausgangsfragen und Definitionen zurück. Wenn der Heimatdiskurs die Handlungen von Politikern, Eliten, Meinungsmachern, Medien und einer interessierten Öffentlichkeit beeinflusst, dann hat er auch Wirkung auf das System, in dem sich diese Akteure bewegen, auf Deutschland. Bei einer Veranstaltung der CDU zu Afghanistan, im Vorfeld der Bonner Konferenz vom 5.11.2011, stellte der Abgeordnete Ruck fest: „Afghanistan hat Deutschland verändert“. Das meint, dass der Auslandseinsatz die Koordinaten der gesellschaftlichen Selbstwahrnehmung und der Wahrnehmung des staatlichen Rahmens verändert hat. Dazu gibt es Ereignisse und Phänomene, auf die zu reagieren wir nicht gelernt haben, bzw. es fehlt uns die Routine im Umgang mit ihnen. Was ist anders geworden?

Vordergründig gibt es eine Reihe von Phänomenen, die neu sind, bzw. die wir nur von anderen kennen. Nicht nur, dass wir Kriegstote haben, sondern wie sie in die Heimat zurückkehren, wie die Totenfeiern stattfinden, was bei uns anders ist als z.B. bei den USA, wo es lange verboten war, die braunen Säcke zu filmen, in denen die Gefallenen angelandet wurden. Oder dass man uns ,,initiieren“ möchte, in dem man uns auffordert, ,töten zu lernen“.

Aus den Medien erfährt das Volk, was es braucht, um in einer anderen Klasse anerkannt zu werden. Oft ist in den letzten Jahren der Satz gedruckt worden, wonach Deutschland in Afghanistan seine Unschuld verloren hätte. Konkret meint diese Metapher, dass unsere Auslandseinsätze mit einer in Kämpfe einbezogenen Bundeswehr dem ursprünglichen Narrativ entzogen wurden. Spätestens beim Bombardement der beiden Laster in Kunduz am 4.9.2009 ist diese Initiation zur Normalität hin offenkundig. Es klingt, als wäre man endlich und überfällig erwachsen geworden. Bei einer Versammlung von Pressesprechern sagte die Stimme des Bundeswehrverbandes fast ehrfürchtig, es handle sich um ,einen 
richtigen Krieg; die Taleban sind richtige Kämpfer...“, das richtig weist darauf hin, dass hier bereits ein normales Muster (im Sinne von normativ) besteht, das jetzt von der Realität bestätigt wird.

Die Situation ist nicht schwer zu dekonstruieren. Das beschriebene pazifistische Nachkriegsnarrativ und eine Haltung zur Leitnation USA haben Deutschland besonders sorgsam darauf achten lassen, dass die anderen foltern mögen und Menschrechte verletzen, man selbst aber nicht. Man kritisiert andere, wenn sie Unrecht tun, indem man sich nur innerhalb der Bündnisverpflichtung beteiligt und genau das zu machen, was man an anderen kritisiert. Bis eben zum Bombardement am 4.9.2011, bis zum ersten erschossenen Afghanen an einem Checkpoint, bis zur ersten öffentlichen Wahrnehmung von Fehlverhalten unserer Soldaten z.B. bei der Totenkopfaffäre. Die tugendhafte Rolle ist ausgespielt. Für die wenigen, die noch an das Weltkrieg II-Narrativ anknüpfen können, ist das weniger schlimm, denn „Krieg ist Krieg“; für die anderen ist es ein Sündenfall.

Warum die Politik ihre Strategie wechseln sollte, ist in dieser Moralisierung des Diskurses nicht sofort erkennbar. Würde man die militärischen Ziele eher teilen, wenn sie ohne Fehlverhalten, ohne Kollateralschäden, ohne Infragestellung der Mittel erreicht werden könnten? Eine Schlüsselszene bei Kurbjuweits Kriegsbraut (Kurbjuweit 2011) legt diese Deutung nahe. Nach dem Einsatz, bei dem auch drei Zivilisten sterben, ist für den Kommandanten am wichtigsten, dass diese Tatsache nicht der deutschen Öffentlichkeit bekannt wird: Die Offizierin hat ein Bombardement eines Gehöfts ausgelöst, von dem aus ihr Konvoi beschossen wurde. Früher hatte sie dort eine Frau mit zwei Kindern gesehen; die wurden jetzt offenbar als menschliche Geiseln benutzt und kamen beim Bombardement um.

„Haben Sie zu einem anderen Zeitpunkt Menschen an diesem Ort gesehen?“, fragte der Kommandeur. ,Ja, immer wieder...“ --- Esther weiß natürlich, dass durch ihre Fluganforderung auch die drei Zivilisten ums Leben gekommen sind. Dass der Hof unbewohnt erschien, an diesem Tag, beruhigt den Kommandeur. ---,,Sind Sie sich absolut sicher, dass Sie keine Zivilisten gesehen haben?““”Absolut“, „Es wäre eine Katastrophe, wenn die Öffentlichkeit erführe, dass wir für den Tod einer Frau und zweier Kinder verantwortlich sind“. (Das ist eine Tatsachenbehauptung, wir sind verantwortlich!). Sind wir doch, dachte Esther. „Sie als Frau müssten das doch in besonderer Weise verstehen“, sagte der Major. ...Nach quälenden Bestätigungen sagt der Kommandeur: „...Sie haben uns versichert, dass Sie nichts von deren Anwesenheit gewusst haben. Das ist gut. Es gibt niemanden, dem wir einen Vorwurf machen können. Es ist alles ordnungsgemäß abgelaufen“....Der Major beugte sich vor: „Wie war das? Wie hat sich das angefühlt mal richtig zu schießen? (256-257). 
Die Situation ist geklärt. Wem können wir einen Vorwurf machen, nicht, wer kann uns einen machen?

Eine andere Deutung ist ungewollt zynisch. Weil man die ohnedies bereits allgemeine Meinung teilt, der Konflikt (mit den Taleban und Aufständischen) sei militärisch nicht zu regulieren, müsse man abziehen. Also könnte man bleiben, würde man erfolgreich sein, gar siegen? Das ist nicht gemeint, sagen wir wohlwollend, aber unbewusst wird es vielleicht doch so gesehen, dass die nichterfolgreiche Militäraktion die Legitimation der Intervention weiter untergräbt. Auch das ist eine neue deutsche Erfahrung.

Wie bereits mehrfach ausgeführt, ist die zunehmende Heimkehrerliteratur insofern „neu“, als über lange Zeit die Literatur über den Zweiten Weltkrieg für die breite Masse abnahm (z.B. Konsalik) viel Kriegsliteratur „fremde“ Kriege behandelte, also solche, an denen deutsche Soldaten nicht teilnahmen, bzw. das Genre in Thriller und Science Fiction verschoben wurde. Hier wird massiv Geschmack verändert und damit in die kulturellen Legitimationen eingegriffen. Afghanistan ist nicht einfach „unser Vietnam“, aber Bezüge sind ganz eindeutig (auch was hier erhältliche und übersetzte amerikanische Literatur betrifft). Afghanistan gehört bereits zu unserem kollektiven Gedächtnis, ist aber noch lange nicht im kulturellen eindeutig festgelegt (vgl. Assmann 1994).

Die Geschmacksfrage ist nicht trivial, weil sie die Voreingenommenheit und positive wie negative Inklinationen verstärkt. Sie steht aber nicht im Vordergrund. Es ist interessanter für die wissenschaftliche Analyse zu erkunden, wie die Botschaften dieser Literatur sich im Diskurs festsetzen und ihn verändern, verstärken oder abschwächen; die unmittelbare Wirkung eines kurzfristigen Memoirenstücks kurz vor der Buchmesse 2011 ist ein Indikator. Tom Koenigs war SRSG für UNAMA 2006-2008. Sein Buch, eine Sammlung von Berichten an Freunde, trägt den paradigmatischen Titel Machen wir Frieden oder haben wir Krieg? (Koenigs 2011). Es enthält förmlich die bisherige Abhandlung zum Heimatdiskurs. Der anekdotische Analysenstil steht einerseits in der Tradition von Diplomatenmemoiren, andererseits schreibt hier ein aktiver und respektierter Politiker Aufklärungsliteratur, die über die Entscheidungsträger hinaus zielt und Afghanistan weniger imaginativ als empirisch macht. Koenigs' Bericht ist so wichtig, weil er in eine politische Analyse eingebettet ist, also eine „Objektivierung“ darstellt, die Befund und Rechtfertigung zugleich enthält. Diese Einbettung unterscheidet das Buch von einer Vielzahl von Berichten, die vor allem der Verarbeitung unmittelbarer Erlebnisse (nichtvorrangig Beobachtungen) dienen. Es darf vermutet werden - und diese Beweisführung steht dringend für die Forschung an - dass Koenigs' Buch der Meinungsbildung unter den Peers erheb- 
lich stärker dient als der Meinungsbildung breiter Massen; d.h. das Buch differenziert weiter, was schon differenziert im politischen Feld vorhanden ist.

Diese Einbettung wird wirkungsvoll transportiert, wenn die Fiktion den Charakter von Doku-Fiktion annimmt, aber nicht wirklich ist (man sieht dem Text die Recherche an, aber die Recherche ist weder Handlung noch verdeckter Zweck des Texts). Dirk Kurbjuweits Roman Kriegsbraut steht nicht in der Tradition der endlosen Reihe von Subjektivierungsromanen der Kriegserfahrung, sondern er imaginiert Unmittelbarkeit und Subjektivität in eine Handlung, deren eines Problem eine Beziehungskonstellation in Deutschland und in Afghanistan ist, die nur beschränkt kulturell different in beiden Realitäten bearbeitet wird. Das andere Problem aber ist der Heimatdiskurs und seine Rechtfertigungskomponente. Kurbjuweits Einbettung ist Koenigs' ähnlich: Menschenrechte und ihre Rückübersetzung in die jeweilige Gesellschaft sind wichtiger als die Beobachtung oder Handlung, aber nur durch die beiden vermittelbar und ihres abstrakten Codes entkleidet. Außerdem geht es nicht um die Klassifizierung der Afghanen, also der Intervenierten. Die Interventionsgesellschaft kommt immer nur im Verständnis bzw. Missverständnis von konkreten, handelnden Personen vor. Darin unterscheidet sich Kurbjuweit ebenfalls von der psychologisierenden, oft therapeutisierenden, Heimkehrerliteratur; er kommt solcher Belletristik nahe, die prototypische Personen und Handlungsschemata präsentiert. Wichtiger erscheint uns, dass er keine ideologische Beeinflussung der Leser in Bezug auf ihre Haltung und Einstellung zum Einsatz versucht, sondern die Subtexte in die Personen des Romans verlagert. Vor allem die erlebte oder fingierte Briefliteratur arbeitet scheinbar an der Oberfläche, Wissen, Meinung und Wertung fallen zusammen und gewinnen Authentizität durch die Beglaubigung des persönlich, wirklich Erlebten. Aber gerade diese parteilich-aufrichtige Literatur transportiert ihre Subtexte nichtsdestotrotz - und oft massiver. Überschriften aus der Einleitung: Was die Bundeswehr verhindern wollte. Von der Friedensmission zum Krieg. Unser Krieg? Der Krieg und die Deutschen. Zwei Textbeispiele:

„Bei uns ist der Stab so mit der Irreführung der der eigenen Truppen beschäftigt, dass er für Briefe keine Zeit hat :)“. (Baumann 2011, 46)

„....aber heute sollte es endlich so weit sein und ich meine Pistole anschießen können. Tatsächlich fahren wir mit Fuchs, Dingo und Wölfen raus. Ich entscheide mich für den Vordersitz des Fuchs und merke erst später, dass mein Fahrer eine blonde Fahrerin ist, mit der man sich angenehm unterhalten kann. Das Schießen selbst ist auch sehr interessant.“ (Baumann 2011: 41)

Fuchs, Dingo und Wölfe sind Fahrzeugtypen. Im zweiten Brief ist das „Auch“ im letzten Satz einer Analyse wert. 


\subsection{Kunduz 4.9.2009}

Eine ausführliche Würdigung der Ereignisse von Kunduz greift in eine Vielzahl von Diskursen ein; sie ist auch deshalb schwierig, weil hier die Perspektive nicht einfach eine arbiträre ist, sondern ganz entscheidend den Anlass und Hintergrund der Recherche und Urteilsfindung zur Offenlegung zwingt. An einigen kleinen Beispielen kann die Bedeutung des Vorfalls im Heimatdiskurs aber deutlich gemacht werden.

Schon die schiere Menge an Kommentaren zu den Dokumenten, die den Vorfall betreffen, macht eine einen Eindruck in den Heimatdiskurs. (14.000 Hits zur Anfrage „Kundus 4.9.2009“ bei Google 27.12.2011). Eine Nacherzählung dessen, was wirklich geschah, hätte ihre Schwierigkeiten. Das Ereignis war ein Bombardement von zwei Tanklastzügen, die Tage zuvor von Taleban entführt worden waren. Die Bomben töteten ca. 90 Menschen. Wie es zum Einsatzbefehl kam, und wie die Geschichte verdreht, korrigiert und ständig verändert wurde, wurde ein politischer Skandal. Wie die Vorgeschichte war, interessierte die meisten Menschen nicht bzw. war ihnen auch dann nicht zugänglich, wenn sie sonst gut informiert waren. Wie die ISAF-internen Abläufe waren, konnte sich nur zusammenreimen, wer die offiziellen Stellungnahmen dazu und die Kommentare zu diesen Stellungnahmen zum Anlass genauerer Recherche nahm. Noch komplexer wurde es, wenn man den politischen Kontext dazu nahm, etwa die Befehle des ISAF Oberbefehlshabers McChrystal, im Zweifelsfall keinen Einsatz mit Waffengewalt zu befehlen und die Rechtfertigungstaktik des Oberst Klein, diesen Einsatz sehr wohl verantworten zu wollen, wenn auch unter Gewissenszweifeln und Skrupeln.

Warum ein derartiges Ereignis so tief in den Heimatdiskurs eingriff, versteht man sofort, wenn man sieht, welche Bastionen des Bundeswehr-Narrativs und der eigenen, moralischen Überlegenheitsposition „Deutschlands“ augenblicklich geschleift wurden (Deutschland ist hier in „“"gesetzt, weil eine andere Diskurskonstellation angesprochen ist: im politisch-populären Diskurs der Auslandseinsätze waren die Amerikaner stets das Modell für Grenzüberschreitungen und militärische Fehlhandlungen - oft mit dem Kriegerbild vermischt, oft aber auch mit einem kruden moralisch zivilisatorischen Vorurteil: rückständig gegenüber den deutschen Errungenschaften an Integrität und Menschenrechtsbeachtung. Man denke an Abu Ghraib, an das Bombardement von Hochzeitszügen, an CIA Folter und Geheimgefängnisse - „wir“ haben all das nicht, und kleine Ausrutscher, wie die Affäre Kurnaz oder Mitwirkung an amerikanischen Vergehen, fallen dann unter den Tisch). Bei Kunduz wurde vom Verlust der „Unschuld“ 
gesprochen und von der Tatsache, dass wir nun wirklich normal seien, d.h. uns so verhielten wie alle anderen kriegführenden oder kämpfenden Nationen. Hier ist das Einlassventil zum Heimatdiskurs. Die Breitenwirkung des Vorfalls war erheblich und dauerte mehr als ein Jahr, die Tiefenwirkung besteht nach wie vor in sehr begrenzten Bereichen, etwa dem militärischen Disziplinarrecht, das für Klein nicht angewendet wurde und in der angeblichen rechtlichen Verunsicherung der Einsatztruppen.

Wir wollen einen Strang beschreiben, der erklärt, wie die Eingriffe in den Diskurs erfolgt sind. Der Strang ist zweigeteilt: ein Zweig beruht auf einer Reihe von Mitteilungen, Stellungnahmen und Dokumenten, die von der Bundesregierung (BMVg, Kanzlerin) veröffentlicht wurden, und von Diskussionen im Bundestag. In diesen Zweig gehören der Rücktritt von Minister Jung, die widersprüchlichen Äußerungen von Minister zu Guttenberg, die Entlassung von Staatssekretär Wichert und Generalinspekteur Schneiderhan. Es musste auch dem wenig informierten Bürger der Eindruck entstehen, dass ein Schutzkordon um den Verteidigungsminister und um den Obersten Klein gezogen werden musste, um das große Ganze, „Deutschland“, integer zu erhalten. Auch wenn viele Medien nachhaltig darüber berichteten, blieb die Analyse und Bewertung fast ausschließlich den Experten vorbehalten, die Zugang zu nichtöffentlicher Information, persönlichen Berichten von Augenzeugen und einige Kenntnis über den militärischen Aufbau von ISAF haben. Diese Experten treten für gewöhnlich nicht in weitverbreiteten Kommentaren an die Öffentlichkeit; die Diskussion im Bundestag überschritt die Skandalschwelle zum Dauerbrenner nicht. Innerhalb der Experten hält die Diskussion um die Folgen des Ereignisses an. Von daher erfolgt eine vielfältige Korrektur und Ablenkung innerhalb des Heimatdiskurses.

Der zweite Zweig beruht auf einer individuellen Recherche eines prominenten Journalisten, der damals für den Stern schrieb und in Afghanistan lebte: Christoph Reuter. Er dokumentierte mit eindringlichen Bildern von Marcel Mettelsiefen eine Reportage über den Vorfall, vor allem aber eine minutiöse Recherche über die Hinterbliebenen der Opfer und wie diese zu den Tankwagen gekommen waren, um Diesel abzuzapfen. Es folgten eine bemerkenswerte und weit kommentierte Ausstellung „Kundus 4.9.2009“ im Kunstraum Potsdam, eine damit verbundene Vortragsreihe und ein von Clemens Bechtel verfasstes und inszeniertes Dokumentarstück am Potsdamer Hans Otto Theater, das im Übrigen von vielen Experten des oben genannten ersten Diskursstrangs beraten wurde. Das urbane aufgeklärte Umfeld der Hauptstadt fand in der Potsdamer Ereigniskette eine Plattform, seine Position im Heimatdiskurs zu testen.

Der Vorfall wird die Politik und die Bundeswehr, indirekt auch die Justiz, noch lange beschäftigen. Letztere nur indirekt, weil sowohl die staatsanwalt- 
lichen als auch die disziplinarischen Ermittlungen niedergeschlagen wurden. Die Halbwertzeit der kollektiven Erinnerung ist relativ kurz; Klein ist nicht zum emblematischen Namen für die neue Bundeswehr geworden, obwohl er wahrscheinlich der kurzfristig bekannteste Name eines aktiven Offiziers geworden ist. Die Spuren im Heimatdiskurs aber sind nachhaltig. Die Einsatzregeln sind ebenso in die Diskussion geraten wie die Erkenntnis, dass im Ernstfall rechtliche, auch menschenrechtliche, Erwägungen mit politischen Rahmungen, etwa der Dominanz der US-Regeln, und mit dem Prinzip verantwortlicher Führerschaft (Leadership) kollidieren. Im August 2012 wird Oberst Klein zum Brigadegeneral befördert. Dirk Kurbjuweit spricht von einer Belohnung: „Da der Oberst in Kunduz brutal handelte, wurde er eine Art Held. Nun steigt er zum Brigadegeneral auf.“ (Der Spiegel 33/2012: 23); hingegen fordert Blechschmidt „Barmherzigkeit für Oberst Klein“, dieser sei mit seiner Tat lebenslang belastet (SZ, 9.8.2012).

\subsection{Fortschrittsberichte und Fortschritt}

In dem Maß, in dem die Realität des Auslandseinsatzes ins Bewusstsein der Öffentlichkeit dringt, gewinnen Aussagen und Informationen der Bundesregierung höheres Gewicht als früher, zumal die öffentliche Meinung eine scheinbar paradoxe Spaltung repräsentiert: eine Mehrheit steht der Bundeswehr positiv gegenüber, eine ebenso große Mehrheit lehnt den Afghanistaneinsatz ab. Da wir eine Parlamentsarmee haben, musste die Bundesregierung um jede Mandatsverlängerung und -veränderung den Bundestag bemühen, und wichtige Diskussionen fanden und finden in Parteigremien statt, bisweilen transparent durch Fraktionsanhörungen und Paneldiskussionen. Die öffentliche Meinung ist lange Zeit über das wirkliche Geschehen in Afghanistan wenig informiert gewesen, stereotype Berichte vermittelten den Eindruck von Routine; z.B. wenn Politiker die Truppe im Feldlager besuchten. Routine bedeutet Normalität, und die wiederum ließ sich nur im Kontext aufrechterhalten, als der Einsatz als Stabilisierung und militärisch gestützte humanitäre Intervention klassifizieren ließ.

Für den Heimatdiskurs ergeben sich hier einige Besonderheiten. Zum einen wurde seit Bonn 2001 kaum Sachinformation als Bürgerqualifikation von Seiten der Regierung ausgegeben; damit war Afghanistan stärker als z.B. Kosovo davor von Anfang an Produkt des Kommentars. Zweitens hat es für die Regierung und das Parlament keine verlässliche Bestimmung einer „Ausgangslage“ gegeben. Das mag bestreiten, wer die Fülle der Detailangaben in Bundestagsdrucksachen und Einzelstellungnahmen zusammenstellt, aber es wäre ja um einen zusammenhängenden Kontext gegangen. Darum ist etwas vermessen, spräche man heute 
von den Kriegszielen des Jahres 2001/2. Im Nachhinein ist das aber gang und gäbe bei den Kritikern des Einsatzes. Das dritte Besondere an dieser Situation ist, dass es eine objektivierende Funktion aus der breiteren politischen Schicht gab, die einen breiten Teil der interessierten Öffentlichkeit informierte, aber nicht unbedingt weitere interessierte Schichten erschloss. Hier ist repräsentativ das Informationsnetzwerk des Abgeordneten Winfried Nachtwei zu nennen, der sich zur Partei-übergreifenden Instanz in Sachen Afghanistan entwickelte. Die politischen Stiftungen trugen ebenfalls zur Schaffung einer informierten Teilöffentlichkeit bei. Schließlich sind hier noch Einrichtungen der kirchlichen politischen Bildung (v.a. evangelische Akademien) zu nennen, die langfristige Informationspolitik zum Einsatz machen, allen voran Villigst oder Meissen, und vor allem Loccum. Das ist demokratietheoretisch und praktisch ein gutes Zeichen für eine funktionierende zivilgesellschaftliche Öffentlichkeit, aber es stellt der Informationspolitik von Regierung und Parlament kein gutes Zeugnis aus.

Im vorletzten Jahr (2010) sollte sich das ändern. Die Bundesregierung erkannte, dass der Unmut in der Bevölkerung, auch angesichts der Diskussionen um den 4.9.2009, über den Einsatz immer größer wurde und dass es schwieriger werden würde, eine parteiübergreifende Zustimmung zur Mandatsverlängerung nur im Insiderkreis zu erlangen. Das war sicher keine opportunistische, wenn auch späte Einsicht. Es liegen nun mehrere Informationen vor, die alle die Handschrift des Sonderbeauftragten der Bundesregierung im Auswärtigen Amt, Michael Steiner, und des Sonderstabes Afghanistan-Pakistan (AFG-PAK) tragen. Zusätzliche Anstöße mögen von zwei weiteren Impulsen gekommen sein: dem Bewertungsbericht des damals neuen Oberkommandierenden von ISAF, McChrystal, an seinen Verteidigungsminister im August 2009 (McChrystal 2009); dieses Dokument sollte nicht nur die Fenster für den population-centered approach und die Aufstandsbekämpfung (COIN) öffnen, sondern gilt als Modell eines umfassend auch selbstkritischen Grundlagendokuments, auf dem Politik aufbauen kann. Dass diese Hoffnung sich unter McChrystals Nachfolger Petraeus nicht erfüllt hatte, steht auf einem anderen Blatt. Der zweite Impuls kam vom Festlegen der Übergangszeit (Transition) bis zum Abzug der Kampftruppen 2014.

In den Heimatdiskurs brachten die Berichte der Bundesregierung gleich mehrere neue Varianten ein: zum ersten die Tendenz, den Abzug als Ergebnis militärischer Erfolglosigkeit zu bewerten. Der ironische Slogan ,declare victory and pull out!" hatte eine neue Facette bekommen. Weil es keinen militärischen Sieg (über wen auch immer) geben konnte, sollte die Transition zur Korrektur von Fehlern der Intervention (4.11.2011, Michael Steiner) benutzt werden. Im Diskurs trat Transition an die Stelle von Transformation oder Wiederaufbau. Nach 
2014 wird es weiter zivile Hilfe der internationalen Gemeinschaft geben, aber nunmehr an ein voll verantwortliches souveränes Afghanistan, das innerhalb kurzer Zeit dazu in die Lage versetzt werden soll.

Zum zweiten wird der Erfolg der deutschen Segmente des internationalen Einsatzes zivil und militärisch normativ festgelegt. Da es keine Zielvereinbarung für den Einsatz gab, bedeutet Fortschritt die relative Bewertung einer jetzt beobachteten Situation im Hinblick auf ihre Tragfähigkeit und die von ihr geschaffenen Ausgangsbedingungen für die Begegnung von Gefahren und das beherrschen von Risiken. Das alles wird durchaus informativ und mit einiger Konsequenz betrieben, nimmt aber viel Rücksicht auf alle Tatbestände, die den nachhaltigen Ausblick auf eine mögliche Erfolgsgeschichte behindern. Innerhalb des Diskurses gibt es nun eine Zangenbewegung: solange der militärische Einsatz mit dem Security first Ansatz die unabhängige Variable jeder Analyse ist, fragt sich, warum die Truppen nicht sofort abziehen und sozusagen einer gefühlten Niederlage dadurch entgehen; wenn aber zugleich die Bewährung der neuen Interventionsarmee in einem neuen Tugendkatalog ebenfalls gewünscht wird, dann müssen die Erfolge gerade der deutschen ISAF-Beteiligung herausgestellt werden - die gibt es zweifelsohne, ebenso wie viele Fehlschläge, und es gibt das Kunduz-Bombardement. Drittens aber deckt gerade der Fortschrittsbericht die Grenzen der deutschen Handlungsfähigkeit, die Schwächen der derzeitigen Bündnispolitik mit den USA und der NATO, die ambivalente Rolle Deutschlands im UN-Sicherheitsrat auf - und animiert geradezu zu einer Dekonstruktion des Nichtgesagten. So wichtig die Information zur Meinungsbildung über die Systemebene des Staates in nuce Afghanistan sein mag, die Lebenswelt der Afghanen, und damit die Möglichkeit der Solidarisierung (nicht Identifikation!) der Öffentlichkeit, werden ausgeblendet.

Die vorliegenden Analysen des Fortschrittsberichts (v.a. Janzen in diesem Band) machen deutlich, warum der Bericht keine Stellungnahme zu wahrscheinlichen Entwicklungen und Tendenzen geben kann, wie sie in Szenarien und lokalen Befunden zur Governance zum Ausdruck kommen. Eine vorläufige Prognose für den Heimatdiskurs in dieser Sphäre kann sein, dass sich die Kluft zwischen der Expertendiskussion und den Laien verfestigt, obwohl sie sich scheinbar verkleinert. 


\section{ZURÜck ZUR Theorie Und Praxis DES HEIMATDISKURSES}

Die Interventionsforschung ist ein Teil einer transdisziplinären Forschung zu den militärischen und humanitären Interventionen in einer zunehmend globalisierten internationalen Politik, oder besser: Weltinnenpolitik. Daraus kann man auch ableiten, dass sie sich nicht mehr auf Zusammenspiel oder Antagonismus von Nationalstaaten allein bezieht, sondern vielfältige Kombination national-staatlicher, anderer staatlicher und nicht staatlicher Akteure und Strukturen zum Forschungsgegenstand hat. Obwohl der Grundlagen-Anteil dieser Forschung relativ hoch ist, warnen wir vor einer Dogmatisierung in „Interventionswissenschaften“, die dann die transdisziplinären Brücken wiederum kappen müssten und zu einer Beratungslehre von und für Interventionen verkommen würden. Im Theoriegerüst der Interventionsforschung spielen Interventionsgesellschaft und Interventionskultur eine wichtige Rolle; zu ihnen tritt der Heimatdiskurs als weiteres konstitutives Element.

Wir können so viel mit Bestimmtheit und Beleg sagen: jede out of areaIntervention provoziert und produziert einen Heimatdiskurs, allerdings in unterschiedlicher Intensität und kultureller Ausprägung, mit unterschiedlicher Reichweite und Wirkung. Da wird davon ausgehen, dass der Heimatdiskurs sowohl die Entscheidungen von Politik und Militär beeinflusst als er auch das Bewusstsein und die Aufmerksamkeit von Medien, Öffentlichkeit und Experten antreibt und von diesen modifiziert wird, gilt es, weitere Beweisführung auf die „Wirkungsforschung“ zu lenken, sofern die Prämissen, wie in diesem Kapitel, als Arbeitsgrundlage akzeptiert werden.

Der Heimatdiskurs ist zunächst eine deutsche Angelegenheit und er ist immer auch eine der intervenierten Gesellschaften, also besonders Afghanistans, aber in Bezug auf Deutschland; es gibt zwar analoge Diskurse in anderen Entsende- und Interventionsländern, aber nicht diesen Heimatdiskurs, wobei eine vergleichende Untersuchung zu den USA ansteht. Auch die „near neighbors“ und besonders Pakistan und Iran müssten hier genauer untersucht werden. Für die westlichen Interventionsländer gilt, dass in vielen dem Heimatdiskurs vergleichbare Thematisierungen nicht stattfinden oder subkutan sich ereignen, also (noch) nicht festgehalten und analysiert werden können. Bei einem Seminar der Universität Marburg mit dem CES und der Universität Coimbra 2011 in Lissabon ${ }^{27}$ wurde deutlich, wie wenig die portugiesische Bevölkerung vom jahrelangen Einsatz ihrer

27 Tagung von CES (Coimbra) und CCS (Marburg) in Lissabon, Sept. 2011. 
Armee in Afghanistan weiß, wie wenig die Gefallenen thematisiert sind und wie sehr die Aktionen der NATO selbstverständlich legitimiert sind.

Politikwissenschaftliche Leserinnen könnten monieren, dass die These, wonach der Heimatdiskurs tatsächlich die Entscheidungen und Wertungen zum Einsatz stärker beeinflusst als viele Ereignisse und Fakten, nicht hinreichend dicht belegt sei. Das gestehen wir zu diesem Zeitpunkt der Forschungen ohne weiteres zu. Wir entgegen aber, dass gerade die sozialwissenschaftliche Aufbereitung eines Feldes, das nicht unter der Dominanz des Staatlichkeitsparadigmas politisch und militärisch begrenzt wird, jene Lücken zu schließen beiträgt, die der State-Building-Ansatz durch seine Engführung der Interventionen so gravierend deutlich macht.

\section{LITERATUR}

Assmann, A. 1999. Erinnerungsräume: Formen und Wandlungen des kulturellen Gedächntnisses. München: Beck.

Bacevich, A. 2012. "Der American Way of War." Blätter für deutsche und internationale Politik 57(6), S. 91-96.

Baecker, D. 2002. „Der Krieg als Ritual der Gesellschaft.“ In Gott gegen Geld. Zur Zukunft des Politischen, hrsg. v. U. Hass-Zumkehr und Dirk Baecker. Berlin: Alexander.

Barcott, R. (2008). “Anthropology in Conflict: An Exchange.” Survival 50(3), S. 127-162.

Baumann, M. et al., Hrsg. 2011. Feldpost - Briefe deutscher Soldaten aus Afghanistan. Reinbek: Rowohlt.

Bonacker, T. et al., Hrsg. 2010. Interventionskultur. Zur Soziologie von Interventionsgesellschaften. Wiesbaden, VS Verlag für Sozialwissenschaften.

Bussemer, T. 2010. „Politik, Presse, Publikum.“ Vorgänge 29(192), S. 8.

Chiari, B., Hrsg. 2012. Auftrag Auslandseinsatz. Freiburg: Rombach.

Danner, M. 2011. „After September 2011: Our State of Exception.” NYRB 58(15), S. 4.

Daxner, M. 2010. We are One Tribe - Live in the Society of Intervention, AAN 13.05.2010. www.aan-afhanistan.org/index.asp?id=750 (aufgerufen am 20. August 2012).

Daxner, M. 2011. „Die Interventionsgesellschaft Afghanistans.“ Vorgänge 50(195), S. 13.

Eckert, J., Hrsg. 2004. Anthropologie der Konflikte. Bielefeld: transcript.

Engelhardt, T. 2010. The American Way of War. Chicago: Haymarket. 
Fontane, T. 1905. Das Trauerspiel von Afghanistan. Gedichte. Stuttgart und Berlin: Cotta.

Franck, T. M. 2001. “Are Human Rights Universal.” Foreign Affairs 80(1): S 13.

Gant, J. 2009. One Tribe at a Time. United States Army Special Forces. (nicht mehr online aufufbar).

Heer, H. 2004. Vom Verschwinden der Täter. Der Vernichtungskrieg fand statt, aber keiner war dabei. Berlin: Aufbau.

Heer, H. et al, Hrsg. 1995. Vernichtungskrieg, Verbrechen der Wehrmacht 1941 1944. Hamburg: Zweitausendeins.

Herberg-Rothe, A. and R. Thiele. 2011. „Vom Staatsbürger in Uniform zum demokratischen Krieger.“ Vorgänge 50(1), S. 27-35.

Hetherington, T. 2010. Infidel. London: Chris Boot Ltd.

Joffe, J. 2009. „The Default Power.” Foreign Affairs 88(5), S. 14.

Junger, S. 2010. War. London: Fourth Estate.

Kirst, H. H. 1994. 08/15. Klagenfurt: Kaiser.

Kisch, E. E. 1993. Asien gründlich verändert. Egon Erwin Kisch - Gesammelte Werke. Berlin: Aufbau.

Koehler, J. 2012. Social order within and beyond the shadows of hierarchy. Governance-patchworks in Afghanistan. Berlin: SFB Governance Working Paper Series 21.

Koenigs, T. 2011. Machen wir Frieden oder haben wir Krieg? Auf UN-Mission in Afghanistan. Berlin: Wagenbach.

Kurbjuweit, D. 2011. Kriegsbraut. Berlin: Rowohlt.

Maass, P. 2011. „The Toppling.“ The New Yorker 10. Januar 2011.

Marx, K. und F. Engels. 1976. Karl Marx und Friedrich Engels: Werke. Berlin: Dietz.

McChrystal, S. A. 2009. ComISAFs initial assessment.

Mingels, G. und T. Würger. 2012. „Ein Opfer, ein Held.“ SPIEGEL (10/2012), S. 6.

Müller, A. 2012. „Kämpfer, Spezialist, Lückenbüßer? Die Reserve der Bundeswehr auf dem Weg zur Einsatzarmee. Auftrag Auslandseinsatz.“ In Auftrag Auslandseinsatz, hrsg. v. B. Chiari, S. 175-186. Freiburg: Rombach.

Quest, E. 2006. Ein Portrait Annemarie Schwarzenbachs mit dem Schwerpunkt auf ihrer Reise nach Afghanistan 1939/40. Konfliktsoziologie Israel, Afghanistan, Balkan.

Reinhardt, K. 2001. KFOR: Streitkräfte für den Frieden. Frankfurt/M.: Blazek \& Bergmann. 
Scharping, R. 1999. „Der Stein auf unserer Seele. Deutschland und der gerechte Krieg - Eine Antwort auf György Konrad." In Der westliche Kreuzzug. 41 Positionen zum Kosovo-Krieg, hrsg. v. F. Schirrmacher, S. 129-136. München: DVA.

Scharping, R. 1999a. Wir dürfen nicht wegsehen. Der Kosovo-Krieg und Europa. Berlin: Ullstein.

Scheil, S. 2003. Legenden, Gerüchte, Fehlurteile. Graz: Stocker.

Schwarzenbach, A. 2001. Alle Wege sind offen. Basel: Lenos.

Seiffert, A., Phil Langer, und Carsten Pietsch, Hrsg. 2012. Der Einsatz der Bundeswehr in Afghanistan. Schriftenreihe des sozialwissenschaftlichen Instituts der Bundeswehr. Wiesbanden: VS.

van Crefeld, M. 2009. Gesichter des Krieges : Der Wandel bewaffneter Konflikte von 1900 bis heute. München: Siedler Verlag.

Waterston, A., Hrsg. 2009. An Anthropology of War. Views from the Frontline. New York: Berghahn. 


\title{
Heimatdiskurs - mediales Konstrukt und empirische Realitäten
}

\author{
HANNAH NEUMANN
}

„Afghanistan hat Deutschland verändert“ (MdB Ruck, Nov. 2011). Unser Versuch ist es, diese Veränderung nachzuzeichnen. Dies ist ein diskursanalytisches Mammutprojekt, welches zugleich nach dem Inhalt des Diskurses und seiner Wirkung fragt. Aus der Medienwissenschaft wissen wir, dass Inhaltsanalysen relativ einfach, ihre Deutung ein wenig komplexer, Aussagen über die Wirkung von Medieninhalten meist höchst spekulativ sind (Weiß 1990: 18-19; Bonfadelli 2005; Jäckel 2011). Dennoch haben wir uns entschieden diesen Spagat zu wagen, unter der Prämisse eines pragmatischen, explorativen und transdiziplinären Vorgehens. ${ }^{1}$

Dies impliziert zweierlei: die Beiträge zu diesem Buch sind explorativ und beleuchten kleine Ausschnitte des Heimatdiskurses mit teils unterschiedlichen methodischen Ansätzen. Sie beruhen auf der Annahme, dass die Analysierenden, die selbst Bestandteil des „Wir“ und „Deutschlands“ sind, auf der Basis eines reflektierten Subjektivismus Aussagen über die Wirkung des Diskurses und die veränderte Selbstwahrnehmung zu der er geführt hat, abgeben können. Es geht uns dabei weniger darum, eine umfassende Analyse des deutschen Heimatdiskurses seit dem Beginn des Kosovo- oder Afghanistaneinsatzes zu liefern. Es geht uns auch nicht darum, eine repräsentative Wirkungsanalyse vorzustellen, die die Auswirkungen der Berichterstattung auf verschiedene Bevölkerungs-

1 Wir haben aber aufgegeben uns dafür zu rechtfertigen, wenn wir Disziplingrenzen und Fachdomänen überschreiten und uns methodisch und was die Forschungsfelder angeht, einer wohlbegründeten transdisziplinären Arbeitsweise bedienen, die wir im Folgenden darlegen. 
gruppen quantifiziert. Dies könnten wir zum bisherigen Zeitpunkt bei Weitem nicht leisten. Dies mag zunächst wie ein methodisch verkürzter Zugang klingen, wird dem Anspruch einer Exploration aber dennoch gerecht. Es geht uns bei den vorliegenden Untersuchungen darum, das Potential und die Tragfähigkeit des Heimatdiskurs-Konzeptes aufzuzeigen. Dies ist uns gelungen. Das Buch präsentiert explorative Analysen die tiefe Einblicke in den Heimatdiskurs seit dem Beginn des Afghanistaneinsatzes liefern und zeigt eine Fülle von Forschungsdesiderata auf, die die Arbeit in den nächsten Jahren bereits skizzieren.

\section{Theoretisches Konzept}

Nun erst einmal zum theoretischen Konzept, das im vorhergehenden Kapitel von Michael Daxner ausführlich vorgestellt wurde und auf dem mein Beitrag aufbaut. Der Heimatdiskurs, so das Konzept, bezeichnet die Summe aller diskursiven Praktiken und Strategien, die sich mit der Legitimation, Anerkennung und Bewertung von Politik und Truppeneinsatz außerhalb des nationalen Territoriums befassen. Dabei strukturiert er, so die Annahme, die es zu beweisen gilt, die öffentliche Meinung, die Wechselwirkung von Medien und Öffentlichkeit, die Hintergründe politischer Entscheidungen und die Legitimationspolitik für Auslandseinsätze und globale Bündnispolitik; nicht nur auf militärische Aktionen out of area beschränkt. Im Falle Deutschlands, und somit im Falle der vorliegenden Untersuchungen, bedeutet das eine Beschäftigung vor allem mit der Außen- und Verteidigungspolitik im Kontext der Einsätze im Kosovo (1999ff.) und Afghanistan (2002ff.), aber auch zunehmend im Kontext globaler Innenpolitik, des Kriegs gegen den Terrorismus und der Abwehr von Piraten auf Handelsrouten.

\section{Realitäten}

Heute kann man fast jeden fragen, auf der Straße, am Stammtisch oder in besser gebildeter Runde, wie es denn wohl aussieht in Afghanistan, was für Menschen dort leben und welche Probleme das Land hat. Das Bild, das einem präsentiert wird, dürfte weitestgehend konsistent sein: karge bergige Landschaften, Männer mit langen Bärten und Frauen, verhüllt in Burkas. Islamismus und Terrorismus, Drogenanbau, Korruption, Entführungen, Anschläge und die Taleban - das dürften die illustrierten Probleme sein. Wir wissen, wo der Hindukusch ist, in Afghanistan und oft weniger, was er ist, ein Gebirgsmassiv. Wir wissen, wer die Taleban sind, radikal-islamische Terroristen, aber selten etwas über ihren Aufstieg nach der Vertreibung der Sowjets und was das Ganze mit Religion zu tun hat. Wir wissen was die Afghanen sind, Paschtunen, aber selten dass nur ein Drittel der Afghanen Paschtunen sind. Wir wissen, was die Scharia ist, ein Gesetz das 
Frauen steinigen lässt, aber nicht, dass sie die Scheidung erlaubt. Diese Aufstellung setzt bereits den Rahmen dessen, was „man“ sagt und was „man“ weiß und zeigt zugleich auf, was „man“ sagen könnte und wissen müsste, was aber nur selten Bestandteil des Heimatdiskurses wird. Das was „man“ sagt und weiß ist öffentliches Meinungsgut und wird überwiegend, wenn auch nicht ausschließlich, von den Medien transportiert. Das was „man“ wissen könnte und müsste sind Ergebnisse von eigenen Erfahrungen und einer tiefer gehenden Recherche, bleibt im Heimatdiskurs aber oft ungesagt. ${ }^{2}$

\section{Akteure}

Das was „man“ sagt und weiß bricht sich dabei oft mit dem, was die sagen und wissen, die für längere Zeit vor Ort waren, als ethnographische Forscher, als Entwicklungshelfer, oder als Militär. Sie nehmen den Diskurs in der Heimat häufig als verzerrt, vereinfachend und realitätsfern war. Für diese Verzerrung sind verschiedene Akteure und Mechanismen verantwortlich. Diejenigen, die direkt am Einsatz beteiligt sind, sei es an ziviler oder militärischer Front, haben ein Interesse daran ihren Einsatz zu rechtfertigen, ihre Arbeitsbedingungen zu verbessern und zusätzliche Finanzmittel (seien es Spenden oder Haushaltsmittel) zu aquirieren. Sie versuchen, denen vor Ort und zu Hause ihr Bild des Geschehens zu vermitteln (vgl. hierzu auch Bliesemann de Guevara in diesem Band). Die Bundesregierung muss ihre Politik gegenüber dem Bürger rechtfertigen und Mehrheiten für neue Mandatsverlängerungen sicherstellen (vgl. hierzu auch Janzen in diesem Band). Und schließlich: die „Gegner“ im Kampf. Sie versuchen durch den Rückgriff auf teils spektakuläre Mittel Aufmerksamkeit zu erregen und Mitstreiter zu gewinnen (vgl. hierzu Kühn in diesem Band).

Die Arena für all diese Bemühungen stellen in der heutigen Gesellschaft die Medien dar. Anders als den einzelnen Akteuren wird ihnen oftmals Neutralität und Objektivität zugeschrieben. Was die Medien berichten, vor allem, wenn es mit Bildern unterlegt ist, wird als „wahr“ aufgenommen. Dabei unterliegt die mediale Berichterstattung einer Eigenlogik, die selbstproduzierten Gesetzmäßigkeiten folgt und für die Verzerrung zwischen wahrgenommener Realität vor Ort und Berichterstattung in den deutschen Wohnzimmern (mit-)verantwortlich ist. Dies gilt insbesondere für Kriegsberichterstattung (Löffelholz 2004). Diese Eigenlogik gilt es zu verstehen, denn sie schafft die mediale Realität, und im Falle der Intervention oft auch die gesellschaftliche (Luhmann 1996). Daraus lassen sich zwei Fragen entwickeln, die den folgenden Beitrag leiten: wie

2 Oftmals reicht für solche Recherche allerdings eine Sucheingabe bei Wikipedia aus. Das Wissen wäre also Allgemeingut, würde es denn gesucht und erfasst werden. 
kommt es, dass der Diskurs so verzerrt ist, wie er ist, und wie wirkt diese Verzerrung auf „uns“, unser Bilder von der Intervention, unser Bild von den Intervenierten und, vor allem, unser Bild von uns als Bürger einer intervenierenden Landes?

\section{Die Ursache der Verzerrung}

Die Frage nach der Eigenlogik der Massenmedien lässt sich weitestgehend mit Theorien der Medienwissenschaft beantworten. Die Medienwissenschaft kann Antworten darauf geben, wie es zu dem Bruch zwischen wahrgenommener Realität vor Ort und medialer Realität im deutschen Wohnzimmer kommt indem sie Produktionsbedingungen, Ökonomisierung und Auswahllogiken thematisiert. In meinem Beitrag versuche ich, diese Frage mit Hilfe eines Überblickes über die Ergebnisse medienwissenschaftlicher Forschung ansatzweise $\mathrm{zu}$ beantworten. Dabei werden sich zwischen den Erläuterungen immer wieder Vor-, Über- und Rückgriffe auf das Konzept des Heimatdiskurses und die einzelnen Beiträge in diesem Buch finden. Das ist in der Logik des Beitrages angelegt, denn für uns macht es wenig Sinn, das wie der Verzerrung zu erfassen ohne die zweite Frage nach den gesamtgesellschaftlichen Veränderungswirkungen mitzudenken.

\section{Die Wirkung der Verzerrung}

Die zweite Frage steht im Zentrum der Heimatdsikursanalyse. Sie befasst sich mit den Auswirkungen der Berichterstattung auf unser Bild auf die Intervention, die Intervenierten, aber auch uns selbst als Bürger eines intervenierenden Staates. Hier zeigt sich der Unterschied zwischen der klassischen Medienwissenschaft $^{3}$, derer wir uns als Hilfsmittel bedienen, und der Heimatdiskursanalyse, die unser Ziel ist. Bei einer Wirkungsanalyse zum Heimatdiskurs geht es uns nicht um monokausale Zusammenhänge, wie sie die Medienwirkungsforschung oder die Idelogiekritik gut herausarbeitet (vgl. hierzu Janzen in diesem Band), sondern um die bewussten (strategischen) und unbewussten Eingriffe in den Diskurs, die man als Abwehr oder Aneignung bezeichnen könnte. Hier nur exemplarisch einige Fragen, wie sie auch in den folgenden Beiträgen dieses Bandes diskutiert werden: Warum fangen wir an, den Bundeswehreinsatz als normal zu empfinden? Warum ist es nicht mehr das größte aller Übel, unser

3 Ich spreche hier nicht von Ansätzen, die in der Tradition der Cultural Studies stehen und die Auswirkungen von Mediennutzung auf ganze Bevölkerungsgruppen betrachten, so bspw. die Studie zu Mediennutzung von MigrantInnen (Hepp, Bozdag, und Suna 2011). Diese haben sich bisher aber wenig mit Fragen der Berichterstattung über Auslandseinsätze beschäftigt. 
Land in einem Krieg verwickelt zu sehen? Warum wird die Beziehung zu Afghanistan in Klischees aufbewahrt, die der empirischen Überprüfung nicht standhalten? Warum werden wir zu Jägern und die Taleban zu Tieren? Wie kann eine streng gläubige Kanzlerin den Tod Bin Ladens gut heißen und dem „Terrorfürsten" damit den Status des Menschlichen versagen?

\section{Die Verbindung zwischen dem Heimatdiskurs und der Medienanalyse}

Es gibt eine doppelte Verbindung zwischen der Heimatdiskursanalyse und den Medienwissenschaften. Die Medien, insbesondere die Massenmedien, aber auch Blogs, Leserbriefe oder Twitterposts so wie sie von den klassischen Massenmedien aufgegriffen werden, bilden die zentrale Arena des Heimatdiskurses. Sie sind das Reservoir, aus dem sich „unser Bild von Afghanistan“ speist. Die Art und Weise, wie Medien Inhalte auswählen, aufbereiten und kommunizieren, hat darüber hinaus zentralen Einfluss darauf, wie der Heimatdiskurs sich entwickelt und müssen in jeder Diskursanalyse ebenso mitgedacht werden, wie die Intentionen zentraler Akteure.

Vieles in den Beiträgen des Buches erinnert daher zunächst an inhaltsanalytische Medienanalysen über die Auslandsberichterstattung zu Bundeswehreinsätzen. Wir nehmen in der Tat dort Anleihen, gehen aber an zwei Stellen bewusst über die klassische Medienanalyse hinaus. Dieses ,darüber hinaus Gehen“ macht das Originäre unserer Heimatdiskursanalyse aus. Wir nutzen Medieninhalte als pragmatisches Instrument um Diskursinhalte, vor allem retrospektiv, zu erfassen und aufzuarbeiten. Die Medienanalyse ist sozusagen fester handwerklicher Boden unter unseren Füßen. Auf ihm stehend erfassen wir weitere Dimensionen: Auf welche Bilder (Metaphern und Frames) rekurriert der Diskurs und warum werden genau diese Bilder im Diskurs ausgewählt? Wie wirkt diese Berichterstattung auf uns, unser Bilder der Intervention und unser Bild von uns selbst als BürgerInnen eines intervenierenden Staates und, schlußendlich, auf uns, die wir den Diskurs untersuchen?

Auf der Basis dieser Überlegungen zur Verbindung von Medien und Heimatdiskurs wird in meinem Beitrag das Originäre der Heimatdiskursanalyse dargestellt und somit der Rahmen, für die folgenden auf ihm aufbauenden Beiträge, skizziert 


\section{Die Medien als Arena des Heimatdiskurses - POLITIK, MEdien UND BÜrger ${ }^{4}$}

Die Öffentlichkeit ist der Ort, an dem Themen und Meinungen gesammelt, verarbeitet und weitergegeben werden, sie ist somit eine der zentralen Kategorien zum Verständnis von Gesellschaft. Im besten Falle schafft eine solche Öffentlichkeit Transparenz, validiert die Vielzahl an Aussagen und bietet dem Bürger Orientierung (Neidhardt 1994: 8). Die Öffentlichkeit, die sich so wenig fassen lässt wie der Diskurs, ist die Arena des Heimatdiskurses, der Ort an dem das "Man" spricht und das Gemurmel der Diskurse zugänglich ist. Nun lässt sich Öffentlichkeit nicht mit Massenmedien gleichsetzen, aber Medien schaffen auch Öffentlichkeit (Becker 2002: 13) und sind zugleich ein, wenn auch verzerrter, Spiegel derselben (Habermas 1996). Die Medien schaffen also keine Themen und Diskurse. Sie sind von ihnen oftmals genauso getrieben wie die verschiedenen Akteure. Sie machen die Diskurse aber der breiten Öffentlichkeit zugänglich und erweitern, zumindest zunehmend durch den Einbezug des Internets, den potentiellen und tatsächlichen SprecherInnenkreis. Und natürlich entwickeln sie Strategien in die Diskurse einzugreifen, sie zu verstärken oder abzulenken.

Wir wissen, was der Hindukusch ist, wir wissen, was die Taleban sind, was die Afghanen sind und was die Scharia ist. Dieses Wissen ist ein öffentliches Meinungsgut und es wird überwiegend, nicht ausschließlich, von Massenmedien transportiert. Die letzten Jahre haben zu einer zunehmenden Medialisierung der Öffentlichkeit geführt. Mediale Kommunikation hat sich ausgedehnt und sie ersetzt an vielen Stellen nicht-mediale Kommunikation sowie andere soziale Organisationen und Institutionen (Eilders und Hagen 2005: 206). Versammlungsdemokratische Institutionen sind vom Aussterben bedroht (Wilke 2000). Politische Akteure orientieren sich zunehmend an medienvermittelter Kommunikation (Kriesi 1994). Nicht-mediales Handeln verschmilzt mit medialem Handeln und politische und militärische Akteure orientieren sich an den funktionalen Erfordernissen und Logiken der Medien (Eilders und Hagen 2005: 206), Guttenberg war hier nur das auffallendste deutsche Beispiel (vgl. hierzu auch Bliesemann de Guevara, Daxner und Aljets et al. in diesem Band); auch der internationale Terrorismus macht sich die Medialisierung zu Nutze (vgl. Beuthner 2003 und Kühn in diesem Band). Medien werden zum „Agenda Setter“ für den außenpolitischen

4 Die Kapitel, die auf die Verbindung zischen dem Heimatdiskurs und den Medien eingehen enthalten eine verknappte Darstellung komplexer Sachverhalte, die der verständlichen Aufbereitung einer Einigen wenig bekannten Forschung geschuldet ist. Die Medienwissenschaftler bitte ich um Nachsicht. 
Apparat, der sich gezwungen sieht, auf massenmediale Berichterstattung zu reagieren (Jakobsen 2000; Robinson 2002; Koller 1996). ${ }^{5}$ Politische Experten berücksichtigen die Medienberichterstattung, vor allem mit Blick auf die $\mathrm{Zu}$ stimmungswerte beim Bürger. Bei der Wahrnehmung und Bewertung von internationalen Krisen gleichen sich die Akteure zunehmend an (Maier et al. 2012: 39).

Die Medien bilden somit eine zentrale Arena des Heimatdiskurses, werden von ihm aber mehr getrieben, als dass er durch sie bestimmt wird; sie sind keineswegs seine Urheber. Ihre Funktion liegt viel mehr darin, der Gesellschaft eine Möglichkeit zur Selbstbeobachtung und Synchronisation zur Verfügung zu stellen (Luhmann 1996). Die gelingt den Medien aber nur, wenn sie gleichzeitig einen kontinuierlichen Abgleich mit der Gesellschaft herstellen und an die Lebenswelt des Publikums anschließen (Wyss 2011). Die Medien knüpfen also in einem diskursiven Prozess an das Wissen der Gesellschaft an und erneuern, bestätigen oder transformieren es zugleich mit ihren Inhalten (siehe bspw. die ambivalente Darstellung von SoldatInnen als zugleich friedliche Aufbauhelfer, Kämpfer und Opfer in Herzog et. al in diesem Band). Es besteht daher ein komplexes System wechselseitiger Abhängigkeit zwischen Medien, Politik und dem Bürger, dem „Wir“ des Heimatdiskurses.

Die Medien sind die Schnittstelle zwischen Bürger und Politik. Sie übernehmen in einer funktional differenzierten und entgrenzten Weltgesellschaft die Funktion der Polis als Ort des Diskurses unter physisch Anwesenden und die Funktion der Adels- und Königshäuser als gesamtgesellschaftliches Archiv. Sie werden zum Ersatz für das unmöglich gewordene zentrale Gedächtnis der Gesellschaft (Luhmann 1996). Die Eigenlogik der Medien wird so zunehmend zur Eigenlogik der Gesellschaft.

Die Medien sind dabei auf die Politik angewiesen und die Politik auf die Medien. Information wird hier gegen Publizität getauscht (Sarcinelli 1994: 39). Die Politik versucht ihre Entscheidungen nach innen und außen zu rechtfertigen und die Bürger im Sinne der Politikmitgestaltung mit Hilfe der Medien einzubinden (vgl. Gebauer 1998 und Janzen in diesem Band). Die Medien hingegen versuchen mit möglichst aktuellen Informationen Rezipienten zu erreichen und zu binden. Die politische Legitimation, die in der Regel in der (medialen) Öffentlichkeit stattfindet, kann kriegsentscheidend sein und wird immer kriegsentscheidender (Eilders und Hagen 2005: 206). Die Medien werden zum Schlachtfeld um Legitimität und Anerkennung (Reeb 2004) und oft selbst zum politi-

5 Diese Rolle der Medien wird vor allem unter dem Begriff CNN Effekt diskutiert. 
schen Akteur (Pfetsch 2008) und Kämpfer in der Schlacht, so beispielsweise Fox News in den USA im Umfeld des Irakkrieges.

In Kriegszeiten entsteht daraus ein komplexes Wechselspiel zwischen Sicherheitspolitik, Medien, Militär und Öffentlichkeit, das nicht mit einfachen Kausalmodellen beschrieben werden kann (Löffelholz 2004: 51). Vielmehr besteht ein gegenseitiges Abhängigkeitsverhältnis zwischen den einzelnen Elementen, das den Diskurs vorantreibt. Journalisten selbst sind ein zentraler Bestandteil des „Wir“. Sie übersetzen die Realität die ihnen in Afghanistan begegnet so, dass ihre Leser sie verstehen, im besten Fall. Im schlechtesten Fall redigieren sie Agenturmeldungen und bereiten sie für ein breiteres Publikum auf. In beiden Fällen sind sie selbst doppelt vom Heimatdiskurs geprägt. Sie sind die Gatekeeper. Ihre eignen Selektionskriterien, die sie ansetzen um das Erlebte, Gehörte oder Gelesene in Texte und Meldungen zu packen, sind kulturell vermittelt und nur zu einem bedingten Maße in der täglichen Arbeit reflektierbar (Shoemaker, Vos und Reese 2009; Lewin 1951; White 1950). Diese Selektionskriterien bestimmen was „wichtig“ ist, was „,sagbar“ ist, was ,interessant“ ist, und letztlich, was der Journalist denkt, dass es von seinem Publikum gelesen wird. Die Vorstellung, die sich Journalisten von ihren Lesern machen, von deren Wissensstand, deren Einstellungen und deren Vorstellungen an die sie zwangsläufig anknüpfen müssen, sind ähnlich kulturell vorgeprägt. Die Medien sind zwar die Arenen des Heimatdiskurses, aber die Inhalte, die sie liefern, sind zentral bestimmt von der Gesellschaft, aus der sie resultieren und in die hinein sie wirken. Sie beeinflussen gesellschaftliche Diskurse und werden durch diese selbst geprägt. Der Journalismus und seine Produkte sind in Friedens- wie in Kriegszeiten an gesellschaftliche Bedingungen, vor allem politische, ökonomische und kulturelle, gekoppelt (Löffelholz 2004: 27) und werden zu ihrem Spiegel. Das gilt für Selektionskriterien ebenso wie für redaktionelle und wirtschaftliche Zwänge und den Umgang mit dem beschränkten Zugang zur Realität in Kriegszeiten. Berichterstattung bleibt oft angewiesen auf wenige und zensierte Bilder, speist sich aus Gerüchten und beruht auf Hörensagen. Eine Überprüfung im Sinne des investigativen Journalismus ist gerade in den ersten Tagen und Monaten einer Intervention kaum möglich.

Eine diskursive Interaktion zwischen der Realität, den Medien und dem „Wir" lässt sich am Beispiel der Vorbereitung und Bezeichnung des Einsatzes in Afghanistan aufzeigen, womit wir uns jetzt in der Heimatdiskursanalyse befinden. Der Bündnisfall und die resultierenden militärischen Angriffe nach dem 11. September wurden durch die rhetorische Figur von „Terror als Krieg“ legitimiert. Diese Einordnung der Anschläge als Kriegserklärung wurde von Präsident Bush und seinen Strategen im Weißen Haus geschaffen und von den deutschen 
Medien weitestgehend unreflektiert übernommen (Bünger 2001). Sie legte die Basis für einen „Selbstverteidigungskrieg“, wo rechtlich ein internationaler Haftbefehl gegen Kriminelle eine gangbare Alternative gewesen wäre. Bei der Bezeichnung des Einsatzes in Afghanistan selbst, war die deutsche Politik vorsichtiger. Er war lange kein „Krieg“, sondern ist nach wie vor ein „nicht internationaler bewaffneter Konflikt“, ein „Friedenseinsatz“ oder ein „AfghanistanEngagement“. Die Medien und die deutschen Bürger scheuten sich bald weniger von „Krieg“ zu sprechen, entsprach doch das, was sie zu sehen meinten, ihrer Vorstellung von dem, was Krieg sei. Die massenmedial geschaffene Realität wurde dabei langsam zur sozialen Realität der internationalen Politik (Weller 2002: 32). 2009 sprach Guttenberg von Krieg, bald darauf auch die Kanzlerin (vgl. hierzu auch Daxner und Robotham/Röder in diesem Band). Das alles ist Heimatdiskurs und die Medien, die Politiker, die Bürger und die Experten interagieren in ihm, treiben ihn, bedienen sich seiner und gleichen ihre Einstellungen, Informationen und Handlungsalternativen über ihn ab.

Dies gilt umso mehr für Themen, wie Interventionen, bei denen ein realweltlicher Zugang schwierig bis unmöglich ist. Das macht die Medien zur zentralen Arena des Heimatdiskurses. ${ }^{6}$ Die Mehrheiten der Menschen ist nahezu ausschließlich auf massenmediale Berichterstattung als Informationsquelle bei Kriegen angewiesen (Weller 2002: 38). Insbesondere in Zeiten von Instabilität wächst die Rolle der Massenmedien, da sie (scheinbar) Information und Orientierung bereitstellen und oft die einzige Quelle in Belangen sind, die der persönlichen Erfahrungswelt verschlossen bleiben (McQuail 1994: 332-333). Für gewöhnlich durchlaufen Themen gewisse gesellschaftliche Selektionsstufen bevor sie medial aufgegriffen werden (Donges und Imhof 2005: 108) und die mediale Berichterstattung kann mit den eigenen Lebenswirklichkeiten abgeglichen und über sie relativiert werden. Diese Kontrollfunktion der Medienberichterstattung entfällt in weiten Teilen bei der Berichterstattung über Auslandseinsätze der Bundeswehr.

Alternative Quellen zu den klassischen Massenmedien stehen zur Verfügung. Blogs, Posts und Foren, unabhängige journalistische Reportagen und wissenschaftliche Studien informieren die politischen Entscheidungsträger, wie auch Teile der Öffentlichkeit. Wirkungsmächtig für eine breite Öffentlichkeit werden sie aber erst dort, wo sie von den Massenmedien aufgegriffen und thematisiert werden, als Handyvideos von Massakern in Syrien, die die Tagesschau zeigt, als Leserbriefe zur Frage zum Umgang mit den Taleban, die der Spiegel abdruckt 
oder als Twitter Posts, die im Heutejournal zitiert werden. Insbesondere im Pressediskurs verschränken sich verschiedene Diskursebenen miteinander, es werden Spezialdiskurse, Politikdiskurse und Meinungsumfragen integriert (Jäger und Jäger 2007: 28). Internetquellen gewinnen an Wichtigkeit, sie werden aber oftmals erst dann zum Gegenstand des kollektiven „Wir“, wenn sie Eingang in die klassischen Massenmedien finden; bzw., was wichtiger ist, ihre Informationen aus diesen destillieren.

Das über die Medien massenmedial erzeugte „Gedächtnis“ der Gesellschaft wird zur „gesellschaftlichen Realität“ und Grundlage nachfolgender Kommunikation (Luhmann 1996). Auf einmal steht es nicht mehr in Frage, dass wir im Krieg sind, dass unsere Soldaten Gefallene sind, dass der Abzug vorbereitet wird. Das massenmedial erzeugte Gedächtnis schafft gesellschaftliche Grundannahmen, zeitliche und normative Orientierungen, die als bekannt vorausgesetzt werden können, ohne immer wieder in die Kommunikation eingeführt werden zu müssen (Luhmann 1996: 12, 176). Die Semantik wird festgelegt. Taleban sind radikal-islamisch, die Burka ist das Zeichen der Unterdrückung. Solche Tatsachen müssen nicht mehr begründet werden und dienen als Hintergrundfolie für kommende Kommunikation. Sie haben sich in die Kultur eingeschrieben (Daxner, in diesem Band) und werden nur noch problematisiert, wenn sie sich allzu stark mit der wahrgenommenen Realität brechen.

\section{Wie die Medien den Heimatdiskurs formen - Befunde aus der MedienWISSenschaft}

Dass die Medien kein getreues Abbild der Wirklichkeit liefern können, ist Konsens. Medienberichterstattung in ihrer Gesamtheit ist das Resultat individueller Beobachtungsprozesse und verkürzt Realität zwangsläufig. Die Selektion zwischen Information und Nicht-Information ist originäre Aufgabe der Medien (Luhmann 1996). Sie ist dabei aber bestimmten Mechanismen unterworfen, die es mitzudenken gilt, wenn wir Medienhinhalte zum Ausgangspunkt unserer Analyse machen. Wenn Krieg vor allem medial vermittelt wird, dann bedarf es der Berücksichtigung der Logik und Produktionsweisen der Massenmedien um seine Darstellung zu verstehen (Reeb 2004; Fengler und Vestring 2009). Es gilt die Selektionsmechanismen und ihre Begründung zumindest in Teilen nachzuvollziehen, um die Diskrepanz zwischen dem, was die Medien berichten und dem, 
was man erlebt, wenn man in Afghanistan ist und sich aus dem Kokon militärischer Überwachung heraus bewegt, zu fassen. ${ }^{7}$

Eine korrekte Abbildung der verzerrenden Funktion der Medien kann uns nicht gelingen. Dazu müssten wir notwendigerweise eine vollständige, objektive Folie der Welt anfertigen und dann die massenmediale Berichterstattung mit ihr vergleichen (Weller 2002: 31). Wir müssten also ermessen können, wie radikalislamisch der konkrete Taleban ist, ob es eine moderate Version gibt und vor allem bräuchten wir objektive Kriterien für eine solche Zuschreibung. Nun sind aber schon die Begriffe selbst, radikal-islamisch, moderat, Taleban, auch Konstruktionen um die Komplexität der afghanischen Welt zu reduzieren. Erkenntnistheoretisch ist es unmöglich, eine objektive Folie der Welt zu schaffen. Wir sind also darauf angewiesen auf theoretischer Ebene und der Basis einer Sekundäranalyse medienwissenschaftlicher Studien die Eigenlogik der Medien zu erfassen, wie sie aus der Menge der Ereignisse auswählen, was zur gesellschaftlichen Realität wird.

Das Forschungsfeld, das sich mit Krieg und Medien auseinandersetzt, ist umfangreich und breit erforscht, aber wenig systematisiert (Eilders und Hagen 2005). Dies liegt vor allem in dem fallstudienorientierten Vorgehen bisheriger Forschung begründet, die sich mehr an den jeweils aktuellen Kriegen, als an dem Aufzeichnen langfristiger Entwicklungen orientiert hat. Ein gemeinsames Dach zwischen Forschungen aus der Kommunikationswissenschaft (hier bspw. Löffelholz 2004; Beuthner 2003; Imhof 2002; Eilders und Hagen 2005) und der Politik- und anderer Sozialwissenschaftlicher Forschungsbereiche (hier bspw. Albrecht und Becker 2002; Kempf 1990, 1998) gibt es bisher nicht (Eilders und Hagen 2005: 206-207). Unser Buch versucht hier die Disziplinen zusammen zu bringen, bleibt aber dennoch mehr der Politikwissenschaft als der Kommunikationswissenschaft verhaftet.

Zentrale Themenfelder des Forschungfeldes in den letzten Jahren waren und sind der Strukturwandel sicherheitspolitischer Kommunikation, die zunehmende Bedeutung der Vereinten Nationen, die generelle Internationalisierung und Globalisierung der Informationsgesellschaft ${ }^{8}$ und der Krieg gegen den Terror und seine mediale Aufarbeitung (Löffelholz 2004: 16-19). Im Verlauf der letzten Jahre war hier eine zunehmende Professionalisierung der Kommunikation sei-

7 Dies gilt nicht nur für Afghanistan, sondern für jeden anderen (Nach-)Kriegsschauplatz dieser Welt.

8 Damit ist der Heimatdiskurs nie ein ausschließlich deutscher. Er bleibt aber deutsch insofern, als dass wir die Diskurse anderer Länder im Rahmen unseres originär deutschen rezipieren. 
tens aller Akteure, militärischer und ziviler, festzustellen (Löffelholz 2004: 2024). Es kam zu einer „Tribunalisierung der internationalen Politik zwecks militärischer Legitimierung militärischer Interventionen“ (Münkler 2003: 26). Die mediale Berichterstattung war dabei geprägt von medientechnologischen Innovationen, ökonomischen Profitinteressen, sicherheitspolitischen Instrumentalisierungsabsichten, sowie Informations- und Unterhaltungsbedürfnissen des Publikums (Löffelholz 2004: 25). Zu diesen Themen gibt es umfassende Überblickswerke (Eilders und Hagen 2005; Löffelholz 2004; Wahl-Jorgensen und Hanitzsch 2009). Hier werden auszugsweise Befunde vorgestellt, wie sie für die Heimatdiskursanalyse von Relevanz sind.

Konditionen der Medienproduktion, beispielsweise, müssen mitgedacht werden, wenn es um die Art des Materials geht auf das sich die Berichterstattung stützt. Hier spielen Fragen nach Propaganda, Zensur und Einbettung eine Rolle (Dominikowski 1993; Filk 1999; Nohrstedt et al. 2000). Weitere Studien haben unterschiedliche Aufmerksamkeitsphasen in der Berichterstattung über Kriege identifiziert (Savarese 1993). Herrscht zu Beginn Überraschung und Interesse, kommt es bald zur Gewöhnung. Zu Beginn eines medial präsenten Krieges, wie etwa den Einsätzen im Kosovo und in Afghanistan, ähnlich stark beim ersten Golfkrieg und dem Einsatz im Irak, findet nahezu eine Monothematisierung statt, die aber bald der Themenkonkurrenz weicht. Der Krieg wird zu einem Ereignis unter vielen. Lediglich im Rahmen gewisser natürlicher (Anschläge, Gefallene, bspw. Kunduz) oder geschaffener (Afghanistankonferenz, Truppenbesuch) Ereignisse nimmt die Berichterstattung wieder zu (Krüger 2003: 400).

Generell sind Medien in Kriegszeiten häufig weniger kritisch und geben ihre Wächterfunktion auf (Eilders und Lüders 2000). Dies war zu Beginn des Afghanistaneinsatzes der Fall, hat sich mit seiner Fortdauer aber relativiert. Was aber blieb, war die Tatsache, dass nationale Identität und Zugehörigkeit medial betont und an eine immer wieder sich rückversichernde Definition des „Eigenen“ gebunden wurde, das sich von einem konstruierten „Fremden“ abzuheben versucht und so politisch-militärisches Handeln legitimeren soll (Klaus, Goldbeck und Kassel 2002; Kirchhoff 2010, siehe auch Aljets et al. Und Al-Ahmad et al. in diesem Band). Länder der Peripherie werden so in der Regel thematisch auf Krisen und Katastrophen verengt (Rössler 2003: 314). In der Berichterstattung zu derartigen Ereignissen herrschen Stereotypisierungen, Freund-Feind Polarisierungen, Militainment, Trivialisierung, Ritualisierung, Personalisierung, Simplifizierung, Kollektivtypisierung, Expertainisierung, Pseudo-Dramatisierung, und Emotionalisierung vor (Löffelholz 2004: 33). Es findet weiter eine einseitige Orientierung an staatlichen Informationsquellen statt. Dabei hat das Leitbild des Wilden, der vom Kolonialherren zivilisiert werden muss in den 1990er Jahren 
seine Fortschreibung gefunden in brutal kämpfenden oder verhungernden Afrikanern denen vom Weißen geholfen werden muss (Schmoll 1998); ein Motiv, das im Diskurs über den Einsatz in Afghanistan nach 2000 an vielen Stellen eine Übertragung auf den Orient erfahren hat (siehe auch Aljets et al. Und Al-Ahmad et al. in diesem Band).

Nun darf nicht automatisch von den Medienangeboten auf ihre Nutzung, Wirkung und Aneignung geschlossen werden. Publikumsvorstellungen basieren auf individuellen, sozialen und kulturellen Konstruktionsprozessen und sind weiter von der Rezeptionssituation, dem persönlichen Beteiligtsein, dem Vorwissen und der wahrgenommenen Glaubwürdigkeit der Medienangebote abhängig (Löffelholz 2004: 38). Die Medienwirkungen auf RezipientInnen können sich von denen auf direkt involvierte AkteurInnen unterscheiden. „Das Publikum“ gibt es nicht und somit ist es schwierig von einem „Wir“ zu sprechen. Informationen über spezifische Konflikte können individuell ganz unterschiedlich aufgenommen, verarbeitet und bewertet werden (Bonfadelli 2005; Jäckel 2011). Dennoch zeigt sich, dass die Bilder, die Journalisten schaffen häufig mit denen kongruent sind, die die Rezipienten wahrnehmen (Maier et al. 2012: 46). In der Medienwissenschaft gibt es daher eine Reihe Ansätze mittlerer Reichweite, denen Wirkungsannahmen zu Grunde liegen und die für die Heimatdiskursanalyse fruchtbar sind: die Nachrichtenwertheorie (Galtung und Holmboe Ruge 1965), das Konzept des Agenda-Settings (Maurer 2010; McCombs 1972; Scheufele und Tewksbury 2007) und die Framing Theorie (Reese und Lewis 2009; Entman 1993; D’Angelo 2002). . Auf der Makroeben lässt sich so durchaus ein „Wir“ im Sinne des „Man“ identifizieren und es werden häufig Versuche unternommen, dieses über Meinungsumfragen zu quantifizieren.

Die Nachrichtenwerttheorie beispielsweise geht davon aus, dass Ereignisse über einen ihnen eigenen Nachrichtenwert verfügen, der die Geschehnisse mehr oder weniger berichtenswert macht (Eilders 2006). Faktoren, die den Nachrichtenwert erhöhen sind beispielsweise Eindeutigkeit, Tragweite, Nähe, Überraschung, Bezug zu Elite-Nationen und Personen, Personalisierung und Negativität. Sie entscheiden darüber, ob ein Ereignis von Journalisten als berichtenswert erachtet und vom Rezipienten wahrgenommen wird (Galtung und Ruge 1965).

9 Ein weiterer Medieneffekt, der vor allem im Bezug auf Kriegsberichterstattung festgestellt wurde, ist der so genannte ,Rally around the flag' Effekt (Parker 1995; McLeod, Eveland, and Signorelly 1994), der besagt dass die militärische und politische Führung in Kriegssituationen zunächst beliebter wird, die Nation sich quasi um ihre Führer schart. Dieser Effekt hat allerdings keine langfristige Wirkung und flaut nach Kriegsbeginn schnell wieder ab. 
Die Nachrichtenwerttheorie baut damit auf allgemeinen menschlichen Selektionskriterien auf (Maier, Stengel und Marschall 2010), die durch die doppelte Selektion der Medien und dem häufig fehlenden individuellen Abgleich mit der Realwelt verstärkt werden. So erregen Attentate mit wenigen Toten kaum noch mediale Aufmerksamkeit. Handelt es sich bei den Toten aber um Bundeswehrsoldaten (Nähe), so nimmt diese drastisch zu. Erklärt sich eine der Familien zu einer Homestory bereit (Personalisierung), so kommt kaum ein Medium an einer Referenz vorbei. Die komplexen Hintergründe solcher Anschläge werden dabei häufig ausgeblendet, es wird auf das persönliche Schicksal des Soldaten als Vertreter der kollektiven Wirs konzentriert (Eindeutigkeit).

Hier setzt eine zentrale Kritik des Friedensjournalisms an (Galtung 1998; Bläsl 2004). Interventionen sind in ihrer Komplexität „,medial schwer vermittelbar" (Münkler 2010: 204), die komplexen Hintergründe der Konflikte haben „keinen rechten Nachrichtenwert“ (Münkler ebd.). Die zunehmende Interdependenz zwischen Massenmedien und Krieg hat dabei zur Folge, dass das prinzipiell „katastrophisch antizivilisatorische Ereignis des Krieges $\mathrm{zu}$ einem zivilisatorischen Akt" (Paul 2004: 11) wird, dem man vom heimischen Sofa aus folgen kann. Durch das Weglassen des Komplexen erscheinen Interventionen zunehmend als kalkulierbar, als sauberer Krieg, bis dieses mediale Bild den Zwängen der Realität vor Ort, die über gefallene Soldaten, verlängerte Mandate und entführte Entwicklungshelfer den deutschen Diskurs erreichen, nicht mehr standhalten kann und „Deutschland seine Unschuld verliert“. ${ }^{10}$

Eine weitere Wirkungstheorie, Agenda-Setting, geht davon aus, dass die Medien darüber entscheiden, welche Themen als wichtig wahrgenommen werden und die öffentliche, und im Falle der Intervention die (außen-)politische, Agenda bestimmen (McCombs 1972). Sie bestimmen also das, worüber man spricht, sprechen muss und sprechen können sollte. Die Agenda-Setting Theorie ist eng verbunden mit der Framingtheorie. Diese nimmt an, dass die Aufmerksamkeit von Rezipienten durch mediale Berichterstattung nicht nur beeinflusst, sondern auch strukturiert wird. In dem der Journalist bestimmte Elemente einer Nachricht auswählt und hervorhebt, erschafft er einen Rahmen, in dem das Ereignis wahrgenommen wird wodurch eine gewisse Interpretation und Wertung des Themas zumindest begünstigt wird (Entman 1993). Frames sind also konsistente Muster von Urteilen und Einstellungen, die weniger die Eigenschaft des Textes, als die Sichtweise auf den Text, beeinflussen (Matthes 2007). Sie nutzen dem Journalisten und dem Rezipienten da sie Komplexität reduzieren und Ereig-

10 Diese Formulierung wurde im Zusammenhang mit dem Bombardement von Kunduz häufig verwendet (siehe Daxner in diesem Band). 
nisse schneller und leichter interpretieren und verstehen lassen in dem sie auf bereits vorhandenem Alltagswissen aufbauen (Scheufele 2003). Frames werden häufig genutzt zur effizienten, und für das Laienpublikum verständlichen, Darstellung relativ komplexer Sachverhalte (Scheufele 2007). Sie produzieren dabei aber Rahmungen der Handlungen und Konflikte, die Interpretationen vorwegnehmen (vgl. hierzu Herzog et al. und Al Ahmad et al. in diesem Band). In diesem Sinne sind auch Metaphern zu verstehen, die ein Framing teilweise mit Hilfe eines einzelnen Wortes oder einer einzelnen Analogie setzen. Die ,Jagd auf Osama bin Laden“ ist eine solche Metapher, die das komplexe Themenfeld der Legitimität einer solchen Jagd (noch dazu auf dem Staatsgebiet Pakistans) sowie der Legitimität einer gezielten und politisch motivierten Tötung auf ein legitimes Mensch-Tier Verhältnis verkürzt, das dem Jäger jedes Recht gibt seine Beute zu erlegen (vgl. Aljets et al. in diesem Band). Die gesamtgesellschaftlichen Konsequenzen einer solchen Rahmung sind dann Grundlage der Heimatdiskursanalyse.

\section{Die Heimatdiskursanalyse ALS KOMPLEMENTÄRE BETRACHTUNG}

Die Medien ermöglichen gesellschaftliche Selbstbeobachtung und schaffen so die „Realität“ der Gesellschaft. Dabei verzerren sie die Wirklichkeit gemäß ihrer eigenen Funktionslogik. Im Falle von Außenpolitik im Allgemeinen, und Interventionen im Besonderen, fehlt der breite lebensweltliche Abgleich der medialen Realität, der nur einigen Wenigen möglich ist. Das sind nicht zwangsläufig die klassischen Eliten, sondern diejenigen, die tatsächlich vor Ort sind und sich aus dem Kokon militärischer Einbettung befreien können. Dies macht die verzerrende Eigenlogik der Medien umso wirkungsmächtiger und hat entscheidenden Einfluss auf den Diskurs und die aus ihm entstehende gesellschaftliche Realität. Das Resultat ist ein Heimatdiskurs, der viel über die deutsche Gesellschaft, oft aber wenig über ihr Sujet, die Intervention und die Intervenierten, verrät. Deswegen der Begriff Heimatdiskurs, nicht nur als Diskurs in der Heimat, sondern auch als Diskurs der Heimat. Deswegen sprechen wir an vielen Stellen von „Feldstudien im eigenen Land“".

Eine Heimatdiskursanalyse, durchgeführt in der Heimat, ist immer auch zu einem gewissen Maß eine Selbstethnologie. Die Rollen als Forschender und Beforschter vermischen sich und manchmal steht man überrascht neben sich und fragt sich wie das, was einem mit dem distanzierten Blick des Forschenden so offensichtlich erscheint, als Beforschtem unbewusst blieb. Diese Komplizität zwischen Forschendem und Beforschtem macht viele der Beiträge subjektiv, 
trotz ihres objektiven Anspruchs. Das war im Forschungsprozess zugleich bereichernd und herausfordernd. Bei jeder Rezeption, Codierung, Clusterung und Bewertung flossen eigenen Erfahrungen ein. Die Rezeption, Codierung, Clusterung und Bewertung veränderte zugleich den eigenen Blick auf den Diskurs. Dabei war es erstaunlich zu sehen, dass in den Gruppenprozessen und den Diskussionen zwischen den AutorInnen weitestgehend kongruente Beobachtungen und Bewertungen zu Tage traten. Diese Kongruenz hat sehr bald zu einem neuen Selbstbewusstsein des reflektierten Subjektivismus geführt. Reflektiert wurde, woher wir wissen was wir wissen, aber darauf vertrauend, dass dieses oft intuitive Wissen die Qualität der Analyse ausmacht.

Besonders auffällig ist der Heimatdiskurs als ein Diskurs über die Heimat wenn sich die medial geschaffene gesellschaftliche Realität an der Wirklichkeit der Intervention mit solcher Stärke bricht, dass Selbstverständlichkeiten überdacht und neue Begriffe gesetzt werden müssen. An dieser Stelle sind wir nun wieder mitten in der Heimatdiskursanalyse. Nehmen wir noch einmal die bereits genannten ,radikalislamischen Taleban“. Eine gute Medienanalyse würde zweifelsohne zu dem Schluss kommen, dass eine Darstellung der Taleban als radikalislamisch eine teilweise unsachgemäße Verkürzung eines komplexen Sachverhaltes darstellt. Sie würde sowohl eine Stereotypisierung, als auch eine in weiten Teilen unzutreffende Verbindung zwischen Terrorismus und Islam konstatieren.

Die Heimatdiskursanalyse geht hier weiter unter Einbezug historischen und gesellschaftspolitischen Wissens. Sie fragt, wie es dazu kommt, dass die $\mathrm{Mu}-$ jaheddin ursprünglich von den Amerikanern im Kampf gegen die Sowjets unterstützt wurden, dann zugunsten der Taleban 1995 fallen gelassen wurden. Sie fragt warum diese nun als radikal-islamische Akteure des globalen Terrorismus gebrandmarkt (ab 1997) und bekämpft werden, während man zugleich Verhandlungen mit ihnen sucht. Die Analyse fragt, welche Bedeutung eine Verkürzung der Taleban auf radikal-islamische Akteure im politischen Diskurs und auf die Handlungsfähigkeit politischer Akteure hat. Sie kommt letztendlich zu dem Schluss, dass eine Darstellung der Taleban als Terroristen, als Tiere, die es zu jagen gilt, ihnen den Subjektstatus versagt. Eine derartige Dehumanisierung steht im Zeichen bester Kriegs- und Mobilisierungsrhetorik (Kirchhoff 2010) und es ist daher umso erstaunlicher, dass sie von deutschen „Qualitätsmedien“ weitestgehend unreflektiert übernommen wird (vgl. Aljets et al. in diesem Band). „Das Jäger-Gejagter-Verhältnis stellt sich als ein unveränderbares dar, eine quasi natürlich gegebene Konstellation, die erst mit der erfolgreichen Erlegung des Beutetiers beendet sein kann.“ (Aljets et al. in diesem Band: 107). Das galt vor allem für die Jagd auf Osama bin Laden, aber eben auch für die auf die Taleban. Die Identifikation der Taleban als Feinde, und ihre Beschreibung als Tiere, legiti- 
miert dabei Kriegführungstaktiken, die mit dem Begriff des „sauberen Krieges“ in keinster Weise im Einklang stehen. Mit Tieren muss nicht verhandelt werden, Tieren muss kein Prozess gemacht werden und Tiere müssen nicht in eine neue Gesellschaftsordnung reintegriert werden.

Die schöne Realität des Heimatdiskurses, die die Komplexität reduziert und ein klares Freund-Feind Schema schafft, kann sich aber an der Realität brechen; oft muss sie es zwangsläufig, spätestens wenn die politische Notwendigkeit erfordert, dass man eben doch mit den Taleban verhandelt und sie in ein neues Staatskonzept integriert. Dann werden Selbstverständlichkeiten hinterfragt und verändern sich. Die komplexe Interaktion zwischen den Medien, der Politik und dem „Wir“ wird plötzlich sichtbar und kann zum Fallstrick werden. Kurt Beck scheiterte im April 2007 kläglich mit seinem Vorstoß Akzeptanz dafür zu schaffen, dass man mit den Taleban verhandeln muss. Mit Tieren verhandelt man nicht, ja, kann man nicht verhandeln. So wurde es notwendig, den Begriff der Taleban zunächst von der direkten Abwertung als radikal-islamisch, terroristisch und unmenschlich zu lösen. Die gesellschaftliche Realität wurde 2009 komplexer, der moderate Taleban betrat den deutschen Heimatdiskurses, sein Ursprung jedoch blieb weitestgehend unklar, was die SZ zur provokanten Schlagzeile veranlasste: „Gesucht: Gute Taliban“ (SZ online; 09.03.2009). Auf einmal fanden Merkel und Jung, später Guttenberg zunehmend Applaus für ihre Forderung mit den „,moderaten“, „gemäßigten“, „gewaltfreien“ und „,verfassungstreuen“ Taleban zu verhandeln. Die Forschung ist sich darüber einig, dass es nicht mehr oder weniger moderate Taleban gibt, sondern mehr oder weniger politische. Die Frage der Gewaltanwendung ist dabei nicht eindeutig zuzuordnen. Der Begriff der radikal-islamischen Taleban musste im politischen Diskurs neu besetzt, oder zumindest qualifiziert, werden um Verständnis für, und Zustimmung zu, Verhandlungen zu ermöglichen; wird aber vielfach unverändert weitergenutzt.

Diese exemplarische Analyse zeigt das Potential und den Anspruch des Heimatdiskurses in seiner Gänze. Die Medienberichterstattung bildet die breite Basis dessen, was wir zu analysieren gedenken. Sie wird in diesem Band explorativ an einigen Stellen auch erweitert und abgeglichen mit anderen Quellen, wie dem Bundeswehrmagazin Y (vgl. Herzog et al.), den direkten Eindrücken von Truppenbesuchern (vgl. Bliesemann de Guevara) und den Fortschrittsberichten der Bundesregierung (vgl. Janzen). Im Vordergrund unsere Betrachtungen aber steht nicht die Inhaltsanalyse dieser Quellen sondern die Frage, wie es zu diskursiven Begriffssetzungen und Bildern kommt und vor allem, wie diese in dem politischen und gesellschaftlichen Gesamtkontext wirken, in den sie eingebettet sind. 


\section{LITERATUR}

Albrecht, Ulrich und Jörg Becker, Hrsg. 2002. Medien zwischen Krieg und Frieden. Schriftenreihe der Arbeitsgemeinschaft für Friedens- und Konfliktforschung e.V. (AFK). Baden-Baden: Nomos.

Becker, Jörg. 2002. „Medien im Krieg.” In Medien zwischen Krieg und Frieden, hrsg. v. Ulrich Albrecht und Jörg Becker, S. 13-26. Schriftenreihe der Arbeitsgemeinschaft für Friedens- und Konfliktforschung e.V. (AFK). BadenBaden: Nomos.

Beuthner, Michael, Hrsg. 2003. Bilder des Terrors - Terror der Bilder? Krisenberichterstattung am und nach dem 11. September. Köln: Halem.

Bläsl, Burkhard. 2004. „Peace journalism and the news production process.” Conflict\&Communication online 3 (1-2): S. 1-12.

Bonfadelli, Heinz. 2005. „Medienwirkungsforschung.” In Einführung in die Publizistikwissenschaft, hrsg. v. Heinz Bonfadelli, Otfried Jarren und Gabriele Siegert, S. 337-381. Bern: Haupt.

Bünger, Iris. 2001. „Apocalypse Now? Kritische Diskursanalyse der Berichterstattung der BILD-Zeitung." PROKLA. Zeitung für kritische Sozialwissenschaft 125: S. 603-624.

D’Angelo, Paul. 2002. „News Framing as a Multiparadigmatic Research Program: A Response to Entman." Communication 52 (4): S. 870 -888.

Dominikowski, Thomas. 1993. „,Massen“medien und ,Massen'krieg: Historische Annäherung an eine unfriedliche Symbiose." In Krieg als Medienereignis: Grundlagen und Perspektiven der Krisenkommunikation, hrsg. v. Martin Löffelholz, S. 33-48. Opladen: Westdeutscher Verlag.

Donges, Patrick und Kurt Imhof. 2005. „Öffentlichkeit im Wandel.” In Einführung in die Publizistikwissenschaft, hrsg. v. Heinz Bonfadelli, Otfried Jarren und Gabriele Siegert, S. 101-135. Bern: Haupt.

Eilders, Christiane. 2006. „News factors and news decisions: Theoretical and methodological advances in Germany." Communications 31: S. 5-24.

Eilders, Christiane und Lutz M. Hagen, Hrsg. 2005. Themenheft „Medialisierte Kriege und Kriegsberichterstattung." Sonderheft Medien- und Kommunikationswissenschaft. Baden-Baden: Nomos.

Eilders, Christiane und Albrecht Lüders. 2000. „Germany at War. Competing Framing Strategies in German Public Discourse." European Journal of Communication 15 (3): S. 415-428.

Entman, Robert M. 1993. „Framing: Toward Clarification of a Fractured Paradigm." Communication 43 (4): S. 51-58. 
Fengler, Susanne und Bettina Vestring. 2009. Politikjournalismus. Wiesbaden: VS Verl. für Sozialwiss.

Filk, Christian. 1999. „Symbolische Politik, historische Analogien, Bilderkrieg: Performanzen des Kosovo-Kriegs in den Medien." Rundfunk und Geschichte: Mitteilungen des Studienkreises Rundfunk und Geschichte 24 (4): S. 263 267.

Galtung, Johan. 1998. „Friedensjournalismus: Was, warum, wer, wie, wann, wo?” In Krieg, Nationalismus, Rassismus und die Medien, hrsg. v. Wilhelm Kempf, S. 3-20. Münster: LIT.

Galtung, Johan und Marie Holmboe Ruge. 1965. „The Structure of Foreign News: The Presentation of the Congo, Cuba and Cyprus Crisis in Four Norwegian Newspapers.” Journal of Peace Research 2 (1): S. 64-91.

Gebauer, Klaus-Eckart. 1998. „Regierungskommnuikation.” In Politische Kommunikation in der demokratischen Gesellschaft: Ein Handbuch mit Lexikonteil, hrsg. v. Otfried Jarren, S. 464-72. Opladen: Westdeutscher Verlag.

Habermas, Jürgen. 1996. Strukturwandel der Öffentlichkeit: Untersuchungen zu einer Kategorie der bürgerlichen Gesellschaft; mit einem Vorwort zur Neuauflage 1990. Frankfurt am Main: Suhrkamp.

Hepp, Andreas, Cigdem Bozdag und Laura Suna. 2011. Mediale Migranten: Mediatisierung und die kommunikative Vernetzung der Diaspora. Wiesbaden: VS Verlag für Sozialwissenschaften / Springer Fachmedien Wiesbaden GmbH Wiesbaden.

Imhof, Kurt, Hrsg. 2002. Integration und Medien. Wiesbaden: Westdt. Verl.

Jäckel, Michael. 2011. Medienwirkungen: Ein Studienbuch zur Einführung. Wiesbaden: VS Verlag für Sozialwissenschaften / Springer Fachmedien Wiesbaden GmbH Wiesbaden.

Jäger, Margarete und Siegfried Jäger. 2007. Deutungskämpfe: Theorie und Praxis Kritischer Diskursanalyse. Wiesbaden: VS Verlag für Sozialwissenschaften.

Jakobsen, Peter V. 2000. „Focus on the CNN Effect Misses the Point: The Real Media Impact on Conflict Management is Invisible and Indirect." Journal of Peace Research 37 (2): S. 205-215.

Kempf, Wilhelm. 1990. Medienkrieg oder „Der Fall Nicaragua“: Politischpsychologische Analysen über US-Propaganda und psychologische Kriegsführung. Hamburg: Argument-Verl.

— Hrsg. 1998. Krieg, Nationalismus, Rassismus und die Medien. Münster: LIT.

Kirchhoff, Susanne. 2010. Krieg mit Metaphern: Mediendiskurse über 9/11 und den „War on Terror“. Bielefeld: Transcript-Verl. 
Klaus, Elisabeth, Kerstin Goldbeck und Susanne Kassel. 2002. „Fremd- und Selbstbilder in der Berichterstattung der deutschen Medien während des Kosovokrieges - am Beispiel des Spiegel." In Integration und Medien, hrsg. v. Kurt Imhof, S. 285-305. Wiesbaden: Westdt. Verl.

Koller, Stephan. 1996. „,War of Annhilation“: Der Tschetschenienkonflikt als Fallbeispiel der CNN-Kommunikation." In Internationale Kommunikation: Eine Einführung, hrsg. v. Miriam Meckel, S. 241-262. Opladen: Westdt. Verl.

Kriesi, Hanspeter. 1994. „Akteure-Medien-Publikum: Die Herausforderungen direkter Demokratie durch dei Transformation der Öffentlichkeit." Kölner Zeitschrift für Soziologie und Sozialpsychologie (Sonderheft 34): S. 234-260.

Lewin, Kurt. 1951. Field Theory in Social Science: Selected theoretical papers. Westport: Greenwood Publ.

Löffelholz, Martin, Hrsg. 2004. Krieg als Medienereignis II: Krisenkommunikation im 21. Jahrhundert. Wiesbaden: VS Verlag für Sozialwissenschaften.

Luhmann, Niklas. 1996. Die Realität der Massenmedien. Opladen: Westdt. Verl.

Maier, Michaela, Georg Ruhrmann, Karin Stengel, Arne F. Zillich, Roland Göbbel, Marion Rahnke, Jonathan Steinert, Kristin Süß und Christoph Warneck. 2012. „Bedrohung auf der (Medien-) Agenda: Krisenkommunikation im Nachrichtenprozess." Forschung DSF No. 32.

Maier, Michaela, Karin Stengel und Joachim Marschall. 2010. Nachrichtenwerttheorie. Baden-Baden: Nomos-Verl.-Ges.

Matthes, Jörg. 2007. Framing-Effekte. Zum Einfluss der Politikberichterstattung auf die Einstellung der Rezipienten. München : Fischer.

Maurer, Marcus. 2010. Agenda-setting. Baden-Baden: Nomos.

McCombs, Maxwell E. 1972. „The agenda-setting function of mass media.” Public opinion quarterly 36 (2): S. 176-187.

McLeod, Douglas, William Eveland und Nancy Signorelly. 1994. „Conflict and Public Opinion: Rallying Effects and the Persian Gulf War." Journalism Quarterly 71 (1): S. 20-31.

McQuail, Denis. 1994. Mass communication theory: An introduction. London: Sage.

Münkler, Herfried. 2003. Der neue Golfkrieg. Reinbek bei Hamburg: Rowohlt. 2010. Der Wandel des Krieges: Von der Symmetrie zur Asymmetrie. Weilerswist: Velbrück Wiss.

Neidhardt, Friedhelm. 1994. „Bedingungen, Strukturen und Funktionen von Öffentlichkeit." Kölner Zeitschrift für Soziologie und Sozialpsychologie (Sonderheft 34): S. 7-41. 
Nohrstedt, Stig, Sophia Kaitatzki-Whitlock, Rune Ottosen und Kristina Rieger. 2000. „From the Persian Gulf War to Kosovo: War Journalism and Propaganda." European Jounal of Communication 15 (3): S. 383-404.

Parker, Suzanne. 1995. „Toward an Understanding of ,Rally“ Effects: Public Opinion in the Persian Gulf War." Public opinion quarterly 59 (4): S. 526546.

Paul, Gerhard. 2004. Bilder des Krieges - Krieg der Bilder: Die Visualisierung des modernen Krieges. Paderborn: Schöningh.

Pfetsch, Barbara. 2008. Massenmedien als politische Akteure: Konzepte und Analysen. Wiesbaden: VS Verlag für Sozialwissenschaften.

Reeb, Hans J. 2004. „Öffentlichkeit als Teil des Schlachtfeldes: Grundlagen der Kriegskommunikation aus militärischer Perspektive." In Krieg als Medienereignis II: Krisenkommunikation im 21. Jahrhundert, hrsg. v. Martin Löffelholz, S. 197-214. Wiesbaden: VS Verlag für Sozialwissenschaften.

Reese, S. D. und S. C. Lewis. 2009. „Framing the War on Terror: The internalization of policy in the US press." Journalism 10 (6): S. 777-797.

Robinson, Piers. 2002. The CNN effect: The myth of news, foreign policy and intervention. London: Routledge.

Rössler, Patrick. 2003. „Botschaften Politischer Kommunikation: Länder, Themen und Akteure internationaler Fernsehnachrichten." In Politische Koтmunikation im internationalen Vergleich: Grundlagen Anwendungen Perspektiven, hrsg. v. Frank Esser und Barbara Pfetsch., S. 305-336. Wiesbaden: Westdt. Verl.

Sarcinelli, Ullrich. 1994. „Mediale Politikdarstellung und politisches Handeln: analytische Anmerkungen zu einer notwendigerweise spannungsreichen Beziehung." In Politische Kommunikation in Hörfunk und Fernsehen, hrsg. v. Otfried Jarren und Uwe Hasebrink, S. 35-50. Opladen: Leske u. Budrich.

Savarese, Rosella. 1993. „The European Press and Saladin the Fierce.” European Journal of Communication 8 (1): S. 53-75.

Scheufele, Bertram. 2003. Frames - Framing - Framing-Effekte: Theoretische und methodische Grundlegung des Framing-Ansatzes sowie empirische Befunde zur Nachrichtenproduktion. Wiesbaden: Westdeutscher Verlag.

Scheufele, Dietmar und David Tewksbury. 2007. „Framing, agenda-setting and priming: The evolution of the three media effects model." Journal of Communication 57 (1): S. 9-20.

Schmoll, Anka. 1998. „Die Wa(h)re Nachricht über Afrika: Stereotype und Standardisierung in der Fernsehberichterstattung." In Krieg, Nationalismus, Rassismus und die Medien, hrsg. v. Wilhelm Kempf, S. 89-96. Münster: LIT. 
Shoemaker, Pamela J., Vos Tim P. und Stephen D. Reese. 2009. "Journalists as Gatekeepers." In The handbook of journalism studies. hrsg. v. Karin WahlJorgensen und Thomas Hanitzsch, S. 73-87. New York: Routledge.

Wahl-Jorgensen, Karin und Thomas Hanitzsch, Hrsg. 2009. The handbook of journalism studies. New York: Routledge.

Weiß, Hans-Jürgen. 1990. „Kommunikationswissenschaftliche Modelle der Mediennutzung und Medienwirkung." In Spracherwerb und Mediengebrauch, hrsg. v. Klaus Neumann und Michael Charlton, S. 17-28. Tübingen: G. Narr.

Weller, Christoph. 2002. „Friedensforschung zwischen Massenmedien und Krieg: Von der Manipulationsforschung zur konstruktiven Friedenstheorie." In Medien zwischen Krieg und Frieden, hrsg. v. Ulrich Albrecht und Jörg Becker, S. 27-44. Schriftenreihe der Arbeitsgemeinschaft für Friedens- und Konfliktforschung e.V. (AFK). Baden-Baden: Nomos.

White, David M. 1950. „The , gate keeper': A case study in the selection of news." Journalism Quarterly 27: S. 383-390.

Wilke, Jürgen. 2000. „Auf langem Weg zur Öffentlichkeit: Von der Parlamentsdebatte zur Mediendebatte." In Zerfall der Öffentlichkeit?, hrsg. v. Otfried Jarren, Kurt Imhof und Roger Blum, S. 23-38. Wiesbaden: Westdt. Verl.

Wyss, Vinzenz. 2011. „Narration freilegen: Zur Konsequenz der Mediensystemrelevanz als Leitdifferenz des Qualitätsjournalismus." In Krise der Leuchttürme öffentlicher Kommunikation: Vergangenheit und Zukunft der Qualitätsmedien, hrsg. v. Roger Blum, Kurt Imhof, Heinz Bonfadelli und Otfried Jarren, S. 31-47. Wiesbaden: VS Verlag für Sozialwissenschaften. 
Dimensionen 



\section{Von „wilden Bergvölkern“ und „islamistischen Bazillen“}

\section{Die Darstellung der Intervenierten in Afghanistan}

\section{Janna Aljets, Alexander Biegler, Anna-Lena Schulz}

Medienanalysen von journalistischen Leitmedien, die einen konstitutiven Bestandteil des Heimatdiskurses bilden, können Erkenntnisse zu den Überzeugungen, Vorstellungen und das Wissen über eine Intervention und der in ihr prozessual vergesellschafteten Gruppen (bzw. Gesellschaften), den Intervenierenden und Intervenierten, produzieren.

Hier setzt dieser Aufsatz an; er basiert auf einer exemplarischen medienanalytischen Untersuchung der Darstellung der intervenierten AfghanInnen (im Folgenden Intervenierte) im deutschen Heimatdiskurs im Kontext der AfghanistanIntervention anhand des Magazins Der Spiegel im Zeitraum 2001-2011. Der Begriff Intervenierte weist darauf hin, dass „Mitglied[er] einer Gruppe, Gemeinschaft oder Gesellschaft, die von einer Intervention betroffen und durch sie definiert werden“ (Daxner 2010: 75) eine nicht unerhebliche Degradierung erleiden, die sie zu einer tendenziell irrelevanten Nebensache der Intervention macht und in die Objektrolle drängt.

\footnotetext{
„Auch wenn die Intervenierten einen legitimatorischen Hintergrund abgeben, sind sie nicht das Subjekt/Objekt der Intervention (...), sondern Randbedingung. Als Subjekte würden sie eine normative Letztbegründung für eine Intervention abgeben, als Objekte sind sie nur instrumentell dem Zweck der Intervenierenden zugeordnet. Sie erhielten Subjektstatus, erfolgte die Intervention in ihrem Namen. Die Aneignung ihrer Interessen durch die Intervention bedeutet nicht nur eine Objektivierung, sondern auch eine Herausforderung für die Gesellschaft der Intervenierenden“ (Daxner 2010: 97).
} 
Der den Intervenierten aus den Interessen der Intervenierenden heraus zugewiesene Objektstatus berührt umfassend die Legitimation und den Verlauf einer Intervention, insofern ,[d] ie Absicht [der Intervenierenden, d.A.], Ownership zu ermöglichen [...] die Emanzipationsbestrebungen von Intervenierten durchkreuzen" (Daxner 2010: 88) kann und mit aller Konsequenz den Intervenierten kein „politischer Raum“ (ebd.: 89) zur Artikulation und Vertretung eigener Interessen zugestanden wird. Kurz, die Anerkennung der Intervenierten als gleichwertige politische Subjekte mit Gestaltungswillen und -kraft kann in dem Gefüge einer Interventionsgesellschaft zur Marginalie reduziert werden.

Dieser These entsprechend fragen wir, wie sich der Heimatdiskurs in Bezug auf die Intervenierten in Afghanistan darstellt. Wie werden die Intervenierten Afghanistans im deutschen Heimatdiskurs dar- und vorgestellt und wodurch werden ihre Eigenschaften in den Diskursen kenntlich? Was bedeutet das für die Intervenierenden, für deren Ziele, Handlungen, Legitimationen und Selbstbilder? Wie korrelieren symbolische Identitäts- und Alteritätsdiskurse und welche Imaginationen, Vorstellungen und Projektionen von den Intervenierten im deutschen Heimatdiskurs sind signifikant?

Diesen Fragen gehen wir in einer miteinander verknüpften Analyse von verbalen und visuellen Medienmaterialien nach.

\section{Theorie Und MethodiK}

Für die aufeinander aufbauende Text- und Bildanalyse haben wir die Wochenzeitschrift Der Spiegel ausgewählt und dessen Titelgeschichten im Zeitraum 2001-2011, die sich im weitesten Sinne mit Afghanistan beschäftigen, analysiert. Die systematisch mit den symbolträchtigen Spiegel-Frontcovern verbundenen Titelgeschichten ermöglichen den gleichzeitigen Zugriff auf Text- und Bildinhalte. Der Spiegel gehört zu den meinungsführenden Leitmedien, dessen Leserschaft und Redaktion zur sogenannten „Bildungs- und Informationselite“ (Kirchhoff 2010: 155f) zählt. Wir haben uns auf die Titelgeschichten des Spiegel konzentriert, da diese eine besonders hohe Aufmerksamkeit der Leserschaft genieBen und die Titelbilder auch von Nicht-LeserInnen durch den massiven Werbeeinsatz (im Fernsehen oder als Aushang bei Zeitschriftenhändlern) wahrgenommen werden. 
Nach mehreren Analyseschritten ${ }^{1}$ wurde die letztgültige Auswahl des Untersuchungsmaterials auf 22 Titelgeschichten beschränkt. Fast die Hälfte der ausgewählten und analysierten Ausgaben des Spiegel ist im Jahr 2001 erschienen. Einige Jahre fielen auf Grund unserer Selektionsmaßstäbe ganz aus der Auswahl (das betrifft die Jahre 2004, 2005 und 2008). ${ }^{2}$ Insgesamt wurden 22 Titelgeschichten (118 Artikel) für die Textanalyse und sieben Titelbilder für die Bildanalyse ausgewählt und untersucht.

\subsection{Metaphernanalyse: Theorie und Methodik der Textanalyse}

Die Basis unserer Ergebnisse bildet eine an die kognitive Metapherntheorie von G. Lakoff und M. Johnson (2003) angelehnte Metaphernanalyse. Das Ziel der Metaphernanalyse ist es nachzuvollziehen, welche Assoziationen, Werturteile und Emotionen mit einer Metapher evoziert werden (sollen). Über diese zentrale Frage versuchen wir uns dem Komplex des Heimatdiskurses anzunähern und dessen Subtexte aufzuspüren. Schließlich sind metaphorische Konzepte immer ein kulturspezifischer ${ }^{3}$ Ausdruck von kognitiven Verstehensprozessen. Metapho-

1 Zunächst wurden alle Ausgaben thematisch nach den Titelbildern ausgewählt, die direkt oder mittelbar mit dem Einsatz in Afghanistan zusammenhängen. Dazu gehörten auch Reportagen über die Ereignisse des 11. September 2001, den sogenannten ,Krieg gegen den Terror", aber auch Titelgeschichten zur Rolle des Islam oder zur Migration in Deutschland. Erst in weiteren Analyseschritten wurde diese Auswahl weiter eingegrenzt und auf die Fragestellung zugeschnitten. So wurden Titelgeschichten nur dann in der Auswahl behalten, wenn sie sich explizit mit Afghanistan auseinandersetzten.

2 Hieran ließ sich schon ablesen, dass die Thematik im Laufe der Jahre wesentlich an Aufmerksamkeit eingebüßt hat. Aufgrund der ungleichen Ausgabenverteilung über den Untersuchungszeitraum haben wir uns dagegen entschieden, die Veränderungen des Heimatdiskurses im Verlauf der Zeit beziehungsweise anhand bestimmter Auslöser zu untersuchen. Hierfür ist die entstandene Auswahl des Materials nicht geeignet.

3 „Ein verbreitetes metaphorisches Konzept in der westlichen Kultur ist beispielsweise ,Macht ausüben ist oben'. Wer schwächer im Kampf ist, unterliegt. Wer überlegen ist, kann aufsteigen und Kontrolle über andere ausüben. (...) Überdies ist diese Metaphorik ein eindrückliches Beispiel dafür, dass wir in Metaphern leben: Die ,Chefetage“ befindet sich meist in einem der oberen Stockwerke, selten im Keller; auf dem Siegertreppchen steht der/die erste ganz oben. In anderen Kulturen kann ,Macht“ auch anders konzeptualisiert werden, beispielsweise über metaphorische Konzepte des Essens (Essensmetaphern): Jemand, der Macht hat, wird in Kamerun als jemand bezeichnet, der essen will““ (Wolf 1996: 220; Kruse/Biesel/Schmieder 2011: 73). 
rische Konzepte verweisen darüber hinaus auf die diskursive Konstruktion von politischen Ereignissen, aber auch auf Handlungen und Identitäten von (politischen) Akteuren.

Der Zielbereich, also die Intervenierten in Afghanistan, wird in zwei Bereiche unterteilt. Den ersten Zielbereich stellen die Intervenierten im weiteren Sinne dar: die Afghanen und Afghaninnen, also die zivile Bevölkerung des Landes. Der zweite Zielbereich umfasst die intervenierten Feinde ${ }^{4}$, die den Interessen und Aktionen der internationalen Interventionstruppe (nicht nur dieser) entgegenstehen. In den ausgewählten Titelartikeln werden Metaphern erfasst und dann auf übergeordnete Konzepte ${ }^{5}$ zurückgeführt. Die verschiedenen Kategorien werden in Tabelle 1 beispielhaft vorgestellt.

\section{Tabelle 1: Kategorien und Unterkategorien der Metaphernanalyse}

\begin{tabular}{|c|c|c|}
\hline $\begin{array}{l}\text { Über- } \\
\text { kategorie }\end{array}$ & Unterkategorien & Beispiele \\
\hline \multirow[t]{7}{*}{$\begin{array}{l}\text { Body - } \\
\text { Politics }\end{array}$} & $\begin{array}{l}\text { Ver-körper-ung } \\
\text { (aus Kirchhoff 2010: 240) }\end{array}$ & z.B. die ,Staatsorgane“ \\
\hline & $\begin{array}{l}\text { Personifikation } \\
\text { (aus Kirchhoff 2010: 211f.) }\end{array}$ & z.B. ,hungerndes Afghanistan“ \\
\hline & $\begin{array}{l}\text { Politik als zwischenmenschliche Be- } \\
\text { ziehung (aus Kirchhoff 2010: 240-246) }\end{array}$ & z.B.: die USA als , großer Bruder ${ }^{\circ}$ \\
\hline & $\begin{array}{l}\text { Politik als Reifungsprozess } \\
\text { (weitgehend induktiv) }\end{array}$ & $\begin{array}{l}\text { z.B.: ,die unreife afghanische } \\
\text { Armee‘. }\end{array}$ \\
\hline & $\begin{array}{l}\text { Krankheitsmetaphern } \\
\text { (aus Steuter/Wills 2009.) }\end{array}$ & z.B.: ,Taliban als Bazillus‘ \\
\hline & $\begin{array}{l}\text { medizinische Metaphern } \\
\text { (weitgehend induktiv) }\end{array}$ & $\begin{array}{l}\text { Situationen oder Zustände müssen } \\
\text {,geheilt' werden oder die Interventi- } \\
\text { on wird als ,Operation' angesehen }\end{array}$ \\
\hline & $\begin{array}{l}\text { Blutsmetaphern } \\
\text { (weitgehend induktiv) }\end{array}$ & z.B.: ,blutige Fehden ‘ \\
\hline
\end{tabular}

4 Wir nehmen diesen Begriff aus der militärischen Alltagssprache, oft ist er synonym mit Taleban, Insurgenten, Aufständischen usw.

5 Wir haben uns zunächst auf Metaphernfelder konzentriert, die bereits von Kirchhoff 2010 entwickelt und angewendet wurden. Während der Analyse haben sich weitere metaphorische Konzepte als nützlich erwiesen. 


\begin{tabular}{|c|c|c|}
\hline \multirow{2}{*}{$\begin{array}{l}\text { Tier- } \\
\text { metaphern }\end{array}$} & (nach Rigotti 1994: 115f) & z.B.: die ,Krake Al-Qaida‘. \\
\hline & $\begin{array}{l}\text { Jagdmetapher } \\
\text { (aus Steuter/Wills 2009: 13) }\end{array}$ & $\begin{array}{l}\text { z.B.: Osama Bin Laden wird, ge- } \\
\text { jagt‘. }\end{array}$ \\
\hline $\begin{array}{l}\text { Orts- } \\
\text { metaphern }\end{array}$ & $\begin{array}{l}\text { Orte zur Charakterisierung der Interve- } \\
\text { nierten } \\
\text { (aus Kirchhoff 2010: 207ff) }\end{array}$ & $\begin{array}{l}\text { z.B.: das Hindukusch Gebirge als } \\
\text {, wild zerklüftetes Schicksalsmas- } \\
\text { siv }^{\text {‘ }}\end{array}$ \\
\hline $\begin{array}{l}\text { Spiel- } \\
\text { metaphern }\end{array}$ & (aus Kirchhoff 2010: 182ff) & z.B.: ,Todesspiel ${ }^{\star}$ \\
\hline \multirow{3}{*}{$\begin{array}{l}\text { Religions- } \\
\text { metaphern }\end{array}$} & $\begin{array}{l}\text { allgemeinen Religionsmetaphern } \\
\text { (aus Kirchhoff 2010: 265ff) }\end{array}$ & z. B.: Taleban als ,Gotteskrieger ‘ \\
\hline & $\begin{array}{l}\text { Teufelsmetaphorik } \\
\text { (weitgehend induktiv) }\end{array}$ & $\begin{array}{l}\text { z.B.: Taleban als, fundamentalisti- } \\
\text { sche Teufel }^{`}\end{array}$ \\
\hline & $\begin{array}{l}\text { Mystik und Mythologie } \\
\text { (weitgehend induktiv) }\end{array}$ & $\begin{array}{l}\text { z.B.: Herrschaft der Taleban als } \\
\text {,Spuk der Taliban“ }\end{array}$ \\
\hline $\begin{array}{l}\text { Licht- } \\
\text { metaphern }\end{array}$ & aus Kirchhoff 2010: 186 & $\begin{array}{l}\text { z.B. das ,Schattenreich der Tali- } \\
\text { ban' }\end{array}$ \\
\hline \multirow{5}{*}{$\begin{array}{l}\text { Historische } \\
\text { Vergleiche }\end{array}$} & $\begin{array}{l}\text { Vergleich mit anderen Kriegen } \\
\text { (aus Kirchhoff 2010: 191ff) }\end{array}$ & z.B.: ,irakische Verhältnisse“ \\
\hline & $\begin{array}{l}\text { historische Personenvergleiche } \\
\text { (aus Kirchhoff 2010: 261f.) }\end{array}$ & z.B.: ,ein islamistischer Nero ‘ \\
\hline & $\begin{array}{l}\text { Geschichte als linearer Prozess } \\
\text { (aus Kirchhoff 2010: 269) }\end{array}$ & $\begin{array}{l}\text { z.B.: , wie schon vor Jahrzehnten } \\
\text { und Jahrhunderten }\end{array}$ \\
\hline & $\begin{array}{l}\text { Bezüge zu literarischen Figuren. } \\
\text { (weitgehend induktiv) }\end{array}$ & $\begin{array}{l}\text { z.B.: ,Sie [die Taleban] kamen } \\
\text { wie Robin Hood aus dem Wald } \\
\text { von Sherwood“ }\end{array}$ \\
\hline & $\begin{array}{l}\text { Andere Historische Vergleiche } \\
\text { (aus Kirchhoff 2010: 218-223) }\end{array}$ & z.B.: ,Pax Talibana“ \\
\hline $\begin{array}{l}\text { Gebäude- } \\
\text { und Gefäß- } \\
\text { metaphern }\end{array}$ & Nach Lakoff/Johnson 2003. & z.B.: ,Hochburg der Taliban“. \\
\hline \multirow{3}{*}{$\begin{array}{l}\text { Naturali- } \\
\text { sierung }\end{array}$} & $\begin{array}{l}\text { allgemeinen Naturmetaphorik } \\
\text { (weitgehend induktiv) }\end{array}$ & z.B.: ,Flüchtlingsströme‘ \\
\hline & $\begin{array}{l}\text { Naturkatastrophenmetaphorik } \\
\text { (weitgehend induktiv) }\end{array}$ & z.B.: ,Sturm auf Kabul' \\
\hline & $\begin{array}{l}\text { Feuer- und Wassermetaphoriken } \\
\text { (weitgehend induktiv) }\end{array}$ & z.B.: ,Flüchtlingswellen` \\
\hline
\end{tabular}




\begin{tabular}{|c|c|c|}
\hline \multirow{4}{*}{$\begin{array}{l}\text { Kultura- } \\
\text { lisierungs- } \\
\text { kategorie }\end{array}$} & $\begin{array}{l}\text { allgemeine Kulturalisierung } \\
\text { (induktiv - angelehnt an die postkolonia- } \\
\text { le Kritik von Edward Said u.a.) }\end{array}$ & z.B.: ,Terror-Stammesland'. \\
\hline & $\begin{array}{l}\text { Äußerlichkeiten als Identitätsmarker } \\
\text { (weitgehend induktiv) }\end{array}$ & z. B.: ,vollbärtige Kämpfer‘ \\
\hline & $\begin{array}{l}\text { Armut/Rückständigkeit } \\
\text { (weitgehend induktiv) }\end{array}$ & $\begin{array}{l}\text { z.B.: Kämpfer der Nordallianz als } \\
\text {,Bauernburschen` }\end{array}$ \\
\hline & $\begin{array}{l}\text { Kriminalisierungskategorie } \\
\text { (weitgehend induktiv) }\end{array}$ & z.B.: ,Räuberbanden“ \\
\hline $\begin{array}{l}\text { Kriegs- } \\
\text { metaphern }\end{array}$ & (weitgehend induktiv) & $\begin{array}{l}\text { z.B.: ,Afghanistan ist ein Pulver- } \\
\text { fass'. }\end{array}$ \\
\hline $\begin{array}{l}\text { Opfer- } \\
\text { diskurs }\end{array}$ & (weitgehend induktiv) & $\begin{array}{l}\text { hierarchisierende und paternalisti- } \\
\text { sche Sprache; nur bedingt meta- } \\
\text { phorisch }\end{array}$ \\
\hline
\end{tabular}

\subsection{Visuelle Kultur und anerkennende Sichtbarkeit: Theorie und Methodik der Bildanalyse}

Die Textanalysen werden durch eine Bildanalyse ergänzt, da ,sprachliche Metaphern nur der deutlichste Verweis auf die grundlegende Metaphorizität unserer Denkprozesse sind“ (Kirchhoff 2010: 114). In Erweiterung dieser Position argumentieren wir, dass sprachliche Metaphern tiefgreifend mit visuellen Phänomenen und Imaginationen, mit inneren und äußeren Bildern verschränkt sind und sich eine gleichzeitige Analyse von sprachlicher und visueller Ebene lohnt, auch wenn sie an dieser Stelle nur explorativ geleistet werden kann.

Die hier entwickelte Forschungsperspektive, die nach repräsentativen Darstellungsweisen der Intervenierten im Heimatdiskurs der Intervenierenden und den damit verbundenen gesellschaftlichen Konsequenzen fragt, ist mit der Erörterung des Problems der Anerkennung in Bezug zu verschiedenen Modi der Sichtbarkeit und Unsichtbarkeit verbunden. So fällt beispielsweise in einer ersten Analyse der Spiegel-Titelbilder auf, dass die Intervenierten als Zivilbevölkerung nahezu abwesend sind. Wenn die AfghanInnen überhaupt visuell repräsentiert werden, dann als Islamisten und Taleban. Elementar für Anerkennungsprozesse ist deren Verschränkung mit politischer Macht und der Konstituierung von Subjekten und Identitäten durch Sichtbarkeitsregime, visuelle Logiken und metaphorische Konzepte (vgl. Schaffer 2008). Um diese Fragen am visuellen Material erörtern zu können, rekurriert die Bildanalyse methodisch auf Pathosformeln, Ikonen und Körperbilder und steht damit im weiteren Sinne in der Tradition Aby Warburgs, der Bildprodukte nicht mehr unter primär ästheti- 
schen, sondern für die Kulturgeschichte und das kollektive Bildgedächtnis funktionalen Aspekten untersuchte.

Pathosformeln sind weitestgehend kanonisierte Darstellungen formelhafter Gestik und Mimik menschlicher Gefühlsausdrücke und grundsätzlich mit Menschen- und Körperbildern verbunden, weil sie Emotionen speichern, transportieren und wieder freisetzen. Die in den verschiedenen Pathosformeln gespeicherten, stets ambivalenten affektiven Energien menschlicher Ausdrucksweisen verweisen auf Ur-Ausdrücke menschlicher Gebärden, Körperhaltungen und Gesten, die im Verlauf der Kulturgeschichte in leicht modifizierter Form wiederkehren. Pathosformeln bezeugen die kontinuierliche Relevanz kultureller visueller Symbole für das kollektive Gedächtnis als sozialen Langzeitspeicher und sind konstitutiv für die Aktualisierung von Identitätsbildungen von Gesellschaften. ${ }^{6}$

Bildikonen sind im Gegensatz zu Pathosformeln nicht ausschließlich auf den menschlichen Körper bezogen, da auch abstrakte oder lebensweltliche Symbole und Darstellungen als Bildikonen gelten. Jedoch haben sie für das kulturelle Gedächtnis eine analoge Funktion und sind hinsichtlich ihrer medialen Qualitäten funktionale Verwandte von sprachlichen Metaphern. Ikonen sind bedeutungstragende Vehikel, insofern sie ein relevantes Bildmotiv über verschiedene visuelle Medien (Malerei, bildende Kunst, Fotografie, Film usw.) diachron und synchron vermitteln und zugleich dessen narrativen Kern bewahren, indem das Dargestellte ,dauerhaft institutionell verankert und in der Folge ritualisiert wiederverwendet werden“ (Grittmann/Ammann: 2008: 4) kann.

Körper- und Menschenbilder entfalten ihre ikonische Wirkmacht vor allem über die Mobilisierung von Gefühlen und dienen als fundamentale Strategie visueller Politik zur subtilen Vermittlung von Idealen, Normen, Werten und Utopien. Gerade die Körperbekleidung gilt als imaginäres und ,symbolisches Bezugssystem“ (Ellwanger 2002: 110) par excellence. Körperbekleidung stiftet nicht nur soziale und politische Identität oder Alterität, sondern verweist in ihren mannigfaltigen symbolischen Dimensionen auf politische und gesellschaftliche Repräsentationsfunktionen. Die den Körper entsprechend umhüllenden oder verhüllenden Insignien, Symbole oder Kleidungsstücke werden damit aussagekräftige Indikatoren für gesellschaftliche Bewertungen, Machtverhältnisse und soziale Strukturen.

6 Die Pietà von Michelangelo kann wohl als prominentestes Beispiel für eine Pathosformel gelten und sollte in diesem Zusammenhang Erwähnung finden, weil Motive dieser Art auch in menschenrechtlich argumentierenden Kontexten verwendet werden, beispielsweise wenn es um den Schutz Hilfebedürftiger geht. 


\section{Ergebnisse der Textanalyse}

An dieser Stelle werden charakteristische Ergebnisse der Textanalyse zu den zwei Zielbereichen (intervenierte Menschen und Feinde) getrennt voneinander vorgestellt. Unter dem Zielbereich der intervenierten Afghanen und Afghaninnen werden alle Menschen in Afghanistan gefasst, die nicht der Kategorie der Feinde (vgl. 2.2) zugeordnet wurden.

\subsection{Die intervenierten AfghanInnen - „Wilde Stammesgesellschaften“ und andere orientalistische Narrative}

Um "Zan, Zar, Zamin" ("Frauen, Gold und Land") drehe sich traditionell die Welt dieses unbezähmbaren Volksstamms, konstatiert die amerikanische Anthropologin Cherry Lindholm. "Bei dem permanenten Kampf um Macht werden nur zwei Typen unterschieden, die Starken und die Schwachen. Die Starken verschaffen sich Prestige durch Aggression, Mut und Selbstbezogenheit, sie müssen die Kunst der Intrige beherrschen." Bestimmt wird das Leben durch den Ehrenkodex des Paschtunwali, der das Recht auf Rache betont, aber auch zur bedingungslosen Gastfreundschaft gegenüber Fremden verpflichtet. (Spiegel 2007/38a; allgemeine Kulturalisierung) ${ }^{7}$

Die wenigen Beschreibungen der AfghanInnen stellen diese meist als rückständig dar. Oft werden sie durch metaphorische Konzepte auf einen engen kulturellen und religiösen Kontext reduziert, essentialisiert und homogenisiert. Demgegenüber wird ein Bild von den Intervenierenden gezeichnet, die erziehend eingreifen und die AfghanInnen auf Basis vermeintlich höherer Werte emanzipieren müssen. Diese Rhetorik greift auf eine lange europäische Tradition ${ }^{8} \mathrm{zu}-$ rück, bei der der ,Orient' stets in Abgrenzung zur ,eigenen Kultur' vorgestellt wird (vgl. dazu auch Attia 2007: 10ff) und ist bereits aus der postkolonialen Orientalismuskritik und der daraus hervorgegangenen Okzidentalismuskritik be-

7 Alle Spiegel-Zitate enthalten Hervorhebungen, die von uns vorgenommen wurden und auf den jeweils wichtigen Aspekt des Zitats verweisen sollen. Andere enthaltene metaphorische Aussagen oder doppelte Kodierungen in den Zitaten wurden auch ausgewertet und sind auf Nachfrage bei den AutorInnen zu erhalten.

$8 \mathrm{Zu}$ einigen der populären Präsentationen, die im deutschsprachigen Raum das Orientund Islambild prägen, gehören neben Musik (wie Mozarts Oper „Die Entführung aus dem Serail“) und Malerei und den Märchen aus 1001 Nacht auch die Reihe des „Orientzyklus“ von Karl May (vgl. hierzu auch Attia 2009: 57-61). 
kannt. ${ }^{9}$ Auffallend ist, wie diese Rhetorik in der Berichterstattung über die Intervenierten unkritisch reproduziert wird. Paradigmatisch für die kulturelle Abwertung der AfghanInnen steht deren kollektive Beschreibung als ,Stamm“.

Niemals konnten fremde Mächte die Bergstämme am Hindukusch auf Dauer beherrschen. (Spiegel 2001/45a; allgemeine Kulturalisierung)

Diese Stämme sind immer in öffentliche und private Kriege verwickelt," schrieb der junge Kriegsreporter Winston Churchill 1898 in seinen Aufzeichnungen. Jeder Mann ist ein Krieger, ein Politiker, ein Theologe. Jeder Clan pflegt seinen Rachefeldzug. Nichts wird jemals vergessen, und sehr wenige Schulden bleiben unbeglichen."(Spiegel 2007/38a; allgemeine Kulturalisierung)

Die mit ,Stammesgesellschaften“ verknüpften Attribute rühren aus der Kolonialzeit und halten sich relativ konstant. So werden ,Stammesgesellschaften ' mit Eigenschaften wie Kollektivismus, Geschlossenheit, sprachlicher und kultureller Homogenität, Patrilinearität und Patriarchat, Vetternwirtschaft und geringer Produktivität etc. belegt, ${ }^{10}$ während Gesellschaftsformationen in modernen Nationalstaaten unter anderem mit funktionierenden, neutralen Staatsorganen, Allgemeinwohlorientierung (im Sinne der Orientierung an der ,Staatsnation'), Offenheit und Lernfähigkeit assoziiert werden. Somit kann exemplarisch der vermeintliche Stillstand der afghanischen Gesellschaft behaupten werden, die sich auch in über 100 Jahren nicht von der „Stammesgesellschaft“" weiterentwickelt habe.

9 Während Edward Said [1978] (1981) sich in besonderer Weise auf die „historisch spezifischen Phantasmen gegenüber einem zu erfindenden ,Orient ‘ in der französischen und britischen Kolonialimagination" und somit auf die Logik des Othering fokussiert hat, nimmt eine okzidentalismuskritische Analyse die Effekte in den Blick, die Othering-Prozesse für das „okzidental-hegemoniale Selbst“ haben (Dietze 2009: 26-27; vgl. Dietze/Brunner/Wenzel 2009).

10 Vgl. hierzu auch Brockhaus Online 2011: Stamm und Brockhaus Online 2011: Tribalismus. Arndt (2011: 669) schreibt dazu: „Menschliche Organisationsformen als eine Linearität von Stadien zu konstruieren, die von Familien, ,Sippen` und ,Clans“ ausgehen, und über ,S. ' und ,S.konföderationen“ schließlich zum Staat(swesen) gelangen, implizieren prinzipiell, dass dort wo ,S. 'existieren, (noch) keine ,vollwertigen', das heißt westlichen Staaten ebenbürtige Staaten existieren. Da ,S.gesellschaft" außerdem in Opposition zum Oberbegriff ,Gesellschaft" verwendet wird und eine analoge Begriffsschöpfung für europäische/westliche Kontexte nicht existiert, ist er in seiner asymmetrischen Spezifizierung eindeutig abwertend“ (Arndt 2011: 669). 
Ähnlich ist die Darstellung des ,orientalischen, gewalttätigen Mannes;, das auf historisch gewachsene Stereotypen zurückgreift. ${ }^{11}$

Tausende weitere afghanische Paschtunen taten es ihnen auf ihrem Marsch nach Norden gleich. Die meisten von ihnen waren blutjung - zwischen 14 und 24 Jahre alt - und hatten noch nie gekämpft, konnten aber wie alle Paschtunen mit Waffen umgehen. (Spiegel 2001/41b; Allgemeine Kulturalisierung)

Das Verhalten der hier beschriebenen jungen Männer wird als triebhaft und urtümlich konstruiert: ihr Verhalten und ihre Entscheidungen scheinen ad-hoc zu sein und keinen reflektierten Entwicklungs- und Entscheidungsprozess durchlaufen zu haben.

Sozio-kulturelle Prozesse werden teils dramatisch verkürzt und biologistisch begründet.

Übersehen worden waren dabei ein paar Binsenwahrheiten zum Selbstverständnis Afghanistans: der Vorrang der Paschtunen, die nahezu die Hälfte der Bevölkerung stellen; und der gleichsam genetisch gesteuerte Drang zum Zusammenhalt, marschiert am Hindukusch ein Feind von außen auf. (Spiegel 2001/45a; Ver-körper-ung)

Die auf der Vererbungslehre gründende Erklärung für ein in allererster Linie soziales Phänomen essentialisiert und ontologisiert die afghanische Gesellschaft auf erschreckende Weise. Somit wird den AfghanInnen jegliches eigenständiges, kontrolliertes, rationales und damit menschliches Handeln abgesprochen. Dies kommt auch durch Metaphern der Politik als Reifungsprozess zum Ausdruck:

Selbst die waffentechnisch hochüberlegenen Briten konnten die Widerspenstigen nie besiegen. (Spiegel 2007/38a; Politik als Reifungsprozess)

Die Intervenierten werden mit Eigenschaften dargestellt, die in einem westeuropäischen Kulturkreis Kindern zugeschrieben werden. Dies ermöglicht es, den Intervenierenden eine legitime ErzieherInnen-Funktion zuzuschreiben.

11 Sylvia Kuske (1994: 254; 257; 261) erläutert diese Entwicklung von der Eroberung Spaniens 711, der sogenannten Reconquista über die osmanische Herrschaft bis hin zur iranischen Revolution und dem Golfkrieg. In jeder Epoche wird dabei auf ein negatives Gegenbild in Formen des ,gewalttätigen, orientalischen Despoten', ,grausamen Türken` oder , wilden Mobs unter Leitung eines finsteren Alten` etc. rekurriert. 
Auch sein Kamerad Saidullah, 15, macht kein Hehl daraus, dass er besser schießen kann als lesen und schreiben. Der Scharfschütze mit dem Kindergesicht rühmt sich, er habe "schon fünf oder sechs Taliban getötet". In kindlicher Tollkühnheit nimmt er seinen erschossenen Gegnern auch noch die Waffen ab. Seine Kalaschnikow, die er wie ein Lieblingsspielzeug umklammert hält, ist ebenfalls eine Beutewaffe. (Spiegel 2001/45c; Politik als Reifungsprozess)

Ein anderes, damit aber korrelierendes Motiv ist der „wilde Afghane“ oder das „wilde afghanische Volk“:

Die beiden haben Gesichter wie aus alten Völkerkunde-Büchern - Paschtunen, ein wildes, freies Volk aus dem Hindukusch - und auch die jüngste Angriffswelle der U. S. Air Force scheint sie nicht aus dem Gleichgewicht gebracht zu haben. (Spiegel 2001/42g; Allgemeine Kulturalisierung)

Im Winter 1842 vernichteten die wilden Afghanen ein ganzes Expeditionsheer des britischen Empire bei dessen Flucht aus Kabul. (Spiegel 2001/39e; Allgemeine Kulturalisierung)

Drei Kriege, den letzten 1919, verloren die Briten gegen die wilden Bergkrieger, einen zehnjährigen Waffengang, 1979 bis 1989, die Sowjets (mit mindestens 15000 Toten). (Spiegel 2001/40a; allgemeine Kulturalisierung)

„Wild“ kann dabei nur zusammen mit ,zivilisiert' gedacht werden, da beide Begriffe in einem binären und dichotomen Verhältnis zueinander stehen.

„,Wildnis‘ wiederum signifiziert in kolonialen Diskursen und Vorstellungen Stummsein, Nicht-sprechen-Können, Unterlegenheit und gleichzeitig Gefahr und Bedrohlichkeit. Die Kennzeichnung > wild « steht für Unmündigkeit, damit ,Wildnis` der Autorität der ,Zivilisation“ unterstellt werden kann. ,W/wild“ darf getötet werden oder auch gezähmt; ,wild` wird als außerhalb der Ordnung dargestellt; (...).“ (Popal 2011: 678).

Die AfghanInnen als ,wildes, freies Volk“ zu bezeichnen geht mit der Konstruktion der Feinde als Tiere einher (vgl. 3.2.1). Während die AfghanInnen so entmenschlicht und auf orientalische Stereotype verkürzt dargestellt werden, entsteht das Bild vermeintlich überlegener westlicher Intervenierender, welche/r die AfghanInnen entweder beschützen, oder aus ihrer Unmündigkeit befreien müssten. 


\subsubsection{Zivilisten und ,unschuldige AfghanInnen“}

Das afghanische Flüchtlingselend konzentriert sich in Lagern jenseits der Grenze. Die älteren Insassen wurden von drei verschiedenen Regimen verfolgt und unterdrückt. Am ärgsten traf es die Frauen - manche organisieren und wehren sich nun. (Spiegel 2001/42f; Opferexkurs)

Für kommenden Freitag rief Haq zu einem Solidaritätsstreik für das hilflose afghanische Volk auf, der den Hass auf den „weltgrößten Terroristen Amerika“ zum Ausdruck bringen soll. (Spiegel 2001/45a; Opferexkurs)

Besonders prägnant in der Beschreibung der intervenierten Menschen ist der $O p$ ferdiskurs $^{12}$. Sicherlich waren die AfghanInnen über Jahrzehnte schwierigen politischen und ökonomischen Bedingungen sowie materiellen und physischen Entbehrungen ausgesetzt. Ihre Darstellung als „hilflose[s] afghanisches Volk“, das über Jahrzehnte ,verfolgt und unterdrückt“" wurde oder die Betonung des „Flüchtlingselend[s]“ erschafft jedoch ein machtvolles und einseitiges Bild, das es dem ,weißen westlichen Betrachter" nahezu unmöglich macht, die AfghanInnen als Subjekte anzuerkennen. Diese Perspektive provoziert wohlmeinendes Mitleid und Bevormundung, die eine Beziehung zwischen ,ihnen` und ,uns` auf Augenhöhe verhindert. Eine Wahrnehmung der AfghanInnen als selbstbestimmte Subjekte der Interventionspolitik in einem gemeinsam gestalteten Prozess wird so entscheidend erschwert.

Durch Verwendung von Naturmetaphern („Flüchtlingsströme“; „Welle von fliehenden Afghanen“) für in Massen fliehende Menschen werden die Flüchtlinge darüber hinaus als Bedrohung und gesichtslose, anonyme Masse wahrgenommen (vgl. hierzu auch Bildanalyse in 4.).

Colville klagt: „Dabei erwarten wir noch viel größere Flüchtlingsströme zur Grenze.“ (Spiegel 2001/40b; Wassermetaphorik)

12 Die folgenden sprachlichen Umschreibungen, die wir in der Kodierung als Opferdiskurs bezeichnet haben, stellen im engeren Sinne keine Metaphern dar beziehungsweise kann hier der metaphorische Wert der Aussagen nicht klar von der realen Bezugswelt getrennt betrachtet werden. Wir denken jedoch, dass die unter diesem Aspekt aufgefundenen Aussagen sehr wichtig für die hier bearbeitete Fragestellung der Darstellung der AfghanInnen sind. Dabei stehen diese Aussagen hier nicht allein für sich, sondern müssen im Kontext des Gesamtbildes, das von Afghanistan und den dort lebenden Menschen im Spiegel geschaffen wird, betrachtet werden. 
Die Flüchtlinge in Pakistan kehrten nicht zurück, stattdessen setzte sich eine neue Welle Flüchtlinge aus Kandahar in Richtung Quetta in Bewegung. (Spiegel 2001/41b; Wassermetaphorik)

Auf dem Rückweg ins Gästehaus begegnet uns ein Strom heimkehrender Flüchtlinge. Viele von ihnen hocken, ihre Habseligkeiten in Decken und Teppichen zusammengeschnürt, auf den Dächern heillos überladener Busse. (Spiegel 2001/47b; Wassermetaphorik)

Flüchtlinge sind damit nicht mehr individuelle Menschen mit eigenen Geschichten und Erfahrungen sondern werden als bedrohliches „menschliches Schwemmgut" (Spiegel 2001/39d) oder als ,heranstürmende Horde " charakterisiert. Motive dieser Art sind mittlerweile eine populäre Chiffre um soziale Probleme zu ethnisieren und finden sich häufig sowohl auf verbaler als auch visueller Ebene in außen- und innenpolitischen Diskursen. Verschiedene Spiegel-Titelbilder haben seit den 1990er Jahren das Motiv herandrängender, meist schwarzer Menschenmassen mitgeprägt und eine standardisierte Bild- und Sprachformel geschaffen, die einen ,emotionalisierende[n] Abwehrdiskurs“ (Pagenstecher 2008: 612) mobilisieren soll.

\subsubsection{Geschlechterdimensionen in der Darstellung der Intervenierten}

Geschlechterdimensionen in der Darstellung der intervenierten Menschen und Feinde spielen eine wichtige Rolle und werden häufig über Äußerlichkeiten als Identitätsmarker (z.B. Burka/Turban/Bart) transportiert. Bei der Darstellung weißer westlicher Menschen wird selten erwähnt, welche Kleidungsstücke sie tragen. Demgegenüber scheint die Burka oder der Schleier bei Afghaninnen sowie der Turban und der lange Bart bei Männern eine paradigmatische Funktion einzunehmen, da diese Symboliken für sich sind und für mehr stehen als Kleidungsstücke oder Frisurentrends. In diesem Sinne haben Kleidung und andere Äußerlichkeiten eine metaphorische Funktion, die mit politischen Konnotationen einhergeht und den Lesenden spezifische Wertekonzepte vermitteln soll.

Entscheidend sind dabei zwei Darstellungs- und Vorstellungsfunktionen: Zum einen findet eine Reduktion statt, da die TrägerInnen auf das Symbol reduziert werden und andere Aspekte ihrer Subjektivität oder Individualität nicht zur Geltung kommen. Zum anderen wird eine Hyperbel, eine Übertreibung, provoziert, da das Kleidungsstück selbst bestimmte Aspekte, die es als Symbol verdeutlicht, hervorhebt. Das Symbol macht so insgesamt aus einem Menschen einen Typus und marginalisiert andere körperbezogene Assoziationspotentiale. Diese Simplifizierung und Zuspitzung in der Sprache evoziert falsche und rassis- 
tische Bilderstereotype und arbeitet gezielt mit der Abwertung anderer Subjektpositionen. Die Afghaninnen werden unabhängig von ihrer jeweiligen Sozialschicht, Herkunft, ihrem familiären Hintergrund und der persönlichen Einstellung homogen zu unterdrückten Objekten deklariert.

Im Nachbarlager Herakat etwa, das Sympathisanten der Taliban kontrollieren, wäre so etwas undenkbar. Dort dürfen Frauen sich nicht alleine bewegen. Nur unter der Burka, der fließenden Ganzkörperrobe mit dem schmalen Gitterfenster, und in Begleitung eines Mannes dürfen sie vor die Tür. (Spiegel 2001/42f; Äußerlichkeiten als Identitätsmarker)

Das Benennen des Schleiers beziehungsweise der Burka hat hier die konstitutive Funktion, eine Grenze zwischen der ,orientalischen Anderen' und der ,westlichen Frau' zu ziehen. Durch das Ablegen des Schleiers beziehungsweise der Burka kann sich die ,Andere' jedoch in eine ,gute Andere" verwandeln (vgl. Kuske 1994: 276).

Auf den Basaren fanden die Frauen, die zögerlich ihre Burkas abzuwerfen begannen, wieder Lippenstifte und modische Kleidung. (Spiegel 2001/47a; Äußerlichkeiten als Identitätsmarker)

Die Händler holten ihre Ware aus den Kellern, Frauen warfen die Burka ab und schminkten sich. Kinder spielten auf der Straße, Radios lärmten, und die Männer gingen, frisch rasiert, zum Fußballspiel ins Stadion. (Spiegel 2001/52; Äußerlichkeiten als Identitätsmarker)

Nur wenige Tage nach dem Sturz des Taliban-Regimes hat Frau Soraya die erste Demonstration von fast 1000 unverschleierten Afghaninnen in Kabul organisiert. (Spiegel 2001/48; Äußerlichkeiten als Identitätsmarker)

Metaphorische Konzepte rund um das Thema, Befreiung der afghanischen Frauen ${ }^{13}$ waren überraschend unterrepräsentiert. Das zentrale Motiv der Burka beziehungsweise das Ablegen derselben als symbolischer Akt der Befreiung nach westlichen Vorstellungen wurde nur in den Ausgaben von 2001 thematisiert.

Zudem wird darauf rekurriert, dass es vor allem religiöse, afghanische Männer sind, die an der Burka festhalten, wodurch diese als patriarchale, orientale Unterdrücker der eigentlich, freiheitsbewussten afghanischen Frauen“ konstitu-

13 Diese Konstruktion lässt (den Körper der) Frauen zum umkämpften Territorium werden. Siehe hierzu Maier/Balz 2010; Klaus/Kassel 2008; Kreile 2002. 
iert werden. Durch die Tendenz, Sexismus und Patriarchat der , orientalischislamischen“ Lebensweise zuzuweisen, können sie diskursiv aus der , westlichen Kultur' herausgelöst werden (vgl. Attia 2007: 13). Dies lässt sich auch in dem hier untersuchten Material der Spiegel-Titelgeschichten wiederfinden.

Doch sein Auftritt weist ihn auch als unverbesserlichen Fundamentalisten aus. Rabbani appelliert an die Frauen, sich entweder mit dem Vollschleier, der Burka, oder zumindest mit einem Kopftuch zu verhüllen. Eine Abschaffung jeglichen Schleierzwangs, so der fromme Religionsprofessor, „dürfen wir nicht zulassen“. Wer den Frauen völlige Freiheit verspreche, gehöre zu den „scharfen Marxisten“. (Spiegel 2001/48; Äußerlichkeiten als Identitätsmarker)

Eine Frau steht mit unverschleiertem Gesicht auf der Straße, doch sie darf auf Fragen nicht antworten - ihr Mann verbietet es ihr. (Spiegel 2001/47b; Äußerlichkeiten als Identitätsmarker)

Unter dem Talebanregime wurden nicht nur Frauen, sondern auch Männer zu einem bestimmten äußeren Erscheinungsbild verpflichtet; so wurde u.a. das Tragen eines langen Bartes verpflichtend. Analog zur Burka beziehungsweise zum Schleier wird in der äußerlichen Beschreibung von Männern in den Ausgaben von 2001 grundsätzlich hervorgehoben, ob diese einen Bart tragen.

Im Mittelgang, Reihe zwei, hockt in grüner Tarnweste der massige General Abdul Rahim Wardak. Als Einziger trägt er keinen Bart, auch keinen Turban, und seine Hautfarbe ist bleich. Wardak war Oberkommandierender der Nationalen Islamischen Front und bis zur Machtübernahme durch die Taliban Generalstabschef der afghanischen Armee. (Spiegel 2001/45e; Äußerlichkeiten als Identitätsmarker)

Am Abend kommt ein bärtiger junger Mann in Mudschahidin-Kluft und Knobelbechern im Hotel an unseren Tisch und stellt sich auf Englisch als Mitarbeiter des Außenministeriums vor. (Spiegel 2001/48; Äußerlichkeiten als Identitätsmarker)

Durch die Erwähnung des Bartes erschließt sich den Lesenden vermeintlich sofort, ob die betreffende Person als ,islamistisch" und damit potentiell ,bedrohlich“ oder als ,westlich-fortschrittlich ' einzuordnen sei. Auch im Falle der intervenierten Feinde wird von diesen einfach als „Turbanträger“ oder „Bärtige“ gesprochen. 
Anfangs waren die Schwarzturban-Fundis aus Paschtunistan bei der ethnisch gemischten Hauptstadt-Bevölkerung wenig beliebt. Vor allem wegen ihrer religiösen Militanz, ihres extremistischen Glaubensbreviers. (Spiegel 2001/45a; Äußerlichkeiten als Identitätsmarker)

Er gehört zur mittleren Befehlsebene und trägt einen schwarzen Turban, dessen Schal fast bis zu den Knien herabhängt, sein Bart ist sehr lang. Die Kalaschnikow hat er wie ein Kleidungsstück über die Schulter geworfen. (Spiegel 2006/47b; Äußerlichkeiten als Identitätsmarker)

\subsection{Die Darstellung der intervenierten Feinde in Afghanistan}

Im Anschluss an die Ergebnisse der Darstellung der intervenierten Afghanen und Afghaninnen werden im Folgenden die wichtigsten Ergebnisse zu den intervenierten Feinden vorgestellt. Dieser Zielbereich umfasst im weitesten Sinne alle diejenigen Intervenierten, die den Zielen der internationalen Interventionstruppen entgegenstehen und diese zu bekämpfen scheinen. Die Kategorie „Feinde“ in Afghanistan nahm mit Abstand die größte Anzahl der gefundenen Metaphern ein. Die friedliche Mehrheit der afghanischen Zivilbevölkerung scheint kaum wahrgenommen zu werden. Die AfghanInnen als Feinde wurden dabei vorrangig als Tiere beschrieben, die es zu jagen, Krankheit, die es zu heilen, oder Kriminelle, die es zu bestrafen gilt.

\subsubsection{Die „Krake Al-Qaida“ und die „Jäger Osama bin Ladens“ - Tiermetaphorik}

Eine Umschreibung der afghanischen Feinde in negativen ${ }^{14}$ Tiermetaphern ist im Spiegel auffällig häufig. Dieses reiht sich in eine lange Tradition der Kriegsrhetorik ein, in der die Feinde in negativen Tiermetaphern beschrieben werden (vgl. Steuter/Will 2009:11). Im Spiegel zeigt sich dies besonders deutlich an den zahlreichen Jagdmetaphern:

Schon im September hat Präsident George W. Bush eine Anweisung unterschrieben, womit er die CIA zur Jagd auf Osama Bin Laden und zur Zerstörung von al-Qaida ermächtigt. Für die verdeckten Aktionen stehen dem Geheimdienst eine Milliarde Dollar zur Verfügung. Um Bin Laden „,aufzuspüren, auszuräuchern und zur Strecke zu bringen“, wie

14 Prinzipiell gibt es im deutschen Sprachgebrauch auch positiv besetzte Tiermetaphern. Werden Menschen beispielsweise als mutige Löwen oder schlaue Füchse umschrieben, so geht damit eine positive Wertschätzung einher. 
der Präsident die gewünschte Abfolge in Wildwest-Diktion nennt, sollen die Agenten und das Militär in Afghanistan zusammenarbeiten, anstatt sich wie üblich mit gegenseitiger Nichtachtung zu strafen. (Spiegel 2001/45d; Jagdmetaphern)

An strategisch wichtigen Punkten hatten US-Kommandosoldaten Straßensperren errichtet und sich sogar Feuergefechte mit feindlichen Truppen geliefert, in der Hoffnung, Bin Laden oder seine Taliban-Helfershelfer würden ihnen ins Netz gehen. (Spiegel 2001/47a; Jagdmetaphern)

„Wir schützen auf diese Weise unsere Soldaten, dazu gehört auch, auf der Grundlage von Geheimdienstinformationen Terroristen aufzuklären, sie zu fangen und zu töten, bevor sie unsere Leute töten“, so ein hochrangiger General im Isaf-Hauptquartier. (Spiegel 2009/49; Jagdmetaphern)

Durch die Jagdmetaphorik wird den Feinden, ähnlich wie den AfghanInnen, der Subjektstatus versagt. Es muss weder erklärt werden, warum es sich um Tiere handelt, noch muss die Jagd gerechtfertigt werden. Das Jäger-Gejagter-Verhältnis stellt sich als ein unveränderbares dar, eine quasi natürlich gegebene Konstellation, die erst mit der erfolgreichen Erlegung des Beutetiers beendet sein kann.

Die Beschreibung der Feinde als Tiere legitimiert darüber hinaus bestimmte Kriegsführungstaktiken; die Feinde können und müssen als minderwertige Lebewesen behandelt werden. Mit Tieren wird nicht verhandelt, Tieren werden keine Prozesse gemacht und Tiere erhalten auch keine Möglichkeit der ReIntegration in eine neue (noch zu schaffende) Gesellschaftsordnung. Auch internationales Völkerrecht gilt nicht für Tiere. ${ }^{15}$ Mit der Jagdmetaphorik einher geht eine allgemeine Beschreibung der Feinde als Tiere, insbesondere im Zusammenhang mit der globalen Terrororganisation Al-Qaida oder auch den Anhängern und Protagonisten des Taleban-Regimes.

Wenn der Saudi-Araber wirklich Drahtzieher des Horrors war, dann trägt die westliche Welt ein gerüttelt Maß an Schuld - vor allem die USA müssen sich vorwerfen lassen, die terroristische Schlange genährt zu haben. (Spiegel 2001/38b; Tiermetaphern).

15 Denn Tieren wird die Fähigkeit zur Vernunft und zur Sprache abgesprochen, sie haben nach menschlichem Verständnis keine Kultur oder Technik. Sie kennen demnach auch die Erfahrung des Todes, der Trauer und des Leids nicht. Jeremy Bentham hat hierzu die philosophische Frage gestellt: „Can they suffer?“. Schon durch die Sprache beginnt Gewalt, denn durch Tiermetaphern wird unterstellt, dass das Tier-Sein eins ist (vgl. Derrida 2009). 
Und auch nur ein Zwischenziel wäre erreicht, wenn Osama Bin Laden entweder gefangen genommen oder getötet würde. Denn dass der saudi-arabische Millionärssohn nur eine Spinne in jenem Netz ist, das etliche Terrorgruppen unter etlichen Anführern aufgespannt haben, versucht Präsident Bush seinen Landsleuten nachhaltig zu erklären. (Spiegel 2001/40a; Tiermetaphern)

Und eine Mahnung, dass der Krake al-Qaida sich trotz zahlreicher abgeschlagener Tentakel neu formiert hat. Einer aktuellen Einschätzung der amerikanischen Geheimdienste zufolge hat sich ,al-Qaida in Pakistans gesetzlosen Gegenden gut eingenistet und ist besser positioniert, um den Westen anzugreifen“. (Spiegel 2007/38a; Tiermetaphern)

Eine Steigerung der Tiermetaphorik findet die Berichterstattung in dem wiederkehrenden Motiv der Hydra, das eine nicht fassbare und fremde Gestalt der intervenierten Feinde impliziert:

Die Erfahrung aus dem Golfkrieg fällt ohnehin desillusionierend aus: Welche Rückwirkungen solche Kriegszüge gegen den Feind Nummer eins - gestern Saddam Hussein, heute Osama bin Laden - haben, ist zumindest in einer Hinsicht deutlich: Selbst wenn der Gegner besiegt ist, wachsen neue Helden mit neuen Gefolgsleuten nach. (Spiegel 2001/40a; Tiermetaphern)

„Die werfen Bomben und warten, statt den Taliban ein intelligentes Angebot zu machen“, stöhnte ein europäischer Botschafter in Islamabad, ,und durch diese Politik wachsen täglich 1000 kleine Osamas nach.“ (Spiegel 2001/45a; Tiermetaphern)

Das Motiv der Hydra unterstreicht die Aussichtslosigkeit, den Feind bekämpfen zu können, da der neunköpfigen Schlangengestalt immer zwei Köpfe nachwachsen, wenn ihr ein Kopf abgeschlagen wird. Es entsteht der Eindruck, diese Art der Bekämpfung der Feinde sei kontraproduktiv, führe zu noch mehr Widerstand und Herausforderungen und zu einer Wahrnehmung der Intervention als aussichtsloses Unterfangen. ${ }^{16}$

\subsubsection{Vom „, islamistischen Bazillus“ - Body-Politics}

Eine weiteres wichtiges Metaphernfeld in der Beschreibung der intervenierten Feinde sind Krankheitsmetaphern. Die intervenierten Feinde werden mit Hilfe

16 Eine fast wörtlich gleiche Aussage bekam Michael Daxner während einer Unterhaltung mit General Mc Chrystal am 09. April 2010 in Berlin zu hören. 
von physischen Krankheitsbildern beziehungsweise Erregern oder als Epidemie beschrieben.

Um den islamistischen Bazillus von seinem Land fern zu halten, hat Karimow seit Monaten schon die Grenzen zu den Nachbarstaaten Kirgisien und Tadschikistan vermint. (Spiegel 2001/40a; Krankheitsmetapher)

„Gut, dass diese Pest weg ist“, jubelte im deutschen Exil der vormalige Herat-Gouverneur Ali Agha Radmer, „die Taliban waren für uns Fremde - Araber und Pakistaner.“ (Spiegel 2001/47a; Krankheitsmetapher)

Stärker noch werden psychische Krankheitsbilder, wie Wahn, Irrsinn oder Fanatismus genutzt um die Feinde zu beschreiben:

Ja, man will die Irren [die Taleban] nicht weiter provozieren, und ein wenig bewundert man auch die Selbstverständlichkeit, mit der sie sich über alle Spielregeln hinwegsetzen. (Spiegel 2001/38f; Krankheitsmetapher)

Als Alternative zum Fußball boten die Fanatiker im Stadion der Bevölkerung an Freitagen gelegentlich ein anderes Schauspiel, das dem blutrünstigen Regime angemessener erschien: öffentliche Erschießungen. (Spiegel 2001/47b; Krankheitsmetapher)

Dass der Wahnwitz der Taliban in weiten Teilen ein Produkt der al-Qaida war und die Terrortruppe keineswegs nur ein Anhängsel des Regimes, davon sind Mitarbeiter des neuen Kabuler Geheimdienstes überzeugt. (Spiegel 2001/48; Krankheitsmetapher)

Es scheint, dass sich religiös Fanatisierte von militärischen Niederlagen kaum beeindrucken lassen - statt der Wirklichkeit ins Auge zu blicken, erleben sie ihre Gottesnähe umso inniger in einem rauschhaften Realitätsverlust, der auch dann ans Suizidäre grenzt, wenn der jeweils Berauschte sich noch keine Bombe um den Bauch gebunden hat. (Spiegel 2001/52; Krankheitsmetapher)

Beide Formen der Krankheitsmetaphern haben eine tiefe Wirkung auf die Lesenden, da sie unmittelbar sinnlich wirken. Krankheit ist ,als menschliche Grunderfahrung und Gesundheit als menschliches Grundbedürfnis“ (Bruchhausen 2009: 337) zu verstehen. Der Feind wird mit metaphorischen Konzepten dieser Art als das schlechte und ungewollte ,Andere" einer leiblichen Erfahrung oder eines geistigen Zustands beschrieben. Beide, sowohl die körperliche als auch die geistige Unzulänglichkeit eines Individuums, stellen für unseren Kulturkreis ein Ri- 
siko und eine Defizienz dar, bei der die/der Einzelne sich durch gesellschaftliche Exklusion oder Stigmatisierung bedroht sieht. Wir gehen davon aus, dass die Lesenden entsprechende geistige oder körperliche Krankheiten mit bestimmten Gefühlen aus ihrer unmittelbaren lebensweltlichen und soziokulturell geprägten Erfahrung assoziieren. Sei es, weil sie körperliche Krankheiten selbst erfahren haben, deren virale oder bakterielle Ursache sie nicht wirklich kennen, sie also nicht wissen, wo sie sich infiziert haben und sich de facto immer einer unsichtbaren Gefahr durch Infektion aussetzen, oder ihnen die Ausschlussmechanismen gegenüber irrationalem, außergewöhnlichem Verhalten und geistigen Störungen im Hinblick auf gesellschaftliche Erwartungen an Normalität und Vernünftigkeit bekannt sind. Der Feind wird durch beide Arten der Metaphorisierung zum schlechthin ,Anderen` der Kultur und Zivilisation stilisiert (dazu Foucault 1969; Derrida 2009).

Der Umgang mit den sich dadurch ergebenden Gefahren für die Kultur in ihrer Gesamtheit ist insofern auf die Abwehr unsichtbarer und sichtbarer Bedrohungen anzupassen und schließt alternative Handlungsweisen, wie Verhandlungen, prinzipiell aus. Da Viren und Bakterien als unsichtbare Bedrohungen überall zu vermuten sind und permanent die Gefahr einer Epidemie evozieren, hilft nur eine permanente Vorsorge, Abwehr und Bekämpfung. Der Umgang mit geistigen Pathologien hingegen verweist auf eine notwendige gesonderte Behandlungsweise des erkrankten Personenkreises, dem nicht mit üblichem Alltagshandeln begegnet werden kann.

Deshalb entsteht ähnlich wie bei den Tiermetaphern der Eindruck, die Gegner seien keine gleichwertigen (und auch keine gleichartigen) Verhandlungspartner. Weder der Verlauf und die Wirkung einer Krankheit, noch die Handlungen von geistig gestörten Menschen lassen sich mit Sicherheit vorhersagen (vgl. Steuter/Wills 2009: 17). Sie handeln eben nicht rational. Das Problematische an dieser Rahmung der Intervenierten ist, dass von vornherein ausgeschlossen wird, dass Verhandlungen auf Augenhöhe stattfinden können. Epidemische Krankheiten werden mit aggressiven Medikamenten bekämpft, geistig Verwirrte werden nicht ernstgenommen.

\subsection{3 ,Kriminelle Strauchdiebe“ und ,Drogenbarone ‘ - Die Kulturalisierungsmetaphorik}

Die intervenierten Feinde werden sehr oft auch, ganz in orientalistischer Tradition, in kriminellen Bildern dargestellt. 
Sollten sie bereit sein, den Terroristenchef Osama Bin Laden sowie dessen „Führer, Leutnants und andere Strauchdiebe und Kriminelle“ endlich "auszuspucken, könnten die USA „neu überdenken, was wir mit ihrem Land machen“. (Spiegel 2001/42a; Kriminalisierung)

Der Rückschlag, er erscheint geradezu unvermeidlich. Fünf Jahre nach dem Einmarsch rücken die Taliban wieder vor, die Drogenbarone verdienen mehr Geld denn je und finanzieren so den Krieg der Nato-Gegner. (Spiegel 2006/47a; Kriminalisierung)

Denn von Anfang an hat man weggesehen, als dieses neue Afghanistan unter die alten Räuber [die Taleban] fiel. (Spiegel 2006/47a; Kriminalisierung)

Ob sich die unendliche Jagd auf das Oberhaupt der globalen Terrorbande noch immer als Krieg einordnen lässt, in dem das Gesetz des Tötens gilt, wird inzwischen von einer Mehrzahl der Völkerrechtler bezweifelt. (Spiegel 2011/19a; Kriminalisierung)

Diese Charakterisierungen folgen einem typischen Muster der Legitimierung und Delegitimierung von Gewalt, drücken sie doch die Superiorität der Position der Intervenierenden aus, die als Gegenbild zum „Schurken, Kriminellen und Räuber" höhere Ideale vertreten und deren „Soldaten [sich dann wiederum, d.Verf.] als Friedensbringer“ (Bergmann 2010: 156) präsentieren können.

Dies entspricht klassischer Kriegsrhetorik, die auch zum Zwecke innerer Solidarisierung der intervenierenden Gesellschaft im Bedrohungsmoment angewendet wird und die Werte und Ideale, für die gemeinsam einzustehen ist, vor einer Negativfolie projiziert. Zweck der Kriminalisierung ist deshalb insbesondere die Delegitimierung des gegnerischen Kampfes. Die Grenzziehung zwischen ,barbarischem“ und ,zivilisiertem“ Gewalteinsatz erfolgt insofern immer auch unter dem Aspekt polarisierter Setzung und greift damit auf Vorstellungen zurück, die in unserem kulturellen Gedächtnis mit entsprechenden Männlichkeitsbildern und Wertvorstellungen vermittelt sind. Diese dichotomen Konstruktionen korrespondieren z.B. mit Vorstellungen aus der Kolonialzeit, insofern dem barbarischen und kriminellen Wilden, dem also jede Vorstellung von Recht- und Ordnungsmäßigkeit abgeht, die kulturelle Höherwertigkeit des zivilisierten und guten Europäers entgegensteht (vgl. Bergmann 2010: 157).

Während in der Beschreibung des Landes und insbesondere der Menschen Afghanistans Armuts- und Opferbeschreibungen überwiegen, die ein allgemeines Bild von unterstützungswürdiger Rückständigkeit provozieren, um westliche Hilfsbereitschaft, Verantwortungsgefühl und insofern westlichen Paternalismus zu aktivieren, wird der Kampf der Feinde als vormodern disqualifiziert und als Bedrohung für uns wie auch für die Menschen vor Ort charakterisiert. 
Mit korrespondierenden und weiterführenden metaphorischen Konzepten wird die vom Gegner ausgeübte Gewalt und die ihr zugrundeliegende ideelle Basis als kulturelle Eigenheit dargestellt. Der Mittelalter-Vergleich bietet sich demgemäß an, denn der implizite Verweis auf Gewaltexzesse, wie Folterungen, Hexenjagd und grausame Hinrichtungspraktiken in der Frühen Neuzeit verschleiert die eigene Bereitschaft der Intervenierenden zur Gewalt. Das Bild der modernen und höheren Idealen verpflichteten VerteidigerInnen ist implizit als Gegenbild im „Steinzeit-Islamisten“ und „Fundamentalisten“ angelegt und appelliert an ein hegemoniales Männlichkeitsideal, dessen zentrale Aufgabe die Verteidigung der eigenen und fremden Frauen, der Kinder und inferiorisierten Männer ist. Der Rekurs auf die Zivilbevölkerung Afghanistans und ihrer Viktimisierung nimmt diesbezüglich nur eine Vermittlungsfunktion zwischen verschiedenen Modellen von Männlichkeit ein und regelt die Legitimationsstrategien von Gewalt und Macht.

Wir werden unsere Art zu leben nicht ändern. Und erst recht nicht, wenn uns ein paar mittelalterliche Fundamentalisten, die ihre Frauen verschleiern und zu Hause einsperren und die auf ihren Videorecordern zu viele Schwarzenegger-Filme gesehen haben, dazu zwingen wollen. [Meinungskommentar Spiegel-Redakteur] (Spiegel 2001/38d; Rückständigkeitsmetaphern)

Denn Pakistan hat - wie die Amerikaner selbst - die Steinzeit-Islamisten gefördert, als es galt, die Sowjetmacht wieder aus Afghanistan zu verjagen. (Spiegel 2001/39b; Rückständigkeitsmetaphern)

Ohne Ausbildung und ohne Kenntnis traditioneller Beschäftigungen wie Ackerbau, Viehzucht oder Handwerkskunst waren sie, was Karl Marx Lumpenproletariat nannte. (Spiegel 2001/41b; Rückständigkeitsmetaphern)

In Wahrheit entspricht die Macho-Geste der Hightech-Militärmacht den Schwierigkeiten, in die sie bei ihrem Kampf gegen die afghanischen Steinzeitkrieger gerät. (Spiegel 2001/42a; Rückständigkeitsmetaphern)

Nach den dramatischen Ereignissen vom 11. September, nach den Einblicken in die archaische Brutalität der Taliban-Diktatur, nach den wiederholten Selbstmordattentaten junger Palästinenser in Israel kann es sich der Westen immer weniger leisten, bloß mit staunender Ratlosigkeit auf dieses makabre Gottesgnadentum des Orients zu blicken. (Spiegel 2001/52; Rückständigkeitsmetaphern) 
Der Spiegel rekurriert auf ein kulturell gefestigtes und tradiertes Bild des Islam im abendländischen kulturellen Gedächtnis und perpetuiert eine Tradition, die sich in klassischen Darstellungen des Orients wiederfindet. Zum einen muss dem Orient geholfen werden, da er sich nicht alleine zivilisieren kann, insofern Gewalt und kulturelle Eigenheit bei ihm gewissermaßen natürlich zusammengehören. Zum anderen sind Motive der Gewalt und des Exotismus deutlich geschlechtsspezifisch konnotiert und damit auch wichtig für den untersuchten Zielbereich der Feinde. Da vor allem an die Verantwortung eines bestimmten Männlichkeitstypus westlichen Zuschnitts appelliert wird, scheint dessen Gewaltausübung als entwicklungstechnische Übung legitimiert zu sein und wird so gegenüber anderen Gewaltformen als ,zivilisiert(er) ${ }^{`}$ konstruiert. Die Frage nach einer Gewalteskalation durch die Intervenierenden wird damit unterbunden. Hier tauchen uralte Kolonialreflexe wieder auf und werden reproduziert: Die europäische imperialistisch-kolonialistische ,Philanthropie“ soll dann bei der zivilisatorischen Mission helfen. Deshalb wird die Andersartigkeit des Fremden, orientalistisch ummantelt, im Gegensatz zum Eigenen erschaffen. „Antimuslimische Diskurse knüpfen gegenwärtig sowohl kontrastierend als auch bestätigend an antisemitische Diskurse an und schöpfen aus dem tradierten Gegenbild des kulturell Anderen“ (Attia 2009: 89).

\section{ERgebnisse der Bildanalyse}

An dieser Stelle werden nun exemplarisch einige Ergebnisse der Bildanalyse vorgestellt, die primär als Ergänzung und Weiterführung der Textanalyse betrachtet werden sollten. Die Relevanz des Spiegel-Titelbildes für die Vermittlung von visuellen Informationen über den Einsatz in Afghanistan kann aus dessen genereller öffentlicher Bedeutung hergeleitet werden. Das Titelbild mit der dazugehörigen Schlagzeile ist für den Verkaufserfolg des Magazins Spiegel maßgeblich und weist aus diesem Grund eine dramaturgische Verdichtung und Gestaltung auf. Es zielt insgesamt auf eine „Emotionalisierung“ (Maier/Balz 2010: 84) des Betrachters, um die Neugierde einer potentiellen Leserschaft anzusprechen und auf gesellschaftlich relevante Themen zu orientieren. Die sehr ausgeprägte Agenda-Setting-Funktion des Spiegel-Titelbilds lässt sich auf die fast mit ikonenhaften Qualitäten versehene, stets gleiche Aufmachung zurückführen. Die Kontinuität und Verlässlichkeit vermittelnde Kraft des gleichbleibenden roten Hintergrunds (,Spiegel-Rot“) in Kombination mit den typischen weißen „DER SPIEGEL"-Lettern hat nicht nur hohen Wiedererkennungswert mit Signalwirkung, sondern ist auch der ideale Kontrapunkt zu einer wöchentlichen Dynamik 
wechselnder Themenschwerpunkte. Diese sich periodisch wiederholende visuelle Systematik bildet einen wichtigen Ankerpunkt für das kollektive visuelle Gedächtnis und die öffentlichen Diskurse in der Bundesrepublik. Das SpiegelTitelbild kann als journalistische und gesellschaftliche Instanz angesehen werden, insofern es gegenwärtig und auch in der retrospektiven, visuellen Geschichtsschreibung einen kaum zu unterschätzenden Einfluss hat. ${ }^{17}$ Die Analyse konzentriert sich auf zwei Spiegel-Titelbilder, eines aus dem Jahr 2002, das andere aus dem Jahr 2010.
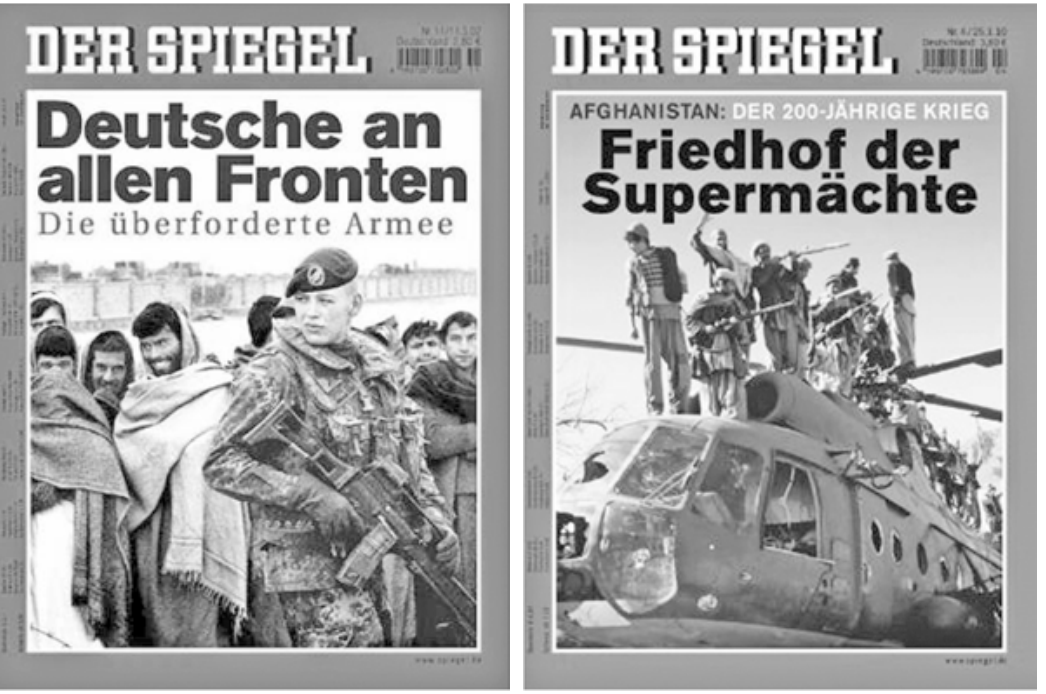

17 Die Spiegel-Titelbilder sind wichtige visuelle Impulsgeber für die Identitätsbildung der deutschen Gesellschaft und zwar in doppelter Hinsicht. Synchron, insofern in der Gegenwart die Spiegel-Titelbilder relevante Autorität in den gegenwärtigen Debatten besitzen und diachron, weil die visuelle Geschichte sehr oft in Bezug auf SpiegelTitelbilder erzählt wird oder erzählt werden kann. Der fast 800 Seiten dicke Bildband des sich vor allem mit visuellen Quellen auseinandersetzenden Historikers Gerhard Paul mit dem Titel „Das Jahrhundert der Bilder (Paul 2008). 1949 bis heute“ widmet sich vor allem dem Bildkanon der deutschen Geschichte und thematisiert wichtige Augenblicke und Zäsuren unter dem Aspekt des visuellen kulturellen Gedächtnisses der Bundesrepublik. Nur beim stichprobenartigen Durchblättern fällt der überproportionale Abdruck verschiedener Spiegel-Titelbilder in unterschiedlichsten Themenbereichen auf. 
Die sehr reduzierte Auswahl der Titelbilder ist durch das Untersuchungsmaterial selbst begründet. Der Spiegel verzichtete auf seinen Titelbildern während des gesamten Untersuchungszeitraumes (2001-2011) weitgehend auf visuelle Repräsentationen von afghanischen Zivilisten. Feindbilder intervenierter Afghanen wurden mit Beginn der Intervention im Jahr 2001 hingegen häufiger verwendet. Diese sind durch ihre reduktionistische oder übertriebene Machart aber leichter dechiffrierbar und für ihre Eingängigkeit und Verständlichkeit auf einige wenige visuelle Topoi und Darstellungsformen begrenzt; so am prominentesten der Turban tragende, langbärtige und grimmig schauende Talebankämpfer mit russischer Luftabwehrrakete. Aus Platzgründen wird an dieser Stelle auf die Einbeziehung solcher Bilder verzichtet. Ebenso wird auf die Erörterung von Titelbildern verzichtet, die die Vorstellung vom Afghanistan-Einsatz durch die Verwendung postmoderner Kriegsikonographie überformen, obwohl gerade solche visuellen Repräsentationsformen den Diskurs seit dem ersten Irakkrieg durchaus dominieren und nachhaltig prägen, wie die Forschungsergebnisse des Historikers Gerhard Paul aufgezeigt haben (vgl. Paul 2004). Nur so viel sei an dieser Stelle diesbezüglich gesagt: nahezu alle visuellen Darstellungsformen, die implizit oder explizit die Glorifizierung militärtechnischer Gerätschaften, vom Nachtsichtgerät bis zum startenden Kampfjet, betreiben, bauen mehr oder weniger auf die Exklusion menschlichen Leids und haben eine derealisierende Wirkung auf den Rezipienten solcher Bilder, der den Krieg zunehmend als lichtgeflutetes Spektakel wahrzunehmen beginnt und die menschlichen Opfer auf ziviler und militärischer (!) Seite ausblendet.

\section{Spiegel Titelbild 2002/11}

Das am Anfang zu erörternde Spiegel-Titelbild 2002/11 zeigt die überhaupt einzige zwischenmenschliche Interaktion zwischen Intervenierten und Intervenierenden während des gesamten Untersuchungszeitraumes von 2001-2011. Die Titelzeile lautet „Deutsche an allen Fronten. Die überforderte Armee“ und gibt entschieden die Interpretationsrichtung vor. Durch das Titelbild wird verallgemeinernd die prekäre Lage der Intervenierenden bei Auslandseinsätzen thematisiert, ohne auf einen konkreten militärischen oder außenpolitischen Anlass bezogen zu sein. Im Fokus des Bildsujets stehen nicht die Intervenierten. Sie geben leicht sichtbar lediglich die Randbedingung für die Selbstreflexion der Intervenierenden ab. Sehr deutlich wird diese Instrumentalisierung anhand des SpiegelTitelbildes 2002/11. Im Zentrum der Bildkomposition steht ein junger, blonder und durch seine weichen Gesichtszüge fast feminin wirkender, Soldat der Intervenierenden. Dessen kontrollierte Körperhaltung kann mit den Attributen auf- 
recht, neutral und defensiv beschrieben werden; dabei sind sein Kopf und der Oberkörper um die eigene Körperachse verdreht. Deutlich wahrnehmbar ist die Laufrichtung des Körpers, der Soldat würde im animierenden Blick des Bildbetrachters nach rechts aus dem Bild herauslaufen, während er nach links zurückschauend blickt. Diese Akzentuierung drückt körpersprachlich eine potentiell kalkulierte Zielsetzung, Souveränität sowie Selbstbeherrschung aus und symbolisiert männliche Haltung, die jedoch in ihrer Gesamtheit diffus und irritiert erscheint. Der Eindruck bedingter, eingeschränkter soldatischer Souveränität und Contenance verstärkt sich durch die Kopfhaltung und den nach rückwärts gewandten Blick. Zudem ist der Kopf des Soldaten leicht nach unten gesenkt, sein konzentrierter Blick horizontal auf eine Sache, einen Gegenstand oder ein Ereignis hinter ihm und außerhalb des Bildbereichs fixiert.

Unsere These ist, dass der dargestellte Soldatentypus nicht den Habitus eines nach Transzendenz strebenden heroischen Kriegers verkörpert, der sich im Schlachtfeld zu verwirklichen trachtet, sondern die Pragmatik eines helfenden und beschützenden Parlamentssoldaten symbolisieren soll, der in der Funktion eines Peacekeepers und im weiteren Sinne als verantwortungsvoller Familienmensch konnotiert wird. ${ }^{18}$ Der Soldat wird in einer für ihn unsicheren und unübersichtlichen Lage dargestellt, wirkt dadurch jedoch nicht gleich hilflos oder gar passiv, da sein Gewehr und seine Gebärden Wehrhaftigkeit andeuten.

Im Rücken des Soldaten und im Mittelgrund des Bildaufbaus befinden sich einige stehende, junge, zivile, afghanische Männer, die mehr oder weniger direkt in die Kamera des Fotografen schauen und mit ihren Blicken vor allem mit dem Betrachter und nicht mit dem Soldaten interagieren. Auffällig ist, dass Intervenierte und Intervenierende der Bildsprache und dem Bildaufbau gemäß nicht direkt miteinander kommunizieren Der Bildbereich wurde so ausgewählt, dass der

18 Soldatenbilder eignen sich gut, um die Selbst- und Fremdwahrnehmung von Gesellschaften zu erörtern. Die entsprechenden Körperbilder verweisen auf die imaginativen Prozesse und Traumorte als Körperutopie, die eine Gesellschaft für sich entwirft. Nationalsozialistische Soldatenbilder sind so zum Beispiel von einer Gesichtsikonographie geprägt, die deutlich pathetisch wirkt, weil der Blick schicksalsergeben inszeniert ist und die Gesichtszüge hart und metallisch gezeichnet sind. Ein dermaßen mit ambivalenten Emotionen beladenes Gesicht im Konnex mit der ebenso ambivalenten Körperhaltung, wie des Soldaten im Spiegel-Titelbild 2002/11 wäre schlicht zu dieser Zeit nicht anerkennungswürdig gewesen, weil es Labilität ausdrückt. Zur Veränderung von Soldatenbildern in der frühen Bundesrepublik (vgl. Loch 2006: 265282). Soldatenbilder der NS-Zeit werden ausführlich analysiert durch Paula Diehl (Diehl 2005; Bilder von SS-Soldaten finden sich auf Seite 16, 184, 197, 219). 
Eindruck provoziert wird, es gäbe mehr Afghanen und Afghaninnen als dargestellt und abgebildet werden konnten. Sie dominieren den einzelnen Soldaten rein quantitativ durch ihre Anzahl.

Die Kleidung der Afghanen gibt sie als intervenierte Dorf- und Zivilbevölkerung zu erkennen; darunter lange, schlichte Ganzkörpergewänder mit darüber liegenden großen Tüchern, mit denen der Kopf und in vielen Fällen auch das Gesicht verdeckt wird. Die für westliche Kulturkreise ungewöhnlichen Textilien unterstreichen diffizil die ,Fremdheit der Anderen“. Das partielle Verdecken der Gesichter verstärkt diesen Eindruck. Die sichtbaren Körper- und Gesichtsausdrücke der dargestellten Intervenierten divergieren hingegen, sie lachen schamvoll, schauen interessiert bis neugierig oder verdecken ihr Gesicht spielerisch mit ihren Händen oder Gewändern. Insgesamt wird durch die unterschiedliche Mimik der Intervenierten der Eindruck von Zweideutigkeit evoziert, was für die BildrezipientInnen eine zeitaufwändigere Lektüre bedeutet und sie subtil zwingt die mentale Situation des intervenierenden Soldaten nachzuempfinden, der durch die mimische Heterogenität geradezu ,überfordert“ wird. Betont man diesen Aspekt, so ist die gesamte Darstellung darauf hin konzipiert, den RezipientInnen das Gefühl nahezulegen, nicht in der ,Haut' des Soldaten stecken zu wollen. Aus der Sicht der Bildbetrachter ist der Soldat in eine unangenehme Szenerie der Fremdheit und Andersheit verwickelt, die er nicht ganz zu überblicken vermag.

Unsere These ist, dass Bildaufbau, Darstellungskonvention und die gezeigten Interaktionen der Menschen in Spiegel-Titelbild 2002/11 kulturelle Differenzen nach einem binär-hierarchischen Muster symbolisieren. Inhaltlich wird durch das Titelbild visuell bestätigt und verstärkt, was sprachlich durch die Verwendung pejorativer Metaphoriken bereits an anderen Stellen vielfach signalisiert und vorgegeben wurde. Die kulturelle Hierarchie zwischen Intervenierenden und Intervenierten verdeutlicht der auf den Soldaten fokussierte Bildaufbau - die intervenierte Zivilbevölkerung erscheint visuell als zweitrangig. Der Soldat symbolisiert aus unserer Sicht zudem die einzige Möglichkeit potentieller Handlungsrationalität, während die ihn umgebenden Gestalten entweder entrückt, verspielt, gelangweilt oder gar ominös und intransparent erscheinen. In einem umfassenderen Sinne verhandelt die Bildthematik Männlichkeitsmodelle und setzt diese in strukturelle Beziehungen zueinander. Die Intervenierten nehmen die Position einer untergeordneten Männlichkeit ein, die ,in der Konstruktion hegemonialer Männlichkeit ähnlich wie Weiblichkeit als konstitutives Außen“ (Kreisky/Löffler 2009: 78) fungiert. Der Gesamteindruck von Armut, Rückständigkeit, gradueller Infantilität und Primitivität symbolisiert die Angewiesenheit auf einen überlegenen, maskulinen Rettertypus und unterstreicht die Unfähigkeit zur Selbstbeherrschung. 
Aus diesen Gründen und vorerst unter Ausklammerung der Titelzeile steht das Bildsujet von Spiegel-Titelbild 2002/11 in einer Kontinuität mit einer symbolischen Bildsprache, wie sie seit Kupferstichen von Theodor De Bruy aus dem 16. Jahrhundert im visuellen Gedächtnis Europas kursieren. Viele Stiche aus der Hochphase der ersten Kolonisierungswelle inszenieren strukturell ein ähnliches Motiv und zeigen ihrem Selbstbild entsprechend höher zivilisierte Kolonisatoren vor paradigmatisch, infantilen Wilden', die in ihren Anlagen noch als entwickelbar erscheinen (vgl. Schmidt 2011: 285-287). ${ }^{19}$

\section{Abbildung 2: Kupferstich von Theodor de Bruy}

\section{„Columbus landing on Hispaniola“}

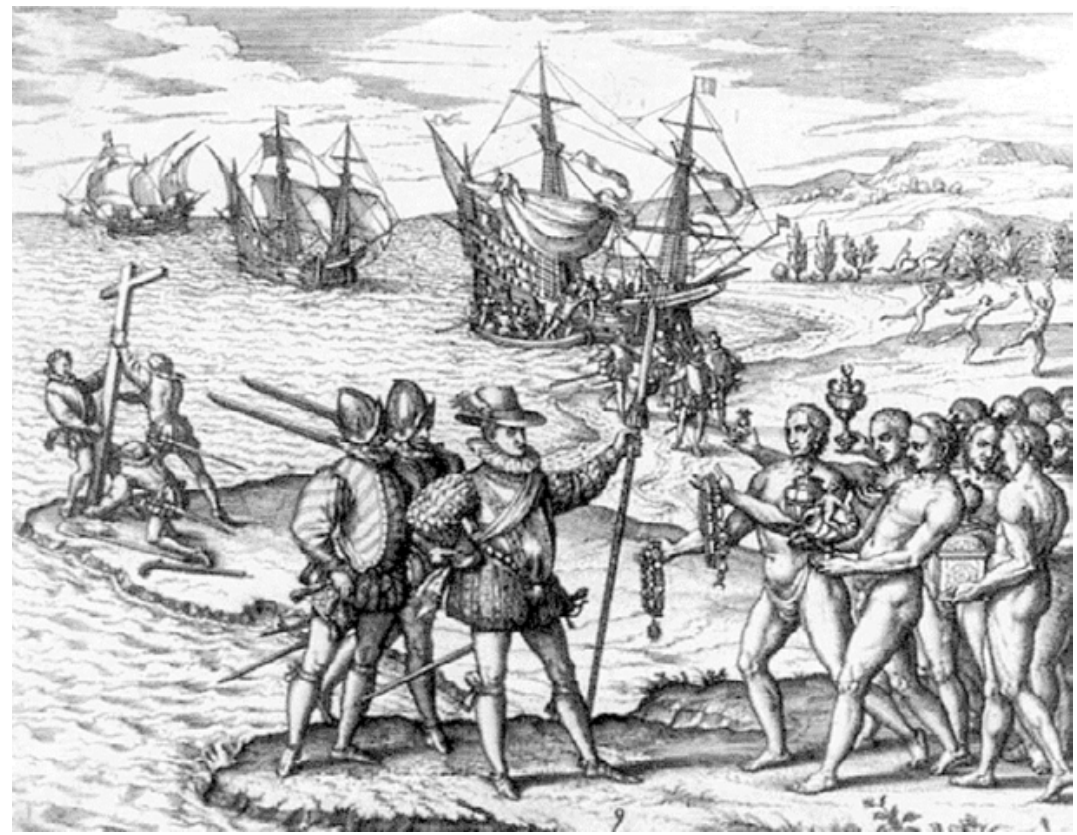

Quelle: http://jbshistoryblog.de/wordpress/wp-content/uploads/706px-Columbus_ landing_on_Hispaniola_adj.jpg (aufgerufen am 07. August 2012).

19 Die Stiche zeigen alle das erste ,Zusammentreffen “ von Kolonisatoren und Indigenen: „Die Rollen sind dabei klar verteilt: Auf der einen Seite die bekleideten, ganz offensichtlich bedächtigen, vernünftigen - also zivilisierten - Niederländer, auf der anderen Seite die nackten und vertrauensseligen - also insgesamt inferioren - Indigenen, die die neuen Akteure auf den Weltmeeren euphorisch und begeistert - mit ,freudenreichem Getös‘, wie es in der Subscriptio heißt - begrüßen“ (Schmidt 2011: 287). 
An ihrer rudimentären bis zur Nacktheit reichenden Kleidung erkennbar werden die indigenen Kolonisierten als inferior den ,zivilisierten“ europäischen Kolonisatoren gegenübergestellt. Die Symbole der europäischen Hochzivilisation dieser Zeit sind deutlich herausgestellt und reichen von der Kleidung und Rüstung, den Waffen, bis zu den Schiffen und dem Aufstellen des christlichen Kreuzes als Emblem für die kommende und im höheren Auftrag erfolgende Missionierung.

In Analogie zum Kupferstich von De Bruy erscheinen die afghanischen Männer in Spiegel-Titelbild 2002/11 tendenziell wie ,freundliche Wilde', die deshalb nicht gleichwertig sind, weil sie als weltfremd, unerfahren und infantil konnotiert werden. Symbolisch stehen die Intervenierten mit den Indigenen auf einer Ebene. Im Gegensatz zu den Kupferstichen De Bruys ist jedoch der formulierte und deutlich ausgedrückte Superioritätsanspruch der Intervenierenden, der durch den Subjekttypus des Soldaten angedeutet wird, seltsam prekär und ignoriert das Potential des Scheiterns der Afghanistan-Intervention und der intervenierenden Gesellschaft im Grunde nicht. Entgegen der verklärenden und beschönigenden Szenerie in den Kupferstichen, die das relativ eindeutige Bild von Demut und Unterwürfigkeit auf der einen, sowie der Überlegenheit und Divinität auf der anderen Seite bekräftigen, argumentiert die Titelzeile von SpiegelTitelbild 2002/11 mit kritischen Untertönen: „Die überforderte Armee“ und unterläuft so mit einer dekonstruktiven Geste die scheinbare Eindeutigkeit des modernen Bildsujets.

Auch in anderer Hinsicht sind Antinomien und Diskrepanzen in SpiegelTitelbild 2002/11 erkennbar, denn die Konzentration auf interagierende Menschenkörper schafft psychische und physische Spannungen und muss durch den Betrachter als hochgradig emotional empfunden werden, da dieser gefühlsmäßig in das Geschehen involviert ist und sich als Teil der intervenierenden Gesellschaft mit dem Soldaten tendenziell eher identifizieren kann. Der Eindruck der Fremdheit des intervenierenden Soldaten im Interventionsgebiet wird zudem durch die Mauer im Bildhintergrund verstärkt und durch die vegetationsarme Umgebung hervorgehoben. Die Mauer als stark assoziatives architektonisches Zeichen symbolisiert Abgeschlossenheit und Isolation des Ortes und betont sowohl Distanz als auch die fundamentale Differenz der aufeinander treffenden Menschen. $^{20}$

Dazu passt auch, dass für die Darstellung Afghanistans das Sujet der kargen Landschaft kanonisch geworden und in vielen untersuchten Spiegel-Titelbildern

20 Mauern sind prinzipiell Sinnbilder für Grenzen, die Bereiche und Territorien gewaltsam ein- und zuteilen, grundsätzlich trennen und die Unzugänglichkeit bestimmter Räume und Erfahrungs- und Existenzweisen verdeutlichen. 
präsent ist. Das Leitmotiv der vegetationslosen Landschaft als imaginärem Raum, dessen symbolische Armut auf Homogenität und Unterentwicklung zugleich verweist, nuanciert nicht nur den unbehaglichen Gesamteindruck der Szenerie in Spiegel-Titelbild 2002/11, sondern kann allgemeiner als integraler Bestandteil (post)kolonialer Herrschaftspraktiken verstanden werden, da ,die Disziplinierung der Raumwahrnehmung und (die) Implementierung einer spezifischen Deutungsmacht und Imaginierung von Raum (...) als zentral für die koloniale Macht- und Herrschaftsformation“ (Varela/Dhawan/Randeria 2010: 177) gelten muss. Visuell erschaffen wird ein imaginär-symbolischer Ort der kulturellen Fremdheit, der durch seine paradigmatische Ödnis und Einfältigkeit als ein Synonym für die Nicht-Kultur der Anderen fungiert und geradezu antithetisch jenen heterogenen imaginativen Ortserfahrungen widerspricht, die wir in unseren verschiedenen urbanen oder medial-virtuellen Räumen der westlichen Welt tagtäglich machen. ${ }^{21}$

Im folgenden, abschließenden Teil der Bildanalyse wird mit dem SpiegelTitelbild 2002/11 assoziativ experimentiert. Unsere These ist, dass SpiegelTitelbild 2002/11 als Referenzpunkt für mögliche negative Körpererfahrungen fungiert. Die Angst vor möglichen physischen Schmerzerfahrungen, die dem Bildsujet potentiell inhärent sind, erscheint implizit mit einer politischen Situationsbeschreibung zusammenzugehören. Deshalb wird der Versuch unternommen, das Spiegel-Titelbild 2002/11 auf prospektive Gehalte und Potentiale hin zu betrachten. Kern dieser Herangehensweise ist die Überzeugung, dass jedes statische Bild dazu anregt Folgebilder zu animieren und Assoziationen anzuregen, die nicht direkt gezeigt werden, aber latent vorhanden sind und mit hoher Wahrscheinlichkeit schon als ikonographische Referenz im kollektiven Bilderhaushalt vorliegen.

Angeregt durch die Lektüre der Zeichnungen „Desastres de la Guerra“ von Francesco de Goya erschien Spiegel-Titelbild 2002/11 als eine subtile chronologische Vorstufe zu dem weitaus eindeutigerem Spiegel-Titelbild 2010/04, das im Folgenden diskutiert wird. Während in letzterem die Gewalt schon geschehen ist und eine Gruppe bewaffneter afghanischer Männer einen halb zerstörten russischen Hubschrauber triumphierend besetzt hält, deutet Spiegel-Titelbild 2002/11 vermittels der psychischen Spannungen zwischen den Akteuren subtil auf einen möglichen Gewaltausbruch hin. Goyas Radierungen, die gleichnishaft eine sich

21 Die Einsicht einer herausgehobenen Bedeutung der Räume, Landschaften und Orte, die wir für die Anderen reservieren, imaginieren und in unseren Vorstellungen hervorbringen, ist fundamental für die Kritik an (post)kolonialen Konstruktionen der visuellen Repräsentation der Anderen (Varela/Dhawan/Randeria 2010: 180). 
zunehmend entgrenzende Gewalt zwischen der französischen Armee und der spanischen Zivilbevölkerung während der Napoleonischen Kriege thematisieren, dienen diesbezüglich als visueller Referenzpunkt, da mit ihnen veranschaulicht werden kann, wie aus Unübersichtlichkeit und Überforderung Gewalt und Chaos entstehen, und das umso wahrscheinlicher im Falle asymmetrischer Konflikte, da die Differenzierung von Kombattanten und Nicht-Kombattanten erschwert ist und die passive oder aktive Unterstützung Aufständischer durch die zivile Bevölkerung militärische Strategien und die Situationskontrolle der intervenierenden Armee(n) vereiteln.

\section{Abbildung 3: Radierungen von Francesco de Goya „Los desastres de la guerra“}
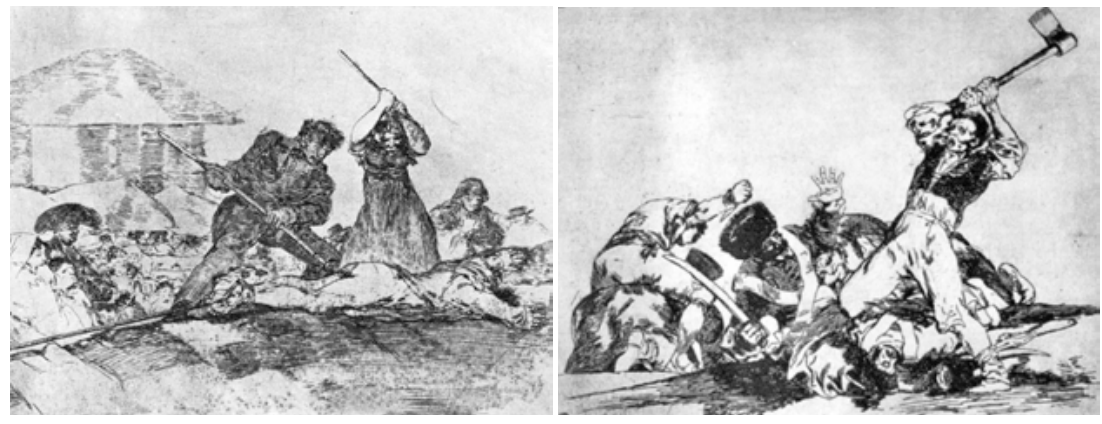

Quelle: http://www.sightswithin.com/Francisco.Goya/Los_desastres_de_la_guerra\%2 C_Plato_28_-_Populacho.jpg (links) und http://www.sightswithin.com/Francisco.Goya/Los_desastres_de_la_guerra\%2C_Plato_3_-_Lo_mismo.jpg (rechts, beide aufgerufen am 07. August 2012)

Goya zeigt in der prägnanten und mit dem Titel „Pöbel“ versehenen Radierung 28 der „Desastres de la Guerra“, wie eine rasend gewordene Menschenmenge über einen Soldaten der Napoleonischen Armee herfällt und den entkleideten und am Boden liegenden Mann schändet und zu Tode prügelt. Andere Bilder aus dem Zyklus Goyas zeigen ähnlich dramatische Motive, bei denen ein ehemals uniformierter Soldat zum Opfer der Gewalt einer entgrenzten und pöbelhaften Menschenmenge wird. Die Drastik solcher Darstellungen von körperlicher Gewalt im Krieg, die nicht zufällig an den misslungenen Somalia-Einsatz der USArmee erinnern, ${ }^{22}$ liegt darin, direkt auf die elementaren Körperempfindungen

22 Die Eskalation des Mogadischu-Einsatzes im Oktober 1993 bedeutete den Abzug der US-amerikanischen Truppen aus dem vom Bürgerkrieg geplagten Somalia. Auslöser für den Rückzug waren primär die Fernsehbilder geschändeter Leichname zweier 
des Betrachters zu zielen und an die Kontingenz und Labilität der eigenen physischen und in aller Konsequenz auch psychischen Unversehrtheit zu rühren. Jede Darstellung von Schmerz fordert den Betrachter mindestens implizit auf, einund mitfühlend zu reagieren, wie die lange visuelle Tradition christlicher Ikonographie beweist (vgl. Schug 2012).

Die RezipientInnen des Spiegel-Titelbilds 2002/11 sind gemäß dieser Argumentation explizit aufgefordert ein tragendes Element der psychosozialen Dynamik zu sein, welche die visuelle Ordnung konstituiert, um Mitleidsempfindungen zu provozieren. Im schlimmsten Fall wird dadurch das denkbar, was Goyas Radierungen so eindrücklich vor Augen führen.

Die emotionale Integration als potentiell Mitleidender lässt für den Betrachter nur wenige Möglichkeiten für den weiteren Verlauf der Szene in SpiegelTitelbild 2002/11 zu. Der einzelne Soldat, umzingelt von Intervenierten, deren Verhalten nur schwer einschätzbar ist, kann sich der Situation entziehen und gesteht sich und den Intervenierenden die Überforderung ein oder er verbleibt in der Situation, die sich, ganz im Sinne einer Eingebung im Stile Kassandras, zum Schlechteren wenden kann. Entweder die dann erwartbaren möglichen Schmerzen tragen nach einem Kampf zur Mann- und Heldwerdung des Soldaten bei und die Überforderung wird in die Eigentlichkeit souveräner Selbstverfügung retransformiert oder der Krieg hinterlässt traumatisierende Spuren am Körper, indem er Verstümmelungen, Verwundungen und Verletzungen in die Physis und Psyche des Soldaten und im übertragenen Sinne in die Krieg führende Interventionsgesellschaft einschreibt. ${ }^{23}$

Delta-Force Soldaten, die durch aufgebrachte Somalis durch die Straßen Mogadischus geschleift wurden. Die Verfilmung der Ereignisse der Schlacht von Mogadischu (2. bis 3. Oktober 1993) wurde von Ridley Scott mit Unterstützung des US-Militärs realisiert und ging unter dem Titel Black Hawk Down in die Filmgeschichte ein. Die Schändung der US-Soldaten wird in dem zugleich patriotisch aufgeladenen, aber auch kritische Untertöne enthaltenden Film nicht gezeigt (vgl. Henning 2006: 255ff.).

23 Die Kriegskrüppelbilder von Otto Dix aus den 1920er Jahren sind berühmt für die Darstellung der irritierenden Rückkehr von beschädigten Soldatenkörpern aus dem Ersten Weltkrieg in die zivile Welt einer auf Vergnügungen fixierten Weimarer Kultur (vgl. Borges 2011: 112f.). Solche verstümmelten Körper symbolisieren den Bruch mit einer sozialen Ordnung, zeigen soziale Diskontinuität an und stellen einen Ort dar, an dem die Realität des Krieges wirklich sichtbar wird (vgl. Diehl 2005: 74f.). Der Expressionist Ernst Ludwig Kirchner hat, um die psychischen Störungen nach seinen Erlebnissen im Ersten Weltkrieg zu verdeutlichen, ein Gemälde konzipiert, in dem er 


\section{Spiegel Titelbild 2010/04}

In Spiegel-Titelbild 2010/04 kulminieren einige der bis hierher angestellten Überlegungen bezüglich des Spiegel-Titelbildes 2002/11 und das sowohl auf der verbalen als auch der visuellen Ebene.

Unter der Titelzeile „Afghanistan: Der 200-jährige Krieg. Friedhof der Supermächte“ ist ein zerstörter russischer Militärhubschrauber zu sehen, der von einer afghanischen Männergruppe besetzt ist, die triumphierend auf dessen Dach stehend Waffen und Arme emporstreckt und mit ihren Gesten Siegesgewissheit symbolisiert. Die Metapher vom „Friedhof der Supermächte“ zeigt nicht nur die Relevanz der Sprache für die Dechiffrierung des Bildsujets an, sondern buchstabiert aus, was in Spiegel-Titelbildes 2002/11 lediglich latent angelegt war.

Der Status der größtenteils bewaffneten Männer bleibt für den Betrachter unklar, kann aber aufgrund des Abbildungskontextes nicht als positiv empfunden werden. Das Fehlen jeglicher Uniformen, die „Gruppenzugehörigkeit“ ausdrücken und „aus ihren Trägern politische Repräsentationseinheiten“ (Diehl 2005: 180) machen, lässt deutlich werden, dass die Bewaffneten vor allem mit irregulären Kombattanten, Guerilla oder Partisanen assoziiert werden sollen. Diesbezüglich sind im visuellen Gedächtnishaushalt eine Unmenge Möglichkeiten für visuelle Anknüpfungspunkte vorhanden. Sie reichen von verschiedenen gewaltsamen Aufständen in der europäischen Geschichte bis hin zu den großen weltgeschichtlichen Zäsuren, wie der Französischen Revolution, der Deutschen Revolution von 1848 oder der Kubanischen Befreiungsbewegung.

\section{Abbildung 4: Bilder von Aufständischen. Revolution in Kuba (links) und} Deutsche Revolution 1848 (rechts)

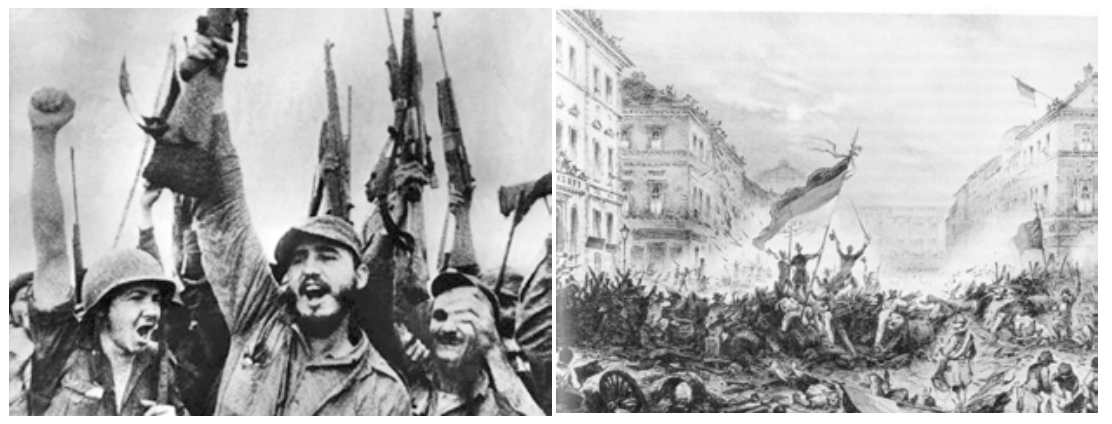

sich in Soldatenuniform mit einer fiktiven Verstümmelung, einer abgeschnittenen Hand, zeigt (vgl. Schug 2012: 163). 
Quelle: http://www.n24.de/media/_fotos/1politik/2008_2/februar/080219_9/bgcastro/2.jpg (links) und http://de.wikipedia.org/w/index.php?title=Datei:Maerz1848_berlin.jpg\&filetimestamp=20051011073610 (rechts, beide aufgerufen am 07. August 2012).

Das Tragen unterschiedlicher Waffen und heterogener ortsgebundener Kleidung, wie sie für die Ikonographie von Partisanendarstellungen üblich ist, verdeutlicht dies (vgl. Skokan 2011: 220). Insgesamt soll der beunruhigende Eindruck von Rebellion, Revolte, Aufstand und unkontrollierbarer Gewalt entstehen. Die wie auf einer Barrikade stehenden Männer symbolisieren die Aufkündigung von bis dato bestehenden politischen Ordnungsprinzipien.

Die Perspektive des Bildes akzentuiert diesen Eindruck. Zum einen ist durch den Blickwinkel die untergeordnete Stellung des Betrachters exponiert, der die auf dem Hubschrauber stehende Masse nur von unten betrachten kann und schlicht durch die Perspektive entmächtigt wird. Zum anderen ist die Szene so fotografiert und beschnitten, dass der Hubschrauber und die auf ihm stehenden bewaffneten Afghanen eine Linie von links oben nach rechts unten bilden. Diese Gegendiagonale wird in der westlichen Kultur negativ konnotiert und versinnbildlicht das Erleiden einer Niederlage.

Der Hubschrauber gibt als vieldeutiges Symbol darüber hinaus Hinweise auf weitere Assoziationspotentiale, die auf ein militärisches Debakel hinweisen. Auf der Oberfläche dient er der Verdeutlichung des historischen Vergleichs der gegenwärtigen Ereignisse mit dem verlustreichen Feldzug des sowjetischen Imperiums in Afghanistan und führt so die Kontinuität einer Geschichtserzählung fort, wie sie spätestens mit den anglo-afghanischen Feldzügen im 19. Jahrhundert begonnen hat. Im Sinne dieses Narrativs waren es immer die technisch und zivilisatorisch überlegen geglaubten Nationen, die sich an ,urtypischen und wilden Völkern“ wie den Afghanen die „Zähne ausbissen“. Dieses Missverhältnis scheint schon in der Karikatur aus der Zeit der anglo-afghanischen Kriege durch das Zertreten einer Melone (Bowler) eines englischen Gentleman durch einen ,wilden Afghanen“" symbolisiert (siehe Bild unten). 
Abbildung 5: Afghane beim Zertreten eines Bowlers, entstanden zur Zeit der anglo-afghanischen Kriege.

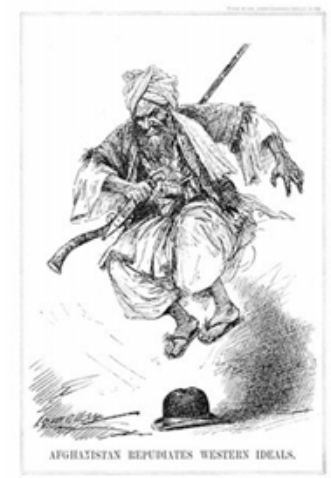

Quelle: http://farm5.static.flickr.com/4141/4861739270_95349f1d1f.jpg (aufgerufen am 07. August 2012)

Auf einer anderen Ebene fungiert der zerstörte Hubschrauber in Spiegel-Titelbild 2010/04 als symbolische Antithese zur Glorifizierung des Luft- und des Hightechkrieges. Die vermeintliche Überlegenheit durch Technik und zivilisatorische Errungenschaften, wie Luftfahrzeuge und modernes Kriegsgerät wird ins Negative gewendet. Das abgeschossene und vom Himmel geholte militärische Vehikel, ehemals Symbol für technische, militärische und kulturelle Superiorität der Supermächte, ist der materielle Beweis für die Bezwingung eines Gegners, der eigentlich als unterlegen vorgestellt wird. Als Trophäe ist der zerstörte Hubschrauber ebenfalls ein symbolisches Surrogat für den Soldatenkörper. Die Zerstörung und Besetzung des militärtechnischen Gegenstands ist damit die Weiterführung dessen, was sich in Spiegel-Titelbild 2002/11 narrativ über die Bedrohung des einzelnen intervenierten Soldaten nur ahnungsvoll andeutete und in den Bildern Goyas schonungslos ausformuliert wurde. Die zersplitterten Scheiben, die ausgefallenen Fenster und die Flugunfähigkeit des Hubschraubers erscheinen wie Paraphrasierungen der Beschädigungen der physischen Integrität eines Menschen- und insbesondere Soldatenkörpers. Die zerstörte und ruinenhafte Militärtechnik verstärkt den Eindruck, Afghanistan als einen in seiner Gesamtheit beschädigten, monströsen und krüppelhaften Ort wahrnehmen zu sollen, der als Projektionsfläche für Dystopien, Degenerationen und Ängste den Idealen körperlicher, als auch sozialer und politischer Einheit widerstrebt. ${ }^{24}$

24 Wenn, wie Jacques Lacans Theorie behauptet, die Ego- und Identitätskonstituierung eines Subjekts primär von visuellen Prozessen und Spiegelbildern, aber auch von Dis- 


\section{Diskussion der Ergebnisse}

Wie in diesem Beitrag mehrfach angesprochen, werden die intervenierten AfghanInnen und die so genannten Feinde entlang essentialisierender Diskurse konstruiert. Für den deutschen Heimatdiskurs bedeutet dies, dass sich die vermeintlich homogene deutsche Mehrheitsgesellschaft durch die Konstruktion eines vermeintlich homogenen ,Anderen“ und ,Fremden“ der eigenen Identität versichern kann. Dieser Prozess erfolgt entlang dichotomer Schemata. Nahezu alle gefundenen metaphorischen Konzepte dienen der Komplexitätsreduktion. Abgrenzungs- und Exklusionsmechanismen, Identitätsbildung und Steigerung des okzidentalen Selbstwertgefühls hängen mit diesem, auf Vereinfachung zugespitzten Bild des Fremden, funktional zusammen.

In der Analyse metaphorischer Konzepte zeigte sich, dass die Intervenierten in orientalisierenden und geschlechterstereotypen Bildern sprachlich erfasst werden. Darüber hinaus konnte ein starker Opferdiskurs evident gemacht werden, der den afghanischen Menschen Passivität, Unterlegenheit und eine geringe $\mathrm{Au}-$ tonomie zuschreibt. Der/die ,Andere‘ muss mit sich verschränkenden Bildern von Armut, Schwäche und Hilfsbedürftigkeit erschaffen werden, damit eine Intervention als sinnvoller Akt begriffen werden kann.

Durch die Art und Weise der Beschreibung der AfghanInnen wird deren $\mathrm{Zu}$ gang zu relevanten politischen Positionen und Rechten und damit zu Macht- und Herrschaftspositionen implizit reguliert. Während dort Menschen in ,Stämmen ‘ leben, ist hier bereits der vollwertige, ,zivilisatorische' Zustand einer liberalen Gesellschaft erreicht. Nur so kann die Intervention westlicher SoldatInnen auch mit einem ,zivilisatorischen“ Anspruch verknüpft werden, sodass „Weiße Männer (...) braune Frauen vor braunen Männern [retten]“ (Spivak [1988] 2008: 78). Der moderne Weiße Held sollte gegen vormoderne Schurken kämpfen. Implizit ist in diesem Diskurs die Regulierung legitimer und de-legitimer Gewaltformen angelegt, wie hier beispielhaft in den Metaphern der „kriminellen Strauchdiebe“ und der „Steinzeitislamisten“ analysiert wurde.

Die intervenierten Feinde werden über andere sprachliche Bilder inferiorisiert. Insbesondere durch Krankheitsbilder, Tiermetaphern und Motive der Un-

kursen, die ebenfalls Imaginationen modifizieren und zurückstrahlen, abhängt, damit das Subjekt sich als unversehrtes Ganzes imaginieren und entwerfen kann, dann sind die soeben besprochenen Spiegel-Titelbilder 2002/11 und 2010/4 negative Projektionsangebote und damit problematische Spiegelbilder, die Ängste vor Verstümmelung, Fragmentierung und Unversehrtheit mobilisieren und mit kognitiven und emotionalen Assoziationen von Körper- und Schmerzvorstellungen argumentieren. 
sichtbarkeit überwog hier eine Degradierung, Entmenschlichung und Entsubjektivierung der Feinde, die in der Kriegsrhetorik eine lange Tradition haben. Gleichzeitig wiesen einige verwendete Bilder aber auch auf die Übermacht und Unkontrollierbarkeit der Feinde hin und somit auf die Unmöglichkeit, diese im Rahmen der Intervention besiegen zu können. Zudem korrespondierten die Befunde über die afghanischen Feinde mit denen der Menschen, in dem Sinne, dass hier ein rückständiges und abwertendes Bild der AfghanInnen entworfen wird, dass kulturalisierende, diskriminierende und rassistische Konnotationen trägt.

In allen gefundenen Metaphern zeigte sich darüber hinaus ein gemeinsames Kernproblem. Metaphern werden verwendet, um komplexe Zusammenhänge in bereits bekannte Kontexte zu übertragen, die Bildhaftigkeit der Aussagen soll bei den Lesenden eine direkte Reaktion oder sogar Emotion hervorrufen. Metaphern sind geeignet, einen hegemonialen Diskurs zu stärken, der das Andere und Fremde durch Rekurs auf relativ stabile und tradierte Bedeutungskonzepte, die im kulturellen Gedächtnis verankert sind, geschickt aktualisiert. Metaphorische Konzepte sind ausgreifend - sie bestimmen Wort und Bild und verdichten sich zu einem mythischen Ganzen und machen es für Gesellschaften schwer, zwischen rationaler Furcht und irrationalen Ängsten zu unterscheiden. Sie zielen direkt auf die Imagination der Lesenden und Zuschauenden und es ist schwer, diesen mit einem besseren Argument zu überzeugen, da dessen „Worte“ quasi synthetisch mit mentalen Bildern, mit inneren und äußeren Vor- und Darstellungen interagieren. Das Problem der Metaphern besteht darin, dass über die Ausblendung von Vielfalt, Komplexität und Widersprüchen ein sehr diskriminierendes Stereotypenregime über die Intervenierten in Afghanistan entsteht. Eine Begegnung auf Augenhöhe innerhalb der Interventionsgesellschaft wird damit (fast) unmöglich.

Mit Rekurs auf die Metaphernanalyse konnte die Bildanalyse zeigen, „dass nationale Identität und Zugehörigkeit in Kriegszeiten medial betont und an eine verbindliche Definition des ,Eigenen“ gebunden werden, die sich von dem konstruierten ,Fremden“ abhebt und so politisch-militärisches Handeln legitimiert (...)“ (Löffelholz 2004: 35). Die elementaren Muster, die der visuellen Repräsentation der Intervenierten und der medialen Darstellung des Krieges selbst zugrunde liegen, veränderten sich im Untersuchungszeitraum kaum. Gleichzeitig wurde der interventionistische Krieg an sich durch konventionelle Darstellungsmethoden und standardisierte visuelle Grundmuster weitestgehend normalisiert und entdramatisiert. ${ }^{25}$

25 „Was Kriege sind, warum sie geführt werden, welche Folgen sie für die Menschen haben, erschließt sich nicht aus Bildern. Diese sind bestenfalls Momentaufnahmen, in 
Die prinzipielle Marginalisierung der Intervenierten innerhalb des deutschen Heimatdiskurses ließ sich sowohl auf der quantitativen als auch der qualitativen Ebene der Visualität besonders ausgeprägt feststellen. Es gab im gesamten Untersuchungszeitraum keine angemessene Menge an Bildmaterial, das die Intervenierten in einer würdigen Art und Weise dargestellt hätte. Dies ist auf die interessengeleitete Selektivität unserer Wahrnehmung zurückzuführen, die sich in den Medien spiegelt, moduliert und fortsetzt und damit den deutschen Heimatdiskurs prägt. Im Hinblick auf die visuelle Repräsentation ziviler Intervenierter kann im Anschluss an Judith Butler behauptet werden, dass eine „Derealisierung des ,Anderen“" stattfindet, der ,weder lebendig noch tot“ ist (Butler 2005: 51). Die Intervenierten erscheinen im Sinne Butlers als „verworfene Subjekte“ (Bublitz 2010: 99), indem sie entweder überhaupt nicht visuell repräsentiert werden oder nur als minoritäre Subjekte oder anormale Existenzweisen erscheinen.

Unter Berücksichtigung der Prämisse, dass Bilder und visuelle Darstellungsformen in der Nachrichtenvermittlung von Mediendemokratien besonders wichtig und wirksam sind, erscheint die fehlende Aufmerksamkeit gegenüber den zivilen Intervenierten als Ausdruck vorenthaltener Anerkennung und damit im Sinne Pierre Bourdieus als symbolische Gewalt (vgl. Fowler 2008: 75-99). Diese Gewaltform erzieht zur Unempfindlichkeit und Indifferenz von Normverletzungen durch gewöhnende Wiederholung spezifischer Narrative und rassistischer, ethnozentrischer, islamophober und insgesamt enthumanisierender Mythen. Die Anderen werden so zu nicht gleichwertigen und nicht anerkennungswürdigen Menschen gemacht, indem sie auf eine bestimmte Weise konstruiert werden oder Subjektpositionen zugewiesen bekommen, die sie entwürdigen, exkludieren oder deklassierend integrieren.

Auf der Ebene des Visuellen bedeutet das, wenn argumentiert wird, dass der Afghanistan-Einsatz zugunsten der unterdrückten und minorisierten Subjekte innerhalb der intervenierten Gesellschaft durchgeführt wird, dass diesen selbst keinerlei Forum zur Artikulation und Repräsentation und damit kein relevanter Zugang zum Diskurs zur Verfügung steht. Der logische Anspruch jedoch wäre auf der Ebene der Bilder viel eher: „Eine Repräsentationspolitik, die nicht riskieren will, die Bedingungen, die sie angreift, indirekt zu reproduzieren, erfordert

der Regel jedoch interessengebundene Projektionen und Inszenierungen. Erst die analytische oder künstlerische Dekonstruktion der Bilder und die gewiss anstrengende Reflexion im Medium der Sprache führt an das Wesen des Krieges heran“ (Paul 2004: 484). 
Darstellungsstrategien, die ihre politischen Forderungen als strukturelles Repräsentationselement enthalten“ (Schaffer 2008: 97).

Deshalb sind zwei Strategien der symbolischen Gewalt ausschlaggebend im visuellen Diskurs der Intervenierten: Zum einen die Art und Weise der Hypervisibilisierung, die mit einer „Methode des Fremdmachens“ (Geis 2007: 181) besonders korreliert und zum anderen die Ausblendung beziehungsweise Auslöschung intervenierter Positionen. Im Anschluss an die Theorie der Subalternität von Gayatri C. Spivak kann diesbezüglich gesagt werden: „Den Subalternen die ästhetische Repräsentation zu versagen, ist eine historische Begleiterscheinung zu der buchstäblichen Versagung einer ökonomischen, rechtlichen und politischen Repräsentation“ (Schaffer 2008: 90).

\section{LITERATUR}

Arndt, Susan. 2011. „Stamm“. In Wie Rassismus aus Wörtern spricht. (K)Erben des Kolonialismus im Wissensarchiv deutsche Sprache. Ein kritisches Nachschlagewerk, hrsg. v. Arndt, Susan und Ofuatey-Alazard, Nadja, S. 668-670. Münster: Unrast-Verlag.

Arndt, Susan und Ofuatey-Alazard, Nadja, Hrsg. 2011. Wie Rassismus aus Wörtern spricht. (K)Erben des Kolonialismus im Wissensarchiv deutsche Sprache. Ein kritisches Nachschlagewerk. Münster: Unrast-Verlag.

Attia, Iman. 2009. Die „westliche Kultur“ und ihr Anderes: Zur Dekonstruktion von Orientalismus und antimuslimischem Rassismus. Bielefeld: TranscriptVerlag.

Attia, Iman, Hrsg. 2007. Orient- und IslamBilder - Interdisziplinäre Beiträge zu

Orientalismus und antimuslimischem Rassismus. Münster: Unrast-Verlag.

Bergmann, Anna. 2010. „Gewalt und Männlichkeit: Wahrnehmungsmuster des ,Fremden' und des ,Eigenen' in der deutschen Berichterstattung über den Afghanistankrieg." In Medien-Krieg-Geschlecht. Affirmationen und Irritationen sozialer Ordnungen, hrsg v. Thiele, Martina et al., S. 153-172. Wiesbaden: VS Verlag.

Borges, Ingo. 2011. „Die wahrhaftige Reportage des Krieges - Otto Dix.“ In Kriegszeit. Kollwitz, Beckmann, Dix, Grosz, hrsg. v. Staatsgalerie Stuttgart, S. 111-126. Tübingen/Berlin: Wasmuth Verlag.

Brockhaus-Online. 2011. http://www.brockhaus-enzyklopaedie.de/ (lizenzierter Zugriff der Freien Universität Berlin; alle aufgerufen im März 2012). 
Bruchhausen, Walter. 2009. „Gesundheit/Krankheit.“ In Handbuch Anthropologie. Der Mensch zwischen Natur, Kultur und Technik, hrsg. v. Bohlken, Elke und Thies, Christian, S. 336-340. Stuttgart: Metzler-Verlag.

Bublitz, Hannelore. 2010. Judith Butler zur Einführung. Junius: Hamburg.

Butler, Judith. 2005. „Gewalt, Trauer, Politik.“ In Gefährdetes Leben: Politische Essays, hrsg. v. Butler, Judith, S- 36-68. Frankfurt: Suhrkamp.

Castro Varela, Maria do Mar; Dhawan, Nikita und Randeria, Shalini. 2010. „Postkolonialer Raum: Grenzdenken und Third Space.“ In Raum. Ein interdisziplinäres Handbuch, hrsg. v. Günzel, Stephan, S. 177-191. Stuttgart: Metzler.

Daxner, Michael. 2010. „Das Konzept der Interventionskultur als Bestandteil einer gesellschaftsorientierten theoretischen Praxis“ In Interventionskultur. Zur Soziologie von Interventionsgesellschaften hrsg v. Bonacker, Thorsten et al., S. 75-100. Wiesbaden: VS Verlag.

Derrida, Jacques. 2009. Positionen: Gespräche mit Henri Ronse, Julia Kristeva, Jean-Louis Houdebine, Guy Scarpetta. Wien: Passagen-Verlag.

Diehl, Paula. 2005. Macht - Mythos - Utopie. Die Körperbilder der SS-Männer. Berlin: Akademie Verlag.

Dietze, Gabriele; Brunner, Claudia und Wenzel, Edith. Hrsg. 2009. Kritik des Okzidentalismus: Transdisziplinäre Beiträge zu (Neo-)Orientalismus und Geschlecht. Bielefeld: Transcript-Verlag.

Ellwanger, Karen. 2002. „Kleiderwechsel in der Politik? - Zur vestimären Inszenierung der Geschlechter im Raum des Politischen." In Kleider machen Politik. Zur Repräsentation von Nationalstaat und Politik durch Kleidung in Europa vom 18. bis zum 20. Jahrhundert, hrsg v. Landesmuseum Oldenburg, S. 108-124. Oldenburg: Isensee.

Foucault, Michel. 1969. Wahnsinn und Gesellschaft. Eine Geschichte des Wahns im Zeitalter der Vernunft. Frankfurt a.M: Suhrkamp.

Fowler, Bridget. 2008. „Pierre Bourdieu und Norbert Elias über symbolische und physische Gewalt: Ein Vergleich.“ In Symbolische Gewalt. Herrschaftsanalyse nach Pierre Bourdieu, hrsg v. : Schmidt, Robert und Woltersdorff, Volker, S. 75-99. Konstanz: UVK.

Geis, Anna. 2007. „Andere, Fremde, Feinde: Bedrohungskonstruktionen in der Demokratie.“ In Bedrohungen der Demokratie, hrsg. v. Brodocz, André et al., S. 170-188. Wiesbaden: VS Verlag.

Grittmann, Elke und Ammann, Ilona. 2008. „Ikonen der Kriegs- und Krisenfotografie.“ In Global, lokal, digital - Fotojournalismus heute, hrsg v. Grittmann, Elke und Ammann, Ilona, S- 296-325. Köln: Herbert von HalemVerlag. 
Henning, Carsten. 2006. „Banal Militarism und die Kultur des Krieges im zeitgenössischen US-amerikanischen Kino.“ In Banal Militarism. Zur Veralltäglichung des Militärischen im Zivilen, hrsg v. Thomas, Tanja und Virchow, Fabian, S. 249-264. Müchen: Transcript.

Kirchhoff, Susanne. 2010. Krieg mit Metaphern. Mediendiskurse über 9/11 und den „,War on Terror“. Bielefeld: Transcript.

Klaus, Elisabeth und Kassel, Susanne. 2008. „Frauenrechte als Kriegslegitimation in den Medien." In Medien - Politik - Geschlecht. Feministische Befunde zur politischen Kommunikationsforschung, hrsg. v. Dorer, Johanna at al., S. 266-280. Wiesbaden: VS Verlag.

Kreile, Renate. 2002. „Dame, Bube, König... - Das neue grosse Spiel um Afghanistan und der Gender-Faktor.“ In Leviathan Nr. 30, S. 34-64.

Kreisky, Eva und Löffler, Marion. 2009. „Maskulinismus und Staat: Beharrung und Veränderung." In Staat und Geschlecht. Grundlagen und aktuelle Herausforderungen feministischer Staatstheorie, hrsg. v. Ludwig, Gundula et al., S. 75-88. Baden-Baden: Nomos: Baden-Baden.

Kruse, Jan; Biesel, Kay und Schmieder, Christian. 2011. Metaphernanalyse. Ein rekonstruktiver Ansatz. Wiesbaden: VS Verlag.

Kuske, Silvia. 1994. „Von Tausendundeiner Nacht zu Tausendundeiner Angst: der Islam in den Medien." In Feindbilder in der deutschen Geschichte, hrsg. v. Jahr, Christoph et al., S. 251-279. Berlin: Metropol-Verlag.

Lakoff, George und Johnson, Mark. 2003. Leben in Metaphern. Konstruktion und Gebrauch von Sprachbildern. Heidelberg: Carl-Auer-Systeme Verlag.

Loch, Thorsten. 2006.: „Soldatenbilder im Wandel. Die Nachwuchswerbung der Bundeswehr in Werbeanzeigen." In Visual History. Ein Studienbuch, hrsg. v. Paul, Gerhard, S. 265-282. Göttingen: Vandenhoeck \& Ruprecht.

Löffelholz, Martin. 2004. „Krisen- und Kriegskommunikation als Forschungsfeld. Trends, Themen, Theorien eines hoch relevanten, aber gering systematisierten Teilgebietes der Kommunikationswissenschaft.“ In Krieg als Medienereignis II. Krisenkommunikation im 21. Jahrhundert, hrsg. v. Löffelholz, Martin, S. 13-55. Wiesbaden: VS-Verlag.

Maier, Tanja und Balz, Hanno. 2010. „Orientierungen. Bilder des ,Fremden“ in medialen Darstellungen von ,Krieg und Terror'“" In Medien - Krieg Geschlecht. Affirmationen und Irritationen sozialer Ordnungen, hrsg. v. Thiele, Martina et al., S. 81-101. Wiesbaden: VS Verlag.

Pagenstecher, Cord. 2008. ,'Das Boot ist voll': Schreckensvision des vereinten Deutschland.“ In Das Jahrhundert der Bilder. 1949 bis heute, hrsg. v. Paul, Gerhard, S. 606-613. Göttingen: Vandenhoeck \& Ruprecht. 
Paul, Gerhard. 2004. Bilder vom Krieg - Krieg der Bilder: Die Visualisierung des modernen Krieges. Paderborn u.a: Schöningh-Verlag.

Paul, Gerhard. 2008. Das Jahrhundert der Bilder. 1949 bis heute. Göttingen: Vandenhoeck \& Ruprecht.

Popal, Mariam. 2011. ,'zivilisiert und wild'““ In Wie Rassismus aus Wörtern spricht. (K)Erben des Kolonialismus im Wissensarchiv deutsche Sprache. Ein kritisches Nachschlagewerk, hrsg. v. Arndt, Susan et al., S. 678. Münster: Unrast-Verlag.

Schaffer, Johanna. 2008. Ambivalenzen der Sichtbarkeit. Über die visuellen Strukturen der Anerkennung. Bielefeld: Transcript-Verlag.

Schmidt, Dorothee. 2011. „Das Fremde im Bild: Ordnung und Unordnung im kolonialen Diskurs um 1600.“ In Bild - Macht - UnOrdnung. Visuelle Repräsentationen zwischen Stabilität und Konflikt, hrsg. v. Blank, Anna-Maria et al., S. 285-313. Frankfurt: Campus.

Schug, Wolfgang. 2012. Grundmuster visueller Kultur. Bildanalysen zur Ikonographie des Schmerzes. Wiesbaden: VS Verlag.

Skokan, Isabel. 2011. „Partisan.“ In Handbuch der politischen Ikonographie. Band 2: Imperator bis Zwerg, hrsg. v. Fleckner, Uwe et al., S. 219-226. München: Beck.

Spivak, Gayatri Chakravorty. 2008. Can the Subaltern Speak? Postkolonialität und subalterne Artikulation. Wien: Turia und Kant.

Steuter, Erin und Wills, Deborah. 2009. "Discourses of Dehumanization: Enemy Construction and Canadian Media Complicity in the Framing of the War on Terror." In Global Media Journal, Canadian Edition 2/2002(2), S. 7-24.

\section{SPIEGEL-PrIMÄRQUELLENVERZEICHNIS}

$\underline{2001 / 38}$

2001/38b: Follath, Erich/Latsch, Gunther (2001): Der Prinz und die TerrorGmbH. In Der Spiegel, Heft 38/2001; 15.09.2001.

2001/38d: Hüetlin, Thomas (2001): Es ist die Atombombe! In Der Spiegel, Heft 38/2001; 15.09.2001.

2001/38f: Broder, Henryk M. (2001): Nur nicht provozieren! In Der Spiegel, Heft 38/2001; 15.09.2001. 
$\underline{2001 / 39}$

2001/39b: Hoyng, Hans/Ilsemann, Siegesmund von/Koch, Dirk/Mettke, Jörg

R./Spörl, Gerhard (2001): USA - Zehn Jahre Krieg?. In Der Spiegel, Heft 39/2001; 24.09.2001.

2001/39d: Hoelzgen, Joachim (2001): Festung ohne Ausgang. In Der Spiegel,

Heft 39/2001; 24.09.2001.

2001/39e: Ihlau, Olaf/Neef, Christian (2001): Die Scharaden der Gotteskrieger.

In Der Spiegel, Heft 39/2001; 24.09.2001.

$\underline{2001 / 40}$

2001/40a: Hoyng, Hans/Ilsemann, Siegesmund von/Koch, Dirk/Mettke, Jörg.

R./Neef, Christian/Spörl, Gerhard (2001): Krieg im Schatten. In Der Spiegel, Heft 40/2001; 01.10.2001.

2001/40b: Hoelzgen, Joachim (2001): Fünfte Kolonne. In Der Spiegel, Heft 40/2001; 01.10.2001.

\section{$2001 / 41$}

2001/41b: Rashid, Ahmed (2001): Gottes eigene Krieger. In Der Spiegel, Heft 41/2001; 08. 10. 2001.

\section{$\underline{2001 / 42}$}

2001/42a: Großbongardt, Annette/Hoppe, Ralf/Hoyng, Hans/Ilsemann, Siegesmund von/Malzahn, Claus Christian/Smoltczyk, Alexander/Spörl, Gerhard (2001): Krieg im Dunkeln. In Der Spiegel, Heft 42/2001; 15. 10. 2001.

2001/42f: Emcke, Carolin (2001): Flüchtlinge. Zu viel Leid für eine Seele. In

Der Spiegel, Heft 42/2001; 15. 10. 2001.

2001/42g: Hoppe, Ralf/Smoltczyk, Alexander (2001): Pakistan. Dschihad im

kleinen Grenzverkehr. In Der Spiegel, Heft 42/2001; 15. 10. 2001.

\section{$2001 / 45$}

2001/45a: Ihlau, Olaf/Ilsemann, Siegesmund von/Klussmann, Uwe/Neef, Christian/Mayr, Walter/Spörl, Gerhard (2001): Afghanistan-Krieg. Eine Region in Brand. In Der Spiegel, Heft 45/2001; 05. 11. 2001.

2001/45c: Klussmann, Uwe (2001): Milchbart mit Panzerfaust In Der Spiegel, Heft 45/2001; 05. 11. 2001.

2001/45d: Spörl, Gerhard (2001): Geheimdienste. Rückkehr der Pensionäre. In Der Spiegel, Heft 45/2001; 05. 11. 2001.

2001/45e: Mayr, Walter (2001): Pakistan. Kleine Könige am Khyber-Pass. In

Der Spiegel, Heft 45/2001; 05. 11. 2001. 
$\underline{2001 / 47}$

2001/47a: Falksohn, Rüdiger/Ihlau, Olaf/llsemann, Siegesmund von/Spörl,

Gerhard (2001): Der trügerische Sieg. In Der Spiegel, Heft 47/2001; 19. 11. 2001.

2001/47b: Klußmann, Uwe (2001):Echte Söhne Afghanistans. In Der Spiegel, Heft 47/2001; 19. 11. 2001.

$\underline{2001 / 48}$

2001/48: Klußmann, Uwe (2001): Wir zerschmettern den Feind. In Der Spiegel, Heft 48/2001; 26. 11. 2001 (keine Titelgeschichte, aber Fortsetzung des Tagebuchberichts aus 2001/47b).

$\underline{2001 / 52}$

2001/52: Mohr, Reinhard/Saltzwedel, Johannes/Schmitter, Elke/Schreiber, Mathias (2001): Die unverschleierte Würde des Westens In Der Spiegel, Heft $52 / 2001 ; 22.12 .2001$

$\underline{2006 / 47}$

2006/47a: Hammerstein, Konstantin von/Hoyng, Hans/Schlamp, HansJürgen/Szandar, Alexander (2006):Das Afghanistan-Abenteuer. In Der Spiegel, Heft 47/2006; 20. 11. 2006.

2006/47b: Koelbl, Susanne (2006): Sterben für Kabul. In Der Spiegel, Heft 47/2006; 20. 11. 2006.

$\underline{2007 / 38}$

2007/38a: Follath, Erich/Stark, Holger (2007): Wo der Terror wohnt. In Der Spiegel, Heft 38/2007; 17. 09. 2007.

$2009 / 49$

2009/49: Darnstädt, Thomas/Goetz, John/Koelbl, Susanne/Meyer, Cordula/ Schult, Christoph (2009): Welt-Streit ums Töten. In Der Spiegel, Heft 49/2009; 30. 11. 2009.

$\underline{2011 / 19}$

2011/19a: Darnstädt, Thomas/Höges, Clemens/Hoyng, Hans/Hujer, Marc/Mayr, Walter/Meyer, Cordula/Puhl, Jan/Rohr, Mathieu von/Rosenbach, Marcel/Sandberg, Britta/Schmitz, Gregor Peter (2011): Ende eines Massenmörders. In Der Spiegel, Heft 19/2011; 07. 05. 2011. 


\title{
Von friedlichen Aufbauhelfern und professionellen Kämpfern
}

\section{Die Darstellung der deutschen SoldatInnen im Heimatdiskurs}

\author{
Laura Mae Herzog, Christian Kobsda, Hannah Neumann und
}

ANNA OEHLAF

„Wenn ihr Grab kein Kriegsgrab, kein Denk- oder Ehrenmal ist, ist es dann das eines Ziviltoten? Wenn die Frage nach dem Sinn des tödlichen Risikos von jedem Bürger in Uniform je und je persönlich erarbeitet werden muss, muss er seine Antwort dann je nach politischer Mehrheitsdoktrin neu formulieren? Wenn es in Demokratien keine kollektiv anerkannt und bereit liegenden Sinn- und Deutungsmuster gibt oder geben soll - gestorben für Volk und Vaterland - kann ein Einzelner den Sinn eines Einsatzes dann überhaupt gegen die öffentliche Sprachlosigkeit individuell behaupten?“" (Y, November 2008 b, Schweiß Blut Tränen, siehe auch Daxner in diesem Band: 43)

Am 22. Dezember 2001 erteilte der Deutsche Bundestag das Mandat zur Entsendung deutscher Truppen nach Afghanistan. Im Rahmen der International Security Assistance Force (ISAF), die nach der ersten Petersberger-Konferenz vom Sicherheitsrat der Vereinten Nationen genehmigt wurde, beteiligte sich die Bundesrepublik daran, ,die vorläufigen Staatsorgane Afghanistans bei der Aufrechterhaltung der Sicherheit in Kabul und seiner Umgebung so zu unterstützen, dass sowohl die vorläufige afghanische Regierung als auch Personal der Vereinten Nationen in einem sicheren Umfeld arbeiten können." (Deutscher Bundestag 2001: 3). Seit der Ankunft der ersten deutschen SoldatInnen in Kabul im Januar 2002 sind inzwischen mehr als zehn Jahre vergangen. Der Einsatz wird mit wechselnder Intensität medial begleitet. Dabei wird nicht nur über die kriegsrelevanten Ereignisse berichtet. Mit der Berichterstattung werden bestimmte Interpretationsschemata (Frames) vermittelt, es kommt zu Etablierung spezifischer 
Bilder, unter anderem über den Einsatz, über Afghanistan und auch über die im Einsatz befindlichen Soldaten. Letztere bilden den Gegenstand unserer Untersuchung.

Das bis 2002 sorgsam gehegte Bild eines „Staatsbürgers in Uniform“ wird mit dem Einsatz neu verhandelt und durch ein ambivalentes Bild auf die Probe gestellt, das zugleich mit Hinblick auf die Gegebenheiten vor Ort und die Diskussionen in der Heimat verhandelt wird. Die Bundeswehr, und mit ihr die SoldatInnen, befinden sich in einem Out-of-area-Einsatz währenddessen das Verhalten der SoldatInnen im öffentlichen Fokus steht. Wenn es nicht prekäre Einzelereignisse sind (wie die Totenkopf-Affäre), dann bringen erst die Heimkehrerberichte und Reportagen dieses Verhalten an die Öffentlichkeit, und es dauert wiederum einige Zeit, bis das Verhalten der SoldatInnen im Einsatz auch kritisch hinterfragt anstatt akzeptiert oder abgelehnt wird. Der Gesichtspunkt der Ungleichzeitigkeit ist von hoher Bedeutung für die Entwicklung des Diskurses.

Seit 2009 findet in Deutschland eine interne Umstrukturierung der Truppe statt. Die Wehrpflicht wird ausgesetzt und die Bundeswehr soll zu einer professionellen Interventionsarmee werden. Das Bild des Staatsbürgers in Uniform wird somit zweifach auf die Probe gestellt: durch Kampfeinsätze, bei denen es auch zu zivilen Opfern unter den Intervenierten und zu eigenen Gefallenen kommt, und durch den Wandel der entsendenden Organisation Bundeswehr von einer Freiwilligen- zu einer Berufsarmee. Die alten Bilder helfender Soldaten, die Kinder schützen und Brunnen bauen, stimmen mit der Realität nur noch bedingt überein. Sie müssen diskursiv neu verhandelt werden. Das hat zunächst ganz unmittelbar Auswirkungen auf das (Selbst-)Bild und (Selbst-)Verständnis der SoldatInnen und ihrer Arbeit, es hat in einem zweiten Schritt aber auch Auswirkungen auf unser Selbstbild als Deutsche, deren Repräsentanten in Afghanistan genau diese SoldatInnen sind. Nicht nur Oberst Klein, sondern „Deutschland" hat seine Unschuld nach Kunduz verloren (siehe Daxner in diesem Band).

Das vorliegende Kapitel arbeitet die Darstellung deutscher SoldatInnen im Rahmen des Heimatdiskurses seit Beginn des Afghanistaneinsatzes auf. Es steht damit in einer neueren Forschungstradition, die sich mit dem Selbst- und Berufsbild von SoldatInnen und ihrer Wahrnehmung in der deutschen Öffentlichkeit auseinandersetzt (siehe bspw. Axer-Dämmer 2011; Fischer 2009; Heinecke 2011; Bergmann 2010; Chiari 2012; Seiffert 2012), setzt aber ganz bewusst seinen Fokus auf zwei teilweise unterschiedliche Diskursstränge: den bundeswehreigenen und den massenmedialen. Im Fokus dieses Beitrages steht das Soldatenbild in seinem Wandel innerhalb der öffentlichen Diskussion und innerhalb der Bundeswehr internen Diskussion, also bei den SoldatInnen selbst. Die Diskursstränge werden innerhalb je eines Printmediums nachgezeichnet und 
vergleichend analysiert. Der Untersuchungskorpus besteht aus Artikeln der Süddeutschen Zeitung (SZ), ${ }^{1}$ der zweitgrößten deutschen Zeitung, deren hohe Auflagezahlen einen prägenden Einfluss auf große Teile der Öffentlichkeit vermuten lässt, und Artikeln des bundeswehreigenen Monatsmagazins Y. Der Untersuchungszeitraum erstreckt sich von Januar 2002, dem Zeitpunkt der Entsendung der Soldaten nach Afghanistan, bis einschließlich 2010.

Auf der Basis des Datenmaterials lässt sich klar zeigen, dass die Ambivalenz zwischen dem Staatsbürger in Uniform und dem professionellen Krieger sowohl in der Eigendarstellung der Y, als auch im massenmedialen Diskurs der SZ bisher nicht aufgelöst wurde. Mit der Begriffswandlung von Friedenseinsatz zu Krieg (siehe Robotham/Röder in diesem Band) ging eine zunehmende Verlagerung des Framings vom friedlichen Aufbauhelfer zum Kämpfer einher. Letztere wurde jedoch meist als Opfer der äußeren Umstände dargestellt, die ihn zum Kämpfer machten. Der professionellen Interventionsarmee fehlt das personifizierte Gegenstück des Kämpfers. Der Heimatdiskurs scheut sich einen solchen Repräsentanten „Deutschlands“ zu denken oder gar zu diskutieren. Der Soldat im Einsatz in Afghanistan ist und bleibt fürsorglich und effektiv arbeitend, belastbar und zuverlässig und wird nur dann zum Kämpfer, wenn er sich und seine Mission verteidigen muss. Die Einsätze von Eliteeinheiten, die der Tradition des männlichen, kalten und teilweise brutalen Kämpfers stehen, werden weitestgehend ausgeblendet. Diese Ergebnisse erklären, warum zwar der Afghanistaneinsatz in der Bevölkerung abgelehnt wird, die Bundeswehr, und mehr noch die SoldatInnen, nach wie vor hohe Anerkennung genießen. ${ }^{2}$

1 Die Entscheidung gegen eine Untersuchung der auflagenstärksten Zeitung - der Bild fiel aus forschungspragmatischen Gründen: Bild stellt kein digitales Archiv zur Verfügung, das eine systematische Recherche ermöglichen würde und Artikel innerhalb der Bild sind oft inhaltlich stark verkürzt, so dass eine Framinganalyse schwer möglich ist. Themen, die in der Bild starke Relevanz heben werden von den Qualitätsmedien in ausführlicherer Form aufgegriffen, so dass es unwahrscheinlich ist, dass zentrale Frames in der Bildzeitung nicht in anderen Medien zu finden sind.

2 Das sozialwissenschaftliche Institut der Bundeswehr veröffentlicht jährlich die Ergebnisse einer Bevölkerungsbefragung zum „Sicherheits- und verteidigungspolitischen Meinungsklima in der Bundesrepublik Deutschland“. Die Forschungsberichte bestätigen Jahr für Jahr diese Tatsache. Siehe bspw. http://www.sowi.bundeswehr.de/resource/resource/MzEzNTM4MmUzMzMyMmUzMTM1MzMyZTM2MzIzMDMwM zAzMDMwMzAzMDY3NzA2MTczNjgzNjM2NjEyMDIwMjAyMDIw/Bev\%C3\%B 6lkerungsumfrage\%202010-farbig\%20Forschungsbericht\%2094_\%202011-06-22.pdf und http://www.sowi.bundeswehr.de/resource/resource/MzEzNTM4MmUzMzMy- 


\section{Theorie Und Methode}

Die Theorie des Heimatdiskurses, wie sie in den einleitenden Kapiteln dieses Bandes eingeführt wurde, gibt weder ein konkretes Diskursverständnis, noch eine Methode der Diskursanalyse vor. Im Rahmen einer konkreten Untersuchung gilt es also, beide Aspekte zu konkretisieren und für die Leser zu erläutern. Der Heimatdiskurs ist zunächst definiert als „Ensemble aller diskursiven Praktiken von Gesellschaften, deren Mitglieder (Soldaten und Zivilisten) in Interventionsgesellschaften tätig sind“ (Daxner 2010: 97 ohne Herv.), als ,,jene diskursiven Strategien, die das Kriegsgeschehen auf die eigene Gesellschaft rückbinden“ (Daxner 2010: 5) bzw. als ,die Summe aller diskursiven Praktiken und Strategien, die sich mit der Legitimation, Anerkennung und Bewertung von Politik und Truppeneinsatz außerhalb des nationalen Territoriums befassen“ (Daxner 2011: 4 ohne Herv.). Wir greifen auf die Konzeptualisierung von „Diskurs“ im Sinne Siegfried Jägers zurück, um das abstrakte Konstrukt des Heimatdiskurses zu konkretisieren und für eine empirische Analyse fruchtbar zu machen.

\section{Diskurs}

Jäger (2009) hat mit Bezug auf Foucaults Diskursbegriff eine Methodologie und Methode der Diskursanalyse entwickelt, die u. a. auf die Analyse medialer Diskurse zugeschnitten ist und sich damit als diskurstheoretisches Fundament der vorliegenden Medienanalyse anbietet. Er definiert den „Diskurs“ als „Fluss von ,Wissen“ durch die Zeit“ (Jäger 2009: 129) und beschreibt den Gesamtdiskurs „als ein großes wucherndes diskursives Gewimmel“ (Jäger 2009: 117). Der Diskurs entfaltet seine Wirkung durch die ständige Wiederholung von „Inhalten, Symbolen und Strategien“ (Jäger 2009: 170), die sich mit der Zeit zu „Wissen“ formieren und verfestigen. Solches „Wissen“ hat keinen absoluten Charakter, sondern bezeichnet, ganz im Sinne Foucaults, die „Erkenntnisverfahren und -wirkungen, die in einem bestimmten Moment und in einem bestimmten Gebiet akzeptabel sind“ (Foucault 1992: 32). Diskurse führen also ein Eigenleben, sie sind zwar „Resultate all der vielen Bemühungen der Menschen, in einer Gesellschaft tätig zu sein“ (Jäger 2009: 148), aber nicht Effekt intendierter Handlungen. Auch stellen sie nicht schlicht eine (geistige) Spiegelung von Wirklichkeit dar, sondern sind selbst Materialitäten (Jäger 2009: 116).

MmUzMTM1MzMyZTM2MzEzMDMwMzAzMDMwMzAzMDY3NjgzNzY5MzM 3NDMxMzUyMDIwMjAyMDIw/FB\%2090_ohne\%20Abb_TabVerz.pdf (beide aufgerufen am 07. August 2012). 


\section{Diskursanalyse und Framing}

Das Diskursverständnis von Jäger wird im Rahmen dieser Untersuchung methodisch durch ein Framing-analytisches Verfahren umgesetzt. Auch in FramingAnsätzen werden - ganz allgemein - Deutungen bzw. Rahmungen von Wirklichkeit und die Vermittlung von ,Wissen “ untersucht. So geht es z. B. um die Interpretation von SoldatInnen als FriedenshüterInnen oder als MörderInnen (Matthes 200: 15f.). Mit Hilfe solcher Rahmungen werden ganz im Sinne Jägers und Foucaults Realitäten und Bewertungen geschaffen, die in einem bestimmten Moment und Gebiet akzeptabel sind. Trotz dieses prinzipiell korrespondierenden Erkenntnisinteresses sowie ähnlicher Forschungsdesigns wurden Framingtheoretische bzw. -analytische und diskurstheoretische bzw. -analytische Ansätze bisher weitgehend separat voneinander durchgeführt ohne aufeinander zu verweisen. ${ }^{3}$ So taucht beispielsweise zwar der Begriff ,Diskurs ' häufig im Kontext von Framing-Analysen auf, es wird aber kein Bezug zu diskurstheoretischen Überlegungen hergestellt. In der diskursanalytischen Literatur auf der anderen Seite findet ,Framing' so gut wie nie überhaupt Erwähnung. ${ }^{4}$ Wenngleich es folglich nicht das Ziel dieser Arbeit ist oder sein kann, einen eigenständigen theoretischen Beitrag zu diesem Forschungsbereich beizusteuern, so muss doch angesichts der Fülle von Ansätzen eine Klarstellung des Zugangs erfolgen, der im Folgenden als methodologische Basis des Verfahrens der Analyse dienen soll.

\section{Frame: Definition}

Frames nehmen Rahmungen von Inhalten vor. Der Forschungsansatz, der diese Rahmen untersucht, entstammt dem Anglophonen. Daher haben sich die Begriffe des Frames, der Framinganalyse und des framens durchgesetzt. Das dem Beitrag zugrundeliegende Framingverständnis orientiert sich an Robert Entmans Konzept (Entman 2003) sowie dessen Weiterentwicklung durch Matthes (Matthes 2007), Matthes/Kohring (Matthes und Kohring 2004) und Sielschott

3 Dies mag auch daran liegen, dass die beiden Ansätze aus unterschiedlichen Disziplinen stammen: Framing-Ansätze werden in erster Linie in den Medien- und Kommunikationswissenschaften rezipiert; Diskurstheorie ist überwiegend in politikwissenschaftlichen und linguistischen Traditionen verwurzelt. Neben ,Diskurs“ und ,Frame' gibt es in den Sozialwissenschaften darüber hinaus noch weitere Begriffe, die separat voneinander in unterschiedlichen Disziplinen für die Erforschung ähnlicher Phänomene geprägt wurden: So spricht die Wissenssoziologie beispielsweise von ,Deutungsmustern“, ,Phänomenstrukturen“ oder ,narrativen Strukturen` (Keller 2008).

4 Kerchner stellt mit ihrem Forschungsüberblick über Diskursanalyse in der Politikwissenschaft eine Ausnahme dar (Kerchner 2006: 52f.). 
(Sielschott 2010). Als einen Frame verstehen wir ein spezifisches Muster von Frame-Elementen, welches sich in einem Text oder über mehrere Texte hinweg zeigt. Angelehnt an Entman identifizieren wir vier Frame-Elemente: Problemdefinition, Ursachenzuschreibung, Lösungsvorschlag und Bewertung (Entman 1993). Als Problemdefinition begreifen wir die Konstatierung eines Problems. Dies bedeutet zunächst, dass es sich um die (nicht unbedingt problematisierte) Darstellung eines Sachverhalts handelt. Auch die Beschreibung eines Sachverhaltes als „kein Problem“ wird demnach kodiert. Soldaten müssen dabei nicht zwangsläufig in der Problemdefinition auftauchen - die Problemdefinition muss jedoch im Zusammenhang stehen mit einem der anderen Frame-Elemente, in dem konkret von Soldaten die Rede ist. In der Ursachenzuschreibung werden im Material genannte Gründe und Ursachen sowie zugeschriebene Verantwortlichkeiten für das jeweilige Problem kodiert. Dabei kann es sich sowohl um verantwortliche Personen als auch um Situationen handeln. Entsprechendes trifft auch auf den Lösungsvorschlag zu, der sowohl durchzuführende als auch zu unterlassende Maßnahmen zur Behebung des jeweiligen Problems erfassen kann. Die Bewertung schließlich kann sich auf jedes der anderen drei Frame-Elemente beziehen und evaluativer oder moralischer Art sein. In Bezug auf unsere Fragestellung heißt das, zu untersuchen, wie in einem Gefüge von bewerteten Problemen, Ursachen und Lösungen bestimmte Rahmungen der Bundeswehrsoldaten, ihrer Aufgaben, Handlungen und Erlebnisse vorgenommen und plausibilisiert werden.

\section{Untersuchungsmaterial}

Der Untersuchungskorpus besteht aus Artikeln mit Bezug zum Afghanistaneinsatz $^{5}$ aus der Süddeutschen Zeitung sowie dem bundeswehreigenen Monatsmagazin Y. In beiden Zeitungen wurde lediglich der reine Text in der Auswertung berücksichtigt. Da unser Interesse der Langzeitentwicklung des Diskurses während des Afghanistaneinsatzes galt, erstreckt sich der Untersuchungszeitraum von Januar 2002 bis einschließlich 2010. Die Gesamtanzahl der Artikel wurde aus forschungspraktischen Gründen durch die Bildung „,künstlicher Wochen“ reduziert. Ab dem Einsatzbeginn wurden alle 12 Wochen die im Laufe einer

5 Die SZ-Artikel wurden mithilfe des Online-Archivs der Süddeutschen Zeitung akquiriert, wobei lediglich Artikel der Print-Deutschlandausgabe berücksichtigt wurden. Die Auswahl der Artikel mit Afghanistanbezug erfolgte anhand der Suchworte ,(Afghan* oder Kabul oder Hindukusch) und (Soldat* oder Bundeswehr*)“. Abgesehen von Leserbriefen wurden alle Ressorts und Artikeltypen berücksichtigt. Da für die Y kein digitales Archiv vorliegt, wurden die Artikel manuell auf ihre Relevanz geprüft und ausgewählt. 
Stichwoche erschienen Artikel berücksichtigt; hinsichtlich der Y wurde die Ausgabe des jeweiligen Monats, in den die Stichwoche fiel, berücksichtigt. Wenn in einer der Stichwochen (SZ) bzw. -monate (Y) keine Artikel mit Bezug zum Afghanistan-Einsatz in einem Medium erschienen, wurde für das spezifische Medium der Betrachtungszeitraum einmalig um eine Woche nach vorn bzw. - für den Fall, dass auch dann keine relevanten Artikel publiziert wurden - nach hinten verschoben. Durch den gewählten Auswahlmechanismus ergaben sich vierzig Stichwochen bzw. -monate und ein Materialkorpus von 390 Artikeln, davon 220 aus der Süddeutschen Zeitung und 170 aus der Y.

\section{Analyse}

Das Material wurde in drei Analyseschritten bearbeitet. Zunächst wurden induktiv Frames aus dem Analysematerial abgeleitet. In den ersten drei Arbeitswochen kodierten wir die ersten acht Stichwochen induktiv. Die Artikel wurden von fünf Personen in einem Rotationsverfahren codiert, um eine möglichst große Intersubjektivität und Intercode-Reliabilität gewährleisten zu können (Flick 1999). Es entstanden ca. 70 überwiegend inhaltsanalytische Kategorien, die sich sowohl hinsichtlich ihrer Abstraktionsebene als auch hinsichtlich ihres inhaltlichen Fokus deutlich unterschieden. Diese wurden gemäß unserer Framingdefinition gruppiert. Zusätzlich kreierten wir provisorisch einige Counterframes, also Frames, die möglicherweise einen inhaltlichen Gegenpart zu beobachteten Frames darstellen könnten und deren Auftreten wir annahmen bzw. prüfen wollten (Entman 2003: 418). So schufen wir beispielsweise einen hypothetischen TäterFrame, da wir schon ein häufiges Framing von Soldaten als Opfer beobachtet hatten und uns interessierte, inwieweit auch gegenläufige Narrative vorhanden seien. Während dieser Arbeit stellte sich heraus, dass ein Frame aus Unterframes bestehen kann. Das bedeutet, dass innerhalb eines Frames unterschiedliche Problemdefinitionen mit dazugehörigen Lösungsvorschlägen, Ursachenzuschreibungen und Bewertungen identifiziert werden können (vgl. Sielschott 2010). Diese neue Struktur aus Frames, Unterframes und Frame-Elementen übertrugen wir in ein Programm zu qualitativen Datenanalyse (WeftQDA) in gleicher Weise für die Y und die SZ, um Vergleichbarkeit zu gewährleisten. Dabei legten wir inhaltlich nur die übergeordneten Frames, Unterframes und die jeweiligen Problemdefinitionen fest. Ursachenzuschreibungen, Lösungsvorschläge und Bewertungen blieben inhaltlich offen und waren anhand ihres Bezugs zu dem Frame und der jeweiligen Problemdefinition zu bestimmen.

Die zweite Arbeitsphase bestand aus dem Kodieren der restlichen Artikel. Die Struktur von inhaltlich bestimmten Frames und Unterframes mit ihrer $\mathrm{Zu}$ sammensetzung aus den vier Frame-Elementen, wie sie im Laufe der ersten Ar- 
beitsphase entwickelt wurde, diente als Leitfaden für die weitere Analyse. Um angesichts der Arbeit in einer Gruppe eine möglichst große Intersubjektivität und Intercoder-Reliabilität zu gewährleisten, wurde das Kodieren der restlichen Artikel von einem Kodierbuch bzw. -leitfaden begleitet. In diesem fand sich erstens eine Kodier-Anleitung; des Weiteren wurden hier die inhaltliche Füllung sowie die Kreation neuer (Unter-)Frames dokumentiert und erläutert. Die angelegten (Unter-)Frames und Frame-Elemente wurden um weitere Textstellen ergänzt und es wurden einige wenige Unterframes neu hinzugefügt. In diesem Arbeitsabschnitt vermischten sich folglich induktive und deduktive Momente. Unser Arbeiten wurde durch die Struktur also systematischer und übersichtlicher; dennoch ließ uns das relativ offene, da induktive, Verfahren die Möglichkeit, im Nachhinein durch qualitative Analyse und Auswertung Veränderungen innerhalb der Frames festzustellen.

Nachdem alle Artikel des Untersuchungskorpus kodiert waren, wurde deutlich, dass einige der (hypothetischen) Frames nicht ausreichend mit Textstellen gesättigt waren, um - gemäß unserer Konzeptualisierung - Frames darzustellen. In unserem dritten Analyseschritt konzentrierten wir uns dementsprechend auf jene vier (hypothetischen) Frames, die uns aussagekräftig und fruchtbar erschienen. Diese werden im folgenden Kapitel ausführlich erläutert. Um auch die Artikel der ersten Stichwochen auf die erst im Laufe der zweiten Arbeitsphase neu kreierten (Unter-)Frames zu überprüfen, wurden sämtliche Artikel erneut auf diese Frames überprüft und ggf. nachkodiert. Anschließend erfolgte ihre Auswertung. 


\section{Ergebnisse}

Im Folgenden werden die vier prägnantesten Frames „Täter“, „Opfer“, „,friedlicher Aufbauhelfer“ und „Kämpfer“ und ihre jeweiligen Unterframes in zusammenfassender Darstellung vorgestellt und in Relation zu einander gesetzt.

Abbildung 1: Frames und Unterframes

\begin{tabular}{|c|c|c|c|}
\hline Opfer & Täter & $\begin{array}{l}\text { Friedlicher } \\
\text { Aufbauhelfer }\end{array}$ & Kämpfer \\
\hline Gefährdung & $\begin{array}{l}\text { Rechtswidrige } \\
\text { Handlungen }\end{array}$ & & $\begin{array}{l}\text { Unsicherheit in } \\
\text { Afghanistan }\end{array}$ \\
\hline Verletzt/ gefallen & Tötung / & & Krieg in \\
\hline $\begin{array}{l}\text { Harte Bedingungen } \\
\text { Psychisch versehrt }\end{array}$ & $\begin{array}{l}\text { Verletzung von } \\
\text { Zivilisten }\end{array}$ & & Afghanistan \\
\hline $\begin{array}{l}\text { Mangelnde } \\
\text { gesellschaftliche } \\
\text { Anerkennung }\end{array}$ & & & \\
\hline
\end{tabular}

\subsection{Opfer}

Zum Opfer-Frame zählen wir alle Darstellungen, die die BundeswehrsoldatInnen in Afghanistan als erleidend und den Umständen ausgesetzt beschreiben. Er besteht aus fünf Unterframes, die wir im Laufe der Textanalyse herausarbeiten konnten: Erstens werden die SoldatInnen als gefährdet geframed, zweitens erscheinen sie als Opfer von Tod und Verwundung, drittens leiden sie unter den harten Bedingungen des Einsatzes, viertens geht mit dem Einsatz psychische Versehrtheit einher und fünftens mangelt es ihnen an gesellschaftlicher Anerkennung.

\section{Gefährdung}

Der Unterframe „Gefährdung“ erweist sich sowohl in der Y als auch in der SZ als ausgeprägter Frame. In Bezug auf das Framing der SoldatInnen ist seine Kernbotschaft, dass sie sich permanent in Gefahr befinden und dass dies ein Problem darstellt. Als Ursachen für die Gefährdung werden mit dem afghanischen Umfeld fast ausschließlich den SoldatInnen und der Bundeswehr externe Faktoren angeführt. Gefährdung durch mögliches eigenes Fehlverhalten, man- 
gelnde Vorsicht oder Unprofessionalität - z.B. im Kontext von Unfällen - finden sich nicht. Dem Unterframe ist in der Y und der SZ insgesamt viel gemein. Unterschiede bestehen in der stärkeren Stereotypisierung der afghanischen VerursacherInnen der Gefährdung in der SZ und dem stärker militärischen und kämpferischen Tönung des Frames in der Y, was sich in den Lösungsstrategien und dem im Laufe der Zeit vermehrten Auftauchen von militärischen Vokabeln äußert.

„Die Lage in Afghanistan bleibt angespannt. Kurz hintereinander wurden zwei Bundeswehr-Feldlager im Norden Afghanistans Ende September mit Raketen beschossen. Unbekannte feuerten mehrfach mit Mörsern oder Raketen auf das Camp Marmal in Mazar-eSharif. Die Granaten und Flugkörper schlugen außerhalb des Lagers ein. Zu Schaden kam niemand. Drei Tage später feuerten Unbekannte aus etwa fünf Kilometern Entfernung drei Raketen auf das Feldlager in Kunduz ab. Auch hier gab es keine Verletzten. Die Geschosse schlugen auch in Kunduz nicht direkt in das Feldlager ein. Es waren lediglich drei Explosionen zu hören, bestätigte ein Pressesprecher des deutschen ISAF-Kontingents.“ (Y, November 2008 a, Bundeswehr mehrfach unter Raketenbeschuss)

\section{Opfer von Tod und Verwundung}

Der Unterframe „verletzt/gefallen“ ist in vielen Artikeln vertreten und eng mit dem Unterframe „Gefährdung“ verbunden. In geschehenen Verletzungen und Tötungen schwingt die Gefahr zukünftiger mit; mit der Thematisierung der Gefährdung von Leben und Gesundheit wird auch allgemein Tod und Verwundung von SoldatInnen verhandelt. Soldatisches Sterben wird im Unterframe „verletzt/gefallen" aber nicht nur anhand konkreter Ereignisse, sondern manchmal auch abstrakter geframed, insbesondere indem sein Sinn und seine Bedeutung thematisiert werden. Hier finden sich zwei konkurrierende Deutungen. Wird SoldatIn-Sein als Beruf verhandelt, erscheinen sowohl der (mögliche) Tod als auch „Leistungen“ eher als selbstverständlicher Bestandteil des Berufsbildes und folglich nicht als besonders aufopferungsvoll, anerkennenswert oder ehrenhaft. ${ }^{6}$ Wird das Sterben - eingebettet in größere Sinnzusammenhänge wie ,Nation oder ,Freiheit “ - als „Dienst für eine höhere Sache“ gewertet, dann werden die ,Leistungen " der SoldatInnen damit hervorgehoben sowie die SoldatInnen selbst erhöht: sie werden als selbstlos, ehrbar, tapfer usw. geframed. Der zweite Frame

6 Gleichzeitig bietet es jedoch auch die Möglichkeit, die SoldatInnen als abgeklärt und verantwortungsvoll zu beschreiben. Trotz der Darstellung einer Bereitschaft, ,,das Leben zu riskieren“, wird das Sterben hier nicht als Aufopferung verhandelt. Stattdessen erscheinen die SoldatInnen als nüchtern, vernünftig und aufgeklärt. 
herrscht in der Berichterstattung vor. Der Tod von SoldatInnen wird in diesem Framing nicht als selbstverständlich bewertet; stattdessen scheint ihm etwas so Skandalöses innezuwohnen, dass er sogar den Einsatz infrage stellen kann. Das ist ein Element des typisch deutschen Heimatdiskurses, der eine andere Einstellung zu seinen „Kämpfern“ hat als bspw. der US-amerikanische Diskurs.

„Vor dem Altar der Kirche waren die Fotos und die Särge der drei Soldaten aufgestellt, auf denen die Helme der Getöteten lagen. Sie waren am Karfreitag gestorben, als ihre Einheit nahe Kunduz auf der Suche nach Minen von Dutzenden Taliban-Kämpfern angegriffen wurde. Der mit 35 Jahren gestorbene Hauptfeldwebel Nils Bruns hinterlässt ein kleines Kind, ebenso der 28-jährige Hauptgefreite Martin Kadir Augustyniak. Der dritte Soldat, Stabsgefreiter Robert Hartert, wurde 25 Jahre alt.“ (SZ, 10.4.2010, Deutschland verneigt sich vor Ihnen)

\section{Harte Bedingungen}

Insgesamt lässt sich festhalten, dass ,harte Bedingungen“ quantitativ zwar weniger vertreten sind als „Gefährdung“ und „verletzt/gefallen“, jedoch trotzdem einen präsenten Unterframe darstellen. In der Y ist er deutlicher ausgeprägt als in der SZ; inhaltlich ähneln sich beide aber stark. Als belastende Umstände werden in erster Linie regionalen klimatische und geographische Umstände sowie das Campleben benannt. Eher umgangssprachliche Begriffe und Formulierungen sowie der Verweis auf Aspekte wie Temperatur und Unterkunft - allägliche Dinge, die alle Lesenden kennen - erzeugen Mitgefühl für die SoldatInnen in ihrer herausfordernden Lage.

„Wenn die Soldaten nachts bei bitterem Frost ihre Drei-Stunden-Wachen schieben, halten sie den Finger stets am Abzug. Zu groß ist die Gefahr eines Heckenschützen-Angriffs. Auch die hygienischen Verhältnisse lassen zu wünschen übrig. Bisher müssen sich die Soldaten mit Latrinen-Gräben und ohne fließendes Wasser arrangieren.“ (SZ, 3.1.2002, Stationiert im Minenfeld)

Die Lösungsdimension umfasst überwiegend Umgangsweisen der SoldatInnen mit den „harten Bedingungen“. Bewertet - und zwar anerkennend - werden in erster Linie die SoldatInnen, ihr Verhalten und ihre ,Leistungen“ unter den ,harten Bedingungen“. Vor allem die Y framed die SoldatInnen so als widerstandsfähig, genügsam, erfindungsreich, professionell und sozial bzw. interkulturell kompetent. Tugenden wie Kameradschaft (Y) und Disziplin (SZ und Y) seien in dieser Einsatzsituation sowohl nötig als auch vorhanden. So widrig die Umstän- 
de auch sein mögen, die SoldatInnen sind ihnen größtenteils gewachsen und werden dafür anerkannt.

\section{Psychische Versehrtheit}

Der Unterframe ,psychisch versehrt“ beschreibt die BundeswehrsoldatInnen als unter psychischen Krankheiten oder quälenden Gefühlen leidend. Dabei nehmen bei der Y psychische Krankheitsbilder mehr Raum ein als in der SZ, in welcher v.a. negative Gefühle aufgeführt werden. In beiden Medien ist der Unterframe im Vergleich zu „Gefährdung“ und ,verletzt/gefallen“ insgesamt weniger vertreten, prägt sich im Laufe des Untersuchungszeitraums jedoch immer stärker aus. Als Ursache der psychischen Versehrtheit werden in erster Linie befürchtete oder schon gemachte Erfahrungen mit Tod und Verletzung geframed. Wiederholt und in beiden Medien führen auch ungenügende Unterstützung durch die Bundeswehr im Falle psychischer Versehrtheit sowie der Campalltag zu psychischen Belastungen. Während Gefährdung, Tod, Verwundung und harte Bedingungen im Einsatz in den vorherigen Frames eher prinzipiell problematisiert wurden, besteht der Opferstatus der SoldatInnen hier v.a. in ihrem emotionalen bzw. psychischen Leiden. Dadurch treten die SoldatInnen stärker als Menschen und Individuen in Erscheinung als dies bspw. im Kämpfer-Frame der Fall ist.

„Sein Wohnzimmer hat Christopher Plodowski in freundlichen Farben gehalten, helles Parkett, warmes Gelb an den Wänden, mittendrin ein weißes Sofa. Doch in seiner Seele herrscht Finsternis. Immer wieder kriechen die Bilder von jenem 7. Juni 2003 hervor. Dann sieht der 41 Jahre alte Bundeswehroffizier um zehn Jahre älter aus. Die Tränen laufen, das Herz rast und Major Plodowski ist mit den Gedanken und Gefühlen wieder in Kabul.“ (SZ, 9.7.2007, Der lange Kampf von Major Plodowski gegen die eigene Armee)

Ihr psychisches Leiden wird in beiden Medien überwiegend und in der SZ ausschließlich in reportageartigen oder porträtierenden Artikeln behandelt, so dass hautnah miterlebbar ist, was den SoldatInnen passiert. Dementsprechend sind die Artikel von einem empathischen Ton geprägt; sie appellieren an das Mitgefühl der Lesenden. Die psychische Versehrtheit wird ausnahmslos als angebracht und verständlich geframed, fraglos werden die SoldatInnen nicht für ihre psychische Versehrtheit verantwortlich gemacht. Während reportageartige Artikel eher ein diffuses Bild leidender Menschen zeichnen, erscheinen die SoldatInnen in der Y als psychologisch erklärbare Subjekte.

„Aktuelle Erkenntnisse zeigen laut Schmidt: Tätigkeiten, bei denen es die Arbeitsrolle erfordert, Emotionen zu zeigen, die der Mensch nicht fühlt und Tätigkeiten, bei denen 
Emotionen unterdrückt werden müssen, können ebenfalls zu einem ,Ausgebrannt-Sein führen. ,Ein Offizier beispielsweise musste ständig seine Emotionen kontrollieren, um stets gelassen zu wirken', erinnert sich der Professor an seine eigene Bundeswehrzeit.“ (Y, Mai 2006, Ausgebrannt).

Es entsteht eine argumentative Wendung; nicht das Erleben von Tod und Verletzung sind vordergründig problematisch, sondern nur der „falsche“ Umgang damit, der demnach zu psychischen Erkrankungen führen kann. Auf diese implizite Weise erhalten der Einsatz und der in Afghanistan erlebte Alltag der SoldatInnen eine unhinterfragbare Legitimation. Indem die SoldatInnen zu psychologisch erklärbaren und behandelbaren Subjekten werden, indem der „falsche“ Umgang als Ursache gilt, geht es nicht mehr um das Vermeiden von, oder Kritik an, Tod und Verwundung. Mit beidem korrespondiert, dass Lösungen in erster Linie in psychologischer Betreuung identifiziert werden.

\section{Mangelnde gesellschaftliche Anerkennung}

Neben den Umständen in Afghanistan macht auch die mangelnde gesellschaftliche Anerkennung in Deutschland die BundeswehrsoldatInnen zu Leidtragende. Der Unterframe nimmt in der SZ deutlich mehr Raum ein als in der Y und zeichnet sich auch durch eine größere Vielfalt aus. Grundsätzlich ähneln sich die Motive sowie die Struktur in beiden Medien jedoch stark. Verglichen mit dem Unterframe „Gefährdung“ ist die „mangelnde gesellschaftliche Anerkennung" weniger präsent und taucht erst relativ spät, zu Mitte (SZ) und Ende (Y) des Jahres 2006 mit großer Regelmäßigkeit auf.

„Die Stimmung in der Truppe ist positiv, was den Auftrag angeht. Doch viele kommen aus Afghanistan zurück und erfahren, dass dieser Einsatz zu Hause nur von ganz wenigen zur Kenntnis genommen wird. Sie werden gefragt: Was macht ihr da eigentlich? Das bringt doch sowieso nichts. Das sitzt dann schon tief. Die Betroffenen finden sich dann in einem Spannungsfeld wieder zwischen der friedlichen Heimat und dem feindlichen Geschehen in Afghanistan. Das ist oft schwer auszuhalten.“ (SZ, 29.8.2008 b, Man kann sich nicht schützen)

Für das Problem der mangelnden gesellschaftlichen Anerkennung wird die deutsche Bevölkerung verantwortlich gemacht; Ursachen und Gründe werden jedoch großflächig vernachlässigt. Dies bereitet den Boden für den im Unterframe anzutreffenden manifesten Appell, die Leistungen der deutschen SoldatInnen anzuerkennen, zu würdigen und ihnen Dank entgegen zu bringen. Denn indem mögliche Ursachen wie eine Ablehnung des Einsatzes ausblendet werden, kann der- 
maßen klar formuliert und gefordert werden, dass SoldatInnen Unterstützung, Anerkennung etc. brauchen und verdienen. Der Appell drückt sich in expliziten Forderungen und in impliziten Appellen aus. Das Interesse der Bevölkerung soll sich auf gute Leistungen und harte Bedingungen konzentrieren.

\section{Synthese}

In sämtlichen Unterframes vollzieht sich eine Konstituierung der SoldatInnen als Opfer und Leidtragende, wobei die Unterframes jeweils verschiedene Aspekte einer Opferschaft in unterschiedlich starker Ausprägung darlegen. Das ihnen Gemeinsame, also die Essenz des „Opfer"-Frames in Bezug auf die Darstellung der SoldatInnen besteht in ihrem Framing als ,gute', anständige, leistende, unfehlbare, naive, genügsame sowie anerkennenswerte aber gleichzeitig missachtete Personen(-gruppe).

„Durch Ihr festes und gleichzeitig freundliches Auftreten, Ihr Mitgefühl konnten Sie das Vertrauen der afghanischen Bevölkerung gewinnen und so helfen, die Sicherheitssituation im Land zu stabilisieren. Dafür, General van Heyst, spreche ich Ihnen und Ihren Männern meinen Dank und meine Anerkennung aus." (Zitat: damaliger Bundesverteidigungsminister Struck, Y, September 2003, Ein Korps geht heim. Ebenso in Y, April 2004, Die stillen Helfer; bezeichnend ist hier auch der Titel des Artikels)

So schwingt bei allen Unterframes mit, wie viel den SoldatInnen abverlangt wird, welchen Umständen sie ausgesetzt sind, was sie auf sich nehmen. Dies kulminiert in der SZ in Vergleichen mit der harten soldatischen Lebensrealität im Zweiten Weltkrieg, die historische Analogien und Kontingenzen suggeriert, die jeglicher Geschichtsschreibung widersprechen:

„Soldaten, die aus Afghanistan zurückkehren, haben Dinge mitgemacht, wie es sie im deutschen Militär seit 1945 nicht mehr gab: Krieg, Tod und Todesangst, gefallene oder verstümmelte Kameraden, traumatische Belastungen.“ (SZ, 20.12.2010 a, In einem fernen Land)

Andere, wenig schmeichelhafte Parallelen zu deutschen SoldatInnen im Zweiten Weltkrieg werden nicht gezogen. Im Framing der BundeswehrsoldatInnen in Afghanistan in SZ und Y leisten die SoldatInnen etwas, das Anerkennung verdient, ${ }^{7}$

7 Jenseits der Frame-Elemente wie z. B. der Verurteilung fehlender Anerkennung im Unterframe ,mangelnde gesellschaftliche Anerkennung ' findet sich häufig explizites Lob für die SoldatInnen. 
sie erfahren keine Kritik, das mögliche Verursachen von Unfällen oder zivilen Toten wird selten erwähnt. SoldatInnen haben gute Absichten, leisten einen höheren Dienst für eine wichtige Sache und machen dies klaglos und finden positive Umgangsweisen mit der teils katastrophalen Situation.

„Die Gefahr, auf den sich in einem erbärmlichen Zustand befindlichen Straßen Genick oder Achse zu brechen, scheint größer als durch ein Feuergefecht oder einen Hinterhalt beziehungsweise durch Minen oder Blindgänger verletzt oder getötet zu werden.“ (Y, März 2002, Erste Hoffnung)

Selbst wenn der Einsatz als nicht erfolgreich beschrieben wird, sind hierfür nie SoldatInnen verantwortlich.

„Dabei erwies sich für die Bundeswehr nicht nur als Problem, dass sie allerorten für ihr originäre Aufgabe herangezogen wurde. Allzu leicht wurde von den Soldaten auch noch verlangt, Straßen und Brücken zu bauen, Gefängnisse zu verwalten und eine einigermaßen unabhängige Justiz sicherzustellen. Die Bundeswehr sozusagen als Mädchen für alles.“ (SZ, 31.10.2006, Mission mit mehreren Unmöglichkeiten)

Der Unterframe „mangelnde gesellschaftliche Anerkennung“ reiht sich in die Konstituierung der SoldatInnen als Opfer ein, unterscheidet sich aber von den anderen Unterframes darin, dass er der einzige ist, in dem die Ursache für den Opferstatus nicht in Afghanistan, sondern in Deutschland verortet wird.

„Am Hindukusch ist eine kleine Parallelgesellschaft entstanden. Eine, die sich unverstanden und missachtet fühlt.“ (SZ, 20.12.2010 b, Kriegsweihnachten)

Während in den anderen Unterframes die Bedingungen in Afghanistan thematisiert werden, geht es in diesem Frame um , die Deutschen' und ihr Verhältnis zu den deutschen SoldatInnen sowie deren Einsatz.

„In Afghanistan gab es weitere Unglücksfälle, dann aber ist ein Bus von Terroristen in die Luft gesprengt worden. Und das war etwas Neues. Damit hat sich nicht die Zinksargthese früherer Jahre erwiesen. Die besagte, dass alle Auslandseinsätze ihr Ende haben werden, wenn die ersten Opfer zu beklagen sind. Dies ist nicht eingetreten. Aber man ist den Soldaten, auch ihren Angehörigen und letztlich der gesamten Gesellschaft noch dringlicher Rechenschaft schuldig, wofür sie das Risiko auf sich nehmen.“ (SZ, 12.8.2003, Nicht überall und jederzeit) 
Zwischen den fünf „Opfer“-Frames finden sich zahlreiche Überschneidungen und Verschränkungen. Verschiedene Unterframes bauen in einem wechselseitigen Zusammenwirken aufeinander auf und verweisen aufeinander. So werden als Ursachen der psychischen Versehrtheit erstens gefürchtete oder schon gemachte Erfahrungen von Tod und Verletzung geframed (,Gefährdung“, ,,verletzt/gefallen"), aber auch ungenügende Unterstützung durch die Bundeswehr im Falle psychischer Versehrtheit sowie die fehlende Anerkennung für die Leistung der SoldatInnen (,mangelnde gesellschaftliche Anerkennung“) und der Campalltag (,,harte Bedingungen“) können zu negativen Gefühlen führen.

Das Framing der BundeswehrsoldatInnen in Afghanistan in der Y und der SZ bezüglich des Opfer-Frames weist keine grundsätzlichen Unterschiede auf. In beiden Medien sind die gleichen Unterframes anzutreffen; in ihrer inhaltlichen Ausprägung sind sie einander sehr ähnlich. In der Y lässt sich eine etwas stärkere Ausprägung kämpferischer Elemente in der Lösungsdimension des Unterframes „Gefährdung“ finden. Ebenfalls werden die SoldatInnen in der Y deutlicher als in der SZ als kompetent charakterisiert, indem ihre Kompetenz und Zähigkeit häufig in den Lösungsdimensionen von „Gefährdung“ und „harte Bedingungen“ auftauchen und in den Bewertungsdimensionen gewürdigt werden.

„Gemeinsam mit afghanischen Polizisten patrouillieren Elitesoldaten aus Varel Tag und Nacht durch Kabul. Zwar sind die Fallschirmjäger aus der Luftlandebrigade 31 bestens ausgebildet und gut ausgerüstet sowie kampfstark, doch so richtig wohl fühlen sich die harten Jungs nicht immer. ,Das erste Mal ist es schon seltsam', meint Obergefreiter Michael Stöhr. Nervös machen ihn und seine Kameraden vor allem die afghanischen Polizisten an den nächtlichen Checkpoints oder bei den gemeinsamen Patrouillen." (Y, März 2002, Erste Hoffnung)

Das Bild der SoldatInnen in der SZ wird hingegen deutlicher als in der Y über die Konstituierung eines negativ bewerteten Gegenübers entworfen (vgl. auch Aljets et al. in diesem Band).

„Viele sind ausgezogen, um zu helfen, manche, um der Arbeitslosigkeit zu entgehen, andere, um das Abenteuer zu suchen - es sind die Motive der westlichen Wohlstandsgesellschaft. Doch dann landen sie in einer Welt der archaischen Gewalt und der bitteren Armut. Sie erleben einen Krieg der Partisanen und Selbstmordattentäter. Sie lernen die Todesangst kennen, das Misstrauen und im Zweifel schneller zu schießen, anstatt selber zu sterben. Manchmal spielen sie mit Menschenknochen, die sie in der Wüste finden, weil die Regeln des zivilen Lebens verblassen. Manchmal schießen sie.“ (SZ, 2.9.2008, Töten und getötet werden) 


\title{
2.2 Täter
}

Die Schaffung eines provisorischen bzw. hypothetischen Täter-Frames zu Beginn unseres Forschungsprozesses entsprang der Beobachtung, dass die Soldaten - zumindest in den ersten acht Stichwochen - häufig als Opfer geframed werden. Im Anschluss daran fragten wir uns, ob es einen Counterframe gibt, in dem sie als Täter verhandelt werden. Das Wissen über - erst später im Untersuchungszeitraum situierte - Affären und Skandale wie beispielsweise die Totenkopfaffäre oder der Luftangriff von Kunduz, verstärkten dieses Interesse.

Bei den Ereignissen, anhand derer mögliche Täterschaft der Soldaten verhandelt wird, handelt es sich bei der SZ erstens um die Misshandlungsvorwürfe von Murat Kurnaz ${ }^{8}$, die Totenkopfaffäre, die Tötung von Zivilisten an einem Kontrollposten sowie den Luftangriff bei Kunduz. Bis auf die Misshandlungsvorwürfe von Murat Kurnaz finden sich in der Y Artikel zu allen Vorfällen, die auch in der SZ besprochen wurden. Die Artikel sind verständlicherweise durch die monatliche Erscheinungsweise der $\mathrm{Y}$ weniger tagesaktuell und haben stattdessen tendenziell eher resümierenden Charakter.

Die Ereignisse werden also thematisiert, die Soldaten werden jedoch fast nie explizit als Täter verhandelt oder für ihre ,Taten '/Handlungen moralisch verurteilt, so hier am Beispiel der Totenkopfaffäre:

\begin{abstract}
„Denn was wäre, wenn sie [die Fotografien] nicht nur den schändlichen Triumph festhielten, sondern darin [sic!] auch die Angst und die Furcht vor der Niederlage? Wie, wenn sie sich in den Gesten der absoluten Souveränität die Enttäuschung und die Verwirrung von Soldaten spiegelt, die nach Afghanistan gekommen waren, um einer gerechten und willkommenen Sache zu dienen, sich dann aber in einer völlig anderen, moralisch zweifelhaften und sogar demütigenden Situation wiederfanden? Wie, wenn sich darin der Schrecken von jungen Männern abbildete, die erwartet hatten, von den Einheimischen als willkommene Helfer behandelt zu werden, dann aber eine Bevölkerung vorfanden, die das Mitmachen verweigert, die sich widersetzt und die Soldaten als Eindringlinge bekämpft?“ (SZ, 26.10.2006 b, Verwirrte Helfer)
\end{abstract}

Zwar wird strafrechtlich relevantes, moralisches oder anderweitiges Fehlverhalten von Soldaten angedeutet, fast immer wird deren Täterschaft jedoch -

8 Der Fall Kurnaz wird jedoch fast ausschließlich in Bezug auf die Verantwortung von PolitikerInnen für seine späte Freilassung problematisiert anstatt hinsichtlich der Handlungen jener SoldatInnen, die die Misshandlungsvorwürfe konkret betrafen. Aus diesem Grund spielt er in der weiteren Auswertung keine Rolle. 
quasi vorauseilend - negiert bzw. relativiert. Im Grunde liegt also kein TäterFrame in der Berichterstattung vor. Die Täterschaft wird relativiert, wenn, dann wird „Deutschland“ zum Täter, nicht aber die SoldatInnen.

„Jetzt fragen alle: Hat die Innere Führung versagt? Deutsche Soldaten trieben Schindluder mit einem Totenschädel in Afghanistan, und die Bundeswehr gerät wieder einmal in Generalverdacht, undemokratisch, unmoralisch und unkontrollierbar zu sein. Wer aber fragt: Hat nicht die Gesellschaft versagt? Dass man den Kopf eines Toten nicht als Spielball missbraucht, sollte jedem halbwegs vernünftig empfindenden Menschen selbstverständlich sein. Und das Gespür dafür sollte er nicht erst bei der Bundeswehr entwickeln (müssen). Das Fundament für Anstand wird viel früher gelegt - in der Familie und im persönlichen Umfeld.

Schon die Schulen erweisen sich vielfach als unfähig, dem schwindenden Respekt vor der körperlichen Unversehrtheit anderer entgegenzuwirken. Die Bundeswehr wäre überfordert, wenn sie all jene Defizite aufarbeiten sollte, welche die Gesellschaft hat entstehen lassen. In manchen Teilen des Landes und der Gesellschaft hat die seelische Verwahrlosung ein Ausmaß angenommen, dessen niemand mehr Herr wird - auch die Bundeswehr nicht. Tatsächlich ist für manchen jungen Mann der Dienst in der Armee der erste Abschnitt, in dem er gezwungen wird, gewisse Regeln einzuhalten. Ein Argument, das man übrigens auch für die Beibehaltung der Wehrpflicht ins Feld führen kann.“ (SZ, 27.10.2006, Ausbilder besser ausbilden)

\subsection{Friedliche Aufbauhelfer}

Wir waren schon zu einem recht frühen Zeitpunkt des Codierens und Artikellesens auf das Framing von SoldatInnen als friedliche Aufbauhelfer aufmerksam geworden, das im Gegensatz zum später verstärkt zu findenden Frame von SoldatInnen als „Kämpfer“ steht. Der Frame stellt die „zivile“ Aufbauarbeit als Herausforderung der Soldaten dar, die sich mit dieser verantwortungsvollen Aufgabe dem gefährlichen Feind stellen und beharrlich eine friedliche Antwort auf seine Attentate und Anschläge geben. Die Argumentationslogik des Frames folgt dem Muster, dass den Aufständischen durch Wiederaufbaumaßnahmen zu begegnen sei, denn ,,[...] eine nachhaltige friedliche Entwicklung erfordert den Einsatz nicht-militärischer Mittel." (SZ, 2.10.2004, Soldaten und Hilfskräfte ergänzen sich). Es wird angenommen, dass durch die ,zivilen“ Aufbaudienstleistungen der afghanische Staat und die afghanische Bevölkerung soweit gestärkt würden, dass den Aufständischen auf Dauer keine Angriffsmöglichkeiten mehr geboten wären und ihre Angriffe erfolglos blieben. Durch die bloße Anwesenheit der ISAF-Truppen sei ,[...] in Kabul alles besser geworden [...]“ und „,[d]er Le- 
benswille erwacht [...]“ (Y, September 2002, Mut zum Neuanfang). Mit der Zunahme der Gefahren für die Soldaten wird allerdings deutlich, dass die bisherigen Lösungsstrategien (Schutz der Bevölkerung und Wiederaufbau) immer weniger greifen. Aus dem codierten Material geht hervor, dass die Wiederaufbaumaßnahmen der Soldaten im Laufe der Einsatzjahre mehr und mehr von Über- und Angriffen der Taleban überschattet werden und die Arbeit nicht den gewünschten Erfolg erzielt. Ungefähr ab dem Jahr 2007 nimmt die Berichterstattung über die Provincial Reconstruction Teams (PRTs) und „zivilen“ Maßnahmen ab und jene über Angriffe und Kampfeinsätze zu. Deshalb zieht sich der Frame in der SZ nur bis ins Jahr 2008; in der Y verschwindet er bereits ab 2007. Der Frame „friedlicher Aufbauhelfer“ ist demnach ein dominanter Frame in der ersten Hälfte des Untersuchungszeitraums. In seinem - vermeintlichen - Counterframe „Kämpfender“ wird er in der zweiten Hälfte der untersuchten Berichterstattung hin und wieder thematisiert.

In der Y wird zwar quantitativ weniger über den ,zivilen“ Aufbau berichtet, dafür sind die verwendeten Begriffe präziser und fachspezifischer als in der SZ. Besonders zu Beginn des Einsatzes wird in der Y das Bild vermittelt, dass Soldaten zu kämpferischen Taten gar nicht im Stande wären und diese auch in keiner Form anstrebten. Wenn militärische Handlungen im späteren Untersuchungszeitraum genannt werden, so geschieht dies immer in der legitimierenden Logik des Selbstschutzes der Soldaten. Dieser Selbstschutz verweist bereits auf die inhaltliche Dimension des Frames „Kämpfender“. Es zeigt sich hier also durchaus eine argumentative Verknüpfung beider Frames.

In der SZ wird das Erscheinungsbild des Soldaten als ,friedlicher Aufbauhelfer" durch immer wiederkehrende Adjektive und Begriffe geformt, welche die Arbeit der Soldaten als „,aufopferungsvolle militärische Friedensarbeit“ (SZ, 14.4.2004, Friedensmissionen schaffen keinen Frieden) beschreiben. Plastisch wird in der Berichterstattung dargestellt, wie die Soldaten ,helfen, Schulen, Brücken und Krankenhäuser zu bauen“ (SZ, 7.8.2003, Struck befürwortet Ausweitung des Afghanistan-Einsatzes) und der afghanischen Polizei bei deren Aufbau zur Seite stehen. Genau wie in der Y wird auch in der SZ beschrieben, dass sich die Soldaten von der ständigen Lebensbedrohung nicht einschüchtern ließen und ihre ,gute“ Arbeit unbeirrt und unnachgiebig weiterführen.

\subsection{Kämpfer}

Der Frame „Kämpfender“ war als Gegenstück zum Frame „friedlicher Aufbauhelfer" angelegt worden. Wir haben angenommen, dass SoldatInnen, die sich in einem Einsatz befinden, früher oder später zur Waffe greifen und deshalb als 
Kämpfende dargestellt werden würden. Diese Annahme hat sich in der SZ nicht bestätigt, in der Y konnte ein selbstständiger Frame identifiziert werden. In der SZ wird zwar von kämpfenden Tätigkeiten der SoldatInnen berichtet; eingebettet ist diese Thematisierung jedoch in den Frame des Opfers: das Leben des Soldaten werde bedroht, weshalb er sich in keiner anderen Lage sehe, als sich gegen die feindlichen Übergriffe zu wehren, sich also zu verteidigen. Und selbst im Moment der Selbstverteidigung laufe er noch Gefahr, verletzt zu werden, oder schlimmer noch, eventuell zu sterben. In der Y hingegen wurde der deutsche Soldat als sich selbst verteidigender und professionell agierender Soldat dargestellt, der Kampfhandlungen aufgrund seiner Berufswahl ausführt.

„In bewaffneten Massenkonflikten beispielsweise im Rahmen der Bekämpfung Aufständischer mit hohem Gewaltpotenzial wird den Akteuren zwar kein Kombattantenstatus zugebilligt, es gelten jedoch für die staatlichen Organe und die zur Hilfe gerufenen Interventionstruppen vergleichbare Regelwerke, die die Bekämpfung , an den Kampfhandlungen ohne Berechtigung Beteiligter" einerseits erlauben und andrerseits grundlegende Schutzpflichten gegenüber Konfliktopfern und Unbeteiligten fordern.“ (Y, November 2008 b, Schweiß Blut Tränen)

In der Y ließen sich daran anschließend zwei Unterframes identifizieren. Der des Kämpfers als Reaktion auf die „Unsicherheit in Afghanistan“ und der des Kämpfers auf Grund des ,Krieges“ in Afghanistan. Bereits hier zeigt sich „,dass der deutsche Soldat, wenn er kämpft, dies nur tut als Opfer der Umstände, oder weil seine Mission es erfordert".

Eine Erklärung für die unterschiedliche Darstellung könnten die Adressaten beider Medien sein. Die Y schreibt für deutsche SoldatInnen, denen sie sicherlich nicht das Bild von Schwäche und Opferdasein vermitteln möchte. Dass Professionalität, gute Vorbereitung und (quasi) Unverletzbarkeit der SoldatInnen bei selbigen gut ankommt, versteht sich von selbst. Die Süddeutsche Zeitung hingegen schreibt für eine breitere Öffentlichkeit, die einen Großteil der deutschen Bevölkerung einschließt. Dieser deutschen Öffentlichkeit muss der Einsatz erklärt und die Rolle der SoldatInnen in diesem Einsatz vermittelt werden, weshalb in diesem Medium möglicherweise die Bewertung der Arbeit und ihrer Folgen für die SoldatInnen und die deutsche Gesellschaft mehr Gewicht hat.

\section{Unsicherheit in Afghanistan}

Im Unterframe „Unsicherheit in Afghanistan“ steht die Gefährdung der SoldatInnen im Vordergrund. Jeglicher Kampf zieht seine Legitimation aus der Le- 
bensgefahr, in der sich die SoldatInnen befinden und gegen die sie sich zur Wehr setzen müssen.

"[I]n Isa Khel peitschen die ersten Schüsse durch die engen Straßen und schlagen in den Lehmmauern der Compounds ein. ,Auf einmal ging's richtig los. Wir wurden mit allem beschossen. AK-47, RPG und was weiß ich noch alles. Uns flogen die Kugeln nur so um die Ohren. ““(Y, Dezember 2010, Dennis Güllners neues Leben)

Selbstverteidigung und Selbstschutz sind die Hauptargumente für den Einsatz der Waffe. Somit wird dieser Unterframe des Kämpfers zu einem Bestandteil des Opfer Frames. Die Soldaten, die ,[...] nach Afghanistan gekommen waren, um einer gerechten und willkommenen Sache zu dienen, sich dann aber in einer völlig anderen, moralisch zweifelhaften und sogar demütigenden Situation wiederfanden[.]“ (SZ, 26.10.2006 a, Der Skandal um die Soldatenfotos) sind Opfer der Umstände in Afghanistan, ständiger Gefahr ausgesetzt und werden nur zu Kämpfenden um ihr Leben zu verteidigen. Der Unterframe beschreibt die SoldatInnen somit als passiv Kämpfende und nicht als aggressiv offensive Kämpfer. Dies ist vor allem in der ersten Hälfte des Untersuchungszeitraums zu erkennen: in den betreffenden Textstellen, in denen von Entwaffnung und Bekämpfung die Rede ist, schwingt die Waffengewalt nur implizit mit. ${ }^{9}$ In einigen Artikeln wird außerdem argumentiert, dass bereits die schlichte Präsenz der SoldatInnen - mit ihrer Waffenausrüstung und der Möglichkeit ihrer Anwendung - für Ordnung sorge. Auch dadurch wird eine kämpferische Passivität ausgedrückt. Mit der Zunahme der Waffengewalt ab dem fünften Einsatzjahr öffnet sich eine zusätzliche Sicherheitsproblematik für die SoldatInnen, die sie rückwirkend wieder als Opfer framed: um sich selbst zu verteidigen, müssen die SoldatInnen kämpfen; dies wiederum birgt ein größeres Risiko, bei Kampfhandlungen zu sterben. Ziel des Einsatzes sei es, den „Machtanspruch der Regierung Karsai gegen Warlords und Provinzfürsten notfalls mit Waffengewalt durchzusetzen“, was aber gleichzeitig das Risiko birgt, „dass deutsche Soldaten dabei sterben“ (SZ, 8.8.2003, Blick in die Presse). Die SoldatInnen sollen sich mit Hilfe der Selbstverteidigung aus dem Status des Opfers befreien, werden jedoch genau dadurch wieder zu Opfern.

9 So bspw. bei der Beschreibung ihrer Aufgaben: die Bevölkerung schützen, die afghanische Polizei ausbilden, Patrouille fahren und Zufahrtswege sichern. Siehe hierzu auch Kapitel 3.4.2. 


\section{Krieg in Afghanistan}

Der Unterframe „Krieg in Afghanistan“ greift viele Thematiken des ersten Unterframes auf, stellt aber die Thematisierung des Krieges in den Vordergrund. Die deutschen SoldatInnen, befänden sich ungewollt in einem Krieg der - genau wie im ersten Unterframe - Opfer von ihnen verlange.

„Mit jedem Todesopfer verliert der Einsatz der Bundeswehr am Hindukusch ein Stück mehr vom Hauch des Abenteuers - und deutlicher zeigt sich, was ein Kriegseinsatz per Definition ist: Ein gefährliches Manöver, das auch immer das Risiko von Todesopfern in sich birgt.“ (SZ, 28.8.2008, Der BW fehlt es an Bewerbern)

Es befinden sich in der Beschreibung explizite Darstellungen des Kampfes und der kriegerischen Auseinandersetzungen, an denen die deutschen SoldatInnen teilnehmen; der Soldat wird hier deutlich als Kämpfender dargestellt. Dennoch wird dieses Kämpfen des Soldaten als Reaktion auf die Angriffe geframed. Er will sich primär schützen.

„Anfang Dezember griffen Unbekannte einen Konvoi von drei geschützten Transportfahrzeugen Dingo südlich von Kunduz mit Handwaffen an, Die deutschen Soldaten blieben unverletzt, ein Dingo wurde leicht beschädigt. Die Patrouille erwiderte das Feuer der Angreifer, die sich unerkannt zurückzogen." (Y, Februar 2007, Deutsche Patrouille angegriffen)

Die Argumentation ist also identisch mit der des ersten Unterframes, lediglich der Fokus auf den Krieg ist hier stärker. Was als Friedenseinsatz innerhalb dessen die SoldatInnen die Rolle des Aufbauhelfers zugeteilt bekamen entwickelt und begonnen wurde, entpuppt sich als handfester Krieg mit all jenen Konsequenzen, die ein Krieg mit sich bringt. Dieser Krieg fordert zivile Opfer, ${ }^{10}$ er schafft Kriegsheimkehrer ${ }^{11}$, er stellt eine Lebensbedrohung für die SoldatInnen im Einsatz dar und er macht sie zu Opfern einer scheinheiligen Kommunikationspolitik der Entsendenden.

10 Diese werden an einer Stelle unter dem Begriff „Kollateralschaden” verbucht, ,wie er leider fast wöchentlich vorkommt.“ (SZ, 28.10.2006, Bis zum Hals im Gefechtssumpf).

11 „Jetzt kehren wieder deutsche Soldaten aus dem Krieg zurück.“ (SZ, 14.2.2009, Der Krieg in uns). 
„Es wäre besser gewesen, wenn man deutlich gesagt hätte: Für unsere Soldatinnen und Soldaten gibt es dort auch echte Kampfhandlungen. Feuergefechte, die 30 Minuten dauern, mit Stellungswechseln und Ausweichmanövern. Zu einem Kampf sollte man auch Kampf sagen.“ (SZ, 29.8.2008 a, Anschlag löst Debatte über Afghanistaneinsatz aus)

Dies zeigt sich insbesondere in der zweiten Hälfte des Untersuchungszeitraums. Mit der Benennung des Einsatzes in Afghanistan als Krieg findet eine zunehmende Verlagerung weg vom zivilen Aufbauhelfer, hin zum Kämpfer statt.

„Militärische Friedensarbeit, wie sie die Deutschen [...] so aufopferungsvoll geleistet haben und in Kundus weiter leisten, mag einigen Menschen in der Region Lohn und Brot und auch Einsicht bringen. [...] Den Frieden bringen sie nicht ein Stückchen näher. (...) Militär kann nur Militärisches leisten. Soldaten können kämpfen. Sie können durch ihre Präsenz Macht demonstrieren und Gewalt verhindern. Sie können ein Vorbild selbst an Zivilität sein.“ (SZ, 14.4.2004, Friedensmissionen schaffen keinen Frieden...)

In der Y wird zunehmend ein SoldatInnenbild vermittelt, das von Professionalität und Entschlossenheit geprägt ist. Selbstsicher erfüllen die SoldatInnen essentielle Aufgaben. Unerschrocken und tapfer bekämpfen sie mit allen ihnen zur Verfügung stehenden Mitteln den Feind. Tapfer und souverän führen sie die ihnen anvertrauten Aufträge aus. Unweigerlich wird dadurch an das Bild soldatischer Tugenden (vgl. Bergmann 2011) angeknüpft. Das militärische Engagement wird dabei mit dem Schutz des Wiederaufbaus und der SoldatInnen selbst legitimiert; Gegenwehr und Selbstverteidigung als logische Konsequenz eines Angriffs beschrieben.

„Am 4. Juni 2009 hatte er den Auftrag, mit seinem Zug in der Nähe der Ortschaft Basoz in der Provinz Kunduz einen von Aufständischen eingekreisten Spähtrupp zu befreien. Zunächst war Hecht dabei als Führer vor Ort auf sich allein gestellt und musste die ersten Maßnahmen koordinieren. Trotz höchster eigener Gefährdung ging er mit seinem Zug gegen einen zahlenmäßig überlegenen Gegner vor und befreite den Spähtrupp aus der lebensbedrohlichen Lage.“ (Y, Juni 2010, Ehrenkreuz für Jan Hecht)

Durch den Frame werden jedoch nicht nur diskursive Strukturen vertieft; die LeserInnen des Magazins, die überwiegend SoldatInnen sein dürften, werden durch die positive Berichterstattung über sie mental unterstützt; es wird ein nach außen hin vorbildliches Bild der SoldatInnen gezeichnet. Dies kann sowohl in der Absicht geschehen sein vermehrt gesellschaftliche Anerkennung zu erhalten, als auch neue SoldatInnen zu rekrutieren. 


\section{FAZIT}

Unser Erkenntnisinteresse lag in der Frage, wie BundeswehrsoldatInnen im Rahmen des Einsatzes in Afghanistan in den Medien dargestellt werden. Dabei galt es auch, herauszufinden, ob sich Unterschiede in einem Massenmedium wie der SZ im Vergleich zu einem bundeswehrinternen Medium wie der Y beschreiben lassen. Im Laufe der Analyse stellte sich recht schnell heraus, dass es einige prägnante Frames gibt, die das Bild der SoldatInnen sowohl in der Y als auch in der SZ formen: Die Darstellung der SoldatInnen als passiv und erleidend - ein Frame, den wir als „Opfer-Frame“ bezeichnen - und die Darstellung der SoldatInnen als helfend und engagiert, die aufopferungsvoll und fürsorglich „militärische Friedensarbeit“ leisten - ein Frame, den wir „friedlicher Aufbauhelfer“ nennen.

Die genaue Funktionsweise der Frames gibt detailliertere Aufschlüsse über das in der SZ und in der Y vermittelte Bild der deutschen SoldatInnen im Afghanistaneinsatz. Die Frames sind in der SZ und in der Y - bis auf die aufkommende Darstellung der SoldatInnen in der Y als Kämpfende - deckungsgleich und unterscheiden sich nur gering in ihren unterschiedlichen Ausprägungen. Die prägnantesten Unterschiede zwischen SZ und Y sind die stereotype Darstellungen der afghanischen Kämpfenden und der Bevölkerung in der SZ, die an tradierte rassistische Dichotomien anknüpfen (siehe auch Aljets et al. in diesem Band), die in der Y weitestgehend abwesend sind. Hinzu kommen die in der Y wesentlich häufiger $\mathrm{zu}$ findenden soldatisch-kämpferischen Handlungen, die ihre Reflektion im Aufkommen eines eigenständigen Kämpfer-Frame finden.

In Relation zum bisher erarbeiteten Forschungsstand anderer AutorInnen lässt sich feststellen, dass der Frame „friedlicher Aufbauhelfer“ dem vorherrschenden Forschungsstand hinsichtlich des medial vermittelten Bildes der deutschen SoldatInnen im Afghanistaneinsatz als helfender und die Sicherheit verteidigender entspricht, der im Kontrast zu seinen „schrecklichen“ Gegnern als „Friedensstifter“ gezeichnet wird (vgl. Axer-Dämmer 2011; Bergmann 2010). Unser Ergebnis der Darstellung der SoldatInnen als Opfer kann hinsichtlich des Forschungsstandes hingegen als ergänzend betrachtet werden. Zwar weist beispielsweise Heinecke (Heinecke 2011) darauf hin, dass die Bundeswehr (jedenfalls bis zum Luftangriff in Kunduz) immer als passiv beschrieben wird, und Fischer (Fischer 2009) erkennt, wie wir auch, innerhalb seines Untersuchungszeitraumes eine umfangreiche Thematisierung der Sicherheitslage in Afghanistan in Bezug auf die deutschen SoldatInnen. Deren Funktion als Teil einer umfassenden Darstellung der SoldatInnen als passiv und erleidend, findet sich jedoch in keiner der uns vorliegenden Studien. 
Wir nehmen dabei an, dass der „Opfer-Frame“ durch den Frame „friedlicher Aufbauhelfer" gewissermaßen notwendig ergänzt werden muss: Kulturell manifeste Bilder eines harten, männlichen, kämpferischen, heroischen Soldatentums bzw. eines informierten, mündigen, demokratische Werte verteidigenden Bürgers werden vom Opfer-Frame herausgefordert. Gefährdete, Schutz benötigende, unter Hitze, Kälte und Staub leidende, aus der öffentlichen Wahrnehmung verschwundene, psychisch angeschlagene oder kranke SoldatInnen beschädigen das gesellschaftlich verwurzelte Bild von SoldatInnen. Die Darstellung der SoldatInnen als Opfer ist vermutlich aus diesem Grund selbst innerhalb des „OpferFrames“ nicht einheitlich. Die SoldatInnen werden auch hier teilweise als aktiv Gestaltende dargestellt. Der Frame „friedlicher Aufbauhelfer“ erhält so eine stützende Funktion hinsichtlich des Gesamtbildes der deutschen SoldatInnen in den Medien. Sie werden als fürsorglich und effektiv arbeitend, belastbar und zuverlässig dargestellt (übrigens Charaktereigenschaften die auch sonst typisch für „die Deutschen“ stehen), als Gegengewicht zu den schwachen, leidenden SoldatInnen im „Opfer“-Frame. Der „Opfer“-Frame und der Frame „friedlicher Aufbauhelfer" existieren also nicht unabhängig voneinander. Das Bild von Selbstlosigkeit, Genügsamkeit, interkultureller/sozialer Kompetenz, Anständigkeit und Hilfsbereitschaft vermittelt sich über beide Frames, als ureigene Qualifikation des Soldaten oder als Kontrastpunkt um die Opferrolle als noch ungerechtfertigter darzustellen.

Was den Frame des „Kämpfender“ betrifft, so steht auch dieser in direktem Bezug zum „Opfer“-Frame. Das Töten und selbstverursachte Leid durch SoldatInnen wird in dieser Argumentationskette, weitgehend ,unsichtbar“ gemacht (vgl. Bergmann 2010). Die Darstellung der SoldatInnen vermittelt die Idee, dass die deutschen SoldatInnen nicht bewusst töten wollen oder Leid zu verursachen suchen, sondern dies - wenn es überhaupt dazu kommen sollte - aus einem Zwang des Selbstschutzes heraus tun. Dieses wird gerade in der SZ durch die Herabwertung des Gegners noch verstärkt. Möglich ist auch, dass dadurch bewusst Anerkennung für die SoldatInnen gewonnen werden soll: wo nur über positive und gerechtfertigte Handlungen gesprochen wird, kann schneller $\mathrm{Zu}$ stimmung entstehen, und doch wenigstens keine Ablehnung (siehe auch Aljets et al. in diesem Band).

Diese Ergebnisse sind charakteristisch für unser Untersuchungsmaterial im Ganzen, fallen aber in unterschiedlicher Gewichtung auf. Ab Mitte 2006 verlagert sich der Fokus weg vom „friedlichen Aufbauhelfer“ hin zur Thematisierung von „kämpfenden SoldatInnen“ und mit zunehmender Einsatzzeit werden die Risiken kämpferischer Handlungen und ihre Rückwirkungen auf die deutsche Öffentlichkeit besprochen. Auch in der Y werden die kämpferischen Handlungen 
der SoldatInnen mit zunehmender Intensität thematisiert. Der Frame „Kämpfender" löst somit den vorhergehenden Frame "friedlicher Aufbauhelfer" ab, die beiden stehen - wie schon in der SZ zu beobachten war - komplementär zueinander.

Die von Bergmann (2010) konstatierte Rehabilitierung eines Männlichkeitsideals, das sich während des 19. Jahrhunderts entwickelte, deckt sich vor allem in der Y mit dem Erstarken einer Darstellung als „Kämpfende“. Dabei spielt jedoch auch der Unterframe ,verletzt/gefallen“ eine Rolle: Hier findet die Verbindung eines soldatischen Todes mit dem Sterben für eine höhere Sache bzw. für Sicherheit respektive Freiheit, Frieden oder Demokratie statt. Ebenso wie Bergmann konnten wir eine weitgehende Ausblendung des Tötens durch deutsche SoldatInnen feststellen. Mit Heinecke (2011) deckt sich unser Ergebnis, dass bei der gelegentlichen Thematisierung strafrechtlich relevanten oder moralischen Fehlverhaltens dieses als Einzelfall dargestellt wurde, über das im gleichen Zuge die Konstituierung eines „Normalfalls“ anständiger SoldatInnen stattfand. Von Heinecke abweichend können wir jedoch nicht bestätigen, dass im Anschluss an die Luftangriffe in Kunduz SoldatInnen als Täter denk- und sagbar geworden sind. Vielmehr lässt sich festhalten, dass die Thematisierung des Todes von afghanischen ZivilistInnen durch Deutsche zum Anlass für eine erneute Darstellung der SoldatInnen als Opfer - Opfer ihrer eigenen Handlungen, der staatsanwaltlichen Ermittlungen oder der psychischen Folgen - genommen wurde.

Hinsichtlich des medial vermittelten Bildes der BundeswehrsoldatInnen im Afghanistaneinsatz lässt sich zusammenfassend festhalten, dass die Frames eine ausschließlich positive Darstellung der SoldatInnen zulassen. Am deutlichsten wird dies an der Unmöglichkeit, die SoldatInnen als TäterInnen zu verstehen; Fehlverhalten oder gar Straftaten finden zwar Erwähnung, mithilfe von Relativierungsstrategien werden diese jedoch erklärt, entschuldigt oder gar zu einem Teil der Darstellung der SoldatInnen als Opfer gemacht. In der Darstellung als ambitionierte, aufopferungsvolle und verständnisvolle AufbauhelferInnen ist ihnen per definitionem eine positive Interpretation ihrer Arbeit und ihrer Leistung sicher, die auch in beiden Medien so zu finden ist. Die Sicht auf die kämpferische Haltung der SoldatInnen schließlich - bei der hätte vermutet werden können, dass sie negativ ausfiele - nimmt in der SZ der Gewalt und dem Kriegsgeschehen, das von SoldatInnen verursacht wurde, ihre Schärfe, indem sie sich auf die Notwendigkeit der Selbstverteidigung konzentriert und „Operationen“ und „Schutzmaßnahmen“ nicht näher ausführt.

Dadurch dass die SoldatInnen zu Beginn als passiv und defensiv beschrieben werden und im späteren Einsatzverlauf ihre Rettung aus dem Opfer-Status im Vordergrund steht, bleibt kein Gefühl eines negativen SoldatInnenbildes zurück. 
Ähnlich verhält es sich in der Y, obwohl hier explizit die Kämpfe beschrieben und thematisiert werden. Dennoch geschähen diese Gefechte und Kämpfe auf eine so hehre, souveräne und logische Weise, werden die SoldatInnen als sich verteidigend und ihre Arbeit gewissenhaft ausfüllend dargestellt, dass auch hier eine überwiegend positive Wahrnehmung der deutschen BundeswehrSoldatInnen haften bleibt.

\section{LITERATUR}

Axer-Dämmer, Gerda. 2011. „Wenn die Staatsbürger in Uniform töten müssen: Bleibt das zivile Leitbild der Bundeswehr auf der Strecke?" In Internationale Politik und Gesellschaft I/2011 (I), S. 96 - 113.

Bergmann, Anna. 2010. „Gewalt und Männlichkeit: Wahrnehmungsmuster des ,Fremden' und des ,Eigenen“ in der deutschen Berichterstattung über den Afghanistankrieg“. In Medien - Krieg - Geschlecht: Affirmationen und Irritationen sozialer Ordnungen, hrsg. v. Martina Thiele, Tanja Thomas, und Fabian Virchow. Wiesbaden: VS Verlag.

Chiari, B., Hrsg. 2012. Auftrag Auslandseinsatz. Freiburg: Rombach.

Daxner, Michael. 2010. „Das Konzept von Interventionskultur als Bestandteil einer gesellschaftsorientierten theoretischen Praxis“. In Interventionskultur: Zur Soziologie von Interventionsgesellschaften, hrsg v. Thorsten Bonacker, Michael Daxner, Jan H. Free, und Christoph Zürcher, S. 75-100. Wiesbaden: VS Verlag.

—. 2011. „Seminarmitschrift vom 20.04.2011; 15375 - PK- Der Heimatdiskurs bei deutschen Auslandseinsätzen - Feldstudien im eigenen Land, FU Berlin".

Deutscher Bundestag. 2001. „Drucksache 14/7930“. http://dip21.bundestag.de/dip21/btd/14/079/1407930.pdf (aufgerufen am 23.08.2012).

Entman, Robert M. 1993. „Framing: Toward Clarification of a Fractured Paradigm“. In Journal of Communication 43(4), S. 51-58.

- 2003. „Cascading Activation: Contesting the White Houses Frame After 9/11“. In Political Communication 20 (4), S. 415-432.

Fischer, Jochen. 2009. „Unsichere Sicherheitskräfte. Die mediale Darstellung der Bundeswehr-Ausrüstungspolitik im Afghanistaneinsatz“. In Sicherheit und Medien, hrsg. v. Jochen Fischer, S. 79-92. Wiesbaden: VS Verlag.

Flick, Uwe. 1999. Qualitative Forschung: Theorie Methoden Anwendung in Psychologie und Sozialwissenschaften. Reinbek bei Hamburg: Rowohlt.

Foucault, Michel. 1992. Was ist Kritik? Berlin: Merve-Verlag. 
Heinecke, Jan. 2011. Der Heimatdiskurs und seine Wirkung auf die BundeswehrSoldaten in Afghanistan - Eine diskursanalytische Untersuchung von Feldtagebüchern und Einsatzberichten deutscher ISAF- Kräfte. Diplomarbeit, Oldenburg: Carl von Ossietzky Universität.

Jäger, Siegfried. 2009. Kritische Diskursanalyse: Eine Einführung. Münster: Unrast.

Keller, Reiner. 2008. „Diskurse und Dispositive analysieren. Die wissenssoziologische Diskursanalyse als Beitrag zu einer wissensanalytischen Profilierung der Diskursforschung“. Historical Social Research 33 (1), S. 73-107.

Kerchner, Brigitte. 2006. „Diskursanalyse in der Politikwissenschaft. Ein Forschungsüberblick“. In Foucault: Diskursanalyse der Politik: eine Einführung, hrsg. v. Brigitte Kerchner. Wiesbaden: VS Verlag.

Matthes, Jörg. 2007. Framing-Effekte. Zum Einfluss der Politikberichterstattung auf die Einstellungen der Rezipienten. München: Fischer Reinhard.

Matthes, Jörg, und Matthias Kohring. 2004. „Die empirische Erfassung von Medien-Frames“. Medien \& Kommunikationswissenschaft 52(1), S. 56-75.

Seiffert, A., Phil Langer, und Carsten Pietsch, Hrsg. 2012. Der Einsatz der Bundeswehr in Afghanistan. Schriftenreihe des sozialwissenschaftlichen Instituts der Bundeswehr. Wiesbanden: VS.

Sielschott, Stephan. 2010. „,Arbeitslos und keine Ahnung - Hier werden Sie geholfen!' Zum Framing stereotyper Bewertungen Arbeitsloser in den Regionalzeitungen Nordkurier und Volksstimme“. Journal für Psychologie 18(2), S. 1-19.

\section{PrimärquellenVerzeichnis}

SZ, 3.1.2002, Stationiert im Minenfeld

SZ, 7.8.2003, Struck befürwortet Ausweitung des Afghanistan-Einsatzes

SZ, 8.8.2003, Blick in die Presse

SZ, 12.8.2003, Nicht überall und jederzeit

SZ, 14.4.2004, Friedensmissionen schaffen keinen Frieden...

SZ, 2.10.2004, Soldaten und Hilfskräfte ergänzen sich

SZ, 26.10.2006 a, Der Skandal um die Soldatenfotos

SZ, 26.10.2006 b, Verwirrte Helfer

SZ, 27.10.2006, Ausbilder besser ausbilden

SZ, 28.10.2006, Bis zum Hals im Gefechtssumpf

SZ, 31.10.2006, Mission mit mehreren Unmöglichkeiten

SZ, 9.7.2007, Der lange Kampf von Major Plodowski gegen die eigene Armee

SZ, 28.8.2008, Der BW fehlt es an Bewerbern 
SZ, 29.8.2008 a, Anschlag löst Debatte über Afghanistaneinsatz aus

SZ, 29.8.2008 b, Man kann sich nicht schützen

SZ, 2.9.2008, Töten und getötet werden

SZ, 14.2.2009, Der Krieg in uns

SZ, 10.4.2010, Deutschland verneigt sich vor Ihnen

SZ, 20.12.2010 a, In einem fernen Land

SZ, 20.12.2010 b, Kriegsweihnachten

Y, März 2002, Erste Hoffnung

Y, September 2002, Mut zum Neuanfang

Y, September 2003, Ein Korps geht heim

Y, April 2004, Die stillen Helfer

Y, Mai 2006, Ausgebrannt

Y, Februar 2007, Deutsche Patrouille angegriffen

Y, November 2008 a, Bundeswehr mehrfach unter Raketenbeschuss

Y, November 2008 b, Schweiß Blut Tränen

Y, Juni 2010, Ehrenkreuz für Jan Hecht

Y, Dezember 2010, Dennis Güllners neues Leben 



\title{
Wie der Westen auszog, Afghanistan zu zivilisieren
}

Legitimationsmuster des Afghanistaneinsatzes zwischen 2001 und 2010

\author{
FARisa Al Ahmad, ZERrin GÜnes, Jeldrik HanschKe, Hannah \\ Materne, Hannah Neumann, Konstantin Rosenberger, Miriam \\ SCHELP UND CAROLIN STEHR
}

Demokratische Staatsordnungen bedürfen in der Öffentlichkeit einer Legitimation ihrer eigenen Herrschaft, um den Glauben an ihre Rechtmäßigkeit durchsetzen zu können. Da die Legitimität einer demokratischen Herrschaft an den Volkswillen gebunden ist, müssen sie ihr Handeln und die damit verbundene Legitimation fortwährend kommunizieren (Kirchhoff 2010: 41). Die Regierenden verfügen zwar gewissermaßen über Entscheidungsfreiheiten, müssen sich bzw. ihr Handeln gegenüber dem Volkssouverän jedoch kontinuierlich rechtfertigen (Heller 1970: 271). Die politische Herrschaft ist demzufolge sowohl begründungspflichtig als auch zustimmungsabhängig, was wiederum durch die politische Kommunikation in der Öffentlichkeit erreicht wird. Die Medien spielen für die Artikulation der Legitimation einer Herrschaft eine wichtige Rolle, da sie als intermediäre Institution zwischen dem politischen System und der Öffentlichkeit fungieren (Kirchhoff 2010: 50, siehe auch Neumann in diesem Band).

Dieses Wechselspiel wird im folgenden Beitrag anhand der Legitimation des Afghanistaneinsatzes dargestellt. Die Entscheidung, BundeswehrsoldatInnen nach Afghanistan zu entsenden, wurde innerhalb des politisch-administrativen Systems getroffen und muss gegenüber der Öffentlichkeit gerechtfertigt werden. Diese Vermittlung erfolgt mittels Rahmungen (Frames). Der Afghanistaneinsatz 
und der Einsatz von SoldatInnen wird auf eine Art und Weise begründet, die eine gewisse Bewertung impliziert. Fischers Äußerung „Nie wieder Auschwitz“ zeigt mit Bezug auf den Kosovo-Krieg, wie wirkmächtig derartige Rahmungen sein können. Mit seinem Ausspruch rahmte Fischer den Krieg als Massenmord und stellte eine direkte Verbindung zu den Kriegsgräueln im Zweiten Weltkrieg her, die insbesondere in Deutschland eine Ablehnung des Einsatzes nahezu unmöglich machten, obwohl der historische Verweis selbst unzulänglich war (Meder 1998: 201-210; Schwab-Trapp 2002). Ähnliche, wenngleich ein wenig subtilere Rahmungen, finden sich auch im Kontext der (De-)Legitimation des Afghanistaneinsatzes.

Der Diskurs zum Einsatz in Afghanistan begann kurz nach den Anschlägen vom 11. September 2001. Er entwickelte und veränderte sich nach und nach durch die Auseinandersetzung mit der Intervention. Der vorliegende Beitrag analysiert diese Entwicklung am Beispiel der Berichterstattung der SZ in den Jahren 2001 bis 2010. Die Arbeit steht damit im Kontext früherer Publikationen (siehe bspw. Liebl und Taheri 2001, Kassel 2004, Pohl 2005, Kassel und Klaus 2008, Maurer et. al 2008 und Kirchhoff 2010), geht aber an einigen Stellen über sie hinaus, weil er insbesondere nach Kontinuitäten und Brüchen der (De-) Legitimationsmuster sucht und die gefundenen Frames im Sinne der Heimatdiskursforschung in den sozialen und kulturellen Kontext der „Heimat“, also Deutschlands, einbettet. Die Ergebnisse beruhen auf einer qualitativen Framinganalyse von Kommentaren und Leitartikeln, die in besagtem Zeitraum in der SZ erschienen sind. Insgesamt wurden 137 Artikel untersucht. Es wurde induktiv ein Kategoriensystem entwickelt, einzelne Kategorien wurden zu Clustern verdichtet. Daraus entstand ein Konzept von fünf Frames, die durch zwei Vorannahmen strukturiert sind: die Rationalität des Westens und die Irrationalität des Gegners. Diese Dichotomie hat nicht nur weite Teile der Berichterstattung geprägt, sondern liegt auch dem folgenden Beitrag zu Grunde.

\section{Theorie Und Methode}

Die Ergebnisse beruhen auf mehreren konzeptionellen Vorarbeiten, die in dem folgenden Kapitel exemplifiziert werden. Unserer Arbeit liegt ein analytischpragmatisches Diskursverständnis zu Grunde (Kerchner 2006). Sie baut auf dem Legitimationsverständis Habermas' auf (Habermas 1973) und setzt dieses in Bezug zu politikwissenschaftlichen Kriegslegitimationstheorien. Operationalisiert wird die Suche nach Legitimationsmustern im empirischen Material mit Hilfe 
des Framingansatzes im Sinne der Pluralismusthese (nach D'Angelo 2010 und Reese 2010).

\section{Diskursverständnis}

Im Sinne des theoretischen Konzepts des Heimatdiskurses steht unsere Arbeit in der Tradition eines analytisch-pragmatischen Diskursverständnisses (Kerchner 2006). Diskurse sind demzufolge ein „Feld komplexer sprachlicher und symbolischer Interaktion, auf dem (politische) Akteure ihr Verständnis von Wirklichkeit sowie die Logik ihres Handelns generieren.“ (Kerchner 2006: 50). Für die Betrachtung von Diskursen ist unter Berücksichtigung der drei Dimensionen Sprachgebrauch, Kognition und Interaktion die Frage entscheidend, wie der Sprachgebrauch unser Denken und unser Handeln beeinflusst und umgekehrt (Dijk 1997: 1f.). Die Diskursanalyse betrachtet die Regeln und Strategien, unter denen das geschieht (ebd: 32). Die diskursive Struktur ist dabei in einen sozialen und kulturellen Kontext eingebettet, den wir bei der Analyse berücksichtigen werden (ebd.).

Am Beispiel der Legitimation des Einsatzes zeigt sich dies bereits bei einer einfachen Betrachtung der AkteurInnen und Sichtweisen. Der Einsatz kann beispielsweise aus der Position des Nationalstaats Deutschland mit einer souveränen Außen- und Sicherheitspolitik legitimiert werden. Eine andere Position zur Intervention kann ein Angehöriger von in Afghanistan stationierten oder getöteten BundeswehrsoldatInnen einnehmen. Ferner kann die Intervention aus der Sichtweise heraus legitimiert werden, dass Deutschland in globale Bündnisse und Allianzen eingebunden ist und daher seiner Bündnisverpflichtung nachkommen sollte. Demnach verbirgt sich hinter jeder Position ein Subtext, der den Heimatdiskurs und damit die politischen Hintergründe von Entscheidungen und die Legitimation von Auslandseinsätzen beeinflusst. Die Aufgabe der Heimatdiskursforschung besteht darin, die Subtexte im Zusammenhang mit dem kulturellen Gedächtnis offen zu legen (Daxner 2008a: 7). Die Diskursanalyse, mit Hilfe derer das geschieht, ist als solche keine konkrete Methode, sondern umfasst unterschiedliche theoretische und methodologische Ansätze, darunter die Frame-Analyse, die hier für die Untersuchung des Heimatdiskurses herangezogen werden soll.

\section{Der Legitimationsbegriff}

Zur Vorbereitung auf die empirische Analyse ist es zunächst erforderlich, den Legitimationsbegriff theoretisch zu bestimmen, um auf ihm aufbauend verschie- 
dene Legitimationsmuster in der deutschen Berichterstattung identifizieren zu können. Unserer Arbeit liegt der Legitimationsbegriff von Habermas zu Grunde, bei dem es darum geht, die Rechtfertigung bestimmter Handlungsweisen - im vorliegenden Fall den Einsatz deutschen Militärs in Afghanistan - zu gewährleisten. Habermas unterteilt den Legitimationsbegriff in drei unterschiedliche Kategorien: Empirisch, normativistisch und rekonstruktivistisch. Wir stützen uns auf den rekonstruktivistischen Legitimationsbegriff. Dieser bestimmt etwas als legitim, sobald es verallgemeinerbare Interessen repräsentiert. Eine einzelne Rechtfertigung nennt Habermas Legitimation. Jede Legitimation erhebt den normativen Geltungsanspruch, verallgemeinerbare Interessen zum Ausdruck zu bringen. Ob dieser Geltungsanspruch anerkannt wird und die Legitimation somit Gültigkeit erlangt, wird in einem Rechtfertigungssystem ausgehandelt. Wird sie als gültig bewertet, so werden die ihr zu Grunde liegenden Annahmen akzeptiert und vice versa (Habermas 1973: 294-299). Gehen wir zur Verdeutlichung zurück zu Fischers Satz „Nie wieder Auschwitz“. Die Verhinderung eines Völkermordes ist im Sinne auch, und ganz besonders, der deutschen Öffentlichkeit. Wir haben uns geschworen, dass nie wieder Krieg geführt werden oder herrschen soll. In der Abwägung zwischen diesen beiden Grundsätzen nimmt Fischer eine klare Wertung vor. Er schafft über einen negativen Zusammenhang nahezu einen Zwang, seinen Geltungsanspruch als gültig anzuerkennen. Wer seinem Ausspruch „Nie wieder Auschwitz“ widersprechen würde, würde im Umkehrschluss den Völkermord der Nazis bejahen. Eine qualifizierte Auseinandersetzung mit seinem Ausspruch - Qualifizierung der Vorkommnisse in Jugoslawien als etwas Anderes als Völkermord und eine gleichzeitige absolute Verneinung von Völkermord - fand in der öffentlichen Diskussion kaum statt.

Der Ausspruch Fischers steht damit in der Tradition politischer und politikwissenschaftlicher Debatten um die Legitimität von Kriegen und Interventionen, geführt in demokratischen Staaten im Allgemeinen und den USA im Besonderen. Hier lassen sich grob drei Legitimationsmuster unterscheiden (Küpeli 2007). Der NATO-Einsatz in Serbien (Kosovo, 1999) wurde durch die Argumentation einer humanitären Katastrophe legitimiert (Arte France 2005). Die Forderung nach der Herstellung von Sicherheit ist das zweite Legitimationsmuster der aktuellen Kriegs- und Interventionsdebatte. Synonyme für diese Legitimation sind beispielsweise der Präventionskrieg, wie er u.a. 2003 von den USA und Großbritannien gegen den Irak geführt wurde, und das Konzept der Schutzverantwortung (Responsibility to Protect; R2P). Als drittes Legitimationsmuster ist die These von den Neuen Kriegen zu erwähnen (Münkler 2006). Im Zuge dieser Kriege kam es zu Asymmetrisierung und Autonomisierung von Kriegen und damit zu einer Auflösung klassischer Grenzen: territorialer Grenzen, Unterschei- 
dungen zwischen Krieg und Frieden, Freund und Feind, Kombattanten und Nichtkombattanten, legaler und illegaler Gewalt und zwischen Gewaltanwendung und Erwerbsleben (Münkler 2006: 284-303), die neue Formen der Kriegsführung, und mit ihnen die Intervention, rechtfertigen.

\section{Framing}

Die verschiedenen Legitimationsmuster in der deutschen Öffentlichkeit, die sich teilweise, aber bei Weitem nicht vollständig mit denen der politikwissenschaftlichen Diskussion decken, werden mit Hilfe einer Framinganalyse von Kommentaren und Leitartikeln in der SZ erfasst. Frames sind Deutungsrahmen, die spezifische Aspekte eines Themas betonen und so eine bestimmte Interpretation des Themas privilegieren (Scheufele 2003: 46). Sie setzen sich aus vier Dimensionen zusammen: einer Problemdefinition, einer Ursachendiagnose, einer moralischen Bewertung und einem Lösungsvorschlag bzw. einer Handlungsempfehlung (Entman 1993: 52).

Konkret fassen wir Frames im Sinne der pluralistischen Definition von Reese als ,organizing principles that are socially shared and persistent over time, that work symbolically to meaningfully structure the social world" (Reese 2010: 17). Diese Definition eignet sich besonders für eine legitimationstheoretische Fragestellung, da sie aus einer kulturwissenschaftlichen Perspektive erlaubt, Rückschlüsse über das Zustandekommen kollektiv geteilter Entscheidungen zu ziehen. So verweist die Formulierung ,socially shared“ auf einen gemeinsamen Sinnhorizont oder spezifischer auf ein geteiltes kulturelles Repertoire. Frames greifen auf Symbole aus diesem Repertoire zurück. Sie strukturieren demnach sinnstiftend die soziale Welt, weil sie in Form von Symbolen kollektiv verfügbares Wissen verwenden, bestehende Sinnangebote aktualisieren und neue unterbreiten. Es handelt sich um ,structures of meaning made up of a number of concepts and the relations among these concepts" (Hertog und McLeod 2001: 140). Eine Analyse in diesem Sinne bleibt nicht deskriptiv, sondern legt die Subtexte der Medien-Frames offen. Eben diese Offenlegung von Subtexten formuliert die Heimatdiskursforschung als ihre zentrale Aufgabe.

\section{Ausgangsmaterial}

Die Berichterstattung über den Bundeswehr-Einsatz in Afghanistan im Meinungsteil der SZ bildet die Grundgesamtheit unserer Untersuchung. Es wurden Leitartikel und Kommentare aus der Printausgabe analysiert. Bei der SZ handelt es sich um die auflagenstärkste überregionale Tageszeitung in Deutsch- 
land. ${ }^{1}$ Neben dem Nachrichtenmagazin „Der Spiegel“ gilt die SZ als bedeutendstes Orientierungsmedium für JournalistInnen (Weischenberg et al. 2006: 359). Dies lässt auf eine Multiplikator-Funktion der SZ schließen und einen - im Vergleich zu anderen Printmedien - relativ großen Einfluss auf den Heimatdiskurs vermuten. Zum anderen existieren bereits Untersuchungen zur Legitimation deutscher Auslandseinsätze, die sich ebenfalls auf Artikel aus der SZ beziehen (vgl. Maurer et al. 2008; Nachtigall 2010; Pohr 2005, siehe auch Herzog et al. in diesem Band). Aufgrund der ähnlichen Quellenbasis wird die Vergleichbarkeit mit den Forschungsergebnissen dieser Studien erhöht. Die Untersuchung von Leitartikeln und Kommentaren auf der Meinungsseite erwies sich für unsere Fragestellung als interessant, da sie als am stärksten normativ aufgeladene Artikeltypen von Tageszeitugen eingestuft werden. Somit lassen sich verdichtete und teilweise explizitere Darstellungen von Legitimationsmustern erwarten (Schrader 2006).

Der Erhebungszeitraum wurde auf die Zeit vom 11. September 2001 bis zum 31. Januar 2010 festgelegt. Aus forschungsökonomischen Gründen wurde die Analyse auf einzelne Zeitabschnitte innerhalb des Untersuchungszeitraums begrenzt. Jeweils ein längerer Abschnitt am Anfang und am Ende sowie regelmäßige Zeitabschnitte innerhalb des Untersuchungszeitraums ermöglichen eine Analyse der zeitlichen Entwicklung der Legitimationsmuster. Als Maßstab für die regelmäßigen zeitlichen Abschnitte wurden die Erteilung und Verlängerungen des Mandats durch den Deutschen Bundestag bestimmt. Dabei wurden zwei Wochen vor und zwei Wochen nach den insgesamt neun Mandatsverlängerungen im Untersuchungszeitraum einbezogen. Diese Langzeitperspektive wird durch die Untersuchung weiterer Critical Points ${ }^{2}$ ergänzt. Die konkrete Materialauswahl innerhalb dieser Zeiträume erfolgte mittels einer Schlagwort-Suche ${ }^{3}$ im Ar-

1 Laut Angaben der Informationsgemeinschaft zur Feststellung der Verbreitung von Werbeträgern (IVW).

2 Critical Points sind im Rahmen unserer Forschung zu definieren als Ereignisse (politische, militärische, soziale o.ä.) innerhalb des Untersuchungszeitraumes, die eine entscheidende Wirkung auf den Heimatdiskurs hatten oder haben konnten, bei denen also eine erhöhte Wahrscheinlichkeit einer Verschiebung innerhalb des Legitimationsdiskurses angenommen werden kann. Die Critical Points wurden auf Basis des Forschungsstands bestimmt und sind die einzelnen Mandatsverlängerungen sowie der 11. September 2001, die Präsidentschaftswahlen 2004, die Totenkopfaffäre 2006, das Kunduz-Bombardement 2009 und die Afghanistankonferenz 2010.

3 Die genutzten Schlagworte lauteten dabei: Afghan*, Kabul und Hindukusch, wobei die Suche nicht auf Groß- und Kleinschreibung achtet. Durch diese Schlagworte wur- 
chiv der SZ. Die so ermittelten 137 Artikel bildeten die Grundlage der intensiven Analyse.

Abbildung 1: Anzahl der untersuchten Artikel nach Monaten ( $n=137)$

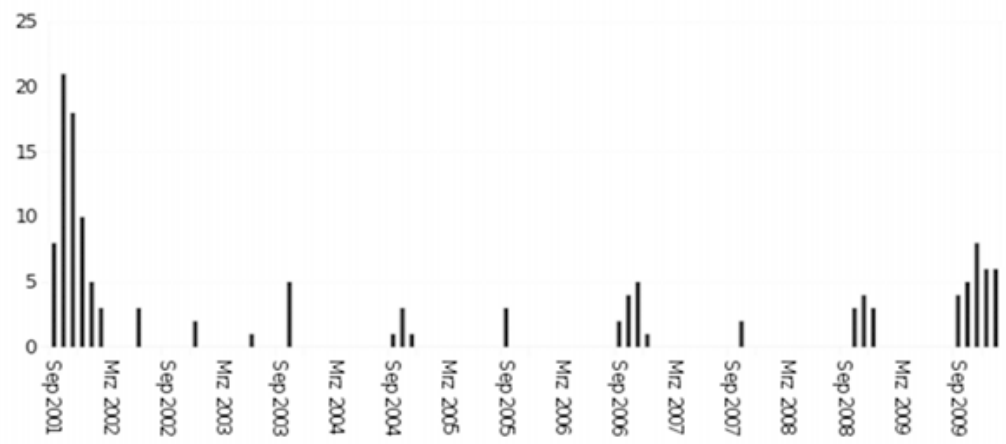

\section{Analyseschritte}

Die Frameanalyse wurde in drei Analyseschritten durchgeführt. Das Material wurde mittels einer qualitativen Inhaltsanalyse nach Philipp Mayring (2010) ausgewertet. Im ersten Analyseschritt wurden die Artikel aus dem ersten Analysezeitraum (vom 11.9.2001 bis Jahresende 2001) mittels zusammenfassender Kategorienbildung analysiert. Diese Analystechnik zielt darauf ab, mittels Reduktion und Abstraktion ein gekürztes, aber dennoch repräsentatives „Abbild des Materials“ (Scheufele 2003: 119) zu schaffen. Für die Fragestellung relevante Textstellen wurden den vier Frame-Dimensionen zugeordnet, ${ }^{4}$ paraphrasiert, gebündelt und zu einem vorläufigen Frame-System zusammengefasst. Um den Einfluss subjektiver Interpretationen bei der Kodierung der Textstellen zu reduzieren und ein möglichst einheitliches, intersubjektiv nachvollziehbares und transparentes Vorgehen zu ermöglichen, wurden ausgewählte Fälle in der Arbeitsgruppe gemeinsam diskutiert.

Im zweiten Analyseschritt wurde das gesamte Untersuchungsmaterial für das vorläufige Frame-System kodiert. Hierbei kam die Analysetechnik der inhaltlichen Strukturierung zur Anwendung. Das Frame-System wurde im Laufe des

den alle möglichen Ableitungen und Konjunktionen von Afghanistan, afghanisch etc. sowie die Benennung über die Hauptstadt oder die geografische Region erfasst.

4 Dabei kam es auch vor, dass eine Textstelle mehreren Dimensionen zugeordnet wurde. 
Analyseprozesses evaluiert und mittels zusammenfassender Kategorienbildung induktiv angepasst und ergänzt.

Am Ende dieses Anlayseschritts stand ein aus fünf Frames bestehendes System. Diese Frames wurden in einem abschließenden Analyseschritt anhand von Leitfragen auf ihre Subtexte hin analysiert: Wer hat was, wann, wie und weshalb gesagt? Welche Begriffe, sprachlichen Mittel und Symbole treten gehäuft auf? Welche Vorannahmen und Konzepte liegen einer Argumentation zugrunde? Welche Assoziationen werden geweckt? Die Antworten auf diese Fragen werden im folgenden Kapitel exemplarisch und verdichtet dargestellt.

\section{ERgebNisse}

Auf der Grundlage der Framinganalyse wurden fünf Frames identifiziert: (1) „Krieg gegen den Terror - Verteidigung des Westens“, (2) „Übernahme von Verantwortung aufgrund Deutschlands weltpolitischer Rolle“, (3) „Militärische und entwicklungspolitische Verantwortung in und für Afghanistan“, (4) „Sauberer Krieg“, und (5) „Begründungspflichtigkeit der Außenpolitik“. Die Unterscheidung sind vor allem analytische. Überschneidungen und Überlappungen der Frames fanden sich im empirischen Material häufig. Dennoch ist die analytische Unterscheidung notwendig, um der Berichterstattung zugrunde liegende Vorstellungs- und Begründungszusammenhänge verstehen und einordnen zu können.

Bei der Auswertung der codierten Textstellen wurde deutlich, dass alle vorgebrachten Argumente und Positionen implizit oder explizit von einer grundsätzlichen Vorannahme gestützt werden: Die eigene Gruppe (Ingroup), meist synonym mit ,dem Westen', handle rational, während das gegnerische Gegenüber (Outgroup) - Terror-Gruppen, Taleban, Warlords - sich irrational ${ }^{5}$ verhalte. Diese Grundannahme wird als absolut gesetzt und gilt als nicht hinterfragbar oder verhandelbar (siehe auch Aljets et al. und Herzog et. al. in diesem Band). Sie wird vielfach über die Konstruktion von Feindbildern verwirklicht, welche die Outgroup als irrationalen, bösartigen Gegner charakterisieren (vgl. Claussen 1990). Die Legitimation des Einsatzes wird, unabhängig von weiteren Begründungsmustern, dadurch erhöht, dass die Outgroup entpersonalisiert und als Bedrohung westlich-aufklärerischer Werte dargestellt wird. Die Rezipienten empfinden keine Sympathie und entwickeln sogar den Eindruck, sich selbst vor dieser Gruppe schützen zu müssen. Mit der negativen Beschreibung der Outgroup

5 Wir beziehen uns hier auf ein Verstädnis von Rationalität im Sinne von ,vernünftig“ oder im Einklang mit dem „,common sense“. 
wird zugleich eine Aussage über die Ingroup getroffen: In der Verurteilung der Irrationalität und Immoralität des Gegners spiegelt sich das Selbstverständnis der Ingroup als rational und ethisch handelnder Akteur. In der SZ waren vor allem die Feindbilder Terror, Osama Bin Laden, Islamismus und Taleban präsent, die im Folgenden anhand ausgewählter Textstellen kurz veranschaulicht werden.

In den ersten Monaten nach dem 11. September 2001 werden die Gegner, gegen die sich eine militärische Intervention richten soll, vielfach mit Terror und Terrorismus in Verbindung gesetzt. Terror wird im Material oft personifiziert, als Ungeheuer dargestellt und durch eine gewalttätige, destruktive und emotionale Handlungslogik charakterisiert:

„Erst wenn der Terror-Hass erdrückt wurde durch demokratische Macht, lässt sich über die nächsten Schritte nachdenken, damit der aus Fanatismus und Zerstörungswur [sic!] gespeisten Hydra nicht neue Köpfe wachsen.“ (Kornelius 2001a)

Der Terror wird hier mit dem neunköpfigen Schlangenwesen Hydra verglichen, die die landwirtschaftliche Lebensgrundlage der sie umgebenden Menschen zerstörte und Angst und Schrecken verbreitete. Im Umkehrschluss wird die ,demokratische Macht“ (ebd.) mit dem altgriechischen Helden Herakles identifiziert, der die Aufgabe übertragen bekam, die Hydra zu erlegen. Herakles' Versuch, die einzelnen Köpfe der Hydra abzuschlagen, erwies sich als erfolglos, da für jeden abgeschlagenen Kopf zwei neue nachwuchsen. Schließlich besiegte Herakles die Hydra, indem er ihre Köpfe ausbrannte und ihr auf diese Weise die Möglichkeit zur Erholung nahm. Er konnte so zu ihrem einen, unsterblichen Kopf vordringen und sie enthaupten (Abenstein 2007: 175). ${ }^{6}$

Unter Rückgriff auf die im kulturellen Gedächtnis verankerte griechische Mythologie wird das Regime in Afghanistan so als ein Kopf des Ungeheuers Terror inszeniert, der effektiv - in diesem Kontext gleichbedeutend mit militärisch - bekämpft werden muss, um zur Wurzel des Übels vordringen und es beseitigen zu können. Die Identifikation der Ingroup mit Herakles rahmt die eigene militärische Gewaltanwendung als heroischen Kampf gegen das Ungeheuer. Die Outgroup wird im gleichen Zug dämonisiert. Ihre Gewaltlogik ist „heimtückisch und hinterhältig“ (Kornelius 2001j), durch „Hass“, „Fanatismus“ und „Zerstörungswut“ (ebd.) getragen und wird so mit Blindwütigkeit und Irrationalität kon-

6 Die Geschichte geht hier in der Mythologie weiter. Nicht Herakles, sondern der listenreiche Odysseus wird zum mythischen Vorbild der Moderne (siehe Weiss 1975, 1978 und 1981). 
notiert. Der Einsatz militärischer Mittel ist notwendig, ,weil die Anführer und Ausführer des Terrors zunächst nur die Sprache der Gewalt verstehen." (Kornelius 2001a) Vernünftiger Verhandlung sind sie nicht zugänglich (vgl. auch Kornelius 2001j). Die eigentliche Verantwortung für eine militärische Intervention liegt somit beim Gegner; die Ingroup wendet Gewalt lediglich als letztes Mittel an.

Zum verantwortlichen Gesicht des Terrors wurde in den ersten Monaten nach 9/11 Osama bin Laden: „Dieser Mann liebt seine Terror-Tat und er will mehr davon." (Kornelius 2001b) Bin Laden wird hier eine irrationale Leidenschaft für Gewalttätigkeit und Grausamkeit zugeschrieben:

„Nein, dieser bin Laden unterdrückt selbst, er steht für ein terroristischtheokratisches Herrschaftssystem, das wie Saddam Hussein nicht vor dem Einsatz von Giftgas zurückschrecken würde, und das wie selbstverständlich foltert und knechtet.“ (Kornelius 2001b)

Die Verknüpfung zwischen Osama bin Laden und den Giftgasangriffen Saddam Husseins auf die kurdische Bevölkerung im irakischen Halabdscha 1988 ruft Bilder von toten Kindern und Frauen - Gruppen, die als besonders verwundbar gelten - auf. Durch diese Konstruktion wird die militärische Intervention nicht als ein willkürlicher Gewaltakt wahrgenommen, sondern als notwendige humanitäre Intervention, welche der Unterdrückung der afghanischen Bevölkerung entgegentritt: „Bin Laden und seine Leute haben in ihrer Vernichtungsphilosophie ausreichend Belege geliefert, die den Einsatz des Militärs rechtfertigen." (Kornelius 2001b)

Islamismus wird im Material oft als gewalttätig und rückständig konstruiert. Er wird im Diskurs eng mit Terror verknüpft, insbesondere im Jahr 2001. Die folgenden Beispiele verdeutlichen diese durchweg negative Konnotation, wobei nicht immer zwischen Islam und Islamismus differenziert wird: „Glaubenskämpfer“ (Münch 2001j), „Radikalisierung der islamischen Welt“ (Kornelius 2001d), „islamistische[r] Terrorismus“ (Prantl 2001b; Münch 2001d), ,islamistische[r] Terror“ (Prantl 2001a), „Korankrieger“ (Münch 2001h), ,islamistische[r] Fanatismus" (Prantl 2001d). Hierbei ist auffällig, dass die Feindbildkonstruktion sich nicht nur auf eine bestimme Gruppe in Afghanistan konzentriert, sondern pauschalisierend auf die gesamte Religion projiziert wird, ihr Rückständigkeit zuschreibt und darüber vom Christentum und „dem Westen“ abgrenzt. Während das Christentum Gewalt als Mittel hinter sich gelassen habe, sei die „Gewalttätigkeit des Islam“ (Prantl 2001d) Gegenwart. Die christliche Religion, die in den 
Gesellschaften der Intervenierenden dominant ist, wird somit in der Moderne verortet. Der Islam befindet sich jedoch weiterhin im Mittelalter und agiert dogmatisch gegen säkulare, aufklärerisch-liberale Werte, die das Selbstverständnis der Ingroup prägen:

„Es geht den Islamisten um den Versuch einer Zeitverschiebung - zurück in die Zeit vor der Aufklärung (...). Gegen Gottes Wort gibt es keinen Protest, da werden Redefreiheit, Pressefreiheit, Glaubensfreiheit, Wissenschaftsfreiheit, da wird die Ausübung von Grundrechten zur Blasphemie.“" (Prantl 2001d)

Das Feindbild Taleban wird in der SZ über den gesamten Untersuchungszeitraum hinweg aufgebaut und stabilisiert. Zu Beginn geschieht dies insbesondere unter Rückgriff auf die Kategorien Islam, Terror und bin Laden. Der Begriff Taleban war vor 9/11 relativ unbekannt, wurde aber rasch mit Inhalten wie ,ultrafundamentalistischen Taliban“ (Avenarius 2001b) und der Gefahr, „dass die Taliban bald ganz Afghanistan kontrollieren.“ (ebd.), besetzt. Damit besteht die Notwendigkeit einer Intervention auch darin, der von den Taleban ausgehenden Gefahr entgegenzuwirken. Innerhalb kürzester Zeit stehen die „weltfremden Korankrieger [...] plötzlich im Mittelpunkt des Weltinteresses“ (Münch 2001j). Bereits der Titel des zitierten Artikels „Steinzeit versus Mikrochip“ (ebd.) verdeutlicht die Dichotomie und vor allem Asymmetrie zwischen „SteinzeitFundamentalisten“ (Blechschmidt 2007) und „uns“, zwischen Rückständigkeit und Fortschritt, denn wenn „Regionalherrscher, Stämme und die Taliban [...] mit allem, was verletzt und tötet, um die Macht kämpfen“ (Kornelius 2009e), ist die Dichotomie zwishen Barbarei und Zivilisation vollends geschaffen.

So entwickelt sich das grundlegende Argument der irrational handelnden Taleban, Terror-Gruppen oder Warlords als unhinterfragbar. Die skizzierte Dichotomie liegt weiten Teilen der Berichterstattung zwischen 2001 und $2010 \mathrm{zu}$ Grunde. Sie durchzieht alle weiteren Frames, wird gegen Ende des Unter suchungszeitraums aber auch argumentativ als Delegitimation des Einsatzes verwendet: verkürzt, wenn den Afghanen nicht zu helfen ist, wofür sterben dann unsere SoldatInnen. Auf der Basis dieses Axioms werden nun die einzelnen Frames entlang der Bestandteile „Problemdefinition“, „Ursachendefinition“, „Moralische Bewertung“ und „Lösungsvorschlag“ (siehe Entman 1993) dargestellt. 


\section{Krieg gegen den Terror - Verteidigung des Westens}

\begin{tabular}{|l|l|}
\hline Problemdefinition & $\begin{array}{l}\text { Mit den Anschlägen auf World Trade Center und Penta- } \\
\text { gon am 11. September 2001 sind die USA Opfer terroris- } \\
\text { tischer Kriegshandlungen geworden. Sie und die gesamte } \\
\text { westliche Welt sind durch Terrorismus bedroht. }\end{array}$ \\
\hline Ursachendiagnose & $\begin{array}{l}\text { Terroristen allgemein und das afghanische Taleban- } \\
\text { Regime im Besonderen verstehen die westliche Welt als } \\
\text { Feind, der mit allen Mitteln bekämpft wird. }\end{array}$ \\
\hline $\begin{array}{l}\text { Moralische Bewer- } \\
\text { tung }\end{array}$ & $\begin{array}{l}\text { Der zivilisierten westlichen Gesellschaft steht ein aggres- } \\
\text { sives, menschenverachtendes Terroregime gegnüber. }\end{array}$ \\
\hline Lösungsvorschlag & $\begin{array}{l}\text { Der Westen muss sich gegen die terroristische Bedrohung } \\
\text { verteidigen und weiteren Anschlägen vorbeugen. Die mi- } \\
\text { litärisch gestützte Intervention ist dafür ein legitimes Mit- } \\
\text { tel. }\end{array}$ \\
\hline
\end{tabular}

Die Anschläge vom 11. September 2001 werden als „terroristische Kriegshandlung“ (Münch 2001c) beschrieben. Dabei kommt es zu einer Verknüpfung der Konzepte des Terrorismus und des Krieges zum „Terrorkrieg“ (Kornelius 2001a). Als Angegriffene in diesem „Krieg“ werden die USA betrachtet. Teilweise wird dies zusätzlich auf abstrakte Konstrukte wie die „mit der westlichen Welt assoziierte (...) liberale (...) Gesellschaft“ (Kornelius 2001c) erweitert. Die Verknüpfung von Terror und Krieg wurde kurze Zeit später zum „Krieg gegen den Terror“" gewendet. Von Beginn des Untersuchungszeitraumes an ist eine militärische Reaktion Gegenstand der untersuchten Artikel der SZ. Dabei wird für die grundsätzliche Legitimität und Notwendigkeit einer solchen argumentiert. In den ersten Tagen herrschte eine breite Heterogenität an Motiven hinsichtlich der Rechtfertigung einer (auch) militärischen Reaktion. Analytisch lassen sich drei Motive unterscheiden: die Vergeltung, die Verteidigung in einem bestehenden „Krieg“ und die Prävention gegen weitere Anschläge. Diese werden im Folgenden genauer beleuchtet.

Die Idee der ,Vergeltung“ ist insbesondere in den ersten Tagen nach den Anschlägen ein zentrales Motiv. So heißt es in der SZ vom 13. September: „Selbst der mehr oder minder gezügelte Verstand fordert im Anblick der Tragödie Vergeltung." (Kornelius 2001a) Von diesem stark emotional aufgeladenen Motiv wird jedoch bereits in den folgenden Tagen schrittweise Abstand genommen. So schreibt die SZ in einem Leitartikel vom 19. September 2001: „Größte Sorge der zivilisierten Welt sollte nicht Vergeltung für den 11. September sein, sondern Verhinderung künftiger Anschläge.“ (Ulrich 2001a, siehe auch Kornelius 2001a) 
Für kurze Zeit bedeutender als das Motiv der Vergeltung wird die Idee der „Verteidigung“, die auch „,als militärischer Angriff geführt“ (Ulrich 2001a) werden könnte. Die Anschläge werden nicht als singuläres Ereignis betrachtet, sondern als Beginn eines fortdauernden Krieges. In diesem bestehe - wahlweise für die USA (Kornelius 2001f) oder für die gesamte ,zivilisierte Welt“ (Münch 2001b) - das legitime Recht auf Selbstverteidigung. So schreibt die SZ am 8. Oktober 2001, dass „,der Militärschlag gegen die Taliban [...] ein Angriff zur Verteidigung der zivilisierten Welt gegen den Terror [sei]“ (Münch 2001b).

Für längere Zeit als tragfähig erwiesen hat sich das dritte Legitimationsmuster: die Prävention. Es gehe um die „Verhinderung künftiger Anschläge" (Ulrich 2001a). Dies ist von der Verteidigung nicht immer trennscharf zu unterscheiden. Der zentrale Unterschied zu diesem Legitimationsmuster ist, dass Prävention keinen permanent gedachten Kriegszustand voraussetzt. Die Idee der Prävention ist von Beginn an mit den beiden vorher genannten Motiven eng verschränkt. Ein plakatives Beispiel bringt ein Leitartikel vom 8. Oktober 2001, welcher mit „Angriff zur Verteidigung“ betitelt ist. Im letzten Absatz heißt es: „Der Kampf gegen den Terror mit militärischen Mitteln muss aus Gründen der Prävention geführt werden.“ (Münch 2001b)

Die Frage, die hinter der Debatte um Vergeltung, Verteidigung oder Prävention als gültige Legitimation steht, ist die um die völkerrechtliche Grundlage einer Intervention in einen souveränen Staat. Auf die Verknüpfung dieser beiden Ebenen wird jedoch wenig eingegangen. Einige Artikel thematisieren vor Kriegsbeginn die Frage, ob eine militärische Intervention ein erfolgversprechendes Mittel sei. Dabei wird problematisiert, welche Rolle andere Mittel, wie Diplomatie oder Entwicklungs- und humanitäre Hilfe, spielen könnten und ob ihre Erfolgsaussichten nicht größer seien (Kornelius 2001b). Ebenso wird diskutiert, in welcher Form die militärische Intervention stattfinden müsse, um den Terrorismus erfolgreich bekämpfen zu können und die Bedrohung des Westens nicht zu erhöhen (Chimelli 2001; Prantl 2001a). Auffällig ist, dass der hier behandelte Frame frühzeitig an die Menschenrechtsthematik anknüpft, um die Legitimität eines präventiven Militärschlags zu stützen. So heißt es bereits am 15. Oktober 2001: „Festzuhalten ist jedoch, dass in Afghanistan [...] kein Krieg gegen das Volk, sondern gegen das menschenverachtende Taliban-Regime und die Terrorkrake al-Qaida geführt wird.“ (Münch 2001d)

Ab 2003 wird der Kampf gegen den Terror als Bedrohung des Westens grundsätzlich nur noch bei gleichzeitiger Benennung der Verantwortung für die afghanische Bevölkerung thematisiert. Dies zeigt die abnehmende Bedeutung dieses Frames für den gesamten Diskurs. Wenn die militärische Bekämpfung des Terrors benannt wird, steht dieser einer positiv konnotierten Friedenssicherung 
gegenüber. Ersterem wird der amerikanische Einsatz, letzterem die deutsche Bundeswehr zugeordnet. Die Argumentation greift dabei auf die institutionalisierte Aufgabentrennung in ISAF und Operation Enduring Freedom (OEF) zurück: Auf der einen Seite stehen die „friedenssicherenden Bundeswehrsoldaten mit Isaf-Mandat“, auf der anderen die „Terroristenjäger der US-Armee“ (Blechschmidt 2005; vgl. auch Münch 2003, 2004b; siehe auch Robotham und Röder in diesem Band)

\section{Militärische und entwicklungspolitische Verantwortung in und für Afghanistan}

\begin{tabular}{|l|l|}
\hline Problemdefinition & Die Sicherheitslage in Afghanistan ist dauerhaft instabil. \\
\hline Ursachendiagnose & $\begin{array}{l}\text { Konkurrierende Interessensgruppen und gesellschaftliche } \\
\text { Praktiken in Afghanistan sowie die Rückkehr der Taleban } \\
\text { erschweren den Aufbau einer stabilen Nachkriegsord- } \\
\text { nung. Deutschland hat sich nicht ausreichend engagiert, } \\
\text { um dem entgegenzuwirken. }\end{array}$ \\
\hline $\begin{array}{l}\text { Moralische Bewer- } \\
\text { tung }\end{array}$ & $\begin{array}{l}\text { Afghanistan ist hilfsbedürftig. Eingeschränktes Engage- } \\
\text { ment und Truppenabzug lassen die Bevölkerung im } \\
\text { Stich. }\end{array}$ \\
\hline Lösungsvorschlag & $\begin{array}{l}\text { Deutschland steht in der Verantwortung, menschliche, } \\
\text { gesellschaftliche und staatliche Sicherheit in Afghanistan } \\
\text { zu gewährleisten. Der Bundeswehr-Einsatz ist hierfür ein } \\
\text { legitimes Mittel. }\end{array}$ \\
\hline
\end{tabular}

Im Januar 2010 legte die Bundesregierung ein Konzeptpapier zum weiteren deutschen Engagement in Afghanistan nach der Afghanistan-Konferenz von London vor. Darin heißt es: „Mit Beginn seines Engagements für Afghanistan hat Deutschland 2001 Verantwortung gegenüber all den Afghaninnen und Afghanen übernommen, die kein Zurück zu den Schrecken der Taliban-Herrschaft mehr wollen." (Die Bundesregierung 2010: 1) Der Begriff der Verantwortung hat in diesem Kontext viele Facetten, die es im Rahmen der Analyse zu konkretisieren gilt. Grundsätzlich sind dabei zwei Dimensionen zu erkennen: Die militärische und die entwicklungspolitische Verantwortung.

Im Verantwortungs-Frame der SZ dient die fragile Sicherheitslage in Afghanistan als Hauptlegitimationsmuster für eine Intervention von 2001 bis 2010. Zu Beginn hat zwar das Ende der Taleban-Herrschaft oberste Priorität, gleichzeitig werden aber Schwierigkeiten für die Installation einer stabilen Nachkriegsordnung wahrgenommen. Als Mittel ihrer Unterstützung werden vornehmlich die 
räumliche Ausweitung der Stationierung sowie die Erhöhung des Truppenkontingents diskutiert. Die Charakterisierung des deutschen Militärs als friedensstiftende Entwicklungshilfe gegenüber der auf die Liquidation und „das Grobe“ spezialisierten US-Armee taucht während des gesamten Untersuchungszeitraums immer wieder auf. „Je mehr Afghanen den Nutzen der fremden Hilfe schätzen lernen, desto mehr lernen sie auch zu unterscheiden.“ (Blechschmidt 2005) Die Differenz zwischen einem „friedenssichernden Bundeswehrsoldaten mit Isaf-Mandat und einem Terroristenjäger der US-Armee“ (Blechschmidt 2005) soll aufrecht erhalten bleiben. Insbesondere bei der Bundeswehr lässt sich eine Erweiterung der Aufgabenbereiche über traditionell militärische hin zu quasi polizeilichen Tätigkeiten feststellen: Sie sind nicht vornehmlich für Kriegshandlungen vorgesehen, sondern für die Durchsetzung einer stabilen, bürgerlichen Rechtsordnung. In den Jahren 2004 und 2005 konstatiert der Autor Klüver, das deutsche Militär habe wichtige Beiträge in Afghanistan geleistet, indem es die Gewalt eingedämmt habe und die Entstehung ,zarte[r] Ansätze bürgerlichen Lebens“ (Klüver 2004) beförderte. Die BundeswehrsoldatInnen seien vorbildlich entwicklungspolitisch tätig, allerdings könnten sie nicht nur „bewaffnete Entwicklungshelfer“ (Klüver 2004) bleiben, sondern müssten auch im Kampf ihre Beteiligung zeigen (siehe auch Herzog et al. in diesem Band). Grundsätzlich wird jederzeit ein notwendiger Zusammenhang zwischen dem militärischen und dem zivilen (Wieder-)Aufbau angenommen. „Wenn es der Nato nicht schnell gelingt, das Zivile und das Militärische so zusammenzubinden, dass die Afghanen wirkliche Hoffnung schöpfen können, dann wird Afghanistan zum Irak der Nordatlantischen Allianz." (Winter 2006a)

Ab 2002 wird die Situation im Land durchgehend als negativ eingeschätzt. Eine Ausnahme bilden die Präsidentschaftswahlen von 2004, die zum Teil zu positiven Zukunftsperspektiven verleiten. Die in Afghanistan wahrgenommenen Probleme lassen sich in zwei Gruppen unterteilen: Zum einen von Afghanistan unabhängige Probleme wie etwa die unterschiedlichen Interessen der Intervenierenden, die Wahl der richtigen Taktik oder die mangelnde Vermittlung des als richtig bewerteten Einsatzes gegenüber der deutschen Bevölkerung. Zum anderen gibt es zahlreiche Schwierigkeiten in Afghanistan, die aber vornehmlich von den afghanischen AkteurInnen selbst verursacht würden: Gewalt gegen Frauen, Korruption, Drogenhandel etc. Ebenfalls wird die Multi-Ethnizität Afghanistans als Erklärung für die Schwierigkeiten beim Aufbau eines bürgerlichen Nationalstaates angeführt. Im Falle der Wahlen 2009 personalisiert sich die Kritik stark auf Präsident Karsai. „Wieso schlagen wir uns für ein durch und durch korruptes Regime, das selbst keinen Finger zu rühren scheint für Wohlstand und Wohlergehen seines eigenen Volkes?“ (Koydl 2009) Der Fehler des sogenannten Wes- 
tens bestehe darin, den Präsidenten zu sehr unterstützt zu haben (Matern 2009). Die Intervenierenden tragen an der Situation lediglich dahingehend eine Mitschuld, dass sie Afghanistan nicht ihr volles Engagement gewidmet haben. Wenn die Intervention überhaupt explizit begründet wird, dann mit einer eher abstrakten Verantwortung für die „leidende afghanische Zivilbevölkerung [...], denen eine Zukunft ohne Minenfelder, Drogenschmuggel und Gewalt gegen Frauen“ (Bork 2002) ermöglicht werden sollte.

Im Jahr 2003 tritt in der SZ erstmals explizit die militärische Verantwortung Deutschlands als Legitimationsmuster für die Intervention in Afghanistan auf. Beispielsweise heißt es im Oktober 2003, dass „,die Bundesregierung [...] militärisch Verantwortung übernehmen [müsse]“. (Klüver 2003) Die Pflicht Deutschlands zur Intervention wiederholt sich unter dem Schlagwort der Verantwortung im Jahr 2007. Auf die Frage, weshalb Deutschland SoldatInnen nach Afghanistan schicke, lautet 2007 die Antwort in der SZ: „Es trägt Verantwortung in einer ziemlich unglücklichen Welt.“ (Blechschmidt 2007) Ein baldiger Abzug der Truppen aus Afghanistan wird während des gesamten Untersuchungszeitraumes abgelehnt. Einem vorzeitigem Abzug erteilt Münch eine klare Absage: Die Bundesregierung müsse sich ,tatsächlich noch mehr und vor allem klarer einlassen auf Afghanistan. Das erfordert Kraft und einen langen Atem, ist aber der einzige Weg - außer dem kopf- und verantwortungslosen Rückzug - der wieder aus dem Hindukusch heraus führt.“ (Münch 2005)

Auffällig ist, dass in den Jahren 2006, 2007 und 2008 Warnungen vor einem verfrühten Abzug vermehrt auftreten und offen bei der deutschen Bevölkerung für Rückhalt zum Afghanistan-Einsatz der Bundeswehr geworben wird. Der „Wiederaufbau verläuft dermaßen schleppend, dass nicht einmal in der Hauptstadt Kabul der Strom fließt. In den Provinzen regiert ohnehin die Finsternis.“ (Münch 2006a) Gerade weil die deutsche Beteiligung Wesentliches für den Wiederaufbau geleistet habe, könne sie sich den internationalen Verpflichtungen nicht länger entziehen (Münch 2006a).

$\mathrm{Ab} 2006$ wird eingeräumt, dass die Taleban als machtvoller Akteur zurückgekehrt sind. Zwar war die Bedrohung durch die Taleban bereits in den Jahren zuvor immer wieder Thema, aber die Berichterstattung stufte die Gefahr für die Sicherheit der afghanischen Bevölkerung und der Intervenierenden von 2002 bis Herbst 2006 als gering ein. Folglich führt dies im Jahr 2010 zu der ambivalenten Feststellung, dass ein endgültiger Sieg über die Taleban nicht möglich sei, die Intervention aber grundsätzlich positive Wirkungen für die Zivilbevölkerung gezeitigt habe. Trotz Truppenerhöhungen müsse sich damit abgefunden werden, dass ein Sieg über den Gegner - die Taleban als ein Hauptfokus zu Beginn der Intervention - nicht möglich sei und sie von der afghanischen Regierung einge- 
bunden werden müssten (Kornelius 2010a). Nichtsdestotrotz ist für Kornelius hinsichtlich eines Abzugs ein eindeutiges Fazit zu ziehen, denn für die „Afghanen, die seit 2001 ein besseres und friedlicheres Leben führen können als zuvor“" (Kornelius 2010b), wäre ein Abzug eine Katastrophe. „Und das sind nicht wenige. " (Kornelius 2010b)

\section{Sauberer Krieg}

\begin{tabular}{|l|l|}
\hline Problemdefinition & $\begin{array}{l}\text { In Kriegen und militärisch gestützten Interventionen ster- } \\
\text { ben auch Zivilisten. }\end{array}$ \\
\hline Ursachendiagnose & $\begin{array}{l}\text { Militärische Auseinandersetzungen werden mit Gewalt } \\
\text { geführt. }\end{array}$ \\
\hline $\begin{array}{l}\text { Moralische Bewer- } \\
\text { tung }\end{array}$ & $\begin{array}{l}\text { Zivile Opfer sind bedauerlich, müssen aber bei der Be- } \\
\text { këmfung tyrannischer Herrschaft in Kauf genommen } \\
\text { werden. }\end{array}$ \\
\hline Lösungsvorschlag & $\begin{array}{l}\text { Präzisionsschläge ermöglichen es, nur ausgewählte Ziele } \\
\text { zu treffen und Opfer unter Zivilisten zu begrenzen. Sie } \\
\text { sind daher ein legitimes Mittel im Rahmen einer militä- } \\
\text { risch gestützten Intervention. }\end{array}$ \\
\hline
\end{tabular}

In der SZ vom 9. Oktober 2001 zeichnet Kornelius das Bild eines Sauberen Krieges in Afghanistan: saubere Militärschläge werden als sinnvolles Mittel verteidigt, da sie „den Tyrannen und nicht den Tyrannisierten gelten.“ (Kornelius 2001b) So wird das Bild vermittelt, dass die Unterdrückten von der illegitimen Gewaltherrschaft befreit werden, ohne selbst Angst vor einer Kriegssituation haben zu müssen. Trotzdem auftretende zivile Opfer im Rahmen der Luftschläge werden als „ungewollt und unglücklicherweise“ (Kornelius 2001j) dargestellt. Tote ZivilistInnen dürfen laut Kornelius nicht auf Basis des Einzelfalls bewertet werden: „Die Luftangriffe aber müssen in einem größeren Zusammenhang betrachtet werden, als Teil eines auf lange Zeit angelegten politischen Plans, für den der Einsatz des Militärs nur ein erster, möglichst kurzer Schritt sein darf." (Kornelius 2001j) Demnach wird das Sterben Unschuldiger mit einem „höheren Ziel“ und einem „politischen Plan“ (Kornelius 2001b) gerechtfertigt. Da es nur einer ersten, kurzen Etappe der Intervention zugeordnet wird, widerlegt es die Idee eines sauberen Krieges nicht.

Im Kontext der Debatte um einen sauberen Krieg, ist die Verwendung medizinischer Metaphern auffällig. Die Bezeichnung der Luftschläge als „,chirurgische[...] Angriffe“ (Münch 2001d) und „Mittel zur Bekämpfung“ (Prantl 2001c) weckt Assoziationen zur medizinischen Behandlung einer Krankheit. Hier wer- 
den zwei Subtexte offenkundig: Zum einen werden die Intervenierenden als Arzt konstruiert, welcher die Aufgabe hat, den vom Terrorismus befallenen Patienten - Afghanistan - zu heilen; zum anderen tritt die Einschätzung der Intervenierenden als durch eine Seuche - den Terrorismus - Bedrohte zu Tage.

Bereits Mitte Oktober desselben Jahres fordern jedoch kritische Stimmen das Framing der Afghanistan-Intervention als sauberen Krieg heraus, denn „immer wieder verfehlen die Bomben ihr Ziel, treffen Flüchtlingszüge statt Militärkonvois wie im Kosovo oder ein Wohnhaus statt einer Taliban-Stellung wie nun in Afghanistan." (Münch 2001d; vgl. auch Prantl 2001c) Markant ist jedoch, dass erst mit den ersten toten Bundeswehrsoldaten im Frühling 2003 eine breite Auseinandersetzung mit den unabwendbaren Verlusten einsetzt, die ein Krieg mit sich bringt. Der Tod von Kameraden werde innerhalb der betroffenen „Truppe als zutiefst verstörendes Ereignis, auf das man nicht vorbereitet war“ (Käppner 2003), empfunden. Es wird jedoch betont, dass im sogenannten Kampf für das Gute die Bereitschaft notwendig sei, ,auch künftig Opfer unter deutschen Soldaten und zivilen Helfern zu ertragen“" (Blechschmidt 2007). Im September 2009 berichtet Kornelius von der „Natur eines Guerilla-Krieges“, in welcher es liege, „den Tod von Zivilisten billigend in Kauf [zu] nehmen“ (Kornelius 2009b). Die Begriffswahl „Guerilla-Krieg“ verhält sich konträr zum Vorangegangenen, da den RezipientInnen das Bild vermittelt wird, es handle sich nicht um einen sauberen und kalkulierbaren Krieg.

Im Oktober 2006 verändert sich das Bild der sauberen und humanitären BundeswehrsoldatInnen kurzzeitig. Fotos von deutschen Soldaten, welche mit Totenschädeln posierten, gelangten an die deutsche Öffentlichkeit. Auch die SZ berichtete über die sogenannte Totenkopf-Affäre. Der Fokus der diesbezüglichen Berichterstattung lag auf der Beschädigung des Ansehens der Bundeswehr als verantwortungsvolle Streitkraft innerhalb der deutschen Bevölkerung sowie auf der Vermutung, dass die „martialisch“ (Schwennicke 2006) posierenden Soldaten das Leben ihrer KameradInnen gefährdeten. Dass die posierenden Soldaten durch ihr erniedrigendes Handeln ihre putative Macht und Männlichkeit ausdrücken wollen, scheint klar erkennbar zu sein und ist in der Geschichte der Kriege und Konflikte kein Einzelfall. Dennoch ist der Ausgangspunkt ein anderer: Die Bundeswehr-SoldatInnen wurden von der Bundeswehr selbst, von der Politik und auch von den Medien vor und zu Beginn des Einsatzes nicht als „klassische“ SoldatInnen porträtiert, sondern als humanitär handelnde ZivilistInnen in Uniform (siehe auch Herzog et al. in diesem Band). Demnach ist der Bruch zwischen diesem Bild und den martialisch posierenden KämpferInnen ein größerer als bei SoldatInnen, KriegerInnen oder SöldnerInnen, deren Bild von vornherein als kriegerisch-militärisch konstruiert wird. 
Eine vermeintlich friedliche und humanitäre Intervention lässt sich im putativ pazifistischen Deutschland besser präsentieren als ein Krieg, in dem die eigenen Leute sterben und zudem für den Tod anderer, auch Unschuldiger, vor Ort mitverantwortlich sind. Das Kunduz-Bombardement am 4. September 2009 und die Berichterstattung darüber sorgten für eine tendenzielle Rollenverschiebung: Die Bundeswehr und die deutsche Politik werden für die „kindermetzelnde[n]“ und „desaströse[n] Bombardements“ (Prantl 2009b) verantwortlich gemacht und gleichzeitig der Vertuschung und Beschönigung beschuldigt. „Wenn diesmal verheimlicht oder beschönigt wurde, was war dann in der Vergangenheit los? [...] Welche Unfälle, Gefechte, Angriffe sind wirklich so verlaufen, wie sie geschildert wurden?" (Fried 2009a) Seit der Kunduz-Affäre wird saubere Kriegsführung in der SZ-Berichterstattung nicht mehr als gültige Legitimation aufgegriffen.

\section{Übernahme von Verantwortung auf Grund Deutschlands weltpolitischer Rolle}

\begin{tabular}{|l|l|}
\hline Problemdefinition & $\begin{array}{l}\text { Deutschlands Außenpolitik ist durch militärische Zu- } \\
\text { rückhaltung geprägt. }\end{array}$ \\
\hline Ursachendiagnose & $\begin{array}{l}\text { Die historische Verantwortung für den Zweiten Welt- } \\
\text { krieg begründet Deutschlands militärische Züruckhal- } \\
\text { tung. }\end{array}$ \\
\hline $\begin{array}{l}\text { Moralische Bewer- } \\
\text { tung }\end{array}$ & $\begin{array}{l}\text { Eine idealistisch orientierte Außenpolitik ist weltfremd, } \\
\text { unrealistisch und vernachlässigt Bündnisverpflichtungen. }\end{array}$ \\
\hline Lösungsvorschlag & $\begin{array}{l}\text { Deutschland muss seine militärische Zurückhaltung auf- } \\
\text { geben, um sich als zuverlässiger Bündnispartner und } \\
\text { weltpolitisch bedeutender Akteur zu etablieren. }\end{array}$ \\
\hline
\end{tabular}

Während der Frame ,Verantwortung in und für Afghanistan“ die Legitimität der Afghanistan-Intervention über die stärker ethisch begründete Verantwortung zur Hilfeleistung argumentiert, hebt der Frame ,Verantwortung aufgrund Deutschlands weltpolitischer Rolle“ Deutschlands Status als wichtiger weltpolitischer Akteur hervor, der in ein System internationaler Allianzen eingebunden ist.

Er rahmt den Bundeswehr-Einsatz in Afghanistan als Nagelprobe für die deutsche Sicherheits- und Außenpolitik. Aufgrund der deutschen Verantwortlichkeit für den Zweiten Weltkrieg habe sich Deutschlands Außenpolitik nach 1945 vornehmlich durch militärische Zurückhaltung ausgezeichnet. Diese Züruckhaltung sei wohlbegründet gewesen, in der aktuellen weltpolitischen Konstellation jedoch weder angemessen noch realistisch. Deutschland müsse 
seine Zurückhaltung überwinden und entsprechend seiner weltpolitischen Rolle außenpolitisch Verantwortung übernehmen.

Dem liegen zwei Argumentationslinien zugrunde, die in der Berichterstattung der SZ als Legitimation für den Einsatz deutscher Soldaten in Afghanistan dienen. Die erste Argumentationslinie legitimiert den Afghanistan-Einsatz über Deutschlands Einbettung in internationale Bündnisse und Allianzen. In den ersten Wochen nach dem 11. September 2001 proklamieren die untersuchten Kommentare und Leitartikel eine „Solidarität der Nationen“ (Kornelius 2001a), welche als zutiefst menschliches Verhalten im deutlichen Gegensatz zu dem animalischen Bild steht, das von den Gegnern gezeichnet wird: „Die Wucht der Detonationen sprengte Wolkenkratzer auseinander - Staaten und Gesellschaften trieb sie zusammen. Einig gegen Terror.“(Ulrich 2001a)

Im deutschen Kontext ist das Bekenntnis zur „uneingeschränkten Solidarität" (Deutscher Bundestag 2001a: 18293) zentral, die Bundeskanzler Gerhard Schröder bereits einen Tag nach den Anschlägen vom 11. September 2001 proklamierte. Diese Solidaritätserklärung nahm innerhalb weniger Tage institutionalisierte Formen an, als „Anti-Terror-Koalition“" und in der Erklärung des Verteidigungsfalls durch die Nato. In diesem Zusammenhang wird in der SZ die historisch begründete Dankbarkeit Deutschlands gegenüber den West-Alliierten, insbesondere den USA, angeführt, die nach 1945 die deutsche Rückkehr auf die politische Weltbühne erst ermöglicht hätten. Der „Zögling Deutschland" (Schwennicke 2001a) habe sich dahingehend zur Dankbarkeit verpflichtet, zumal die westlichen Länder auch einer gemeinsamen Wertegemeinschaft (Kornelius 2001e) angehörten: „Gefolgschaft entsteht nicht aus Zwang, sondern aus dem Gefühl heraus, dazuzugehören.“ (Kornelius 2002) Daran anknüpfend wird der Afghanistan-Einsatz als Verantwortung Deutschlands gegenüber internationalen Bündnispartnern wie der NATO oder der „Völkerfamilie“ (Kornelius 2009a) angemahnt. Das ,,militärisch zur Zurückhaltung sozialisierte NachkriegsDeutschland“" (Schwennicke 2001a) versuche im Fall Afghanistan mit großer Anstrengung, Pazifismus mit internationaler Einbindung zu verknüpfen. Pazifistische Orientierungen werden jedoch als „utopisch“ (Kornelius 2001e) und unrealistisch (Prantl 2001a) negativ bewertet. „Wer sich einer multilateralen Politik

7 Der Begriff taucht in fünf Artikeln, die in diese Untersuchung eingeflossen sind, auf. Der älteste der fünf Artikel ist vom 10. Januar 2002. Aus diesem Zeitraum wurden insgesamt 60 Artikel ausgewertet. In jedem 12. dieser Artikel taucht also der Begriff der „Anti-Terror-Koalition“ auf. In weiteren Artikeln finden sich Synonyme wie „Koalition gegen den Terrorismus" und ähnliches. Nach dem 10. Januar 2002 wird in keinem der untersuchten Artikel mehr von der „Anti-Terror-Koalition“ gesprochen. 
verschreibt, wer sich in Bündnissen gut aufgehoben fühlt, der darf es nicht bei warmen Worten belassen." (Kornelius 2009a)

In Verbindung mit den außenpolitischen Verpflichtungen Deutschlands wird der Afghanistan-Einsatz zudem mit der Argumentation verknüpft, dass Deutschland sich als bedeutender außenpolitischer Akteur etablieren müsse: „Wer gleich ein Bündnis in Frage stellt (...), der unterschätzt die Zerbrechlichkeit außenpolitischer Systeme. Und er gefährdet ein System, dem das Land seine außenpolitische Gestaltungskraft überhaupt erst verdankt." (Kornelius 2001e) So ergibt sich aus historisch bedingter Dankbarkeit und der Zusammengehörigkeit zur gleichen Wertegemeinschaft (Kornelius 2001e) ein Verantwortungsbewusstsein für Deutschland.

Die Textstelle vermittelt zum einen den Eindruck, Deutschland dürfe sich seiner Verantwortung nicht entziehen und begebe sich zum anderen im Falle einer illoyalen Handlung in die Gefahr, ins außenpolitische Abseits zu geraten. Deutschland müsse auf der Grundlage verantwortungsvollen Handelns sein außenpolitisches Profil schärfen: „So zahlt sich dann der deutsche Einsatz aus in weltweiter Anerkennung.“ (Münch 2005) Deutsche Entscheidungen wögen schwer, im gleichen Zuge müsse die einhergehende Verantwortung ernst genommen werden. „Am Hindukusch wie im Nahen Osten, auf dem Balkan wie in Brüssels EU-Betrieb - überall wird Deutschlands Beitrag gebraucht. Und überall erwartet die Welt konkretere Antworten von der Bundesrepublik." (Wernicke 2009) Dafür werden Pragmatismus und die Absage an ,einen nicht erfüllbaren Idealismus“ (Kornelius 2001j) gefordert. Internationaler Vertrauens- und Machtverlust könnten sonst die Folge sein. 


\section{Begründungspflichtigkeit der Außenpolitik}

\begin{tabular}{|l|l|}
\hline Problemdefinition & $\begin{array}{l}\text { Die Regierungsparteien vernachlässigen in Bezug auf den } \\
\text { Afghanistan-Einsatz ihre demokratisch gebotene Begrün- } \\
\text { dungs- und Rechenschaftspflicht. }\end{array}$ \\
\hline Ursachendiagnose & $\begin{array}{l}\text { Die Regierungsparteien befürchten, dass sich die Umset- } \\
\text { zung ihrer außenpolitischen Linie und der Erhalt der Re- } \\
\text { gierungsmacht nicht vereinbaren lassen. }\end{array}$ \\
\hline $\begin{array}{l}\text { Moralische Bewer- } \\
\text { tung }\end{array}$ & $\begin{array}{l}\text { Die Vermeidung einer kritischen Auseinandersetzung aus } \\
\text { machtpolitischen Erwägungen ist unverschämt, unehrlich } \\
\text { und undemokratisch. Kritische Hinterfragung ist vernünf- } \\
\text { tig und demokratisch angemessen. }\end{array}$ \\
\hline Lösungsvorschlag & $\begin{array}{l}\text { Die Regierung muss die Öffentlichkeit in einer offen und } \\
\text { sachbezogen geführten Debatte von der deutschen Betei- } \\
\text { ligung in Afghanistan überzeugen. Ist dies nicht möglich, } \\
\text { müssen die demokratisch gebotenen Konsequenzen ge- } \\
\text { zogen werden. }\end{array}$ \\
\hline
\end{tabular}

In den Jahren 2001 und 2009 wird verstärkt das Spannungsverhältnis zwischen der Unpopularität des deutschen Einsatzes und der außenpolitischen Linie thematisiert. Unter Rückgriff auf die demokratietheoretische Logik, dass legitime politische Herrschaft im Allgemeinen und politische Entscheidungen im Besonderen begründungspflichtig und zustimmungsabhängig sind, wird die deutsche Beteiligung in Afghanistan als Output demokratischer Außenpolitik gerahmt. Ihre Legitimität ist von der Einhaltung informeller demokratischer Praktiken abhängig, die in der politischen Kultur der Bundesrepublik Deutschland etabliert sind.

In den ersten Monaten nach Beginn der OEF wird die Schwierigkeit der Regierung angesprochen, sich stabile Unterstützung für eine deutsche Beteiligung in Afghanistan zu sichern (Fried 2001b, 2001c; Kornelius 2001e; Schwennicke 2001b; Kilz 2001). Die Skepsis an der Basis und in den Fraktionen der Regierungsparteien stelle die Regierung auf die „Popularitätsprobe“ (Ulrich 2001b). Die Regierung begegne kritischen Stimmen jedoch nicht nicht mit der Begründung der eigenen Position in einer offenen Auseinandersetzung, sondern mit Delegitimierung (Fried 2001b) und Unterdrückung von Kritik:

„Jegliche Kritik am Krieg und der Kriegsführung (...) wird behandelt, als handele es sich um Widerstand gegen die Staatsgewalt. Man könnte den Eindruck haben, als habe das erste Sicherheitspaket (...) auch die Gedankenpolizei eingeführt.“ (Prantl 2001a) 
Die Formulierung von Kritik als Widerstand gegen die Staatsgewalt stellt den Umgang der Regierung in die Nähe der Praxis autoritärer Regime; mit dem Vorwurf der Gedankenpolizei wird das Bild eines totalitären Überwachungsstaats, wie George Orwell ihn in seinem dystopischen Roman 1984 entwirft, aufgerufen (Orwell 1981). Der Umgang der Regierung wird hier demnach als undemokratisch und tendenziell repressiv gewertet. Demgegenüber werden Kritik und Zweifel als vernünftig, „richtig“ (Prantl 2001a) und angemessen hervorgehoben. Auch im Kontext der Bundestagsabstimmung über die Entsendung der Bundeswehr wird das Regierungshandeln negativ und demokratischer Praxis nicht angemessen gerahmt. Die Regierung baue mittels machtpolitischer Mittel Zustimmungsdruck auf, statt inhaltlich zu begründen und zu überzeugen (Fried 2001b; Kilz 2001; Prantl 2001c). Bundeskanzler Gerhard Schröder habe die innenpolitische Machtkonstellation instrumentalisiert, indem er die Abstimmung über die Entsendung an die Vertrauensfrage geknüpft habe. Das Vorgehen der Regierung wird als „machtpolitisches Muskelspiel“ (Kilz 2001) und „Chuzpe, die atemberaubend ist" (Schwennicke 2001d), negativ gewertet. Als Ursache wird wiederholt der Willen der Regierung diagnostiziert, die außenpolitische Linie durchzusetzen, ohne dabei den Verlust der Regierungsmacht zu riskieren (Fried 2001c; Prantl 2001c; Schwennicke 2001d).

„Koalitionsbruch? Kanzler Schröder am Ende? I wo! (...) Trägt die SPD-Fraktion maßgeblich zur Schlappe bei, müsste der Kanzler eigentlich Konsequenzen ziehen. Aber dazu regiert Gerhard Schröder wahrscheinlich einfach zu gern.“ (Schwennicke 2001d)

Die ironischen rhetorischen Fragen und die Schlussfolgerung, Gerhard Schröder regierte einfach zu gerne, legen nahe, dass dem Handeln der Regierung letztlich keine begründete inhaltliche Position, sondern reines Machtkalkül zu Grunde liegen. Die Regierung umgehe somit etablierte Praktiken bundesdeutscher Demokratie, indem sie bei einer der „,weitreichendsten“ (Schwennicke 2001d) Beschlüsse, die der Bundestag je gefasst habe, so tue, ,als könne man darüber hinwegregieren, dass man den Beschluss nicht aus eigener Kraft zu Stande bringt." (Schwennicke 2001d)

Im Kontext des Bundestagswahlkampfs und der Kunduz-Affäre Ende 2009 wird der Frame im SZ-Meinungsteil wieder aktualisiert. Als Problem wird eine sträfliche Vernachlässigung der Rechenschaftspflicht sowohl in den vorangegangenen Jahren als auch gegenwärtig definiert: „Im Moment fällt jenes Lügengebäude in sich zusammen, das seit Beginn des Afghanistan-Engagements im Jahr 2001 errichtet worden war" (Kornelius 2009g; vgl. auch Fried 2009b, 2009d; Prantl 2009b). 
Als Ursache wird einerseits der „Selbstbetrug“ der Regierung (Kornelius 2009c, 2009g) genannt, der in dem Glauben bestanden habe, die deutsche Beteiligung in Afghanistan ließe sich trotz des faktischen Kriegszustandes im Land als ,sauberer' Demokratisierungs- und Aufbaueinsatz führen (Kornelius 2009b; Prantl 2009a). Demnach sei Wunschdenken statt realistischer Einschätzung handlungsleitend gewesen. Des Weiteren werden wiederum machtpolitische Erwägungen festgestellt (Fried 2009a; Prantl 2009a). Aus wahlkampftaktischen Gründen wolle man aktuell eine Diskussion über den Einsatz vermeiden, obwohl durch die Kunduz-Affäre klar geworden sei, dass ein offener Umgang mit dem Einsatz nötig wäre:

„In Deutschland wollte die große Koalition den Einsatz aus dem Wahlkampf heraushalten, so wie sie über Jahre diese wichtigste Militärmission des Landes keiner breiten öffentlichen Debatte unterworfen hat.“ (Kornelius 2009b)

Das Verhalten der Regierung wird vielfach scharf verurteilt, indem wiederholt von „Lügen“ (Fried 2009a; Kornelius 2009g) und „Vernebelung“ (Kornelius 2009g; Prantl 2009a) gesprochen wird und Feigheit und Unehrlichkeit impliziert werden (Fried 2009b, 2009a; Kornelius 2009g; Prantl 2009a). Eine bewusste Täuschung der Öffentlichkeit wird nahegelegt. Dem wird der Lösungsvorschlag entgegen gestellt, dass die Debatte um eine deutsche Beteiligung in Afghanistan sachbezogen und kritisch geführt werden müsse (Drobinski 2010; Fried 2001b, 2009a, 2009d; Kornelius 2009b; Koydl 2009; Prantl 2001a): „Aussprechen heilt, sagt Sigmund Freud.“ (Prantl 2009a) Zustimmung müsse durch Überzeugen erreicht werden. Ist sie auf diesem Wege nicht zu gewinnen, müssen die demokratisch gebotenen Konsequenzen gezogen werden, auch wenn sie gegebenenfalls den Verlust der Regierungsmacht oder die Entscheidung gegen eine deutsche Beteiligung bedeuten können (Fried 2001b; Prantl 2001a, 2001c; Schwennicke 2001d).

\section{FAZIT}

Die dargestellten Frames betonen jeweils unterschiedliche Aspekte des Afghanistan-Einsatzes, um seine Legitimität zu begründen. Sie nehmen dabei nicht nur eine Interpretation der Intervention vor, sondern kreieren auch ein Bild von Deutschland. Was also lässt sich aus den Framings für das deutsche Selbstbild schließen? 
Die Annahme der deutschen Intervenierenden als rational erweist sich in allen Frames als unabdingbar für die Legitimität des Einsatzes. In den Frames Krieg gegen den Terror - Verteidigung des Westens, Verantwortung in und für Afghanistan, Sauberer Krieg und Verantwortung aufgrund Deutschlands weltpolitischer Rolle wird die Rationalität wirkmächtig über die Repräsentation der Intervenierten als irrational und tendenziell primitiv konstruiert. In den drei erstgenannten Frames erfolgt dies vor allem unter Rückgriff auf Feindbilder, über die der Gegner als gewaltbereit dargestellt wird.

Im Frame Verantwortung in und für Afghanistan steht dagegen die afghanische Bevölkerung im Fokus, deren Irrationalität sich in Hilfsbedürftigkeit und Unselbständigkeit ausdrückt.

Im Frame Begründungspflichtigkeit der Außenpolitik und zu Teilen auch im Frame Sauberer Krieg dagegen werden Rationalität und Irrationalität innerhalb der Gruppe der Intervenierenden, der deutschen Politik und Gesellschaft, diskutiert. Im Frame Begründungspflichtigkeit wird der Umgang der Regierenden mit Kritik und durch Machtkalkül geleitetes Handeln als unvernünftig bewertet.

Im Frame Sauberer Krieg wird die Annahme der rational und ethisch agierenden Bundeswehr im Kontext der Totenkopf-Affäre herausgefordert. Im Gegensatz zur Irrationalität der Intervenierten wird das irrationale Verhalten innerhalb der Ingroup jedoch in beiden Frames nicht als repräsentativ für die Intervenierenden gerahmt. Die Totenkopf-Affäre wird als Ausdruck individuellen Fehlverhaltens gedeutet, welches das Ansehen der eigentlich sauberen und verantwortungsvollen Bundeswehr beschädigt. Das durch Machtkalkül geleitete Handeln der Politik steht im Gegensatz zu etablierten Regeln der demokratischen Gesellschaft. Irrationales Verhalten von Mitgliedern der Ingroup leitet somit keine Überprüfung des rationalen Selbstverständnisses ein, sondern wird als Ausnahmefall gedeutet.

Darauf aufbauend ordnen alle Frames Deutschland der westlichen Welt zu, die durch liberal-aufklärerische Werte gekennzeichnet ist. Während die Frames Verteidigung des Westens - Krieg gegen den Terror und Sauberer Krieg eher kulturalistisch argumentieren, wird in den Frames Verantwortung in und für Afghanistan und Verantwortung aufgrund Deutschlands weltpolitischer Rolle ein Wandel in der Deutung von Deutschlands Status und Rolle in der internationalen Gemeinschaft deutlich.

Beide Framings grenzen sich von einer historisch bedingten militärischen Zurückhaltung Deutschlands ab. Der Frame Verantwortung in und für Afghanistan begründet den Einsatz mit einer ethisch gebotenen Verantwortung zur Hilfeleistung. Er porträtiert die Bundeswehr als Armee der zivilen AufbauhelferInnen, die nicht in Kampfeinsätze verstrickt ist. Auf diese Weise wird das Bild eines mi- 
litärisch aktiven, aber dennoch nicht kriegerischen Deutschlands entworfen, dessen Engagement guten Gewissens unterstützt werden kann. Deutsches Militär steht nicht mehr, wie historisch überliefert, für Aggression und Bedrohung, sondern verkörpert im Gegenteil Hilfe, Aufbau und Friedenssicherung. Die Rolle des Aggressors wird nun anderen zugeschrieben.

Im Frame Verantwortung aufgrund Deutschlands weltpolitischer Rolle wird Deutschland als gleichberechtigtes Mitglied in internationalen Bündnissen und Allianzen beschrieben. Auch hier wird ein Bruch mit der historischen Rolle Deutschlands deutlich: Die deutschen Verpflichtungen gegenüber den Bündnispartnern liegen nicht mehr darin, die Waffen ruhen zu lassen, sondern darin, sie für die Gemeinschaft einzusetzen. Die Afghanistan-Intervention scheint die Chance zu bieten, die Rolle des Stiefkinds der West-Alliierten hinter sich zu lassen und deutsche Interessen in der Außenpolitik selbstbewusst zu vertreten.

\section{LITERATUR}

Abenstein, Reiner. 2007. Griechische Mythologie. Paderborn, München u.a.: Schöningh.

Arte France. 2005. Mit offenen Karten - Eine Neue Form Des Krieges. Arte France.

Bonacker, Thorsten. 2008. „Interventionskultur und die Struktur der Weltgesellschaft. Neue Perspektiven für die Friedens- und Konfliktforschung“. In Reader der Fachtagung. Folgekonflikte nach militär-gestützten humanitären Interventionen, hrsg. v. Arbeitsstelle Interventionskultur, Universität Oldenburg, S. 4-8. Oldenburg: BIS Verlag.

Bonacker, Thorsten; Daxner, Michael; Free, Jan H. u. a., Hrsg. 2010. Interventionskultur: zur Soziologie von Interventionsgesellschaften. Wiesbaden: VS Verl. für Sozialwissenschaften.

Die Bundesregierung. 2010. Auf dem Weg zur Übergabe in Verantwortung: Das deutsche Afghanistan-Engagement nach der Londoner Konferenz. http://www.auswaertiges-amt.de/cae/servlet/contentblob/343832/publication File/3752/100128-StrategiePapier.pdf (aufgerufen am 20. August 2012)

Claussen, Bernhart. 1990. „Politische Sozialisation durch Massenmedien und die Vermittlung über fremde Völker, Gesellschaften und Nationen“. In Medien, Sozialisation und Unterricht, hrsg. v. Dieter Schmidt-Sinns. Bonn: Bundeszentrale für politische Bildung.

D’Angelo, Paul. 2002. „News Framing as a Multiparadigmatic Research Program: A Response to Entman“. In Journal of Communication. 52(4), S. 870888. 
D’Angelo, Paul; Kuypers, Jim A, Hrsg. 2010. Doing News Framing Analysis: Empirical and Theoretical Perspectives. New York: Routledge.

Daxner, Michael. 2010. „Das Konzept von Interventionskultur als Bestandteil einer gesellschaftsorientierten Praxis“. In Interventionskultur. Zur Soziologie von Interventionsgesellschaften, hrsg. v. Thorsten Bonacker et al., S. 75-100. Wiesbaden: VS Verlag.

Daxner, Michael. 2008a. Der Heimatdiskurs. Unveröffentliches Manuskript.

Daxner, Michael. 2008b. „Die Interventionsgesellschaft in der Interventionspraxis“. In Reader der Fachtagung. Folgekonflikte nach militär-gestützten humanitären Interventionen, hrsg. v. Arbeitsstelle Interventionskultur, Universität Oldenburg, S. 9-15. Oldenburg: BIS Verlag.

Daxner, Michael; Free, Jan H.; Bonacker, Thorsten; u. a. 2010. „Einleitung“. In Interventionskultur. Zur Soziologie von Interventionsgesellschaften, hrsg. v. Thorsten Bonacker et al., S. 7-17. Wiesbaden: VS Verlag.

Deutscher Bundestag. 2001. „Stenographischer Bericht. 186. Sitzung. Berlin, Mittwoch, den 12. September 2001. Plenarprotokoll 14/186.

Dijk, Teun Adrianus van. 1997. Discourse as structure and process. London [u.a.]: Sage Publ.

Entman, Robert M. 1993. „Framing: Toward Clarification of a Fractured Paradigm“. In Journal of Communication. 43(4), S. 51-58.

Flick, Uwe, Hrsg. 1995. Handbuch qualitative Sozialforschung: Grundlagen, Konzepte, Methoden und Anwendungen. Weinheim: Beltz.

Habermas, Jürgen.1973. Legitimationsprobleme im Spätkapitalismus. Frankfurt am Main: Suhrkamp.

Heller, Hermann. 1970. Staatslehre. Leiden: Sijthoff.

Hertog, J.K. und McLeod, D.M. 2001. „A multiperspectival approach to framing analysis: A field guide." In Framing public life: Perspectives on media and our understanding of the social world, hrsg. v. Reese, Stephen D. et al., S. 139-162. Mahwah, NJ: Erlbaum.

Kassel, Susanne. 2004. „Krieg im Namen der Frauenrechte? Der Beitrag der Medien zur Konstruktion einer Legitimationsfigur“. In Demokratien im Krieg, hrsg. v. Christine Schweitzer et al., S. 161-179. Baden-Baden: Nomos.

Kassel, Susanne; Klaus, Elisabeth. 2008. „Frauenrechte als Kriegslegitimation in den Medien“. In Medien - Politik - Geschlecht: Feministische Befunde zur politischen Kommunikationsforschung, hrsg. v. Johanna Dorer et al., S. 266280. Wiesbaden: VS Verlag Sozialwissenschaften. 
Kerchner, Brigitte. 2006. „Diskursanalyse in der Politikwissenschaft. Ein Forschungsüberblick“. In Foucault: Diskursanalyse der Politik: eine Einführung, hrsg. v. Kerchner, Brigitte, S. 33-67. Wiesbaden: VS Verl. für Sozialwissenschaften.

Kirchhoff, Susanne. 2010. Krieg mit Metaphern: Mediendiskurse über 9/11 und den ,war on terror“. Bielefeld: transcript.

Küpeli, Ismail. 2007. „Die neuen Kriege - einige Anmerkungen zu Kriegslegitimationen des 21. Jahrhunderts“. In Europas „Neue Kriege“: Legitimierung von Staat und Krieg, hrsg. v. Ismail Küpeli, S. 7-25. Berlin: Hinrichs, Norbert.

Matern, Tobias. 2009. „Karsais schöne Worte“. Süddeutsche Zeitung. 20.11.2009.

Maurer, Torsten; Vogelsang, Jens; Weiß, Moritz; u. a. 2008. „Aktive oder passive Berichterstatter? Die Rolle der Massenmedien während des Kosovo-, Afghanistan- und Irakkriegs“. In Massenmedien als politische Akteure: Konzepte und Analysen, hrsg. v. Pfetsch, Barbara und Adam, Silke, S. 144-167. Wiesbaden: VS Verlag.

Mayring, Philipp. 2010. Qualitative Inhaltsanalyse: Grundlagen und Techniken. Weinheim [u.a.]: Beltz.

Meder, Gerhard. 1998. „Zur Neubestimmung der Rolle der Bundeswehr in den deutschen Printmedien“. In Krieg, Nationalismus, Rassismus und die Medien, hrsg. v. Wilhelm Kempf und Irena Schmidt-Regener, S. 201-210. Münster: LiT.

Münkler, Herfried. 2006. Der Wandel des Krieges - Von der Symmetriezur Asymmetrie. Weilerswist: Velbrück.

Nachtigall, Andrea. 2010. „Embedded Feminism“ Frauen(rechte) als Legitimation für militärische Intervention in den Medien - Variationen und Veränderungen einer Legitimationsfigur. http://www.gwi-boell.de/web/gewaltkonflikt-nachtigall-embedded-feminism-legitimation-medien-3421.html (aufgerufen am 20.06. 2012).

Orwell, George. 1981. 1984. Berlin [u.a.]: Ullstein.

Pohr, Adrian. 2005. „Indexing im Einsatz“. In $M \& K$ - Medialisierte Kriege und Kriegsberichterstattung. 2-3/2005, S. 261-276.

Reese, Stephen D.; Gandy, Oscar H. und Grant, August E., Hrsg. 2001. Framing public life. Perspectives on media and our understanding of the social world. Mahwah, NJ: Erlbaum. 
Reese, Stephen D. 2010. „Finding Frames in a Web of Culture - The Case of War on Terror". In Doing News Framing Analysis: Empirical and Theoretical Perspectives, hrsg. v. D’Angelo, Paul und Kuypers, S. 17-42. New York: Routledge.

Scheufele, Bertram. 2003. Frames - Framing - Framing-Effekte: theoretische und methodische Grundlegung des Framing-Ansatzes sowie empirische Befunde zur Nachrichtenproduktion. Wiesbaden: Westdt. Verl.

Schrader, Toralf. 2006. Kommentar und Leitartikel im Ressort „Politik“ der Zeitung. Norderstedt Deutschland: GRIN Verlag.

Schwab-Trapp, Michael. 2002. Krieg-Diskurse. Die politische Kultur des Krieges im Wandel. 1991-1999. Opladen: Leske + Budrich.

Weischenberg, Siegfried; Malik, Maja; Scholl, Armin. 2006. „Journalismus in Deutschland 2005“. In Media Perspektiven. 7/2006, S. 346-361.

Weiss, Peter. 1975. Die Ästhetik des Widerstands. Band 1. Frankfurt: Suhrkamp. Weiss, Peter. 1978. Die Ästhetik des Widerstands. Band 2. Frankfurt: Suhrkamp. Weiss, Peter. 1981. Die Ästhetik des Widerstands. Band 3. Frankfurt: Suhrkamp.

\section{PrimärquellenVerzeICHNIS}

Avenarius, Tomas. 2001a. „Afghanische Alternativen“. Süddeutsche Zeitung. 29.10.2001.

Avenarius, Tomas. 2001b. „Triumph der Parias aus Kabul“. Süddeutsche Zeitung. 12.9.2001, S. 4.

Avenarius, Tomas. 2002a. „Afghanistans Aufbau“. Süddeutsche Zeitung. 3.12.2002.

Avenarius, Tomas. 2002b. „Karsais bittere Klagen“. Süddeutsche Zeitung. 13.2.2002.

Avenarius, Tomas. 2006. „Bagdad und Hindukusch“. Süddeutsche Zeitung. 24.10.2006.

Avenarius, Tomas. 2010a. „Afghanische Realitäten“. Süddeutsche Zeitung. 18.1.2010.

Avenarius, Tomas. 2010b. „Ein Islam für die Zukunft“. Süddeutsche Zeitung. 12.1.2010.

Bänziger, Andreas. 2001. „Das Bombenrisiko“. Süddeutsche Zeitung. 5.11.2001. Blechschmidt, Peter. 2005. „Friedensarbeit im Krieg“. Süddeutsche Zeitung. 14.9.2005.

Blechschmidt, Peter. 2006. „Mitten in der Gesellschaft“. Süddeutsche Zeitung. 25.10.2006. 
Blechschmidt, Peter. 2007. „Verantwortung wagen“. Süddeutsche Zeitung. 12.10.2007.

Blechschmidt, Peter. 2010. „Erhöhtes Risiko“. Süddeutsche Zeitung. 26.1.2010.

Bork, Henrik. 2002. „Tokioter Füllhorn“. Süddeutsche Zeitung. 22.1.2002.

Brössler, Daniel. 2008. „Angriffsfläche verringern“. Süddeutsche Zeitung. 6.10.2008.

Chimelli, Rudolph. 2001. „Seiltanz zwischen den Welten“. Süddeutsche Zeitung. 27.9.2001.

Chimelli, Rudolph. 2002. „Der gekränkte Islam“. Süddeutsche Zeitung. 28.12.2002.

Drobinski, Matthias. 2010. „Reden über den Krieg“. Süddeutsche Zeitung. 12.1.2010.

Fried, Nico. 2001a. „Alte Konflikte bei den Grünen“. Süddeutsche Zeitung. 5.11.2001.

Fried, Nico. 2001b. „Demokratie von der Kanzel“. Süddeutsche Zeitung. 2.11.2001.

Fried, Nico. 2001c. „Ein Ja wie ein leises Nein“. Süddeutsche Zeitung. 23.11.2001.

Fried, Nico. 2001d. „Fischers gefährliche Option“. Süddeutsche Zeitung. 22.10.2001.

Fried, Nico. 2008. „Minister Franz Josef Sprachlos“. Süddeutsche Zeitung. 22.10.2008.

Fried, Nico. 2009a. „Die Lügen des Kriegs“. Süddeutsche Zeitung. 27.11.2009.

Fried, Nico. 2009b. „Ein unehrliches Mandat“. Süddeutsche Zeitung. 26.11.2009.

Fried, Nico. 2009c. „Es ging ums Töten“. Süddeutsche Zeitung. 11.12.2009.

Fried, Nico. 2009d. „Wie viel Töten ist erlaubt?“. Süddeutsche Zeitung. 19.12.2009.

Käppner, Joachim. 2003. „Irgendwo in Afrika“. Süddeutsche Zeitung. 21.6.2003.

Kilz, Hans Werner. 2001. „Kanzler des Vertrauens“. Süddeutsche Zeitung. 14.11.2001.

Kister, Kurt. 2001. „Feldzug ohne Bundeswehr“. Süddeutsche Zeitung. 2.10.2001.

Klüver, Reymer. 2003. „Marschbefehl mit Hintersinn“. Süddeutsche Zeitung. 25.10.2003.

Klüver, Reymer. 2004. „Missionen mit Mut“. Süddeutsche Zeitung. 23.9.2004.

Kornelius, Stefan. 2001a. „Amerikas Antwort“. Süddeutsche Zeitung. 13.9.2001.

Kornelius, Stefan. 2001b. „Bin Ladens Krieg“. Süddeutsche Zeitung. 9.10.2001. 
Kornelius, Stefan. 2001c. „Bündnisse und Beweise“. Süddeutsche Zeitung. 4.10.2001.

Kornelius, Stefan. 2001d. „Bushs Versprechen“. Süddeutsche Zeitung. 22.9.2001.

Kornelius, Stefan. 2001e. „Die Kunst des Möglichen“. Süddeutsche Zeitung. 20.11.2001.

Kornelius, Stefan. 2001f. „Einsam in Kabul“. Süddeutsche Zeitung. 25.9.2001.

Kornelius, Stefan. 2001g. „Einsatz ins Bodenlose“. Süddeutsche Zeitung. 31.10.2001.

Kornelius, Stefan. 2001h. „Krieg führen und Frieden schaffen“. Süddeutsche Zeitung. 6.10.2001.

Kornelius, Stefan. 2001i. „Krieg und Frieden in Berlin“. Süddeutsche Zeitung. 21.11.2001, S. 4.

Kornelius, Stefan. 2001j. „Mythen des Krieges“. Süddeutsche Zeitung. 20.10.2001.

Kornelius, Stefan. 2001k. „Nächste Phase: Politik“. Süddeutsche Zeitung. 7.12.2001.

Kornelius, Stefan. 2002. „Nato in Not“. Süddeutsche Zeitung. 2.2.2002.

Kornelius, Stefan. 2008. „Zu viel des Guten“. Süddeutsche Zeitung. 27.12.2008.

Kornelius, Stefan. 2009a. „Deutschland von außen“. Süddeutsche Zeitung. 1.10.2009.

Kornelius, Stefan. 2009b. „Die afghanische Zäsur“. Süddeutsche Zeitung. 7.9.2009.

Kornelius, Stefan. 2009c. „Ein Mandat zum Fürchten“. Süddeutsche Zeitung. 2.12.2009.

Kornelius, Stefan. 2009d. „Ein Preis als Bürde“. Süddeutsche Zeitung. 10.10.2009.

Kornelius, Stefan. 2009e. „Karsais Wahl“. Süddeutsche Zeitung. 20.10.2009.

Kornelius, Stefan. 2009f. „Obamas Fahnenappell“. Süddeutsche Zeitung. 3.12.2009.

Kornelius, Stefan. 2009g. „Terrain der Lügen“. Süddeutsche Zeitung. 14.12.2009.

Kornelius, Stefan. 2010a. „Die Londoner Krücke“. Süddeutsche Zeitung. 28.1.2010.

Kornelius, Stefan. 2010b. „Termindruck in Afghanistan“. Süddeutsche Zeitung. 29.1.2010.

Kornelius, Stefan. 2011. „Wie Kriegsangst entsteht“. Süddeutsche Zeitung. 2.10.2001. 
Koydl, Wolfgang. 2001. „Der Knoten der Geschichte“. Süddeutsche Zeitung. 15.11.2001.

Koydl, Wolfgang. 2009. „Afghanische Wahrheiten“. Süddeutsche Zeitung. 7.11.2009.

Lepenies, Wolf. 2001a. „Das Ende der Hegemonie“. Süddeutsche Zeitung. 10.10.2001.

Lepenies, Wolf. 2001b. „Rückkehr von Krieg und Glauben“. Süddeutsche Zeitung. 27.10.2001.

Münch, Peter. 2001a. „Afghanistans K-Fragen“. Süddeutsche Zeitung. 6.12.2001.

Münch, Peter. 2001b. „Angriff zur Verteidigung“. Süddeutsche Zeitung. 8.10.2001.

Münch, Peter. 2001c. „Der Feind im Fadenkreuz“. Süddeutsche Zeitung. 15.9.2001.

Münch, Peter. 2001d. „Der tödliche Irrtum - unvermeidbar“. Süddeutsche Zeitung. 15.10.2001.

Münch, Peter. 2001e. „Die ungleichen Brüder“. Süddeutsche Zeitung. 18.10.2001.

Münch, Peter. 2001f. „Ein guter Anfang für Afghanistan“. Süddeutsche Zeitung. 24.12.2001.

Münch, Peter. 2001g. „Kabuler Chaos-Theorien“. Süddeutsche Zeitung. 21.11.2001.

Münch, Peter. 2001h. „Kein Königsweg nach Kabul“. Süddeutsche Zeitung. 14.11.2001.

Münch, Peter. 2001i. „Kleine Münzen für Kabul“. Süddeutsche Zeitung. 22.12.2001.

Münch, Peter. 2001j. „Steinzeit versus Mikrochip“. Süddeutsche Zeitung. 20.9.2001.

Münch, Peter. 2002a. „Afghanistans Aufbruch“. Süddeutsche Zeitung. 10.6.2002.

Münch, Peter. 2002b. „Arbeit für Amerika“. Süddeutsche Zeitung. 16.1.2002.

Münch, Peter. 2003. „Afghanische Ausflüchte“. Süddeutsche Zeitung. 1.10.2003.

Münch, Peter. 2004a. „Staaten aus dem Baukasten“. Süddeutsche Zeitung. 12.10.2004.

Münch, Peter. 2004b. „Strucks Deckung hinterm Hindukusch“. Süddeutsche Zeitung. 14.10.2004.

Münch, Peter. 2004c. „Todeszeichen der Taliban“. Süddeutsche Zeitung. 25.10.2004. 
Münch, Peter. 2005. „Heldensaga am Hindukusch“. Süddeutsche Zeitung. 29.9.2005.

Münch, Peter. 2006a. „Optionen für Afghanistan“. Süddeutsche Zeitung. 29.9.2006.

Münch, Peter. 2006b. „Wenn drei sich streiten“. Süddeutsche Zeitung. 28.9.2006.

Nienhuysen, Peter. 2006. „Zu Gast bei Despoten“. Süddeutsche Zeitung. 4.11.2006.

Oldag, Andreas. 2003. „UN kapituliert am Hindukusch“. Süddeutsche Zeitung. 27.10.2003.

Prantl, Heribert. 2001a. „Angst vor der Angst“. Süddeutsche Zeitung. 17.10.2001.

Prantl, Heribert. 2001b. „Das Sichere ist nicht sicher“. Süddeutsche Zeitung. 11.10.2001.

Prantl, Heribert. 2001c. „Der Ernstfall““. Süddeutsche Zeitung. 8.11.2001.

Prantl, Heribert. 2001d. „Die Gewalt der Frommen“. Süddeutsche Zeitung. 29.12.2001.

Prantl, Heribert. 2009a. „Krieg und Wahlkampf“. Süddeutsche Zeitung. 8.9.2009.

Prantl, Heribert. 2009b. , 's ist Krieg“. Süddeutsche Zeitung. 28.11.2009.

Richter, Nicolas. 2008. „Regime der Banditen“. Süddeutsche Zeitung. 19.11.2008.

Schwennicke, Christoph. 2001a. „Abenteuer Afghanistan“. Süddeutsche Zeitung. 7.11.2001.

Schwennicke, Christoph. 2001b. „Der Kanzler und der General“. Süddeutsche Zeitung. 29.10.2001.

Schwennicke, Christoph. 2001c. „Friedensmission ohne Führung“. Süddeutsche Zeitung. 18.12.2001.

Schwennicke, Christoph. 2001d. „Schröders Vertrauensfrage“. Süddeutsche Zeitung. 12.11.2001.

Schwennicke, Christoph. 2002. „Posieren fürs rot-grüne Familienalbum“. Süddeutsche Zeitung. 12.6.2002.

Schwennicke, Christoph. 2006. „Die Schuld bleibt“. Süddeutsche Zeitung. 8.12.2006.

Ulrich, Stefan. 2001a. „Die wehrhafte Demokratie“. Süddeutsche Zeitung. 19.9.2001.

Ulrich, Stefan. 2001b. „Nackt nach Kabul“. Süddeutsche Zeitung. 21.12.2001, S. 4. 
Wernicke, Christian. 2009. „Eine deutsche Rede“. Süddeutsche Zeitung. 4.11.2009.

Winter, Martin. 2006a. „Dolchstoß Afghanistan“. Süddeutsche Zeitung. 21.11.2006.

Winter, Martin. 2006b. „Nato auf gefährlichem Gelände“. Süddeutsche Zeitung. 6.10.2006.

Winter, Martin (2007. „Die Illusionen der Nato“. Süddeutsche Zeitung. 26.10.2007. 


\title{
Die Bundeswehr in Afghanistan
}

\section{Analysen an den Grenzen des Heimatdiskurses}

\author{
CHRISTOPHER ROBOTHAM UND SASCHA RÖDER
}

Die Ereignisse des 11. September 2001 in New York markieren den Anfangspunkt einer deutschen Debatte um eine zunächst potentielle, ab Anfang 2002 dann faktische Präsenz der Bundeswehr in Afghanistan. Wir analysieren die diesbezügliche Berichterstattung in den Tageszeitungen Frankfurter Allgemeine Zeitung $(F A Z)^{1}$ und die tageszeitung $(\text { taz })^{2}$ sowie in der Wochenzeitung Die Zeit ${ }^{3}$ im Zeitraum vom 11.09.2001 bis 31.12.2011. Die Bezugnahmen auf die Thematik Bundeswehr in Afghanistan im untersuchten Pressediskurs sind vielfältig. Nur ein Teil der Berichterstattung bezieht sich unmittelbar auf das Agieren der Bundeswehr in Afghanistan und das dortige Geschehen. Auf den Bundeswehreinsatz in Afghanistan wird auch häufig argumentativ zugegriffen, wenn es letztlich um deutsche Themen und die Durchsetzung von Politik in Deutschland geht.

Unsere Analysen des Zeitungsmaterials sind einerseits Ausgangspunkt für eine thematische Erschließung und Kritik des Heimatdiskurses. Sie fließen anderseits in unsere theoriekritischen Überlegungen ein. Hier geht es darum, einige methodische, theoretische und thematische Grenzziehungen, die mit der Theorie des Heimatdiskurses eingeführt werden, zu problematisieren. Wir gliedern unsere Untersuchung in zwei Teile.

1 Die Ausgaben der Frankfurter Allgemeine Sonntagszeitung (FAS) wurden ebenfalls berücksichtigt.

2 Inklusive Le Monde Diplomatique Deutschland (LMD).

3 Berücksichtigt werden Artikel, die im Zeit Online Print-Archiv enthalten sind (www.zeit.de/archiv). 
Im ersten Teil setzen wir uns mit der Abgrenzung des Zivilen vom Militärischen auseinander. Wir beobachten dazu in der Berichterstattung wiederholt Kontroversen. Dies betrifft die Unterscheidung von International Security Assistance Force (ISAF) und Operation Enduring Freedom (OEF), die semantischen Kämpfe um Begriffe wie Einsatz, Intervention, Krieg und Frieden sowie die Auseinandersetzung mit Konzepten bzw. Praktiken zivil-militärischer $\mathrm{Zu}-$ sammenarbeit. Die Theorie des Heimatdiskurses ist in diese Abgrenzungsproblematiken verwickelt.

Im zweiten Teil spitzen wir unsere Kritik zu und fragen nach den Grenzen der Theorie des Heimatdiskurses. Es geht hierbei um Aspekte wie den Zuschnitt des Gegenstandsbereichs, die Ausrichtung des Erkenntnisinteresses und den Umgang mit der Empirie. Auch wir - nicht nur die Herausgeber - stoßen im von uns gesichteten Material auf eine Reihe an Indizien dafür, dass es spezifisch deutsche Diskurselemente gibt. Es stellt sich aber die Frage, ob der analytische Fokus auf diese und den deutschen Heimatdiskurs dazu führt, die afghanische Perspektive auszublenden. Wir diskutieren dies, indem wir verstärkt unser Augenmerk auf die Beziehung zwischen Deutschland und Afghanistan legen.

Anderseits kritisieren wir die Herauslösung des Heimatdiskurses aus umfassenderen gesellschaftlichen und diskursiven Kontexten. So betrachten wir den Interventionsdiskurs als umkämpften Bestandteil eines größeren Diskurszusammenhangs. Die Konstruktion und Definition des Heimatdiskurses sind politisch bedeutsame wissenschaftliche Akte. Wissenschaft und Interventionspolitik hängen miteinander zusammen. Wir untersuchen die Problematik anhand exemplarischer wissenschaftlicher Positionen, wie sie im Pressediskurs auftauchen. Unser Interesse ist letztlich darauf gerichtet, herauszuarbeiten, inwiefern der Forschungsansatz des Heimatdiskurses selbst politisch Stellung bezieht.

\section{Methodik und Materialauswahl}

Unsere Analyseschwerpunkte kristallisierten sich erst im Laufe des Forschungsprozesses im Rahmen der Auseinandersetzung mit der Theorie des Heimatdiskurses und dem von uns untersuchten Zeitungsmaterial heraus. Sie sind Ergebnis eines explorativen Forschungsprozesses.

Unser Erkenntnisinteresse war von Beginn an ein doppeltes: einerseits die thematische Erschließung des Heimatdiskurses voranzutreiben, anderseits eine Kritik der Theorie des Heimatdiskurses anzustoßen. Wir nehmen damit eine Zwischenposition zwischen dem „Innen“ des konstruierten Heimatdiskurses und dem „Außen“ externer Kritik ein. Wir befinden uns innerhalb der Theorie des 
Heimatdiskurses, was die Auswahl unseres empirischen Untersuchungsmaterials und den thematischen Fokus angeht. Wir befinden uns außerhalb der Theorie des Heimatdiskurses, was bestimmte Deutungsmuster, Thesen, Setzungen und Lesarten angeht, die mit ihr eingeführt werden. Wir wählen diese Positionierung an der Grenze, weil wir einerseits die Problematik der Auslandseinsätze der Bundeswehr für bedeutsam und erforschenswert halten, anderseits den wissenschaftlichen Umgang mit der Thematik, wie ihn die Theorie des Heimatdiskurses vorschlägt, in einiger Hinsicht für problematisch halten.

Die Theorie des Heimatdiskurses macht die faktischen Äußerungen von Journalisten, Politikern, Soldaten, Experten, Wissenschaftlern u.a., wie sie in den Printmedien, Fach- und Populärliteratur, Film, Kunst etc. empirisch observierbar sind, auf eine bestimmte Art und Weise sichtbar und interpretierbar, ordnet sie theoretisch an und kontextualisiert sie. Die Analysen zum Heimatdiskurs gehen selbst in den Heimatdiskurs ein. Wir sprechen daher von einem faktischen Heimatdiskurs, ${ }^{4} \mathrm{zu}$ dem auch wissenschaftliche und metareflexive Beiträge gehören.

Die Materialauswahl war unter diesen Gesichtspunkten herausfordernd. Es galt sowohl dominante Diskursbestandteile als auch thematische Randzonen und Grenzbereiche des faktischen Heimatdiskurses zu erschließen, um diese dann miteinander und mit der Theorie des Heimatdiskurses konfrontieren zu können. So können Entsprechungen und Abweichungen markiert und neue Perspektiven aufgeworfen werden. Mit der Auswahl von FAZ, taz und Zeit haben wir versucht ein gewisses Spektrum politischer Ausrichtungen innerhalb der Presselandschaft einzufangen ${ }^{5}$ und heterogene Textsorten (Leitartikel, Interviews, Reportagen aus Afghanistan, Gastbeiträge von Experten und Wissenschaftlern, Artikel aus Poli-

4 Wir führen eine Differenzierung hinsichtlich des Begriffs des Heimatdiskurses ein. Bei Daxner überlagern sich zwei Bedeutungsebenen: Heimatdiskurs als Summe empirisch nachvollziehbarer diskursiver Praktiken (vgl. Daxner in diesem Band): und Heimatdiskurs als „Macht im Dunkel des Nichtgesagten“ (ebd.: 35) bzw. als mysteriöses, anonymes Subjekt, das die Gesellschaft auf etwas „vorbereitet“, sich auf Optionen „einrichtet“, Handlungen „beeinflusst“. In letzterer Bedeutungsvariante steht „Heimatdiskurs“ letztlich für die Deutungsvorschläge, Dekonstruktionen und Belehrungen, die Forscher innerhalb des theoretischen Rahmens des Heimatdiskurses artikulieren. Wie Daxner sind wir der Meinung, dass die Analyse des Nicht-Sagbaren wichtig ist, weisen aber auf die Differenz zum Ausgeschlossenen, Ungedachten und Marginalisierten hin.

5 Wir gehen aber davon aus, dass wir im Wesentlichen hegemoniale Artikulationen und den medialen Mainstream untersuchen. Wir untersuchen Artikel, die vornehmlich in Deutschland und von Deutschen geschrieben wurden. 
tik- und Feuilletonressorts, Buchbesprechungen etc.) einzubeziehen. Uns interessiert der Pressediskurs, da sich in diesem eine gewisse Komplexität reflektiert. Verschiedene Diskursebenen verschränken sich hier miteinander: z.B. der journalistische Diskurs, wissenschaftliche Spezialdiskurse und der Politikerdiskurs (Jäger und Jäger 2007: 28).

Aufgrund der Entscheidung mehrere Zeitungen über einen längeren Zeitraum in Betracht zu ziehen, sahen wir uns mit einer erheblichen Materialmenge konfrontiert. Um zu einer bearbeitbaren Anzahl an Artikeln zu gelangen, war eine manuelle Feinauswahl nötig. ${ }^{6}$ Im Laufe des Forschungsprozesses wurden zusätzliche Artikel nachrecherchiert, nachdem sich bestimmte Analyseschwerpunkte herauskristallisiert hatten. In Stichproben wurden alternative Suchstrategien erprobt, um quantitative Abschätzungen vornehmen zu können oder den Materialkorpus thematisch fokussiert zu ergänzen. ${ }^{7}$ Am Ende umfasste unser Materialkorpus 218 Artikel.

Das Material diente uns gleichermaßen als thematische Quelle, Denkhorizont und Kritikinspiration in der Auseinandersetzung mit der Theorie des Heimatdiskurses. Dies erfordert unsere Lesarten $^{8} \mathrm{zu}$ problematisieren und das Zeitungsmaterial auf einige konkrete Fragen hin zu untersuchen: Wer kommt im Heimatdiskurs zu Wort? Welches symbolische Kapital wird eingesetzt und mit welcher Autorität wird gesprochen? Woher kommt das Wissen, welche praktischen Effekte produziert es? Welche Bedeutung kommt Theorie, wissenschaftlichem Wissen und Spezialwissen zu?

6 Diese Feinauswahl war insofern strategisch, als es uns darum ging Material zu identifizieren, das die Thesen des Heimatdiskurses in seiner jetzigen Form irritiert. Kriterium für die Feinauswahl war die oben beschriebene Mischung aus thematischer Einschlägigkeit und Heterogenität.

7 Die ursprünglichen Suchwörter waren „Afghanistan“ und „Bundeswehr“. Wir suchten in einem ersten Schritt über die jeweiligen Online-Suchportale nach 5 einschlägigen Artikeln pro Jahr pro Zeitung, die die Suchwörter „Afghanistan“ und „Bundeswehr“ enthalten. Diese wurden ergänzt um Schlagworte die auf nicht-militärische Dimensionen verwiesen (zivil*, Frieden*, Aufbau*) und Schlagworte die auf wissenssoziologisch interessante Texte hindeuten (Wissen*, Philosoph*, Intellektuell*, Expert*).

8 Worin besteht der politische Gehalt der von uns vorgenommenen Deutungen? Mit welchen wissenschafts-, diskurs- aber insbesondere auch politik- und gesellschaftstheoretischen Hintergrundannahmen treten wir an das Material heran? 


\section{ZIVIL-MILITÄRISCHE GrENZZIEHUNGEN IM HeimATdisKuRS}

Wir beobachten in der Berichterstattung über den gesamten Zeitraum hinweg Kontroversen bezüglich der Abgrenzung zwischen Zivilem und Militärischem. Die Problematik durchzieht mehrere Themenstränge. Wir zeigen zunächst am Beispiel bestimmter Begriffssetzungen, wie der Eindruck von Uneindeutigkeit im untersuchten Zeitungsmaterial entsteht. ${ }^{9}$ Die Diagnose von Uneindeutigkeit selbst erklärt wenig. Es wird daher darauf ankommen zu ergründen, worauf sie im jeweiligen Kontext beruht - politischen Streit, Mehrdeutigkeit der Begriffe, Unwissenheit der Sprecher, Sprechverbote?

\section{ISAF/OEF - Frieden/ Krieg}

Zivil-militärische Grenzziehungen prägen die Diskussionen um die formelle Trennung zwischen der Operation Enduring Freedom (OEF) und der International Security Assistance Force (ISAF). Die Trennung wird früh von Journalisten thematisiert (Weiland in taz 22.12.2001: 1) und in verschiedener Hinsicht kritisiert (z.B. Innacker in FAS 10.03.2002: 3, Schwarz in taz 13.03.2002: 6, Chauvistré in taz 28.09.2005: 6, Löwenstein in FAZ 29.10.2005: 12). So wird hinterfragt, ob die Trennung eine Strategie der Euphemisierung sei:

„Vor allem grüne Politiker unterscheiden gern zwischen dem ,guten“ Auftrag der Friedenstruppe und dem zwiespältig gesehenen Kampfeinsatz amerikanischer, britischer und deutscher Einheiten zur Jagd auf Al Qaida. ,So können nur Politiker reden', meint ein hoher Bundeswehroffizier und ergänzt: ,Die Kommando-Soldaten und die Soldaten der Friedenstruppe führen zwar unterschiedliche Aufträge aus, doch sie dienen einem Ziel dem Kampf gegen den Terror. [...] Das KSK, so heißt es in der Fraktionsspitze der Grünen als Selbstberuhigung, führe ja ,polizeiliche Aktionen“ durch.“ (Innacker in FAS 10.03.2002: 3)

Eine andere Kontroverse besteht darin, ob die Rede von einer formellen Trennung der Mandate den militärpraktischen Realitäten vor Ort in Afghanistan an-

9 Die wichtigen Fragen, die eine Heimatdiskursanalyse allein nicht abschließend beantworten kann, lauten: In welchen Hinsichten ist die Rede vom Zivil-Militärischen realitätsadäquat? Welche Effekte hat sie, und was macht sie möglich? Unter welchen gesellschaftlichen Bedingungen ist die Verbindung ziviler und militärischer Komponenten ein legitimes und wirksames Instrument der Konfliktbearbeitung? 
gemessen ist. Besonders sichtbar wird diese 2006 in den Debatten um die Entsendung von Tornados im Rahmen von ISAF:

„Die Wirklichkeit auf dem Papier ist überschaubar und relativ ungefährlich. Die Aufklärungs-, Tornados' der Bundeswehr dürfen in Afghanistan nicht zur Unterstützung von kämpfenden Einheiten am Boden eingesetzt werden. [...] Selbst in der Bundeswehr betrachtet man die Trennung zwischen ISAF und OEF nur als theoretisch. Über die Nutzung der von den ,Tornados ' gelieferten Bilder entscheidet der Nato-Oberkommandierende in Afghanistan. Dies ist US-General Dan McNeill. Er dürfte eine Trennung beider Missionen kaum unterstützen.“ (König in taz 07.02.2007: 5)

Bettina Gaus weist schon früher darauf hin, dass die ISAF auf die Absicherung durch OEF angewiesen ist:

„Mohammed Daud ist besser ausgerüstet als die deutschen Soldaten. Er verfügt über Panzer, diese hingegen nicht über panzerbrechende Waffen. Der regionale Fürst könnte die Deutschen jederzeit aus seinem Gebiet vertreiben. Allerdings hätte er dann wohl die USLuftwaffe am Hals, die nicht unter UN-Mandat, sondern im Rahmen der Operation Enduring Freedom operiert, also einen Kampfauftrag erfüllt. Krieg und Frieden scheinen sich in Afghanistan nicht eindeutig voneinander trennen zu lassen." (Gaus in taz 28.02.2004: 4)

Das Zitat von Gaus signalisiert, dass die Abgrenzungsschwierigkeiten zwischen Frieden und Krieg mit der Trennung von ISAF und OEF zusammenhängen. Dieselbe Journalistin der $t a z$ hatte bereits im März 2002, es ging um eine mögliche Führungsrolle Deutschlands beim „Friedensprozess“, ein Problem mit der Koexistenz von Krieg und Frieden diagnostiziert:

„Es gibt kaum eine ehrenvollere Aufgabe als die, im Auftrag der Vereinten Nationen einen Friedensprozess zu überwachen. Warum also reißt sich Deutschland - in den eigenen Augen eine verantwortungsbewusste Mittelmacht - nicht um die Gelegenheit, die Führungsrolle des UN-mandatierten Einsatzes in Afghanistan zu übernehmen? [...] Der Hauptgrund für die deutsche Zurückhaltung aber dürfte in etwas anderem zu sehen sein: nämlich in der Erkenntnis, dass man schwerlich gleichzeitig Krieg führen und Frieden bringen kann.“ (Gaus in taz 15.03.2002: 12)

Hier fragen wir, ob ein Friedensprozess ein Kriegsende voraussetzt oder ob es sich um einen Prozess weg vom Krieg und hin zum Frieden handelt. Krieg und Frieden werden nicht als gesellschaftliche Zustände angesprochen, sondern als 
Aktivitäten. Frieden wird gebracht, wie Krieg geführt wird. Gerade in dieser Hinsicht wird Gaus' These aber fragwürdig. Unterschiedliche Praxisformen können, mehr noch als gesamtgesellschaftliche Zustandsbeschreibungen, koexistieren, ggf. aber nicht in denselben Territorien. Das Problem liegt wohl eher darin, in Deutschland nicht gleichzeitig kommunizieren zu können, ausschließlich Frieden zu bringen und auch Krieg zu führen.

Uneindeutigkeit findet sich auch in Wortschöpfungen wie der Rede von einem „halben Frieden“ - so der Titel eines Kommentars von Theo Sommer Ende 2001 (Sommer in ZEIT ONLINE 13.12.2001). Sommer differenziert die Dichotomie von „Krieg führen“ und „Frieden schaffen“ weiter aus. Letzteres umfasse „Stabilisierung“, „Aussöhnung der verfeindeten ethnischen Gruppen“, „Nationbuilding“, „humanitäre Hilfe“ und „Wiederaufbau“. Der Frieden muss erst geschaffen werden, ist noch nicht da, erfordert also aktives Tun. Der Prozess des Frieden-Schaffens muss ,von außen militärisch abgesichert“ werden. Ist diese militärische Dimension Teil des „Krieg führen[s]“ oder „Frieden schaffen[s]“? Das lässt Sommer im Unklaren. Das Verhältnis Frieden-Krieg ließe sich an vielen anderen Fundstellen diskutieren und vertiefen. Beispielsweise wird es noch viel später in der Ausdeutung des symbolträchtigen Ereignisses der Totenkopfaffäre 2006 angesprochen:

„Der Bilderskandal bringt etwas näher, was wir uns lieber fernhalten wollen. Das ist die Auseinandersetzung darüber, was Afghanistan bedeutet: Krieg. Jedenfalls eher Krieg als Frieden, und vielleicht sogar einen Krieg, dessen Sieger nicht feststeht. Und dass auch Deutschland, nicht weniger als jedes andere Land, von Soldaten verlangt, für politische Ziele ihr Leben in die Waagschale zu werfen." (Zastrow in FAZ 29.10.2006: 3)

Wenn auch in anderem Kontext, deutet die sprachliche Wendung ,eher Krieg als Frieden" auch hier darauf hin, dass die Abgrenzung keine dichotome mehr ist. Es wird von einem Kontinuum zwischen Frieden und Krieg ausgegangen.

\section{Dominanz des Kriegsbegriffs}

Die zivil-militärische Abgrenzungsproblematik spielt weiterhin in den sehr präsenten semantischen Kämpfen um die Verwendung der Begriffe Einsatz, Intervention und Krieg eine wichtige Rolle. Wir diskutieren hier erneut den Kriegsbegriff, allerdings in Relation zu anderen Begriffen und in anderen Kontexten. 
Wir konstatieren insgesamt eine latente Dominanz des Kriegsbegriffs. ${ }^{10} \mathrm{Zu}$ dieser scheinen viele Faktoren beizutragen. Einerseits wird der Umgang mit dem Kriegsbegriff häufig als eine spezifisch deutsche Problematik angesprochen, in engem Zusammenhang mit dem Thema einer außenpolitischen Normalisierung Deutschlands (siehe auch Al Ahmad et al., in diesem Band). Er bildet eine Reibungsfläche (Ist es nicht doch eher Krieg?) und ist besonders umkämpft. Der Nationalsozialismus und der 2. Weltkrieg sind hier Bezugspunkte, wobei sich der Zugriff auf diese Themen wandelt. Ende 2001 postuliert Stefan Reinecke noch einen „Krieg ohne Hitler“ (so der Titel des Artikels):

„2001 ist die NS-Zeit als politischer Bezugsrahmen verschwunden. [...] Die AfghanistanDebatte zeigt, dass solche Vergleiche überflüssig geworden sind. Das ist Indiz eines fundamentalen Umbruchs: Die Nachkriegszeit ist endgültig vorbei. Was am 9. November 1989 begann, ist jetzt vollendet: die Normalisierung Deutschlands. Damit ist auch die rhetorische Nutzung der NS-Zeit stillgelegt.“ (Reinecke in taz 08.11.2001: 12)

Viel später, im Jahr 2009 - inzwischen hatte sich längst eine explizite Sprachthematisierung um den Kriegsbegriff herausgebildet - (siehe z.B. Winkelmann in taz 20.09.2008: 12, Haas in ZEIT ONLINE 22.04.2010), schreibt Heinrich Wefing:

„Man muss nur einmal den Alten zuhören, wenn sie vom Krieg erzählen. Den betagten Eltern, den Großeltern, den greisen Tanten. Da bleiben keine semantischen Zweifel. Krieg, das ist nicht irgendein Feldzug. ,Der Krieg` - das ist der Zweite Weltkrieg. Brennende Städte, Millionen Tote. Väter, Söhne, Brüder, die nicht mehr nach Hause kamen. Man

10 Vgl. hierzu auch die Einschätzung bei Daxner: „Der Begriff Heimatdiskurs ist ohne (s)eine Verbindung zum Krieg in unserer Sprachtradition kaum zu verfolgen.“ (Daxner ebd.: 33). Ein Indiz ist auch die Häufigkeit mit der der Kriegsbegriff in Titeln von Zeitungsartikeln auftaucht (für unsere Auswahl in 24 von 218). Bereits die Titelbezeichnungen lassen die Bedeutungsvielfalt des Kriegsbegriffs im Heimatdiskurs erahnen: z.B.: „Fischer, der Krieg, und die Vision“ (Geis in ZEIT ONLINE 27.09.2001), „Krieg ohne Hitler“ (Reinecke in taz 08.11.2001: 12), „Deutschland im Krieg“ (Innacker in FAZ 10.03.2002: 3), „Krieg gegen die Deutschen?“ (Lau in ZEIT ONLINE 23.08.2007), „Unser erster Krieg“ (Böhm in ZEIT ONLINE 21.02.2008), „Der Krieg der anderen“ (Willeke in ZEIT ONLINE 15.09.2008), „Es ist Krieg - und keiner schaut hin“ (Tenberg in FAZ 02.02.2009: 13), ,,Krieg'“ (Wefing in ZEIT ONLINE 12.11.2009), „Krieg ist plötzlich ein tröstendes Wort“ (Haas in ZEIT ONLINE 22.04.2010). 
kann nicht vom Krieg sprechen in Deutschland, ohne vom Zweiten Weltkrieg zu sprechen. Das war bei den Balkankriegen in den neunziger Jahren so, das ist jetzt wieder so beim Bundeswehreinsatz in Afghanistan.“ (Wefing in ZEIT ONLINE 12.11.2009)

Ein paar Wochen später liest man bei Cora Stephan im Artikel „Wir Friedensverwöhnte“:

„Die historische Erinnerung hierzulande ist mit Umweg über Bombennächte im Zweiten Weltkrieg beim Dreißigjährigen Krieg angelangt. Das heißt fürs Kriegsbild: Wir denken dabei an maximale Verwüstung und Vernichtung der Zivilbevölkerung. Dieses Bild des Krieges macht die Debatte über den Einsatz in Afghanistan so hochemotional. [...] Zivile Opfer sind in Afghanistan schwer zu vermeiden, da sie von der Gegenseite gewollt sind das ist das Kennzeichen eines asymmetrischen Krieges." (Stephan in FAS 06.12.2009: 13)

Hier sieht man wie solche historischen Fixpunkte miteinander verknüpft werden, sich überlagern und verschieben - die Rede vom ,asymmetrischen Krieg“ beispielsweise hat nach den Anschlägen am 11.September besonderen Auftrieb bekommen. Deutlich wird hier besonders, dass historische Äußerungen im Heimatdiskurs nur in ihrem Kontext verständlich werden. Reinecke bezieht sich im Wesentlichen auf die Legimationsdebatte um den Afghanistaneinsatz, hier spielten Referenzen auf den Nationalsozialismus möglicherweise wirklich eine geringe Rolle. Unter Bedingungen einer verschärften Sicherheitslage und nach dem Luftangriff bei Kunduz schreibt Wefing über etwas ganz anderes - Kriegsassoziationen in bestimmten Teilen der deutschen Bevölkerung. Die Ausführungen müssen hier kursorisch bleiben. Klar ist jedenfalls, dass eine Analyse der Stellung des Kriegsbegriffs im Heimatdiskurs ein anspruchsvolles Unternehmen ist.

Wir haben damit bereits einen weiteren Faktor für die Dominanz des Kriegsbegriffs gestreift - etwas, dass wir als semantische Öffnung des Kriegsbegriffs bezeichnen würden. Diese wurde nach 9/11 politisch und teils wissenschaftlich vorangetrieben. In einem Zeit-Interview kurz nach den Anschlägen in New York mit dem damals amtierenden Bundeskanzler Gerhard Schröder wird der Kriegsbegriff explizit thematisiert, wobei von zwei „Kriegen“ die Rede ist: zum einen ist, bezogen auf die Anschläge des 11. Septembers 2001, von einem (speziell aus völkerrechtlicher Perspektive) Krieg ,neuer“ Art die Rede:

„Es handelt sich nicht um einen Krieg im klassischen Sinne. Es ist - und das haben die Entschließungen 1368 und 1373 des Sicherheitsrats legitimiert - die Antwort auf einen nicht ausdrücklich erklärten Krieg der Terroristen mit kriegerischen Mitteln. Deswegen 
stimmt der Begriff Krieg nur dann, wenn man ihn seiner historischen Bedeutung ein wenig entkleidet." (Schröder in Hofmann in ZEIT ONLINE 18.10.2001)

Zum anderen stimmt Schröder hinsichtlich der amerikanisch geführten militärischen Operationen in Afghanistan der These Gunter Hofmanns zu, dass diese „der Form nach [...] militärisch ganz traditionell angelegt“ (Hofmann in ZEIT ONLINE 18.10.2001) seien. Denn:

„Zunächst einmal geht es darum, die Unterschlupfmöglichkeiten für Terroristen zu zerstören und auf dieser Basis ihrer dann habhaft zu werden." (Schröder in Hofmann in ZEIT ONLINE 18.10.2001)

Als es zuvor darum ging, ob die Deutschen ,in einem Krieg landen“ würden, holt Schröder weit aus, verweist auf „einen militärischen Beitrag“ und darauf, dass es der Realität angemessen sei, ,militärische Interventionen“ nicht zu tabuisieren. Es gehe um eine „neue Form der Selbstverteidigung“ (so auch der Titel unter dem das Interview veröffentlicht wurde). Eine Analyse des SchröderInterviews macht deutlich, dass bedeutsame Merkmale des Heimatdiskurses schon vor der Präsenz der Bundeswehr feststellbar sind, bzw. dass diskursive Weichenstellungen frühzeitig vorgenommen wurden. Krieg ist durchaus sagbar, nur nicht in bestimmten Kontexten, nämlich wenn es um eine deutsche Beteiligung geht. Hier weicht Schröder auf den Begriff militärischer Interventionen aus. Die Verwendung des Kriegsbegriffs in diesem Zusammenhang ist ein Problem politischer Eliten, weniger eines von Journalisten. Ob Krieg sagbar ist, oder was Krieg bedeutet, und welche Effekte das Aussprechen dieses Wortes hat, hängt stark von Kontexten und Sprechertypen ab.

\section{Wissenschaft, Politik und Neue Kriege}

Die Öffnung des Kriegsbegriffs vergrößert die politischen Handlungsspielräume. Es gibt hier Verbindungslinien zu (politik)-wissenschaftlichen und international geführten Debatten um Begriffe wie „Neue Kriege“ und ,asymmetrische Kriege“. Man kann dies für den Heimatdiskurs exemplarisch diskutieren indem man Äußerungen Gerhard Schröders mit solchen, die dem Politikwissenschaftler Herfried Münkler zugeschrieben werden, konfrontiert. Bei Schröder heißt es im besagten Interview:

„Seit dem 11. September ist, weil der Konflikt privatisiert und internationalisiert worden ist, eine neue Bedrohungslage entstanden [...] Das ist das qualitativ Neue, nicht etwa der 
Wunsch, weltweit intervenieren zu können.“ (Schröder in Hofmann in ZEIT ONLINE 18.10.2001)

Im Artikel „Der Ein-Mann-Think-Tank“ wird zwei Jahre später rückblickend Münklers Beitrag zur Debatte verhandelt:

„Wir sind, sagt er [Münkler], Zeitzeugen einer weitreichenden Entstaatlichung des Krieges. Anders gesagt: einer Privatisierung des Krieges. Die Gestalten, in denen sich dieser neue, privatisierte Krieg verdichtet, sind der Söldner, der Kindersoldat, der Warlord und der international vernetzte Terrorist. [...]Herfried Münkler hat als einer der ersten Politologen hierzulande begriffen, dass unsere althergebrachten Vorstellungen vom Krieg untauglich geworden sind.“ (Lau in ZEIT ONLINE 30.10.2003)

Ob dieser letzte Satz stimmt, ist umstritten, nicht nur aus historischer Perspektive, sondern auch insofern, als eine solche Behauptung eine Form von Komplizenschaft mit einem Diskurs impliziert, der die problematische Entwicklungen in der internationalen Sicherheitspolitik und -Praxis legitimiert. Die Feststellung allein, dass Schröder und Münkler in bestimmter Hinsicht fast dasselbe sagen, ist an sich nicht besonders aufschlussreich. Hat Münkler die Politik beeinflusst, oder liefert Münkler die Theorie zu einer politisch gewollten Praxis? Sollten wir die ausgeprägte Präsenz von Münkler im Heimatdiskurs ${ }^{11}$ als ein Indiz für eine äußerst limitierte Rezeption von Wissenschaft verstehen? Oder fungiert Münkler als Übersetzer und Katalysator militärnaher Wissensformen, die international zirkulieren, in die deutsche Debatte? (dazu Rid in ZEIT ONLINE 10.04.2008, Malinowski in ZEIT ONLINE 05.01.2011).

\section{Einsatz, Intervention, Krieg}

Die Problematik zivil-militärischer Uneindeutigkeit tritt zutage, wenn nach dem Verhältnis des Kriegsbegriffs zu den Begriffen Einsatz und Intervention gefragt wird, genau genommen nach dessen Stellung in einem komplexen Begriffsnetz zu dem auch Begriffe wie Frieden, Konflikt, (Wieder-)Aufbau, Entwicklung, Kampf, Polizeiaktion und Nation-building gehören. Einfache Zuordnungen funktionieren hier nicht. Begriffe wie Einsatz, Intervention und Krieg transportieren unter anderem Assoziationen hinsichtlich der Praktiken von Akteuren (hier: Sol-

11 Münkler bleibt über den gesamten Zeitraum 2001-2011 hinweg präsent, ob als Stichwortgeber (Lau in ZEIT ONLINE 30.10.2003), Autor (Münkler in FAZ 09.10.2006: 8) oder zu Kritisierender (Walther in taz 19.08.2010: 15-16). 
daten der Bundeswehr). Brückenbauen als Praktik von Soldaten dürfte beispielsweise mit Assoziationen zu Friedenseinsatz kompatibel sein. Partnering als Bestandteil von Interventionen verweist auf eine Interaktion zwischen Intervenierenden und Intervenierten bzw. interaktive Praktiken. Kämpfen und Töten wird eher Krieg zugeordnet. Damit steht Krieg in dieser Hinsicht für ein eher einfaches, eindimensionales Geschehen (Verwüstung, Gewalt). Dennoch geht Krieg nicht in militärischen Kampfhandlungen auf, sondern greift auf zivile Elemente zurück. Dass dies schon länger gilt, ließe sich am Begriff der „Heimatfront ${ }^{\text {" } 12}$ diskutieren, der in der Berichterstattung zu Afghanistan wieder auftaucht (siehe z.B. Amendt in FAZ 08.03.2004: 40, Ehrhardt in FAZ 16.10.2008, Walther in taz 27.05.2010: 12). Krieg kann sowohl geführt werden (Praktik), als auch herrschen (gesellschaftlicher Zustand). Man könnte argumentieren, dass mit der Theorie der Interventionsgesellschaft nahe gelegt wird, dass es Sinn macht davon zu sprechen, dass Intervention herrscht. ${ }^{13}$

Frieden hat eine Konnotation des Zivilen. Diese wird aber fragwürdig, wenn er erst geschaffen und militärisch abgesichert werden muss. Einsatz hingegen bezieht sich eher auf den Akteur, der aktiviert wird (Bundeswehr), als auf die Gesellschaft, in der dieser eingesetzt wird. Ob Friedens- und Stabilisierungseinsatz adäquate Bezeichnungen sind, wird damit unter anderem davon abhängig, was die Bundeswehr tut. Was die politisch forcierte Verwendung des scheinbar neutralen Wortes Einsatz angeht, ist interessant, dass es mit Wortbestandteilen aus der Sphäre des Zivilen verknüpft wurde: Friedenseinsatz, Stabilisierungseinsatz. Es war aber auch von „Armee im Einsatz“ (Struck in Innacker in FAS 10.08.2003: 4) ohne weitere Qualifikation die Rede. Diese Bezeichnung war zu bestimmten Zeitpunkten und in Bezug auf bestimmte Territorien möglicherweise sogar angemessen, da die Bundeswehr nicht mehr als „reine Präsenz" war. Wir können diese Beobachtungen an dieser Stelle nicht ausführen, es

12 Der Begriff Heimatfront weist auf die Komplexität der Trennung zwischen Zivilem und Militärischem hin, da mit dem Begriff suggeriert wird, dass zivile Aktivitäten zuhause Teil des Krieges sind (,part of the war effort“, würde man im Englischen sagen). Bezogen auf Provincial Reconstruction Teams (PRTs) könnte man fragen, ob die zivile Komponenten der PRTs so etwas wie eine exportierte, ausgelagerte Heimatfront darstellen.

13 Dies wäre insofern plausibel als ,intervenieren“ (von lat. Interven̄ire: dazwischen-, dazukommen, hindernd oder vermittelnd eingreifen) semantisch implizit mit auf die Zielgesellschaft verweist, als den Ort zu dem etwas dazukommt bzw. in den eingegriffen wird. Siehe Etymologisches Wörterbuch des Deutschen (online verfügbar unter http://www.dwds.de/?qu=intervenieren). 
ging uns vielmehr darum die Bezeichnungskomplexitäten zu entfalten und auf die Notwendigkeit differenzierter Analysen hinzuweisen. Narrative, die eine chronologische Entwicklung entlang von Bezeichnungen wie „Friedenseinsatz“, „Stabilisierungseinsatz, „Kampf“, „kriegsähnliche Zustände“ und „Krieg“ beschreiben, greifen jedenfalls zu kurz. Die Vorstellung einer Abfolge temporär angemessener Bezeichnungen ist unplausibel. Dies zeigt bereits die ausgeprägte Auseinandersetzung mit den diesbezüglichen semantischen Kämpfen in den Printmedien (z.B. Winkelmann in taz 20.09.2008: 12, Wefing in ZEIT ONLINE 12.11.2009, Encke in FAS 13.09.2009: 23, Haas in ZEIT ONLINE 22.04.2010, Walther in taz 27.05.2010:12).

\section{Zivil-Militärische Zusammenarbeit}

Besonders explizit wird die Verknüpfung des Zivilen und Militärischen in $\mathrm{Zu}$ sammenhang mit dem Thema zivil-militärischer Zusammenarbeit thematisiert. Es geht hier einerseits um militärnah entwickelte Konzepte wie "civil-military cooperation“ (CIMIC), „Zivil-Militärische Zusammenarbeit“ (ZMZ) und „Provincial Reconstruction Team“ (PRT), anderseits um sicherheitspolitische Konzepte wie „Vernetzte Sicherheit“. Letzteres taucht im so genannten Weißbuch aus dem Jahr 2006 auf. Franz Josef Jung dazu im Interview:

„Und wir müssen über eine vernetzte Sicherheitspolitik sprechen, die zivil-militärische Zusammenarbeit. Das Drogenproblem in Afghanistan, das eine große Herausforderung darstellt, bekämpft man natürlich effektiver, wenn die Bauern auch ohne Mohnanbau eine wirtschaftliche Perspektive haben. Wenn die sogenannten ,Failing States ' wieder zu stabilen, friedlichen Entwicklungen kommen sollen, brauchen sie auch soziale Stabilisierung." (Jung in Löwenstein in FAZ 29.10.2006: 5)

Während Äußerungen wie diese auf einer abstrakten Konzeptebene bleiben, ist die Berichterstattung in Reportagen praxisnäher. Theo Sommer gibt Ende September 2002 ein etwas schizophrenes Bild wieder. Erst wird eine Bedrohungslage skizziert, danach wird aber das idyllische Aufbaubild vermittelt:

„Und sie helfen viel. 70 zivilmilitärische Kooperationsobjekte sind abgeschlossen, 45 im Gang, 75 weitere werden vorbereitet. Diese Projekte unterstützen zum Beispiel Kindergärten und Schulen mit Möbeln und Lernmitteln. Als die Ratsversammlung Loya Jirga tagte, hielten Bundeswehrsoldaten 24 Stunden am Tag auf den Hügeln rund um das riesige Oktoberfestzelt aus Deutschland Wache. Die Truppe arbeitet auch mit dem Institut für Germanistik an der Universität zusammen. Bei der Bevölkerung genießt sie Vertrauen. 
Außerdem gibt die multinationale Brigade vielen Afghanen Arbeit.“ (Sommer in ZEIT ONLINE 26.09.2002). ${ }^{14}$

Besonders intensiv wird zivil-militärische Zusammenarbeit in Zusammenhang mit den Provincial Reconstruction Teams (PRT) ab 2003 verhandelt. Schon kurz vor Errichtung des ersten PRTs merkt Constanze Stelzenmüller in einer Reportage mit dem Titel „Schnauze voll vom Krieg“ an:

„Regionale Aufbaumannschaften aus zivilen Helfern, Polizeiexperten und Soldaten sollen in ausgewählten Provinzen ,Inseln“ der Ordnung und des Wohlstands schaffen. Was das konkret heißt - Dächer decken? Dachdecker bewachen? Gar Drogenschmuggler verhaften oder Opiumfelder unterpflügen? -, darüber herrscht im Nato-Botschafterrat noch keineswegs Einigkeit. [...]Auch die Deutschen haben jenseits der forschen Losung ,So viel Zivile wie möglich, so wenig Soldaten wie nötig' nicht viele Ideen, dafür aber jede Menge Dampf.“ (Stelzenmüller in ZEIT ONLINE 23.10.2003)

Henning Kober berichtet zwei Jahre später im Rahmen eines Truppenbesuches:

„In Kundus [...] erprobt die Bundeswehr ein neues Konzept, so die offizielle Information. ,PRT‘ nennt sich das und steht für ,Provincial Reconstruction Team‘, was heißt: zivilmilitärische Zusammenarbeit. Was heißt: Die Soldaten kämpfen hier nicht und bauen auch keine Brunnen. Sie fahren durch die Gegend, zeigen Präsenz und protokollieren. Wird ein neues Klassenzimmer benötigt, stellen sie den Kontakt zu einer NGO her, die dann mit deren Geld baut. So weit die Theorie.“ (Kober in taz 28.09.2005: 13).

Aus der Berliner Distanz formuliert Anett Keller im Artikel „Wenn Soldaten Brücken bauen“ eine Kritik anderer Art:

„Die PRTs, bestehend aus vielen Spezialtruppen und wenigen zivilen Ingenieuren, sollten einerseits Zellen der Aufstandsbekämpfung und militärischen Informationsgewinnung sein. Andererseits sollten sie mit Wiederaufbaumaßnahmen für Akzeptanz in der Bevölkerung werben. Die Trennung zwischen militärischer Operation und humanitärer Hilfe im zivilen Gewand ist klar aufgehoben.“ (Keller in taz 11.11.2006: 2).

14 Der letzte Satz ist wichtig, weil er auf eine weitere Dimension des Zivilen hinweißt die Ökonomische, siehe hierzu "Sicherheit für Kabul, Starthilfe für afghanische Firmen" (Martens in FAZ 12.02.2002: 3). 
Die Liste an Beispielen ließe sich mühelos fortsetzen. ${ }^{15}$ Erkennbar ist, dass die Rezeption und Auseinandersetzung mit Konzepten wie den PRTs in den Printmedien nicht unproblematisch ist. Es wird über Funktionsweisen geschrieben und Spezialvokabular eingeführt, vieles bleibt aber letztlich konzeptuell unklar und die Perspektivsetzung scheint oft beliebig. Kritik an der Rede vom ZivilMilitärischen wird häufig (und oft in ironischem Unterton) von Journalisten artikuliert, sie bleibt aber harmlos, da häufig uninformiert, undifferenziert oder partiell.

Mit der Fortdauer der Präsenz deutscher Truppen nimmt die Zahl der Reportagen aus Afghanistan zu. Mit diesen kommt zwar eine der Empirie etwas näher stehende Mikroperspektive hinzu. Es werden aber häufig nur sehr kleine Realitätsausschnitte eingefangen (ein Bundeswehrlager/ PRT, eine lokale Region, eine Problematik usw.). Aus Deutschland mitgebrachte, vorgefertigte Deutungsmuster dürften daher zum Teil auch bei Vor-Ort-Reportagen intakt bleiben. Der Zugang zu Information in einem unsicheren Gebiet ist schwierig, was eine Kritik der Informationspolitik der Bundesregierung und der Öffentlichkeitsarbeit der Bundeswehr erschwert. Daher kommt auch die Existenz sehr typischer Artikel zu Afghanistan, die immer wieder auftauchen, und sich erstaunlich ähnlich sind. Diese Feldberichte fangen oft mit dem Flug in der Transall an, beschreiben dann das Lager und die Bedingungen der Soldaten. Sie enthalten die Beschreibung einer Patrouille, ein Interview mit einem Bundeswehr-Soldat oder Offizier und ein paar allgemeine Überlegungen zum Einsatz. (z.B. Sommer in ZEIT ONLINE 26.09.2002, Bacia in FAZ 30.10.2006: 3)

\section{Heimatdiskurs - theoretische Verwicklungen}

Die Verknüpfung des Zivilen und Militärischen ist politisch und wissenschaftlich umkämpft. Die zivil-militärischen Kontroversen sind in besonderem Maße normativ aufgeladen. Kritiklinien verlaufen entlang der Unterscheidung Zivil/Militärisch. Die Deutungshoheit hierüber ist folglich Gegenstand politischen Streits.

15 Die zivil-militärische Problematik lässt sich bis zum Ende des Jahres 2011 verfolgen: „Militärberater wie Vogt könnten nach den Worten von Bundeskanzlerin Angela Merkel auch noch in Afghanistan bleiben, wenn die internationalen Truppen längst abgezogen sind. [...] Die Arbeit in einem der sogenannten Verbindungs- und Mentorenteams (OMLT) sei ,ein relativ unmilitärischer Auftrag', sagt Vogt.“ (Böge in FAZ 29.12.2011: 4). 
Wenn unklar ist, was „zivil“ und „militärisch“ umfasst und wie die Komponenten gewichtet sind, dann entstehen Spielräume für intransparente Politikanpassung. Klaren normativen und analytischen Gegenargumenten wird teils die Schlagkraft genommen, da die diskursive Angriffsfläche uneindeutig und komplex erscheint. Die Ausarbeitung von Details zivil-militärischer Konzepte (wie PRT, CIMIC, ,vernetzte Sicherheit“) und deren Verständnis verbleibt bei politischen Eliten, Experten, Spezialisten, Wissenschaftlern und wird somit einer breiteren Öffentlichkeit entzogen. Militärisches und völkerrechtliches Spezialwissen spielen eine wichtige Rolle; Erfahrungswissen und Lokalexpertise werden zur Voraussetzung glaubwürdiger Kritik (siehe Bliesemann de Guevara in diesem Band). Es stellt sich die Frage, ob die Rede vom Zivil-Militärischen nicht prinzipiell die Akzeptanz von militär-gestützten Ansätzen befördert und ob sie eine Rolle spielt für die Rekrutierung von Soldaten und deren Identifikation mit Einsätzen out of area. Wenn man sich als „Entwicklungshelfer in Uniform“ bewirbt und als ,professioneller Krieger“, um nur einige Stereotype zu nennen, zum Einsatz kommt, dann kann dies dramatische Folgen für das individuelle Selbstbild haben (siehe Herzog et al. in diesem Band).

Die Frage, wie man mit diesem Problemkomplex aus wissenschaftlicher Perspektive kritisch umgehen kann, ist kompliziert. Dies berührt die Analyseperspektive des Heimatdiskurses. Diese ist zum einen militärzentriert. Es geht darum aufzuzeigen, ,wie die Auslandseinsätze der Bundeswehr Deutschland verändern“ (Untertitel des Buches, Hervorhebg. der Autoren). Truppeneinsatz bzw. -entsendung sind definitorische Bedingung, um von einem Heimatdiskurs zu sprechen (Daxner in diesem Band). Andererseits wird mit der Theorie der Interventionsgesellschaft, aus der auch der Heimatdiskursbegriff resultiert, ein Versuch unternommen die zivil-militärische Problematik zu fassen. Der in ihr eingeführte Begriff „,militärisch-gestützten humanitären Interventionen“ verweist auf die Verknüpfung ziviler und militärischer Komponenten (Daxner 2010: 75). Interventionen sind hier etwas qualitativ Anderes als Krieg. Der Interventionsbegriff transportiere ein Mehr an Komplexität. ${ }^{16}$ Ein Aspekt dieser Komplexität liegt in der Verbindung ziviler (humanitäre Hilfe, nation- and statebuilding, Wiederaufbau, Entwicklung etc.) und militärischer Komponenten. Hier tritt ein anderer Aspekt neben die These politischer Nützlichkeit. In bestimmter Hinsicht verlangt die Empirie vom Zivil-Militärischen zu sprechen. Ist es dann die Aufgabe von Wissenschaft die Komplexität eines Phänomens realitätsadä-

16 „Vor allem die Abgrenzung zum ,Krieg’ hat mehr als nur semantische Bedeutung. Allein die völkerrechtliche Dimension der Interventionsfolgen in diesem Kontext ist erheblich komplexer geworden.“ (Daxner 2010: 76). 
quat sichtbar zu machen? Oder geht es um die Erzeugung von Klarheit und Simplifizierung? Erfordert Kritik nicht sowohl den Zusammenhang zu verstehen und $\mathrm{zu}$ definieren, als auch politische Instrumentalisierungen kenntlich $\mathrm{zu}$ machen?

Der Interventionsbegriff hat in diesem Kontext gegenüber den Begriffen von Einsatz und Krieg möglicherweise seine Vorzüge. Die Koppelung der Theorie des Heimatdiskurses an den Interventionsbegriff ist in anderen Hinsichten aber problematisch, da hier eine gebotene analytische Distanz zur untersuchten Empirie verloren geht. Es muss zwischen Intervention als wissenschaftlichem Begriff im Rahmen der Theorie der Interventionsgesellschaft und des Heimatdiskurses und seiner Präsenz und Funktion im öffentlichen Diskurs unterschieden werden.

Im Pressediskurs bleibt der Interventionsbegriff gegenüber Einsatz und Krieg randständig. ${ }^{17}$ Er findet vorwiegend Verwendung in Äußerungen aus Wissenschaft, Expertenkreisen, Völkerrecht und institutionalisierter Politik. Es scheint kaum Verknüpfungen zu Erfahrungen und Wissensvorräten der breiteren Öffentlichkeit zu geben. Hier bleibt der Kriegsbegriff dominant. Vor dem Hintergrund unserer Analysen zur zivil-militärischen Uneindeutigkeit bleibt fraglich, ob eine Vermittlung in die Öffentlichkeit wissenschaftlich wünschenswert wäre, denn der Interventionsbegriff macht, mehr als der Kriegsbegriff Dynamiken der Gewalteskalation unkenntlich. ${ }^{18}$ Soll der Interventionsbegriff analytisch fruchtbar gemacht werden, sind implizite Annahmen zum Verhältnis von Zivilem und

17 Eindrucksvoll ist beispielsweise, dass in der FAZ im gesamten untersuchten Zeitraum die Stichwortsuche „Afghanistan und Bundeswehr und Intervention“ nur 176 Treffer liefert, hingegen „Afghanistan und Bundeswehr und Krieg“ 1563 Treffer.

18 Die Theorie der Interventionsgesellschaft, aus der sich die Analyse des Heimatdiskurses ableiten soll, geht vom Ende eines Quellkonflikts mit Interventionsbeginn aus, wobei dies scheinbar als post-war gefasst wird (Daxner in diesem Band: 25ff.). Mit der Intervention treten dann Folgekonflikte auf. Im faktischen Heimatdiskurs ist die Voraussetzung eines Kriegsendes als Bedingung für eine deutsche Beteiligung an einer Friedenstruppe ein Streitpunkt (SEV in TAZ 03.12.2001: 5). Mit Ende des Krieges wurde damals auf die aus US-amerikanischer Perspektive „erfolgreich“ verlaufenden Kampfhandlungen in Afghanistan Bezug genommen. Hier schien für einige Diskursteilnehmer also die klassische Trennung von Krieg und Frieden noch zu gelten, der Krieg musste beendet werden, bevor man von Frieden oder einer Friedenstruppe reden kann. Unsere Ausführungen zum Kriegsbegriff und dessen Präsenz im Heimatdiskurs, lassen eine derartige Trennung von Intervention und Krieg fragwürdig erscheinen. 
Militärischen offen zu legen. Der Heimatdiskurs als Interventionsdiskurs hätte dann seine Fokussierung auf das Militärische zu überwinden.

\section{Grenzen und Politik DER THEORIE des HeimatdiskuRses}

Unsere Analysen bis hierher folgten weitgehend der Theorie des Heimatdiskurses, insofern als unsere Perspektive militärzentriert, deutschlandzentriert und interventionszentriert war. Im Weiteren arbeiten wir daran, diese Zentrierungen ein Stück weit aufzubrechen.

Wir konzentrieren uns auf zwei Problemkomplexe. Einerseits diskutieren wir die Fokussierung auf Deutschland. Wir reflektieren die Konsequenzen dieser Theorieentscheidung für die Thematisierung der Beziehungen zwischen Deutschland und Afghanistan bzw. Deutschen und Afghanen. Anderseits kritisieren wir die Isolierung des Heimatdiskurses als deutschen Interventionsdiskurs in dreifacher Hinsicht. Erstens halten wir gesellschaftliche Kontexte und angrenzende Diskurse, die nicht unmittelbar mit der engeren Interventionsproblematik assoziiert werden, bedeutsam für eine Analyse des Heimatdiskurses. Zweitens weisen wir darauf hin, dass Interventionsdiskurse international strukturiert sind. Drittens argumentieren wird dafür Militärintervention als eine umkämpfte Variante im Spektrum der Ansätze ziviler und militärischer Konfliktbearbeitung sichtbar zu machen. Hier deutet sich bereits an, dass die Problematik der ZivilMilitärischen Abgrenzung erneut eine wichtige Rolle spielt.

\section{Hier, Dort, Anderswo: Deutschland und Afghanistan}

Wir rücken zunächst den Gedanken einer Beziehung zwischen einem hier (Deutschland, Heimatgesellschaft) und einem dort (Afghanistan, Interventionsgesellschaft) in den Mittelpunkt unserer Überlegungen.

Die deutsche (Militär-)Präsenz in Afghanistan tangiert die Lebensrealitäten von Menschen in Deutschland und Afghanistan unmittelbar und existenziell. Sie ist darüber hinaus bedeutsam, weil sie auf diskursiver Ebene in weit reichenden, symbolischen Auseinandersetzungen verhandelt wird, die selbst wieder lebenspraktische Konsequenzen nach sich ziehen können. Wir gehen von einigen Asymmetrien aus. Die unmittelbaren gesellschaftlichen Effekte von Auslandseinsätzen sind in den Einsatzgebieten out of area ungleich höher als in Deutschland. Die symbolischen Kämpfe um die Einsätze und ihre Verarbeitung zu Politik sind schwerpunktmäßig hier lokalisiert. Deutschland als Ort des Sprechens, der Diskurse; Afghanistan als Ort des Handelns, der gesellschaftlichen Dyna- 
mik. ${ }^{19}$ Zumindest wird diese Verortung politisch, medial und mitunter auch wissenschaftlich befördert.

Als Forscher, die auf Deutsch und in Deutschland publizieren, sind wir selbst klar im hier lokalisiert und sprechen in den deutschen Diskurs als Komplizen hinein. Wir lokalisieren die zentrale Kontroverse allerdings weniger darin, ob zur Kenntnis genommen werden darf, was der Fall ist, ${ }^{20}$ als darin zu bestimmen, was es bedeutet, die in der Heimatdiskurs-Forschung angesprochenen Probleme realitätsadäquat zu analysieren. Für uns ist die Frage nach den politischen und praktischen Effekten von wissenschaftlicher Forschung hier auf die Beziehung zwischen hier und dort zentral.

Wir nehmen an, dass es eine nicht vollständig einholbare Differenz zwischen den Realitäten und sozialen Praxen des dort (vor Ort in Afghanistan) und unserem Blick auf diese von hier aus - dem anderswo - gibt, wie er in den diskursiven Konstruktionen von Wirklichkeiten etwa in den deutschen Printmedien sichtbar wird. ${ }^{21}$ Hier schließen grundlegende Fragen der Repräsentation der und des Sprechens für die Anderen, die Afghanen auf, wie sie die postkoloniale und dekoloniale Kritik artikuliert. ${ }^{22}$

19 Zwar wird mit der Theorie des Heimatdiskurses betont, dass sich auch die deutsche Gesellschaft verändert. Betrachtet man aber den größeren Theorierahmen, fällt auf, dass von Heimatdiskurs und Interventionsgesellschaft die Rede ist, und zumindest auf dieser Ebene die problematische Zuordnung reproduziert wird.

20 Die von Daxner in Anlehnung an Dirk Baecker angeführte „Komplizenschaft“ (z.B. durchgängig Daxner in diesem Band) führt hier unseres Erachtens nach in die Irre, da es die Frage, wie etwas erforscht werden soll, der Frage unterordnet, ob es erforscht werden darf.

21 Diese Differenzierung von hier, dort und anderswo beziehen wir aus der gerade wieder einsetzende Auseinandersetzung mit Jean-Luc Godards und Anne-Marie Mievielles 1975 erschienen Film ,ici et allieurs“ (here and elsewhere). (siehe z.B. Alessandrini 2011).

22 Walter Mignolo, ein Impulsgeber für Grenzdenken der Gegenwart, spricht von einer „Geopolitik des Wahrnehmens und Erkennens“:,Grenzdenken [ist] eine epistemische Besonderheit jedes dekolonialen Projektes. [...]Wir anthropoi [Mignolo meint, die Anderen', welche erst diskursiv und zu Herrschaftszwecken geschaffen wurden], die wir mit dekolonialer Sensibilität Grenzen denken und bewohnen, sind auf dem Weg der Entkoppelung, und um sich zu entkoppeln muss man epistemisch ungehorsam sein. Man wird zur Rechenschaft gezogen werden, denn die Journale, Magazine und Disziplinen der Sozial- und Humanwissenschaften sind ebenso wie die sozialwissenschaftlichen und berufsbildenden Schulen territorial verfasst. Das Grenzdenken 
Aus dieser Perspektive scheint uns eine kritische Auseinandersetzung mit der Theorie des Heimatdiskurses angebracht. Diese thematisiert zwar explizit die Beziehung zwischen „Auslandseinsätzen“ der Bundeswehr out of area und deutschen Diskursen bzw. der deutschen Gesellschaft. Es werden auch Effekte des deutschen Heimatdiskurses auf das Geschehen in Afghanistan angesprochen. Wir weisen allerdings auf einen möglichen Widerspruch hin. Einerseits wird festgestellt, dass Nähe zur Interventionsgesellschaft in Afghanistan und damit zu den Afghanen wichtig sei (Daxner in diesem Band: 25ff.), anderseits ist der analytische Fokus auf Deutschland und Heimat gerichtet. Die Darstellung der Intervenierten in den deutschen Medien macht eine Analysedimension des Heimatdiskurses aus (vgl. Aljets et al. in diesem Band). Afghanistan und die Afghanen, so scheint es, werden aber in erster Linie in ihrer Bedeutung für Heimat und Deutschland verhandelt. Beispielsweise interessiert der beinamputierte Afghane in seiner Bedeutung für die deutsche Heimkehrer-Debatte:

„Der bettelnde Beinamputierte ist heute auf den Straßen von Kabul gegenwärtig, aber er ,erinnert“ (noch) nicht an unser Alltagsstraßenbild. Die Verletzungen sind andere geworden, und sie werden anders repräsentiert, vor allem medizinisch, um im Bereich der Wohlfahrts-Governance aufgehoben zu sein - das kann man an der Diskussion von PTSS (Posttraumatisches Stresssymptom) studieren.“ (Daxner in diesem Band: 50)

Es geht gerade darum, das Augenmerk darauf zu legen ,wie die Auslandseinsätze der Bundeswehr Deutschland verändern“" (Untertitel unseres Buches, Hervorhebung der Autoren). Ein Analyseschwerpunkt ist, spezifisch deutsche Diskursmerkmale herauszuarbeiten. Die Rede vom Heimatdiskurs als einem deutschen Problem verweist in diesem Zusammenhang unter anderem darauf, dass Auslandseinsätze in Deutschland häufig als problematisch und nicht-normal thematisiert werden. Hinzu kommt der Aspekt eines besonderen Maßes an Selbstbezogenheit der deutschen Debatten. Dieser Forschungsschwerpunkt des Heimatdiskurs-Ansatzes ist produktiv insofern, als er einen empirisch stichhaltigen und brisanten Problembereich der wissenschaftlichen Aufmerksamkeit zuführt. Er ist aber, wie wir zeigen, aus relationaler Perspektive nicht unproblematisch.

ist die notwendige Voraussetzung für das dekoloniale Denken. [...] wir wohnen und denken an der Grenze von lokalen Geschichten und wir widersetzen uns globalen Entwürfen.“ (Mignolo 2011). 


\section{Ausschlüsse und Reproduktion}

Es kommt zu einem Ausschluss afghanischer Perspektiven und Stimmen, sofern sie nicht bereits im deutschen Diskurs präsent sind. Wir stoßen hier auf ein allgemeines Charakteristikum der Theorie des Heimatdiskurses. Analysiert und kritisiert wird das, was in Deutschland in hegemonialen Debatten empirisch auffindbar und wirkmächtig ist. Ein großer Teil des in Afghanistan (und Deutschland) Gedachten, Geschriebenen und Gesprochenen bleibt somit außerhalb der Analyse - als das Nichtsichtbare, Ausgeschlossene, Marginalisierte oder Ungedachte. Hier schließt die Frage an, inwiefern der Ausschluss afghanischer Sichtweisen und Stimmen kritikwürdig ist. Einfache Kritikmuster versagen an dieser Stelle. Einerseits könnte es sein, dass gerade erst die Reflektion und das Verständlichmachen des deutschen Problems einen realitätsadäquaten Blick auf Afghanistan und die Afghanen ermöglichen. Andererseits besteht die Gefahr der wissenschaftlichen Reproduktion empirisch bereits dominanter Diskursbestandteile. Nicht Reproduktion an sich ist problematisch, sondern die Inhalte die reproduziert werden. Dies gilt gleichermaßen für deutsche und afghanische Stimmen. Zwar wäre mehr Präsenz afghanischer Stimmen im deutschen Diskurs wünschenswert, mit diesen würde der Heimatdiskurs aber nicht zwangsläufig differenzierter. Zudem ist eine kritische Aufarbeitung hier vorhandener Wissensbestände über die Afghanen Voraussetzung dafür, dass ein adäquateres Verständnis der Anderen entstehen kann. ${ }^{23}$ Es ist nichts verkehrt daran, wenn Heimatdiskursanalyse die Deutschen (adressiert ist ja vorwiegend die Politik) mehr über sich selbst wissen lässt. Dieses Wissen wird aber nicht zwangsläufig Empathie für die Afghanen befördern, und schon gar nicht die Handlungsfähigkeit (bestimmter Teile) der afghanischen Bevölkerung vergrößern. Es bleibt offen, inwieweit wir die Interessen der Afghanen erkennen können und mehr noch in welchem Maße und auf welche Weise diskursive Aufklärung hier die praktischen Lebensrealitäten dort berührt. Die These der Teilsteuerung der Intervenierenden durch den Heimatdiskurs ist hier bedeutsam, da sie sich auch auf den in Afghanistan präsenten Teil der Intervenierenden bezieht, der direkt in Interaktionen mit den Afghanen tritt. Implizit wird damit ein deutscher Diskurs zu einem Raum emanzipativen Handelns für die Afghanen erklärt, ohne dass die

23 Dazu Bettina Gaus: „Die Bedeutung solcher Nachrichten [es geht um afghanische Stammesfürsten,SR] lässt sich für diejenigen nur schwer einschätzen, die keine Ahnung von den inneren Verhältnissen in Afghanistan haben. Also für ungefähr 99 Prozent der Öffentlichkeit und der politischen Klasse.“ (Gaus in taz 15.03.2002: 12). 
Bedeutung einer Beteiligung afghanischer Sprecher thematisiert würde. ${ }^{24}$ Wir können hier auf diese theoretische Leerstelle nur hinweisen, ohne sie selbst füllen zu können. Dies würde eine andere empirische Materialgrundlage erfordern, die auch Quellen aus Afghanistan berücksichtigt. Unsere Analysen des Zeitungsmaterials liefern theoriekritische Impulse anderer Art.

\section{Die deutsch-afghanischen Beziehungen in den Medien}

Wir schlagen vor, die expliziten Thematisierungen der Beziehungen zwischen Deutschland und Afghanistan, bzw. Deutschen und Afghanen in den Medien verstärkt zum Gegenstand der Analyse zu machen. Besondere Aufmerksamkeit verdienen in diesem Zusammenhang mediale Vermittlungsprozesse und Informationsflüsse zwischen Deutschland und Afghanistan.

Auffällig häufig ist von einem besonderen (oft: besonders gutem) deutschafghanischen Verhältnis die Rede. Das Motiv taucht in vielen Variationen auf. Es wäre auch auf seine legitimatorischen Effekte hin zu analysieren. Nachfolgend einige Beispiele:

„Und auch weil die Deutschen schon immer als neutrale Partner galten, die ihnen nie etwas aufzwingen wollten, genießt Deutschland unter den Afghanen einen sehr guten Ruf.“ (Hansen in taz 01.12.2001: 1)

„,Wenn man sagt, man kommt aus Deutschland, sieht man ein Leuchten in den Augen“, so Wilhelm. Der Siemens-Manager Oberg ergänzt: ,Wir haben alle gespürt, dass Deutschland für Afghanistan ein Wunschpartner ist".“ (Hansen in taz 13.02.2002: 6)

„,Manchmal ist es fast schon unangenehm, wie beliebt die Deutschen bei den Afghanen sind“, bemerkt Presseoffizier Oberstleutant Paul Weber.“ (Böhm in taz 23.10.2002: 11)

24 Ein Artikel wie „Der afghanische Blick“ von Niels Minkmar verspricht hier, dem Titel zufolge, einen Gegenakzent zu setzten. Es zeigt sich aber, dass auch der Blick des afghanischen Intellektuellen Masoud Rahel auf die deutsche Problematik gerichtet bleibt: „Masoud Rahels Gedanken kommen ohne Kitsch und Pathos aus. Es gelingt ihm besser, die Aufgabe der Bundeswehr in Afghanistan zu beschreiben, als den deutschen Intellektuellen, ja sogar den dafür zuständigen Politikern. Sie könnten seine intellektuelle Entwicklungshilfe annehmen und künftig sagen: Die Soldaten der Bundeswehr sind Pioniere des in der Geschichte der Menschheit neuen Versuchs, weltweite Probleme gemeinsam zu lösen. Das ist jedenfalls die Idee.“ (Minkmar in FAS 25.04.2010: 23). 
„Der Gouverneur hat nach eigenem Bekunden eine Schwäche für die Deutschen. ,Wir sind froh, dass sie hier sind. Wir sind beide Arier, wir sind also Vettern“ " (Taheri in FAZ 03.06.2006: 2)

Dieses Motiv wird erst mit Verschlechterung der Sicherheitslage brüchig. Man beachte das in Klammern eingefügte „Immer noch“ im Zitat aus Ullrich Ladurners Artikel „Sie mögen uns“: „Es gibt kein westliches Land, das in Afghanistan einen (immer noch) so guten Ruf genießt." (Ladurner in ZEIT ONLINE 08.03.2007).

Ein deutscher Journalist beantwortet gar den Sinn seiner Präsenz in Afghanistan mit dem Hinweis auf eine besondere Nähe zwischen Deutschen und Afghanen:

„Die Afghanen sind Geiseln eines Krieges, den sie nicht begonnen haben und den sie allein nicht beenden können. Sie sind Opfer einer pervertierten Großmachtpolitik, die den Islamismus erst hervorgerufen hat. Und in dieser Lage sind sie uns - gerade den Deutschen, denen sie sich wie keiner anderen westlichen Nation verbunden fühlen - auf einmal unheimlich nahe.“ (Hanfeld in FAZ 22.05.2007: 37)

Ein Konstrukt wie „Zivilisierung“ weist auf ein weiteres kritikwürdiges Beziehungsmodell hin. Der Wortbestandteil Zivil steht hier nicht für das NichtMilitärische. Es verweist auf Modernisierung und Fortschritt. Schon Ende 2001 heißt es zum Beispiel in einem Leitartikel:

„Bündnisse über alte Konfliktlinien hinweg zu schmieden und eine legitime staatliche Grundordnung aufzubauen, das wird die Aufgabe der neuen Übergangsregierung unter dem designierten Ministerpräsidenten Karsai sein. Ohne internationale Hilfe wird er sie kaum erledigen können; ohne ein Mindestmaß an Zivilisierung wird er nicht erfolgreich sein. Darum ist die Präsenz einer internationalen Schutztruppe unerlässlich.“ (Frankenberger in FAZ 18.12.2001: 1).

Wer oder was soll unter Mithilfe deutscher Soldaten zivilisiert werden? Die Afghanen? Afghanistan? Wenn in einem deutschen Interventionsdiskurs Konstrukte wie „Zivilisierung der Afghanen“ eine Rolle spielen, forciert das die Frage, auf welche Weise die Theorie des Heimatdiskurses die Beziehungen zwischen Intervenierenden und Intervenierten analysiert. 
Friederike Böge ${ }^{25}$ thematisiert im Artikel „Wortgefecht“ ausführlich die Informationsgewinnung und -zirkulation in Afghanistan (Böge in FAZ 03.07.2010: 44). Hier wird die Beziehung zwischen Intervenierenden und Intervenierten als konfliktreich beschrieben:

„,Richtigkeit ist uns wichtiger als Schnelligkeit‘, sagt Josef Blotz und führt gegen den Vorwurf, die ISAF informiere nicht schnell genug, die Sorgfaltspflicht ins Feld. [...] Oft seien Gefechtssituationen unübersichtlich und Fakten müssten erst überprüft werden. Das klingt einleuchtend, überzeugt die Journalisten aber nicht. ,Die internationalen Truppen sind langsamer, weil sie über die Wahrheit erst noch diskutieren müssen', scherzt einer der Afghanen in der Teepause.“ (Böge in FAZ 03.07.2010: 44)

Eine weitere These ist, dass die Berichterstattung in lokalen Medien stark von westlichen Quellen abhängig ist:

„,Viele Informationen erfahren wir erst aus der internationalen Presse“, sagt Noor Muhammad Sahim in Kundus. ,Die Soldaten vertrauen den westlichen Journalisten mehr als uns. 'Dabei seien die Nachrichten für die Menschen vor Ort viel relevanter als für die Bevölkerung in Deutschland. [...] Die meisten Lokalzeitungen in Afghanistan schreiben von der ,New York Times“ ab.“ (ebd.: 44).

Die mediale Vermittlung des Einsatzes wird als praktischer Bestandteil von Interventionsprojekten kenntlich gemacht (siehe auch Neumann in diesem Band):

„,Dies ist ein Krieg der Wahrnehmungen', hat der gerade abgesetzte ISAF-Kommandeur Stanley McChrystal über den Afghanistan-Einsatz gesagt. Doch weder den Militärs noch den Hilfsorganisationen ist es während der Dauer dieses Krieges offenbar gelungen, der Bevölkerung zu erklären, welche Absichten sie verfolgen. [...] Die Journalisten in dieser Geschichte haben durch ihre Arbeit mehr westliche Werte verinnerlicht als die Mehrheit der Bevölkerung. Sie haben mehr von der westlichen Intervention profitiert als die meisten ihrer Landsleute. Sie haben Zugang zu mehr Informationen. Wenn es so schwer ist, mit diesen Journalisten einen Dialog zu führen, wie schwer muss es erst sein, die lokale Bevölkerung zu überzeugen?““ (ebd.: 44)

25 Friederike Böge bringt erkennbar Lokalexpertise zu Afghanistan ein. Sie schreibt regelmäßig Reportagen aus Afghanistan für die FAZ. Sie ist Chefredakteurin der Website www.afganistantoday.org, einem vom Auswärtigen Amt unterstützen Projekt, das die Ausbildung afghanischer Journalisten fördert und damit das Ziel verfolgt die Stimme der Afghanen im Ausland vernehmbar zu machen. 
Auch in Deutschland publizierende Sozialwissenschaftler sind in diesen „Krieg der Wahrnehmungen“"verwickelt. Welche Rolle spielen sie?

Im Artikel „Krieg gegen die Deutschen?“ von Jörg Lau wird die Blickrichtung umgekehrt - es geht um vermeintliche Eingriffe der Intervenierten in den deutschen Heimatdiskurs:

„,Die Deutschen sind das schwächste Glied in der ISAF-Kette, weil sie als Einzige jedes Jahr über das Mandat abstimmen ${ }^{26}$, sagt der in Kabul tätige Ingenieur Peter Timm. ,Es ist zweifellos ein Ziel der Taliban, unsere Debatte zu beeinflussen. 'Der CDU-Außenpolitiker Ruprecht Polenz, Vorsitzender des Auswärtigen Ausschusses im Bundestag, glaubt zwar nicht, dass alle Attacken der vergangenen Monate einer einheitlichen Strategie folgen. ,Aber es ist zweifellos ein Ziel der Taliban, die Debatte bei uns zu beeinflussen“." (Lau in ZEIT ONLINE 23.08.2007)

\section{Ausweitung der Analyseperspektive}

Wir halten es für analytisch produktiv die Beziehung zwischen Deutschland und Afghanistan umfassender zu denken. Einiges spricht dafür, das Geschehen in der Interventionsgesellschaft analytisch in den Mittelpunkt zu rücken. Dort ist der Ort, an dem die Intervention vollzogen wird, wo ein Wort wie Krieg mehr als ein umkämpfter Diskursbestandteil ist. Eine kritische Auseinandersetzung mit der Praxis von Militärinterventionen hat sich aber auch mit den gesellschaftlichen Bedingungen der Entsendeländer zu beschäftigen. Die zugrunde liegende Frage lautet: Inwieweit lenken Interventionen als Sozialreformprojekte out of area von Handlungsbedarf und Defiziten hier ab? So fragt Dan Smith, Generalsekretär der Organisation International Alert in London, kürzlich in der ZEIT:

„Wenn wir heute auf Europa blicken, können wir uns die Frage stellen, ob eigentlich unsere eigene heimische Friedenszone noch so stabil und verlässlich ist - oder ob wir nicht in Erwägung ziehen sollten, den Auftrag der Friedenskonsolidierung auch auf Staaten innerhalb der EU selbst zu beziehen." (Smith in ZEIT ONLINE 12.01.2012)

Im Zeitraumzwischen 2008 und 2011 finden wir am thematischen Rand des Heimatdiskurses weitere Artikel, anhand derer wir dieser Frage nachgehen kön-

26 Wird hier die jährliche Mandatsverlängerung als eine Angriffsfläche thematisiert, so legen unsere Analysen nahe, dass es sich auch um ein Instrument der Reaktualisierung offizieller Deutungsmuster über den Einsatz handelt. 
nen. Wir stellen hier einige exemplarische Positionen skizzenhaft nebeneinander und überlassen es den Lesern die angedeuteten Konturen zu schärfen.

In Cora Stephan's Artikel „Wir Friedensverwöhnte“ klingt ein Thema an, auf das wir später zurückkommen werden - die Verbindungen zwischen Auslandseinsätzen und der politischen und rechtlichen Verfasstheit westlicher Gesellschaften:

„Demokratien tun sich mit dem Militärischen schwer; anders als jeder dahergelaufene Diktator können gewählte Regierungen Soldaten nicht ohne triftigen und möglichst eng an die Interessen des Landes gebundenen Anlass ins Feld schicken." (Stephan in FAZ 06.12.2009: 13)

Während die daran anschließende Frage der politischen Durchsetzbarkeit und Legitimation von Interventionsentscheidungen keineswegs randständig ist, werden Fragen der gesellschaftlichen Voraussetzungen hier, sofern sie über die Problematik der militärischen Einsatzfähigkeit hinausweisen, wenig thematisiert. Interventionen als Bestandteil der Außen- und Sicherheitspolitik von Demokratien zu denken - so unsere These - verweist aber gerade auf viele Voraussetzungen. Jedenfalls dürften Interventionen dann keine Projekte politischer und militärischer Eliten sein, die dem Volk lediglich verkauft werden. Es ginge zumindest um Interessiertheit, Informiertheit und Mitsprache.

Es ist eher selten, dass so deutlich auf den geringen Handlungsspielraum deutscher Politiker hingewiesen wird, wie im Zeit-Dossier von Stefan Willeke mit dem Titel „Der Krieg der anderen“, das die Reiseerfahrungen des Politikers Niels Annen in Afghanistan verarbeitet:

„Ahnen seine Kritiker überhaupt etwas von seinen Zwängen? Da ist die Partei, an der seine Zukunft hängt. Da sind die Amerikaner, mit denen man es sich nicht verscherzen darf. Da sind die Wähler, die den Krieg in Afghanistan nicht wollen. Da ist der Kanzlerkandidat, der im Wahlkampf keine Bilder von toten Soldaten braucht." (Willeke in ZEIT ONLINE 11.09.2008)

In diesem Artikel wird auch auf Konflikte zwischen den Realitäten deutscher Lokalpolitik und einer verantwortlichen Politik für die Afghanen hingewiesen:

„Niels Annen könnte von Steuern erzählen, die niemand zahlt, von einem Staat, den niemand spürt, er hat genug erfahren, um sich in Hamburg auf einen Marktplatz zu stellen und in ein Megafon zu brüllen, dass Afghanistan eine Aufgabe für Dekaden sein wird, eine Jahrhundertaufgabe vielleicht. Er müsste es tun, damit jeder die Wucht des Problems 
spüren kann. Aber er tut es nicht. Niels Annen fährt nach seiner Rückkehr durch seinen Wahlkreis im Hamburger Westen, seine traditionelle Tour am Ende der Sommerpause, 56 kleine Auftritte.“ (Willeke in ZEIT ONLINE 11.09.2008)

Im Artikel „Es ist Krieg - und keiner schaut hin“ von Natalie Tenberg werden Aufmerksamkeitsökonomien problematisiert. Die Interventionsproblematik konkurriert mit anderen Themen:

„Ab und an werden Berichte gesendet, aber die Deutschen, sagte der Afghanistan-Experte Herbert Sahlmann, seien mit anderen Dingen beschäftigt, beispielsweise der Finanzkrise. [...] Der ehemalige Verteidigungsminister Peter Struck (SPD) saß in der Runde, wie auch ein ehemaliger Hauptfeldwebel, der in Afghanistan Opfer eines Selbstmordanschlags wurde und seitdem unter Angstzuständen leidet. Seine Geschichte war bestürzend. Aber auch wirklich für den Zuschauer nachhaltig erschütternd? Nein. Zu wenig wurde, und man mag es dem Mann keinesfalls vorhalten, auf effekthascherische Details geachtet. [...]“ (Tenberg in TAZ 02.02.2009: 17).

Hier stellt sich auch die Frage, welchen Stellenwert Auslandseinsätze für die Bevölkerung und ihre Konzeptionen von Heimat haben.

Die militärische Problematik „Bundeswehr in Afghanistan“ wird mit anderen als „zivil“" verstandenen gesellschaftlichen Dimensionen zuhause zusammengedacht. In „Unter Postheroen“ bringt Gunter Franzen in der FAS die kollektive, psychische Verfasstheit der Deutschen mit dem Auftreten der Bundeswehr in Afghanistan in Verbindung:

„Die prinzipielle Ablehnung könnte auf eine dem kollektiven Selbstbild schmeichelnde, der geschichtlichen Erfahrung geschuldete pazifistische Grundhaltung zurückzuführen sein. Oder sie deutet auf eine allgemeine Schwächung der Resilienz hin. Der soziologische Begriff bezeichnet die Fähigkeit von Individuen und Gruppen, dem Verlust nahestehender Menschen oder flächendeckenden Verheerungen wie Kriegen und Naturkatastrophen mit robuster Widerstandskraft zu begegnen und diese ohne anhaltende psychische Beeinträchtigungen durchzustehen. Angesichts des glücklosen und halbherzigen militärischen Agierens des deutschen ISAF-Kontingents in Afghanistan drängt sich der Eindruck auf, dass es unseren ebenso freundlichen wie feinfühligen Soldaten an keiner Tugend mangelt, bis auf eine: Gewalt zu erleiden und Gewalt auszuüben.“ (Franzen in FAZ 27.02.2011: 10)

Folgt man Franzens Vermutung einer allgemeinen Schwächung der Resilienz, dann wird im Verhalten der Soldaten etwas sichtbar, das auch für deutsche Zivilisten gilt. In „Universitäten im Krieg“ benennt Schwarzbeck ein weiteres wich- 
tiges Problemfeld - die Wechselwirkungen zwischen Wissenschaft und dem untersuchten Phänomen:

„Die Friedens- und Konfliktforscherin Mechthild Exo sieht eine insgesamt bedenkliche Entwicklung: ,Während die Militarisierung an den Universitäten vorangetrieben wird, blutet die klassische Friedensforschung aus', sagte sie am Samstag in der HumboldtUniversität auf einem Kongress zum Afghanistankonflikt. [...] Häufig ist es Auslegungssache, ob es sich um Militärforschung handelt. [...] Die zunehmende Vermischung von militärischer und ziviler Forschung sei allerdings typisch für die derzeitige Entwicklung.“ (Schwarzbeck in taz 08.02.2010: 21)

Unsere Frage nach der Politik der Theorie des Heimatdiskurses berührt dieses Problemfeld. Uns geht es jedoch nicht primär darum, zu entscheiden, ob die Theorie zivile oder militärische Forschung bzw. eine Mischform anleitet. Wichtiger erscheint uns zu untersuchen, wie sich der Ansatz zur deutschen Interventionspolitik verhält.

\section{Wissenschaft, Interventionspolitik, Heimatdiskurs}

Interventionspolitik ist umstritten. Die Narrative entlang derer dieser Streit ausgetragen wird, ändern sich - was für Afghanistan gilt, kann für Syrien schon ganz anders angeordnet werden. Der reine Fakt der Intervention/ Nichtintervention und die Art von Intervention (Umfang, Gewichtung ziviler und militärischer Komponenten) strukturieren die diskursiven Auseinandersetzungen und normativen Stellungnahmen maßgeblich. Der Ansatz des Heimatdiskurses bezieht sich, so wie er bisher konstruiert wurde, lediglich auf ,empirische Fälle“ in denen tatsächlich out of area „,militärisch-gestützt“ interveniert wurde. ${ }^{27}$ Fälle der Nicht-

27 Wir halten es für wenig plausibel, von Heimatdiskurs nur zu sprechen, wenn ein aktives Engagement im Sinne von Truppenpräsenz gegeben ist. (vgl. Daxner in diesem Band). Dazu dürfte doch beispielsweise folgende Äußerung von Jürgen Todenhöfer im Zuge einer Auseinandersetzung um die Berichterstattung über den Syrien-Konflikt für den Heimatdiskurs relevant sein: „Den Westen aber interessieren die Menschen in Syrien nicht wirklich. So wie ihn die Menschen im Irak nie interessiert haben. Öl und das Machtspiel im Mittleren Osten sind ihm wichtiger. Die bundesdeutsche Politik aber marschiert weiter im Gleichschritt mit. Seit 9/11 ist es schwer geworden, sich in unserem Land für friedliche Lösungen einzusetzen. Deutschland, du hast dich verändert!“ (Todenhöfer in taz 20.03.2012: 4-5) Welche guten Gründe lassen sich anführen, die teils langfristige Präsenz von deutschen Nichtregierungsorganisationen, Kulturin- 
intervention (oder potentiellen Intervention) bzw. der Intervention ohne Truppenentsendung werden nicht betrachtet. Es handelt sich um eine partielle Theorie, die mit einem spezifischen Erkenntnisinteresse entwickelt wird - die Folgen von Auslandseinsätzen der Bundeswehr in Deutschland zu erklären.

Intervention sind somit etwas Gegebenes, ein Fakt, den Wissenschaft zur Kenntnis nehmen oder ignorieren kann, der aber jedenfalls praktische Konsequenzen hat. Bei Daxner heißt es:

„Man kann sinnvolle Aussagen zum Thema Intervention fast nur machen, wenn man sich in ein affirmatives Verhältnis zu genau den Systemen begibt, die man auch kritisiert. Oder man bewegt sich in einem moralischen Diskurs, der sich unsensibel gegenüber empirischen Befunden zeigen muss, wo seine Prinzipien angegriffen werden [...]“. (Daxner in diesem Band: 18)

Hieran schließt eine Konzeption von Wissenschaft an, die sich der Politikberatung öffnet.

Wissenschaftliche Forschungsprogramme wie der Heimatdiskurs, die sich so unmittelbar und zeitnah auf das politische Zeitgeschehen beziehen, stehen in Relation zu und Konkurrenz mit Äußerungen aus anderen gesellschaftlichen Feldern. Die implizite These lautet, dass eine Forschung, die praktische Effekte (auch was das Geschehen out of area anbelangt) erzielen möchte, die politischen Entscheidungsträger adressieren muss und die Forschungsergebnisse an diese kommunizierbar sein müssen. Aus einer so justierten Perspektive kann keine radikale Kritik formuliert werden. Es wird immanente Kritik an der bestehenden Praxis artikuliert, bzw. inkrementelle Verbesserungsvorschläge gemacht. Diese Tatsache allein ist noch nicht so problematisch.

Das Problem resultiert daraus, dass die Kritik sich aus der Analyse hegemonialer Debatten selbst speisen soll. Daxner analysiert den Heimatdiskurs arbeitspragmatisch bisher ausgehend von dominanten Diskursereignissen, Äußerungen und „salienten Sätzen“ innerhalb des medialen Mainstreams. ${ }^{28}$ Die hegemonialen Debatten sind offenbar für ihn insofern zentral, als sie stark durch Eliten geformt werden - viele der bisher analysierten Äußerungen kommen von politischen Entscheidungsträgern. Eine Forschung, die den Heimatdiskurs politi-

stitutionen oder Journalisten out-of-area definitorisch anders zu gewichten als eine Militärpräsenz?

28 Demgegenüber ist die Bedeutung von komplexen Argumentationsmuster und Problemzusammenhängen für die Analyse des Heimatdiskurses hervorzuheben. 
schen (und militärischen) Entscheidungsträgern erklären möchte (Politikberatung), wird hiermit realpolitisch anschlussfähig.

Einzelne Aspekte innerhalb der enger gefassten Problematik von Auslandseinsätzen können so analysiert werden. Wir vermuten allerdings, dass die starke Anlehnung an Realpolitik ein Faktor dafür ist, dass stellenweise die unserer Meinung nach notwendige analytische Distanz abhanden kommt. Zudem wird die Interventionsproblematik tendenziell isoliert und entkontextualisert. Wir versuchen der Aufforderung von Andreas Hirseland und Werner Schneider zu Kontextualisierung und Historisierung ein Stück weit Folge zu leisten:

„Aus der Annahme der prinzipiellen Kontingenz und damit des politischen Charakters von diskursiven Prozessen folgt, daß diskursiv erzeugte (Bedeutungs-) Ordnungen durch partielle Sinnfixierungen bestimmte Formen der Problemlösung institutionalisiert und damit zugleich andere Möglichkeiten ausgeschlossen haben. In diesem Sinne sind Diskurse und Diskursformationen als historisch kontigente, aber (infolge ihrer Durchsetzung immer schon) hegemoniale Artikulationen von bestimmten Interessen und Bedürfnissen zu verstehen, über die Identitäten konstruiert werden. Weil diese nur über die Konstruktion eines jeweiligen ,Außen` zu verstehen sind, das unausgesprochen im Inneren der jeweiligen Diskurse operiert, erfordert Diskursanalyse, nicht nur den einzelnen empirischen (Spezial-) Diskurs zu rekonstruieren, der ihren jeweils konkreten Forschungsgegenstand darstellt, sondern diesen in seine historischen und politischen, in Gegendiskursen oder anderen Diskursformationen aufscheinenden Kontexte zu setzen.“ (Hirseland und Schneider 2011: 423-24)

Es wird zwar angenommen, dass Verbindungslinien zu anderen Diskursen verlaufen, aber der Heimatdiskurs existiert für sich und lässt sich losgelöst von anderen analysieren: „Die Emergenz dieses Diskurses, sein Auftauchen als Ergebnis und Bedingung der Verstetigung von Out of area-Einsätzen, hat die Erzählungs- und Darstellungsebenen erheblich verändert.“ (Daxner ebd.: 54)

Gerade diese Verengung des analytischen Fokus auf „Präsenz“, ,Auslandseinsätze out of area“ bzw. „Interventionen“ führt dazu, zu verkennen, in welchem Maße diese Realitätsauschnitte praktisch in größere diskursive und gesellschaftliche Verhältnisse eingebettet sind. Wir zeigen eine mögliche Weiterführung der Analyse im Folgenden entlang der Aspekte „Internationale Strukturierung“ und „Umkämpfter Interventionsdiskurs“ auf. 


\section{Internationale Strukturierung}

Die internationale Strukturierung des Diskurses wird zwar vielfach thematisiert, aber analytisch ausgegrenzt. Dies ist problematisch, da bestimmte Angriffsflächen für Kritik, außerhalb des Heimatdiskurs-Ansatzes verortet und als gegeben gesetzt werden. Wir haben es praktisch nicht mit einer dualen Interventionsbeziehung (Deutschland-Afghanistan) zu tun, sondern einer multilateralen. Lässt sich wirklich von einem „Zustand des Fluiden“ in der deutschen Außen -und Sicherheitspolitik bzw. von einem noch nicht festgelegten „Dispositiv der künftigen globalen Innen-/Außenpolitik Deutschlands“ (Daxner ebd.: 54) sprechen? Im bereits zitierten Interview sagte Franz Josef Jung 2006:

„Wir haben in unserer Verfassung verankert, dass Landesverteidigung die Aufgabe der Bundeswehr ist. Aber unsere derzeitige Hauptaufgabe der Krisen- und Konfliktbewältigung oder der Bekämpfung des internationalen Terrorismus sind im Grundgesetz nicht ausdrücklich erwähnt.“ (Jung in Löwenstein in FAZ 02.05.2006: 5)

Die Frage ist, wer oder was diese Hauptaufgabe fixiert. Im selben Interview spricht Jung von der Stabilisierung von ,Failing States“. Wir lesen dies als Indiz dafür, dass international zirkulierende (auch akademisch geprägte) Diskurselemente den deutschen Diskurs maßgeblich mitprägen. Eine Fokussierung auf das „,deutsche Problem“ läuft Gefahr dies zu verkennen. Im Zuge einer deutschen Beteiligung an Militäreinsätzen wie in Afghanistan werden nicht nur spezifisch deutsche, historische Erfahrungen aktualisiert, sondern auch (und womöglich ohne größere Thematisierung) an hier unvertraute, aber in den USA, Großbritannien und Frankreich zirkulierende militärische Wissensbestände angeknüpft. Diese Problematik lässt sich im Anschluss an Stephan Malinowski’s Artikel „Siegen lernen“ in der Zeit entwickeln, in dem der Autor argumentiert, dass die Militäreinsätze in Afghanistan und im Irak nach dem Vorbild europäischer Kolonialkriege geführt werden:

„Auch in den fünfziger Jahren hatten westliche Demokratien in geografisch und kulturell weit entfernten Regionen asymmetrische Kriege gegen schwer $\mathrm{zu}$ identifizierende Guerilla-Einheiten geführt. Counterinsurgency (Aufstandsbekämpfung) war und ist das Kennwort dieser Kriegsführung. [...]Allein deutsche Deutungsdebatten scheinen diese Zusammenhänge noch nicht erreicht zu haben - was kaum verwundert: Die deutschen Kolonialerfahrungen liegen fast 100 Jahre zurück und werden militärisch eher mit Massenund Völkermord als mit Aufstandsbekämpfung assoziiert. [...] Von den für die Öffentlichkeit westlicher Staaten unerträglichen Elementen entschlackt [...] erscheint die 
Koppelung von vergleichsweise dosiertem Gewalteinsatz und ,Entwicklungsarbeit“ eher zukunftsträchtig denn vorgestrig. Diese Politik als eine gegen ,Terroristen ' gerichtete bewaffnete Aufbauhilfe darzustellen macht den Krieg auch für postheroische Gesellschaften akzeptabel. Ob es allerdings gelingen kann, eine ,zivilisierte‘ Form kolonialer counterinsurgency von ihren kolonialen Schrecken - Entmündigung Unterdrückung und nicht zuletzt: traumatische Niederlagen - zu trennen, daran lässt sich beim Stand der Dinge zumindest zweifeln.“ (Malinowski in ZEIT ONLINE 05.01.2011, Hervorhebg. im Original). ${ }^{29}$

Hier werden Zusammenhänge zwischen militärzentrierten Diskurskonstruktionen wie dem Heimatdiskurs und solchen, die das Zivile in den Mittelpunkt rücken, sichtbar. Wir nehmen an, dass etwa zum Entwicklungsdiskurs oder postkolonialen Diskurs nicht nur Verbindungslinien verlaufen, sondern mitunter von grundlegenden Deutungskonkurrenzen auszugehen ist.

\section{Umkämpfter Interventionsdiskurs}

Indem der Heimatdiskurs-Ansatz weitestgehend innerhalb des Interventionsparadigmas argumentiert, gehen von ihm auch legitimatorische Effekte aus. Es wird der Eindruck vermittelt, dass Interventionen nicht prinzipiell fragwürdig wären.

Uns stellt sich hier die Frage, wie im Rahmen der Theorie des Heimatdiskurses mit den empirischen Evidenzen für das „deutsche Problem“ umgegangen wird. Wir können dies am Beispiel des überaus präsenten Narrativs der außenpolitischen Normalisierung Deutschlands und der damit verbundenen Rede vom Erwachsenwerden diskutieren (siehe auch Al Ahmad et al. in diesem Band). Die außenpolitische Normalisierung wird früh in Leitartikeln forciert ${ }^{30}$ (z.B. Frankenberger in FAZ 18.12.2001, Feldmeyer in FAZ 12.11.2001), aber auch kritisiert:

29 Siehe dazu auch Thomas Rid's Artikel „Wenn Generäle Politik machen“ in dem die Bedeutung militärnaher Wissensformen und ein neues Verhältnis von Militär und Politik verhandelt werden: „General Petraeus, der selbst in Politikwissenschaft in Princeton promoviert wurde, versammelte eine Gruppe von akademisch und politisch ausgebildeten Offizieren um sich, um die strategische Richtung im Irak vorzugeben.“ (Rid in ZEIT ONLINE 10.04.2008).

30 Dies wird noch im Jahr 2010 explizit kritisiert: „In Deutschland wird man mit Durchhalteparolen auf künftige Tote eingestimmt. Es muss sein, repetieren die politischen und die publizistischen Leitartikler.“(Willemsen in ZEIT ONLINE 08.07.2010). 
„,Erwachsen` zu werden heißt nicht militärische Potenz und Geringschätzung des Zivilen. Leute, die auf ihr Erwachsensein so stolz sind, verdienen fast schon wieder Misstrauen." (Reinecke in taz 08.11.2001: 12)

Hier begegnet uns erneut die Unterscheidung zivil/militärisch. In diesem Kontext bezieht sie sich auf den Gesamtcharakter der deutschen Außen- und Sicherheitspolitik. Das Narrativ wird später von dieser abstrakten nationalen Ebene auf die konkrete Problematik des Bundeswehreinsatzes in Afghanistan bezogen:

„Bisher sind die Auslandseinsätze für die Bundeswehr glimpflich verlaufen. Doch gibt es ein Bewusstsein dafür, dass der schwierige Weg in die Wirklichkeit noch nicht zu Ende ist. [...] Die ,wirklich harte Bewährungsprobe‘ stehe noch aus, sagte dieser Tage jemand aus der militärischen Führung in Berlin. Was damit gemeint war, ist eindeutig: Ein Kampfeinsatz mit hohen Verlusten an Menschenleben, wie ihn die Bundeswehr bislang noch nicht erlebt hat.“ (Lohse in FAS 18.03.2007: 3)

Wir zitieren Jan Ross, weil dieser eine nuancierte Gegenthese einbaut, die darin besteht, Normalisierung nicht auf die militärische Dimension zu reduzieren:

„Die Veränderung der Weltlage betrifft alle, das ,Erwachsenwerden“ dagegen, das Hinausfahren auf die hohe See der internationalen Politik und in die Kältezone des Militärischen, ist ein spezifisch deutsches Thema. [...] Das vielberufene ,Erwachsenwerden ' der Bundesrepublik hat nicht in erster Linie mit Wehr und Waffen zu tun - das ist, wie wichtig auch immer, ein Nebenaspekt. Vor allem anderen geht es um Entprovinzialisierung.“ (Ross in ZEIT ONLINE 31.10.2001)

Im Rahmen der Theorie des Heimatdiskurses wird die Normalisierungsthese, wie es scheint, weitgehend akzeptiert und mit „Wehr und Waffen“ assoziiert.

„Dass jetzt allmählich der Selbstbetrug unserer moralischen und pragmatischen Sonderstellung aufgeweicht wird, ist - angesichts der globalen Sicherheitspolitik - ,an der Zeit", andererseits ist es auch eine Chance für eine Neuorientierung ohne Rückfall in den alten Militarismus." (Daxner in diesem Band: 41)

In einigen Fällen scheint der Heimatdiskurs sogar eine integrative Funktion zu haben. Er bereitet die Gesellschaft auf zukünftige Veränderungen vor:

„Veteranen sind in der Gesellschaft noch nicht angekommen, der Heimatdiskurs bereitet sie aber darauf vor.“ (Daxner ebd.: 20) 
Solche (teils implizit bleibenden) politischen Stellungnahmen der Theorie des Heimatdiskurses lassen sich problematisieren und sichtbar machen, indem man sie mit wissenschaftlichen Positionen, wie sie im Pressediskurs auftauchen, kontrastiert. Zeitgleich mit der Verschärfung der Sicherheitslage in Afghanistan (um das Jahr 2006 herum) beobachten wir eine sich intensivierende Diskussion in Deutschland über Interventionsprojekte. In diesem Zusammenhang häufen sich Beiträge von Wissenschaftlern und Experten. ${ }^{31}$ Als ein wesentlicher Problemkomplex wird die Durchführbarkeit groß angelegter Interventionen seitens westlicher Demokratien verhandelt. Ein Problem, das diskutiert wird, ist eine unterstellte, mangelnde Bereitschaft der Bevölkerung hier, auch kostenintensive und gefährliche Interventionsprojekte zu unterstützen. Es finden sich einige wissenschaftliche und Expertenpositionen, die für das politische Festhalten an der Interventionspolitik auch unter schwierigen Bedingungen argumentieren und damit die Akzeptanz in der Bevölkerung befördern sollen. Notwendig sei auf eine realistische Politik einzuschwenken. In einem langen Artikel von Herfried Münkler heißt es:

„Auf eineinhalb Jahrzehnte des Interventionismus könnte schon bald eine neue Epoche des Isolationismus folgen. Dessen politische Kosten dürften auf Dauer freilich höher ausfallen als politisch gut vorbereitete und operativ umsichtig angelegte Militäreinsätze in Krisengebieten. [...] Auf lange Sicht kommt es aber auf die Bereitschaft an, humanitäre Interventionen zu unterstützen, auch wenn sie Opfer kosten und ihr Ende nicht absehbar ist.“(Münkler in FAZ 09.10.2006: 8)

Amitai Etzioni positioniert unter dem aussagekräftigen Titel „Weniger ist mehr" einen langen Artikel in der FAZ. Etzioni sieht Interventionen als hochkomplexe Projekte, in denen es darum geht ,Sozialverhalten in großem Stil zu steuern“ bzw. Versuche „Afghanistan und andere vergleichbare Länder in west-

31 Darunter Politik- und Sozialwissenschaftler aus Universitäten (z.B. Münkler in FAZ 09.10.2006: 8, Etzioni in FAZ 28.07.2008: 8, Bredow in FAS 29.03.2009: 11, Theisen in FAS 02.08.2009: 9, Bliesemann de Guevara und Kühn in ZEIT ONLINE 03.02.2011) sowie aus Forschungsinstituten und Thinktanks (Kaim in FAZ 24.01.2011: 8). Eine Rolle spielen auch Militärexperten (Rühle in FAZ 04.02.2008: 8). Die Afghanistanpräsenz der Bundeswehr wird auch Anlass zu einer Reihe von Artikeln, die im Ressort Wissenschaft erscheinen, bspw. in der der FAZ (,Natur und Wissenschaft") (vgl. Speckmann in FAZ 02.12.2009: 4, Croitoru in FAZ 09.06.2010: 4, Speckmann in FAZ 01.12.2010: 4). 
liche Gesellschaften zu verwandeln.“ (Etzioni in FAZ 28.07.2008: 8). Weiter heißt es:

„Es sollte Schluss sein mit unrealistischen Versprechen und hochgezüchteten Erwartungen wie denen, dass ganze Länder aus der Armut befreit werden können und zu Reichtum gelangen; dass aus Tyrannei schnell eine funktionierende Demokratie wird; oder dass diese Länder aus dem Zustand des Terrors in den Zustand des Friedens ,katapultiert“ werden können. Stattdessen sind ständige Warnungen angebracht, dass der vorausliegende Weg lang und beschwerlich sein wird. Eine solche Abschwächung der Erwartungshaltung ist nicht nur notwendig, um zu verhindern, dass die Moral eines Tages zusammenbricht, sondern auch, dass die Unterstützung für Hilfsmaßnahmen in den Geber- wie den Empfängerländern gleichzeitig abbricht.“ (Etzioni in FAZ 28.07.2008: 8)

Es geht in diesem Kontext explizit darum, die Debatte nicht auf normative Aspekte zu verengen, sondern die Praxis des Intervenierens in den Blick zu nehmen. Eric Chauvistré bringt dies im Artikel „Fluch der guten Absicht“ auf den Punkt:

„Die Frage nach der Legitimation reicht nicht aus. Dieser in Deutschland so gern geführte Diskurs ist notwendig - aber er ist nicht hinreichend. Was fehlt, ist die Frage nach der technischen und politischen Machbarkeit, nach der Effektivität militärischer Macht. Auch das schönste UN-Mandat ist keine Gewähr für das Gelingen einer Mission. [...] Die Beschränkung auf Fragen nach den juristischen und ethischen Grundlagen ist umso problematischer, als der Streit zumeist über Krieg und Gewaltanwendung im Allgemeinen und nicht mit Bezug auf einen konkreten Fall geführt wird.“(Chauvistré in taz 21.01.2010: 12)

Mit Berit Bliesemann de Guevara und Florian Kühn kommen in dieser Debatte auch Forscher zu Wort, die dem Forschungsnetzwerk Interventionskulturen angehören und AutorInnen dieses Bandes sind. Innerhalb dieses Netzwerks wird auch die Heimatdiskurs-Forschung vorangetrieben. Sie weisen auf praktische Probleme der Umsetzung von Interventionsprojekten hin. Ein Aspekt ist die mangelnde Anerkennung durch die Lokalbevölkerung. In diesem Zusammenhang werden mangelnde Mitspracherechte thematisiert:

„Dass die Politik des Statebuilding in westlichen Hauptstädten gemacht wird, bringt Bündniserwägungen, wirtschaftliche und normative Überlegungen ins Spiel, die häufig nichts mit der sozialen Wirklichkeit zu tun haben. Lokale Bevölkerungen haben darin wenig bis keine Mitwirkungsmöglichkeiten: Weder stehen ihnen die Planungen für Hilfsmaßnahmen offen noch können sie die zugrunde gelegten Wertvorstellungen beeinflussen. 
Der internationale Interventionismus ist insofern doppelt verantwortungslos: Zum einen strebt er danach, die Situation von Bevölkerungen zu verbessern, ohne diese an der Zielplanung oder gar deren Überprüfung zu beteiligen. Und zum anderen versuchen nationale Regierungen mit Verweis auf Bündnisverpflichtungen und internationale Absprachen, ihren heimischen Wählern diese Politik als alternativlos zu verkaufen.“ (Bliesemann de Guevara und Kühn in ZEIT ONLINE 03.02.2011)

Die Kopplung an die Theorie der Interventionsgesellschaft bringt den Heimatdiskurs in die Nähe bestimmter Diskurspositionen. Sie steht den oben zitierten Äußerungen näher als etwa der interventionsskeptischen Argumentation Heinz Theisens, Professor für Politikwissenschaft an der Katholischen Hochschule Nordrhein-Westfalen in Köln:

„Wir müssen die Grenzen zwischen den Kulturen stärker beachten und uns wie bereits im Kalten Krieg auf die Verteidigung der eigenen Hemisphäre beschränken. Die erste Niederlage wird der Nato in Afghanistan nicht erspart bleiben. Wenn der geordnete Rückzug mit einer plausiblen Erklärung des Scheiterns und mit einer realistischen Zukunftsstrategie verbunden wird, muss diese Niederlage keineswegs zum Zerfall der Nato führen. Das Vertrauen der interventionsskeptischen Bürger im Westen könnte angesichts realistischer Ziele sogar wieder zunehmen. Die Nato braucht eine Art Realpolitik der Kulturen.“ (Theisen in FAS 02.08.2009: 9)

Die Akzentsetzung auf das Militärische im Heimatdiskurs - es geht um Auslandseinsätze der Bundeswehr - korrespondiert letztlich mit einem ,realistischen“ Politikverständnis, wie es in einer Äußerung des Leiters des Planungsreferats der Politischen Abteilung der Nato in Brüssel, Michael Rühle, anklingt:

„Der Versuch, unter Hinweis auf die globale Erwärmung den Klimaschutz als visionäre Sicherheitspolitik anzupreisen, ist allerdings zu durchsichtig - und zu ,typisch deutsch ' -, um sich damit unliebsamen militärischen Fragen entziehen zu können. Würde sich die deutsche Sicherheitspolitik tatsächlich in diese Form des Eskapismus flüchten, wäre sie am Ende - und dies, lange bevor die Polkappen geschmolzen sind.“ (Rühle in FAZ 04.02.2008: 8)

Hier wird das Motiv des typisch Deutschen argumentativ gegen Formen nichtmilitärischer Konfliktprävention und -bearbeitung gewendet. 


\section{Resümee und Ausblick}

Der Interventionsdiskurs ist Teil eines umfassenderen, umkämpften Heimatdiskurses. Mit der Engführung von Heimatdiskurs auf einen ganz bestimmten Typ von Interventionsdiskurs, der ,sein Zentrum in einem Land hat, das sich aktiv an einer Intervention engagiert und Truppen für diese Intervention entsendet“ (Daxner in diesem Band: 26) wird „Heimat“ in einen bestimmten Denkhorizont eingeordnet: Es geht um die Heimat der Intervenierenden. Aus der Interventionsgesellschaft wird auf Heimat zurückgeblickt und in die Heimat zurückgekehrt. An der Heimatfront wird diskutiert. Assoziationen mit vorhandenen, nicht unproblematischen Deutungsmustern liegen nicht fern: Verteidigung unserer friedlichen Heimat am Hindukusch oder gar unserer ökonomischen Heimat weltweit. Ist dies die „definitions- und ausdeutungsfähige Qualität.“ (ebd.: 30) die das Wort Heimat im Kontext des Interventionsdiskurses gewinnt?

Es soll ja gar nicht um Heimat gehen, wird betont. Aber der Begriff wird eingeführt und in einem Problemzusammenhang artikuliert, in dem er Bedeutung entfaltet. Die Reduktion des Bedeutungsgehalts von Heimatdiskurs auf die Problematik von Auslandseinsätzen der Bundeswehr ist kaum anders als eine intendierte, strategische Intervention und Provokation zu verstehen: Eine Erinnerung, dass man sich hierzulande - wenn es um Heimat geht - auch mit Sicherheit, Militär, Gewalt und Krieg auseinandersetzen muss.

Eine Kontroverse darüber, inwieweit Heimatdiskurs darüber hinaus als kritischer Analysebegriff brauchbar ist, steht teilweise aus. „Heimat“ ist ein Begriff, der als „Assoziationsgenerator“ (Gebhard, Geisler und Schröter 2007: 9) das Potential in sich trägt zahlreiche semantische Verknüpfungen herzustellen. Seine politische Geschichte ist brisant. Er stößt auf einen subjektiven Resonanzboden, spielt eine Rolle bei Selbst- und Fremdbildern. Heimat verweist auf eine Reihe von Grenzziehungen: das Eigene/ das Fremde, Wir/ die Anderen, Hier/ Dort, Nähe/ Ferne. Gerade seine Mehrdeutigkeit und die historische Erinnerung, die sich in ihm verdichtet, machen den Begriff des Heimatdiskurses interessant.

Ein erster Schritt wäre Heimatdiskurs als Grenz- und Relationsbegriff zu diskutieren: Heimat hier in Beziehung zu Heimaten dort; Bewahrung unserer Heimat hier, Reform der Beheimatung dort; der deutsche Entwicklungshelfer und afghanische Intellektuelle, die in ihre Heimat zurückkehren; afghanische Flüchtlinge, die ihre Heimat verlassen, und auf die Grenzen unserer ökonomischen Heimat stoßen. 


\section{LITERATUR}

Alessandrini, Anthony. 2011. The Others, the Elsewhere of Our Here. http://www.jadaliyya.com/pages/index/2861/the-others-the-elsewhere-ofour- here (aufgerufen am 08.08.2012).

Amendt, Günter. 2004. „Not macht Mohnbauern.” Frankfurter Allgemeine Zeitung, 8.3.2004, S.40.

Bacia, Horst. 2006. „Psychologische Überlegenheit.” Frankfurter Allgemeine Zeitung, 30.10.2006, S.3.

Bittner, Jochen. 2007. „Wettlauf um Afghanistan.” Die Zeit (31), 26.07.2007 http://pdf.zeit.de/2007/31/Afghanistan.pdf (aufgerufen am 08.08.2012).

Bliesemann de Guevara, Berit, und Florian Kühn. 2011. „Wir sind nicht nur hier, um zu helfen." Die Zeit (6), 3.2.2011. http://pdf.zeit.de/2011/06/P-Intervention.pdf (aufgerufen am 08.08.2012).

Böge, Friederike. 2010. „Wortgefecht.” Frankfurter Allgemeine Zeitung, 3.7.2010, S. 44.

- 2011. „Hand in Hand in verschiedenen Welten.” Frankfurter Allgemeine Zeitung, 29.12.2011, S.4.

Böhm, Andrea. 2008. „Unser Erster Krieg.” Die Zeit (9), 21.02.2008. http://pdf.zeit.de/2008/09/Unser_erster_Krieg.pdf (aufgerufen am 08.08. 2012).

Böhm, Peter. 2002. „Eine Frage des politischen Willens.” die tageszeitung, 23.10.2002, S. 11.

Bredow, Wilfried von. 2009. „Verdammt zum Erfolg.” Frankfurter Allgemeine Sonntagszeitung, 29.03.2009, S.11.

Chauvistré, Eric. 2005. „Eine blasse Linie zwischen Schutz und Kampf.” die tageszeitung, 28.09.2005, S. 6.

—. 2010. „Fluch der guten Absicht.” die tageszeitung, 21.01.2010, S.12.

Croitoru, Joseph. 2010. „Der sensible Soldat im Einsatzgebiet.” Frankfurter Allgemeine Zeitung, 9.06.2010, S. 4.

Daxner, Michael. 2010. "Das Konzept von Interventionskultur als Bestandteil einer gesellschaftsorientierten theoretischen Praxis." In Interventionskultur: Zur Soziologie von Interventionsgesellschaften, hrsg. v. Thorsten Bonacker, et al., S. 75-100. Wiesbaden: VS Verlag.

Ehrhardt, Christoph. 2008. "Werben an der Heimatfront." Frankfurter Allgemeine Zeitung, 16.10.2008, S.3.

Encke, Julia. 2009. "Die Stimmen der Soldaten.” Frankfurter Allgemeine Sonntagszeitung, 13.09.2009, S.23. 
Etzioni, Amitai. 2008. "Weniger ist mehr." Frankfurter Allgemeine Zeitung, 28.07.2008, S.8.

Feldmeyer, Karl. 2001. "Die neue Wirklichkeit." Frankfurter Allgemeine Zeitung, 12.11.2001, S.1.

Frankenberger, Klaus-Dieter. 2001. "Truppen am Hindukusch.” Frankfurter Allgemeine Zeitung, 18.12.2001, S.1.

Franzen, Günter. 2011. "Unter Postheroen.” Frankfurter Allgemeine Sonntagszeitung, 27.02.2011, S. 10.

Gaus, Bettina. 2002. "Bombige Diplomatie." die tageszeitung, 15.03.2002, S.12.

—. 2004. "Einsatz auf der Insel der Stabilität." die tageszeitung, 28.02.2004, S.4.

Gebhard, Gunther, Oliver Geisler, und Steffen Schröter. 2007. "Heimatdenken: Konjunkturen und Konturen. Statt einer Einleitung." In Heimat: Konturen und Konjukturen eines umstrittenen Konzepts, hrsg. v. Gunther Gebhard, Oliver Geisler, und Steffen Schröter, S. 9-56. Bielefeld: transcript.

Geis, Matthias. 2001. "Fischer, der Krieg und die Vision." Die Zeit (40), 27.09.2001. http://pdf.zeit.de/2001/40/Fischer_der_Krieg_und_die_Vision. pdf (aufgerufen am 08.08.2012).

Haas, Claude. 2010. "Krieg ist plötzlich ein tröstendes Wort." Die Zeit (17), 22.04.2010. http://pdf.zeit.de/2010/17/Soldaten.pdf (aufgerufen am 08.08.2012).

Hanfeld, Michael. 2007. "Denn sie wissen, dass sie ein Ziel abgeben." Frankfurter Allgemeine Zeitung, 22.05.2007, S.37.

Hansen, Sven. 2001. "A wie Afghanistan, B wie Bundeswehr." die tageszeitung, 1.12.2001, S.1.

- 2002. "Vorwärts zum Aufbau." die tageszeitung, 13.02.2002, S.6.

Hirseland, Andreas, und Werner Schneider. 2011. „Wahrheit, Ideologie, Diskurs: Zum Verhältnis von Diskursanalyse und Ideologiekritik.” In Handbuch sozialwissenschaftliche Diskursanalyse: Band 1: Theorien und Methoden, hrsg. v. Reiner Keller, Andreas Hirseland, Werner Schneider, und Willy Viehhöver, S. 401-432. Wiesbaden: VS-Verlag.

Hofmann, Gunter. 2001. „Eine neue Form der Selbstverteidigung.” Die Zeit (43), 18.10.2001. http://pdf.zeit.de/2001/43/Eine_neue_Form_der_Selbstverteidigung.pdf (aufgerufen am 08.08.2012).

Innacker, Michael. 2002. „Deutschland im Krieg.” Frankfurter Allgemeine Sonntagszeitung, 10.03.2002, S.3.

- 2003. „,Wir formen eine Armee im Einsatz‘: Peter Struck über seine Gespräche mit Soldaten-Witwen - und warum die Nato in den Irak soll." Frankfurter Allgemeine Sonntagszeitung, 10.08.2003, S.4. 
Jäger, Margarete, und Siegfried Jäger. 2007. Deutungskämpfe: Theorie und Praxis Kritischer Diskursanalyse. Wiesbaden: VS Verl. für Sozialwiss.

Kaim, Markus. 2011. „Es fehlt der strategische Konsens.” Frankfurter Allgemeine Zeitung, 24.01.2011, S.8.

Keller, Anett. 2006. „Wenn Soldaten Brücken bauen.” die tageszeitung, 11.11.2006, S.2.

Kober, Henning. 2005. „Hindukusch, Kohlroulade und Kraut.” die tageszeitung, 28.09.2005, S.13.

König, Jens. 2007. „Mandat für den Sturzflug.” die tageszeitung, 7.2.2007, S.5.

Ladurner, Ulrich. 2007. „Sie mögen uns.” Die Zeit (11), 8.03.2007. http://pdf.zeit.de/2007/11/Afghanistan.pdf (aufgerufen am 08.08.2012).

Lau, Jörg. 2003. „Der Ein-Mann-Think-Tank.” Die Zeit (45), 30.10.2003. http://pdf.zeit.de/2003/45/P-M_9fnkler.pdf (aufgerufen am 08.08.2012).

—. 2007. „Krieg gegen die Deutschen?” Die Zeit (35), 23.08.2007. http://pdf.zeit.de/2007/35/Krieg_gegen_die_Deutschen.pdf (aufgerufen am 08.08.2012).

Lohse, Eckart. 2007. „Noch ist es immer glimpflich ausgegangen.” Frankfurter Allgemeine Sonntagszeitung, 18.03.2007, S.3.

Löwenstein, Stephan. 2005. „Mehr Soldaten auf dem Boden.” Frankfurter Allgemeine Zeitung, 29.10.2005, S.12

2006. „,Verteidigung neu definieren“: Minister Jung über die Bundeswehr und das Grundgesetz." Frankfurter Allgemeine Zeitung, 2.5.2006, S.5.

Malinowski, Stephan. 2011. „Siegen lernen.” Die Zeit (2), 5.1.2011. http://pdf.zeit.de/2011/02/Kolonialkrieg.pdf (aufgerufen am 08.08.2012).

Martens, Michael. 2002. „Sicherheit für Kabul, Starthilfe für afghanische Firmen." Frankfurter Allgemeine Zeitung, 12.02.2002.

Mignolo, Walter. 2011. Geopolitik des Wahrnehmens und Erkennens: (De)Kolonialität, Grenzdenken und epistemischer Ungehorsam. Europäisches Institut für Progressive Kulturpolitik. http://eipcp.net/transversal /0112/mignolo/de (aufgerufen am 08.08.2012).

Minkmar, Nils. 2010. „Der afghanische Blick.” Frankfurter Allgemeine Sonntagszeitung, 25.04.2010, S.23.

Münkler, Herrfried. 2006. „Militärinterventionen in aller Welt.” Frankfurter Allgemeine Zeitung, 9.10.2006, S.8.

Reinecke, Stefan. 2001. „Krieg ohne Hitler.” die tageszeitung, 8.11.2001, S.12.

Rid, Thomas. 2008. „Wenn Generäle Politik machen.” Die Zeit (16), 10.04.2008. http://pdf.zeit.de/2008/16/Wenn_Generaele_Politik_machen.pdf (aufgerufen am 08.08.2012). 
Ross, Jan. 2001. „Arbeit am neuen Weltbild.” Die Zeit (45), 31.10.2001. http://pdf.zeit.de/2001/45/Arbeit_am_neuen_Weltbild.pdf (aufgerufen am 08.08.2012).

Rühle, Michael. 2008. „Am Rubikon der Kampfeinsätze.” Frankfurter Allgemeine Zeitung, 4.02.2008, S.8.

Schwarz, Patrick. 2002. "KSK kämpft in Afghanistan nur punktuell." die tageszeitung, 13.03.2002, S.6.

Schwarzbeck, Martin. 2010. „Universitäten im Krieg.” die tageszeitung, 8.2.2010, S.21.

SEV. 2001. „Deutsche Truppen in den Hindukusch?” die tageszeitung, 3.12.2001, S.5.

Smith, Dan. 2012. „Von Afrika lernen heißt siegen lernen.” Die Zeit (3), 12.01.2012. http://pdf.zeit.de/2012/03/P-Europa.pdf (aufgerufen am 08.08.2012)

Sommer, Theo. 2001. „Ein halber Frieden.” Die Zeit (51), 13.12.2001. http://pdf.zeit.de/2001/51/Ein_halber_Frieden.pdf (aufgerufen am 08.08. 2012)

2002. „Nach Kabul? Nur mit Schutzweste.” Die Zeit (40), 26.09.2002. http://pdf.zeit.de/2002/40/Nach_Kabul_Nur_mit_Schutzweste.pdf (aufgerufen am 08.08.2012)

Speckmann, Thomas. 2009. „Vom unschuldigen Zivilisten.” Frankfurter Allgemeine Zeitung, 2.12.2009, S.4.

—. 2010. „Ritter, Tod und Taliban oder Vom unheroischen Westen.” Frankfurter Allgemeine Zeitung, 1.12.2010, S.4.

Stelzenmüller, Constanze. 2003. „Schnauze voll vom Krieg.” Die Zeit (44), 23.10.2003. http://pdf.zeit.de/2003/44/Kundus.pdf (aufgerufen am 08.08.2012)

Stephan, Cora. 2009. „Wir Friedensverwöhnte.” Frankfurter Allgemeine Sonntagszeitung, 6.12.2009, S.13.

Taheri, Ahmed. 2006. „Mörderische Hitze im ruhigen Norden.” Frankfurter Allgemeine Zeitung, 3.6.2006, S.1.

Tenberg, Natalie. 2009. „Es ist Krieg - und keiner schaut hin.” die tageszeitung, 2.2.2009, S.13.

Theisen, Heinz. 2009. „Der Kulturkrieg.” Frankfurter Allgemeine Sonntagszeitung, 2.8.2009, S.9.

Todenhöfer, Jürgen. 2012. „Der syrische Knoten.” die tageszeitung, 20.03.2012, S.4-5.

Walther, Rudolf. 2010. „Unser Vietnam.” die tageszeitung, 27.05.2010, S.12. . 2010. „Die Geister des Krieges.” die tageszeitung, 19.08.2010, S.15-16. 
Wefing, Heinrich. 2009. „Krieg،.” Die Zeit (47), 12.11.2009. http://pdf.zeit.de /2009/47/Kriegsbegriff.pdf (aufgerufen am 08.08.2012)

Weiland, Severin. 2001. „Der Einsatz steht.” die tageszeitung, 22.12.2001, S.1.

Willeke, Stefan. 2008. „Der Krieg der anderen.” Die Zeit (38), 11.09.2008. http://www.zeit.de/2008/38/DOS-Afghanistan (aufgerufen am 08.08.2012).

Willemsen, Roger. 2010. „Kriegsgötterdämmerung.” Die Zeit (28), 8.07.2010. http://www.zeit.de/2010/28/Afghanistan-Krieg (aufgerufen am 08.08.2012).

Winkelmann, Ulrike. 2008. „Sind wir schon im Krieg?” die tageszeitung, 20.9.2008, S.12.

Zastrow, Volker. 2006. „Bild mit Tod.” Frankfurter Allgemeine Sonntagszeitung, 29.10.2006, S.3. 


\title{
Von Mücken und Elefanten
}

\section{Reflexionen über den Terrorismusdiskurs}

\author{
FLORIAN P. KÜHN
}

Seit dem 11. September 2001 hat sich der Diskurs über den Terrorismus, der ein definierender Bestandteil des Heimatdiskurses über internationale Politik ist, wesentlich gewandelt. In diesem Kapitel soll die Wandlung dessen, was als Terrorismus verstanden wird und die Wahrnehmung des Terrorismus als etwas unmittelbar und existenziell Bedrohliches zu einer durchaus beherrschbaren, das Gemeinwesen nicht im Kern gefährdenden Störung nachgezeichnet werden. Zu diesem Zweck soll daran erinnert werden, dass der Begriff des Terrorismus seit seiner Entstehung im Nachklang des ,Terreur' der Jakobiner (Laqueur 1987, 11) immer ein politischer Kampfbegriff war: Ronald Reagan wird das Bonmot zugeschrieben, dass des einen Terrorist des anderen Freiheitskämpfer sei. Viele Autoren weisen jedoch darauf hin, dass dieser Ausspruch nicht nachgewiesen sei beziehungsweise halten ihn für Allgemeingut (vgl. exemplarisch Gießmann 1997: 264 oder Hoffman 2002: 34-51).

Die Art, wie der Diskurs über den Terrorismus geführt wird, wird ebenso dargelegt wie die polit-medialen Mechanismen, die Terrorismus als politisches Thema erhalten. Dieser Diskurs unterscheidet sich von Diskursgemeinschaft zu Diskursgemeinschaft, knüpft an unterschiedliche Vorerfahrungen an, weist aber erhebliche Überschneidungen und thematische Ähnlichkeiten auf. Er entkoppelt die Auseinandersetzung mit dem Terrorismus vom politischen Umgang mit ihm und schafft so eine Scheinwirklichkeit, welche die Gestaltung der Herrschaftsarchitektur in den betroffenen Staaten prägt, etwa in Form von Sicherheitsgesetzgebung, die bürgerliche Freiheitsrechte einschränkt und die außenpolitische Politikgestaltung wesentlich beeinflusst. Um zu verdeutlichen, wie der Terrorismusdiskurs die Etablierung von Wirklichkeit bedingt, werde ich einige Überlegungen skizzieren, wie Terrorismus als vorrangiges Sicherheitsproblem westlicher 
Staaten auch betrachtet werden und die politischen Botschaften des Terrorismusdiskurses dekonstruiert werden können. In Abgrenzung vom Diskurs wird hier begründet, warum Terrorismus keine existenzielle Bedrohung für westliche Staaten darstellt. Ich argumentiere, dass die selbstreferenzielle Bedrohungswahrnehmung letztlich mehr schadet als Terroristen dies je könnten. Damit ist nicht gesagt, dass es keinen Terrorismus gibt, aber dass er hinsichtlich seiner sicherheitspolitischen Bedeutung, begünstigt durch die Art, wie sich die westlichen Gesellschaften und im besonderen Fall die deutsche darüber verständigen, weit überschätzt wird.

Abschließend wird festgehalten, welche Veränderungen die Reaktion auf die Anschläge des 11. September 2001, aber auch die späteren in Madrid und London, hervorgebracht hat und welche sozialen Probleme sie geschaffen und verschärft hat; zu nennen sind Ausgrenzung und ein fortan begrenztes Repertoire politischer Handlungsoptionen in tendenziell eskalierenden Beziehungen zu Staaten außerhalb der westlichen Sicherheitsgemeinschaft (Kühn 2010, 203-204; Kühn 2012a \& b).

\section{Medien Und Experten}

„Terrorism is theatre“ schrieb Brian Jenkins (1975), um auf die Inszeniertheit terroristischer Anschläge hinzuweisen. Die russischen Anarchisten der Narodnaya Volya verstanden Terrorismus als „Propaganda der Tat“, ein auf Carlo Pisacane zurückgehendes Epitheton (Hoffman 2002, 19). Counter-InsurgencyGuru David Kilcullen, dessen Strategieplanung das Vorgehen im Irak und in Afghanistan entscheidend beeinflusst hat, sagt: ,If bin Laden didn't have access to global media, satellite communications, and the Internet, he'd just be a cranky guy in a cave" (Packer 2006). Wenn man Terrorismus als Instrument der Schwachen begreift, die für die Übermittlung ihrer politischen Ideen nicht auf die überlegenen Mittel eines Staates zurückgreifen können, unterstreicht dies die Bedeutung, die Medien für terroristische Kampagnen haben. Um ein möglichst großes Publikum zu erreichen ist deshalb ausschlaggebend, wie medienwirksam Anschläge ,in Szene gesetzt“ werden. „Terrorists want a lot of people watching, not a lot of people dead" schrieb deshalb Brian Jenkins; für manche Forscher ist dies der Grund, warum chemische Kampfstoffe, wie sie etwa von der milleniaristischen Sekte Aum Shinrikyo 1995 in der Tokyoter U-Bahn verwendet wurden, selten eingesetzt werden: Gas, aber auch Radioaktivität bleiben - aus medialer 
Sicht - visuell unerschreckend wirkungslos (Laqueur 1996 ${ }^{1}$ ). In den vergangenen zwei Jahrzehnten war dennoch eine Eskalationsdynamik am Werk, die zunehmend spektakulärere Anschläge benötigte, um Aufmerksamkeit zu erzeugen. 2006 schreibt Jenkins deshalb, seine eigene Aussage aus den 1970ern revidierend: „Many of today's terrorists want a lot of people watching and a lot of people dead" (Jenkins 2006, 119; siehe auch JDW 1997).

Eine Tendenz zu Anschlägen mit mehr Opfern ist also evident. Ob dies an der Wahrnehmung liegt, innerhalb derer kleinere Anschläge kaum mehr Beachtung finden, oder weil die zeitgenössische Terroristen mit ihrer Botschaft eine Vernichtungsabsicht vermitteln wollen, die kleinere Anschläge nicht enthalten, mag dahinstehen: Während gezielte, kleine Anschläge vermitteln, dass mit der ausführenden Gruppe zu rechnen sei und ihre politischen Anliegen Beachtung finden sollen - entsprechende Gruppen also ihr politisches Gewicht erhöhen wollen - sagt die Vernichtungsabsicht aus, dass keine politische Akkommodation möglich und denkbar ist (Kühn 2004). Gleichwohl wurden Szenarien, nach denen Terroristen Massenvernichtungswaffen einsetzen würden, nie Wirklichkeit. Dies mag an nennenswerten Schwierigkeiten in der Entwicklung, Transport und Handhabung liegen, die für nichtstaatliche Akteure kaum überwindbare Hürden für chemische, biologische oder gar nukleare Kampfstoffe darstellen. Insbesondere erstere bleiben, wenn nicht ihre Dosis genau angemessen ist, weitgehend wirkungslos. Aber selbst sogenannte ,schmutzige‘ Bomben mit Nuklearmaterial würden die betroffenen Gebiete weit weniger kontaminieren als oft angenommen wird. Der riesige Aufwand, den die japanische Aum-Sekte betrieb, die Stoffe herzustellen, die für ihre Anschläge benötigt wurden, steht in keinem Verhältnis zu ihrem Effekt: Viele Versuche, biologische Waffen zu versprühen, wurden nicht wahrgenommen, auch weil sie keine Opfer forderten. 300 Wissenschaftler und 1 Mrd. US-\$ reichten nicht aus, die Kampfstoffe einsetzbar zu machen (Mueller 2005, 488-489).

In Gesellschaften, in denen Gewalt weitgehend tabuisiert wird und lediglich virtuell bleibt, etwa im Krimi oder in Videospielen, sind Medien in einem Zwiespalt. Einerseits sind Anschläge natürlich berichtenswert, obendrein liefern spektakuläre Bilder ,eine gute Nachricht`. Andererseits werten Medien Gewalttäter politisch auf, wenn diese durch die Berichterstattung ein (erzwungenes) Forum erhalten, um ihre teils obskuren Zielsetzungen einer massenmedialen Öffentlich-

1 Laqueur widersteht allerdings nicht einer alarmistischen Argumentation, derzufolge man nie wissen kann, was in der Zukunft passieren wird. So banal das klingt, so wirksam war es, seine Bücher zu verkaufen. Implizit weist er allerdings auf die hohen Kosten hin, die die Reaktion auf Terrorismus verursachen kann. 
keit kundzutun: eine solche Öffentlichkeit wäre ihnen ohne Gewalt in jedem Fall verwehrt. Medien sehen sich deshalb häufig dem Vorwurf ausgesetzt, die Sache der Terroristen zu betreiben, wenn sie diese thematisieren (Hoffman 2002, 172197). Forderungen, die Berichterstattung zu reglementieren, sind dann auch in freiheitlichen Rechtsstaaten zu hören, deren zentrales Grundprinzip Öffentlichkeit ist.

Während solch offene Regulierungsbemühungen beispielsweise in Südafrika, Pakistan oder Georgien zu beobachten sind (Freedom House 2011), hat der sogenannte ,Krieg gegen den Terror' in vielen Staaten die Rechte von Journalisten zur Geheimhaltung ihrer Informanten und zur freien Recherche deutlich untergraben. Repressive Staaten, sofern sie die Medien umfassend kontrollieren können, sind weitaus eher in der Lage, ein terroristisches Problem kleinzuhalten, indem sie es ,totschweigen'. Laqueur argumentiert sogar, in Staaten, in denen keine freie Presse existiere, könne es keinen Terrorismus geben (Laqueur 1987, 6). In jedem Fall können Staaten, sofern sie die Berichterstattung kontrollieren oder gar selbst leisten, politischen Profit aus der Gewalt schlagen, die repressive Gegenmaßnahmen zu rechtfertigen erlaubt. ${ }^{2}$ Dieser Mechanismus war auch in den westlichen Staaten, allen voran den USA zu beobachten, wo im Patriot Act unter anderem die Aussetzung bürgerlicher Rechte und die Bespitzelung der Bevölkerung legalisiert und gängig wurden. Zugleich wurden Mittel neu alloziert, das heißt auf die ,Produktion“ von Sicherheit umgeschichtet - allein, Wachleute die wenn auch minderbezahlt, vor allem herumstehen, produzieren nichts ökonomisch Verwertbares. Sie müssen aus der normalen Mehrwertproduktion mit bezahlt werden. ${ }^{3}$ Wenn eine terroristische Taktik auf die Zermürbung des staatlichen Gegners abzielt, ist eine solche Ressourcenreallokation sogar ganz in deren Sinne: „The more costs the United States inflicts on itself in the name of coun-

2 Weltweit war die Gründung von Al Jazeera 1996 aus einem vergleichbaren Grund revolutionär, weil dadurch die globale Hegemonie westlich-liberaler Medienkonzerne in der Informationsproduktion gebrochen wurde, die auch die Medienlandschaft in nichtwestlichen Staaten dominierten. Neue Möglichkeiten, Probleme zu definieren und politische Entwicklungen zu interpretieren, wurden so eröffnet. Gleichwohl muss sich auch Al Jazeera in einem volatilen Beziehungsgeflecht zwischen dem Emir von Qatar, von dem die Finanzierung kommt, und dem Machtgefüge in der arabischen Welt bewegen (Miles 2011). Die Rivalität zwischen Qatar und Saudi-Arabien spiele sich insbesondere in der Berichterstattung über Al Qaida aus, so dass man nicht von einer Opposition westlicher und arabischer Medien sprechen könne (El-Ibiary 2011).

3 Diesen Hinweis verdanke ich Christian Häßlein. 
terterrorism policies of dubious utility, the more likely a war of attrition strategy is to succeed" (Kydd und Walter 2006, 66).

Zum Wesen medialer Berichterstattung gehört die Anhörung von Experten. Diese häufig stereotypisierte Vorgehensweise, bei der das Format bereits verhindert, dass Zusammenhänge erklärt werden können, folgt einem Muster, in dem der ,Experte" eine These validieren soll, die vorher schon journalistisch impliziert wurde. Die ,Experten“ können keine klare Aussagen machen, und bei näherer Analyse des Gehalts ihrer Aussagen stellt man fest: Sie wissen es auch nicht besser als Du und ich. Zum einen erlaubt das Format der Expertenbefragung keine tiefer gehenden Analysen, die über das (angenommene) Vorwissen der $\mathrm{Zu}$ schauer hinausgehen. Die kurzen, für Experten reservierten Zeitfenster verhindern eine vermeintlich ausschweifende, Zusammenhänge aufzeigende Analyse. Zum anderen werden die ,Experten“ von den Sendern natürlich am meisten dann nachgefragt, wenn etwas passiert ist; sie geben Auskunft über Dinge, die sie nicht wissen und häufig gar nicht wissen können. Da außer einigen, häufig auch noch in Endlosschleife wiederholten, Bildern selten klar ist, wer hinter einem Anschlag steckt, wie viele Opfer es gibt und was die ideologischen Triebkräfte sein mögen, beschränkt sich die Berichterstattung dann auf die pure Oberfläche; man könnte das Format direkt im Anschluss an Anschläge als ,organisierte Spekulation' bezeichnen. Meist folgt dabei einer suggestiven Frage eine spekulative Antwort: Was in Echtzeit geschieht, entzieht sich naturgemäß analysierender Kommentierung. Hinzu kommt, dass spezialisierte Denkfabriken, die häufig aus Militärhaushalten finanziert werden, zu eng eingegrenzten Themen forschen und ihr - oft begrenztes - epistemisches Handwerkszeug zur Deutung des Geschehens einsetzen. Das ist logisch, und dazu sind sie ja auch da, aber sie verstärken damit das Problem, dass ,viele Denkfabriken so sehr am Rockzipfel des Militärs hängen, dass sie als Bestandteil eines einzigen Komplexes angesehen werden können“ (van Creveld 2009, 257). Die schiere Masse und damit verbundene Meinungsmacht dieser Institute, deren Funktions- und Besetzungslogik van Creveld anschaulich macht, prägt den Diskurs mehr als alternative Deutungsmodelle dies könnten: ,in Diskussionen [werden] die Themen am ausführlichsten diskutiert [...], von denen die Teilnehmer am meisten wissen, und nicht unbedingt die wichtigsten Themen" (van Creveld 2009, 255).

Aber, darauf hat Ulrich Schneckener $(2005,4)$ hingewiesen: Die Existenz von Experten macht andere zu Laien. Die soziale Funktion dieser Berichterstattung ist deshalb vor allem eine, die in einer hoch ausdifferenzierten Gesellschaft Fachwissen suggeriert, mit dem zumindest im Prinzip die Welt beherrschbar ist. In einer Welt, die in ihren Dynamiken und technisierten Einzelheiten von niemandem zu durchschauen ist, bedarf es eines legitimierenden Grundvertrau- 
ens, dass dennoch alles seine Richtigkeit hat. Das is die Kehrseite dessen, was Max Weber die ,Entzauberung der Welt‘ (Weber 1994, 9) genannt hat:

„Wer von uns auf der Straßenbahn fährt, hat - wenn er nicht Fachphysiker ist - keine Ahnung, wie sie das macht, sich in Bewegung zu setzen. Er braucht auch nichts davon zu wissen. Es genügt ihm, daß er auf das Verhalten des Straßenbahnwagens ,rechnen“ kann, er orientiert sein Verhalten daran; aber wie man eine Trambahn so herstellt, daß sie sich bewegt, davon weiß er nichts. Der Wilde weiß das von seinem Werkzeug ungleich besser. Wenn wir heute Geld ausgeben, so wette ich, daß, sogar wenn nationalökonomische Fachkollegen im Saale sind, fast jeder eine andere Antwort bereit halten wird auf die Frage: Wie macht das Geld es, daß man dafür etwas - bald viel, bald wenig - kaufen kann? Wie der Wilde es macht, um zu seiner täglichen Nahrung zu kommen, und welche Institutionen ihm dabei dienen, das weiß er. Die zunehmende Intellektualisierung und Rationalisierung bedeutet also nicht eine zunehmende allgemeine Kenntnis der Lebensbedingungen, unter denen man steht. Sondern sie bedeutet etwas anderes: das Wissen davon oder den Glauben daran: daß man, wenn man nur wollte, es jederzeit erfahren könnte, daß es also prinzipiell keine geheimnisvollen unberechenbaren Mächte gebe, die da hineinspielen, daß man vielmehr alle Dinge - im Prinzip - durch Berechnen beherrschen könne. Das aber bedeutet: die Entzauberung der Welt.“ (M. Weber 1994: 9, Hervorhebungen im Original).

Entzaubert ist die Welt dadurch, dass man also im Prinzip alles verstehen könnte, dass man es aber nicht selbst verstehen muss. Experten, seien es Fachbeamte, Wissenschaftler oder spezialisierte Journalisten, geben dann Deutung und Orientierung, um im Angesicht von das Tabu brechenden Gewalttaten den Glauben an die Beherrschbarkeit der Welt und die soziale Machbarkeit von Utopien zu restaurieren.

Dass diese Aufgabe an Grenzen stößt, liegt schon daran, dass es keine allseits akzeptierte Definition von Terrorismus gibt. So verändert sich das Verständnis von Terrorismus, ohnehin ein politischer Kampfbegriff (,,des einen Terrorist ist des anderen Freiheitskämpfer“, siehe oben), mit den gesellschaftlichen Diskursen, in denen er auftaucht. Das heißt, im Begriff werden allgemein verstandene Elemente reproduziert, es kommt also Vorwissen zur Anwendung, das nicht unbedingt der Wirklichkeit entsprechen muss. Indem es aber permanent reproduziert wird, verfestigt sich Gewusstes in einer Art, die resistent wird gegen konkurrierende Informationen und Deutungen. Für die politische Praxis ist auf dieser Basis dann zu beobachten, was Barbara Tuchman als ,Torheit' bezeichnet:

Auf seiner ersten Stufe legt der geistige Stillstand die Grundsätze und Grenzen fest, die für ein politisches Problem maßgeblich sind. Auf der zweiten Stufe kommt es, wenn erste 
Dissonanzen und Unstimmigkeiten mit der Realität auftauchen, zur Erstarrung der anfänglichen Grundsätze. In dieser Phase könnte es, wenn Weisheit am Werke wäre, zu Überprüfung, Überdenken und Kursänderung kommen, aber die sind so selten wie Rubine in einem Hinterhof. Die Erstarrung führt zur Erhöhung des Einsatzes und bringt die Notwendigkeit mit sich, das Ego des Verantwortlichen zu schützen; die Politik, die auf dem Irrtum fußt, vervielfacht sich, nie zieht sie sich zurück. Je größer der Einsatz und je größer sich das Ich des Verantwortlichen engagiert, desto unannehmbarer ist ein Disengagement. (Tuchman1984, 480).

Im Umgang mit Terrorismus, insbesondere an der Fantasielosigkeit des Sicherheitsapparates gegenüber rechtsextrem motivierten Morden an Immigranten, aber auch im Krieg in Afghanistan ist dieser Effekt zu erkennen.

Bevor der Aspekt der Produktion und Reproduktion der Deutung von Gewalt weitergeführt wird, die im größeren sicherheitspolitischen Zusammenhang zu den allgegenwärtigen Risiken gezählt wird, soll ein weiteres Beispiel erläutert werden. Die Berichterstattung nach den Anschlägen von Anders Breivik in Oslo demonstrierte anschaulich, wie reflexhaft die Rede vom islamistischen al Quaeda-Terrorismus geworden war. Unbewusst liegt dieser die Annahme zugrunde, dass im 21. Jahrhundert nur radikale Islamisten ruchlos und ohne mit der Wimper zu zucken massenhaft Leute abschlachten - und andere, zumal Christen, dazu nicht in der Lage seien. Vielfach geteilt, aber besonders dezidiert äußerte diese Annahme Tony Blair in seiner Rede vor dem Labour-Parteitag kurz nach 9/11: „They have no moral inhibition on the slaughter of the innocent. If they could have murdered not 7,000 but 70,000 does anyone doubt they would have done so and rejoiced in it?" (Blair, so zitiert in Croft 2012, 204). Dieses Bild ist einer der ,Kollateralschäden ‘ der ausufernden Berichterstattung über den und politische Instrumentalisierung des Terrorismus; unter Zuhilfenahme der ,Experten', nicht zuletzt vom Schlage Peter Scholl-Latours (vgl. zu dessen Argumentationslinien Klemm und Hörner 1993), wurde im letzten Jahrzehnt ein viel weiter zurückreichender, schleichender, aber letztlich profunder Antiislamismus repetiert. ${ }^{4}$ Manches in Breiviks Argumentation spricht dafür, dass dieser im gesamten Westen Identitäten in Frage stellende Diskurs dazu beigetragen hat, dass der norwegische Attentäter sich umzingelt fühlte und auszog, das, was er für seine Kultur hielt, zu verteidigen. Auf bizarre Weise entspricht also die Berichterstat-

4 Wie verschiedene Diskurse ineinandergreifen zeigt sich daran, in welchem Ausmaß diese stereotypisierten Vorstellungen der ,Anderen` den Thesen Thilo Sarazins zugrunde liegen. 
tung über Breiviks Taten dessen Weltbild, in dem die westliche, intern pazifizierte Lebensart vom Islam als bedroht anzusehen sei.

Worauf nicht zuletzt die begrenzten Erkenntnisse aber hinweisen, die der Prozess gegen Breivik zutage zu bringen vermochte, ist, wie wenig man über das, was gewissermaßen „,im Innern“ des Terrorismus abläuft, wirklich wissen kann: Auf der Oberfläche der Tat lässt sich nichts über die Hintergründe ablesen. Gleichwohl spiegelt die Nachfrage nach den medialen ,Terrorismusexperten “ eine Nachfrage nach Wissen wider, die spezifisch westlich ist und der Aufklärung entspringt: Mit Wissen (statt beispielsweise durch Beschwörung des Okkulten) können Probleme bearbeitet und die Umwelt selbst gestaltet werden (Porter 2001). Auch die staatliche Nachfrage nach Wissen hat nach dem 11. September einen Berufszweig ausgebaut, der nachgerade unausweichlich das Thema aufzublähen mithilft. Einerseits ist dieser sich in den postmodernen Gesellschaften ausbreitende Wissensdurst ein Motor für Erkenntnis und Innovation; er schafft eine sich beständig verbreiternde gesellschaftliche Wissensbasis. Wer, beispielsweise, hätte vor zehn Jahren etwas über Denkströmungen im Islam gewusst? Wer hätte den Unterschied zwischen Shia und Sunna erklären können oder sagen können, dass es diese beiden Zweige des Islam gibt? Wer hätte gewusst, was Jihad (der kleine und der große) bedeutet, Salafismus oder Wahhabismus? Es gibt also durchaus gesellschaftliches Lernen - andererseits haben die Experten aber zum Eindruck beigetragen, dass die größte Gefahr, die droht, vom Terrorismus ausgeht (siehe Daxner in diesem Band).

Nach dem 11. September 2001 wurden große Summen bereitgestellt, um Terrorismus zu erforschen. Dagegen spricht nichts, aber unter der Bedingung begrenzter Ressourcen ist deren Allokation ein politischer Akt, denn indem etwas beforscht wird, bleibt anderes unerforscht. Die politische Entscheidung zugunsten der Terrorismuserforschung hat also im Wettbewerb um Finanzen, in dem sich Forschungszweige immer befinden, naturgemäß ein Ungleichgewicht erzeugt. Lösungsmöglichkeiten zu erforschen ist zudem attraktiver als Grundlagen, also im konkreten Fall etwa Studien zu den gesellschaftlichen Gründen von politischer Gewalt - problemlösende Forschungsansätze werden gegenüber kritischen bevorzugt. Politisch bedeutsamer ist aber der Popanz, der durch die medial verwertbar dargestellten Ergebnisse aufgebaut wird: Denn es sind nicht etwa wirkliche Lösungsmöglichkeiten, die da präsentiert werden, sondern welche, die sich auf ein von vorneherein überhöhtes Problem beziehen. Ein Problem wird in überzogener Dimension aufgebaut, um dann eine Lösung zu präsentieren, die wesentlich dazu dient, die geschaffene Bedrohungsperzeption aufrechtzuerhalten. 
So galten die diktatorischen und kleptokratischen Regime im Nahen Osten als genehm, weil sie billiges Öl zu liefern bereit waren - den Preis an Unterdrückung, mangelnder politischer Freiheit und Radikalisierung zahlten die Bevölkerungen. Im Fall der zentralasiatischen Staaten vom Azerbaijan über Kasachstan, Turkmenistan und Usbekistan ist das stillschweigend noch immer so. ${ }^{5}$ Auch Saudi-Arabien, das über prinzliche Stiftungen seit Jahrzehnten eine aggressive Kampagne zur Verbreitung des Wahhabismus finanziert, die unter anderem in Pakistan zu einer eskalierenden Radikalisierung führt, bleibt von kritischer Berichterstattung weitgehend ausgenommen. ${ }^{6}$ Die meisten der Attentäter um Mohammad Atta waren saudische Staatsbürger. Die Terrorismusforschung kann zeigen, dass ein Mangel an politischen Ausdrucksmöglichkeiten mitunter zur Radikalisierung führt - umgekehrt gibt es aber auch die Fälle, wo ein solcher Mangel nicht zu Gewalt führt. Die Grenzen solcher Erkenntnisse liegen etwa darin, dass Gruppierungen Gewalt dann einsetzen, wenn sie in einer politischen Umbruchphase die Chance sehen, ihre Anliegen auf die Agenda zu setzen - wie dies im Fall der ETA während der Transitionsphase von der Franco-Diktatur zur spanischen Demokratie zwischen 1974-1982 der Fall war (Clark 1984, 132/133).

Der repetitive Charakter vermeintlich gesicherten Wissens im Terrorismusdiskurs kann also irreführend sein und somit kontraproduktive politische Entscheidungen hervorrufen. Der etwas sperrige Begriff der „Versicherheitlichung“ beschreibt, wie etwas als sicherheitsrelevant deklariert und damit gewissermaßen politisch isoliert wird (Wæver 1995). Etwas als Sicherheitsproblem zu beschreiben bedeutet, politische Prioritäten zu setzen. Die Maßnahmen, die ergriffen werden, um einem Sicherheitsproblem zu begegnen, sind politisch kaum zu kri-

5 Mit der zeitlich begrenzten Ausnahme, dass Menschenrechtsfragen diskutiert wurden, als 2012 in Baku der Eurovision Song Contest stattfand. Über Turkmenistan berichtete die hervorragende finnische Dokumentation "Shadow of the Holy Book" von Arto Halonen, das die niedrigsten Ratings für Menschenrechte und Informationsfreiheit mit einer der höchsten Erdgas- und -ölproduktion weltweit vereint, viele Geschäfte mit westlichen Unternehmen macht und weitgehend von Kritik verschont wird. Kasachstan, beispielsweise, durfte hingegen trotz autoritärer Staatsführung im Jahr 2010 den Vorsitz der den Menschenrechten verpflichteten OSZE führen (OSZE 2010).

6 Lediglich die angebliche Ausfuhrgenehmigung von bis zu 200 Leopard-2-Panzern durch den Bundessicherheitsrat (SPON 2011) im Juli 2011 führte zu einer Diskussion, wie diese Waffensysteme gegen Dissidenten und Demonstranten eingesetzt werden könnten. Mit den Mitteln der modernen Informationsmedien gegen derlei Waffengeschäfte setzt sich beispielsweise das Kunstprojekt ,Zentrum für politische Schönheit` ein (www.politicalbeauty.de). 
tisieren - sie erscheinen als unvermeidlich. Wer will schon verantworten, dass ein Anschlag stattfindet und sich herausstellt, dass nicht alles Erdenkliche getan worden ist, um ihn zu verhindern? Anders als die ursprünglichen Ansätze der sogenannten Kopenhagener Schule (vgl. Buzan et al. 1998) suggerierten, hat sich die Diskussion um die Versicherheitlichung heute weiterentwickelt. So wurde darauf hingewiesen, dass die Identität von Individuen und Kollektiven wesentlicher Gegenstand eines Sicherheitsdiskurses ist. Der Prozess der Versicherheitlichung des Anderen, oft mit orientalistischen Grundannahmen, in jedem Fall aber in der Abgrenzung konstruiert-homogener Opponentengruppen, dient so betrachtet der Selbstvergewisserung von Kollektiven (Croft 2012, 74).

Allerdings sind die Möglichkeiten, etwas als sicherheitsrelevant zu erklären, ungleich verteilt und vermachtet. Staatliche Agenturen, insbesondere wenn sie überlegenen Kenntnisstand aus gemeinhin nicht zugänglichen Quellen für sich reklamieren können, sind ungleich besser fähig, solche Prozesse der gesellschaftlichen Konstruktion von Wirklichkeitsdeutungen anzuführen als andere Akteure. Dies liegt nicht zuletzt an der Schwierigkeit, spekulative Szenarien zu falsifizieren. Während die Bürger in Aesops Fabel ${ }^{7}$ schnell begreifen, dass entgegen des Warnrufs kein Wolf die Schafe der Herde anfällt, könnten sie wenig dagegenhalten, klänge die Warnung des Kindes in etwa so: „Ich habe Zugang zu klassifizierter Information, derzufolge es nicht unwahrscheinlich erscheint, dass ein Wolf zukünftig die Herde anfallen könnte“ (vgl. Mueller 2005, 500).

Die Gesetze, die der damalige Innenminister Otto Schily durchsetzte, der so genannte ,Otto-Katalog', wurden zügig nach dem 11. September als notwendige Maßnahmen beschlossen; sie wurden in ihrer Geltungsdauer zeitlich begrenzt, aber ohne umfassende Prüfung ihrer Effektivität oder Effizienz im Jahr 2011 zum zweiten Mal nach 2006 verlängert, obwohl heute ein viel differenzierteres Bild vom Terrorismus und der Bedrohung möglich ist, die von ihm ausgeht. Die Befristung war Ausdruck dafür, dass es sich um Ausnahmegesetze handelte, die obendrein in Rekordzeit durchgesetzt wurden. Das Parlament hatte kaum Zeit, zu durchdenken, welche Folgen und welche Reichweite die Regelungen hatten. Wie Heribert Prantl geschrieben hat: „Keiner blickte durch, aber alle waren dafür“ und weiter: „Aus den Sonderregeln wurde binnen zehn Jahren Alltag“ (Prantl 2011). Die Übertreibung, mit der das Ausmaß der Anschläge beschieiben wurde, als Kriegserklärung und die Reaktion darauf als ,Krieg gegen den Ter-

7 In dieser Fabel ruft ein Hirtenjunge aus Langeweile laut „Wolf!“. Die herbeieilenden Dorfbewohner, die ihre Schafe schützen wollen, stellen daraufhin fest, dass der Junge falschen Alarm gegeben hat. Als kurze Zeit später tatsächlich ein Wolf auftaucht, reagiert niemand mehr auf seine Rufe. 
ror', hat eine öffentliche Diskussion darüber verhindert, ob diese Gesetze gebraucht werden. Vielleicht dienen sie vor allem einem staatlichen Bedürfnis nach Überwachung der Untertanen? Gleichwohl scheint die Ansicht zu dominieren, dass damit klarkomme, wer nichts zu verbergen hat. Auch anderswo wurde die Konstruktion des identitär gefestigten Anderen zur Grundlage von Politik gegenüber jenen, die potenziell gefährlich sein könnten (Gutkowski 2011, 353; Croft 2012).

Am sich entfaltenden politischen Reformprozess nach den sogenannten ,Arabellionen“ ist dies jedenfalls zu beobachten. Schon früh fürchteten viele im Westen, dass die Muslimbrüder bei Wahlen die meisten Stimmen holen. Sie folgen damit einem schon in den letzten zehn Jahren verfestigten (aber eigentlich viel älteren) Stereotyp vom „Orient“, in dem Rückständigkeit und Religiosität als Basis einer gefährlichen Irrationalität gilt. Dass diese sich religiös definierenden Gruppen, wie vor einigen Jahren die Hamas in Palästina, populär sind, liegt schlicht daran, dass sie als unkorrupt gelten und ihre Botschaften verstanden werden; ihr Aktivismus, auch unter Einsatz von Gewalt, wird von vielen als Aufopferung für die Gemeinschaft interpretiert (Malthaner 2011, 38-41). Dass dabei terroristische Taktiken angewendet werden, nehmen in Gesellschaften mit hoher Gewaltsozialisation (etwa weit verbreiteten Gewalterfahrungen) viele in Kauf: schließlich haben viele ihrerseits Gewalt durch den jeweiligen Gegner, oft staatliche Sicherheitsagenturen, erfahren. Gewalt, so banal es ist, erzeugt Gegengewalt, und das gilt auch umgekehrt: Staatliche Repression hat das Zeug, eine politische Konfrontation tendenziell zu eskalieren (Wilkinson 2005, Waldmann 2005, 207). Die Dynamik von Gewalt und Gegengewalt war zuletzt in Syrien zu beobachten, wo die Opposition anfangs und obendrein sehr lange gewaltlos blieb; das war bewundernswert, es war aber abzusehen, dass diese Strategie durch fortgesetzte Gewalt seitens des Assad-Regimes delegitimiert würde und gewaltsamer Widerstand dann nicht mehr zu vermeiden war.

Während der Jahre der Diktatur(en) haben die Muslimbrüder und vergleichbare Gruppen sich als am wenigsten korrupt und mit einer schlüssigeren Ideologie erwiesen als die jeweiligen Staaten sie generieren konnten: im Fall der Hamas war es vor allem die abgewirtschaftete PLO/Fatah, die aus alten Männern bestand, die sich selber bereicherten; es handelte sich nicht etwa um eine glühende Begeisterung, die die Wähler veranlasste, die Fatah ab- und die Hamas an die Macht zu wählen. Aber die PLO, die ja auch als terroristische Organisation angefangen hatte, hatte zwischenzeitlich das Existenzrecht Israels anerkannt, die Hamas hingegen nicht. Der Westen hat den Wahlsieg der Hamas deshalb nicht akzeptiert und damit die eigene Rede von der Demokratie entwertet: gewählt sollte schon werden, aber das Ergebnis sollte gerne kein Machtwechsel weg von 
den erprobten ,Partnern' sein (Fischer 2006; Baumgart-Ochse 2010). In den Augen der palästinensischen Bevölkerung schwand dadurch die Hoffnung auf eine faire Rolle der Europäer als Broker im Nahostkonflikt (Turner 2012).

\section{Produktion und Reproduktion von Risiken}

Von Luhmann wissen wir, dass sich Systeme selbst reproduzieren, und so ist klar, dass Leute, die den Terrorismus erforschen, auch über Terrorismus reden. Viele Sender haben mittlerweile ihren eigenen Terrorismusexperten. Peter Bergen, der vor vielen Jahren mal Osama Bin Laden interviewt hat, ist der Terrorismusexperte von $\mathrm{CNN}$ und gilt weltweit als führend - seine spannende Beschreibung des Netzwerkes Al Qaida ist bemerkenswert für ihren Mangel, herauszustreichen, wie wenig strategisch organisationsfähig die darin beschriebenen Großsprecher und gewalttätigen Revoluzzer sind. Bergen hält daran fest, dass die Terroristen nicht einige wenige sind: ,[...] hinter ihnen stehen viele tausend Mitglieder und Ableger von al-Qa'ida, nicht nur in Afghanistan, sondern in sechzig Ländern auf der ganzen Welt: eine Hydra mit unzählichen Köpfen“ (Bergen 2002, 287). Auch Elmar Theveßen, Terrorismusexperte des ZDF (der eigentlich Historiker ist), hält die Antworten des Westens auf den Jihadismus für nicht effektiv oder sogar kontraproduktiv. Er beklagt in einem seiner Bücher die stereotypisierte Homogenisierung des Islam (Theveßen 2002), aber schon 2005 raunt er: „Madrid und London waren nur der Anfang [...]“ (Theveßen 2005, 7); der Mangel an Bildung bei Migranten sei ein Problem. Dass es paradox ist, dass aus dieser unterprivilegierten Schicht vor allem Studenten wegen Vorbereitung terroristischer Aktivitäten entdeckt wurden, fällt ihm nicht auf (194). Unter dem Deckmantel, Missstände aufzudecken, von denen muslimische Migranten betroffen sind, wird deren (für alle Migranten angenommene) Opfersituation als potenziell in Täterreaktionen umschlagend geschildert. So verknüpft er Terrorismus mit der Unterprivilegierung von Muslimen, deren Gewaltneigung dadurch quasi direkt aus ihrer sozialen Situation belegt erscheint. Dass dadurch der Terrorismus als allgegenwärtige, letztlich in der Nachbarschaft beheimatete Gefahr erscheint ist nicht die individuelle Schuld der Experten: Es ist eine Frage der Blickrichtung. Dass Forscher in Drittmittelprojekten über Terrorismus und an Friedensforschungsinstituten zu dem Ergebnis kommen könnten, der Terroris- 
mus brauche eigentlich nicht weiter erforscht zu werden, ist logischerweise nicht zu erwarten: Wer nach Terrorismus sucht, findet ihn auch. ${ }^{8}$

Zusammen mit den Experten sitzen wir in einer Blase, die sich selber spiegelt und aus der man, von der Gewalt fasziniert, nicht vom Terrorismus wegschauen kann. Die Faszination für die Gewalt, so verbreitet sie in gewalttabuisierten Gesellschaften ist, wo sie sich in Videospielen und anderen ritualisierten Betätigungen äußert (Žižek 2011), kann allerdings auch strategisch eingesetzt werden. Denn die Konstruktion einer permanenten Bedrohungssituation erfordert Gegenmaßnahmen - immerhin ist der Mensch der Postaufklärung einer, der sein Schicksal selbst in der Hand hat. Dabei dient die damit produzierte Risikountermalung des täglichen Lebens in nicht vernachlässigbarem Ausmaß dem Profit eines lukrativen Geschäftszweigs, den man Terrorismusindustrie nennen könnte. Wir unterstellen damit ein Interesse der Experten am Verkauf ihrer Expertise ebenso wie der Hersteller von Body-Scannern und anderer Sicherheitstechnologie. Diese Industrie lebt von der kostenträchtigen Vorbereitung auf das äußerst Unwahrscheinliche und von einer verzerrten Wahrnehmung von Risiken und Gefahren (Gardner 2008, 124-154).

\section{Von Mücken und Elephanten: Der Überschätzte TERRORISMUS}

John Mueller hat schon 2005 darauf hingewiesen, dass es verschiedene Methoden gibt, die Gefährlichkeit eines Phänomens einzuschätzen. Eine davon ist, die statistische Wahrscheinlichkeit anzuschauen, mit der eine Gefahr auftritt. Welcher Personenkreis betroffen ist, ist von erheblicher Bedeutung für die Bedrohlichkeit: Es ist eben ein Unterschied, ob wahllos Zivilpersonen angegriffen wer-

8 Vergleichbares gilt im Übrigen für Piraterie; Forschungsaufsätze kommen selten ohne eine Beschreibung aus, welch arme Teufel da auf hoher See ihr Leben riskieren; im insbesondere militärischen - Diskurs spielt Piraterie die Rolle eines auf See annähernd allmächtigen Phänomens, das den Welthandel jederzeit zum Erliegen bringen und den Weltfrieden dadurch gefährden könnte (ich verdanke diesen Hinweis Niklas Schörnig). Auch wenn ein Anstieg von Angriffen im Zusammenhang mit Piraterie belegbar ist, werden diese Zahlen jedoch selten mit belastbaren Zahlen zum Anstieg des Schiffsverkehrs in betroffenen Regionen verglichen; es wird also nicht korreliert, welche statistische Wahrscheinlichkeit, gekapert zu werden, auf einzelne Schiffe und deren Besatzungen im Verhältnis zu zurückgelegten Wegstrecken entfällt (vgl. Petretto 2011). 
den oder Mitglieder von Sicherheitsapparaten; wenn, wie im Fall der frühen Baader-Meinhof-Gruppe/RAF oder auch der baskischen ETA, Finanzinteressen und Politiker attackiert werden, leistet sich die Bevölkerung zumindest teilweise noch einige Sympathien - erst im Lauf der Zeit, insbesondere dann, wenn ,Unbeteiligte‘ zu Schaden kommen, entzieht die Bevölkerung den Gewalttätern die ideelle und in der Folge auch Schritt für Schritt die materielle Unterstützung (Müller 1996, 244). Es spricht daher Bände, wenn die deutsche Gesellschaft und Politik rechtsextremistische Gewalt, die insbesondere in Ostdeutschland endemisch ist, so weitgehend gleichgültig gegenübersteht (Amadeu Antonio Stiftung 2012). Man ist ja nicht betroffen, aber der Einschüchterungseffekt bei den Betroffenen, die sich in manche Gegenden schlicht nicht zu gehen trauen, tritt trotzdem ein.

Als politische Kommunikationsstrategie betrachtet kann Terrorismus durchaus eine politische Botschaft an einen Adressatenkreis übermitteln, der in Gegner und potenzielle Unterstützer unterteilt werden kann. Auch im Fall der infamerweise ,Döner-' genannten Morde wurde die Botschaft von den Migranten durchaus verstanden, von der Mehrheitsbevölkerung (zu schweigen von den Sicherheitsapparaten) hingegen nicht. In den meisten Fällen ist für Terroristen aber die Mobilisierung von Unterstützern wichtig, so dass vollständig klandestines Vorgehen nachteilig ist. Wenn es Terroristen nicht gelingt, ihre potenziellen Fans zu erreichen, also deren Sympathien zu erringen, ist ihre Kampagne nahezu sicher bald zu Ende. Zwar gehörten Banküberfälle (wie im Fall der NSU) immer zum Repertoire von Terroristen, um ihre Kampagnen zu finanzieren, größere Gruppierungen brauchen zudem wachsende Mittel; zudem ist das Leben im Untergrund extrem teuer. Eine konzise Finanzierungspolitik ist deshalb notwendig und wird mit zunehmender organisatorischer Komplexität anspruchsvoller (Waldmann 2005, 71-76; 208). Wo aber ein - oftmals nur stillschweigender Konsens herrscht, dass terroristisches Vorgehen legitim ist und ein Mittel, einem wahrgenommenen Übel abzuhelfen, dauern Gewaltkampagnen oft Jahrzehnte an.

Die Frage nach der Zielsetzung terroristischer Kampagnen sagt jedoch nichts aus über die Gefährlichkeit des Terrorismus: Mueller hat das statistische Risiko berechnet, indem er einen arbiträren Berechnungszeitraum von 100 Jahren zur Grundlage genommen hat, um die Gefahr einer letalen Betroffenheit, also Tod durch terroristische Anschläge, für den einzelnen in einem Kollektiv (im untersuchten Fall in den USA) einzugrenzen. Er kommt zu dem Ergebnis, dass außer im Jahr 2001 im Schnitt weniger Menschen in den USA durch Terrorismus ums 
Leben kamen als in Toiletten ertranken. ${ }^{9}$ Außerhalb der USA kamen mehr Amerikaner um, aber deren Zahl ist immer noch nur in etwa so hoch wie die der Opfer von Blitzschlägen - das gilt übrigens auch, wenn man 9/11 einbezieht. Auch, so rechnet er nicht ohne ironische Distanz vor, sind mehr Menschen im Straßenverkehr ums Leben gekommen als am 11. September, die aus Angst vor Flugzeugattentaten auf das Auto umgestiegen sind:

„The reaction to September 11 has even claimed more—far more-human lives than were lost in the terrorist attacks. Out of fear, many people canceled airline trips and consequently traveled more by automobile than by airline after the event, and one study has concluded that over one thousand people died in automobile accidents in 2001 alone between September 11 and December 31 because of this. If a small percentage of the one-hundredthousand-plus road deaths since 2001 occurred to people who were driving because they feared to fly, the number of Americans who have perished in overreaction to September 11 in road accidents alone could well surpass the number who were killed by the terrorists on that terrible day" (Mueller 2006, 492; mit Bezug auf Sivak und Flannagan 2004).

Natürlich käme deswegen niemand auf die Idee, Toilettenschüsseln, Badewannen oder den Straßenverkehr zu verbieten; um fair zu sein, muss man natürlich bemerken, dass die Regulierung des Straßenverkehrs und (zum Teil teure) Verbesserungen der Sicherheitsvorkehrungen im Auto ja durchaus der Anstrengung geschuldet ist, die Gefahren des Straßenverkehrs einzudämmen. Gleichwohl ist das statistische Risiko, Opfer eines Anschlags zu werden, sehr niedrig. Der größte Schaden durch Terrorismus entsteht in der Regel durch schnelle, unüberlegte, überzogene und disproportionale Reaktionen auf terroristische Taten - darin zumindest sind sich die meisten Wissenschaftler einig.

Mit diesen Hinweisen soll Terrorismus nicht verharmlost werden; es geht vielmehr darum, zu verdeutlichen, dass es sich bei der politischen Konzentration auf Terrorismus um eine Prioritätensetzung unter vielen Möglichen handelt. Terrorismusbekämpfung, welche Form auch immer sie annimmt, ist nicht alternativlos - viele Gefahren werden hingegen nicht adressiert, weil man sie gar nicht kennt. Das Gegenteil von Sicherheit, die mit so viel Eifer hergestellt werden soll, ist nämlich nicht Unsicherheit, sondern schlichtweg ,nichts': Wo kein Sicherheitsproblem festgestellt wird, existiert auch keine Unsicherheit (Wæver 1995;

9 In den USA ertrinken im Schnitt pro Jahr 4 Menschen in Toiletten, 320 in Badewannen; etwa 100 sterben bei Unfällen mit Wildtieren, 90 durch Blitzschlag: Im Schnitt sind das deutlich mehr als bei terroristischen Anschlägen ums Leben kommen (vgl. statistische Angaben bei Mueller 2006: 488 \& FN 2). 
Kühn 2010, 219, insb. FN 133). Indem dem Terrorismus eine solche Bedeutung zugeschrieben wurde, wurde die politische Sache der Islamisten unglaublich aufgewertet. Der Westen begann in Afghanistan sogar Krieg zu führen, der im Kernverständnis der Verteidigung gegen eine existenzielle Bedrohung gilt, und brauchte viel zu lange, um zu erkennen, dass er zunehmend in einen Zermürbungskrieg mit terroristischen und Guerillataktiken geraten war; damit erlaubte er den Islamisten den Propagandaerfolg, die westlichen Staaten als zwar in der Gewaltanwendung weit überlegenen, aber in deren Dosierung und Steuerung unterlegenen Gegner darzustellen. Das führte dazu, dass die afghanische Bevölkerung, der Intervention aus Hoffnung auf Entwicklungsfortschritte anfangs zugeneigt, dem Westen mehr und mehr zu misstrauen begann. Indem sie dem Westen die Unterstützung entzog, konnte kein legitimes Staatsaufbauprojekt mehr ernsthaft betrieben werden - fixiert auf den Staat als Ordnungsgarant war es für die Intervention um ISAF aber längst zu spät, damit aufzuhören (Suhrke 2011, 219228, Kühn 2010).

Jeder Widerstand gegen diese vom Westen im Kern vorgegebene Ordnung wurde in diesem Rahmen als Terrorismus betrachtet, während der avisierte Staat nur mehr nach dem Vorbild des westlichen, kapitalistischen, liberalen Staats gedacht werden konnte. Alles was davon abweicht, wird als problematisch angesehen - auch wenn die in Afghanistan zwischenzeitlich eingetretene Ernüchterung mittlerweile nur noch erlaubt, von ,good enough governance', also ,gerade so ausreichend gutem Regieren' zu sprechen, das etabliert werden soll. Mangels Alternative hält der Westen am Hamid Karzai als Präsident und Partner der westlichen Geldgeber fest, obwohl der mittlerweile zum pauschalen Sinnbild für alles, was schlecht ist in Afghanistan herhalten muss. Gilles Dorronsoro, der seit vielen Jahren über Afghanistan forscht, hält deshalb mittlerweile alles, was der Westen in Afghanistan noch macht, für diskreditiert:

„The Western countries have less and less leverage on the regional powers (India, Pakistan) and not much more on the Afghan regime. On a more ideological ground, [the West has] discredited the idea of democracy and human rights (especially women's) for a very large segment of the population. The most [the West] can do is to be a go-between in a negotiation process, but ultimately a new phase of the civil war will probably start soon after the withdrawal". ${ }^{10}$

10 Priv. Konversation, Waterloo (ON), 19. Mai. 2011, sowie per e-mail, 19. Mai.2012; siehe auch Johnson (2011: 296-297) für eine ähnliche Einschätzung der begrenzten Rolle, die die UN spielen könnten. 
Das Misstrauen gegenüber westlichen Akteuren, aber auch westlicher Akteure gegenüber ihren afghanischen ,Partnern' ist, mit anderen Worten, so groß, dass kein externer Einfluss mehr ausgeübt werden kann. In einem solchen Klima gegenseitiger Abneigung kann keine Befriedung gelingen - und wohl auch keine gedeihliche Zusammenarbeit. Umgekehrt wird die Kampfmotivation der Aufständischen häufig überzogen dargestellt: Für viele junge Männer ist der Konflikt ein Abenteuerspielplatz, auf dem sich in einer männlich dominierten Gesellschaft ein Kriegermythos ausprobieren und Männlichkeit beweisen lässt (Giustozzi 2007, 39-40; 69-72).

Nicht alles, was dabei als Terrorismus angesehen wird, ist also auch wirklich Terrorismus von Leuten, die morgens mit dem Vorsatz aufstehen, den Westen heimzusuchen. Diese Wahrnehmung überlagert aber den Umgang mit den Staaten und Gesellschaften der islamischen Welt: Verstärkt noch durch den Irakkrieg nach 2003 wuchsen Misstrauen und Ablehnung gegenüber westlicher Politik. Nicht jeder jedoch, der diese Art von Außenpolitik ablehnt, ist deshalb ein Terrorist. Die Verstärkung einer vorwiegend gewaltbasierten Außenpolitik, die, betrieben in den USA von Neokonservativen, ihre eigene Form des Umgangs mit den Problemen der Welt als alternativlos darzustellen bemüht war, hatte anfangs durchaus Erfolg. Zu erinnern sei an Peter Strucks Hindukush-These (vgl. Michael Daxners Beitrag in diesem Band); aber auch nach dem Machtwechsel in Spanien, wo das katastrophale Krisenmanagement der Aznar-Regierung nach den Anschlägen auf die Vorortzüge mit ihrer Abwahl endete, geraunt wurde, Terroristen könnten auf jede Wahl Einfluss nehmen, wenn Wähler auf Anschläge mit Einknicken reagierten. Dabei ist gerade die Korrektur einer falschen politischen Entscheidung, im spanischen Fall die Teilnahme am Irakkrieg, Ausdruck souveränen Wählerverhaltens, das darin weit unabhängiger ist als stures Festhalten an falscher Politik (Kühn 2004). Die Argumente, die abweichende Meinungen als tendenziell den Terroristen dienlich demarkieren und so den eigenen Standpunkt untermauern wollten, sind inzwischen zwar weitgehend verschwunden und der Standpunkt der Neo-Cons weitgehend diskreditiert; gleichwohl verblieb ein Umgang mit insbesondere der islamischen Welt, der diese immer noch hierarchisch unter den Westen einordnet (Clapton 2009; Berlet 2007, siehe auch Aljets et al. in diesem Band). 


\section{AufWERTUNG, SEMANTISCH: TERRORISMUS UND TERROR}

Die Bedeutung des Terrorismus wurde noch in einem weiteren Aspekt aufgewertet: Gibt es einen semantischen Unterschied zwischen Terrorismus und Terror? Bis 2001 wurden unter „Terror“ in erster Linie staatliche Maßnahmen zur Einschüchterung missliebiger, oft dissidenter Personengruppen verstanden. Stalins Säuberungen oder auch die Khmer Rouge mit ihren Morden an Tausenden aus der intellektuellen Elite ihrer jeweiligen Länder, weil diese ihren Herrschaftsanspruch in Frage stellten, fielen unter diesen Begriff. Auch das Vorgehen der Nazis gegen die jüdische Bevölkerung wurde unter dem Begriff „Terrorregime“ gefasst. Dabei war die öffentliche Wahrnehmung nicht zentral; die Betroffenen wussten schon, dass sie gemeint waren.

„Terrorismus“ wurde demgegenüber genannt, wenn substaatliche, weit weniger mächtige Gruppen mit öffentlichkeitswirksamen Anschlägen Aufmerksamkeit auf ihre Sache lenken wollten. Der erste, auf weltweite Aufmerksamkeit abzielende Anschlag war 1972 die Geiselnahme im olympischen Dorf in München durch den Schwarzen September - die Augen der Weltöffentlichkeit waren auf München gerichtet, so dass die erreichte Publizität enorm war. Ein Propagandaerfolg, gewiss, aber einer, der aus der Machtlosigkeit, diese Publizität auf anderem Wege zu erreichen, geboren war. Terrorismus wurde deshalb auch die Taktik der Machtlosen genannt (Hoffman 2002, 27-32; Chalk 1996, 17-22). Indem insbesondere die Bush-Administration, aber auch ungeprüft die meisten europäischen Regierungen nurmehr vom ,Terror' zu sprechen begannen, schrieben sie den Terroristen semantisch viel mehr Macht zu als diese eigentlich hatten. Sie wanderten semantisch in einen Topf mit den Massenmördern, die durch Terror ihre Bevölkerungen einschüchterten und häufig zu Tausenden ermordeten. In der Anknüpfung an dieses semantische Wissen der Zuhörer wurden aus Studenten mit Teppichmessern kategorial dasselbe wie es Stalin, Hitler oder Pol Pot gewesen waren. Freilich nutzten diese hoch ausgefeilte und spezialisierte Repressionsapparate konsolidierter Staaten für ihre Zwecke. Die Überhöhung der Islamisten fand ihre Fortsetzung im permanent wiederholten Gerede vom ,Islamo-Faschismus', das ihn auch auf der ideologischen Ebene dem Kampf gegen Hitlerdeutschland gleichsetzen sollte. Dem Terrorismus wurde dadurch ein gleichsam staatlicher Status zugeschrieben - wie ein Staat, der einen anderen angreifen und mit kriegerischer Gewalt überziehen kann, so sollten die Terroristen in der Lage sein, die Existenz eines Staates zu bedrohen. Um zu zeigen, wie gefährlich die Terroristen seien, wurde die Vorstellung vom klassischen Staatenkrieg aufgerufen. Dies ging bis zum Gerede von der ,mushroom cloud', also 
vom Atompilz, den es zu verhindern gelte. Ähnlich den Denkfabriken mussten die Geheimdienste Erkenntnisse liefern: ,saying ,we don't know“ in 2002 was not a politically viable option“ (Huisken 2004, 14). Um Stimmung für den Krieg gegen den Irak zu machen, der ja angeblich mit den islamistischen Terroristen paktiert habe (eine aufgrund ideologischer Inkompatibilität vollkommen absurde Vorstellung), wurde eine für eine breite Öffentlichkeit nicht nachprüfbare Gemengelage von angeblich miteinander zusammenhängenden, kerngefährlichen Sicherheitsbedrohungen angerührt, der kaum zu widersprechen war.

Diese Argumentation setzte sich fort: Noch Ende 2011 verknüpfte Michael Steiner, Beauftragter der Bundesregierung für Afghanistan und Pakistan bis Anfang 2012, einen funktionierenden Staat in Afghanistan mit der Erwartung, dass dieser Terrorismus verhindere: Ein fortgesetztes Engagement liege deshalb im direkten Sicherheitsinteresse Deutschlands (Steiner 2011, 96). Auch bekräftigt Steiner, dass Afghanistan und Pakistan als ein Problem gedacht werden müssten - obwohl erhebliche Zweifel an der strategischen Weisheit der AfPak genannten Politik bestehen (vgl. dazu Kühn 2011, Lieven 2008, Horlohe 2009).

Daran wird nochmals erkennbar, mit welcher Übertreibung die Terroristen aufgewertet wurden, aber auch, wie schwer hinter die dabei verankerten vermeintlichen Gewissheiten zurückzugehen ist. Früher wurden Terroristen wie Kriminelle behandelt: In der alten Bundesrepublik wurden die Mitglieder der RAF explizit nicht als ,Kriegspartei' behandelt, sondern aufgrund ihrer Taten strafrechtlich, nicht politisch verfolgt. Ihr Versuch, sich selbst aufzuwerten, wurde so durchkreuzt - in den letzten zehn Jahren waren die westlichen Staaten da sehr viel entgegenkommender, die Terroristen zumindest implizit als gleichwertige Gegner im ,Krieg gegen den Terror' anzuerkennen. Gefangen genommene als ,unlawful combattants', also als ,unrechtmäßige Kämpfer' zu bezeichnen und sie mit diesem völkerrechtlich erfundenen Sonderstatus in Guantanamo auf unabsehbare Zeit festzusetzen, änderte daran wenig. Diese Praxis geht übrigens weiter - zwar hat Präsident Obama als ersten Amtsakt die Order erteilt, Guantanamo zu schließen. Das ist aber an rechtlichen Problemen und dem Widerstand gegen eine Überstellung der Gefangenen auf das amerikanische Festland bisher gescheitert. Weniger bekannt ist aber, dass die Verhöre und das Festhalten in Afghanistan selbst, namentlich auf dem Stützpunkt Baghram, weitergehen. Auch die Presse, die in Afghanistan aus Sicherheitsgründen so gut wie nur noch ,embedded' berichten kann, weiß darüber wenig zu sagen. Die unter Obama ebenfalls intensivierte Praxis, Menschen, die für Terroristen gehalten werden, mittels Drohnen gezielt zu liquidieren, ist ebenfalls kaum eine Zeile oder eine Sendeminute wert. Der Tod von Osama bin Laden wurde kaum als Tötung außerhalb gesetzlicher Bestimmungen problematisiert; die deutsche Kanzlerin 
drückte sogar ihre Freude über dieses Ereignis aus, in der Erwartung, dass die Mehrheit der Diskursbeteiligten diese Freude teilen und die Tötung dadurch moralisch exkulpieren würden. Auch Präsident Obamas Diktum, dass der Gerechtigkeit damit Genüge getan sei (,justice has been done') weist in diese Richtung (Bowcott 2011). In Pakistan wird demgegenüber häufig die Frage gestellt, wie die USA mit stillschweigender Billigung der anderen westlichen Staaten Demokratie und Rechtsstaatlichkeit predigen können, selbst aber foltern und ohne Gerichtsverfahren Menschen töten.

Gibt es darauf eine Antwort? Jedenfalls ist nicht bewiesen, dass diese Praxis ihre sicherheitspolitischen Ziele wirklich erreichen kann (Kühn 2006, 183). Hans-Joachim Gießmann hat darauf hingewiesen, dass der ,Krieg gegen den Terror" mit großer Sicherheit mehr junge Menschen radikalisiert hat und zu potenziellen Terroristen gemacht hat als bekämpft wurden (Gießmann 2004, 3437). Diese Vorgehen weist aber auf das wohl größte Risiko hin, das Terrorismus für den demokratisch verfassten Staat darstellt, nämlich die Versuchung der Herrschenden, ihre Macht auf Kosten der Freiheit im Namen der Sicherheit auszubauen. Repressive Terrorismuspolitik neigt dazu, die elementaren Grundlagen des Staates zu unterlaufen, wie Paul Wilkinson warnt:

„It must be a cardinal principle of a liberal democracy in dealing with the problems of terrorism $[\ldots]$ never to be tempted into using methods which are incompatible with the liberal values of humanity, liberty and justice. It is a dangerous illusion to believe one can ,protect" liberal democracy by suspending liberal rights and forms of government. Contemporary history abounds in examples of ,emergency“ or , military“ rule carrying countries from democracy to dictatorship with irrevocable ease“ (Wilkinson 2005, 115).

Zusammenfassend ist zu sagen: dass der Terrorismus so überzogen dargestellt und dadurch politisch aufgewertet wurde, hat den Extremisten geholfen, ihre Sache weit über ihre gesellschaftliche Bedeutung hinaus publik zu machen. Mehr noch: Wenn Terrorismus eine ,Provokation der Macht' ist, wie der Untertitel zu Peter Waldmanns ausgezeichnetem Buch über den Terrorismus (2005) lautet, dann hat das Zurückschlagen nach dem 11. September die Glaubwürdigkeit westlicher Werte erheblich untergraben und die moralische Überlegenheit des liberalen Modells in Frage gestellt. Der Glaubwürdigkeitsverlust der westlichen Normen dürfte eine der langfristigsten Schäden sein, die zu beobachten sind (Pugh 2012, Kühn 2010, 342-344; 2012). In diesem Verständnis fordern die machtlosen Terroristen ihre Gegner heraus, um durch dessen überzogene Reaktion allen dessen Schlechtigkeit zu verdeutlichen. Überzeugt davon, dass der Angegriffene böse sei, wollen die Gewalttäter ihm die Maske vom Gesicht rei- 
ßen, um auch anderen zu zeigen, dass sie damit recht haben. Dies scheint gelungen zu sein: Denn weltweit steht es nicht mehr gut um die Vorbildfunktion des Westens, und als Leuchtturm der Freiheit, als den sich die USA gerne begreifen, werden sie heute außerhalb nur noch von Wenigen angesehen. Die Art der Reaktion erlaubte es den islamistischen Propagandisten, ihre Sache als Reaktion auf eine vom Westen ausgehende Aggression gegen die Religion, letztlich als ,Kampf der Kulturen“ darzustellen - der Ausdruck vom Kreuzzug gegen den Terror, leichtfertig geäußert, dann halbherzig dementiert und implizit immer wieder bekräftigt, war Wasser auf den Mühlen derjenigen auf beiden Seiten, die den Konflikt eskalieren wollten. Indem der Terrorismus überschätzt und überzogen dargestellt wird, macht man es den Terroristen leicht.

\section{Ausgrenzung Und Generalverdacht: DIE DÄMONISIERUNG DES ISLAM}

Die implizite Annahme, die ich schon erwähnt habe, derzufolge vor allem Islamisten, im weiteren Sinne Muslime, in der Lage zu sein scheinen, mit großer Kaltblütigkeit wahllos Menschen umzubringen, hat ein Klima von Islamophobie verstärkt, das politisch mittlerweile überall in Europa durch rechtsextreme Parteien instrumentalisiert wird. Das dadurch permanent ausgesendete Signal, dass man Muslime für potenziell gefährlich und im Grunde für Fremdkörper in westlichen, aufgeklärten, säkularen Gesellschaften hält, führt in vielen Fällen aber gerade nicht dazu, dass sich Muslime akzeptiert fühlen und sich mit den Gesellschaften identifizieren, deren Teil sie sind. Auch der mantraartige Hinweis, besonders in Deutschland, die Muslime müssten sich integrieren, kann da nicht weiterführen. Was hängen bleibt beim Leser des schon erwähnten ZDF-Experten Theveßen ist jedenfalls nicht seine Kritik am Umgang mit Migranten in Deutschland, sondern : „Was für ein mächtiges Signal wäre es, wenn hunderttausende von Muslimen gegen jede Art von Gewalt demonstrierten, meinetwegen gegen Kriege des Westens, aber eben auch gegen den Terrorismus der Islamisten in $\mathrm{Pa}$ lästina, Irak und Tschetschenien“ (Theveßen 2005, 214). Muslime sind, mehr noch als die deutsche Mehrheitsbevölkerung, zum primären Gegenstand des Präventionsstaats geworden, also nicht nur gesellschaftlichem, sondern vor allem auch institutionellem Misstrauen ausgesetzt.

Die immer nach Anschlägen geäußerte Forderung, die Muslime sollten sich von der Gewalt distanzieren, ist dabei besonders absurd. Jenseits der Geschichtsvergessenheit, dass sich christliche Kirchen etwa von der Gewalt in Nordirland nicht distanziert haben oder oft sogar mit den schlimmsten Regimen, etwa in La- 
teinamerika, ideologisch kooperierten: Es ist beinah so absurd wie vom Fan eines Fußballvereins, dessen Anhänger eklatant gegen Regeln verstoßen haben, zu fordern, er oder sie solle sich öffentlich von Becher-/Feuerzeug-/Papierknollenwerfern oder Bengalozündlern distanzieren. Das heißt: Die Annahme, es gebe eine Art ideelles Band, das Muslime in stiller Übereinkunft zusammenhalte ist ebenso vormodern wie es die Vorstellung wäre, dass Fußballfans sich einig wären über Spieler, Taktik, Auswechslungen etc. Wer jemals in einem Fußballstadion war (das ließe sich wohl auf andere Sportarten übertragen), weiß, dass diese Vorstellung schlichtweg Unsinn ist.

Gefährlich an dieser Fiktion einer ideell homogenen Gruppe allerdings ist die damit verbundene Neigung, Konfliktlinien zu übertünchen und zu übersehen. Indem die westlichen Gesellschaften sich in ihrer Bedrohungswahrnehmung eingerichtet haben und ihre Selbsttäuschung von der Verteidigung der Freiheit reproduzieren (Croft 2012, 244-261), entgehen ihnen die Modernisierungsdynamiken und dadurch hervorgerufenen Modernisierungskonflikte, die in den muslimischen, insbesondere den arabischen Gesellschaften wirken. Diese sind komplex, haben wirtschaftliche Aspekte, zum Beispiel den Widerspruch zwischen Eigentümer- und Rentiersökonomien, aber kulminieren auch entlang religiöser Auffassungsunterschiede. Im Westen oft übersehen tobt ein Konflikt zwischen verschiedenen Interpretationsansätzen von Religion im Islam - einerseits zum Beispiel zwischen Schiiten und Sunniten (in ihrer verschärften Form des Wahhabismus und Salafismus). Gleichzeitig gibt es liberale Reformbewegungen, die aber nicht säkular sind und damit in die Kategorie ,Islamisten' fallen (Etzioni 2007: 162-173; Baker 2010: 256). Aber auch solche Dichotomisierungen laufen Gefahr, Grauzonen zu übertünchen und insbesondere die zeitlichen Dynamiken zu übersehen, die Identitäten verändern. Die ,Umgebungsbedingungen“ vieler Gruppen sind religiös polarisierte Herrschaftssysteme, deren Legitimität in Frage steht und mit religiösen Begründungsmodellen erhalten werden soll. Religiöse Fragen nach dem Wahrheitsanspruch sind deshalb eng vermengt mit politischen Fragen der Herrschaft und Dominanz. Der schon erwähnte Zugriff auf Ressourcen verschärft dieses Problem oft noch (Tétreault 2004: 267-270).

Von vereinfachender Identitätspolitik sind also alle Gesellschaften betroffen, zumal kulturelle Diversität in einer globalisierten Welt, die auf das Eigene und das Andere fixiert ist, prägnanter auffällt. So spielen viele Regime im Nahen und Mittleren Osten ihre Machtrivalität aus, indem sie mit religiösem Sentiment ihre jeweiligen Bevölkerungen mobilisieren. Diese Politik der gesellschaftlichen Homogenisierung, also der fiktiven Vorstellung als politisches Konzept, Gesellschaften seien Kollektive Gleicher, ist zur existenziellen Bedrohungen für alle Arten von Minderheiten geworden (Becker 2009). Dabei leben vor allem religiö- 
se Minderheiten gefährlich, und der gespiegelte Effekte der Islamophobie in Europa und Amerika (nicht nur den USA) ist eine Welle von Gewalt und Verfolgung von Christen, Zoroastrern und anderen religiösen Gemeinschaften, beispielsweise auch und gerade muslimischer Sufis, in Staaten islamischer Prägung. Der gewaltsam ausgetragene Konflikt über die Deutungshoheit über die Wirklichkeit spielt sich besonders eskalierend in Pakistan aus, wo eine staatliche Ideologie, also eine nichtreligiöse Sinnstiftung des Staates immer vermieden wurde, indem die Eliten davon ausgingen, dass Pakistan als Heimstatt aller Muslime auf dem Subkontinent hinreichende Integration bewirke. Gesellschaftliche Widersprüche und Konkurrenz verschiedener Volks- und Interessensgruppen wurden so geleugnet und die Konflikte viel zu lange nicht adressiert (Cohen 2004, 226; Wilke 2005).

Ein großer Teil der Gewalt, die die westliche Öffentlichkeit als auf sich bezogen wahrnimmt, entspringt innermuslimischer Konflikte und Widersprüche. Selbst die wohlmeinendste Einmischung wirkt unter dieser Voraussetzung wie die Bevorzugung einer Seite, was wiederum die Abneigung gegen den Westen wachsen lässt. Umgekehrt lässt die Gewalt, deren Opfer vor allem Muslime sind, islamische Gesellschaften als weit hinter dem im Westen erreichten ,Standard der Zivilisation“ erscheinen. Der Begriff ,Standard der Zivilisation“, den Gerrit Gong (1984) geprägt und untersucht hat, beschreibt dabei einen überwölbenden Modus internationaler Politik. Die Staaten, die sich als auf vergleichbarem Level der Zivilisation sehen, sind untereinander erheblich dichter vernetzt als mit jenen, bei denen eine ,Zivilisationsgefälle“ wahrgenommen wird. Das beginnt bei diplomatischen Beziehungen, und es erstreckt sich auf Wirtschafts- und Kommunikationsbeziehungen, wechselseitiges Wissen um gesellschaftliche Strömungen, Mentalitäten, Diskurse bis hin zu stereotypen Zuschreibungen von Feindbildern. Anders formuliert: Der Westen kommuniziert vor allem mit sich selbst (Bliesemann de Guevara und Kühn 2010, 194-198). Umgekehrt herrscht in vielen muslimischen Ländern in Eliten aus Wissenschaft, Presse oder Politik ein oft schmerzhaftes Wissensdefizit über den Westen. Dass der Austausch mit anderen Gesellschaften nicht mehr gefördert wird, um dieses Wissensdefizit zu überbrücken oder wenigstens der Ausbeutung durch Populisten und Propagandisten zu entziehen, ist aus diesem Grund politisch kurzsichtig.

Zusammenfassend ist also festzuhalten, dass die Schablone, auf der ein Konflikt zwischen islamischen Gesellschaften und dem Westen, im kulturellen Sinn zwischen rückständigem Islam und westlich-liberaler Moderne konstatiert und interpretiert wurde, deutlich zu kurz greift, um a) die Konfliktdynamik überhaupt $\mathrm{zu}$ verstehen und b) sie angemessen zu bearbeiten. Stattdessen erlaubt diese vereinfachende Gegenüberstellung, politisches Kapital zu schlagen aus einer Be- 
drohungsperzeption, die letztlich auf beiden Seiten der konstruierten „Lager“ vorherrscht. Dieses modifizierte Sicherheitsdilemma, indem zwei Partner den jeweils anderen als Bedrohung wahrnehmen und deshalb so agieren, dass sie die Wahrnehmung des anderen erst recht untermauern, scheint die Politik der letzten zehn Jahre entscheidend geprägt zu haben. Aus Mangel an Informationen dem anderen die schlechtesten Absichten zu unterstellen galt zu Zeiten des Kalten Kriegs als sinnvolles Vorgehen, um nicht von den wirklich sinistren Absichten des anderen überrascht zu werden (Alexander 2012). Erst Gorbatschow, der diesen Teufelskreis durchbrach und glaubhaft machte, dass keine bösen Absichten vorhanden seien und so gegenseitige Vertrauensbildung ermöglichte, veränderte diese Wahrnehmung und erlaubte Reformen, die letztlich zum Ende der OstWest-Konfrontation führte. Eine nüchterne Evaluation des Terrorismus, seiner Ursachen und seiner Akteure wäre deshalb ebenso vonnöten wie eine klare Vorstellung davon zu gewinnen, wo westliche Politik selbst Gewalt eskaliert, wo es ihr an Ideen, und letztlich auch wo es ihr an Gestaltungsmacht mangelt.

\section{SCHLUSSBemerkung: HeimatdiskURS, Feindbilder UNd MaINSTREAMING DER (VERMACHTETEN) WISSENSPRODUKTION}

Zusammenfassend bleibt festzuhalten, dass die westliche Selbstvergewisserung noch nicht abgeschlossen ist. Der Kampf gegen den Terrorismus, der ja keineswegs beendet ist, sondern solange anhalten wird, solange eine (Be-) Drohung hinreichend glaubhaft in der Bevölkerung Bestand hat, schafft sich dabei zumindest teilweise die Realität, gegen die er vorzugehen vorgibt. Es hat sich erwiesen, dass es kontraproduktiv ist, den Kampf gegen Terrorismus dorthin zu tragen, wo er vermeintlich herkommt. Zu den Doppeldeutigkeiten zeitgenössischer Weltpolitik gehört dabei, dass mit starkem Impuls zur Veränderung und Reform nichtwestlicher Gesellschaften eigentlich die Erhaltung des Status Quo in machtpolitischer Dimension gemeint ist (Kühn 2012b). Während der Staat innergesellschaftlich entmachtet wird, beispielsweise indem seine Finanzierungspotenziale ideologisch ausgehöhlt werden, bleibt er sicherheitspolitisch die gesellschaftliche conditio sine qua non. Dies hat zu einer verzerrten Wahrnehmung, aber auch Erwartung an den Staat geführt. Die demokratische Errungenschaft, dass nicht der Mensch dem Staat dient, sondern der Staat den Menschen, muss jeden Tag aufs Neue eingeklagt werden - manchmal buchstäblich.

Dabei gilt es zu unterscheiden, was politisch dienlich ist und was die Gesellschaft, unter dem Vorwand, sie zu erhalten, so stark verändert, dass sie ihre ei- 
genen normativen und ideellen Grundlagen verliert. Zuviel Rechte wurden bereits einfach preisgegeben, die Balance zwischen Freiheit und Sicherheit hat sich in der letzten Dekade gefährlich verschoben. Das Postulat eines „Grundrechts auf Sicherheit", das im Grundgesetz implizit vorhanden sei, würde bedeuten, dass der Staat verpflichtet wäre, in unbegrenztem Ausmaß für Sicherheit zu sorgen, um sich keiner Versäumnisse schuldig zu machen (Meyer 2011, 254). Nur wenn die Wahrscheinlichkeit hinreichend sei, dass eine Gefahr auch eintrete, seien präventive Eingriffe in Grundrechte überhaupt möglich. Wie gezeigt worden ist, ist die Wahrscheinlichkeit allerdings zu gering, um überhaupt tätig zu werden. Außenpolitisch wäre überdies zu folgern, dass es keinen Sinn hat, die Welt nach eigenem Vorbild gestalten zu wollen - insbesondere dann, wenn nicht klar ist, welchem Zweck diese Umerziehung der Welt nach liberalem Vorbild dienen soll. Die Selbstverarmung der liberalen Gesellschaften jedenfalls bietet nur einen Anhaltspunkt, welche Gründe es gibt, dieses System für problematisch zu halten. Sicherheitspolitisches Handeln wirkt aus der Außenperspektive zumeist repressiv und untergräbt die Zielsetzungen. Terroristische Akte werden von den allermeisten Menschen in allen Kulturen abgelehnt. Wir sollten Terrorismus, mit Augenmaß und den Mitteln, die das Recht zur Verfügung stellt, wieder als kriminelles Handeln betrachten und nach zehn Jahren Hysterie damit beginnen, den Untergang der westlichen Welt als noch einmal vertagt anzusehen. Es ist an der Zeit für mehr Gelassenheit.

\section{LITERATUR}

Alexander, Andrew. 2012. America and the Imperialism of Ignorance. US Foreign Policy since 1945. London: Biteback Publishing.

Amadeu Antonio Stiftung. 2012. „Rechtsextremismus in Zahlen.” http://www.amadeu-antonio-stiftung.de/materialien/statistiken/ (aufgerufen am 19. Juli 2012).

Baker, Raymond W. 2010. „Getting it wrong yet again: America and the Islamic mainstream." In Islam in the Eyes of the West. Images and Realities in an Age of Terror, hrsg. v. Tareq Y. Ismael und Andrew Rippin, S. 251-268. London und New York: Routledge.

Baumgart-Ochse, Claudia. 2010. „An Hamas führt kein Weg vorbei.” In Friedensgutachten 2010, hrsg. v. Christiane Fröhlich et al., S. 120-131. Berlin und Münster: LIT Verlag. 
Becker, Carmen. 2007. „Identitäten in translokalen Räumen: Islam in der arabischen Öffentlichkeit." In Der Nahe Osten im Umbruch, hrsg. v. Martin Beck at al., S. 277-298. Wiesbaden: VS.

Berlet, Chip. 2007. „The new political Right in the United States: Reaction, Rollback, and Resentment." In The New Conservatism: The Rise of the Right in America, hrsg. v. Michael J. Thompson, S. 71-106. New York und London: New York University Press.

Bliesemann de Guevara, Berit und Kühn, Florian P. 2010. Illusion Statebuilding. Warum sich der westliche Staat so schwer exportieren lässt. Hamburg: edition Körberstiftung.

Bowcott, Owen. 2001. „Osama bin Laden: US responds to questions about killing's legality." The Guardian, 3. Mai. 2011, http://www.guardian.co.uk/ world/2011/may/03/osama-bin-laden-killing-legality (aufgerufen am 23. Juli 2012).

Buzan, Barry, Wæver, Ole und de Wilde, Jaap. 1998. Security. A New Framework for Analysis. Boulder und London: Lynne Rienner.

Chalk, Peter. 1996. West-European Terrorism and Counter-Terrorism. The Evolving Dynamic. Houndmills und London: Macmillan.

Clapton, William. 2009. „Risk and hierarchy in international society.” Global Change, Peace \& Security 21 (1), S. 19-35.

Clark, Robert P. 1984. The Basque Insurgents: ETA, 1952-1980. Madison und London: University of Wisconsin Press.

Cohen, Stephen P. 2004. The Idea of Pakistan. Washington: Brookings Institution Press.

El-Ibiary, Rasha. 2011. „Questioning the Al-Jazeera Effect: Analysis of AlQaeda's media strategy and its relationship with Al-Jazeera." Global Media and Communication. 7 (3), S. 199-204.

Etzioni, Amitai. 2007. Security First. For a muscular, moral foreign policy. New Haven und London: Yale University Press.

Fischer, Susanne. 2006. Wählen lassen bis es passt? Demokratieförderung und Terrorismusbekämpfung in den palästinensischen Gebieten. HSFKStandpunkte, 5/2006, Frankfurt am Main.

Freedom House. 2011. License to Censor. The Use of Media Regulation to restrict Press Freedom. http://www.freedomhouse.org/sites/default/files/ inline_images/License\%20to\%20Censor\%20\%20Media\%20Regulation\%20Re port (aufgerufen am 23. Juli 2012).

Gardner, Daniel. 2008. The Science of Fear. New York: Dutton. 
Gießmann, Hans-Joachim. 1997. „Das „logische Viereck“ - Anmerkungen zum Terrorismusbegriff." Vierteljahresschrift für Sicherheit und Frieden 15 (4), S. 264-269.

Gießmann, Hans-Joachim. 2004. „Terrorismus und Frieden.“ In Friedensgutachten 2004, hrsg. v. Christoph Weller et al., S. 33-41. Münster: LIT Verlag.

Giustozzi, Antonio. 2007. Koran, Kalashnikov and Laptop. The Neo-Taliban Insurgency in Afghanistan. London: Hurst and Company.

Gong, Gerrit. 1984. The Standard of ,Civilization“ in International Society. Oxford: Clarendon.

Gutkowski, Stacey. 2011. „Secularism and the Politics of Risk: Britain’s Prevent Agenda, 2005-2009.” International Relations 25(3), S. 346-362.

Hoffman, Bruce. 2002. Terrorismus: Der unerklärte Krieg. Frankfurt am Main: Fischer.

Horlohe, Thomas. 2009. „Die neue US-Strategie für Afghanistan und Pakistan.” Sicherheit + Frieden 27 (4), S. 251-259.

Huisken, Ron. 2004. We don't want the smoking gun to be a mushroom cloud: intelligence on Iraq's WMD. Canberra: Australian National University.

JDW. 1997. „Terrorism: fewer incidents, higher casualties.” Jane's Defence Weekly 27 (18), S. 3.

Jenkins, Brian M. 1975. „International Terrorism: A New Mode of Conflict” In International Terrorism and World Security, hrsg. v. David Carlton und Carlo Schaerf, S. 13-49. London: Croom Helm.

Jenkins, Brian M. 2006. „The New Age of Terrorism.” In McGraw-Hill Homeland Security Handbook, hrsg. v. David G. Kamien, S. 117-130. New York: McGraw-Hill.

Johnson, Rob. 2011. The Afghan Way of War. Culture and Pragmatism: A Critical History. London: Hurst and Company.

Klemm, Verena und Hörner, Karin, Hrsg. 1993. Das Schwert des Experten. Peter Scholl-Latours verzerrtes Araber- und Islambild. Heidelberg: Palmyra.

Kühn, Florian P. 2004. „Dem Terror nicht nachgegeben.“ Das Parlament 29. März, S. 11.

Kühn, Florian P. 2006. „Politische Partizipation der Hamas - eine Friedensstrategie für Palästina?" In Zum Verhältnis von Religion und Konflikt im Nahostkonflikt, hrsg. v. Christiane Fröhlich und Tanja Rother, S. 181-210. Heidelberg: Forschungsstätte der Evangelischen Studiengemeinschaft.

Kühn, Florian P. 2010. Sicherheit und Entwicklung in der Weltgesellschaft. Liberales Paradigma und Statebuilding in Afghanistan. Wiesbaden: VS Verlag. 
Kühn, Florian P. 2011. „Less is more: International intervention and the limits of external stabilization. “ Canadian Foreign Policy Journal 17 (1), S. 62-74.

Kühn, Florian P. 2012a. „Why statebuilding upends state-formation” In Statebuilding and State-Formation. The political sociology of intervention, hrsg. v. Berit Bliesemann de Guevara, S. 21-39. London und New York: Routledge.

Kühn, Florian P. 2012b. „The Peace Prefix: Ambiguities of the Word ,Peace““ International Peacekeeping 19 (3), im Druck.

Kydd, Andrew H. und Walter, Barbara F. 2006. „The Strategies of Terrorism.” International Security 31 (1), S. 49-80.

Laqueur, Walter. 1987. The Age of Terrorism. Boston und Toronto: Little, Brown and Company.

Laqueur, Walter. 1996. „Postmodern Terrorism.” Foreign Affairs 75 (5), Sept./Oct., S. 24-36.

Lieven, Anatol. 2008. „Do no harm.” The National Interest March/April, S. 1620.

Malthaner, Stefan. 2011. Mobilizing the Faithful. Militant Islamist Groups and their Constituencies. Frankfurt am Main und New York: Campus.

Meyer, Berthold. 2011. Konfliktregelung und Friedensstrategien. Wiesbaden: VS Verlag.

Miles, Hugh. 2011. „The Al Jazeera Effect.” Foreign Policy 8. Februar, http://www.foreignpolicy.com/articles/2011/02/08/the_al_jazeera_effect (aufgerufen am 18. Juli.2012).

Müller, Erwin. 1996. „,Terrorismus“: Bemerkungen zu einem brisanten Thema.” Vierteljahresschrift für Sicherheit und Frieden 14 (4), S. 242-247.

Mueller, John. 2005. „Six rather Unusual Propositions about Terrorism.” Terrorism and Political Violence 17, S. 487-505.

OSZE. 2010. OSZE Jahresbericht 2010. http://www.osce.org/de/sg/76335 (aufgerufen am 18. Juli 2012).

Packer, George. 2006. „Knowing the Enemy.” The New Yorker 18. Dezember.

Petretto, Kerstin. 2011. Diebstahl, Raub und erpresserische Geiselnahme im maritimen Raum. Eine Analyse zeitgenössischer Piraterie. Hamburg: PiraTArbeitspapiere zur Maritimen Sicherheit Nr. 8.

Porter, Roy. 2001. The Enlightenment. Houndmills und New York: Palgrave.

Prantl, Heribert. 2011. „Vergiftete Paragraphen.” Süddeutsche Zeitung 21.Juli. http://www.sueddeutsche.de/politik/rechtsstaat-nach-vergiftete-paragraphen1.1122669 (aufgerufen am 18. Juli 2012).

Pugh, Michael. 2012. „Reflections on Aggressive Peace.” International Peacekeeping 19 (3), im Druck. 
Schneckener, Ulrich. 2005. Die soziale Konstruktion des Terrorexperten. Terrorismusforschung zwischen Medienlogik und Politikberatung. SWPDiskussionspapier 2005/03, Berlin.

Sivak, Michael und Flannagan, Michael J. 2004. „Consequences for Road Traffic Fatalities of the Reduction in Flying Following September 11, 2001" Transportation Research Part F, 7, S. 301-305.

SPON. 2011. „Deutschland will Saudi-Arabien Kampfpanzer liefern.” Spiegel online 2. Juli 2011. http://www.spiegel.de/politik/deutschland/waffen-dealdeutschland-will-saudi-arabien-kampfpanzer-liefern-a-771989.html (aufgerufen am 18. Juli 2012).

Steiner, Michael. 2011. „Die Konsequenz der Solidarität“ Internationale Politik 66 (6), S. 94-99.

Tétreault, Mary Ann. 2004. „The Political Economy of Oil.“ In Understanding the Contemporary Middle East, hrsg. v. Deborah J. Gerner und Jillian Schwedler, S.249-272. Boulder und London: Lynne Rienner.

Theveßen, Elmar. 2002. Schläfer mitten unter uns. München: Droemer Knaur.

Theveßen, Elmar. 2005. Terroralarm. Deutschland und die islamistische Bedrohung. Berlin: rowohlt.

Tuchman, Barbara W. 1984. Die Torheit der Regierenden. Von Troja bis Vietnam. Frankfurt am Main: S. Fischer.

Turner, Mandy. 2012. „Completing the Circle: Peacebuilding as Colonial Practice in the Occupied Palestinian Territory.” International Peacekeeping 19 (3), (im Druck).

Van Creveld, Martin. 2009. Die Gesichter des Krieges. Der Wandel bewaffneter Konflikte von 1900 bis heute. München: Siedler Verlag.

Waldmann, Peter. 2005. Terrorismus - Provokation der Macht. Hamburg: Murmann Verlag.

Wæver, Ole. 1995. „Securitization and Descuritization.” In On Security, hrsg.v. Ronnie D. Lipschutz, S. 46-86. New York: Columbia University Press.

Weber, Max. 1994. „Wissenschaft als Beruf, 1917/1919 - Politik als Beruf 1919“. In Max Weber Studienausgabe (MWS), I/17, hrsg. v. Wolfgang J. Mommsen und Wolfgang Schluchter. Tübingen: J.C.B. Mohr.

Wilke, Boris. 2005. „Boundaries of state and military in Pakistan.“ In The dynamics of states. The formation and crises of states, hrsg. v. Klaus Schlichte, S. 183-210. Aldershot: Ashgate.

Žižek, Slavoj. 2011. Gewalt: sechs abseitige Reflektionen. Hamburg: Laika Verlag. 



\title{
InterventionsTheater
}

\author{
Der Heimatdiskurs und die Feld- und Truppenbesuche \\ deutscher Politiker - eine Forschungsskizze
}

BERIT BLIESEMANN DE GUEVARA ${ }^{1}$

In den letzten Jahren sind viele deutsche Politiker und Ministerialbeamte in die Einsatzgebiete der Bundeswehr - etwa nach Afghanistan, Bosnien und Herzegowina, Kosovo und an das Horn von Afrika - gereist, um sich ,vor Ort persönlich ein Bild von der Lage zu machen“, so die gängige Begründung dieser Dienstreisen. Sie beruht auf der Vorstellung, dass Truppen- und Feldbesuche an den Orten der Out-of-area-Einsätze der Bundeswehr einen authentischen Einblick in die Lage im Konfliktgebiet erlauben: Persönliche Gespräche und Beobachtungen erster Ordnung ermöglichen demnach eine „direkte“ Wissensgenerierung, die nicht durch die Medien, durch Politikberater, Wissenschaftler oder andere Dritte gefiltert ist. Etwas „mit eigenen Augen gesehen“, ,im persönlichen Gespräch erfahren“ oder „selbst erlebt“ zu haben wird in politischen Diskursbeiträgen zum Themenfeld Intervention als wertvolle Ergänzung zur Informationsgewinnung aus Berichten und Analysen dargestellt, manchmal (im- oder explizit) gar als „,bessere“ oder ,wertigere“ Form der Wissensgenerierung präsentiert.

Die Politiker werden bei diesen Reisen oft von Medienvertretern begleitet, wobei jedoch nicht alle Reisen in gleichem Maße medienwirksam sind. Einerseits erregen die Truppenbesuche von Ministern, der Kanzlerin oder des Bun-

1 Mein herzlicher Dank gilt Sybille Münch (Universität Darmstadt), die mit ihrer profunden Theoriekompetenz erheblich zum Artikel in seiner jetzigen Form beigetragen hat. Für konstruktive Anregungen sei zudem Dieter Senghaas, Klaus Schlichte und den Herausgebern gedankt. Verbleibende Unklarheiten und Fehler gehen allein auf das Konto der Verfasserin. 
despräsidenten höhere mediale Aufmerksamkeit als diejenigen von Abgeordneten. Geht es bei Letzteren vor allem um die Idee des „,sich ein Bild Machens“, ist der Inszenierungs- und Symbolcharakter bei Minister-, Kanzler- und Präsidentenreisen stärker ausgeprägt. Andererseits hängt der Grad der medialen Inszenierung aber auch von der Politikerpersönlichkeit ab. So nutzte beispielsweise Verteidigungsminister zu Guttenberg seine Afghanistanbesuche stärker als Bühne zur politischen Selbstinszenierung, als dies bei seinem Amtsvorgänger Jung oder seinem Nachfolger de Maizière der Fall war bzw. ist.

Zurück in Deutschland finden die Vor-Ort-Eindrücke der Politiker Eingang in Reiseberichte (z.B. Keul 2010a, 2010b, 2012), Interviews (z.B. BMVg 2012), Reden und nicht zuletzt Bundestagsdebatten (z.B. AG Friedensforschung 2009). In politischen Auseinandersetzungen im Bundestag, in Fachausschüssen und anderswo werden Vor-Ort-Besuche von Politikern als strategisches Stilmittel beim Versuch eingesetzt, Deutungshoheit im interventionsbezogenen Diskurs zu erlangen. Der Verweis auf die Authentizität des Gesagten, die aus dem direkten Erleben während der Reise in das Einsatzgebiet abgeleitet wird, oder auf die gemeinsame Reise mit anderen Akteuren, bei der gemeinsam geteilte Orientierungsmuster, sogenannte Rahmen (frames) (Goffman 1977), in unmittelbaren situativen Zusammentreffen hergestellt wurden, soll dem Argument Gewicht verleihen.

Allerdings ist die Idee, dass solche Reisen der gleichsam unmittelbaren, ungetrübten Generierung von Wissen über die Einsatzgebiete der Bundeswehr dienen, auf dessen Grundlage Politiker dann informierte Entscheidungen treffen können, in mehrfacher Hinsicht zu kurz gedacht. Aus einer wissenspolitologischen Perspektive drängt sich die grundlegende Kritik auf, dass politisches Wissen nicht jenseits sozialer Konstruktionen gedacht werden kann und die Idee eines authentischen, weil „selbst gesammelten“ Wissens somit eine Illusion ist. Vielmehr versteht eine an der Produktion von Wissen interessierte Politologie politisch relevantes Wissen immer als das Ergebnis von Machtkämpfen um legitime Deutungen der Vergangenheit, Gegenwart und Zukunft - als „wissensbasierte Wirklichkeitskonstruktionen“ (Rüb 2006: 346ff.; vgl. weiterführend auch Nullmeier 2006; Maier und Wiesner 2007). Die bei solchen Reisen erlebte und wahrgenommene Wirklichkeit ist also nur eine mögliche Wirklichkeitsperzeption unter vielen, oder mit Rüb (2006: 345) gesprochen: „Die Wirklichkeit der Politik ist eine Politik mit ,Wirklichkeiten““.2

2 Die „Realität im Einsatzgebiet“, wie sie im Heimatdiskurs der Interventen gezeichnet wird, ist ein offensichtliches Beispiel einer - von den Medien verstärkten - konstruierten Wirklichkeit (vgl. Neumann in diesem Band). Ihr gegenüber stehen zum einen so- 
Ein genauerer Blick auf die Praxis von Feld- und Truppenbesuchen zeigt zudem, dass diese von diversen Akteuren mit unterschiedlichen sozialen Rollen, institutionellen Interessen und normativen Zielsetzungen in verschiedenen politischen Arenen bzw. für verschiedene Publika ,inszeniert“ werden, was ebenfalls die Vorstellung von der Authentizität des Erlebten oder der Möglichkeit von „objektivem Wissen“ grundlegend infrage stellt. So bestimmt beispielsweise die Bundeswehr im Einsatz in großem Maße über den Feldbesuch der angereisten Politiker mit, indem sie Tagesabläufe plant und Gesprächspartner organisiert. ${ }^{3}$ Somit vermag sie im Sinne eines Agenda-Settings vielleicht nicht zu bestimmen, was die hochrangigen Gäste denken, wenigstens aber worüber sie nachdenken. Gleichzeitig setzen sich gerade führende Politiker selbst noch vor Ort etwa mittels der mitgereisten Medienvertreter oder im Gespräch mit Soldaten aus dem eigenen Wahlkreis für eine heimische Wählerschaft in Szene oder nutzen die Tatsache ihrer Reise argumentativ für Inszenierungen in politischen Auseinandersetzungen im Heimatland.

Der vorliegende Beitrag verwendet den Begriff „InterventionsTheater“, um diese vielschichtigen sozialen und politischen Schauspiele zu erfassen. Dahinter steht die Beobachtung, dass politische Vor-Ort-Besuche zentrale Elemente theatralischer Inszenierungen aufweisen: Sie sind zeitlich und räumlich begrenzte Aufführungen, die von einem Regisseur(-Team) inszeniert werden. Sie weisen eine bestimmte Dramaturgie auf, die auf der zeitlichen und räumlichen Planung der Darstellungen beruht und bei deren Umsetzung Bühnenbild, Laiendarsteller, Statisten und Techniker eine Rolle spielen. Und nicht zuletzt finden wir Darsteller(-Ensembles), die einen bestimmten Eindruck bei ihren Zuschauern zu vermitteln suchen. Anders als im Theater handelt es sich bei sozialen Schauspielen jedoch meist um mehr als nur ein Darsteller-Ensemble und auch um mehr als nur

ziale Wirklichkeitskonstruktionen der Intervenierten und zum anderen wissenschaftliche Wirklichkeiten, die bestenfalls auf sorgfältiger empirischer Analyse und historisch-kultureller Einordnung basieren und den Anspruch größerer Objektivität oder Differenziertheit erheben können, letztlich aber ebenfalls Wissenskonstrukte darstellen. „Realität“ als Wirklichkeitskonstrukt zu begreifen ist insofern wichtig, als dies auf „Realismus“ pochende politische Diskursbeiträge in einem anderen Licht erscheinen lässt: als eine politische Option unter anderen.

3 Neben der Bundeswehr gibt es weitere organisierende Stellen, etwa die Deutschen Botschaften im jeweiligen Land, die Auslandsbüros der politischen Stiftungen oder die GIZ. Auch in Bezug auf diese Akteure wäre eine Untersuchung, inwiefern die Idee des InterventionsTheaters greift, gewinnbringend - und die Unterschiede zur Inszenierung durch die Bundeswehr vermutlich geringer als evtl. zunächst vermutet. 
ein Publikum; vielmehr können auf unterschiedlichen Ebenen mehrere Darbietungen gleichzeitig stattfinden. InterventionsTheater meint also komplexe soziale Interaktionen zwischen unterschiedlichen Gruppen, die den Logiken sozialer theatralischer Performance ${ }^{4}$ folgen. Ziel dieser theatralischen Darstellungen ist es, eine emotionale Verbindung von Zuschauern, Darstellern und Text herzustellen, um auf diese Weise (kulturelle) Sinngehalte zu transportieren (Alexander 2004: 547). Allerdings sind nicht alle theatralischen Darstellungen erfolgreich darin, authentisch zu wirken; wie gezeigt wird, sind die Verläufe und Wirkungen sozialer Schauspiele vielmehr kontingent, weil sie voraussetzungsvoll und kontextabhängig sind.

Vor dem Hintergrund dieser einleitenden Beobachtungen und Gedanken stellen sich im Hinblick auf den „Heimatdiskurs“, der im Mittelpunkt dieses Bandes steht, zwei zentrale Fragen: Welche Funktionen haben Feld- und Truppenbesuche in der Produktion Interventionen de-/legitimierender Diskurse? Und welche Rolle spielen darin die vielschichtigen Inszenierungen durch die anreisenden Politiker ebenso wie die Bundeswehr und andere Beteiligte im Einsatzland - nicht zuletzt die so genannten lokalen Partner -, die solche Besuche im Sinne des InterventionsTheaters kennzeichnen?

Der Artikel skizziert, wie diese Fragen erforscht werden können. Dabei stützt er sich auf den um Bourdieu'sche Konzepte erweiterten Diskursansatz von Michael Schwab-Trapp $(2004,2011)$ und den Ansatz theatralischer sozialer Performance nach Jeffrey C. Alexander (2004, 2006; vgl. auch Alexander und Mast 2006). Mittels der Kombination dieser Ansätze lässt sich zeigen, dass Feld- und Truppenbesuche im politischen Heimatdiskurs vor allem eine hohe symbolische Bedeutung haben: Sie können die unterschiedlichen beteiligten Akteure mit symbolischem Kapital im Sinne Bourdieus ausstatten und ihren Diskursbeitragen dadurch entsprechendes Gewicht und Höherwertigkeit verleihen. Ihre Wirkung ist jedoch kontingent - d.h. nicht immer ist die symbolische Aufladung der Diskursteilnehmer und -beiträge erfolgreich. Die jeweilige Wirkung und die Bedingungen eines kommunikativen Erfolgs oder Misserfolgs im Rahmen des Heimatdiskurses sind an die (geglückte oder gescheiterte) Umsetzung von Feld- und

4 Der Ansatz theatralischer Performance unterscheidet sich von dem der Performativität (z.B. Callon 2008) bzw. dem Performance-Begriff bei Judith Butler (2005): Mit theatralischer Performance sind soziale Handlungen von Subjekten gemeint, während die beiden anderen Begriffe davon ausgehen, dass autonome, intentional Handelnde nicht existieren, sondern dass Äußerungssubjekte und deren Handeln erst durch die Kraft des Äußerungsaktes selbst hervorgebracht werden. 
Truppenbesuchen als Akte sozialer Performance gekoppelt. Empirisch kann dies nur am konkreten Einzelfall bestimmt werden.

Im Folgenden werden zunächst vier Schlaglichter auf Feld- und Truppenbesuche im deutschen Heimatdiskurs geworfen, die als empirische Ausgangsbeobachtungen dienen sollen. Anschließend wird die theoretische Herangehensweise an die Rolle dieser politischen Vor-Ort-Besuche in Interventionen de/legitimierenden Diskursen entworfen, die einen soziologischen Diskursanalyseansatz mit dem Ansatz theatralischer sozialer Performance verbindet. Durch die Synthese lassen sich beide Aspekte, die diese Reisen charakterisieren, erfassen: (a) Truppenreisen als Referenzpunkt in Diskursbeiträgen sowie (b) als politische und soziale Praxis im Sinne sozialer Performance. Anhand der Schlaglichter wird diskutiert, wie sich Feld- und Truppenbesuche mithilfe dieser Ansätze deuten lassen, wobei dies aufgrund der begrenzten empirischen Basis nur tentativ und vorläufig geschehen kann. Abschließend formuliert der Beitrag Aufgaben für eine zukünftige Erforschung von politischen Vor-Ort-Besuchen als pragmatischen Aspekt ${ }^{5}$ einer Heimatdiskursanalyse.

\section{FELD- UND TRUPPENBESUCHE - VIER SCHLAGLICHTER}

Die folgenden Schlaglichter stellen ausgewählte Beispiele aus unterschiedlichen Arenen dar, in denen die Feld- und Truppenbesuche von Politikern eine Rolle spielen können. Weil eine eingehende empirische Beschäftigung mit dem Thema noch aussteht, werden die Beispiele hier als explorative empirische Grundlage für die theoriegeleitete vorläufige Deutung der Rolle solcher Politikerreisen im deutschen Heimatdiskurs genutzt. Bei den Arenen handelt es sich um (1) den Deutschen Bundestag als Bühne für Debatten um die Verlängerung von Bundeswehrauslandseinsätzen, (2) politische Parteien, hier: BÜNDNIS 90/DIE GRÜNEN, als Arenen, in denen parteiinterne Auseinandersetzungen um militärische Interventionen stattfinden (können), ${ }^{6}$ sowie (3) die Arenen des Truppen-

5 Gemeint ist hier Pragmatik im Unterschied zur Semanntik: Während die Diskursanalyse - und damit auch der Heimatdiskurs - das Semantische fokussiert, nimmt der Ansatz theatralischer Performance auch die Handlungsebene in den Blick.

6 Die Partei BÜNDNIS 90/DIE GRÜNEN ist in dieser Hinsicht besonders spannend, weil sich dort in den 1990er Jahren ein starker Wandel im Hinblick auf militärische Interventionen vollzogen hat - von der pazifistischen Haltung, dass Deutschland sich aufgrund seiner NS-Vergangenheit nie wieder an militärischen Handlungen beteiligen 
besuches selbst, also etwa die Feldlager der Bundeswehr, die Exkursionen an diverse Orte im Einsatzgebiet und die Treffen mit Gesprächspartnern vor Ort, die Gegenstand von Inszenierungen durch die Bundeswehr im Einsatz sind sowie (4) als Bühne für die Inszenierungen von Politikern beleuchtet werden.

\section{Schlaglicht 1: Bundestagsdebatte über eine Verlängerung des Afghanistaneinsatzes 2009}

In Bundestagsdebatten, in denen es um die personelle und/oder finanzielle deutsche Beteiligung an Interventionen geht, verweisen Abgeordnete häufig auf ihre Feld- und Truppenbesuche. Besonders hitzig sind die Debatten in der Regel dann, wenn die Entsendung von Bundeswehrsoldaten in Konfliktgebiete oder die Verlängerung von Auslandseinsätzen Gegenstand ist. Der folgende kurze Auszug aus der Debatte im Bundestag am 3. Dezember 2009 über die Verlängerung des Bundeswehreinsatzes in Afghanistan veranschaulicht exemplarisch, wie Verweise auf Vor-Ort-Besuche in solchen Auseinandersetzungen Verwendung finden:

„Rainer Arnold (SPD):

Kollege Schäfer [Abgeordneter der LINKEN, die sich gegen den Afghanistaneinsatz ausspricht; Anm. BBdG], wir waren ja wiederholt zusammen in Afghanistan. Ich sage ausdrücklich,

\section{(Zurufe von der LINKEN)}

dass alle Gespräche, die wir dort geführt haben - auch in der Nachbereitung mit Kollegen Schäfer -, hilfreich und konstruktiv waren. Wir konnten über den richtigen Weg für Afghanistan streiten und ringen. Das finde ich in Ordnung. Wir müssen uns nicht einig sein. Wenn man aber aus Afghanistan zurückkommt, dann muss man seiner Fraktion auch differenziert über die Situation in Afghanistan berichten. Wir stellen fest, dass es in Kunduz, im Norden unseres Verantwortungsbereiches, Kämpfe gibt. Wir stellen fest, dass die Taliban stark sind und deshalb die Bundeswehr und andere Verbündete jeden Tag unter Druck stehen. Wir sehen aber auch, dass in Faizabad ziviles Leben entsteht, dass sich die Wirtschaft entwickelt, dass es Strom gibt, dass es Schulen gibt, dass es Krankenhäuser und sichere Straßen gibt. Wir sehen, dass sich in Masar-i-Scharif, einer Großstadt, von Halbjahr zu Halbjahr ein richtiges Leben entwickelt und dies auch für den Laien sichtbar ist.

dürfe, hin zu der Sicht, dass sich die Bundesrepublik angesichts schwerer Menschenrechtsverbrechen in anderen Staaten gerade aufgrund ihrer Geschichte an humanitären Interventionen beteiligen müsse. 
Warum reden Sie nicht auch über dieses Afghanistan? Afghanistan ist eben ein Land, in dem es nicht nur Krieg gibt, wie manche glauben, und in dem es auch nicht nur Frieden gibt, sondern es gibt beides parallel. Es gehört zu unserer Verantwortung, dies auch so darzustellen. Ich habe Ihnen als Verteidigungspolitiker überhaupt nicht vorgeworfen, dass Sie sich nicht um Afghanistan kümmern. Sie tun das zweifellos. Ich sage nur: Die beiden Vertreter Ihrer Fraktionsspitze, die die lautesten Reden zu diesem Thema halten, die dabei den oberflächlichsten und billigsten Applaus einheimsen,

(Zurufe von der LINKEN: Pfui!)

die alles tun, um Anhänger der Friedensbewegung oder grundsätzliche Pazifisten für sich allein zu vereinnahmen - diese haben allerdings auch in Zukunft in meiner Partei Platz -, diese beiden waren noch nie in Afghanistan. Es wäre jedoch lehrreich, wenn Herr Lafontaine und Herr Gysi einmal nach Afghanistan fahren, mit allen möglichen Menschen dort sprechen, sich umhören und davon lernen würden. Bei dieser Aufforderung bleibe ich. Ich habe den Eindruck, das könnte zumindest den Ton in der Auseinandersetzung ein Stück weit verändern. Das halte ich für notwendig.

Danke schön.

(Beifall bei der SPD sowie bei Abgeordneten der CDU/CSU, der FDP und des BÜNDNISSES 90/DIE GRÜNEN).“ (AG Friedensforschung 2009)

\section{Schlaglicht 2: Die parteiinterne Frage der militärischen Gewalt bei den GRÜNEN}

Das zweite Beispiel bezieht sich auf die Rolle, die Besuche in Konfliktgebieten im Rahmen der innerparteilichen Debatte um militärische Interventionen bei BÜNDNIS 90/DIE GRÜNEN hatten. Das folgende Zitat stammt aus einem Interview mit Winfried Nachtwei, außen- und sicherheitspolitischer Experte der GRÜNEN, das als Teil der Oral History-Dokumente zur 30-jährigen Parteigeschichte auf der Internetseite www.gruene.de veröffentlicht wurde. In dem Interview wird Nachtwei zu den innerparteilichen Debatten der 1990er Jahre um die Frage der militärischen Gewalt befragt, bei denen es im Kern darum ging, ob und wie die Werte des Friedens und der Gewaltfreiheit einerseits und des Schutzes der Menschenrechte andererseits angesichts schwerer Menschrechtsverbrechen in anderen Staaten in Einklang gebracht werden könnten - kurz: ob militärische Interventionen ein zulässiges Mittel zum Schutz der Menschenrechte darstellen. In dem Interview schildert Nachtwei zunächst die grundsätzlichen innerparteilichen Meinungsdifferenzen in dieser Frage und beschreibt, wie die Kluft zwischen den Lagern in der Frage des Umgangs mit der Gewalt im Bosnienkrieg und angesichts der Massaker von Srebrenica 1995 immer größer wurde. Als 
Wendepunkt im Prozess der innerparteilichen Spaltung verweist er dann auf einen Feldbesuch führender GRÜNEN-Politiker in Bosnien:

\section{„Was war schließlich der Wendepunkt?}

Winfried Nachtwei: Im Oktober 1996 besuchten die Vorstände von Bundestagsfraktion und Partei Bosnien-Herzegowina. (Zur 18-köpfigen Delegation gehörten Kerstin Müller, Joschka Fischer, Krista Sager, Jürgen Trittin, Marieluise Beck, Gerd Poppe, Werner Schulz, Uli Fischer, Achim Schmillen, Eva Biehler, ich und einige Journalisten. Obwohl wir gegensätzlicher Meinung und innerlich zerrissen waren, haben wir uns damals für diese gemeinsame Reise entschieden - als erste deutsche Partei!) Irgendwann standen wir dann oberhalb von Sarajevo und später schrieb ich in meinem Reisebericht: ,Vom Hang oberhalb dieser Straße schossen serbische Geschütze, Mörser, Panzer wie sie wollten in die Stadt hinein. Sarajevo auf dem Präsentierteller, wehrlos in der Mausefalle - und das drei Jahre lang! Hier packt es mich: Schmerz, Scham ... Joschka stichelt gegen Kerstin: Da hätten Zollbeamte sicher was geholfen, mit Zollstock .... Später sagt er mir, dass er sich hier geschämt habe, nicht eher für's Eingreifen gewesen zu sein. Das solle ihm nicht wieder passieren. ' In diesem Moment ist mir im Kopf und Herzen richtig klar geworden, was hier geschehen war. Ich habe die Opferperspektive ganz unausweichlich wahrgenommen. So ging es auch den anderen. Später hatten wir noch eine Audienz beim katholischen Bischof von Banja Luka, Franjo Komarica. Er nahm uns so zur Brust, dass selbst hartgesottenen Politikern die Tränen in den Augen standen. Er hat uns vorgehalten: ,Was habt ihr wieder mal in einem Teil Europas zugelassen. ' (Abgesehen von Österreich hatten die Europäischen Länder ja gar nicht wahrgenommen, was sich dort schon Anfang der 90er Jahre abspielte. Sie schauten erst verspätet hin und da war der Karren schon tief im Kriegssumpf.)

Und nach dieser Reise war alles anders bei den Grünen?

Winfried Nachtwei: Die persönlichen Berichte und Erlebnisse wirkten in die Partei und in die Fraktion und änderten grundsätzlich unsere Position. Für mich bedeutete das: So etwas wie Srebrenica und Sarajevo darf es im Einflussbereich europäischer Politik nicht noch mal geben. Das war später auch ein wichtiger Hintergrund für die Kosovo-Entscheidung. (Nur befreit eine solche Motivation nicht davon, später mit guten Beweggründen wieder andere Fehler zu machen.).“ (Bündnis 90/Die Grünen 2010)

\section{Schlaglicht 3: Truppenbesuche aus der Bundeswehr-Perspektive}

Für die Bundeswehr im Einsatz stellen die Truppenbesuche von Politikern und anderen Gästen einen Einbruch in die Einsatzroutine dar. Schon allein deswegen ist es aus ihrer Sicht sinnvoll und notwendig, Besuchsroutinen zu entwickeln, um 
den Aufwand möglichst gering zu halten. Ihr Gestaltungsspielraum hinsichtlich des Besuchsprogramms variiert. Handelt es sich beispielsweise um die Kanzlerin oder den Bundespräsidenten, die konkrete Gesprächspartner wie etwa den afghanischen Präsidenten Karzai treffen wollen, sind die Vorgaben vergleichsweise starr, und die Rolle der Bundeswehr ist auf Geleitschutz reduziert. Bei anderen Reisen von Ministern oder Abgeordneten kann der Anteil der Bundeswehr an der Programmgestaltung, die in der Regel um den jeweiligen Schwerpunkt des Einsatzes kreist, erheblich größer sein.

2009 lag ein solcher Schwerpunkt auf der Ausbildung von afghanischen Polizisten in Masar-i-Scharif, eine Aufgabe, die zunächst von der Bundeswehr durchgeführt, später von internationalen Polizisten übernommen wurde. Besuche im Polizeiausbildungszentrum gehörten in dieser Zeit zum Standardprogramm bei Truppenbesuchen. „Die Politiker sollten das sehen“, so ein Bundeswehrsol$\mathrm{dat}^{7}$, ,aber wir fühlten uns unwohl. Wir wurden aus der Routine rausgerissen, und dann war alles show-of-force-mäßig. Das war das reinste Schaulaufen, bei dem gezeigt wurde: ,Das und das machen wir‘."Die Ausbildungsstätte lag in der Nähe des Feldlagers. Dort wurde den Besuchern die Ausbildung der afghanischen Polizisten - „wie eine Art Schulklasse“ - vorgeführt. Zu den verschiedenen Stationen gehörten unter anderem Durchsuchung von Kraftfahrzeugen und Tatort-Arbeit. Ein Soldat erinnert sich: „Das waren zwar alles Sachen, die irgendwann im Stundenplan vorgesehen waren, aber das hatten die afghanischen Polizisten da bislang noch gar nicht gelernt. Also wurde das alles ein paar Tage vorher eingeübt. - Das war mehr so eine Theatervorführung. “

\section{Schlaglicht 4: Die Base als Bühne - das Beispiel Guttenberg}

Auch die angereisten Politiker können das Feldlager in eine Bühne verwandeln. Kein anderer deutscher Politiker hat wohl mehr Gebrauch von der Möglichkeit gemacht, Truppenbesuche für Inszenierungen zu nutzen, als Karl-Theodor zu Guttenberg, der während seiner kurzen Amtszeit als Verteidigungsminister (Oktober 2009 - März 2011) neunmal nach Afghanistan reiste. Die folgenden Auszüge aus einem Artikel der Süddeutschen Zeitung beziehen sich auf Guttenbergs Afghanistanreise im Dezember 2010, auf die er seine Ehefrau Stephanie mitnahm. Außerdem dabei war ein Fernsehteam um Sat1-Moderator Johannes B.

7 Die Eindrücke, die in Schlaglicht 3 geschildert werden, stammen aus mehreren Interviews der Verfasserin mit Bundeswehrsoldaten mit Einsatzerfahrung in Afghanistan. Die Interviewten möchten anonym bleiben. 
Kerner, der im Feldlager in Masar-i-Scharif eine Talkshowfolge „Kerner Spezial" mit Guttenberg aufzeichnete.

„Es war der medienwirksamste Truppenbesuch des Verteidigungsministers, als er am Montagmorgen samt Gattin und Johannes B. Kerners Talkshow-Set zu einem Überraschungsbesuch am Hindukusch eintraf. [...]

Das Echo war wie erwartet enorm, kaum eine Tageszeitung, auf deren Titelseite am Montagmorgen kein Bild des Guttenberg 'schen Familienausflugs prangte. Doch auch der Spott war groß: ,Familienbesuch in Afghanistan‘, titelte der Tagesspiegel, ,Operation Stephanie' die Berliner Zeitung und ,Paar-Lauf am Hindukusch' die TZ. Nach Art eines patriotischen Hollywoodfilms bearbeitete die Frankfurter Rundschau die Aufnahmen aus Afghanistan und überschrieb es mit ,Die Schönen und der Krieg‘

Weitaus weniger ironisch ist die Kritik aus der Opposition: SPD-Chef Sigmar Gabriel nannte das Programm , absolut unangemessen', Generalsekretärin Andrea Nahles den Verteidigungsminister einen ,Staatsschauspieler`. Auch Fachpolitiker griffen Guttenberg an. Der verteidigungspolitische Sprecher der SPD-Bundestagsfraktion, Rainer Arnold, sagte ,Guttenberg nutzt die Bundeswehr als Kulisse und Dekoration für seine Inszenierungen. [...]

Der so gescholtene Minister verteidigte seine Reise. ,Ich tue das, was ich für richtig halte, um den Soldaten hier im Einsatz die Anerkennung und die Aufmerksamkeit zu verschaffen, die sie verdienen', sagte Guttenberg gegenüber Spiegel Online. Rückendeckung erhielt er dabei vom Wehrbeauftragten des Bundestags, Hellmut Königshaus (FDP). Er sehe ,keinen Grund zur Empörung', sagte Königshaus dem SWR. Die Soldaten würden sich freuen, , dass der Minister nach Afghanistan kommt und deutlich macht, auch seine Familie steht dahinter'. [...]

Auch Berlin Unions-Fraktionsgeschäftsführer (sic!) Peter Altmaier (CDU) stellte sich hinter Guttenberg. Er habe den Eindruck, dass der Besuch von den Soldaten am Hindukusch sehr gut aufgenommen worden sei, sagte Altmaier. Allein das sei entscheidend. Der Besuch der Guttenbergs sei nicht aus dem Rahmen anderer Besuche von Politikern herausgefallen.

Guttenberg bedankte sich über Spiegel Online auch bei Moderator Johannes B. Kerner für die Produktion der Talkshow. Dadurch werde, ein weiteres Stück Realität des Einsatzes der Bundeswehr' für die deutsche Bevölkerung sichtbar, sagte der Minister. [...]“ (Süddeutsche Zeitung 14.12.2010: „Guttenberg in Afghanistan: Staatsschauspieler ohne Gespür). 


\section{INTERVENTIONSTHEATER UND HEIMATDISKURS: ZUM ZUSAMMENHANG VON DISKURS UND PERFORMATIVEM HANDELN}

Wie lassen sich die Funktionen von Feld- und Truppenbesuchen theoretisch im Heimatdiskurs verorten, also in der Re-/Produktion und im Wandel des Diskurses, der die deutsche Beteiligung an militärischen Interventionen mit Bedeutung versieht und legitimiert? Wie lassen sich die vielschichtigen theatralischen Performances, die solche Besuche begleiten, analytisch fassen und deuten? Und wie erklären sich die kontingenten Wirkungen, die diese Darstellungen offenbar entfalten können?

\subsection{Feld- und Truppenbesuche als symbolische Referenz in der Re-/Produktion des Heimatdiskurses}

Die Verbindung zwischen dem performativen Handeln von Politikern, das sich in Feld- und Truppenbesuchen verdichtet, und den diskurstheoretischen Annahmen, die dem Konzept des Heimatdiskurses zugrunde liegen, liegt nicht automatisch auf der Hand. Geht man von der Strömung der post-strukturalistischen Diskurstheorie aus, deren bedeutendster Vertreter Michel Foucault ist, so besteht eine zentrale Grundannahme darin, dass sich Diskurse aus Ordnungsmustern ergeben, die nicht auf das individuelle Bewusstsein (und damit individuelles Handeln) zurückgeführt werden können; vielmehr müssen die Subjekte selbst als das Ergebnis von Wissen/Macht-Strukturen verstanden werden. Foucault betont „die Art, wie Diskurse Leute machen, geht damit über linguistische und kommunikative Analyse hinaus und beschäftigt sich mit sozio-historischen diskursiven Formationen, begriffen als ein System von Regeln, die einige Aussagen aber nicht andere an bestimmten Orten, Zeiten und Institutionen ermöglichen“ (Fischer 2003, 38). Diskursive Formationen sind hier also relativ abstrakt und im Sinne von Epistemen weit gefasst. Ereignisse sind im Foucault'schen Vokabular immer Aussageereignisse, die eine relativ statische Sagbarkeitslogik aufweisen, welche durch die jeweiligen Macht/Wissen-Komplexe determiniert ist. Nicht gemeint sind damit Ereignisse im Sinne eines materiellen Kontextes, wie ihn Feld- und Truppenbesuche darstellen. Dieses „,metaphysische Verständnis“ von Diskursen als anonymer Ausdruck von Macht/Wissen-Komplexen lässt sich folglich nur schwer mit Konzepten menschlicher Handlungsfähigkeit verbinden (Keller 2005: 142); eine Analyse der Wirkung von performativen Ereignissen oder Handlungen wie Feld- und Truppenbesuchen auf den Heimatdiskurs ist aus einer streng post-strukturalistischen Sicht mithin nicht möglich. 
Vertreter der angewandten Diskursforschung halten Foucaults Theorie entsprechend für unzureichend, wenn es um eine soziologische Anwendung des Diskurskonzepts geht. Erst in der Verbindung mit anderen soziologischen Ansätzen, etwa dem sozialkonstruktivistischen Ansatz von Berger und Luckmann oder der spätstrukturalistischen Theorie Pierre Bourdieus, können diskursanalytische Ansätze aus ihrer Sicht den empirischen Nachweis erbringen, „dass und wie (!) diskursive Praktiken als wirkmächtige soziale Praxisformen das movens sozialer Konstruktionen sind“ (Diaz-Bone 2006, 81). Eine solche Mikrophysik sozialer Konstruktionen fragt danach, was die Momente des Zusammenwirkens waren, ,in denen diskursive Praktiken anderen Praktiken unterlagen oder mit ihnen zusammenwirkten, so dass sich Ereignisse und Resultate [...] einstellt haben und Kontingenzen [...] zu Notwendigkeiten [...] transformiert wurden“ (Diaz-Bone 2006, 81). Statt auf Strukturen heben diese Ansätze des so genannten interpretive turn also stärker auf Prozesse ab. Darüber hinaus eröffnen sie die Möglichkeit, den Wandel gesellschaftlicher Institutionen und Werte nicht nur über strukturelle Machteffekte zu erklären, sondern auch auf konkrete menschliche Handlungen zurückzuführen (Travers 2004, 28).

Mit seinem Verständnis von „Diskurs als soziologische[m] Konzept“ hat Michael Schwab-Trapp (2011) einen solchen hermeneutisch-interpretativen Ansatz zur Diskursanalyse vorgelegt. Sein zentrales Interesse gilt der Frage, wie legitime, kollektiv verbindliche Sichtweisen diskursiv produziert und reproduziert werden. Durch die Verbindung von Diskurstheorie mit der Feldtheorie Bourdieus stellt sein Ansatz ein Instrumentarium bereit, mittels dessen die sozialen Re-/Produktionsbedingungen von Diskursen untersuchen werden können.

Als ,diskursive Formation“ bezeichnet er

,institutionalisierte und legitimierungsfähige Formen des Sprechens über spezifische Themenfelder und Gegenstandsbereiche, in denen verschiedene thematisch gebundene Diskurse aufgegriffen, in Beziehung zueinander gesetzt und auf spezifische Weise organisiert werden. [...] Sie interpretieren, erklären und rechtfertigen soziale und politische Handlungszusammenhänge und sind das Produkt eines Interpretationsprozesses, in dem Diskurse miteinander verbunden oder voneinander abgegrenzt werden." (Schwab-Trapp 2011, 269-270).

Oder kurz gesagt: „Diskurse legitimieren soziales und politisches Handeln“, und sie ,institutionalisieren kollektiv anerkannte und mehr oder weniger verbindliche Deutungsvorgaben" (Schwab-Trapp 2011, 270). Beim Heimatdiskurs ist dies die Art, wie deutsche Beteiligungen an Interventionen gedeutet werden - etwa ob sie humanitäre Einsätze sind oder ob es sich um einen Krieg handelt - und welches 
politisch legitime Handeln sich aus diesen Deutungen ableitet - etwa die Frage, wie das Mandat gestaltet ist oder welches Kampfgerät eingesetzt werden darf. In diesem Sinne verstandene diskursive Formationen zeichnen sich neben ihrer Historizität durch Prozesshaftigkeit aus, d.h. sie können auch innerhalb eines Paradigmas (Kuhn 2006) dynamisch sein, sind aber dabei meist in ältere Diskurse und kulturelle Symbolwelten eingebettet (Schwab-Trapp 2011, 269f.). Beim Heimatdiskurs sind dies etwa tradierte kulturelle Vorstellungen beispielsweise des Kriegshelden, die in aktuellen Diskursen aufscheinen können (siehe Aljets et al. in diesem Band).

Solcherart verstandene diskursive Formationen sind das Ergebnis der Kämpfe von Trägergruppen konkurrierender Deutungen - den Diskursgemeinschaften (Schwab-Trapp 2011, 272) -, die vor dem Hintergrund von Strukturen stattfinden, welche sich in Anlehnung an Bourdieu als Diskursfelder bezeichnen lassen und die Kämpfe in gewissem Maße strukturieren. ${ }^{8}$ Thematisch bestimmte diskursive Felder sind sowohl Austragungsort von Kämpfen um Deutungshoheit und Legitimität als auch eine Struktur, in der diese Kämpfe stattfinden, denn: „Diskursfelder reglementieren die Zugangschancen zum Diskurs und gewichten den Wert wie die angemessene Form diskursiver Beiträge. Ihre soziale Struktur besteht aus den Machtverteilungen, Bündniskonstellationen und Konfliktlinien zwischen politischen Akteuren. Ihre diskursive Struktur besteht aus Konventionen und Regeln für eine diesen Feldern angemessene Produktion diskursiver Beiträge“ (Schwab-Trapp 2011, 271). Um die Diskursproduktion zu verstehen, gilt es also zu ergründen, welche Regeln es in einem spezifischen Feld für die Produktion diskursiver Beiträge und die Teilnahme am Diskurs gibt und welche

8 Mit Feld meint Bourdieu einen sozialen Raum verstanden als „,ein Kraftfeld, das für die in ihm engagierten Akteure eine zwingende Notwendigkeit besitzt, und als Feld von Kämpfen, in dem die Akteure mit je nach ihrer Position in der Struktur des Kraftfelds unterschiedlichen Mitteln und Zwecken miteinander rivalisieren und auf diese Weise zu Erhalt oder Veränderung seiner Struktur beitragen“ (Bourdieu 1998: 49f.; vgl. auch Bourdieu und Wacquant 1992: 20f., 98ff. zur Idee des enjeu). Die Position der Akteure in einem spezifischen Feld, ihre Macht und soziale Stellung, ergibt sich aus ihrer jeweiligen Ausstattung mit verschiedenen Sorten und Mengen an Kapital und aus ihrer Laufbahn (trajectoire). Die drei Grundkapitalien sind das ökonomische Kapital, das soziale Kapital (z.B. Beziehungen, Netzwerke) und das kulturelle Kapital (z.B. Erziehung, Bildungstitel und Fachwissen) (Bourdieu 1983). Zusätzlich führt Bourdieu als besondere Form das symbolische Kapital ein, verstanden ,als wahrgenommene und als legitim anerkannte Form der drei vorgenannten Kapitalien (gemeinhin als Prestige oder Renommée bezeichnet)“ (Bohn und Hahn 2000: 263). 
Strategien eingesetzt werden können, um sich im „,Kampf der Interpretationen um die legitime Sichtweise sozialer und politischer Ereignis- und Handlungszusammenhänge“" (Schwab-Trapp 2011: 275) zu behaupten.

Im empirischen Beispiel in „Schlaglicht 1“ wendet der SPD-Abgeordnete Arnold zwei diskursive Strategien an, in denen Vor-Ort-Besuche eine zentrale Rolle spielen, um die Argumente der Einsatzgegner zu relativieren bzw. zu entkräften. Zum einen verweist er auf das differenzierte Lagebild vom Verantwortungsbereich der Bundeswehr in Afghanistan, das er und andere Abgeordnete darunter auch Gegner der Intervention von der LINKEN - auf der Grundlage einer Reise ins Einsatzgebiet gewonnen hätten. Hier geht es um das Wissen, das durch den Vor-Ort-Besuch erlangt wurde, und den herausgehobenen Stellenwert, den Argumente, die auf diesem Wissen aufbauen, aus Sicht des SPDAbgeordneten gegenüber anderen Argumenten haben sollten. Der Verweis auf die gemeinsame Reise soll dabei der Überbrückung von Divergenzen und der Herstellung eines „Arbeitskonsenses“ über die legitime Sichtweise der Situation im Einsatzland Afghanistan dienen. Zum anderen wird der Parteispitze der LINKEN die Glaubwürdigkeit und ihren Argumenten damit die Stichhaltigkeit abgesprochen, indem Arnold hervorhebt, dass die Partei- und Fraktionsvorsitzenden Lafontaine und Gysi keine entsprechende Reise unternommen hätten. Der Truppenbesuch wird somit gleichsam zur Zugangsvoraussetzung und Teilnahmebedingung im Diskursfeld der Intervention - dem Heimatdiskurs - erhoben. ${ }^{9}$

Daneben erfüllen Truppenbesuche noch eine weitere Funktion im Diskurs. Oft lassen sich spezifische Diskurseliten ausmachen, die als ,individuelle Hauptakteure diskursiver Auseinandersetzungen“ Diskursgemeinschaften anführen (Schwab-Trapp 2011: 274f.). Sie wirken richtungsweisend, repräsentieren spezifische Positionen und deren Wandel und bilden einen Bezugspunkt und eine mögliche Quelle symbolischen Kapitals für andere Diskursteilnehmer. Ihren Elitencharakter erlangen diese Diskursakteure, ,weil sie im Bourdieuschen Sinne über ein ,symbolisches Kapital ' verfügen, das sie in Auseinandersetzungen einsetzen können und das ihren Deutungsangeboten Gewicht verleiht" (SchwabTrapp 2011: 274). In seiner empirischen Untersuchung des GRÜNEN-Diskurses über den Jugoslawienkrieg arbeitet Schwab-Trapp (2011: 279- 284) die besondere Rolle Joschka Fischers im Sinne der diskursiven Eliten heraus. Mit seinen

9 Umgekehrt gilt wahrscheinlich, dass diejenigen, die nicht im Einsatzgebiet waren - in diesem Falle Lafontaine und Gysi -, diese argumentative Leerstelle mit der „Macht des Prinzipiellen“, die losgelöst von konkreten Situationen und Schicksalen Geltung beansprucht, anstelle der „Macht des Empirischen“ zu füllen versuchen. 
diskursiven Strategien sei Fischer in der Lage gewesen, einen Identitätswandel bei den GRÜNEN einzuleiten, der in der Folge die Zustimmung der Partei zur deutschen Beteiligung an der Kosovo-Intervention der NATO möglich gemacht habe (Schwab-Trapp 2004).

Die Diskursanalyse mit ihrem Fokus auf dem Aspekt der Semantik schreibt also vor allem den diskursiven Strategien Fischers und Kopplungseffekten seiner Diskursbeiträge die Hauptrolle im innerparteilichen Identitätswandel zu. Wie die eigene Geschichtsschreibung ${ }^{10}$ der GRÜNEN mit ihren Verweisen auf die Reise der Parteivorstände nach Bosnien und Herzegowina (Schlaglicht 2) jedoch nahe legt, waren es (auch) performative Handlungen, die der neuen Parteilinie in Sachen Interventionen Mitte der 1990er Jahre zum Durchbruch verhalfen. Fischers Argument der „Normativität des Faktischen“, dass also die Situation in Jugoslawien keine alternativen Handlungsmöglichkeiten zur militärischen Intervention zugelassen hätte (vgl. Schwab-Trapp 2011: 282f.), setzte sich Nachtwei zufolge innerhalb der Partei erst mit der gemeinsamen Bosnienreise durch. Erst das physische Nachempfinden der Belagerung Sarajevos durch bosnisch-serbisches Militär an den Schauplätzen der serbischen Stellungen, die Gespräche mit Bosniern, die die Tatenlosigkeit der europäischen Staaten im Angesicht der Gewalt vor ihrer Haustür anklagten, und die starken Emotionen, die diese Erlebnisse bei der Delegation auslösten, verliehen in dieser Lesart den Argumenten der Interventionsbefürworter im „Realo“-Lager der Partei das nötige symbolische Gewicht, um sich gegen die pazifistischen Argumente der „Fundi“-Seite durchzusetzen.

Bis heute dienen Verweise auf diese Bosnienreise GRÜNEN-Politikern in Debatten um internationale Interventionen zur Rechtfertigung ihrer Parteilinie in dieser Frage, nach der humanitäre Interventionen mittlerweile zum außen- und sicherheitspolitischen Repertoire gehören. Als die Verfasserin dieses Beitrags 2010 in der Parlamentarischen Gesellschaft in Berlin einen Vortrag ${ }^{11}$ über die Ergebnisse ihrer sechsjährigen Forschung zur Bilanz der StatebuildingIntervention in Bosnien und Herzegowina (Bliesemann de Guevara 2009) hielt, meldete sich in der anschließenden Diskussion eine GRÜNEN-Abgeordnete zu

10 Aus Historikersicht sind eigene Geschichtsschreibungen von Personen oder Organisationen kritisch zu betrachten, weil sie keine auf wissenschaftlichen Kriterien fußenden Ergebnisse, sondern subjektive Sinngebungen und invented traditions im Sinne Hobsbawms (2008) darstellen. Für das Erkenntnisinteresse dieses Beitrags hingegen ist dies jedoch nicht nur unproblematisch, sondern sogar zentral, weil es nicht um eine detaillierte Rekonstruktion der tatsächlichen Bedeutung von Ereignissen geht, sondern um das, was die Akteure selbst für solche Ereignisse und deren Bedeutung halten.

11 Salon Junge Wissenschaft, 14. Juni 2010. 
Wort und erklärte, sie könne die pessimistische Einschätzung nicht nachvollziehen; für sie sei das Engagement der internationalen Gemeinschaft in Bosnien ein Erfolg. Als Begründung verwies sie auf zwei persönliche Besuche in Bosnien der erste im Rahmen der von Nachtwei beschriebenen Reise 1996, der zweite im Juli 2005, als die Böll-Stiftung eine Konferenz in Sarajevo organisierte, um über zehn Jahre Friedensprozess in Bosnien zu reflektieren. Bei der zweiten Reise habe die Delegation unter anderem eine Schule in einem einst ,ethnisch gesäuberten" Stadtteil Sarajevos besichtigt, die zehn Jahre nach dem Krieg wieder von serbischen und muslimischen Kindern gemeinsam besucht wurde. Dies deutete die Abgeordnete als starkes Zeichen für die erheblichen Fortschritte, die der Friedensprozess gemacht habe, und als Ausdruck des Erfolgs der internationalen Intervention in Bosnien. Wie diese Szene vermuten lässt, gehören Verweise auf Feld- und Truppenbesuche mittlerweile fest zum symbolisch-diskursiven Repertoire der Partei. ${ }^{12}$

Feld- und Truppenbesuche, so die erste These dieses Beitrags, stellen also eine Möglichkeit für Teilnehmer am Heimatdiskurs dar, eine „,symbolische Aufladung" zu erfahren - also symbolisches Kapital zu akkumulieren, das ihnen ein besonderes Gewicht oder eine Höherwertigkeit verleiht. Im Rahmen der Diskursordnung kann eine solche Reise z.B. eine Strategie sein, den Stellenwert des eigenen Diskursbeitrags zu erhöhen, sich von anderen, nicht auf einem Vor-OrtBesuch beruhenden Beitragen abzugrenzen oder auf der Grundlage geteilter Erfahrungen einer Reise den eigenen Diskursbeitrag mit anderen zu verkoppeln, sei es, um bestehende Konvergenzen zu verstärken oder Divergenzen zu überbrücken. In besonderen Fällen kann die Reise auch zur symbolischen Aufladung

12 Die Episode ist noch in anderer Hinsicht interessant: Bei Politikern (und Sozialwissenschaftlern) lässt sich eine (unbewusste) Neigung beobachten, trotz der Fülle an verfügbarem Wissen selbst Erlebtes stärker zu gewichten. Der Psychologe Kahneman (2012: 112-115) nennt dieses Phänomen „What you see is all there is” (WYSIATI): "Wie aus der WYSIATI-Regel folgt, wirken sich weder die Quantität noch die Qualität der Informationen nennenswert auf den Grad der subjektiven Überzeugung aus. Das Ausmaß, in dem wir an unsere Überzeugungen glauben, hängt überwiegend von der Qualität der Geschichte ab, die wir über das erzählen können, was wir sehen, auch wenn wir nur wenig sehen" (Kahneman 2012: 115). 2004 gab es in Bosnien viele Schulen, in denen ethno-nationale Segregation an der Tagesordnung war; außerdem ist unklar, ob die positiven Entwicklungen in der genannten Schule überhaupt Ergebnis der Intervention waren. Nichtsdestotrotz nahm die Abgeordnete die beiden Reisen als Referenzpunkte einer kohärenten Geschichte, in denen die Folgen kriegerischer Gewalt mittels internationaler Intervention sukzessive rückgängig gemacht wurden. 
der Person selbst führen und damit zur Herausbildung der jeweiligen Diskurselite beitragen. Es ist dabei zu vermuten, dass sich der Stellenwert von Vor-OrtBesuchen im Laufe der Zeit gewandelt hat: War die gemeinsame Reise der Parteivorstände der GRÜNEN 1996 noch ein Besonderheit, gehört es heute zum „guten Ton“ des außen- und sicherheitspolitischen Berliner Establishments, sich vor Ort ein Bild von der Lage zu machen. Es kann also vermutet werden, dass sich die Rolle von Feld- und Truppenbesuchen im Heimatdiskurs von einer starken symbolischen Aufladung einzelner Diskursbeiträge hin zu einer Zugangsbedingung zum politischen Diskursfeld Intervention im Sinne des symbolischen Kapitals gewandelt hat: Ein angemessener Diskursbeitrag zur politischen Afghanistandebatte setzt heute einen Vor-Ort-Besuch gleichsam voraus.

\subsection{InterventionsTheater: Feld- und Truppenbesuche als theatralische soziale Performance}

Die oben formulierte These, dass Feld- und Truppenbesuche zur symbolischen Aufladung von Personen oder Diskursbeitragen führen können, ist bewusst als Möglichkeit (und nicht als automatische Folge) formuliert, denn wie die Schlaglichter bereits erkennen ließen, besteht eine erhebliche Kontingenz ihrer Rolle und Wirkung. So können solche Vor-Ort-Besuche, wie die kollektive Parteigeschichte der GRÜNEN erahnen lässt, in bestimmten Kontexten zur Produktion einer diskursiven Formation beitragen, indem sie Individuen im Sinne von Goffmans Rahmen ermöglichen, in dem unmittelbaren situativen Zusammentreffen des Feld- und Truppenbesuchs ,einen Arbeitskonsens über die Beschaffenheit ihrer Wirklichkeit“ (Hettlage 2000: 190) herzustellen. In anderen Kontexten dagegen scheinen sie von den Zuschauern als Selbst-/Inszenierung im pejorativen Sinne wahrgenommen zu werden, wie im Falle der Guttenberg-Reise (Schlaglicht 4). Wieso haben die Feld- und Truppenbesuche also eine so unterschiedliche Wirkung auf Teilnehmende und/oder Zuschauer? Oder anders gefragt: Wie gelingt die symbolische Erhöhung von Diskursbeiträgen mittels Vor-OrtBesuchen, und unter welchen Umständen sind sie zum Scheitern oder zur Bedeutungslosigkeit verurteilt?

Um diese Fragen beantworten zu können, greift der Beitrag auf den Ansatz theatralischer sozialer Performance nach Jeffrey C. Alexander (2004) zurück, der darauf zielt, eine Brücke zwischen Semantik und Pragmatik zu schlagen, denn: „Cultural practices are not simply speech acts“ (Alexander und Mast 2006: 3). ${ }^{13}$

13 Anders als in Goffmans „Wir alle spielen Theater“ (1973), in dem die Performance im instrumentalistischen Sinne eine Fassade darstellt, hinter der Akteure ihren Egoismus 
Kollektive Repräsentationen, so die Kernannahme, sprechen nicht für und durch sich selbst, sondern es gibt eine Notwendigkeit für ,walking and talking and seeing - and listening to the walking and talking", kurz: für die soziale Aufführung eines Textes, um kulturellen Sinn zu transportieren (Alexander 2004, 530). Weil in komplexen, fragmentierten modernen Gesellschaften soziale Bindungen lose sind, die Verteilung materieller und ideeller Ressourcen relativ offen ist und Macht stetig herausgefordert werden kann, müssen Eliten ihre Interessenkonflikte in überzeugende symbolische Formen und vereinfachende Narrative kleiden sie ritual-ähnlich aufführen -, um sich gegen Konkurrenten durchzusetzen (Alexander 2004, 545). Die Feld- und Truppenbesuche von Politikern, so die zweite These dieses Beitrags, sind solche ritual-ähnlichen, sozialen Aufführungen.

Unter sozialer theatralischer Performance versteht Alexander

"the social process by which actors, individually or in concert, display for others the meaning of their social situation. This meaning may or may not be one to which they themselves adhere; it is the meaning that they, as social actors, consciously or unconsciously wish others to believe" (Alexander 2004: 529).

Soziale Aufführungen bestehen aus unterschiedlichen Elementen wie Rollenbuch bzw. Skript, Darsteller, Publikum und Inszenierung. Eine soziale Aufführung ist dann erfolgreich, wenn es gelingt, alle Elemente in Einklang zu bringen, denn nur dann erscheint sie authentisch. Als gelungene symbolische Kommunikation und kulturelle Interaktion erzeugt sie intuitives und unreflektiertes Vertrauen (Alexander 2004: 528). Gelingt es, eine emotionale Verbindung von Publikum, Darsteller und Text herzustellen, kann kultureller Sinngehalt transportiert werden (Alexander 2004: 547). Das Problem in komplexen modernen Gesellschaften ist allerdings, dass die Performance-Elemente in der Regel voneinander entkoppelt sind; die Kunst der sozialen Aufführung besteht also darin, die Elemente in Einklang zu bringen: „To the degree they achieve re-fusion, social performances become convincing and effective - more ritual-like. To the degree that social performances remain de-fused, they seem artificial and contrived, less like rituals than like performances in the pejorative sense. They are less effective as a result" (Alexander 2004: 529).

verstecken, erlaubt es dieser Ansatz, die Möglichkeit für starke Verbindungen zwischen psychologischer Motivation, sozialer Performance and kulturellem Text in der Analyse offen zu halten (Alexander und Mast 2006: 13): Nicht jede soziale Performance ist instrumentalistisch im Goffman'schen Sinne. 
Soziale Performances spielen sich vor dem Hintergrund von Symboliken ab, also von Mustern symbolischer Bedeutung, die sich auf die Erfahrungs- und Bedeutungswelten von Darstellern und Publikum beziehen. Auf ihrer Grundlage entstehen Rollenbücher oder Skripte, die als unmittelbare Referenzen für Handlungen dienen. Hintergrund-Symboliken und Handlungsskripte müssen zueinander passen (Alexander 2004, 530). Die Herausforderung des Skripts besteht darin, Symbolwelten, kontingente Darstellungen und Publikum in Einklang zu bringen, damit die Performance wahrhaftig und real erscheint. Anders als im Theater (das Stehgreiftheater vielleicht ausgenommen) sind die Skripte sozialer Performances jedoch nicht in jedem Falle vorgegeben; häufig entstehen sie erst in der sozialen Interaktion selbst (Ridderhof de Wilde 2012: 4). Als dramatische Technik, durch die eine Verschmelzung von kulturellen Symboliken, Handlungsskript und Performance erreicht werden soll, dient vor allem kognitive Vereinfachung durch simple Handlungen, Wiederholungen und die Verwendung stereotyper Rollenbilder (Alexander 2004: 551).

Während Hintergrundsymboliken und Skript nur die Basis einer theatralischen Performance bilden, kommt in der konkreten Aufführung das Element der Inszenierung hinzu, verstanden als zeitliche und räumliche Sequenzierung der sozialen Performance. Eine erfolgreiche Darstellung schafft einen Zusammenhang von Handlung, Raum und Zeit sowie von Kontinuität, Grund und Wirkung (Alexander 2004: 552). Ebenso wie das Skript entsteht auch die Inszenierung in sozialen Performances manchmal erst während der Darbietung selbst (Alexander 2004: 555). Die Herausforderung der Inszenierung besteht darin, soziale Probleme symbolisch zu gestalten, zu rahmen und aufzuführen. Als Mittel symbolischer Reproduktion - als Requisiten - dienen dabei Objekte, die als bildliche Repräsentationen der Dramatisierung und Visualisierung des gemeinten Sinns genutzt werden.

Diejenigen Personen, die Texte in tatsächliche Handlungen übersetzen, sind die Darsteller sozialer Performances. Sie müssen bestimmte Fähigkeiten mitbringen, um die Bedeutungsgehalte ihrer Aufführungen erfolgreich auf die $\mathrm{Zu}$ schauer zu projizieren (Alexander 2004: 530-531). Die größte Herausforderung besteht dabei darin, Darsteller und Rolle so zu verschmelzen, dass die Aufführung nicht als ein Schauspiel, sondern als natürlich wahrgenommen wird. Allerdings müssen auch die Zuschauer sozialer Performances in der Lage sein zu dekodieren, was von den Darstellern kodiert wurde; sie müssen sich emotional mit den Darstellern identifizieren können (zur Bedeutung von Emotionen auch Ridderhof de Wilde 2012: 5f.). Der Erfolg des Entschlüsselns hängt dabei nicht nur von der Qualität des Darstellers ab; auch ein unkonzentriertes oder uninteressiertes Publikum kann Grund des Misserfolgs einer sozialen Performance sein 
(Alexander 2004: 531). In komplexen Gesellschaften stellen sich diesbezüglich zwei Hauptherausforderungen: Zum einen besteht eine Distanz zwischen dem kulturellen Text der Aufführung und dem Zuschauer; politische Darstellungen sind in der Regel medial vermittelt (siehe Neumann in diesem Band). Zum anderen sind komplexe Gesellschaften sozial und kulturell fragmentiert, was in „,multiplen öffentlichen Räumen“ zum Ausdruck kommt. Die für eine erfolgreiche Darstellung zentralen Mechanismen der psychologischen Identifikation und kulturellen Extension erreichen so selten alle Segmente der Gesellschaft bzw. können bei unterschiedlichen Gruppen ganz unterschiedliche Wahrnehmungen und Reaktionen hervorrufen. Soziale Performances, die bestehende Gruppen bestätigen sollen, sind deswegen einfacher als universelle Schauspiele (Alexander 2004: 564; vgl. Ridderhof de Wilde 2012).

Wie bei Schwab-Trapp spielt auch im Ansatz der sozialen theatralischen Performance die soziale Positionierung und Macht von Akteuren eine zentrale Rolle, denn sie entscheidet darüber, wer überhaupt darstellend agieren und wer einer Performance beiwohnen kann oder darf (Alexander 2004: 532). Auch Akteure mit interpretativer Macht, also beispielsweise die Medien oder Kritiker, können auf den Erfolg einer sozialen Performance Einfluss nehmen. Und nicht zuletzt ist die materielle Macht, die etwa darin bestehen kann, die Mittel symbolischer Reproduktion oder den Zugang zu einem Schauplatz zu kontrollieren, entscheidend für die Möglichkeit sozialer theatralischer Darbietungen.

Feld- und Truppenbesuche sind Manifestationen theatralischer sozialer Performance. Diese direkten Begegnungen zwischen politisch Verantwortlichen aus dem Entsendestaat Deutschland, den durchführenden Organisationen vor Ort, also Bundeswehr und zivile staatliche und nichtstaatliche Hilfsorganisationen, und den so genannten lokalen Partnern im intervenierten Land werden in vielerlei Weise und von unterschiedlichen Akteuren inszeniert und aufgeführt.

Auf Seiten der Bundeswehr scheint der Inszenierungscharakter von Truppenbesuchen sowohl aus der organisatorischen Notwendigkeit, die Besuche möglichst zu routinisieren, als auch aus bundeswehrinternen Karrierelogiken zu erwachsen (Schlaglicht 3). Die Idee hingegen, dass Truppenbesuche dazu dienen könnten, dass sich Politiker ein möglichst genaues Bild von der Lage machen, hielten meine Gesprächspartner eher für unrealistisch. Während ihres Feldaufenthalts bekämen die Besucher ein straffes Programm vorgesetzt und würden häufig „zugebombt mit Informationen“; es bleibe ihnen kaum Zeit, sich Gedanken zu machen oder nachzufragen. Zudem sei „Schönrederei“ an der Tagesordnung: Probleme würden bei den Feldbesuchen in der Regel nicht angesprochen, vermutlich aus Angst der Vorgesetzen, „einen auf den Deckel zu kriegen“, also eine Abmahnung oder im schlimmsten Falle ein Karriereende zu riskieren, soll- 
ten Unzulänglichkeiten in ihrem Zuständigkeitsbereich bekannt werden. Entsprechend gering seien auch die Möglichkeiten der Besucher, ,sich mit normalen Soldaten zu unterhalten“. Wünscht ein Politiker ausdrücklich, mit Soldaten zu reden, würden diese vorher ausgesucht (Ausnahme: Gesprächsrunden mit dem Wehrbeauftragten). Die Elemente der theatralischen Performance in den Besuchsprogrammen der Bundeswehr müssen also vor dem Hintergrund der internen Logiken des Militärs im Einsatz und im Heimatland interpretiert werden. Ähnliches gilt für die Inszenierungen der anreisenden Politiker, deren Intentionen nur vor dem Hintergrund der Machtkämpfe im politischen Feld des Entsendelandes verstanden werden können.

Einige dieser sozialen Schauspiele, die sich in Feld- und Truppenbesuchen manifestieren, sind erfolgreich; sie werden als authentisch wahrgenommen und zeitigen die beabsichtigten Effekte. Obwohl wir aus Schlaglicht 2 wenig über die konkreten Umstände der Bosnienreise der GRÜNEN erfahren (Wer hat die Reise geplant? Wer war für die Dramaturgie des Besuchs zuständig? etc.), gibt der Interviewausschnitt doch Hinweise darauf, dass es sich um eine gelungene Performance handelte. $\mathrm{Zu}$ den dramaturgischen Elementen erfahren wir nur, dass dazu Fahrten zu den Schauplätzen des Krieges ebenso wie Begegnungen mit Zeugen der Gewalt gehörten. Wichtiger ist, dass wir erfahren, dass die emotionale Identifikation der Zuschauer mit der Performance perfekt funktionierte. Die Tränen, die Nachtwei schildert, sind Ausdruck dafür, dass die Botschaft vom menschlichen Leid durch einen Krieg, in den die internationale Gemeinschaft erst spät und nur zögerlich eingriff, vom Publikum, also den GRÜNEN-Politikern, nicht rational begriffen wurde - tatsächlich waren Informationen über die Belagerung Sarajevos, die „ethnischen Säuberungen“ und das Massaker von Srebrenica den angereisten Politikern auch vorher schon bekannt. Vielmehr wurde die Botschaft emotional im Sinne einer Katharsis nachempfunden.

Andere soziale Performances im Rahmen von Truppenbesuchen scheitern hingegen. Eigene Erfahrungen mit einer gescheiterten Performance machte die Verfasserin 2004 als Teilnehmerin einer wissenschaftlichen Feldforschung zu zivil-militärischer Zusammenarbeit (CIMIC) in Bosnien und Herzegowina und im Kosovo. Der Kommandeur des deutschen Kontingents der SFOR (Stabilisation Force) im Feldlager Rajlovac nahe der bosnischen Hauptstadt Sarajevo empfing unsere vierköpfige Wissenschaftlerdelegation am ersten Abend zu einem zwanglosen Beisammensein. Nach anfänglichem Smalltalk ging er zügig dazu über, uns seine Interpretation des Bosnienkrieges darzulegen. Er lastete die Hauptschuld für den Kriegsausbruch sowie die Kriegsgräuel den bosnischen Serben an, als deren Gewaltmotivation er ethnischen Hass diagnostizierte. Einige der anwesenden Offiziere brachten sich mit spezifischen Details zu den serbi- 
schen Menschenrechtsverbrechen und der „Mentalität der Balkanbewohner“ ein, andere wohnten der Szene als stumme Statisten bei. ${ }^{14}$ Am nächsten Tag stand ein für Besucher des Kontingents offenbar standardmäßiger Ausflug zu den Schauplätzen der Gräueltaten serbischer Militärs im Raum Sarajevo an, darunter die Hügel, von denen aus die Stadt mit Mörsern und Scharfschützenfeuer beschossen worden war (und von denen aus auch die GRÜNEN-Politiker 1996 auf die Stadt blickten), sowie ein Tunnel, in dem weibliche Kriegsgefangene sterilisiert worden seien, was noch an einer Wandzeichnung der inneren weiblichen Geschlechtsorgane abzulesen wäre. Die gespenstische, mit Ressentiments erfüllte Stimmung, die der Abendvortrag und die „Kriegsgräuel-Tour“ bei uns hervorriefen, überschattete alle anderen Programmpunkte des bosnischen Teils unserer Reise. Bei den Programmpunkten, in denen es konkret um die CIMIC-Arbeit ging, wurde klar, dass die CIMIC-Kompanie in Bosnien gerade erheblich verkleinert werden und eine neue Aufgabe bekommen sollte: Statt Unterstützung beim Wiederaufbau (als Teil des Truppenschutzes) sollte ihre Aufgabe nun die offene wie geheime Informationsgewinnung in der lokalen Bevölkerung sein, um etwaigen obstruktiven Kräften entgegenzuwirken. Auch bei diesen Programmpunkten dominierten Misstrauen und Ressentiments den Eindruck, der vom Land vermittelt wurde und nun zur Legitimierung der Neuausrichtung der CIMIC-Arbeit herangezogen wurde. ${ }^{15}$ Anders als bei der Reise der GRÜNEN,

14 Die Sicht der Jugoslawienkriege, die uns hier präsentiert wurde, entsprach der kruden Theorie des „,ethnischen Krieges“, wonach sich Anfang der 1990er Jahre der jahrzehntelang von der sozialistischen Führung Jugoslawiens ,,gedeckelte“ oder „,eingefrorene Hass“ zwischen den südslawischen Volksgruppen im Zuge des Staatszerfalls Bahn brach. Diese Sichtweise konnte auch 2004 bereits als überzeugend widerlegt gelten (siehe beispielsweise Calic 1995, 2003 und Höpken 1997, 2000).

15 Ganz anders war dagegen der zweite Teil der Reise, der uns in das Feldlager Prizren im Kosovo führte. Der Eindruck, der uns hier von der Arbeit der CIMIC-Kompanie, dem Einsatz der KFOR (Kosovo Force) und dem Land vermittelt wurde, war viel stärker auf Kooperation und Erfolge beim Wiederaufbau ausgerichtet, und der Reiseplan enthielt zahlreiche Treffen mit internationalen und lokalen Akteuren sowie touristische Programmpunkte wie eine Fahrt in die Berge und einen Besuch im „besten Forellenrestaurant des Südkosovo“. Die Bilder, die uns mittels sozialer Performance von den beiden Balkan-Einsatzgebieten vermittelt wurden, sind insofern bemerkenswert, als das Jahr 2004 in Bosnien eher einen Höhepunkt des Friedensprozesses markierte, während es im Kosovo einen herben Rückschlag in Form der gewaltsamen März-Unruhen gegeben hatte - also gewissermaßen das Negativ der vermittelten Bilder. 
die ein ganz ähnliches Thema hatte, löste diese Performance jedoch keine Identifikation der Zuschauer mit dem Dargestellten aus - im Gegenteil: In der Atmosphäre eines weitgehend befriedeten Landes, das selten mit so wenig Konflikten im Nachkriegsprozess zu kämpfen hatte wie zu diesem Zeitpunkt, wirkte das Besucherprogramm der Bundeswehr grotesk und das simplifizierende Bild der komplexen Kriegsursachen und -verläufe unangemessen. Das Ziel, das damit verfolgt wurde, blieb unklar; eine emotionale Identifikation fand nicht statt.

Manche Performances sind in ihren Wirkungen ambivalent, was sich auf das Problem der multiplen öffentlichen Räume zurückführen lässt. Der in Schlaglicht 4 geschilderte Truppenbesuch Guttenbergs in Afghanistan ist ein solcher Fall. Für die Botschaft der medial in Szene gesetzten Reise gibt es zwei Lesarten: In der einen dient der Besuch dazu, die heimische Öffentlichkeit für die Lage der Soldaten zu sensibilisieren. Die Rolle Guttenbergs darin ist die des fürsorglichen Vorgesetzten und des Manns der klaren Worte. Immerhin war es gewesen, der erstmals von ,kriegsähnlichen Zuständen“ gesprochen und damit eine Debatte über die Rolle der Bundeswehr in Afghanistan angestoßen hatte (siehe Daxner in diesem Band). In der anderen Lesart ist das Ziel Guttenbergs, mittels der Afghanistanreise seine eigene Popularität zu steigern und sich damit im politischen Feld zu positionieren. Zum Zeitpunkt der Reise profitierte Guttenberg bereits von einer enormen Sympathiewelle: Beim ZDF-Politbarometer, das nach der Wichtigkeit und Beliebtheit von Politikern fragt, stand er im Juli 2009 erstmals auf Platz eins, von Oktober 2009 bis März 2011 führte er die Liste ununterbrochen an. Im Herbst 2010, also nur zwei Monate vor der Reise, war er erstmals als künftiger Kanzlerkandidat gehandelt worden (Infratest dimap 2010). Die Reaktionen auf die Performance Guttenbergs waren entsprechend gespalten: Seine CDU/CSU-Parteifreunde und große Teile der Soldatenschaft ${ }^{16}$ nahmen den Truppenbesuch und die Talkshowaufzeichnung im Sinne der ersten Lesart positiv auf. Guttenbergs Handeln entsprach ihren Vorstellungen eines verantwortungsvollen Verteidigungsministers, der den Einsatz auch im Heimatland zum Thema macht. Eine emotionale Identifikation dieses Zuschauerteils mit dem Dargestellten war möglich. Das Gros der heimischen Medien sowie die Oppositionsparteien hingegen nahmen die Performance als Schauspiel im pejorativen Sinn war. Die Wortwahl „Staatsschauspieler“, „Kulisse“ und „Inszenierungen“

16 Die Einschätzung der Perzeption Guttenbergs durch die Soldaten beruht teilweise auf persönlichen Gesprächen der Verfasserin mit Bundeswehrsoldaten an der HelmutSchmidt-Universität Hamburg. Für punktuelle Eindrücke der Wahrnehmung von „Gefechtsfeldtouristen“ durch die Soldaten im Einsatz siehe auch die Auszüge aus der Feldpost deutscher Soldaten in Afghanistan in Baumann et al. (2011). 
verdeutlicht, dass der Auftritt als künstlich wahrgenommen wurde. ${ }^{17}$ Obwohl die Botschaft Guttenbergs also bei Teilen des Publikums ankam, war er insgesamt nicht in der Lage, sein proklamiertes Ziel, nämlich ,,den Soldaten hier im Einsatz die Anerkennung und die Aufmerksamkeit zu verschaffen, die sie verdienen“, umzusetzen. Die erhoffte Wirkung blieb begrenzt.

\section{SChlussbemerkUngen UND Forschungsausblick}

Die landläufige Begründung der Feld- und Truppenbesuche von Politikern ist, „sich persönlich ein Bild von der Lage machen“ zu wollen. Implizit steht dahinter der Gedanke, dass das eigene Sehen, Hören und Erleben einen direkten Blick auf die „Wirklichkeit“ des Einsatzalltags der Intervenierenden, die Probleme der Friedensschaffung und im idealen Falle auf die Welt der Intervenierten eröffnet. Bedenkt man die große Tragweite, die Entscheidungen über Interventionen in andere Staaten für die Gesellschaften von Intervenierenden wie Intervenierten haben, ist dies ein lobenswertes Anliegen. Tatsächlich jedoch muss die Begründung von Feld- und Truppenbesuchen anders gelesen werden: Das Bild, das sich Politiker dabei von der Intervention machen, ist ein mögliches Bild der Realität unter anderen - eine kollektive Konstruktion, die durch die Diskursstränge des Heimatdiskurses vorstrukturiert ist und in die unterschiedliche Beteiligte mittels sozialer Performance einzugreifen suchen. Die Kluft, die sich zwischen dem Einblick in die Besuchsroutinen der Bundeswehr in Afghanistan einerseits und der Idee einer „Lagebestimmung vor Ort“ im Rahmen einer Reise in das Einsatzgebiet andererseits auftut, ist groß und bedarf ebenso einer genaueren Untersuchung wie die vielfältigen symbolischen Funktionen, die Feld- und Truppenbesuche im Heimatdiskurs erfüllen können.

Die Mechanismen der symbolischen Aufladung von interventionsbezogenen Diskursbeiträgen, die über die künftige deutsche Haltung in Fragen von Krieg und Frieden entscheiden, erfordern eine Analyse auf einer breiten empirischen Basis. Methodisch erfordert ein solches Projekt teilnehmende Beobachtung im Rahmen der Feld- und Truppenbesuche von Politikern, sei es in Afghanistan oder in anderen Einsatzgebieten. Die soziale Performance erschließt sich, wie

17 Siehe weiterführend auch die Beiträge in „Inszenierung als Beruf. Der Fall Guttenberg“ (Lepsius und Meyer-Kalkus 2011). Für David Hugendick (2010) von der ZEIT lag der Fokus der Inszenierung hingegen gar nicht allein bei Guttenberg, sondern auch bei Moderator Kerner, der sich als ,großer Versteher nationaler Sorgen, der dranbleibt, wo andere aufhören“ in Szene gesetzt habe. 
gezeigt, nicht nur aus Texten, sondern vor allem daraus, wie diese Texte aufgeführt werden. Genauso wichtig, wie das, was gesagt wird, ist also das, was getan wird, welche Orte besucht werden, welche Requisiten zum Einsatz kommen, wie der Besuch dramaturgisch inszeniert und durchgeführt wird. Diese Elemente des InterventionsTheaters können nur mittels teilnehmender Beobachtung erfasst werden. Die aufgezeichneten Beobachtungen sollten durch Interviews mit den beteiligten Politikern, Diplomaten, Bundeswehrpersonal und anderen Akteuren ergänzt werden. Dadurch können die Intentionen der Handelnden und die Wahrnehmungen durch das jeweilige Publikum genauer ergründet werden. Schließlich sollten die Beobachtungen mittels der Auswertung persönlicher Reiseberichte der teilnehmenden Politiker, ihrer Reden und Interviews und ihrer Beiträge zu Parlamentsdebatten an den breiteren Heimatdiskurs rückgebunden werden, um die symbolischen Funktionen der Feld- und Truppenbesuche zu bestimmen.

Ein solches Projekt ist auch in vergleichender Perspektive denkbar, etwa indem verschiedene Entsendestaaten einer Intervention einander gegenübergestellt werden. Eine andere Möglichkeit des Vergleichs besteht darin, die Rolle von Feldbesuchen in unterschiedlichen Ressorts (etwa Verteidigung, Entwicklungszusammenarbeit etc.) zu untersuchen und an das jeweilige Diskursfeld rückzubinden, um etwaige Unterschiede in den Funktionen herauszuarbeiten. In Anlehnung an Lowis (1972) These ,policy determines politics“ ließe sich diesbezüglich im Hinblick auf unterschiedliche Politikfelder die These ,policy determines performance“ aufstellen, deren Stichhaltigkeit dann zu prüfen wäre. Die Aufarbeitung dieser Forschungsdesiderata in Bezug auf die performative Seite von Politik kann einem wertvollen Beitrag zu einem tieferen Verständnis der Eigenlogiken internationaler Interventionen leisten.

\section{LITERATUR}

AG Friedensforschung. 2009. Dokumentiert: Debatte und Abstimmung im Bundestag am 3. Dezember 2009 über die Verlängerung des Bundeswehreinsatzes in Afghanistan. http://www.ag-friedensforschung.de/regionen/Afghani stan/bt-03-12-2009.html (aufgerufen am 20. Juli 2012).

Alexander, Jeffrey C. 2004. „Cultural Pragmatics: Social Performances Between Ritual and Strategy." Sociological Theory 22 (4), S. 529-573. 
Alexander, Jeffrey C. 2006. „From the depths of despair: performance, counterperformance, and ,September 11'." In Social Performance. Symbolic Action, Cultural Pragmatics and Ritual, hrsg. v. Jeffrey C. Alexander, Bernhard Giesen und Jason L. Mast, S. 91-114. Cambridge et al.: Cambridge University Press.

Alexander, Jeffrey C., und Jason L. Mast. 2006. „Introduction: Symbolic action in theory and practice. The cultural pragmatics of symbolic action." In Social Performance. Symbolic Action, Cultural Pragmatics and Ritual, hrsg. v. Jeffrey C. Alexander, Bernhard Giesen und Jason L. Mast, 1-28. Cambridge et al.: Cambridge University Press.

Baumann, Marc, Martin Langeder, Mauritius Much, Bastian Obermayer und Franziska Storz, Hrsg. 2011. Feldpost. Briefe deutscher Soldaten aus Afghanistan. Reinbek: Rowohlt.

Bliesemann de Guevara, Berit. 2009. Staatlichkeit in Zeiten des Statebuilding. Intervention und Herrschaft in Bosnien und Herzegowina. Frankfurt a. M.: Peter Lang Verlag.

BMVg. 2012. Interview: Schmidt zur Sicherheitslage in Afghanistan. 18. Mai 2012. http://www.bmvg.de/portal/a/bmvg/!ut/p/c4/NYuxDsIwDET yE4_YE GKjlIENVUKlbGk-bRUZ1UhmnLHw8ycCd9IZ7OnxiaXQbBaeUolvwgcN Ex_EDI28BXilLWYEp0lu9UGbs62f2MKXotVJ9VCoM4jQJrEl0qSaLFAM 042Bs2xhr_rHfw_1y7m-7vWmvTYcr8-kHqi0CFQ!!/ (aufgerufen am 20. August 2012).

Bohn, Cornelia, und Alois Hahn. 2000. „Pierre Bourdieu.“ In Klassiker der Soziologie. Band 2: Von Talcott Parsons bis Pierre Bourdieu, hrsg. v. Dirk Kaesler, S. 252-271. München: Beck.

Bourdieu, Pierre. 1983. „Ökonomisches Kapital, kulturelles Kapital, soziales Kapital.“ In Soziale Ungleichheiten, hrsg. v. Reinhard Kreckel, S. 183-198. Göttingen: Schwartz.

Bourdieu, Pierre. 1998. Praktische Vernunft. Zur Theorie des Handelns. Frankfurt a. M.: Suhrkamp.

Bourdieu, Pierre, und Loïc Wacquant. 1992. An Invitation to Reflexive Sociology. Cambridge: Polity Press.

Bündnis 90/Die Grünen. 2010. „30 Grüne Jahre (18): Die Frage der militärischen Gewalt. Nach dem Massaker von Srebrenica 1995." Interview mit Winfried Nachtwei, 6. Juli 2010. http://www.gruene.de/30-gruene-jahre/die-frage-dermilitaerischen-gewalt.html (aufgerufen am 20. August 2012).

Butler, Judith. 2005. „Imitation und die Aufsässigkeit der Geschlechtsidentität.“ In Queer denken: Gegen die Ordnung der Sexualität, hrsg. v. Andreas Kraß, S. 144-168. Frankfurt a. M.: Suhrkamp. 
Calic, Marie-Janine. 1995. „Zehn Thesen über den Zusammenhang von Kultur und Konflikt im ehemaligen Jugoslawien.“ In Der Konflikt der Kulturen und der Friede in der Welt. Wie können wir in einer pluralistischen Welt zusammenleben?, hrsg. v. Jörg Calließ, S. 59-72. Rehburg-Loccum: Loccumer Protokolle 65/95.

Calic, Marie-Janine. 2003. „Explaining Ethnic Violence in BosniaHerzegovina." In Radical Ethnic Movements in Contemporary Europe, hrsg. v. Farimah Daftary und Stefan Troebst, S. 105-130. New York et al.: Berghahn.

Callon, Michel. 2008. „What Does It Mean to Say That Economics Is Performative?" In Do Economists Make Markets? On the Performativity of Economics, hrsg. v. Donald MacKenzie, Fabian Muniesa und Lucia Siu, S. 311-357. Princeton: Princeton University Press.

Diaz-Bone, Rainer. 2006. „Die interpretative Analytik als methodologische Position.“ In Foucault: Diskursanalyse der Politik. Eine Einführung, hrsg. v. Brigitte Kerchner und Silke Schneider, S. 68-84. Wiesbaden: VS Verlag für Sozialwissenschaften.

Fischer, Frank. 2003. Reframing Public Policy. Discursive Politics and Deliberative Practices. Oxford: Oxford University Press.

Goffman, Erving. 1973. Wir alle spielen Theater. Die Selbstdarstellung im Alltag. 2. Aufl. München: Piper.

Goffman, Erving. 1977. Rahmenanalyse. Ein Versuch über die Organisation von Alltagserfahrungen. Frankfurt a. M.: Suhrkamp.

Hettlage, Robert. 2000. „Erving Goffman (1922-1982).“ In Klassiker der Soziologie. Bd. 2: Von Talcott Parsons bis Pierre Bourdieu, hrsg. v. Dirk Kaesler, S. 188-205. München: Beck.

Hobsbawm, Eric. 2008. „Introduction: Inventing traditions” In The Invention of Tradition, hrsg. v. Eric Howbsbawm und Terence Ranger, S. 1-14. Cambridge et al.: Cambridge University Press.

Höpken, Wolfgang. 1997. ,,Blockierte Zivilisierung'? Staatsbildung, Modernisierung und ethnische Gewalt auf dem Balkan (19./20. Jahrhundert)." Leviathan, 25 (4), S. 518-538.

Höpken, Wolfgang. 2000. „Das Dickicht der Kriege. Ethnischer Konflikt und militärische Ge- walt im früheren Jugoslawien 1991-1995.” In Wie Kriege entstehen. Zum historischen Hintergrund von Staatenkonflikten, hrsg. v. Bernd Wegner, S. 319-367. Paderborn et al.: Schöningh.

Hugendick, David. 2010. „Kerner erzählt vom Krieg.“ Die ZEIT online, 17.12.2010. http://www.zeit.de/kultur/film/2010-12/kerner-guttenberg-afghanistan.de (aufgerufen am 20. August 2012). 
Infratest dimap. 2010. Zwei Drittel sehen in Guttenberg ein Vorbild für andere Politiker. http://www.infratest-dimap.de/de/umfragen-analysen/bundesweit/ umfragen/aktuell/zwei-drittel-sehen-in-guttenberg-ein-vorbild-fuer-anderepolitiker/ (aufgerufen am 20. August 2012).

Kahneman, Daniel. 2012. Schnelles Denken, langsames Denken. München: Siedler Verlag.

Keller, Reiner. 2005. Wissenssoziologische Diskursanalyse. Grundlegung eines Forschungsprogramms. Wiesbaden: VS Verlag für Sozialwissenschaften.

Keul, Katja. 2010a. Reisebericht zum Besuch der Bundestagsdelegation mit dem PSts Thomas Kossendey in Afghanistan und anschließender Einzeldienstreise nach Kabul (AFG) 17. bis 20. Oktober 2010. http://katjakeul.de/uploads/media/Katja_Keul_Reisebericht_AFG_Oktober_2010_01.pd f (aufgerufen am 20. August 2012).

Keul, Katja. 2010b. Reisebericht zur Delegationsreise des BMVg (Montenegro, Kosovo und Djibouti) vom 10.-14. Februar 2010. http://katjakeul.de/uploads/media/Katja_Keul_Reisebericht_Februar_2010.pdf (aufgerufen am 20. August 2012).

Keul, Katja. 2012. Reisebericht Afghanistan 13. bis 17. Mai 2012. http://katjakeul.de/userspace/NS/katja_keul/Dokumente_2012_2/120519_Reisebericht_ Katja_Keul_Afgfhanistan_13._-17.05.12.pdf (aufgerufen am 20. August 2012).

Kuhn, Thomas S. 2006. Die Struktur wissenschaftlicher Revolutionen. 2., rev. und um das Postskriptum von 1969 erg. Aufl. Frankfurt a. M.: Suhrkamp.

Lepsius, Oliver, und Reinhart Meyer-Kalkus, Hrsg. 2011. Inszenierung als Beruf. Der Fall Guttenberg. Berlin: Suhrkamp.

Lowi, Theodore J. 1972. „Four Systems of Policy, Politics and Choice.“ Public Administration Review (Juli/August), S. 298-310.

Maier, Matthias Leonhard, und Achim Wiesner. 2007. „Politik und Wissen.“ In Handbuch Wissenssoziologie und Wissensforschung, hrsg. v. Rainer Schützeichel, S. 613-622. Konstanz: UKV.

Nullmeier, Frank. 2006. „Politikwissenschaft auf dem Weg zur Diskursanalyse?“ In Handbuch Sozialwissenschaftliche Diskursanalyse. Band 1: Theorien und Methoden. hrsg. v. Reiner Keller, Andreas Hierseland, Werner Schneider und Willy Viehöver, S. 287-313. Wiesbaden: VS Verlag für Sozialwissenschaften.

Ridderhof de Wilde, Mandy. 2012. „,Getting into the spirit“: Performing Community in Policy Practice" Unveröffentlichtes Papier, 7th International Conference in Interpretive Policy Analysis, Tilburg, 5.-7. Juli. 
Rüb, Friedbert W. 2006. „Wissenspolitologie.“ In Methoden der Politikwissenschaft. Neuere qualitative und quantitative Analyseverfahren, hrsg. v. Joachim Behnke, Thomas Gschwend, Delia Schindler und Kai-Uwe Schnapp, S. 345-354. Baden-Baden: Nomos.

Schwab-Trapp, Michael. 2004. „Methodische Aspekte der Diskursanalyse. Probleme der Analyse diskursiver Auseinandersetzungen am Beispiel der deutschen Diskussion über den Kosovokrieg." In Handbuch sozialwissenschaftliche Diskursanalyse. Band 2: Forschungspraxis, hrsg. v. Reiner Keller, Andreas Hierseland, Werner Schneider und Willy Viehöver, S. 169-195. Wiesbaden: VS Verlag für Sozialwissenschaften.

Schwab-Trapp, Michael. 2011. „Diskurs als soziologisches Konzept. Bausteine für eine soziologisch orientierte Diskursanalyse." In Handbuch Sozialwissenschaftliche Diskursanalyse. Band 1: Theorien und Methoden, hrsg. v. Reiner Keller, Andreas Hierseland, Werner Schneider und Willy Viehöver, S. 283307. Wiesbaden: VS Verlag für Sozialwissenschaften.

Süddeutsche Zeitung. 2010. „Guttenberg in Afghanistan: Staatsschauspieler ohne Gespür.“ Süddeutsche.de, 14. Dezember 2010. http://www.sueddeutsche .de/politik/2.220/guttenberg-in-afghanistan-reaktionen-staatsschauspieler-ohn e-gespuer-fuer-grenzen-1.1035889 (aufgerufen am 20. August 2012).

Travers, Max. 2004. „The Philosophical Assumptions of Constructionism.” In Social Constructionism in Housing Research, hrsg. v. Keith Jacobs, Jim Kemeny und Tony Manzi, S. 14-31. Aldershot: Ashgate. 



\title{
„Durchbruch“ zur „Trendwende“?
}

\author{
Eine Analyse des Fortschrittsberichts Afghanistan 2010 \\ der Bundesregierung im nationalen und internationalen \\ Kontext
}

\section{VANESSA JANZEN}

Blickt man in die Afghanistanliteratur der letzten vier Jahre, trifft man auf Titel wie „Ruhet in Frieden, Soldaten! - Wie Politik und Bundeswehr die Wahrheit über Afghanistan vertuschten“ (Reichelt und Meyer 2010), „Die afghanische Misere“ (Mercy 2008), „Afghanistan: Ein Krieg in der Sackgasse“ (Becker und Wulf 2010) und „Unter Beschuss - Warum Deutschland in Afghanistan scheitert" (Lindemann 2010). Alle Titel implizieren eine irgendwie ausweglose Pattsituation nach zehn Jahren internationalem Einsatz in Afghanistan und beinhalten Kritik an der fehlenden Kenntnis der Umstände der deutschen bzw. internationalen politischen Akteure zum Zeitpunkt der Intervention in die Region im Jahr 2001.

Mangelnde Sachkenntnis und Information zu Afghanistan und zum Kontext des Auslandseinsatzes waren seit der ersten Petersberg-Konferenz im Dezember 2001 auf allen Ebenen offensichtlich. Die ersten gefallenen deutschen Soldaten ab 2005, der Totenschädelskandal im Jahre 2006 und die Kunduz-Affäre im Jahre 2009, führten zu einem Stimmungsumschwung in der deutschen Öffentlichkeit. Die Wahrnehmung des Einsatzes wandelte sich: Aus Desinteresse und Unkenntnis wurden Unverständnis, Empörung und Ablehnung des deutschen Bundeswehreinsatzes und mit jeder Mandatsverlängerung wuchs die Kritik an der regierungsamtlichen Nicht-Äußerung.

Die „Wende“ kam im Dezember 2010, als der Erfolg der integrierten Aufstandsbekämpfung (COIN) noch sehr im Vagen lag. Zu diesem äußerst späten Zeitpunkt versuchte das Auswärtige Amt der Kritik mit der Veröffentlichung ei- 
nes umfangreichen Regierungsdokumentes gegenzusteuern: So erschien einen Monat vor der benötigten zwölften Mandatsverlängerung des Bundeswehreinsatzes in Afghanistan der erste „Fortschrittsbericht Afghanistan 2010 - zur Unterrichtung des Deutschen Bundestages“ (im Folgenden mit ,F' abgekürzt). Zehn Jahre nach der Petersbergkonferenz, welche die Entsendung von NATO-Truppen nach Afghanistan ebnete, war dieser Bericht die erste umfassende, öffentliche Bestandsaufnahme des Afghanistaneinsatzes durch die deutsche Bundesregierung (BR). Die Wortwahl „Fortschrittsbericht“ ist ähnlichen Dokumenten anderer NATO-Staaten entnommen und impliziert eine eindeutige Verbesserung der Sicherheitslage und der Lebensbedingungen für die afghanische Bevölkerung. Dieser Duktus steht im starken Gegensatz zu dem späteren Trendwechsel in der Einsatzdefinition des Verteidigungsministers Thomas de Maizière, der kurz nach seiner Amtsübernahme im März 2011 verkündete, man agiere in Afghanistan „wie im Krieg“ (Frankfurter Rundschau 28. März 2011, 12). Diese Ambivalenz zieht sich durch den gesamten F, welcher im Bundestag (BT) am 16. Dezember 2010 von Außenminister Guido Westerwelle vorgestellt wurde. Federführend bei der Berichterstellung war das Auswärtige Amt unter der Leitung von Botschafter Michael Steiner, dem damaligen Sonderbeauftragten der BR für Afghanistan und Pakistan. Das BMI, BMZ und das BMVg wurden eng in den Arbeitsprozess mit einbezogen. Rund 100 MitarbeiterInnen aus den genannten Ministerien, der Botschaft in Kabul, der PRTs, deutsche VertreterInnen in den internationalen Stäben und weitere ExpterInnen waren an dem Dokument beteiligt.

Die BR erweckt durch das gesamte Dokument hindurch den Anschein einer schonungslosen und realistischen Selbstkritik, ohne jedoch von ihrem Optimismus abzulassen:

„Das deutsche Engagement in Afghanistan hat im Zuge seiner Anpassungen an die Herausforderungen des Einsatzes wirksame neue Instrumente der zivilmilitärischen $\mathrm{Zu}$ sammenarbeit in Konfliktgebieten hervorgebracht, angesichts der anfänglichen Erfolge jedoch zuweilen auch unrealistische Zielsetzungen [...] Das Jahr 2010 könnte jedoch auch als Wendepunkt betrachtet werden." (F 5, Hervorhebung durch die Autorin) ${ }^{1}$

Der F wurde bei seiner Veröffentlichung zunächst dankbar aufgenommen und die öffentliche Kritik hielt sich in Grenzen, da die Erstellung des Berichts allein schon einen Fortschritt in der Kommunikation darstellte, wenn es schon keinen in Afghanistan gab. Man könnte ironisch sagen, dass dies die eigentliche und

1 Zitate aus dem Fortschrittsbericht werden im Folgenden mit (F Seitenzahl) belegt. 
einzige Trendwende markierte. Durch eine einseitige Betrachtungsweise und die nicht ausreichend begründete Vorhersage einer Trendwende in Afghanistan, beförderte sich die BR so jedoch noch tiefer in die spätestens seit der KunduzAffäre im September 2009 bestehende Legitimationskrise.

\section{ForschungsfRAGE, HYPOTHESEN UND METHODISCHES VORGEHEN}

Dieser Beitrag unterzieht F einer diskurszentrierten Analyse. Die übergeordnete Forschungsfrage lautet: Welche Funktion erfüllt der „Fortschrittsbericht Afghanistan 2010 der Bundesregierung " im nationalen und internationalen Kontext? Die Analyse des F dient folglich der Herausarbeitung möglicher Effekte, die die BR mit der Veröffentlichung dieses Dokuments erzielen wollte. Zwei Hypothesen stehen im Mittelpunkt der Analyse:

Hypothese I: Auf nationalem Niveau soll der Bericht die Zustimmung der deutschen Bevölkerung zum militärischen Einsatz festigen, also dessen Legitimation erhöhen.

Hypothese II: Auf internationalem Niveau dient der Bericht der Festigung einer bedeutenden deutschen Stellung in der Weltpolitik.

Die Analyse des F reiht sich ein in die Fragen rund um den Heimatdiskurs und stellt ein kleines Element im noch andauernden Forschungsprozess dar. Da es sich bei dem F um ein Regierungsdokument handelt, wird in diesem Artikel hauptsächlich die Seite des Diskurses der BR beleuchtet. Im Fokus der Analyse liegt die Selbstdarstellung der BR und die Kritik des eigenen Regierens mit besonderem Fokus auf den Auslandseinsatz.

Der F wird in drei aufeinanderfolgenden Analyseschritten bearbeitet. (1) Zunächst wird eine grobe Zusammenfassung des Inhalts gegeben. (2) In einem zweiten Schritt erfolgt eine ideologiekritische Betrachtung des Berichts. Hierbei werden gruppenspezifische Interessen der BR kritisch hinterfragt. Laut Gerhard Hauk bringt Ideologiekritik zwar nicht die besseren Argumente hervor, kann jedoch aufdecken, welche Einflüsse eine Interessensgruppe davon abhalten, die besseren Argumente zu vertreten (Hauk 1992: 120). Die Ideologiekritik ist demnach keine Polemik gegenüber dem F, sondern zeigt auf, an welchen Stellen des Berichts die spezifischen Interessen der BR besonders deutlich sichtbar werden. (3) In der anschließenden Diskursanalyse werden Diskursstränge und Fragmente basierend auf der Methode von Keller (2011) herausgearbeitet. Der Abschnitt fasst die beobachteten Ergebnisse zusammen und verdeutlicht sie mit Beispielen 
aus dem Fließtext. Siegfried Jägers Begriffsdefinitionen zur Diskursanalyse, Diskursstrang und Diskursfragment, werden verwendet, um die Beobachtungen zu strukturieren und verständlich zu machen. Die Diskursanalyse legt Subtexte auf, die im Bericht auf den ersten Blick nicht sichtbar sind. So wird das „diskursive Gewimmel“" (Jäger 2001: 84) geordnet. Im Gegensatz zur Ideologiekritik wendet sich die Diskursanalyse von den akteursspezifischen Interessen der BR ab und einem weiter gefassten Blickwinkel zu, der die im Text verborgenen Botschaften zu entschlüsseln hilft.

\section{INHALTE DES FORTSCHRITTSBERICHTS}

Der Bericht zeichnet durch die Missstände und Rückschritte zwar kein positives Bild der Lage in Afghanistan, vermittelt aber dennoch einen optimistischen Blick in die zukünftige Entwicklung des Landes. Durch die Ankündigung einer Trendwende ab Ende 2010 scheint bei weiterlaufender internationaler Anstrengung und durch intensive Mitarbeit der afghanischen Regierung ein Erfolg möglich.

Die Struktur des Fortschrittsberichts Afghanistan 2010 ist gegliedert in drei Hauptabschnitte: (1) Sicherheit, (2) Staatswesen und Regierungsführung, (3) Wiederaufbau und Entwicklung. Hierbei orientiert sich der Bericht an international abgestimmten Schemata (F 4), vor allem an den Fortschrittsberichten der US-Regierung. ${ }^{2}$

Die Unterkapitel geben ihr Themenfeld zunächst im geschichtlichen Kontext wieder, zeigen Fort- und Rückschritte auf, nehmen Bezug auf von der afghanischen Regierung durchgeführte oder angestrebte Reformen und stellen durch das AA, BMI, BMZ und des BMVg geleitete oder finanzierte Projekte vor. Hierbei werden auch die jeweils verwendeten finanziellen Mittel aufgezeigt. Erfolge und Fortschritte werden zumeist durch die Anstrengungen und Maßnahmen der internationalen Gemeinschaft begründet, während die Verantwortlichkeit für Rückschritte hauptsächlich der afghanischen Regierung und den Behörden zugeschrieben wird.

2 Das US-Verteidigungsministerium bringt seit Juni 2008 im viertel- bis halbjährlichen Rhythmus einen sehr umfangreichen Fortschrittsbericht mit dem Namen „Report on Progress towards Security and Stability in Afghanistan“ heraus. Ähnliche Dokumente werden seit 2008 auch von der Regierung Kanadas (,Quarterly Reports to the Parliament: Canada's Engagement in Afghanistan“) und seit 2010 von der britischen Regierung (,Operations in Afghanistan“) angefertigt. 
In der Einleitung des Berichts gibt die BR als Grund und Zweck der Erstellung die Notwendigkeit einer umfassenden Bestandsaufnahme des deutschen Engagements in Afghanistan an. Der Einsatz ist ihrer Meinung nach ein Beitrag zur Sicherheitsvorsorge gegen den internationalen Terrorismus und islamistischen Extremismus (F 4).

(1) Im Bereich Sicherheit gibt es laut BR eine stetige Verschlechterung der Sicherheitslage, es zeichnet sich jedoch Ende 2010 eine Trendwende ab. Das Versöhnungsprogramm mit den Aufständischen läuft an und die afghanische Armee verbessert sich stetig. Außerdem bekommt die NATO durch die neue ISAF-Strategie mit einer Aufstockung der Truppenstärke auf ca. 133.000 Mann die Lage allmählich unter Kontrolle. Auch wenn die Zahl der sicherheitsrelevanten Zwischenfälle und die Zahl der Gefallenen so hoch sind wie nie zuvor, ist nach Meinung der BR davon auszugehen, dass das Jahr 2010 einen Wendepunkt darstellt (F 9).

Der Bericht geht außerdem auf die Situation im Norden des Landes und somit dem Verantwortungsbereich der deutschen Kräfte ein. Auch wenn der Norden im regionalen Vergleich eine relativ ruhige Region darstellt, hat sich auch hier die Lage verschlechtert.

Die Ausbildung der afghanischen Sicherheitskräfte verläuft dennoch besser als geplant. Quantitative Vorgaben sind sowohl bei der Polizei als auch bei der Armeeausbildung frühzeitig erreicht worden. Ein langfristiges Engagement ist laut BR in diesem Bereich jedoch weiterhin notwendig, um eine erfolgreiche „Übergabe in Verantwortung“ im Jahr 2014 zu gewährleisten (F 19, 22, 26).

Im Bereich internationaler Kooperation ist ein vernetzter Ansatz (Comprehensive Approach), der zivile und militärische Elemente miteinander verbindet, in Afghanistan unabdinglich (F 31). Im Zuge der Transition wird Deutschland nicht mehr benötigte Fähigkeiten ab Ende 2011 abbauen. Die Vereinbarung des Inteqal-Prozesses wird von der BR als „Durchbruch“ für die künftige Entwicklung des internationalen Engagements gewertet, da sie den Abzug ausländischer Militärs determiniert.

(2) Unter Staatswesen und Regierungsführung wird die Regierungsführung Karzais in den letzten zehn Jahren evaluiert. Die vier bisher stattgefundenen Wahlen (sowohl Präsidentschafts- als auch Parlamentswahlen) und deren landesweiten Durchführungen, werden im Bericht als Erfolge gewertet. In Kombination mit willkürlichen Entscheidungsprozessen und personellen Engpässen zeichnet sich jedoch ein Vertrauensverlust seitens der afghanischen Bevölkerung, und somit eine Delegitimierung der Zentralregierung in Kabul, ab. Der F bewertet die 
durch die Zentralregierung ausgeübte Kontrolle auf die Provinzen als unzureichend. (F 45)

Im Bereich der Menschenrechte erklärt der Bericht, dass im Gegensatz zu der Zeit der Talebanherrschaft schon bedeutsame Fortschritte erzielt worden sind. Internationalen Standards entspricht die Situation laut BR jedoch noch nicht. Die Lage zeigt vor allem Mängel in den Bereichen der Strafverfolgung und der Rechtsstaatlichkeit. Rückschritte sind nicht ausgeschlossen. (F 55)

(3) Im dritten Teil des F, Wiederaufbau und Entwicklung, wird zu den Sektoren Wirtschaft, Gesundheit und Bildung Bilanz gezogen. Die Wirtschaft hat sich dynamisch entwickelt, bleibt mit einem Handelsbilanzdefizit von 3,3 Mrd. USDollar aber weiterhin von Importen abhängig. Infrastrukturmaßnahmen sind im großen Maße durchgeführt worden. Der Bericht beurteilt die Fortschritte bei der Trinkwasser- und Energieversorgung sowie bei dem Ausbau der Verkehrswege als erheblich. Das Gesundheitswesen in Afghanistan bleibt ungenügend mit erheblichen Defiziten in allen Bereichen; steigende Impfraten und sinkende Sterberaten (Mütter- und Säuglingssterblichkeit) implizieren jedoch eine langsame Verbesserung (F 97). Zum Thema Bildung fügt der F hinzu, dass sich vor allem für Mädchen und Frauen der Zugang zur Grundbildung ,grundlegend geändert“ hat (F 93), da sie unter der Talebanherrschaft vom Bildungswesen komplett ausgeschlossen waren. In der Berufs- und Erwachsenenbildung gibt es jedoch noch einen beachtlichen Rückstand im Bezug auf fehlende Studienplätze und Lehrende sowie im Hinlick auf einen gleichberechtigten Zugang von Männern und Frauen.

Zuletzt thematisiert der F den gesellschaftlichen Wandel in Afghanistan. Der stark traditionell-konservativen Bevölkerung tritt eine große Anzahl junger AfghanInnen gegenüber, die teilweise im Ausland gelebt haben, moderne Medien konsumieren und so große Erwartungen an die Zukunft hegen. Bei Enttäuschung dieser Hoffnungen droht eine Abkehr in die Radikalisierung (F 100).

Am Ende des Dokuments wird mit Hinblick auf die internationale Unterstützung in Afghanistan noch einmal betont, dass die aufgezeigten Fortschritte nur durch internationale Hilfe geschehen konnten und diese deshalb noch für einen langen Zeitraum notwendig sind. Damit dieser positive Trend weiter verfolgt werden kann, muss die afghanische Regierung laut BR weitere Anstrengungen unternehmen und die Hilfe auf afghanische Bedürfnisse abgestimmt werden (F 102). 


\section{IDEOLOGIEKRITIK}

Die Journalistin Christiane Hoffmann kritisierte nach Veröffentlichung des Fortschrittsberichts 2010, dass ein Dokument, welches den Begriff „Fortschritt“ im Titel trägt, eine unvoreingenommene Prüfung der Lage in Afghanistan und des Handelns der BR von vornherein ausschließe (FAZ Dezember 2010). Um zu verstehen, warum das Dokument diesen Titel trägt und ein Aufzeigen der Fortschritte aus Sicht der BR notwendig war, muss zunächst die BR als Akteur und Gruppe mit den dazugehörigen gruppenspezifischen Interessen und Handlungsmustern genauer betrachtet werden. Die BR ist in einer Machtposition und somit daran interessiert, diese Macht zu erhalten. In einem demokratischen System wird die Regierung durch Wahlen legitimiert. Herfried Münkler (Münkler 2006: 338) und Ulf von Krause (2011: 207) stellen fest, dass die deutsche Bevölkerung Krieg grundsätzlich ablehnend gegenüber steht und so denjenigen wählt, der Krieg verhindert und Frieden und Sicherheit gewährleistet.

Der Einsatz wurde bis zum Jahre 2007 einseitig dargestellt. Damals kam dem Afghanistaneinsatz noch keine große mediale und öffentliche Aufmerksamkeit $\mathrm{zu}$ und die BR stand so nur bedingt unter öffentlichem Rechtfertigungszwang: So lange keine Schreckensnachrichten bei der Bevölkerung ankamen, konnte die BR das Bild eines „Entwicklungshelfers in Uniform“ aufrechterhalten. Mit steigender Aufmerksamkeit, häufigeren Todesopfern unter den deutschen Soldaten und der Kunduz-Affäre im Jahr 2009 wurde Aufklärung und eine abweichende Positionierung der Machthaber zu der harmlosen Darstellung des Afghanistaneinsatzes notwendig. Um die Legitimierung des Einsatzes durch den BT und die Bevölkerung weiterhin zu gewährleisten, musste ein Dokument geschaffen werden, welches umfangreiche Informationen zur Lage und zum Einsatz bot, nicht mehr beschönigte und gleichzeitig eine positive Tendenz in der Entwicklung aufzeigte. Denn bei $62 \%$ Zuspruch für einen Truppenabzug unter der deutschen Bevölkerung (Forsa April 2010) konnte Zustimmung nur noch durch eine Trendwende in die ,richtige“ Richtung erreicht werden. Eine Zustimmung war wiederum notwendig, um auf internationaler Ebene im Sicherheitsrat und als Bündnispartner in der NATO die übernommenen Pflichten weiterhin bewerkstelligen zu können und so eine einflussreiche Stellung auf internationaler Ebene zu bewahren (siehe auch Al-Ahmad et al. in diesem Band). So ist zu erklären, dass der Bericht zwar einerseits auf viele Missstände und Verschlechterungen hinweist, andererseits jedoch trotzdem von einer Trendwende ausgeht.

Die BR befindet sich in ihrer gruppenspezifischen Rolle in einem Spannungsfeld wieder: Einerseits muss sie zum Machterhalt ihre Kompetenz beweisen und zeigen, dass sie dazu fähig ist, positive Veränderungen in Afghanistan 
zu erreichen, andererseits wird ihr Handelsspielraum durch unterschiedliche Akteure beschränkt (NATO, Ressourcen, Zustimmung der Bevölkerung und des Bundestages). Dieses Spannungsfeld wird im Folgenden beispielhaft durch die genauere Betrachtung von Adressat, Widersprüchen, nicht belegten Behauptungen und einer Analyse der Quellenlage im F verdeutlicht:

Laut Einleitung wurde der Bericht auf Wunsch des Bundestages erstellt. Es handelt sich jedoch um ein Dokument, das sowohl Abgeordnete also auch die Allgemeinheit informieren soll. Das Lesen wird einem in der Einleitung leicht gemacht. Sie fasst grob die Ergebnisse des Berichts zusammen. Schlüsselwörter sind im F fett hervorgehoben: „Terrorangriffe“, „Bedrohung “, „, Sicherheitslage“, „Wendepunkt“, „Trendwende“, ,Transitionsprozess“, ,langfristige Aufgabe“ (F 5). Sie vermitteln so vor allem in der Zusammenfassung des Abschnitts der Sicherheitslage eine politisch klare Botschaft an den Bürger und bilden die Hauptargumentationslinie der BR: Die Terrorangriffe vom 11. September 2001 haben die Welt erschüttert und auch uns (die Deutschen) in eine Lage der potentiellen Bedrohung versetzt. Der Einsatz in Afghanistan war (deshalb) erforderlich. Die Sicherheitslage in Afghanistan hat sich zwar verschlechtert, es zeichnen sich jedoch ein Wendepunkt und eine Trendwende ab. Somit kann der Transitionsprozess begonnen werden, auch wenn eine Übergabe der Sicherheitsverantwortung die Deutschen von einem langfristigen Engagement nicht entbindet.

Die Einleitung des Berichts gibt somit anscheinend alle wichtigen Informationen, die einen kritischen Bürger interessieren: Warum sind wir in Afghanistan? Lohnt sich ein Engagement für die deutsche Bevölkerung? Sterben viele deutsche Soldaten/innen? Was passiert mit meinen Steuern / wie viel wird mich der Einsatz kosten? Wann wird Deutschland seine Truppen abziehen? Die letzte Frage ist besonders interessant, denn zum ersten Mal wird in einem offiziellen Dokument der BR auf einen möglichen Abzug eingegangen.

Man kann den $\mathrm{F}$ also aus ideologiekritischer Perspektive als politische Schrift an die BürgerInnen betrachten, die in ihrer Einleitung eine politische Botschaft übermittelt, welche durch die darauffolgende Analyse in den drei Teilbereichen Sicherheit, Staatswesen und Regierungsführung sowie Wiederaufbau und Entwicklung unterfüttert wird. Nach anfänglichem Desinteresse während der ersten sieben Einsatzjahre ist die deutsche Bevölkerung besorgt und verärgert und möchte endlich verstehen, was in Afghanistan eigentlich geschieht (Von Krause 2011: 152f). Sie soll durch den Bericht davon überzeugt werden, dass Verbesserung und Fortschritt greifbar sind.

Widersprüche und Behauptungen sind schwer zu identifizieren, da Informationen selten mit Quellenverweisen versehen wurden. Dennoch lassen sich vor 
allem im ersten Teil des Berichts, Sicherheit, markante Widersprüche und Behauptungen finden, die hier exemplarisch angesprochen werden.

Im Kapitel 1 zur Sicherheitslage im gesamten Land wird wiederholt davon gesprochen, dass der Abwärtstrend in der Sicherheitslage Ende 2010 erstmals gestoppt sei und es Grund zur Hoffnung auf Verbesserung gebe. Die folgenden 10 Seiten geben dann jedoch ein ganz anderes Bild der Lage ab: Im selben Kapitel steht, dass das Jahr 2010 das verlustreichste Jahr auf allen Seiten war und der Süden, Südwesten und Osten des Landes weiterhin sehr unruhig seien. Im Kapitel 2 zur Sicherheitslage im ISAF Regionalkommando Nord heißt es weiterhin, dass eine Trendwende ungewiss sei, was sich frühestens im Frühsommer 2011 zeigen werde. Eine schlecht lesbare Grafik auf Seite 15 veranschaulicht die Bewegungsfreiheit der Entwicklungshelfer im Norden von Afghanistan. Nur in der Hälfte der Distrikte im Norden könnten sich die Entwicklungshelfer bei Tageslicht voll bewegen. Diese Darstellung stellt in Frage, was in Kapitel 3 der angebliche Zurückgewinn der Initiative von ISAF und ANSF gegenüber der Insurgenz $\mathrm{zu}$ bedeuten hat. Es wird in dem Kapitel 3 in keinem weiteren Wort auf diese Aussage eingegangen. Die zwei Aussagen zum gestoppten Abwärtstrend und zur zurückgewonnenen Initiative decken sich also nicht mit den sehr negativen Darstellungen der Sicherheitslage. Zwar wird im Kapitel 2 bezüglich der Nordregion als positives Beispiel die Eroberung des Distrikts Chahar Darrah genannt, dieses einzige erfolgreiche Ereignis passierte jedoch einen Monat (November 2010) vor Herausgabe des F; ein Halten des Distriktes konnte nach so kurzer Zeit noch nicht garantiert werden.

In F 12 wird weiterhin behauptet, dass die hohe Truppenstärke und die zunehmende Professionalisierung der ANSF begründete Erwartungen dafür geben, dass es zu einer nachhaltigen Stabilisierung kommen werde. Gleichzeitig wird aber auch festgestellt, dass die ersten Truppen ab Ende 2011 abziehen werden und dass bei der Ausbildung der ANSF quantitative Ziele zwar erreicht würden, es aber vor allem noch an der notwendigen Qualität der Ausbildung und Loyalität zur Zentralregierung fehle. Die begründete Erwartung kann man somit bestenfalls als Hoffnung bezeichnen. Auch im Kapitel 7 zum Beitrag der Staatengemeinschaft zur Stabilität und Sicherheit wird ein weiteres Mal versucht, eine positive Tendenz zu beweisen, die nicht sichtbar ist: Im Norden würden die Neuausrichtung der deutschen Truppen, die bedeutende Unterstützung von ca. 5000 US-Soldaten und zusätzliche Fähigkeiten „,beginnen erste Wirkung zu entfalten." (F 32) Diese Behauptung wird ohne faktischen Beleg in den Raum gestellt.

Im Kapitel 3 des F zur „Bedrohung durch regierungsfeindliche Kräfte“ wird deutlich, wie sich die Verfasser im Ringen um eine plausible Rechtfertigung des 
Einsatzes in Widersprüche verstricken. Wird der Einsatz in der Einleitung zunächst mit dem 11. September 2001 und somit als Intervention zur Bekämpfung der terroristischen Organisation Al Qaida begründet, wird im Kapitel 3 eingeräumt, dass sich Al Qaida-Kämpfer kaum noch auf afghanischem Boden befinden würden, was dem noch anhaltenden Einsatz somit Legitimation entzieht. Die BR „rettet“ ihre Argumentation dann allerdings unter Heranziehung des Haqqani-Netzwerks, welches im Jahre 2009 einen Anschlag auf die deutsche Botschaft verübte und „nachweislich auch Verbindungen zu Al-Qaida“ (F 17) unterhalte. Außerdem würde auch die Islamische Bewegung Usbekistan (IBU) Deutschland durch islamistischen Terrorismus bedrohen. Beispiele oder Präzisierung dieser Behauptungen bleiben aus, das Feindbild und somit auch die Legitimationsgrundlage des Einsatzes können auf diese Weise jedoch aufrechterhalten werden.

Zum Thema Demokratisierung sieht Kapitel 10 die viermalige Durchführung von landesweiten Wahlen in den letzten zehn Jahren als beachtlichen Fortschritt an. Auch wenn der F nicht leugnen kann, dass es im Jahre 2009 und 2010 zu erheblichen Mängeln und Wahlbetrug kam, seien die Wahlen aber dennoch in Anbetracht der erschwerten Sicherheitslage für die Demokratisierung des Landes ein Erfolg gewesen. Es bleibt folglich problematisch von einer Festigung demokratischer Strukturen zu sprechen, vor allem, wenn Karzai verfassungswidrig ein Sondertribunal einsetzt, um vermeintliche Wahlbetrüger zu ahnden und so das Parlament nach seinem Belieben neu zusammensetzt (International Crisis Group 2011: 2). Das Verhältnis zwischen „hinnehmbarer“ Korruption und Wahlen in einer sich entwickelnden Demokratie wird nicht problematisiert.

In Kapitel 11 wird die Kontrolle der Zentralregierung über die Provinzen als unzureichend beschrieben und behauptet, die Übergabe der Sicherheitsverantwortung werde hier Handlungsdruck erzeugen. Diese Aussage impliziert, dass sich durch den Zeitdruck des Transitionsprozesses bald etwas ändern werde. Einen Absatz weiter wird jedoch beschrieben, dass die Zentralregierung die Provinzen im geschichtlichen Verlauf des Landes nie vollständig unter Kontrolle hatte und Präsident Karzai gar keinen Wert darauf lege, sein klientelistisches Verhalten gegenüber den Provinzen zu ändern. Es fällt also schwer anzunehmen, dass sich innerhalb der nächsten vier Jahre viel verändern wird, wenn man sich auf die Zentralregierung und die Provinzgouverneure verlässt. Der Handlungsdruck wird sich folglich eher auf die internationale Gemeinschaft übertragen. Forschungen haben gerade für den Nordosten belegt, dass auf Dorf- und Distriktebene (und nicht auf Provinzebene) selbstorganisierte Kommunikation und Governance erfolgreich durchgeführt werden können, was nicht unbedingt eine Stärkung der Zentralregierung bedeutet (vgl. Koehler 2011). 
In Kapitel 17 wird behauptet, dass im Justizsystem eine Richtungsveränderung deutlich spürbar sei. Wenn aber eine Seite weiter davon gesprochen wird, dass $80 \%$ der Bevölkerung weiterhin Stammes- und Dorfräte bevorzugen weil die staatlichen Gerichtshöfe korrupt und willkürlich handeln, lässt sich ein Wechsel in eine andere Richtung schwer erkennen. Es wird weiterhin von einem massiven Aufbau der Unterstützung zur Verbesserung des Justizwesens ab 2007 gesprochen, nachdem es ab 2002 zunächst schleppend anlief. Bei den vorgestellten Projekten datiert aber lediglich eines aus der Zeit nach 2007.

Weiterhin auffällig ist, dass in den Kapiteln, in denen es an klar erkennbaren Fortschritten und Projektergebnissen mangelt, zurzeit durchgeführte Projekte und bereitgestellte Finanzmittel aufgezählt werden. Dies soll einen Fortschritt implizieren der faktisch noch nicht messbar ist und lässt sich vor allem in dem zweiten Teil Staatswesen und Regierungsführung beobachten. Mit Ausnahme von drei Kapiteln ${ }^{3}$ zeigt ein Mangel an explizit genannten Ergebnissen ein großes Defizit im Bereich Good Governance auf, welches der Bericht durch angeblich erfolgreiche Projekte und Finanzstützen abzumildern versucht. Positiv ist in diesem Zusammenhang allerdings anzumerken, dass der dritte Teil Wiederaufbau und Entwicklung auf eine differenzierte Darstellung expliziter Ergebnisse Wert legt und somit ein Erkennen des Fortschritts erleichtert.

Außerdem für die ideologiekritische Analyse interessant ist die Frage nach der Verwendung von empirischen Daten im Dokument. Dies findet vor allem durch die Einbettung von Zahlen im Fließtext statt. Bei der Analyse des Fortschrittberichts zeigt sich jedoch, dass die wenigen ausführlichen, empirischen Stellen meistens auf negative Entwicklungen hinweisen. ${ }^{4}$ Eine solche Beobachtung könnte erklären, dass auf weitere umfangreiche Auswertungen von Zahlen und Daten verzichtet wurde, um den Anschein des Fortschritts nicht zu gefährden.

Zusammenfassend lässt sich sagen, dass sich vor allem in den Teilen 1 und 2 viele Widersprüche und Behauptungen aufdecken lassen, die für eine ideologiekritische Betrachtung des Berichts als Bemühung der BR zur Darstellung ihrer Fähigkeiten und Kompetenz zum Machterhalt spricht. Wo richtige Ergebnisse fehlen, wird Fortschritt durch Scheinerfolge und Projektbeschreibungen suggeriert. Gleichzeitig wird auf Missstände hingewiesen. Diese Beobachtung lässt auf zunehmenden Druck durch die deutsche Öffentlichkeit schließen, der die BR zu

3 Kapitel 13 „Ansehen der Regierung bei der Bevölkerung“, 17 „Justizwesen“, 18 „Bekämpfung der Korruption“.

4 Beispiele hierfür auf S. 10 Sicherheitsrelevante Zwischenfälle, S. 51 Ruf der Regierung, S. 71 Korruption, S. 76 Drogenanbau. 
einer genaueren Berichterstattung veranlasste, ohne jedoch von dem Fortschrittsgedanken abzulassen.

\section{Diskursanalyse}

Die folgende Diskursanalyse legt Subtexte offen, die für den Leser des F auf den ersten Blick schwer zu erkennen sind. Sie dekonstruiert den Text mit dem Ziel, die Ergebnisse der Ideologiekritik zu überprüfen und weitere Subtexte zu verdeutlichen. Hierfür wird die Methode der qualitativen Kodierung angewendet, bei der einzelne Textpassagen begrifflich verdichtet werden. Während des Prozesses der Kodierung werden Kommentare hinzugefügt, die die Benennung des Kodes sowie die Zuordnung zur Textpassage erklären. In einem nächsten Schritt werden die gesammelten Daten in einer Matrix erfasst, um den roten Faden zu rekonstruieren. Diskurse unterteilen sich in Stränge und Fragmente: Ein Diskursstrang ist ein thematisch einheitlicher Diskursverlauf im gesellschaftlichen Gesamtdiskurs. Er besteht aus unterschiedlichen Fragmenten, die Unterthemen des Stranges behandeln. Der nun folgende Abschnitt fasst die Ergebnisse der Diskursanalyse des F zusammen und nennt zur Veranschaulichung der Diskurse einige Beispiele aus dem Regierungsdokument.

Während der Analyse wurden die Diskursstränge „Legitimation“, ,Eigenverantwortung“, „Good Enough Governance“, „Global Player“ und „Gender“ herausgearbeitet. Sie teilen sich in folgende Diskursfragmente: 
Tabelle 1: Diskursstränge und -fragmente im Fortschrittsbericht 2010

\begin{tabular}{|l|l|}
\hline Diskursstrang & Diskursfragment \\
\hline Legitimation & $\begin{array}{l}\text { Bedrohung } \\
\text { State-Building } \\
\text { Kompetenz } \\
\text { Freund und Helfer } \\
\text { Internationale Gemeinschaft }\end{array}$ \\
\hline Eigenverantwortung & $\begin{array}{l}\text { Komplexität } \\
\text { Bewusstseinswandel }\end{array}$ \\
\hline Good Enough Governance & Keine Fragmentierung \\
\hline Global Player & $\begin{array}{l}\text { Verpflichtung } \\
\text { Größe } \\
\text { Leitnation }\end{array}$ \\
\hline Gender & Keine Fragmentierung \\
\hline
\end{tabular}

\section{Diskursstrang „Legitimation“}

Der Diskursstrang „Legitimation“ ist im Bericht am umfassendsten und sehr fragmentiert vertreten. Die Rechtfertigung des Einsatzes und der deutschen Präsenz in Afghanistan nehmen so den Hauptteil des Berichts ein. Während der Analyse wurden die fünf Fragmente „Bedrohung“, „State Building“, „Kompetenz“, „Freund und Helfer“" sowie „Internationale Gemeinschaft“ herausgearbeitet.

\section{a) Diskursfragment „Bedrohung“}

Wie auch schon in der Ideologiekritik erwähnt, wird der deutsche Einsatz vorrangig mit der weiterhin bestehenden Bedrohung durch den internationalen Terrorismus begründet. Diese Argumentation findet sich vor allem im ersten Teil „Sicherheit“ des Berichtes wieder. Deutschland sei 2001 mit in Afghanistan eingezogen, um an der Seite der internationalen Gemeinschaft gegen die Bedrohung vorzugehen, die aus der Region rund um Afghanistan entspringt.

„Der Bericht erinnert auch an den Ausgangspunkt und fortgeltenden Grund für die enormen Anstrengungen und Opfer der Bundeswehr wie der zivilen Vertreter und Aufbauhelfer bei ihrem Einsatz: Die Bedrohung auch der Bundesrepublik Deutschland durch inter- 
nationalen Terrorismus und islamistischen Extremismus. Um es hier deutlich zu sagen: Das vielfältige, zivil-militärische und diplomatische deutsche Engagement in Afghanistan ist ein Beitrag zur Sicherheitsvorsorge gegen Gefahren, die nicht erst an unseren Grenzen entstehen." (F 4, Hervorhebung durch die Autorin)

Diese Aussage impliziert, dass Afghanistan zwar territorial weit entfernt erscheint, die Gefahr ihren Ursprung jedoch in diesem Gebiet hat, welches Terroristen einen Unterschlupf gewährt. Auch Deutschland sei kein sicherer Ort mehr. Distanzen relativieren sich in einer ,immer enger verflochtenen Welt“ (F 4) und rechtfertigen so ein Eingreifen an einem für Deutschland fernen Ort mit allen Mitteln (zivil-militärisch, diplomatisch): „Die Terrorangriffe vom 11. September 2001 haben gezeigt, wie leicht unsere Sicherheit durch radikale Fanatiker aus entlegensten Gegenden der Welt bedroht werden kann.“ (F 5)

Der Begriff „radikaler Fanatiker“ erweckt den Eindruck, dass die westliche Welt es mit verrückten und nicht zurechnungsfähigen Kriminellen zu tun hat, die das Wohlergehen der Menschheit gefährden, an welchem Ort auf der Welt sie sich auch aufhalten mögen (,entlegenste Gegenden“). Mit verrückten, von ihrer Idee besessenen und rücksichtslosen Personen kann man nicht verhandeln und Frieden erzielen. Hat man es mit FanatikerInnen und nicht mit RebellInnen zu tun, dann muss man diese schwächen, dominieren oder beherrschen, um Sicherheit garantieren zu können. Afghanistan sei ein gefährlicher und quasi rechtsfreier Ort gewesen, der solchen FanatikerInnen einen Rückzugsraum ermöglichte. So hätte der deutsche Einsatz im Rahmen der internationalen Gemeinschaft der Schwächung der Al-Qaida gedient und habe den in Afghanistan ,,agierenden Terrornetzwerken den sprichwörtlichen Boden entzogen“ (F 5) (siehe kritisch hierzu Kühn in diesem Band).

\section{b) Diskursfragment „State-Building“}

Wie auch schon in der Ideologiekritik erwähnt, wird der „State-Building“ Diskurs weitaus weniger als Begründung für den Einsatz angeführt. Es lassen sich nur wenige Stellen finden, so zum Beispiel auf F 4 und F 9:

,[Es] wurde versucht, unser Engagement in Afghanistan so abzubilden, wie es ist: ein langfristiger, solider Beitrag zu den Fundamenten und dem weiteren Aufbau eines eigenständigen und stabilen Staats.“

„Ziel der Staatengemeinschaft ist und bleibt ein souveränes und hinreichend stabiles Afghanistan, das die in seiner Verfassung verankerten Menschenrechte achtet und von dessen Boden keine Gefahr für die Region und die Staatengemeinschaft ausgeht.“ 
Die Stabilität und Souveränität des Staates Afghanistan tritt in diesem Diskurs in den Vordergrund, wird jedoch mit dem Bedrohungsdiskurs verknüpft. Nur durch Stabilität könne die Bedrohung gemindert werden, die aus der Region entspringe. Während das Diskursfragment „Bedrohung“ erklärt, warum sich Deutschland seit 2001 in Afghanistan engagiert, formuliert der „State Building“ Diskurs Ziele, die sich nach der Intervention und der Verschlechterung der Sicherheitslage ergeben haben.

\section{c) Diskursfragment „Kompetenz“}

Das Diskursfragment „Kompetenz“ nimmt einen großen Teil des Legitimationsdiskurses ein und vermittelt die Aussage, dass die BR und die internationale Gemeinschaft die Situation in Afghanistan unter Kontrolle haben und die notwendigen Fähigkeiten besitzen, die Situation in Afghanistan nachhaltig zu verbessern.

Die Feststellung einer Trendwende dient der Demonstration deutscher Kompetenz: Sie soll suggerieren, dass sich der deutsche Bundeswehreinsatz nun in die richtige Richtung bewege und die deutsche, zivil-militärische Unterstützung die Fähigkeiten dazu besitze, Veränderungen hervorzubringen. Der Abwärtstrend sei „gestoppt“ und sollte der Versöhnungsprozess, wie von der afghanischen Regierung geplant, anlaufen, dann seien alle Voraussetzungen geschaffen, um im Jahr 2011 eine „spürbare Trendwende“ zu erreichen (F 5). Die Verwendung des Wortes „spürbar“ impliziert, dass die Verbesserung erheblich und sichtbar sein wird. Im Zusammenhang mit der Trendwende wird in dem Bericht auch von einem möglichen Abzug von deutschen Truppen gesprochen:

„Die Bundesregierung hat stets betont, dass sie nicht dauerhaft militärisch in Afghanistan bleiben wolle." (F 5) Mit dieser Aussage werden Vorwürfe aus dem Weg geräumt, dass Deutschland strategische Interessen in Afghanistan vertreten könnte. Der Abzug der Bundeswehr hätte nie in Frage gestanden. Wie schnell ein Abzug jedoch möglich sei, richte sich nach der Sicherheitslage und den erreichten Erfolgen.

Es lässt sich die Beobachtung machen, dass die Trendwende an mehreren Stellen prophezeit, im Nebensatz jedoch wieder relativiert wird. Beispiele hierfür finden sich auf F 9, wo davon gesprochen wird, dass in Schlüsseldistrikten ,beachtliche Erfolge“ erreicht worden wären, sich die Trendwende jedoch frühestens im Frühsommer 2011 zeigen werde.

Diese Beobachtung zeigt, dass die BR gern ihre Kompetenz mit Hilfe einer Trendwende untermauern möchte, sich jedoch der Gefahren bewusst ist, welche zu sehr übertriebene Behauptungen für sie bedeuten könnten. Die deutsche Öffentlichkeit schaut nun genauer auf den Afghanistaneinsatz und steht dem deut- 
schen Engagement kritischer gegenüber. Der Wunsch nach baldigem Abzug der Truppen wird immer stärker. Deshalb muss der Öffentlichkeit eine halbwegs realistische Abzugsperspektive geboten werden.

Abgesehen von dem Trendwendediskurs ist, wie auch schon in der Ideologiekritik erwähnt, die Vielzahl an Projektpräsentationen hervorzuheben, in denen vor allem durch die Nennung der finanziellen Ausgaben der Eindruck von einem ambitionierten deutschen Engagement vermittelt wird. Im F wird beispielsweise allein viermal erwähnt, dass Deutschland in verschiedenen Trust Funds drittgrößter Geber in der internationalen Gemeinschaft ist (F 29, 33, 65, 83).

Darüber hinaus macht die BR an mehreren Stellen jedoch auch deutlich, dass ihre Hilfszahlungen nicht ohne Gegenleistung zur Verfügung stehen würden. Sie stelle Bedingungen zur Korruptionsbekämpfung, dem Bürokratieabbau und dem Versöhnungsprogramm (z.B. F 7, 65, 72), welche den Eindruck erwecken, dass die BR die afghanische Regierung zumindest teilweise unter Kontrolle hat und sie in eine bestimmte Richtung drängen kann.

\section{d) Diskursfragment „Freund und Helfer“}

Die Begriffe „Freund“ und „Helfer“ werden nicht direkt im Text genannt. Dennoch lassen sich im F einige Stellen finden, welche den Eindruck einer Selbstdarstellung der BR als „Freund und Helfer“ vermitteln. Die Bundesregierung betont beispielsweise, dass es auf dem Gebiet des Polizeiaufbaus historische Beziehungen mit Afghanistan gibt (Aufbau der nationalen Polizeiakademie in Kabul durch Deutschland in den 1960er Jahren, F 20). Eine solche Aussage zeigt, dass positive Ereignisse in der Vergangenheit das Verhältnis von Deutschland und Afghanistan geprägt haben und Deutschland gern bereit ist, schon Aufgebautes zu rekonstruieren.

Des Weiteren legt die neue NATO-Strategie laut BR großen Wert auf den Schutz der Zivilbevölkerung (F 62). Die Bundeswehr wird so in das Licht des Freundes der afghanischen Zivilisten gerückt. Ein weiteres Beispiel ist die Thematik der Unterstützungszahlungen: Deutschland habe Afghanistan den Erlass aller Altschulden zugesagt und Unterstützungszahlungen kämen als nicht rückzahlbare Zuschüsse Schenkungen gleich (F 81). So stellt sich die BR als großzügiger Helfer dar, der Afghanistan nicht nur alte Schulden erlässt sondern, darüber hinaus, sogar noch einen Neuanfang finanziert.

Zusammenfassend legitimiert die BR in diesem Fragment den Einsatz deutscher SoldatInnen mit dem Argument, dass sich Deutschland schon vor 2001 in Afghanistan engagiert hätte und so auf den Willen und die Bedürfnisse eines hilfsbedürftigen Freundes eingeht. 


\section{e) Diskursfragment „Internationale Gemeinschaft““}

Zur weiteren Legitimierung des deutschen Engagements wird die internationale Gemeinschaft herangezogen. Dieses Diskursfragment ist jedoch nicht sehr ausgeprägt. Zunächst wird auf die Bündnissolidarität verwiesen, die durch den Terroranschlag am 11. September 2001 im NATO-Bündnis erstmals ausgerufen wurde. Der Terroranschlag sei als Angriff auf das gesamte Bündnisgebiet gewertet worden. „Die Bundesregierung stimmte dem ausdrücklich zu und erklärte ihre Solidarität.“(F 10)

Des Weiteren wird auf Seite 32 behauptet, dass die Beteiligung von inzwischen 48 Nationen die ,breite Legitimität der internationalen Sicherheitspräsenz" unterstreiche. Wenn sich so viele andere Staaten in Afghanistan engagieren, dann ist auch eine Beteiligung Deutschlands gerechtfertigt.

Außerdem werde der auf internationaler Ebene neu entwickelte und momentan in Afghanistan angewendete vernetzte Ansatz (Comprehensive Approach), der sicherheitsspezifische, politische und entwicklungsökonomische Aspekte miteinander verbinde, die notwendigen Veränderungen bringen. Besonders betont wird in diesem Zusammenhang in Kapitel 7, dass zivil-militärische Zusammenarbeit keine Militarisierung der Entwicklungshilfe bedeute und sich zivile und militärische Komponenten gleichberechtigt ergänzen würden. Dieser Aspekt weist die Vorwürfe verschiedener NGOs zurück, dass die Zusammenarbeit von Entwicklungshelfern und dem Militär die zivilen MitarbeiterInnen unnötig in Gefahr bringen und Entwicklungshilfe unter militärischer Dominierung zu einem politischen Instrument verkommen würde (Schetter 2010: 41; Barnett und Weiss 2008: 4).

\section{Diskursstrang „Eigenverantwortung“}

Im Diskursstrang „Eigenverantwortung“ zeigt die BR Grenzen auf, an die sie während der letzten zehn Jahre gestoßen ist und weiterhin stößt. Die begrenzten Möglichkeiten der deutschen Einsatzkräfte zeigen sich in den Fragmenten „Komplexität“ und „Bewusstseinswandel“".

\section{a) Diskursfragment „Komplexität“}

Das Diskursfragment „Komplexität“ betont, dass allzu umfassende Prognosen und schnelle Erfolge mit Vorsicht zu beurteilen sind. Viele Probleme (ethnische Rivalitäten, Korruption, Willkür), denen sich die BR in Afghanistan nun stellt, existierten schon Jahrzehnte vor der internationalen Intervention. In Verbindung mit der organisierten Kriminalität würde sich im Norden so eine „schwer zu durchschauende Gemengelage“ ergeben (F 14). 
Im Hinblick auf die Gesamtsituation in Afghanistan im Bereich Staatswesen stellt der Bericht fest:

„Die afghanische Bevölkerung hat wegen der traumatisierenden Erfahrungen der vergangenen Jahrzehnte nur geringes Vertrauen in ihre Regierung, was den parallelen Organisationsstrukturen der Taleban in die Hände spielt. Hinzu kommt: Afghanistan war im Laufe seiner Geschichte weitgehend kein zentral regierter Staat.“ (F 41)

Es bilden sich folglich Probleme in der Vertrauensbildung und in der Ausbildung eines Zentralstaates. Beide Problematiken werden durch negative oder mangelnde Erfahrungen in der Vergangenheit erschwert. Dass die Provinzen momentan noch wenig unter der Kontrolle des Zentralstaates stehen, sei vor allem auf die ,geographischen, ethnischen und religiösen Bruchlinien der afghanischen Gesellschaft“ (F 45) zurückzuführen.

Die Vielzahl an gegnerischen Gruppierungen mit unterschiedlichen Interessen (Kapitel 3) und der Analphabetismus aufgrund eines über Jahrzehnte kaum existenten Bildungssystems (Kapitel 12), sowie die wichtige Rolle, die der Drogenanbau seit vielen Jahren in dem Land spiele (Kapitel 19), würden Veränderungen erschweren.

\section{b) Diskursfragment „Bewusstseinswandel“}

Kritik an Karzais Regierungsführung wird mit ihren blockierenden Effekten begründet. Karzai sei durch das Aufrechterhalten eines klientelistischen und korupten Systems maßgeblich an dem Vertrauensverlust der afghanischen Bevölkerung beteiligt. Sollte sich nicht bald etwas ändern, dann drohe eine Vertrauenskrise. Der afghanische Staat sei seiner Verantwortung im Bereich der Korruptionsbekämpfung und Justizwesen nicht ausreichend nachgekommen (F 6, 67, 71) und würde die Stärkung der Provinzen nicht ausreichend unterstützen, weil dieses als Schwächung des Präsidenten interpretiert werde. So würden Provinzgouverneure auch nicht nach ihren politischen Fähigkeiten benannt, sondern ,aus Gefälligkeit, aus machtpolitischem Kalkül oder zur Wahrung des ethischen Proporzes“ (F 45). Der Wille zum Aufbau eines transparenten Verwaltungsapparats sei gering (F 48). Die BR könne nur begrenzt agieren, weil „die Thematisierung konkreter, hochrangiger Korruptionsfälle [...] als unzulässige Einmischung des Auslands" (F 72) angesehen werde.

Der $\mathrm{F}$ fordert einen schnellen Bewusstseinswandel in der afghanischen Regierung um sowohl das Vertrauen der Bevölkerung, als auch das der internationalen Gemeinschaft zurückzugewinnen: „Hier sind in erster Linie eigene afgha- 
nische Anstrengungen erforderlich, die mit einem Bewusstseinswandel einhergehen müssen.“ (F 41)

\section{Diskursstrang „Good Enough Governance“}

Der Diskursstrang „Good Enough Governance“ befasst sich mit den an die Wirklichkeit angepassten Zielsetzungen der BR für den Afghanistaneinsatz. Auch die Bezeichnung „Good Enough Governance“ findet sich nicht direkt im Bericht wieder, wird jedoch von Guido Westerwelle so in seiner Regierungserklärung vom 16. Dezember 2010 benutzt und bietet sich deshalb als Bezeichnung des Diskursstrangs an. Schon in seiner Rede hatte der Außenminister eingestanden, dass sich die BR in ihrer anfänglichen Zielsetzung in Afghanistan überschätzt habe und die Situation im Einsatzgebiet nun nüchterner und realistischer betrachte. Diese Einstellung spiegelt sich auch im F wieder. Deutschland habe sich „unrealistische Zielsetzungen“ gegeben und sich von der „trügerisch ruhigen Sicherheitslage“ im Jahr 2002 täuschen lassen (F 5). Bereits 2003 hatte sich herausgestellt, dass der ISAF Zeitplan den wirklichen Verhältnissen vor Ort nicht entspreche (F 31).

Auch wenn diese Verschlechterung der Sicherheitslage teilweise mit der Aufstockung des NATO-Kontingents und der erhöhten Operationsdichte und dem Operationstempo erklärt wird, täuschen die Zahlen nicht über eine ernstzunehmende Situation hinweg. Deutschland habe außerdem einen Imageverlust unter den Afghanen erlitten (F 51).

„Die Anschläge und Gefechte von Kundus haben die dort eingesetzten Soldaten, Beamten und Aufbauhelfer, aber auch die deutsche Öffentlichkeit mit der Wirklichkeit eines nichtinternationalen bewaffneten Konflikts konfrontiert.“ (F 13)

Auch wenn im Bericht das Wort „Krieg“ vermieden wird, verdeutlich dieses Zitat dennoch die Einsicht über den Ernst der Lage und die Tatsache, dass das Militär vor Ort keine Entwicklungshilfe betreibt sondern direkt an Kämpfen beteiligt ist. Des Weiteren zeigt der Verweis auf die deutsche Öffentlichkeit, dass sich die BR der öffentlichen Kritik und Meinung durchaus bewusst ist.

Als logische Schlussfolgerung aus der veränderten, und an die Wirklichkeit angepassten, Perspektive folgt eine Herabsetzung der Ziele: Im Bericht wird in Bezug auf Korruption, Menschenrechte, Sicherheit und Polizeiaufbau mehrmals betont, dass das Ziel des internationalen und deutschen Engagements ein ,hinreichend stabiles“ Afghanistan sei (F 5, 9, 19, 26, 34). „Hinreichend“ bedeutet „gerade genug“ (good enough), so dass es ohne internationale Unterstützung 
funktionieren kann. Es werde ein „Mindestmaß an effektiver und guter Regierungsführung“ (F 41) angestrebt.

\section{Diskursstrang „Global Player“}

Nach dem Legitimationsdiskurs ist der „Global Player“ - Diskurs im Dokument quantitativ am häufigsten präsent. Fast in jedem Kapitel hebt die BR ihre bedeutende Rolle auf internationaler Ebene hervor und dass der Beitrag Deutschlands im internationalen Vergleich signifikant sei. Dies tut sie auf dreierlei Weise:

\section{a) Diskursfragment „Verpflichtung“}

Zunächst stellt sie sich mit anderen internationalen Akteuren auf eine gleichberechtigte Ebene und betont ihre Verpflichtungen, die sie als Mitglied in einer internationalen Organisation zu leisten hat. Dadurch rückt sich die BR in ein Licht der verantwortungsvollen und verlässlichen Partnerin. Im Text finden sich hierfür beispielsweise folgende Aussagen: „Gemeinsam mit der afghanischen Regierung und der internationalen Gemeinschaft hat sich die BR zu einem Beitrag an der Aufgabe verpflichtet“ (F 4) und „Deutschland hat sich gemeinsam mit internationalen Partnern verpflichtet, zur Schaffung selbsttragender afghanischer Polizeistrukturen beizutragen.“(F 26). Des Weiteren würde Deutschland regelmäßig Verhandlungen zwischen Indien und Pakistan anregen und durch den deutschen Sitz im Sicherheitsrat und der Teilnahme an der $\operatorname{RECCA}^{5}$ zu einer „konstruktiven Lösung“ in der Region beitragen (F 39). Interessant in diesem Zusammenhang ist die Beobachtung, dass sich Deutschland im Kapitel 9 zum Einfluss der Region im gleichen Atemzug mit den Nachbarstaaten nennt und so den Eindruck einer territorialen Nähe vermittelt, die faktisch nicht existent ist.

\section{b) Diskursfragment "Größe“}

Des Weiteren versucht die BR ihre Bedeutung im internationalen Vergleich durch „Größe“ zu verdeutlichen. Wie schon im Kompetenzfragment erläutert, stellt sich die BR an mehreren Textpassagen als drittgrößte Geberin dar. „Als größter EU-Mitgliedsstaat“" würde Deutschland 20\% des EU-Finanzbetrags leisten und gestalte das Engagement der EU in Afghanistan so ,aktiv“ mit (F 31). Außerdem stelle Deutschland in EUPOL das ,größte Kontingent“ (F 30).

5 Regionale Konferenz zur ökonomischen Kooperation zu Afghanistan. 


\section{c) Diskursfragment „Leitnation“}

Zuletzt versucht die BR ihre Bedeutung auf internationaler Ebene weiter zu unterstreichen, indem sie sich als Vorbild für andere Nationen und initiativgebend darstellt:

Deutschland sei in der Nordregion eine „Leitnation“, hätte ,bereits 2003“ als erste Nation ein PRT übernommen und somit eine „Vorreiterrolle“ gespielt (F 13, 25, 32, 46). Seit 2002 übernehme Deutschland die „Führungsrolle“ im Polizeiaufbau und der „deutsche Ansatz“ (Verbindung der Bereiche Ausbildung, Ausrüstung und Infrastruktur) sei „zielführend“ und werde ,,von der afghanischen Seite begrüßt“" (F 20, 26).

\section{Diskursstrang „Gender“}

Es wird an vielen Stellen im F explizit auf die verbesserte Rolle der Frauen hingewiesen. Auch wenn dieser Diskursstrang im Fortschrittbericht nicht sehr ausgeprägt ist, tritt er dennoch konsequent in allen Teilen des Berichtes zum Vorschein.

Die konsequente Evaluierung der Rolle der Frau im deutschen Engagement zeigt das gesellschaftliche Interesse der Öffentlichkeit an der Heimatfront. Mit Fortschritten im Frauen- und auch im Kinderschutz lässt sich eine Zustimmung zum militärischen Einsatz in Afghanistan akquirieren. Diese Beobachtung unterstreicht die Aussage Gillian Youngs, dass „Gender“-Themen in der Afghanistanintervention stark dazu instrumentalisiert werden, Zustimmung an der „Heimatfront“" zu erreichen (Youngs 2010: 935).

\section{Diskurse im Fortschrittsbericht 2011}

Im Fortschrittsbericht Afghanistan 2011 (F II), der ein Jahr später als das in diesem Abschnitt analysierte Dokument erschien, bleiben die identifizierten Hauptdiskursstränge bestehen. Es wird weiterhin von einer Trendwende gesprochen, die jedoch anhaltend fragil sei. Auch das Terrorismusargument bleibt Hauptbegründung zum Einsatz deutscher Kräfte in Afghanistan. Ein neuer Diskursstrang, der im Einklang mit der Einführung des Konzepts und Begriffs der „Transformationsdekade“ durch die Bonn Konferenz im Dezember 2011 steht, ist der „Wir lassen Afghanistan nicht im Stich“-Strang. Somit wird dem Einwand entgegengewirkt, die ausländischen Truppen würden das Land nach ihrem Abzug 2014 komplett sich selbst überlassen.

Während die Diskurse im FII weitestgehend gleich bleiben, lassen sich bei der formellen Berichterstattung jedoch schon einige Verbesserungen finden. Be- 
sonders in den Abschnitten „Menschenrechte“, „Frauen“, „Kinder“ und „Bildung“"wird weitaus mehr wert auf aussagekräftige Beispiele gelegt. Positiv anzumerken ist außerdem, dass die Berichterstatter sich teilweise bemühen, ihre Methode zu erklären. ${ }^{6}$ Das Dokument bleibt dennoch weit davon entfernt, ein „objektives“ Bild der Lage in Afghanistan zu bieten, obwohl solche Bilder die langfristigen Bemühungen der BR eher unterstützen als behindern könnten.

\section{AnAlyseergebnisse Und Schlussbetrachtung}

Hypothese I (Auf nationalem Niveau soll der Bericht die Zustimmung der deutschen Bevölkerung zum militärischen Einsatz festigen) und Hypothese II (Auf internationalem Niveau dient der Bericht der Festigung einer bedeutenden deutschen Stellung in der Weltpolitik) werden durch die vorliegende Analyse bestätigt. Für Hypothese I machen die Ergebnisse der Ideologiekritik deutlich, dass sich der F vorrangig an die deutsche, informationsbedürftige Öffentlichkeit richtet und mit Behauptungen und Übertreibungen an solchen Stellen einen positiven Trend aufzuzeigen versucht, an denen das empirische Datenmaterial nicht ausreicht oder einen gegenteiligen Trend belegen könnte. Dementsprechend ist die Quellenlage teilweise sehr einseitig und für eine unvoreingenommene Evaluation ungenügend. ${ }^{7}$ Die Notwendigkeit des Aufzeigens einer positiven Entwicklung liegt in der Tatsache begründet, dass sich in der deutschen Öffentlichkeit mehr und mehr ein Klima der Ablehnung ausbreitete. Einerseits wollte die BR positionsbedingt durch die Bevölkerung wiedergewählt werden, war andererseits jedoch auch daran interessiert, ihre Stellung in der internationalen Gemeinschaft durch pflichtbewusste Ausführung ihres Auftrags zu festigen. Die Zustimmung der WählerInnen zum militärischen Einsatz muss folglich noch bis Ende 2014 (vollständige Übergabe der Sicherheitsverantwortung an die Afghanen) gesichert sein. Dass die BR zugibt, die Situation in der Vergangenheit falsch eingeschätzt zu haben und sich um eine realistischere Darstellung bemüht, zeigt die Einsicht über die eigene Unkenntnis und Unsicherheit auf Regierungsebene - ein Zugeständnis, welches von der deutschen Öffentlichkeit (Presse, Bundestag...) in den Monaten vor der Veröffentlichung des BR immer lauter gefordert wurde und so Druck auf die BR ausübte.

6 Ein Beispiel hierzu findet sich auf der Seite 27 des Berichts wieder, in dem versucht wird die Frage zu beantworten, wie man Sicherheit überhaupt messen kann.

7 Eine differenziertere Einschätzung der Lage geben zum Beispiel McChrystal 2009, International Crisis Group März 2012, International Crisis Group August 2011 and UN Security Council Secretary-General's Report 2011. 
In der Diskursanalyse ist vor allem der Diskursstrang „Legitimation“ für die erste Hypothese entscheidend. Auf umfangreiche Weise wird den Bürgern gezeigt, dass der Einsatz zu ihrem Schutz und Wohl geschieht (Fragment „Bedrohung"), die BR alles unter Kontrolle hat, zu einer Verbesserung der Lage fähig ist (Fragment „Kompetenz“: Trendwende in Verbindung mit einer klaren Abzugsperspektive als Beschwichtigung der deutschen Wählergemüter) und der Einsatz von den Afghanen gewollt ist (Fragment „Freund und Helfer“). Das „State-Building“ Fragment spielt nur bedingt eine Rolle. Große Übertreibungen in die positive Richtung werden jedoch vermieden, was zeigt, dass die BR nun vorsichtiger mit Behauptungen umgeht und sich der öffentlichen Kritik bewusst ist.

Die Diskursstränge „Eigenverantwortung“ und „Good Enough Governance“ zeigen die Grenzen der deutschen Fähigkeiten auf und rücken die afghanische Regierung in ein schlechtes Licht. Die BR sei sich nun der realen Verhältnisse bewusst, habe demzufolge ihre Ziele herabgesetzt und sei auf die Mitarbeit der Afghanen angewiesen. Die Einsicht der realen Verhältnisse dient als Antwort auf den Vorwurf, die BR führe eine „Vernebelungstaktik“. ${ }^{8}$ Durch mehr Ehrlichkeit soll erneut Vertrauen aufgebaut werden. Auch wenn der „Gender“ Diskurs keinen zentralen Teil im Bericht einnimmt, kann er als weiteres Nebenargument zur Überzeugung der Bevölkerung gewertet werden, welche großen Wert auf Menschenrechte und Frauenschutz legt.

Dass die BR einen Narrativwechsel vom „Helfer in Uniform“ zum „Global Player" vollzogen hat, zeigt sich im Bericht sehr deutlich und bestätigt somit Hypothese II. Die Ideologiekritik legt offen, dass sich der F an anderen internationalen Modellen orientiert und vor allem den Progress Report der Amerikaner an vielen Stellen als Quelle heranzieht.

Der „Global Player“ Diskurs verdeutlicht den Narrativwechsel: Die BR stellt sich teils als gleichberechtigte Partnerin, teils als große Geberin und Truppenstellerin, und zuletzt sogar als Vorreiterin und Leitnation, dar. Auf diese Weise wird ein gewisser Machtanspruch auf internationaler Ebene geäußert. Außerdem geht mit dem Narrativwechsel eine größere Bereitschaft zur (mandatierten) Gewaltanwendung im Peacekeeping (Friedenerzwingen) einher.

Der „Global Player“ Diskurs zeugt von einem neuen Selbstbewusstsein, welches die BR durch den F zu vermitteln versucht. Die Fragmente „Internationale Gemeinschaft" und „Freund und Helfer“" im Legitimationsdiskurs unterstreichen diesen Befund, da einerseits die internationalen Pflichten betont werden und an-

8 Wie er zum Beispiel durch MdB Jan van Aken in seiner Rede vor dem deutschen Bundestag am 16. Dezember 2010 geäußert wurde. 
dererseits der Eindruck erweckt wird, dass Deutschland schon seit langer Zeit als Gobal Player agiert.

In der Ausgabe des Spiegel vom 5. September 2011 wird aufgedeckt, dass Deutschland diese Rolle ganz aktiv gewählt hat und Ende 2001 unter dem Motto der ,uneingeschränkten Solidarität“ nicht nur mit den USA zusammen in Afghanistan interveniert ist, um ihre Bündnispflicht gegenüber den Amerikanern zu erfüllen. Es war vielmehr ein machtpolitisches Kalkül, welches von den Amerikanern zunächst wenig begrüßt wurde (Der Spiegel Nr. 36 2011, 76). Die BR suchte nach Anerkennung auf internationaler Ebene, welche ihr momentan nur bedingt zu Teil wird.

Tabelle 2: Hypothesen und Ergebnisse

\begin{tabular}{|c|c|}
\hline Hypothese & Ergebnisse der Analyse \\
\hline $\begin{array}{l}\text { I. Auf nationalem } \\
\text { Niveau soll der } \\
\text { Bericht die Zu- } \\
\text { stimmung der } \\
\text { deutschen Bevöl- } \\
\text { kerung zum mili- } \\
\text { tärischen Einsatz } \\
\text { festigen. }\end{array}$ & $\begin{array}{l}\text { Ergebnisse der Ideologiekritik: } \\
\text { Adressat: Der Bericht ist an den einfachen Bürger adres- } \\
\text { siert. Er soll davon überzeugt werden, dass Verbesserung } \\
\text { und Fortschritt greifbar sind. } \\
\text { Behauptungen und Widersprüche: } \\
\text { - Teile } 1 \text { und 2: große Anzahl an Widersprüchen und } \\
\text { nicht weiter begründeten Behauptungen. } \\
\text { - Bei fehlenden Ergebnissen: Suggerieren des Fort- } \\
\text { schritts durch bestimmtes Vokabular (Bsp. Trend- } \\
\text { wende). } \\
\text { - Trotz Hinweis auf Missstände, die schlussendliche In- } \\
\text { terpretation betont den „Durchbruch“ und einen posi- } \\
\text { tiven Trend. } \\
\text { Quellenlage: } \\
\text { - Teil } 1 \text { und 3: fehlende unabhängige Evaluierung und } \\
\text { Expertise } \\
\text { - Bestätigung des von Presse und Opposition vorge- } \\
\text { brachten Vorwurfs der voreingenommenen Eva- } \\
\text { luierung. }\end{array}$ \\
\hline
\end{tabular}




\begin{tabular}{|c|c|}
\hline $\begin{array}{l}\text { II. Auf internatio- } \\
\text { nalem Niveau } \\
\text { dient der Bericht } \\
\text { der Festigung ei- } \\
\text { ner bedeutenden } \\
\text { deutschen Stel- } \\
\text { lung in der Welt- } \\
\text { politik. }\end{array}$ & $\begin{array}{l}\text { Ergebnisse der Ideologiekritik: } \\
\text { Struktur und Quellenlage: Ist anderen internationalen Be- } \\
\text { richten ähnlich. Der Progress Report der USA wird oft zi- } \\
\text { tiert. } \\
\text { Ergebnisse der Diskursanalyse: } \\
\text { Legitimation (vor allem die Fragmente „Bedrohung“ und } \\
\text { „Kompetenz“) } \\
\text { Eigenverantwortung } \\
\text { Good Enough Governance } \\
\text { Gender }\end{array}$ \\
\hline
\end{tabular}

Mittlerweile liegen der Öffentlichkeit weitere Regierungsdokumente zur Information vor, zu denen zwei Zwischen- und ein Fortschrittsbericht (F II, siehe Diskursanalyse), das Abschlussdokument der Bonner Konferenz vom 5. Dezember 2011 (welches ganz bewusst in leicht verständlicher Sprache formuliert wurde) sowie der bilaterale Vertrag zwischen Deutschland und Afghanistan vom 16. Mai 2012 zählen.

Es wird deutlich, wie die BR in den neu veröffentlichten Dokumenten langsam „lernt“ und wie sich das seit Langem bestehende Informationsdefizit in eine Auseinandersetzung über die Kriterien von Erfolg und Scheitern verwandelt hat. An dieser Stelle wird die diskursanalytische Übung allerdings nicht wiederholt, die an den F II angelegt werden könnte. Der Fokus dieses Beitrags liegt auf dem Fortschrittsbericht 2010, weil er ein spätes, aber erstes Dokument einer diskursiven Strategie darstellte, der über die institutionellen und ausdeutenden Eliten (Parlament, Wissenschaft, Leitmedien) hinaus in das Vorbewusstsein und letztlich in die Aufmerksamkeit der Öffentlichkeit dringt. Dass dieser Versuch 2010 unternommen wurde, wird bis heute von diesen Eliten positiv gewürdigt, gleich der seitdem offeneren Informationspolitik der BR. Konterkariert wird der Effekt dieser Informationspolitik durch die mit dem Abzugsdatum verknüpfte abnehmende Attraktivität des Themas „Afghanistaneinsatz“. Dieser Trend erleichtert es den Kritikern der Intervention momentan, an ihren Bildern von Scheitern und Erfolglosigkeit festzuhalten und gleichzeitig den Unterstützern des Einsatzes, die Argumentation des undifferenzierten Fortschrittsmotiv fortzuführen, da aus der Öffentlichkeit zur Zeit wenig Widerspruch erklingt.

Nach zehn Jahren deutschen Engagements in Afghanistan war es im Dezember 2010 höchste Zeit, den Einsatz auf umfangreiche Weise zu bewerten. Deshalb ist die Veröffentlichung des F ein wesentlicher Schritt zur Lösung der Pattsituation, in der sich die BR momentan befindet. Aber ein wenig Einsicht der realen Verhältnisse in Verbindung mit dem Verweis auf internationale Pflichten 
und auf die wichtige Rolle Deutschlands in der Weltpolitik sind nicht ausreichend. Die Öffentlichkeit braucht nun eine Darstellung der ungeschönten Wirklichkeit, damit eine Legitimationskrise auf lange Sicht abgewendet werden kann. Denn das afghanische Volk ist angewiesen auf die ausreichende Stärkung und Unterstützung der internationalen Gemeinschaft, um seinen eigenen Weg gehen zu können. Nur durch die öffentliche Unterstützung und Legitimation an der „Heimatfront“ besteht die Chance, dass deutsche Truppen diese Mission erfolgreich beenden können.

\section{LITERATUR}

Becker, Johannes und Wulf, Herbert. 2010. Afghanistan: Ein Krieg in der Sackgasse. Münster: LIT.

Beste, Ralf; Demmer, Ulrike et al. 2011. „Ein deutscher Krieg“. in Der Spiegel, 36: 75-87.

Barnett, Michael und Weiss, Thomas G. 2008. „Humanitarianism - A Brief History of the Present“. In Humanitarianism in Question - Politics, Power, Ethics, hrsg. v. Barnett, Michael und Weiss, Thomas, S. 1-48. New York: Cornell University Press.

Bundesregierung. 2010. Fortschrittsbericht Afghanistan - zur Unterrichtung des Deutschen Bundestags. Berlin.

Bundesregierung. 2011. Fortschrittsbericht Afghanistan - zur Unterrichtung des Deutschen Bundestags. Berlin.

Forsa. 2010. „Immer mehr Deutsche plädieren für Afghanistan-Rückzug“. In Stern, 14. April. http://www.stern.de/politik/ausland/stern-umfrage-immermehr-deutsche-plaedieren-fuer-afghanistan-rueckzug-1558211.html (aufgerufen am 07. August 2012).

Hauck, Gerhard. 1992. Einführung in die Ideologiekritik - Bürgerliches Bewußtsein in Klassik, Moderne und Postmoderne. Hamburg: Argument-Verlag.

Hebestreit, Steffen. 2011. „Wie im Krieg - mit Plastikmessern, Verteidigungsminister Thomas de Maizière kommt als Lernender nach Afghanistan“. In Frankfurter Rundschau, 28. März.

Hoffmann, Christiane. 2010. „,,Fortschrittsbericht“ zu Afghanistan - Schöner reden, schöner reisen“. In Frankfurter Allgemeine Zeitung, 18. Dezember. http://www.faz.net /artikel/C30089/fortschrittsbericht-zu-afghanistan-schoener-reden-schoener-reisen-303222 72.html (aufgerufen am 07. August 2012). 
International Crisis Group. 2011. „Afghanistan's Elections Stalemate”. In Asia Briefing Nr. 117, 23. Februar. Kabul/Brüssel, http://www.crisisgroup.org/ en/regions/asia/south-asia/afghanistan/B117-afghanistans-electionsstalemate.aspx (aufgerufen am 07. August 2012).

International Crisis Group. 2011. „Aid and Conflict in Afghanistan”. In Asia Report Nr. 210, 4. August. Kabul/Brüssel. http://www.crisisgroup.org/ / media/Files/asia/south-asia/afghanistan/210-\%20Aid\%20and\%20Conflict\% 20in\%20Afghanistan.pdf (aufgerufen am 07. August 2012).

International Crisis Group. 2012. „Talking About Talks: Towards a Political Settlement in Afghanistan“, In Asia Report Nr. 221, 26. März. Kabul/Brüssel. http://www.crisisgroup.org/ /media/Files/asia/south-asia/afghanistan/221talking-about-talks-toward-a-political-settlement-in-afghanistan (aufgerufen am 07. August 2012).

Jäger, Siegfried. 2001. „Diskurs und Wissen - Theoretische und methodische Aspekte einer Kritischen Diskurs- und Dispositionsanalyse“. In Handbuch Sozialwissenschaftliche Diskursanalyse - Band I: Theorien und Methode. hrsg. v. Keller, Reiner; Hirseland, Andreas et al., S. 81-112. Opladen: VS Verlag.

Keller, Reiner. 2011. Diskursforschung - Eine Einführung für SozialwissenschaftlerInnen. Wiesbaden: VS Verlag.

Koehler, Jan. 2011. Sub-district governance. Social engineering and local governance in north-east Afghanistan. Loccumer Protokolle 2/2011, S. 3965.

Lindemann, Marc. 2010. Unter Beschuss - Warum Deutschland in Afghanistan scheitert. Berlin:Econ.

McChrystal, Stanley. 2009. Commander's Initial Assessment. 30. August. http://media.washingtonpost.com/wp-srv/politics/documents/Assessment_ Redacted_092109.pdf?sid=ST2009092003140 (aufgerufen am 07. August 2012).

Mercy, Can. 2008. Die afghanische Misere - Warum der Westen am Hindukusch zu scheitern droht. Weinheim: Wiley-VCH.

Münkler, Herfried.. 2006. Der Wandel des Krieges - Von der Symmetrie zur Asymmetrie. Weilerswist: Velbrück Wissenschaft.

Reichelt, Julian und Meyer, Jan. 2010. Ruhet in Frieden, Soldaten! - Wie Politik und Bundeswehr die Wahrheit über Afghanistan vertuschten. Köln: Fackelträger. 
Schetter, Conrad. 2010. „Von der Entwicklungszusammenarbeit zu humanitären Interventionen - Die Kontinuität einer Kultur der Treuhandschaft". In Interventionskultur - Zur Soziologie von Interventionsgesellschaften, hrsg. v. Bonacker, Thorsten; Daxner, Michael et al., 31-47. Wiesbaden: VS-Verlag.

UN-Security Council. 2011. "The situation in Afghanistan and its implication for international peace and security", Secretary General's Report S/2011/759, Dezember. http://daccess-dds-ny.un.org/doc/UNDOC/GEN/N11/622/56/PDF /N1162256.pdf?OpenElement (aufgerufen am 07. August 2012).

Van Aken, Jan. 2010. Rede - Afghanistan-Bericht ist ein Dokument des Scheiterns, 16. September. http://www.linksfraktion.de/reden/afghanistan-berichtdokument-scheiterns/ (aufgerufen am 07. August 2012).

Von Krause, Ulf. 2011. Die Afghanistaneinsätze der Bundeswehr - Politischer Entscheidungsprozess mit Eskalationsdynamik. Wiesbaden: VS-Verlag.

Youngs, Gillian. 2010. „The ,new home front " and the war on terror: ethical and political reframing of national and international politics". International Affairs, 4/86 (2010), S. 925-937. 


\title{
Ausblick und Perspektiven
}

\author{
MICHAEL DAXNER
}

Afghanistan gerät in Vergessenheit, so wie Kosovo längst aus der Aufmerksamkeit entrückt ist. Wen kümmert es, dass bereits der sechste Kommandeur der KFOR ein deutscher General ist? Wenn kümmern die Wirtschaftsdaten und die Regierungsumbildungen in Afghanistan, wenn nur unsere Soldaten gut zurückkommen und wenn es keine verheerenden, d.h. großen und bizarren, Anschläge gibt? Die Normalität der Intervention hat die Medien längst erreicht; der Heimatdiskurs ist vom Vorbewussten und etlichen Sicht- und Sagbarkeiten wieder zurückgesunken; so scheint es. Es ist aber nicht so. Die Bundeswehr-Reform geht weiter, wie man hört mit Erfolg - es melden sich überraschend viele zur professionellen Interventionsarmee. Ein öffentlicher Bezug zur Belohnung von Oberst Klein mit dem Generalstern wurde nicht hergestellt.

Der Auslandseinsatz in Afghanistan hat Deutschland verändert. Was im Kosovo begann, hat sich fortgesetzt. Vieles ist dabei noch nicht zu Tage gebracht. Es bleiben wichtige Forschungsbereiche noch abzuarbeiten.

Wir haben einige davon in diesem Buch angesprochen. Eine kleine Aufzählung mag eine Vorstellung davon geben, wie sehr das Work in progress nach vorne drängt:

An vielen Beispielen kann man die Ungleichzeitigkeiten im Heimatdiskurs feststellen: das heisst, dass manche seiner Ströme und Verzweigungen das Material schneller transportieren als andere. Die Diskussion um Helden, Krieger und demokratische Soldaten läßt sich Zeit, die Fragen nach dem Umgang mit Toten, Verwundeten und Heimkehrern sind schon drängender, was aber bislang unterbleibt, ist eine Verknüpfung dieser Themen mit dem Zweifel, ob Deutschland unbemannte Angriffsflugzeuge (Drohnen) anschaffen soll - weil es dann einer Neubestimmung der Bedienungs- und Befehlsstrukturen bedürfte. Die Öffentlichkeit zeigt wenig Bedürfnis nach einer konsistenten und vor allem breit disku- 
tierten Verteidigungsdoktrin und einer Einsatz-"Philosophie“. Wie solche Fragen besprochen werden, wie man ihre Subtexte offenlegt, sollte weiter erforscht werden, um nicht Gefahr zu laufen, eine anachronistische Debatte zu ,popularisieren", während die Avantgarde der politischen Vordenker und Entscheider schon ganz wo anders ist.

Eine ganze andere Forschungslücke tut sich im medialen Bereich auf: die Übergänge zwischen den u.E. noch immer dominierenden traditionellen Medien und dem Einfluss von neuen Kommunikationsformen, v.a. im Netz, sind im Bezug auf den Heimatdiskurs noch wenig erforscht. Es geht hier nicht um Wirkungsforschung (allein), noch um eine durch die Medien veränderte Semantik. Es ist vielmehr wichtig zu wissen, ob und wie diese neuen Medien Anlass und Arena für neue diskursive Strategien, für Abwehr und Akzeptanz bestimmer Diskurselemente, sind.

Am 21.8.2012 strahlte das ZDF einen neuen Beitrag unter dem Titel „Kulturkrieger" aus. ${ }^{1}$ Auf den ersten Blick eine saubere Reportage, wie sie einer „typischen“ Nachkriegssituation entspricht. Musik, Sprayer, MalerInnen, Disco, Wiedereinführung des von Kleidervorschriften befreiten (weiblichen Körpers) also alles Anzeichen für eine Interventionsgesellschaft mit starker Interaktion zwischen Intervenierenden und Intervenierten; emanzipiert westliche Deutungsmuster werden afghanischen Ansichten konsensfähig entgegengestellt. Die tatsächlichen und wahrgenommenen Gefahren und Risiken dieser vielfältigen Kulturbewegung werden benannt, ihre Konsequenzen aber nicht gezeigt: Verhaftungen, Ausgrenzung, Drohungen etc. Die eher zahmen Drohungen eines hochrangigen Geistlichen gegen westliche kulturelle Überformung sind fast gemütlich, bei Tee und Plätzchen ausgestoßen. Alles auf dem guten Weg? Man kann auch sagen, dass hier die Erwartungen des deutschen Heimatdiskurses in die Hoffnungen der Afghanen projiziert werden. Das Problem des Films ist, dass dem deutschen Publikum die prekäre Situation junger afghanischer Künstler gezeigt wird, aber die Beziehungen zwischen Kultur und Politik nicht aufgeklärt wird. Schließlich arbeitet Deutschland ja mit der Regierung zusammen, die für die Zukunft mehr Schleier und weniger Körper im Fernsehen verlangt.

Es ist nicht ausgeschlossen, dass die Normalität von Interventionen dazu führt, dass diese aus der öffentlichen Wahrnehmung ebenso ausgeblendet werden wie wir dies für Portugal festgestellt haben (siehe Daxner in diesem Band). Es kann aber auch sein, dass die Schwelle für die nächste, größere, Intervention nach dem Ausgang der afghanischen Dekade so hoch angesetzt wird, dass es zu

1 www.zdf.mediathek/beitrag/video/1642526/Kulturkrieger\%3AGraffiti+in+Kabul\#. (aufgerufen am 22.08.2012). 
einer politischen Auseinandersetzung kommt, etwa dem Konflikt zwischen auf die Probe gestellter Bündnistreue zu NATO und USA und dem Ruf nach Reformen im UN-Sicherheitsrat und einer deutschen oder europäischen transnationalen Friedenspolitik, die z.B. Einsatztruppen (also Interventionsarmeen) nur den Vereinten Nationen zugestehen will. Diese und andere Beispiele sollen nur verdeutlichen, wie sehr die von uns aufgerufenen Elemente des Heimatdiskurses bis weit hinein in unsere Vorstellungen von Souveränität, Nationalität und Rolle im weltgesellschaftlichen Kontext wirken.

Während wir an diesem Buch gearbeitet haben sind einige von uns mitverarbeitete Texte zu verwandten Themen veröffentlicht worden. Auf eine breite Diskussion des Diskurses daraufhin zu hoffen, ist vielleicht verfrüht. Aber die Forschungsdesiderate brennen ja unter den Nägeln. Die (west)deutschen Nachkriegsnarrative sind kaum mehr aufzurufen, wenn in neuen Kriegen und extern angeleiteten Interventionen die Bilder des Zweiten Weltkriegs nicht mehr zur Verfügung stehen, wenn es einen Bruch zum (gesamt)deutschen Nachkrieg gibt, wenn Zeitzeugenschaft zur Intervention, zur Gewaltwahrnehmung und zur Friedenserfahrung neue Bedeutungen erhalten.

$\mathrm{Zu}$ diesen neuen Bedeutungen gehört auch, dass auf die Stimmen und Bilder der Intervenierten mehr und genauer geachtet wird. Und zwar nicht einfach benevolent in Empfang nehmend, sozusagen Wissen über die aneignen, denen wir als Intervenierende gegenüberstehen, bevor wir eine Verbindung in Interventionsgesellschaften mit ihnen eingehen. Um die Äußerungen der Intervenierten produktiv zu verarbeiten, müssen wir auch mehr über uns im Kontext in Erfahrung bringen. Ein solches Vorhaben wird die Grenzen der Disziplinen und legitimen Methoden etwas durcheinanderbringen, es wird auch die Forschungsförderung herausfordern: wichtige Akteure werden sich exponieren müssen, um in ihren diskursiven Strategien erkennbar zu sein. Es wird Abwehr und Verdrängung geben, wie bisher, aber auch einen starken Drang sich zu äußern, wo die Frage nach der Legitimation vor allem für Politik und Medien unabweisbar wird. 



\title{
Autorinnen und Autoren
}

\begin{abstract}
Al Ahmad, Farisa, studierte Politikwissenschaften an der Freien Universität Berlin, an der Damascus University in Syrien, sowie an der Universidad Cardenal Herrera Valencia in Spanien. Ihr Studienschwerpunkt ist der Nahe Osten. Sie engagiert sich ehrenamtlich im Vorstand von OMRAS e.V. (Organisation für Menschenrechte in den arabischen Staaten).
\end{abstract}

Aljets, Janna, studiert Politikwissenschaft. Ihre Forschungsinteressen sind Gender, postkoloniale Theorien und Friedensforschung. Zurzeit forscht sie für ihre Masterarbeit zu Landgrabbing und Geschlechterdifferenzen in ruralen Haushalten in Tanzania.

Biegler, Alexander, ist Musiker, DJ, Eventmanager und Student der Politikwissenschaft an der FU Berlin. Bevorzugte Gebiete des geistigen Erlebens sind Politische Theorie und Philosophie, Poststrukturalistismus, Postmoderne, Staatstheorie, Gender. Momentan schreibt er seine Diplomschrift zum Thema: Rekonstruktion des Politischen bei Jacques Derrida.

Bliesemann de Guevara, Berit, ist Politikwissenschaftlerin und Trägerin des Deutschen Studienpreises 2009. Sie ist Senior Lecturer für „Peacebuilding, PostWar Reconstruction and Transitional Justice“ an der Aberystwyth University, Wales, wo sie sich derzeit mit wissensbezogenen Fragen internationaler Interventionenspolitik beschäftigt. Zuvor lehrte und forschte sie an der Universität Bremen und der Helmut-Schmidt-Universität Hamburg zu Statebuilding und Staatlichkeit, Krieg und kollektiver Gewalt sowie politischem Charisma.

Daxner, Michael, Präsident der Universität Oldenburg 1986-1998, UNMIK 2000-2002, in Afghanistan engagiert seit 2003, ist Soziologe und lehrt und forscht zu Intervention und Konflikt an der FU Berlin. 
Günes, Zerrin, studiert Politikwissenschaften an der Freien Universität Berlin.

Hanschke, Jeldrik, studiert Politikwissenschaften an der Freien Universität Berlin. Zuletzt erschienen: Deutsch-türkische Fans der deutschen Nationalmannschaft im Spiegel der Medien. Fußball und Nationale Identität in Europa, hrsg. v. Christian Haberecht und Boris Herrmann. 2009.

Herzog, Laura Mae, ist Studentin der Politikwissenschaft an der Freien Universität Berlin. Während ihres Grundstudiums studierte sie ein Jahr am Institut d'Études Politiques in Lyon. Schwerpunktmäßig beschäftigt sie sich mit dem Themenbereich Friedens- und Konfliktforschung unter besonderer Berücksichtigung sogenannter Gemeinressourcen.

Janzen, Vanessa, studierte Politikwissenschaften an der Freien Universität Berlin und am Institut d'Études Politiques in Lyon, Frankreich. Während ihres Studiums spezialisierte sie sich auf die Themenbereiche Friedens- und Konfliktforschung, Arabische Welt sowie Afghanistan. Heute ist sie Beraterin in einer deutsch-französischen Public Affairs-Agentur in Berlin.

Kobsda, Christian, hat in Passau und Rostock Politikwissenschaft, Philosophie und Wirtschaftswissenschaften studiert, bevor er zum Masterstudium an die Freie Universität Berlin wechselte. 2010 erhielt er den Kurt-von-FritzWissenschaftspreis der Friedrich Ebert Stiftung und 2011 den Examenspreis Rostocker Politikwissenschaft. Er arbeitet in Berlin für das Auswärtige Amt.

Kühn, Florian P., ist wissenschaftlicher Mitarbeiter am Institut für Internationale Politik der Helmut-Schmidt-Universität Hamburg. Er veröffentlichte „Sicherheit und Entwicklung in der Weltgesellschaft" (Wiesbaden: VS Verlag), wofür er 2010 den Dissertationspreis der Deutschen Arbeitsgemeinschaft Vorderer Orient (DAVO) verliehen bekam. Sein aktuelles Forschungsprojekt fokussiert Risiko und Resilienz staatlicher und substaatlicher Figurationen in Zentralund Südasien.

Materne, Hannah, studiert Politikwissenschaften an der Freien Universität Berlin.

Neumann, Hannah, ist Medien- und Politikwissenschaftlerin. Sie lehrt und forscht zu Kriegsberichterstattung und Konfliktsoziologie an der FU Berlin. 
Oehlaf, Anna, ist Studentin der Politikwissenschaften an der FU Berlin. Sie forscht insbesondere zu gesellschaftlichen Machtverhältnissen sowie deren Reproduktion und Subversion in medialen Diskursen.

Robotham, Christopher, ist Student der Politikwissenschaft and der FU Berlin.

Röder, Sascha, studiert den Masterstudiengang Politikwissenschaft am OttoSuhr-Institut der Freien Universität Berlin. Eines seiner Interessensgebiete ist die Verbindung von Praxistheorie und Konfliktforschung.

Rosenberger, Konstantin, studiert Politikwissenschaften an der Freien Universität Berlin.

Schelp, Miriam, studiert Politikwissenschaft an der FU Berlin. Ihre Studienschwerpunkte liegen in den Bereichen Gedächtnisforschung, Nationalismusforschung und Friedens- und Konfliktforschung.

Schulz, Anna-Lena, ist Studentin der Politikwissenschaft an der FU Berlin.

Stehr, Carolin, studierte Politikwissenschaften an der Technischen Universität Chemnitz (Bachelor) und an der Universität Kopenhagen. Derzeit absolviert sie ihren Master Politikwissenschaften an der Freien Universität Berlin. 


\section{Edition Politik}
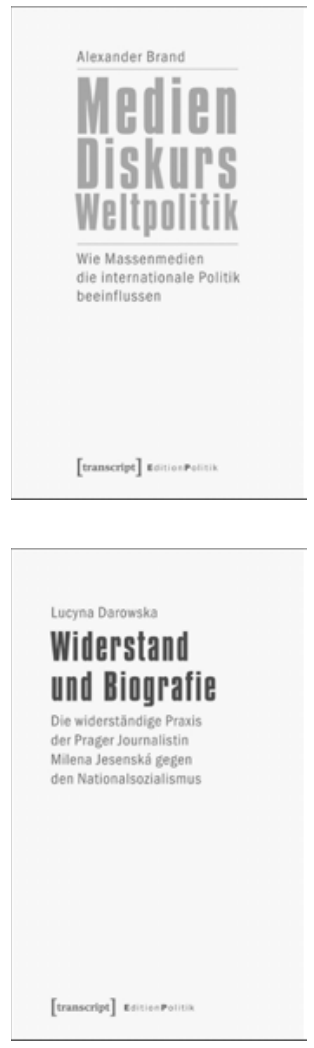

Peter Engelhard Die Ökonomen der
Alexander Brand

Medien - Diskurs - Weltpolitik

Wie Massenmedien die internationale Politik

beeinflussen

Februar 20I2, 530 Seiten, kart., zahlr. Abb., 39,80€, ISBN 978-3-8376-I83I-O

\section{LUCYNA DAROWSKA}

\section{Widerstand und Biografie}

Die widerständige Praxis der Prager Journalistin

Milena Jesenská gegen den Nationalsozialismus

Mai 20I2, 528 Seiten, kart., 39,80€, ISBN 978-3-8376-I783-2

Peter Engelhard

Die Ökonomen der SPD

Eine Geschichte sozialdemokratischer

Wirtschaftspolitik in 45 Porträts

20I0, I4 8 Seiten, kart., zahlr. Abb., I6,80€,

ISBN 978-3-8376-I53I-9 


\section{Edition Politik}
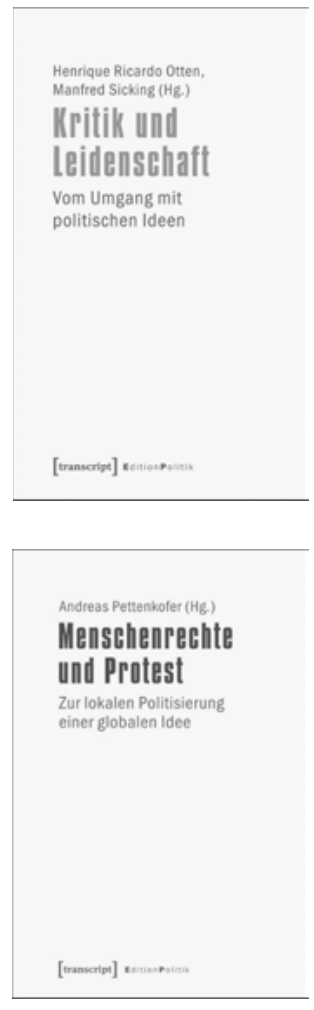

Shamim Rafat

Ethik und Qualität

in der Politikberatung

Zur Entwicklung von professionellen

Standards und Grundsatzen

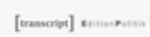

Henrique Ricardo Otten, Manfred Sicking (Hg.)

Kritik und Leidenschaft

Vom Umgang mit politischen Ideen (unter Mitarbeit von Julia Schmidt)

20II, 310 Seiten, kart., 29,80€, ISBN 978-3-8376-1590-6

Andreas Pettenkofer (Hg.)

Menschenrechte und Protest

Zur lokalen Politisierung einer globalen Idee

März 20I3, ca. 250 Seiten, kart., ca. 28,80€, ISBN 978-3-8376-2II2-9

\section{Shamim Rafat}

Ethik und Qualität in der Politikberatung

Zur Entwicklung von professionellen Standards und Grundsätzen

April 20I2, 272 Seiten, kart., zahlr. Abb., 32,80€, ISBN 978-3-8376-2085-6 
